\title{
Heritage Regimes and the State
}

\section{Regina F. Bendix, Aditya Eggert and Arnika Peselmann (dir.)}

Publisher: Göttingen University Press

Year of publication: 2013

Published on OpenEdition Books: 12 April 2017

Serie: Göttingen Studies in Cultural Property

Electronic ISBN: 9782821875470

\section{Qbooks}

http://books.openedition.org

\section{Printed version}

ISBN: 9783863951221

Number of pages: 413

\section{Electronic reference}

BENDIX, Regina F. (ed.) ; EGGERT, Aditya (ed.) ; and PESELMANN, Arnika (ed.). Heritage Regimes and the State. New edition [online]. Göttingen: Göttingen University Press, 2013 (generated 10 décembre 2020). Available on the Internet: <http://books.openedition.org/gup/348>. ISBN: 9782821875470.

(c) Göttingen University Press, 2013

Terms of use:

http://www.openedition.org/6540 


\section{Heritage Regimes and the State}

ed. by Regina F. Bendix, Aditya Eggert and Arnika Peselmann

Göttingen Studies in Cultural Property, Volume 6 

Regina F. Bendix, Aditya Eggert, Arnika Peselmann (Eds.) Heritage Regimes and the State

This work is licensed under the Creative Commons License 3.0 "by-nd", allowing you to download, distribute and print the document in a few copies for private or educational use, given that the document stays unchanged and the creator is mentioned.

You are not allowed to sell copies of the free version.

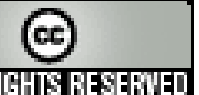


Published in 2013 by Universitätsverlag Göttingen as volume 6 in the series "Göttingen Studies in Cultural Property" 


\title{
Heritage Regimes and the State
}

\author{
Edited by \\ Regina F. Bendix, Aditya Eggert \\ and Arnika Peselmann
}

Second, revised Edition

Göttingen Studies in

Cultural Property, Volume 6

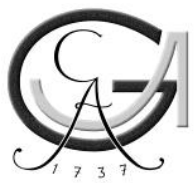

Universitätsverlag Göttingen 2013 


\title{
Bibliographische Information der Deutschen Nationalbibliothek
}

Die Deutsche Nationalbibliothek verzeichnet diese Publikation in der Deutschen Nationalbibliographie; detaillierte bibliographische Daten sind im Internet über $<$ http://dnb.ddb.de $>$ abrufbar.

\author{
Address of the Editors \\ Prof. Dr. Regina F. Bendix \\ Institut für Kulturanthropologie/Europäische Ethnologie \\ Georg-August-Universität Göttingen \\ Humboldtallee 19 \\ D-37073 Göttingen
}

This work is protected by German Intellectual Property Right Law.

It is also available as an Open Access version through the publisher's homepage and the Online Catalogue of the State and University Library of Goettingen

(http://www.sub.uni-goettingen.de). Users of the free online version are invited to read, download and distribute it. Users may also print a small number for educational or private use. However they may not sell print versions of the online book.

Set and layout: Franziska Lorenz, Jutta Pabst

Cover: Margo Bargheer

Titelabbildung: "Refreshing Memories" - Abandoned kiosk in the wandering sands of the Curonian Spit's bi-national heritage landscape

Foto by Ullrich Kockel, spring 2011

(C) 2013 Universitätsverlag Göttingen

http:/ / univerlag.uni-goettingen.de

ISBN: 978-3-86395-122-1

ISSN: $2190-8672$ 
„Göttinger Studien zu Cultural Property“ / "Göttingen Studies in Cultural Property”

\section{Reihenherausgeber}

Regina Bendix

Kilian Bizer

Brigitta Hauser-Schäublin

Gerald Spindler

Peter-Tobias Stoll

\section{Editorial Board}

Andreas Busch, Göttingen

Rosemary Coombe, Toronto

Ejan Mackaay, Montreal

Dorothy Noyes, Columbus

Achim Spiller, Göttingen

Bernhard Tschofen, Tübingen

\section{Homepage}

http://gscp.cultural-property.org 



\section{Contents}

Regina F. Bendix, Aditya Eggert and Arnika Peselmann:

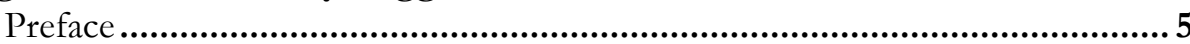

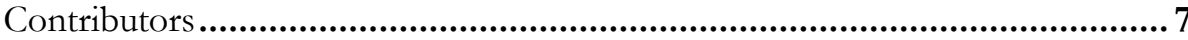

Regina F. Bendix, Aditya Eggert and Arnika Peselmann:

Introduction: Heritage Regimes and the State .................................................11

Kristin Kuutma:

Between Arbitration and Engineering Concepts and Contingencies in the

Shaping of Heritage Regimes....................................................................................21

\section{The Reach of (Post-)Colonial Sentiment and Control}

\section{Adelheid Pichler:}

The Dynamics of Heritage Choice and Heritage Regimes in the "Making of Old Havana".

Maria Cardeira da Silva:

Castles Abroad. Nations, Culture and Cosmopolitanisms in African

Heritage Sites of Portuguese Origin

Philip W. Scher:

Uneasy Heritage: Ambivalence and Ambiguity in

Caribbean Heritage Practices 


\section{Anaïs Leblon:}

A Policy of Intangible Cultural Heritage between Local Constraints and

International Standards: "The Cultural Space of the yaaral and the degal"

\section{Layers of Preservation Regimes and State Politics}

\section{Katia Ballacchino:}

Unity Makes...Intangible Heritage: Italy and Network Nomination ....

\section{Cristina Sánchez-Carretero:}

Heritage Regimes and the Camino de Santiago: Gaps and Logics

\section{Máiréad Nic Craith:}

Heritage Politics and Neglected Traditions: A Case-Study of

Skellig Michael

\section{Nicolas Adell:}

The French Journeymen Tradition: Convergence between French Heritage

Traditions and UNESCO's 2003 Convention

\section{Markus Tauschek:}

The Bureaucratic Texture of National Patrimonial Policies

\section{Gabriele Mentges:}

The Role of UNESCO and the Uzbek Nation Building Process

\section{Ullrich Kockel:}

Borders, European Integration and UNESCO World Heritage:

A Case Study of the Curonian Spit

\section{States and their 'Thing': Selection Processes, Administrative}

\section{Structures, and Expert Knowledge}

\section{Caroline Bodolec:}

The Chinese Paper-Cut: From Local Inventories to the UNESCO

Representative List of the Intangible Cultural Heritage of Humanity

\section{Chiara Bortolotto:}

The French Inventory of Intangible Cultural Heritage: Domesticating

a Global Paradigm into French Heritage Regime .265

\section{Alessandra Broccolini:}

Intangible Cultural Heritage Scenarios within the Bureaucratic Italian State ...283 


\section{Florence Graezer Bideau:}

Identifying "Living Traditions" in Switzerland: Re-enacting Federalism

through the UNESCO Convention for the Safeguarding of

Intangible Cultural Heritage

\section{Laurent-Sébastien Fournier:}

Intangible Cultural Heritage in France:

From State Culture to Local Development

\section{Jean-Louis Tornatore:}

Anthropology's Payback: "The Gastronomic Meal of the French".

The Ethnographic Elements of a Heritage Distinction

\section{Closing Commentaries}

\section{Donald L. Brenneis:}

Sand, Stability and Stakeholders

Rosemary J. Coombe:

Managing Cultural Heritage as Neoliberal Governmentality

Laurajane Smith:

Discussion.

\section{A Comparative Assessment}

\section{Chiara De Cesari:}

Thinking Through Heritage Regimes. 



\section{Preface}

\section{Regina Bendix, Aditya Eggert and Arnika Peselmann}

The present volume is the result of two conferences, both focused on the interface of international heritage regimes and their implementation at the state level. One event was held at the University of Göttingen within the framework of the multiyear interdisciplinary research group 772, "The Constitution of Cultural Property," from June 17-19, 2011, supported with funds from the German Research Foundation (DFG), and also co-organized by the Göttingen Center for Modern Humanities. The other set of papers, focusing on the same overall concerns, was initially presented within the framework of the French-German-Italian trilateral inquiry on the impact of intangible cultural heritage under the title "Institutions, territoires et communautés: perspectives sur le patrimoine culturel immatériel translocal." Held at Villa Vigoni in Loveno di Menaggio, Italy, from June 30-July 3, 2011, participants were supported by the Maison des Sciences Humaines, the German Research Foundation (DFG) and the Villa Vigoni, respectively.

In addition to our thanks for the financial support which made these meetings and the present publication possible, we also thank the many students who assisted in carrying out the Göttingen event, and the wonderful staff of Villa Vigoni for the luxurious workshop held in Italy. We would like to express our appreciation furthermore to Don Brenneis, Rosemary Coombe and Laurajane Smith who were present as commentators at the Göttingen event and willing to turn their oral comments into written contributions, as well as to Chiara De Cesari, who was not present at either event and was thus capable of offering a concluding, commenting chapter from an outside perspective. A number of individuals participated in the Göttingen conference who are not included in this volume, but whom we would 
like to thank for enriching the discussion: Peter Hoerz, Karin Klenke, Sven Mißling, Keiko Miura, Thomas Schmitt, Tatiana Bajuk Senčar, Dong Wang, and Andreas Hemming who also assisted in the planning of the conference. Similarly, interventions by Pietro Clemente, Michael di Giovine, Ellen Hertz, Bernardino Palumbo, Marta Severo, Dana Diminescu, and Paola Elisabetta Simeoni enriched the meeting at Villa Vigoni. Dorothy Noyes and Stefan Groth gave valuable comments and support in finalizing this volume. Thanks, furthermore, go to the student assistants Karolin Breda, Malte von der Brelie and Nathalie Knöhr, who assisted with preparing the manuscript for copy editing. Finally, we would like to thank Philip Saunders for his careful final editing of the full manuscript.

The second revised edition is published due to the fact that one of our authors corrected an essay.

Göttingen, June 2013 


\section{Contributors}

Nicolas Adell, Professor of Anthropology at the University of Toulouse Le Mirail, is currently conducting research on the anthropology of "heritage knowledge" in a culturally comparative perspective.

Katia Ballacchino holds a $\mathrm{PhD}$ in Ethnology and Ethno-anthropology from the Sapienza University of Rome. She is an Adjunct Professor at the University of Molise and at the Academy of Human and Social Sciences, and also works as a cultrice della materia at the University Suor Orsola Benincasa of Naples and the Sapienza University of Rome. Her research focuses on popular traditions, the inventory of Intangible Cultural Heritage in central and southern Italy, visual ethnography, migration, social and cultural mediation, and human rights.

Regina F. Bendix is Professor of Cultural Anthropology/European Ethnology at the University of Göttingen and leads the Göttingen Research Group on Cultural Property. Her research focuses on the intersection of culture, economics and politics.

Caroline Bodolec is a junior researcher with the French National Scientific Research Center (CNRS) at the Centre d'études sur la Chine moderne et contemporaine (UMR 8173 Chine, Corée, Japon), Paris, France. Her fields of research are Intangible Cultural Heritage in China, especially in the Shaanxi province, and the history of construction and anthropology of techniques during late-imperial and contemporary China. 
Chiara Bortolotto is a Marie Curie Fellow at the Universite Libre de Bruxelles (Laboratoire d'Anthropologie des Mondes Contemporains). Her research investigates the development of global policies of Intangible Cultural Heritage within UNESCO and their implementation in France and Italy.

Donald L. Brenneis is Professor of Anthropology at the University of California, Santa Cruz. His current research involves an ethnographic study of peer review, scholarly publication, assessment practices, higher education policy, and the ongoing shaping of scholarly and scientific knowledge within and beyond anthropology.

Alessandra Broccolini is an anthropologist and researcher at the Sapienza University of Rome, Italy. Her current research focuses on Intangible Cultural Heritage and UNESCO Conventions in Italy, Inventories of Intangible Cultural Heritage, traditional fishing in Bolsena Lake (Viterbo, Central Italy) as Intangible Cultural Heritage, and Urban Ecomuseums and participation.

Rosemary J. Coombe is the Tier One Canada Research Chair in Law, Communication and Culture at York University in Toronto, Canada, and works on issues pertaining to cultural property, cultural rights, indigeneity, intellectual property, and human rights.

Chiara De Cesari is an anthropologist and Assistant Professor of European Studies and Cultural Studies at the University of Amsterdam. Her new research focuses on the making of a European memory in relation to its blind spots, with particular reference to the carceral heritage of Italian colonialism in Libya.

Aditya Eggert is a $\mathrm{PhD}$ candidate in Social and Cultural Anthropology within the Research Group on Cultural Property at the University of Göttingen. Her research focuses on the concept of Intangible Cultural Heritage and the politics of heritage implementation in Cambodia.

Laurent Sébastien Fournier is a French social anthropologist, Assistant Professor at the University of Nantes and researcher at the CNRS (IDEMEC, UMR 7307, Maison Méditerranéenne des Sciences de l'Homme, Aix-en-Provence). As an anthropologist of Europe, he works on the revival of local festivals, traditional games and sports as Intangible Cultural Heritage.

Florence Graezer Bideau is Deputy Director and lecturer at the Center for Area and Cultural Studies (CACS), College of Humanities, Swiss Federal Institute of Technology in Lausanne (EPFL) and SNSF post-doctoral researcher at the Anthropology Institute, University of Neuchâtel. Her research interests include cultural policy in China, heritage processes in Malaysia and the implementation of the 
UNESCO Convention for Safeguarding Intangible Cultural Heritage in Switzerland.

Ullrich Kockel is Professor Emeritus of Ethnology, University of Ulster, Professor of Culture and Economy, Heriot Watt University, Edinburgh, and Visiting Professor of European Ethnology at Vytautas Magnus University, Kaunas. His current research focuses on cultural resource development, place memory and human ecology, especially in Germany, the Baltic region and the British Isles.

Kristin Kuutma is Professor of Cultural Research at the University of Tartu, Estonia. Her research and teaching focus on cultural theory, cultural history and anthropology, ethnographic studies and knowledge production, and critical studies of cultural heritage and representation. She is the head of the UT program of the Graduate School of Culture Studies and Arts.

Anaïs Leblon completed a $\mathrm{PhD}$ in anthropology at Aix-Marseille University focused on the process of heritagization of Fulani pastoral institutions in Mali. She is currently a postdoctoral fellow at Lahic (Laboratoire d'Anthropologie et d'Histoire de l'Institution de la Culture) in Paris, within the framework of a French research consortium: the "Labex CAP" (Créations, Arts et Patrimoines).

Gabriele Mentges is a Professor at the Institute of Art and Material Culture, at the Technical University of Dortmund. Her current research interests include the Uzbek textile culture as a cultural and economic resource.

Máiréad Nic Craith is Professor of European Culture and Heritage at Heriot Watt University in Edinburgh. Her research interests include cultural translation, cultural policy and Intangible Cultural Heritage in a European context.

Arnika Peselmann is a $\mathrm{PhD}$ candidate in the field of cultural anthropology within the Research Group on Cultural Property at the University of Göttingen. Her research interests include a comparative approach to the implementation of UNESCO conventions (Czech Republic, Germany), civil society in post-socialist states, and border studies.

Adelheid Pichler is currently working as a lecturer at the Department of Social and Cultural Anthropology at the University of Vienna, Austria. Her research covers memories of slavery in Afro-Cuban religions, education and adaptive capacity to climate change and the comparative study of social vulnerability patterns to hurricanes in Cuba and the Dominican Republic (within the IIASA - International Institute for Applied System Analysis, Laxenburg-Vienna). 
Cristina Sánchez-Carretero has been a tenured researcher in anthropology at the Institute of Heritage Sciences (Incipit), Spanish National Research Council (CSIC), since August 2008. Her areas of interest include processes of traditionalization, heritagization and memorialization, the intersection of migration and cultural heritage, and the politics of cultural heritage in conflict situations.

Philip W. Scher is an Associate Professor of Anthropology at the University of Oregon. He is currently conducting research on the politics of heritage in the Caribbean.

Maria Cardeira da Silva is a Professor at the New University of Lisbon and senior researcher at the CRIA - Center for Research in Anthropology, Lisbon. Mainly focused on Arabic and Islamic contexts, her research interests include cultural displays and political uses of culture, especially regarding international cooperation and diplomacy.

Laurajane Smith is an Australian Research Council Future Fellow at the School of Archaeology and Anthropology at the Australian National University, Canberra. Her research covers the area of heritage and museum studies.

Markus Tauschek is Assistant Professor of European Ethnology at ChristianAlbrechts-University in Kiel, Germany. His main research interests concern the emergence of Intangible Cultural Heritage, tradition and performative culture in late-modernity and competitive logics and practices in everyday life.

Jean-Louis Tornatore is a social anthropologist and Professor at the Institute Denis Diderot, University of Burgundy, Dijon, France. He explores two main issues together: The relationship with the past and the ways of living within time according to a pragmatist approach. He emphasizes the involvement of the researcher in a radical and non-authoritarian perspective. 


\title{
Introduction: Heritage Regimes and the State
}

\author{
Regina F. Bendix, Aditya Eggert and Amika Peselmann
}

What happens when UNESCO heritage conventions are ratified by a state? How do UNESCO's global efforts interact with preexisting local, regional and state efforts to conserve or promote culture? What new institutions emerge to address the mandate? The contributors to this volume - which builds on two conferences devoted to heritage regimes and the state - focus on the work of translation and interpretation that ensues once heritage conventions are ratified and implemented. Framed by introductory reflections and concluding assessments, the seventeen case studies provide comparative evidence for the divergent heritage regimes generated in states that differ in history and political organization. The gaze here is thus on the layered metacultural operations that constitute heritage in the first place - the host of regulatory steps, actors and institutions that transform a cultural monument, a landscape or an intangible cultural practice into certified heritage. Placed next to each other, the cases illustrate how UNESCO's aspiration to honor and celebrate cultural diversity diversifies itself. The very effort to adopt a global heritage regime forces myriad adaptations to particular state and interstate modalities of building and managing heritage.

Heritage research has grown into a large, multidisciplinary field of scholarship. Variously concerned to document the local impact of heritage nominations, improve heritage preservation and management, assess the economic potential of heritage's intersection with tourism and leisure, or offer critical perspectives on 
heritage-making's history and present, heritage scholarship is proliferating in tandem with its object of study. Dozens of national and international journals have been initiated, some as multidisciplinary as the field itself, others with a disciplinary specialization. International organizations participate in this scholarly endeavor, with UNESCO - as the United Nations agency responsible for bringing the global heritage listings into the world - and advisory bodies such as the International Council of Museums (ICOM) or the International Council on Monuments and Sites (ICOMOS) keenly interested to see their respective activities continually supported with sound scholarly research.

The Interdisciplinary Research Group on Cultural Property at Göttingen University, created in 2008, devotes several projects to the actors, contexts and dynamics of heritage-making. Ongoing case studies include the German-Czech border region Eragebirge, Cambodia, and Indonesia, with some of the work already in print (cf. volume 1 and 2 of the present book series). Our group assembles expertise from cultural and social anthropologists, folklorists, and economists as well as scholars in economic and international law. The present volume has its origins particularly in the fruitful cooperation of the ethnographic disciplines with international law. While our cultural and social anthropologists confronted highly divergent outcomes of heritage measures within their respective field sites, the participating specialists in international law registered the cultural and political specificities ensuing once a state has ratified the UNESCO's World Heritage Convention or its Intangible Cultural Heritage ( $\mathrm{ICH}$ ) Convention. In particular with regard to the ICH convention, we were startled to realize that ratification can give states new power over the dynamic resource of intangible culture - a "good" that even without international regulatory attention shows complex ownership and attendant rights structures. An international convention, we realized, meets not only with highly divergent state-based politics, but also with the corresponding bureaucracies, which may or may not have their own existing practices of heritage selection and management. This area has thus far seen no comparative research. Comparison of state implementation raises further questions of form-function relationships in cultural policy: similar bureaucratic forms across nation-states may have very different uses and effects, while the same purpose may be served by a wide range of formal strategies. We made it therefore our task to invite scholars with ethnographic experience on the heritage regime in states with divergent historical experiences and different political systems. Though European states (France, Germany, Italy, Ireland, Lithuania, Russia, Spain, Switzerland) are over-represented in our sample, Africa (Mali, Mauretania, Morocco), Asia (China, Uzbekistan), and the Caribbean (Barbados, Cuba) are represented in this assembly of cases: together they offer rich insights into the interplay of states and heritage regimes.

In framing this volume, we use the concept of regime as it has been developed in international regulatory theory. If 'regime' in classical terms refers to a set of rules and norms regulating the relations between a state-government and society, international regimes come about through negotiations among actors on an inter- 
national level. In issues such as trade and labor, information technology, public health, and others where international regulation is widely seen as beneficial, states and non-state actors will engage in negotiations aimed at producing conventions or treaties. To accompany the implementation of such outcomes, new institutions are typically formed. Dedicated organizations and standardized governance procedures are created in response to the recurrent and repetitive need to make decisions and generate rules. These institutions, such as the intergovernmental committees charged with promoting UNESCO's heritage conventions, also review progress towards the convention's goals and identify new concerns as they arise.

The United Nations do not constitute an international government, nor are they the only regulatory body on the international level. We thus rely on the broader concept of governance, which opens a view toward processes involving extrastate actors. In this way, we can fathom the web of systems of deliberation and regulation emanating from the $\mathrm{UN}$, its subsidiary bodies and the other actors who populate the international scene with ever-growing density in the post-colonial and post-socialist era. International networking hardly undoes the inequalities of history and economics, and empirical work such as the case studies assembled here contributes to the continuing critical reappraisal of a UN ideology that seeks to be globally inclusive toward interested states, regional associations and interest groups.

While global governance of a given policy construct does not constitute a government, it generates a bureaucratic apparatus with actors responsible for interpreting and applying procedures emanating from conventions and treaties. Once state actors ratify an international convention, they face the challenge of implementing it. This entails acts of interpretation or translation into the local system. It is the interface of international governance with state governance that is the focal interest of this volume. We are primarily interested in this dynamic with regard to heritage as one arena of cultural propertization - that is, how heritage-making intersects with the uncovering and utilizing of culture's resource potential and the ensuing questions of ownership rights and responsibilities. It may, however, be worthwhile asking what, if anything, is different about international conventions addressing cultural goods and areas of cultural practice as opposed to conventions dealing with the environment, security, trade, traffic and so forth. All conventions, once ratified, result in administrative procedures with attendant bureaucratic measures. Most will generate new offices and officers in charge of implementing new norms in complex social systems. Taking in account the broader landscape of international norm setting would be helpful to put the UNESCO heritage regime into the context of overall international governance.

In the post-WWII era, state parties in the international organization UNESCO negotiated a series of heritage conventions, the first one on world heritage adopted in 1972 followed by the underwater and intangible heritage conventions in 2001 and 2003. Each of these sets rules for the nomination and selection of cultural 
goods and practices to be placed on global lists, with the overall aim of encouraging the preservation and safeguarding of humanity's collective cultural riches. Each convention is accompanied by operational guidelines. And each convention requires its own administrative body which advises applicants, processes nominations, and identifies problems and concerns for the intergovernmental committees in charge of deciding on the worthiness of nominations. Once they have ratified a heritage convention, member states in turn need to devise administrative structures and regulatory frameworks on the national level that will permit both the generation of heritage application dossiers and, if successful, the implementation of heritage management plans.

In planning the two conferences reflected in this volume, we pursued the intuitions that 1) a great deal of UNESCO's agenda is "lost in translation" or invariably transformed, as heritage conventions enter the level of state governance, and 2) the implementation of the international heritage regime on the state level brings forth a profusion of additional heritage regimes, endowing actors at state, regional and local levels with varied levels of power over selective aspects of culture that prior to the UNESCO initiatives had rarely seen attention or control on the part of the state.

To assemble evidence to substantiate these assumptions, we approached the contributors to this volume with questions that would generate comparable case studies on the implementation of the heritage regime in diverse state systems. We list these questions here as well, not least to sensitize others working within the realm of heritage research and heritage practice to the ways in which heritage regimes emerge and what impact this in turn has on actors on all levels of the heritage-making process --in particular those who are the caretakers of tangible monuments, cultural landscapes, and intangible "excerpts of culture."

The first set of questions concerned the application for heritage nomination, the selection procedures (and the potential exclusion from the list), the groups of actors and institutions legitimated to participate in the process and the unfolding components of heritage governance:

How was the object/practice selected for UNESCO candidature? Do local ideals about cultural heritage exist that may have influenced the choice for a specific cultural feature? What is the relationship of this concept to the cultural heritage concept propagated by the UNESCO? How and by whom is the selection legitimated? Which rules and policies can be identified in this process?

What actors and actor groups can be identified in the nomination process? What kinds of (competing) interests do they represent in connection with the UNESCO nomination? How and by what means are the respective interests advertised, if necessary? Who took the initiative to launch the nomination? Can negotiation processes be identified and who is involved? Can bottom-up initia- 
tives be realized in them? Can non-state actors be involved in the procedure? Can exclusion mechanisms be identified?

What form does the interplay and interaction between local/national and international levels in the constitution process take? Are there discrepancies between international organizations and member states?

What legally (and/or socially) binding institutions have been created to shape the nomination procedure? Are local legal practices taken into consideration?

Who carries the costs of a nomination? Is assistance available and if so, from whom?

What professions have emerged in the development of nomination procedures for tangible and intangible cultural heritage?

What knowledge resources exist and who holds them with regard to the nomination process on the meaning of UNESCO World Heritage status and the obligations which come with it? How is this knowledge disseminated (print, training, etc.)? What role do experts and expert knowledge have in the nomination process?

A second set of questions concerned the implementation of a successful UNESCO nomination, drawing attention again to actors and institutions admitted to participation, as well as issues concerning user rights, and observations on the impact of heritage-making on the cultural elements selected and those in charge of them:

Which institutions, agencies and actors are responsible for the implementation? Do state criteria exist for regulating responsibility for the implementation of UNESCO World Heritage rules structures?

Who "owns" a certified ICH, World Heritage monument, cultural landscape or memory? Who defines the rights of use and how does this take place?

Which groups and individuals are involved in the valuation and development of a cultural heritage object/practice and with what interests? Can forms of competition or cooperation be observed in these processes? How is this competition managed or controlled? Who may use an $\mathrm{ICH}$ and for what purposes?

What kinds of programs are developed and what ideological perspective on culture do these programs reveal? How do pre-existing structures of valuing cultural pasts and traditions figure in generating new institutions? 
What is the impact of certification on the further development of the listed objects and practices - in terms of their definition and commoditization?

Following up on all these questions goes beyond what a lone ethnographer can reasonably document and query, and hence each author chose particular aspects to illustrate and elaborate within their particular case study. Yet in placing the cases next to each other, we see our initial assumptions confirmed and find ample evidence for the conflicting powers of heritage regimes. Indeed, it is worthwhile emphasizing that it is not simply human actors seeking or wielding power and holding control: the regimes themselves, as realized in unfolding bureaucratic institutions and processes, discipline both actors and their cultural practices into (perhaps) unforeseen dynamics.

The concluding commentaries of Don Brenneis, Rosemary Coombe and Laurajane Smith as well as the summarizing chapter by Chiara De Cesari each uncover diverging facets of heritage governance depending on the political setting within which they unfold. Our own comparative insight, which also draws on the aforementioned project case studies, finds the following issues worthy of critical reflection and relevant to heritage policy-making. These issues are intertwined and further illustrate how and why the international heritage regime turns into multiple, unequal heritage regimes: the diversity of bureaucracy, political history, precursor value regimes, heritage strategies from the local to the international level, and the power of go-betweens and interpreters.

\section{Diversity of Bureaucracy}

The UNESCO heritage regime originated in the effort to celebrate cultures in all their diversity, yet what is in the limelight in the day to day heritage-making business is the diversity of bureaucratic cultures, the actors enacting them, the tools employed for the purpose, and the comparable functions they are meant to fulfill. Generating and administering regulations that facilitate the composition of heritage nomination dossiers has grown into a cultural practice of its own. Councils, temporary or permanent decision-making bodies take shape - but they will differ from state to state, and the functions they are to carry out in the implementation of heritage conventions will thus also be differently parsed, not least depending on what prior institutions of heritage governance are (re-)activated for this new task. Actors within these institutions will devise paper and digital forms and formats to streamline the work. Yet the shape they will take, what actors have access to them, and which ones are empowered as a result will differ and thus tell us something about how the benefits and burdens of achieving international heritage recognition are distributed from national to regional to local levels. The Italian parsing of an intangible tradition into its constituent components for the sake of a normative application form invokes as distinct a bureaucratic tradition as does the Chinese redoing of a dossier compilation under different administrative auspices or the Swiss reli- 
ance on micro-federalist principles ensuring the participation of all who wish to do so. Similarly, the implementation of a successful heritage nomination engenders bureaucratic procedures enacted by new or pre-existing actors and institutions. There are states where the bureaucratic implementation of preservation and safeguarding measures is upheld by state police; there are others, where local or nonstate actors find themselves practically unencumbered in carrying out whatever management plan they have devised.

We are not claiming that these differences are entirely independent of the UNESCO heritage conventions and their respective operational guidelines. UNESCO's intergovernmental heritage committees continually monitor the results of heritage application and implementation procedures and deliberate on how to improve them. There may even be an incremental rapprochement between statespecific bureaucratic practice and international regulatory intent. But this does not alter the fact that states are free to interpret and implement UNESCO conventions: there are but few tools available to UNESCO to interfere - in supporting application processes with staff expertise for instance, or in threatening to take a successfully nominated item off a heritage list if management plans are not executed as proposed.

\section{Intersecting Political Histories}

As is particularly evident in post-colonial and post-socialist states, a state's political history leaves a mark on all heritage regimes and this not only due to the fact that bureaucratic infrastructures tend to survive changes in political systems. In postcolonial and similarly in post-socialist situations (which in some cases conflate), such bureaucracies may still maintain the language and habits of a former political era. Initiatives - including those concerning heritage - may be viewed with suspicion not least due to the idiom in which they are represented. Such states are also more thickly layered with cultural and political pasts and presents than states with a longer, autonomous history. Different sets of actors will opt to bring into play or disregard these valued, contested or even detested layers vis-à-vis the opportunities presented by heritage lists, as evident for instance in the quite different cases of Cuba and Barbados. In some instances, such as the Portuguese example, the international heritage regime offers a chance to polish the former colonial reach, not least by offering know how and resources - for such complex and fractured histories also contribute to present economic infrastructures and the social capacity or lack thereof even to consider participation in the heritage competition.

\section{Value-Regime Precursors}

The heritage regime did not invent the valuing and valorizing of culture. Ever since the Enlightenment many Western states have developed regimes thatselect and foster appreciation for aspects of culture, in particular cultural monuments. In 
other global regions (e.g. Japan and Korea), systems safeguarding intangible heritage go back to the late nineteenth century, and were influential in the shaping of the devising of UNESCO's ICH regime. Tourism, furthermore, has been a powerful motor for maintaining cultural resources. Such pre- and co-existing valorization systems wield their own power structures and are, in many cases, endowed with bureaucratic subsystems and political as well as administrative actors to enact them. This can lead to competing or contradictory enactments of heritage policies, as illustrated in the German case study. In some instances, pre-existing heritage regimes may be utilized as stepping stones toward the selection for a UNESCO application; in other cases, competition may arise between different heritage goals and associated financial support structures, as evident in the case of the Curonian Spit.

\section{Heritage Strategies}

Heritage-making is never pursued simply for the sake of preserving and safeguarding. Many actors of different persuasions are needed to pull off a successful heritage nomination, and those with a "pure" interest in protecting a rare archeological site, a landscape or a unique cultural testimony will invariably mingle with actors pursuing goals for which heritage holds strategic potential. Heritage nominations can be mobilized for purposes of economic development and nation-building, as seen in both the tentative Uzbek efforts and the Barbadian plan to draw on heritage in its nation branding. States may use heritage listings to enforce plans for urban renewal and touristic "clean-up" by removing inhabitants from their homes and land, such as in the Cuba case as well as the Cambodian Angkor. Development incentives play a role in the Portuguese-African co-operations, though here the donor institution's hope to build cultural and political capital as well as economic influence is not to be underestimated. Economic development is an heritagemaking incentive for many actors also in industrial nations, especially in depopulated areas and/or sites unable to attract other economic investors. The heritage card holds a promise that successful nomination might bring tourism and associated private and public investors.

Not unlike international sports championships, heritage listings bring out competitive aspirations among states. Thus while industrial nations initially refrained from the ICH regime, which had been expressly devised through UNESCO to afford the global South more opportunities to participate, Western ICH nominations - as illustrated for instance by the case studies from France and Italy, but also in the emerging efforts of Switzerland - now exhibit crafty and unusual approaches by state actors. Local actors, in turn, recognize in the heritage regime a global value system that might silence internal critique -as in the Italian Siena's (still unsuccessful) effort to silence animal rights protests regarding the treatment of horses in the Palio. The French compagnons employ the heritage regime in an effort to improve 
the prestige and thus pay of craftsmanship. Other local groups, as in the Spanish case study, may use heritage instruments to strengthen their own position. On a larger scale, social groups may seek empowerment through the heritage regime, seeking to jostle the power balance within the state, as is the case - not represented in this volume - with Indonesian groups' efforts to revive traditional legal structures.

\section{The Power of Go-Betweens and Interpreters}

Depending on the agency that can be negotiated within a given political system, and depending on the viscosity of an established heritage regime, powerful individual actors may move mountains where an army of administrators slog through the swamp of rules and regulations. An individual expert can circumvent a march through various local and regional levels and negotiate directly with the state, as the Irish case illustrates. Without the efforts of individual interpreters and gobetweens, many heritage nominations would never get off the ground. Expertise in regional culture and history as well as thorough familiarity with UNESCO instruments and protocol are required. One might go as far as to say that successful nominations are often led by skillful individuals, capable of navigating a given state's governmental and bureaucratic structure and of interpreting the present and shifting - "spirit" of UNESCO conventions.

These analytic insights have guided the grouping of the individual contributions in this volume. We begin with Kristin Kuutma's opening plenary at the Göttingen conference. As one of the foremost European heritage scholars and simultaneously a long-time participant in Estonian national as well as in international heritage decision making, her admonition to temper deconstructionist scholarship offers a thoughtful entry into the volume. Critical analysis ought not to disable the positive potential inherent to heritage-making but rather support the infusion of reflexivity in heritage decision-making processes. A first set of papers is then grouped under the heading "The Reach of (Post-)Colonial Sentiment and Control" and assembles cases from Cuba, Barbados, Mali and - through the reach of Portugal - Mauretania and Morocco. The section "Layers of Preservation Regimes and State Politics" brings into focus West European cases from Italy, Spain, Ireland, France and Germany, the post-socialist example of Uzbekistan and the case of the Curonian Spit, contested between Russia and Lithuania. Detailed views of nomination procedures from within, finally, are assembled under the heading "States and their 'Thing': Selection Processes, Administrative Structures, and Expert Knowledge" and feature studies on China, Italy, Switzerland and three different takes on France. In this last section, the role of anthropologists, ethnologists and folklorists as both expert consultants within and researchers of the heritage-making process comes to the fore quite poignantly. These fields of research have contributed to the societal appreciation of cultural diversity and, inadvertently or not, they have 
helped to shape some fundamental precepts of the heritage regime. The fact that heritage-making has now turned into a field of employment for practitioners in these fields presents both scholarly and ethical questions which, to echo again Kuutma's admonition, ought to be faced in productive rather than dichotomous ways.

Some of the authors in this volume rarely publish in English and one of the hopes we hold is that Heritage Regimes and the State may serve as an encouragement to engage seriously both with the power of these regimes and with the ethnographic work and theorizing of non-Anglophone scholars in the field. 


\title{
Between Arbitration and Engineering: Concepts and Contingencies in the Shaping of Heritage Regimes ${ }^{1}$
}

\author{
Kristin Kuntma
}

\section{Introduction}

The booming field of current heritage studies is complex, versatile, and often characterized by contradictory significance or interpretation, as claims for heritage can appear to be simultaneously uplifting and profoundly problematic. In essence, heritage is a value-laden concept that can never assume a neutral ground of connotation. Heritage indicates a mode of cultural production with reformative significance. My discussion of cultural heritage focuses on the practices of arbitration and engineering in the context of cultural politics. I propose to investigate the framework of concepts and contingencies that situate the emergent heritage regimes. To start with the semantics of the core terms presented in the title, the act of arbitration conveys the idea of giving an authoritative decision, of judging or deciding in case of a dispute; engineering, in turn, signifies the making or achieving or getting something through contrivance, thus implying invention and formulation. In the following paragraphs, I will observe some aspects of engineering and arbitration from an abstract perspective, via the lens of concepts and contingencies that have

\footnotetext{
1 This article is based on a paper presented as a keynote address at the conference Heritage Regimes and the State at Göttingen University in June 2011. The current research was supported by the EU through the European Regional Development Fund (the Center of Excellence in Cultural Theory), and by the Estonian Science Foundation, Grant No. 7795.
} 
proven instrumental in shaping and situating the discussion of heritage regimes. This reflection on the concepts draws from the anthropology of (cultural) politics concerning the domain of cultural heritage and its emergent regimes of engineering and arbitration while exploring relations between the communities, the state and international institutions, which are defined by the circumstances of globalization, postcolonial empowerment, cross-cultural relations, and "translation" and management of cultural heritage.

When criticizing the notion of authorized heritage discourse, Laurajane Smith contends that the ways in which we write, talk and think about heritage issues matter a great deal: This discourse privileges some social actors while disengaging others from an active use of heritage (cf. Smith 2006). Dissonance and intangibility form the core qualities that channel and guide the perception of the nature of heritage and its effects; this fundamentally concerns the domain of cultural rights. Heritage is about the regulation and negotiation of the multiplicity of meaning in the past, and it is about the arbitration or mediation of the cultural as well as social politics of identity, belonging and exclusion. Perhaps it would be appropriate to use here the concept "ideo-logic," suggested by Marc Augé, to designate configurations that articulate both relations of power and relations of meaning (Augé and Colleyn 2006: 47).

\section{Curative Concerns}

Regardless of the commonly prevailing celebratory approach, the fundamental conceptualization of the phenomenon comprises negative emotions and painful experience - destruction and loss are constitutive of heritage. The discordant nature of heritage preservation becomes poignantly revealed in the context of the veneration of archaeological sites: Their identification as such is the result of modern Western scholarship and its knowledge production process. The preservationist agendas involved often have a noble cause of care for heritage deemed to be of universal value but may, however, reveal a severe friction with local perceptions of priorities in representational symbols of cultural practice, or priorities concerning sustainable livelihood among the locals in proclaimed heritage sites, as studies by archeologist Lynn Meskell have shown, for example, in the case of the erasure of Bamiyan Buddhas in Afghanistan or the conflict with Qurna communities in Luxor, Egypt (cf. Meskell 2002, 2010).

Originally, UNESCO's mandate was to engage in a worldwide educational campaign aimed at preventing new destructive conflicts like those endured in the first half of the 20th century. It has been proposed more recently that the mission of UNESCO is an experiment in social engineering on a global scale (Stoczkowski 2009: 7). Here is the curative concern and ambition from the very beginning, finding a more recent translation into new metanarratives of redemption and global reconstruction in the context of heritage care (cf. Rowlands and Butler 2007: 1). 
The concept of care emerges as a central theme in the discussion of conflict and preservation. Phenomenologically, caring for something or somebody is fraught with anxiety, for it is contingent on unpredictable future events. Heritage care takes the notion of caution out of the museum - the birthplace of cultural curation and re-embeds it in personal life (Rowlands and Butler 2007: 2). The fundamentalist ideology of heritage preservationism derives from the modernist obsession with loss, although David Lowenthal pointed out nearly three decades ago that loss expressed in the form of a monumental past is a feature of the present (cf. Lowenthal 1985). When discussing the basic tenets of UNESCO's doctrine of human diversity, Wiktor Stoczkowski proposes calling it a "secular soteriology," referring to the doctrines of salvation, and giving it an extended meaning of deliverance not only from spiritual evil, but also material, social, economic, psychological, demographic, intellectual, etc., evil (Stoczkowski 2009: 8).

The multivalent connotation of the verbal noun of "engineering" has, in turn, inspired Ulf Hannerz, who has claimed UNESCO's strategies to be a mode of "cultural engineering" that is based on nation-state logics and global governance (Hannerz 2006: 79). Heritage emerges from the nexus of politics and power; it is a project of symbolic domination: Heritage privileges and empowers an elitist narrative of place, while dominant ideologies create specific place identities which reinforce support for particular state structures and related political ideologies (see Graham; Ashworth; Tunbridge 2000: 37). In addition, it correlates with economic concerns, which reversibly relate to poverty and deprivation when we think about cultural expressions and environments in marginal communities or less-affluent non-Western settings or countries. Heritage maintains a deep and complicated relationship with poverty. Heritage regimes and mobilizations create new arenas for competing political and economic interests that seek to appropriate viable heritage resources.

\section{Arbitration}

Barbara Kirshenblatt-Gimblett has argued that heritage as a mode of cultural production emanates from a metacultural relationship - heritage is created through metacultural operations (cf. Kirshenblatt-Gimblett 1998, 2004), which gear the analysis of cultural heritage towards the examination of socio-political and economic entanglements. Heritage is about identifying and managing, defined by selection and ownership. The policies of cultural heritage reveal presumably conflicting individual, communal or state perspectives observable in the predicaments of appropriation, contested restitution or celebration. Property relations are ultimately social and political. The making of heritage depends not only on conceptual valorization, but value is added both to symbolic and material resources (see Kirshenblatt-Gimblett 2006). Cultural heritage has reformative and powerful organizational and economic significance. In addition, even if the heritage under consideration 
or identified as such is claimed to be intangible, the process involved assumes materiality and tangibility, whereas the vice versa stands true, depending on at which end one stands or observes. At the same time, the metacultural is inevitably turned into or embraced by the cultural. Decisions and judgments are cultural, and they produce cultural reverberations. While a communal practice like Seto singing or a cultural space like Kihnu Island in Estonia, for example, have been deemed "cultural heritage" by the state nomination on UNESCO's celebratory representative list, my research continues to observe how various actors concerned operated in the emergent situation within and without, and how the Seto and Kihnu communities have negotiated with or contest this status, which has been incorporated into their self-identification as well as reflected in cultural practices. ${ }^{2}$

The frequently pronounced and instrumentalized claims for materiality or intangibility of heritage unravel an essential ambivalence. On the one hand, cultural heritage is more widely known to be about place or about the situated, material, esthetic, and experiential aspects of culture. The dominant perception of "heritage" draws heavily on the Western European architectural and archeological conservation and preservation practices that define it as material, monumental, good, esthetic, and of universal value. On the other hand, a conceptual shift has occurred in the last decade that has legitimized the term "intangible" to define cultural expressions and practices (storytelling, craftsmanship, rituals, etc.). The aim is to be universally inclusive in avoiding references to social stratum or inferiority that are perceived to be present in terms such as "folklore," "traditional" or "popular culture." Global cultural politics considers these terms too delimiting or prescriptive. At the same time, the historicity of heritage needs to be formalized through material symbolism, which makes the intangible and ephemeral into something that has material form, be it in a book, an audiovisual recording, as a particular element of a festival, or in an archive. Nevertheless, Laurajane Smith has argued that in an epistemological sense, all heritage is intangible through the value ascribed and its social impact (Smith 2006). The concept of heritage is used to sanction, give status and make material the intangibilities of culture and human experience. In essence, the polarization into tangible and intangible is organizational and political, largely applied to demarcate target spheres and areas of expertise; it is the institutional distinction inside heritage industries that needs this division between tangible and intangible heritage.

The recent re-theorization of heritage not only as sites, places, performances or events, but rather as a social construction and cultural practice, draws attention to the process of heritage-making by applying and recognizing the social significance of objects and expressions. Heritage is a social construction, a result of the process of "cultural work" wherein the creation of heritage is directed by the "authorized heritage discourse" that generates institutional positions and legitimizes certain

\footnotetext{
${ }^{2}$ See, for example, Kuutma 2009. For a study of cultural property as cultural practice, see Tauschek 2009.
} 
experiences and identities (Smith 2006: 299). The authorization of heritage discourse emanates from a close interconnection of relevant national institutions with international organizations, such as UNESCO, that has distinguished between the three major areas of heritage through its legal instruments of conventions: cultural, divided into tangible and intangible, and natural heritage. The major documents that stand in the focus of, provide impact on and initiate heritage studies are the Convention Concerning the Protection of the World Cultural and Natural Heritage, adopted in 1972, and the Convention for the Safeguarding of the Intangible Cultural Heritage, adopted in 2003.

\section{Engineering}

An international convention is a legal instrument for United Nations member states. They are invited to ratify it and subsequently follow the operational guidelines for implementing the prescription of the document. The UNESCO conventions call for signatory states to prepare inventories. If entries for various heritage lists are sought, this entails the presentation of vast amounts of descriptive material. In sum, the states need to carry out documentation, which poses a problem from the vantage position concerned with the corollary effect in the reification of culture. At the same time, any documentation is a parallel act to the historically prevalent practices of collecting ethnographic artifacts in settings esteemed exotic, whereas those collection endeavors were and are complexly (and often disturbingly) related to the issues of ownership. Another disruptive impact of documentation is related to the insurmountable discrepancy in making a judgment between singularity and commonality in elements of culture. Documentation for UNESCOnomination purposes concerns itself with and highlights the exceptional, even if the opposite is what is aspired to. That is, the member state who proposes a nomination in the sphere of Intangible Cultural Heritage, may claim to celebrate thus a representational phenomenon in national culture, which tacitly refers to the quality of typical in case of a widely disseminated practice. Nevertheless, what may have appeared a habitual element for a community becomes singled out ever after. Regina Bendix has described heritage nominations as reflecting small-scale powerplay with large-scale effects of moralizing and ennobling. She contends that regimes of quality control and evaluation are always present in the process of heritagization (Bendix 2009). These activities build on the late-modern competitive practices that correspond to and signify the tendencies of "audit culture," thus labeled and studied within academia by Marilyn Strathern (2000).

Inventorying is by default an act of classification that entails construction of models and categorization of cultural knowledge. However, classification tends to be historically contingent, while classificatory systems of thought appear to be culturally biased (cf. Arantes 2009: 57). Therefore, particular segmentations of social reality, assignment of categories and naming of diversities may not apply 
universally but reflect predominantly Western concerns or practice in reifying the products of human agency. The conflict becomes poignant when observed from the perspective of the triangle of indigenous groups, issues of collective or individual ownership, and the state. Indigenous groups, for example, may not wish or allow their intellectual property or environmental knowledge to be registered, because once documented, its ownership may easily pass out of their hands (cf. Napier 2002). Inventorying reflects interests and ideologies that are often driven by external agendas, whereas it is rarely taken up on the initiative of the cultural communities themselves, but is carried out by external "intermediaries" as has been pointed out by Antonio Arantes, an anthropologist from Brazil (Arantes 2009: 62). Inventorying raises the problem of subjectivity and agency in relation to the state - who has the right to travel, to document, to preserve? Who are the ones bearing the license to travel from place to place in order to initiate inventorying? What is the role of communities in this undertaking, or who are the ones with whom local people would be willing to interact? In addition, would the depositories thus accumulated be in available for public access, or are they subject to restriction, and who sets these regulations? The questions posed here seem to generate an endless array of new ones.

The categorization described entails choices of inclusion that are based on representational agendas and preservation policies which are usually defined by cultural custodians and preservation institutions. In their input to making public policies concerning preservation procedures, however, they may ignore the sphere of cultural communities. The politics of representation and decision-making happen to favor particular social groups. According to Arantes, the construction of public policies in cultural preservation tends to be biased by hegemonic values and conceptions about national culture that serve elitist perspectives that, in the case of Brazil, have historically highlighted "white, catholic and colonial cultural landmarks" (Arantes 2009: 63). An international organization like UNESCO depends on the institutionalization and maintenance of elite power and expert knowledge, while experts are often derived from the ranks of economic elites.

Another significant aspect of a national or elitist perspective in culturalpolitical representation is the notion of purity presumed for symbolic reference of cultural phenomena. Hybridity continues to be regarded as a negative feature from the perspective of heritage politics, particularly in the preservationist camp. This aspect can create additional friction: To continue with the example discussed and considering Brazilian culture in general, one observes that the overall richness of cultural phenomena and practices derives in a substantial part from hybrid mixtures. It may eventually appear an impossible task to pin down and define the moment when "a hybrid" begins, in other words, when or where a mixture, combination, blend, cross-breeding commences. ${ }^{3}$ Even if in this "era of cultural en-

${ }^{3}$ Cf. the Latin-American-centered discussions of two-way borrowing and lending between cultures by Rosaldo (Rosaldo 1995: xi) and Canclini's understanding of fusions that generate new structures, 
counters" we should not seek firm cultural frontiers but acknowledge "the cultural continuum" (Burke 2009: 2), the heritage engineering agenda seems to hang on to the notion of "purity" in origin particularly in its political implications.

The identification and the evaluation of cultural heritage are inevitably surrounded by contestation. Programs for preservation and safeguarding pertain simultaneously to the politics of inclusion and exclusion: About who matters, who is counted in, who defines. The veneration of heritage tends to overshadow social inequalities (Bendix 2000). Heritage politics is never neutral: It is all about choice where different and often oppositional interest groups concurrently select and promote their symbols (cf. Klein 2006). Furthermore, the relationship between community and heritage need not always be good and comfortable (see Smith and Waterton 2009). Communities are not homogeneous and neither is their heritage; disjunctions occur and heritage claims may not be consensual. A lot of social experience and practice can be related to contrast and conflict; they denote pain and suffering, as has been shown by studies on dissonant heritage (Tunbridge and Ashworth 1996). This reflects the complexities of how communities define and negotiate memory and identity, and how they communicate and engage with each other.

On the other hand, defining the notion of community is problematic in universalist terms as it has become more complex in a diverse and globalized world. Community refers to social cohesion based on mutuality, affiliation, proximity, or propinquity, but also implies by default the immanent agenda of contestation and exclusion (cf. Hoggett 1997). Communities may be linked by a merger of social and cultural experiences; criteria extend from objective (ethnicity, language, etc.) to subjective ones (self-identification, solidarity, etc.); communities are segmented into those of culture, location, interests, etc. The denotation of community has broadened, but it brings with it layers of historical meaning and carries varied political significance in international settings. ${ }^{4}$ The matter of ascribing the quality of "community" seems to depend on whether it happens within or without as a prescriptive act by outsiders, whether it is an affiliation by choice or a result of an external organizational agenda, particularly in reference to state politics. The choice as to how we define community membership can have serious social, political and economic impact on individuals and groups within the state. ${ }^{5}$

subjectivities and practices (cf. Canclini 1995). The derogative biological origin of "hybrid" has been discussed by Bendix (see Bendix 2000).

${ }^{4}$ For example, the 2003 Convention does not define "communities" in its text, which has caused recurring elaborations on the matter (e.g. Blake 2009, Kono 2009). During my participation in the meetings of expert bodies and of the intergovernmental committee of this Convention between 2006 and 2011, I have repeatedly observed the tensions that the urge or dismissal for such a solid categorization creates.

${ }^{5}$ Another mechanism that is tacitly dependent on cultural engineering and arbitration is the institutionalization of development programs, which encompass the ideologies of potential achievement and concurrent deprivation that either neglect or manipulate culture, with the potential involvement of communities. 
To recount the contrivances described, they refer mostly to the demarcating identification of practices into manageable categories, to the imposition of hierarchies or exploitation of positions, but also to the consolidation into collective bodies under the aegis of particular signifiers. However, I do not propose to dismissively categorize these acts of engineering as metacultural products of heritage regime, but would rather point them out as being embedded in culture. An identification of external manipulation that stops short of looking beyond this deplorable disclosure seems to me a simplified approach to the recognizable reconfiguration of culture that is in progress here and now, being observable everywhere, including the most remote locale.

\section{Universalism and Representation}

The argumentation of the present article circles around the notion of cultural (or ethnic) community in relation to heritage management. Both community activists, in other words, members of ascribed leadership, and heritage custodians on various levels perceive it as a source for endorsing the sense of communal belonging. Heritage is deployed to define a community, but it functions similarly as a political asset in negotiating governance. Ambivalently, the aspect of administration also plays a defining role in formatting a community, according to Tony Bennett (cf. Bennett 1998: 201). Though the realms of government or of the state may be considered external, impositional and antagonistic to the creative cultural life of communities, seen as natural organizations of the populous, they actually come into existence through a need to organize boundaries and interact with the government. This becomes apparent in the context of making cultural policies. Here, local communities find an outlet for activism, and seek to create an operational mechanism that provides them with agency within the deployment of local cultural policies. Policy-making will function and activate at the community level depending on the inclusion (as well as exclusion) of community representatives. The claims for heritage involve policy-making embedded in the framing of culture, its history and expression, which combine insider activism with outside interests involving political gain.

The politics of heritage protection have been traditionally mobilized from a Euro-American platform based on the presumed universality of "World Heritage"- referring here to architectural monuments, man-made sites or natural formulations of unique quality - the logic of which has widespread effects on international and localized settings (Meskell 2010: 196), as this logic builds on the notions of development, neoliberalism, and governmentality. The ultimate beneficiaries are then not only the state authorities who manage to showcase "culture," but also transnational companies of tourism and perhaps those gaining employment in the process, mostly via consumption practices within global tourism. 
The universalist preservation agendas pertain to the perception that transnational concerns for conserving buildings, objects or sites should be granted unequivocal priority. However, even if sustained on the organizational institutionalized level with international conventions, these convictions do not hold ground everywhere, being met with contradictory response on the local level. In general, relations between the global and the local in the workings of the heritage regime are not onedimensional but a rather complex mechanism. The concept of "World Heritage" carries a universalist pretense combined with a complex, highly-structured praxis, based on uniform criteria descending from global to local contexts, endorsing thus inadvertently a globalizing program (Turtinen 2000). Nevertheless, the concept's impact with consequential reverberations still occurs most poignantly in the context that is referred to as the local.

The paradigm of the Intangible Cultural Heritage presumably differs from the "world heritage" focus on monuments, architecture and natural sites. "Intangible heritage" is an outcome of a cultural relativist perspective influenced by postmodernist trends. If the UNESCO World Heritage designates and promotes "outstanding universal value," then Intangible Cultural Heritage manifests "representativeness" in the regulatory conventions and nominations on the UNESCO listing systems. The concept of Intangible Cultural Heritage involves a reflexive approach, dependent on the "human factor," as heritage potential is assumed to be established by its "bearer" (cf. Bortolotto 2010: 98). We might refer here to the notion of "grassroots globalization" by Arjun Appadurai when such collaborative response is assumed to heritage agendas furthered by international prescriptive policies (cf. Appadurai 2002).

However, the involvement of communities - who are implied when invoking the grassroots perspective - is predestined to being weakened by the national validation process that is necessary for heritage authorization in the UNESCO system. The United Nations address only a "state party." To what extent would protecting or safeguarding mechanisms go beyond securing the interest of state parties, in order to be capable of addressing localized needs and deliver a culturally appropriate mechanism of safeguarding? On the other hand, in the representational validation process, the state leans on the constructive participation of various "intermediaries." These mediators are instrumental for the state in the course of identifying and defining heritage. In the field of heritage policy, authority is accorded to expert knowledge and precedence given to professional interventions that create, in turn, particular communities of interest, involving stakeholders and stewardship. The discursive impact of the concept and perception of cultural heritage paves the way for a battleground of celebration and contestation among those entangled in the process of heritage production. Frictions appear based on cultural competence, debates and conflicts arise between conservationists and innovators, while hierarchies of authority become structured and expand. To a certain extent, such expertbattles may reflect institutional agendas that do not reverberate with locallygrounded concerns. Those could include, for example, issues of authenticity or 
debates related to hybridity, arguments on historical documentation or generic features that contradict claims of singularity. These argumentations may not resonate across the field or become eventually opposed by local communities who claim ownership of particular cultural heritage, by communities for whom reaffirmation of their sense of belonging matters and who thus participate in the process of heritage production. On these occasions, mediated representation can become contested when community values are accentuated by their leaders.

\section{Governmentality and Management of Culture}

When heritage accentuates values for the communities, it signifies interests for the state who promotes it with an expectation of accumulating symbolic and economic capital as well as presumably procuring a political position, either internally, among geographic neighbors, or on a wider international scale.

From the perspective of the state, the implementation of the framework of "culture" stands out as a prominent preference: "Culture" is endorsed on a state level for its capacity to provide a relief in potential conflict situations; it serves the state as an alternative to politics that might complicate the state's authority. With that in mind, I am including here a passage to consider the notion of governmentality in relation to heritage. Cultural forms and activities are governmentally deployed as parts of social management programs. My current exercise in the conceptualization of heritage in relation to cultural politics points to the need to investigate the construction and modalities of legitimate authority. As Marc Augé has proposed, one should study not only the rules in institutionalized power relations, but also the practices which may be observed that contravene those normative pressures (Augé and Colleyn 2006: 49). The state - a structured and centralized political organization, a mode of grouping and control of people - is mostly perceived as a source of administrative authority, control and repressive force. It is the entry point of international funds and it exercises control over different kinds of resources. However, it would be preferable not to understand the state simply as an apparatus of power, but to study the diversity of ways in which power is exercised: The mechanisms of domination and stratification, the extension of political networks, the hierarchy of central institutions, the configurations and articulations of authority. One should similarly investigate the mechanism of power distribution, while making a distinction, with Max Weber (Weber 2002), between power and authority, the latter implying a promulgated measure of legitimacy.

Political discourse of a nation-state entails disjunctions and discontinuities that are embedded in the center-periphery political distinctions. To complicate the often applied prescriptive approach to state governing as an external and hegemonic administrative and coercive apparatus, its investigation should move further to analyze it from the perspective of the opposite end. Anna Tsing has analyzed the formation of state authority from the perspective of the periphery by looking 
at the imposed quality of state authority, and how the categories of state rule are actualized in local politics (Tsing 1993). The "peripheral" politics contribute to making the state, but the formation of local communities begins with the subjective experience of being both outside and subject to state power, which infers simultaneous placement inside and outside the state. Her conceptualization of body politics and proposal to expand the analysis by including the "out-of-the-waypeople" (Tsing 1993: 25) reaffirms the agenda to look into the construction of agency in the "periphery" and to study the negotiations with the state in making local cultural politics. Concurring with Tsing's conclusion that official state categories do not have an "always already" quality, I consider it meaningful to probe cultural politics not as an "always already," but as an emergent framework formed in the nexus of culture, management and community. My interest in the dynamics of community, and the cultural politics exercised by authorities, be they local or national, and the problem of agency for members of the community who are framed either as subjects or objects of cultural policies emanating from local authorities or the state, which may concur or manifest contradiction, makes it similarly meaningful to examine cultural management from a reflexive position on the ground.

Tony Bennett has argued that the field of culture is now increasingly governmentally organized and constructed (Bennett 1998: 61). He investigates the relation between culture and the social sphere by analyzing the organization of contemporary cultural life through the various levels of engagement in policy-making, with special attention to the management of cultural resources, cultural maintenance and administrative requirements in multicultural policies. Bennett looks at the triangle of community, culture and government, to bring out the potential tensions between indigenous community and government. The latter is usually observed from the position of cultural critique with indignation, condemning it as external and impositional, being indifferent or antagonistic to creative cultural life. However, it is within the practices of government that "community" acquires a paradoxical quality of being "nurtured into existence by government while at the same time standing opposed to it" (Bennett 1998: 201). He reaffirms a reformative centrality of policy to the constitution of culture, while in his view, the management of cultural resources concurs with the intention to reform ways of life in contemporary society (Bennett 1998: 104). Among the reforming endeavors, heritage politics is also situated, guided by ambivalent relations between culture and power, depending on the organizational frameworks and institutional spaces under observation, embedded in the condition of either self-determination or its absence. Bennett's contention for the vital significance of cultural politics stands in opposition to Zygmunt Baumann's view of culture as a spontaneous process devoid of administrative or managerial centers. From Baumann's position of postmodernist critique, culture cannot be "made" or "remade" as an object of practice, but should be considered a reality in its own right and beyond control, being "mastered cognitively, as a meaning, and not practically, as a task" (cf. Bennett 1998: 102). Bennett con- 
siders this position particularly erroneous in multicultural situation (with marginal, minority communities in modern society without nationalist uniformity) and points to the necessity of legislative mechanisms for respectful and tolerant relations of cross-cultural understanding. In accord with the view that such cross-cultural understanding does not emanate naturally from the postmodern condition, I highlight here an important reason for studying cultural politics and how it is applied, or manipulated, on the local or grassroots level. Bennett locates a task of cultural management in the effort to recognize dissimilar cultural values and to promote forms of exchange between them when stating that our interpretation of the world also shapes it (Bennett 1998: 104).

\section{$7 \quad$ Situatedness and Particularities}

To conclude, let me return to what constitutes a heritage regime and how to go about its investigation. Heritage is a project of ideology that is dependent on ambivalent temporal entanglements. Its conceptualization depends on modernity's sense that the present needs to re-forge links with a past that appears to be severed and lost in the changing world. Value-laden in nature, heritage alludes to preservation and celebration of past elements of a reified culture that is intended to manifest ethnicity, locality and history; and yet, the cultural politics involved with heritage proposes to address the concerns of the present, with a foreseeable perspective for the future. However, like all terms in the discourse of culture, heritage is an abstraction, and what it signifies is subject to interpretation and evaluation that may fluctuate between positive and negative over time and through space.

The deconstruction of an international "authorized heritage" regime seems an obvious, though perhaps also the easiest undertaking. It is not too difficult to point out the arbitrariness and contingencies in heritage production, while it has recently become rather widespread to partake in the deconstructive academic analysis of UNESCO programs as an infamous example of cultural engineering. But what kind of agency will be gained or lost as a result of such an academic exercise? What is the moral agenda of this investigation and critique? The descriptive, explanatory attitude towards the act of contrivance in order to unveil the bureaucratic manipulation of "innocent" communities (of practitioners) continues unavoidably to assume normative dimensions such as social criticism and prescribed political commitment. Perhaps based on Utopian longings or even in defense of treasured ideals, this view, nevertheless, seems to regard "culture" and those who act in it to be drifters deficient of will in a "timeless" space. From such a perspective, heritage "happens" to people and not with people. In my view, however, the heritagization process is cultural and polyvalent. It is happening as part of the 21st century condition of global processes that resonate in the making of the local and should be studied from a multi-sited perspective (cf. Marcus 1998). 
Having that in mind, my suggestion is to take the situated character of globalization seriously also in the critical study of heritage regimes, despite their seemingly common mechanism on an abstract level. While considering the contended perceptions of globalism, Anna Tsing has asked anthropologists to extend their study of communities as narrowly defined social spheres to a wider-ranging scope of (transnational) networks, social movements and state policies (Tsing 2002: 472). Transnational and global networks glossed as "universal" tendencies need to be ethnographically studied to unravel encounters, trajectories and engagements. Nevertheless, such processes with their global implications should not be observed simply as cases of imposed hegemony or self-evident homogenization: Global phenomena may unify, but they also show local cultural divergence (Tsing 2002: 477).

Richard Handler has contended that cultural processes (such as heritage curation) are inherently particular and particularizing, so it would be unjustified to expect the reverberations and effect of a global policy to function and produce similar results under diverse circumstance (Handler 2002). An anthropological approach advocates an investigation that utilizes different perspectives to contribute to our understanding of the social world by complicating simplicities. Concrete cases will benefit from being studied from a multi-sited perspective (as suggested by George Marcus 1998), which analyzes decision-making on various levels: international, national and particularly local. Thus this "local" also needs to be studied and analyzed as a multi-sited field.

Research on communities will penetrate deeper if investigated as particularities. Different circumstances make communities of people perceive and employ the emergent potential of recognized agency and the acknowledgment of their cultural rights differently. The claim of universality is found fault with as embodying Western values and codes of behavior that are perceived to be similarly interpreted and ready for application everywhere with insufficient consideration of the local experience. Critical concerns voiced in this respect suggest instead that communities and their insider experience should be involved in studies that employ pluralist approaches (cf. Messer 1997). It seems important not only to elucidate negative experience and the violation of rights, but also to define and investigate moments of empowerment, real instances of emergent agency, and situations where local actors partake in grassroots policy-making. "Universal" rights acquire meaning as they are applied in local variation. Therefore, carefully explored particularities should help us complicate the simplicity of a detached universalism of criticizing an institutional regime.

\section{References}

Appadurai, Arjun (2002): Grassroots Globalization and the Research Imagination. In The Anthropology of Politics: A Reader in Ethnography, Theory, and 
Critique. Joan Vincent, ed. Pp. 271-284. Malden, Massachusetts: Blackwell Publishers.

Arantes, Antonio A. (2009): Heritage as Culture: Limits, Uses and Implications of Intangible Cultural Heritage Inventories. In Intangible Cultural Heritage and Intellectual Property: Communities, Cultural Diversity and Sustainable Development. Toshiyuki Kono, ed. Pp. 51-75. Antwerp/Oxford/Portland: Intersentia.

Augé, Marc, and Jean-Paul Colleyn (2006): The World of the Anthropologist. Oxford/New York: Berg.

Bendix, Regina (2000): Heredity, Hybridity and Heritage from one Fin-de-Siècle to the Next. In Folklore, Heritage Politics and Ethnic Diversity. Pertti J.

Anttonen, Anna-Leena Siikala, and Stein R. Mathisen, eds. Pp. 37-54. Botkyrka, Sweden: Multicultural Centre.

- (2009): Heritage between economy and politics: An assessment from the perspective of cultural anthropology. In Intangible Heritage. Laurajane Smith and Natsuko Akagawa, eds. Pp. 253-269. London/New York: Routledge.

Bennett, Tony (1998): Culture: A Reformer's Science. London: Sage Publications. Blake, Janet (2009): UNESCO’s 2003 Convention on Intangible Cultural Heritage: the Implications of Community Involvement in 'Safeguarding'. In Intangible Heritage. Laurajane Smith and Natsuko Akagawa, eds. Pp. 45-75. London/New York: Routledge.

Bortolotto, Chiara (2010): Globalising intangible cultural heritage? Between international arenas and local appropriations. In Heritage and Globalisation. Sophia Labadi and Colin Long, eds. Pp. 97-114. London/New York: Routledge.

Burke, Peter (2009): Cultural Hybridity. Cambridge/Malden: Polity Press. Canclini, Néstor García (1995): Hybrid Cultures: Strategies for Entering and Leaving Postmodernity. Minneapolis: University of Minnesota Press.

Graham, Brian, Gregory J. Ashworth, and John E. Tunbridge (2000): A Geography of Heritage: Power, Culture and Economy. London: Arnold. Handler, Richard (2002): Comments on Masterpieces of Oral and Intangible Culture. Current Anthropology 43(1): 144.

Hannerz, Ulf (2006): Cosmopolitanism. In A Companion to the Anthropology of Politics. Joan Vincent and David Nugent, eds. Pp. 69-85. Oxford: Blackwell. Hoggett, Paul (1997): Contested communities. In Contested communities:

Experiences, struggles, policies. Paul Hoggett, ed. Bristol: Policy Press. Kirshenblatt-Gimblett, Barbara (1998): Objects of Ethnography. In Destination Culture: Tourism, Museums, and Heritage. Barbara Kirshenblatt-Gimblett, ed. Pp. 17-78. Berkeley/Los Angeles/London: University of California Press. - (2004): Intangible Heritage as Metacultural Production. Museum International 56(1-2): 52-65.

- (2006): World Heritage and Cultural Economics. In Museum Frictions: Public Cultures/Global Transformations. Ivan Karp and Corinne Kratz, with 
Gustavo Buntinx, Barbara Kirshenblatt-Gimblett, Ciraj Rassool, Lynn Szwaja, and Tomás Ybarra-Frausto, eds. Pp. 161-202. Durham: Duke University Press.

Klein, Barbro (2006): Cultural Heritage, the Swedish Folklife Sphere, and the Others. Cultural Analysis 5: 57-80.

http://socrates.berkeley.edu/ caforum/ <accessed June 30, 2012>

Kono, Toshiyuki (2009): Convention for the Safeguarding of Intangible Cultural

Heritage: Unresolved Issues and Unanswered Questions. In Intangible Cultural Heritage and Intellectual Property: Communities, Cultural Diversity and Sustainable Development. Toshiyuki Kono, ed. Pp. 3-39.

Antwerp/Oxford/Portland: Intersentia.

Kuutma, Kristin (2009): Who Owns Our Songs? Authority of Heritage and

Resources for Restitution. Ethnologia Europaea. Journal of European

Ethnology 39(2): 26-40.

Lowenthal, David (1985): The Past Is a Foreign Country. Cambridge: Cambridge

University Press.

Marcus, George E. (1998): Ethnography in/of the World System: The Emergence of Multi-sited Ethnography. In Ethnography through Thick and Thin. George

E. Marcus, ed. Pp. 79-104. Princeton, NJ: Princeton University Press.

Meskell, Lynn (2002): Negative Heritage and Past Mastering in Archaeology.

Anthropological Quarterly 75(3): 557-574.

- (2010): Conflict Heritage and Expert Failure. In Heritage and Globalisation.

Sophia Labadi and Colin Long, eds. Pp. 192-201. London/New York:

Routledge.

Messer, Ellen (1997): Pluralist Approaches to Human Rights. Journal of Anthropological Research 53(3): 293-315.

Napier, A. David (2002): Our Own Way. On Anthropology and Intellectual

Property. In Exotic No More: Anthropology on the Front Lines. Jeremy

MacClancy, ed. Pp. 287-319. Chicago: University of Chicago Press.

Rosaldo, Renato (1995): Foreword. In Hybrid Cultures: Strategies for Entering and

Leaving Postmodernity. Néstor García Canclini, ed. Pp. xi-xvii. Minneapolis:

University of Minnesota Press.

Rowlands, Mike, and Beverly Butler (2007): Conflict and heritage care.

Anthropology Today 23(1): 1-2.

Smith, Laurajane (2006): Uses of Heritage. London: Routledge.

Smith, Laurajane, and Emma Waterton (2009): Heritage, Communities and

Archaeology. London: Duckworth.

Stoczkowski, Wiktor (2009): UNESCO's Doctrine of Human Diversity: A Secular

Soteriology? Anthropology Today 25(3): 7-11.

Strathern, Marilyn (2000): Introduction: New accountabilities. In Audit Cultures:

Anthropological studies in accountability, ethics and the academy. Marilyn

Strathern, ed. Pp. 1-18. London/New York: Routledge. 
Tauschek, Markus (2009): Cultural Property as Strategy: The Carnival of Binche, the Creation of Cultural Heritage and Cultural Property. Ethnologia Europaea. Journal of European Ethnology, 39(2): 67-80.

Tsing, Anna L. (1993): In the Realm of the Diamond Queen. Princeton: Princeton University Press.

- (2002): Conclusion: The Global Situation. In The Anthropology of

Globalization: A Reader. Jonathan Xavier Inda and Renato Rosaldo, eds. Pp. 453-485. Malden/Oxford/Carlton: Blackwell Publishing.

Tunbridge, John E., and Gregory J. Ashworth (1996): Dissonant Heritage: The Management of the Past as a Resource of Conflict. Chichester: J. Wiley.

Turtinen, Jan (2000): Globalising Heritage: On UNESCO and the Transnational Construction of a World Heritage. SCORE Rapportserie (12). Stockholm:

Stockholm Centre for Organizational Research.

http://www.score.su.se/polopoly_fs/1.26651.1320939806!/200012.pdf

$<$ accessed June 30, 2012>

Weber, Max (2002): Võimu ja religiooni sotsioloogiast. Tallinn: Vagabund. 
The Reach of (Post-)Colonial Sentiment and Control 



\title{
The Dynamics of Heritage Choice and Heritage Regimes in the "Making of Old Havana"
}

\author{
Adelheid Pichler
}

\section{Introduction}

Today's representations of tangible and intangible culture in the image of the city of Havana are part of a new politics of identity in Cuba which began in 1994 with first efforts at city-planning. ${ }^{1}$ The representations are the products of a historical and political process, a program of selection, suppression and deliberate omission which expresses an "interpretational heritage choice" (Bhabha 2006: 9). I take up Homi Bhabha's concept to analyze the new dynamics of valuation and devaluation in the framework of heritage productions in Havana since 1994, and consider what it means, in concrete terms, to "appropriate" or "alienate" (Bhabha 2006: 9) specific representations of cultures and societies according to dominant historical, social and scientific contexts.

To what extent are the sites and objects which UNESCO terms World Cultural Heritage products of a blend of science and politics, knowledge and power? To what extent do they represent remains of what was created by colonizing processes, or, in other words, to what extent has scholarship, in particular anthropology

\footnotetext{
${ }^{1}$ I would like to thank the Austrian Institute for International Relations of the University of Vienna (1993 and 1996), the Austrian Fund of Scientific Research (Grant from 2002 to 2006 at the Austrian Academy of Sciences) and the International Institute for Applied System Analysis (IIASA Luxemburg 2011) for financing my studies in Havana.
} 
and history, informed what is pronounced worth preserving and presenting? To what extent can this chosen "cultural heritage" be attributed to scientific and cultural politics up to and including those of UNESCO itself (cf. Csáky 2005; Pichler and Kreff 2009)?

The strategies employed in the determination of cultural heritage are not autonomous. Rather they are themselves a product and part of a cultural heritage of strategies, and illustrate different heritage regimes at work.

From this vantage point, hegemony is revealed as an important and overlooked component in the production of cultural heritage. Hegemony is evident in the practices, strategies and knowledge that are immanent to the undertaking, and work as a third category of cultural heritage that is implicit, but neither material nor immaterial: A "tacit cultural heritage" which conveys the participation of hegemony in the process of cultural inheritance.

My contribution to this volume raises general considerations about hegemony in the making of heritage. Hegemony in the production of cultural heritage becomes visible, firstly, in the politics and form of government which goes hand-inhand with, secondly, a set of rules and cultural, social and ethical norms that regulate the operation of its implementation in urban space, and its control, financing and interactions within society. This leads us to define the legal and administrative heritage regime, which in my usage of the term refers to a particular form of supervision. Rules, principles, norms, and procedures authorize social institutions or international financiers of the tourist industry and their local counterparts to carry out the decision-making process of "choosing" heritage.

I will first examine processes of urban renewal and the transformation of $\mathrm{Ha}$ bana Vieja (Old Havana) to a site of cultural tourism. The territory ${ }^{2}$ has held the title of National Monument since 1978, Cultural Patrimony since 1979, World Cultural Heritage since 1982, Priority Zone for Preservation since 1993, and Highly Significant Zone for Tourism since 1995. The territory has been protected by the Decree Law 143 of 1993 which serves to guide the different regulatory bodies in administering the Convention concerning the Protection of the World Cultural and Natural Heritage and also contains guidance on the protection of national patrimony.

These laws gave the necessary backing to new processes of intervention in the Old Town of Havana starting in 1983, and have promoted a fundamental change in city life and in the perception of the city. The historical centre is no longer late-socialist in appearance and character, but rather a high-priced consumer zone for mass tourism. This is an observation, not a judgment, but the significance of this transformation is far-reaching and will be the subject of my paper.

The description of the process focuses on the implementation of heritage formats within legal and administrative heritage regimes. This process is demonstrated

\footnotetext{
2 The territory covers 2.14 square kilometers and compasses 3,370 buildings. Many of them represent the value of architecture from the 18th to the 20th century. The territory spans different municipalities in Havana Center, Regla and East Havana.
} 
by the example of the Plaza Vieja in Old Havana. Revitalization and the preservation and commercialization of heritage have transformed the entire Plaza over the last 20 years. My description and analysis focuses on different periods of the ongoing preservation process in which local legal administrative regimes have been at work implementing various heritage formats.

In the second section of this paper, I introduce the notion of choice into my analytical framework. Viewing heritage as a result of interpretational choices helps us to put the claims of cultural authenticity and historical genealogies into proper perspective, and addresses the vehicle of the undertaking from the outset. This allows me to look at aspects of tacit hegemony in the production of heritage. This is illustrated with three short case-studies.

The fourth and concluding section of the paper shows that the link between heritage choice and heritage regime is ethical (not only epistemological or symbolic). Heritage choices point to the ethics of cultural transmission and demand that respect for cultural diversity and human creativity need not necessarily come out of the continuity of tradition created by dominant elites. This section examines interstitial cultural practices which work against the dominant interpretation of lateCuban socialist elites and will focus on individuals operating in the interstices of legal administrative regimes.

\section{Legal Regimes, Changing Heritage Formats and the Development of New Agencies to Promote Tourism in Havana $^{3}$}

At one point during my long-term field research in Havana, I lived in the Calle Mercaderes, once the most important business street of colonial Havana. It joins the Plaza Vieja to the Plaza de Armas (the two oldest squares in the city). In 1996, I was working in collaboration with the Office of the City Historian and had the opportunity to be present during their socio-demographic survey of the quarter's inhabitants, accompanying a team of sociologists of the Taller San Isidro. The Talleres de Transformación Integral (workshops-neighborhood offices) link the planners and the inhabitants. Their job is to guarantee the integration of the residents' participation in the development of the neighborhood (Oficina del Historiador 1995; Rodríguez Alomá 1996; Pichler 2004). Working with the specialists of this office, I had access to a broad variety of houses in the quarter, and got to know the neighborhood of San Isidro in the Old Town. I regularly visited residents of one of the ciudadeles (tenements) directly on the square.

The need to take great care in urban renovation and the lack of developmental conceptions for the city as a whole, led as early as 1988 to the founding of a group of experts for urban development (Grupo para el Desarrollo Integral de la Capital,

\footnotetext{
${ }^{3}$ I am focusing on the period of my field research stretching from 1993 to 2011.
} 
GDIC). They initiated the founding of the first neighborhood offices. They were headed by the Office of the City Historian (OHC). The OHC's Master Plan Group was established in 1994 to address the needs of the UNESCO listed area, of central Havana and parts of the Malecon (seaside promenade). The 1994 Master Plan was prepared by a multidisciplinary team with the assistance of the Spanish Agency for International Cooperation (Joynt 2006: 34). The plan's main aims are to preserve the historical patrimony of the city, address urban problems and promote responsible community and urban development, and to manage the social, economic and physical environment through participative planning. In 1995, a register of buildings was produced, including current state and future interventions with respect to all buildings in the historical core.

The Master Plan Group has also produced a Special Plan for the integrated development of the designated Priority Zone aiming at preservation and the creation of a Highly Significant Zone for Tourism. The plan has four main policies which address housing and the potential displacement of current residents, the creation of new employment opportunities for residents and the provision of infrastructure.

The collaboration (with sociologists, architects, archaeologists, artisans, and local informants from the neighborhood) and my own long-term observations have provided me with the opportunity to illustrate processes of symbolic, economic and political appropriation - or, more precisely, preemption - of the oldest square in Old Havana, the Plaza Vieja. Apart from this, I was able to observe the development of the main planning agency - the Office of the City Historian, headed by Eusebio Leal Spengeler - and the establishment of a far-reaching network of specialists, directories and enterprises.

\subsection{Site of Study: La Plaza Vieja}

Since its founding, the Plaza Vieja has been a site for the projections of the varied elite who wanted to give it a face. Its name has been changed several times in the past 400 years and, together with the name, its social and functional identity.

As Plaza Nueva (1559-1632), it served as a ceremonial square; bullfights are mentioned, as well as religious processions. ${ }^{4}$ Under the name Plaza Principal (16321772), it was the economic center of the city and its market square. A fountain was built in the middle of the square during this period, and decorative houses were erected around the park. The aristocratic owners of the houses completed the facades with representative balconies and arcades. Shops, warehouses and stables

\footnotetext{
${ }^{4}$ Sources used for reconstructing the history of the Plaza Vieja: Centro Nacional de Conservación Restauración y Museología, CENCREM. 1983; Núñez Jimènez-Venegas Fornìas, 1986; Oficina del Historiador, 1995; Fornet Gil, 1998. The physical description of the palacios was communicated to me by the architectural historian Ada Valdes López, MSc.Arq.
} 
were installed on the ground floor, while on the first floor, the six-meter-high rooms served as Beaux Étages for the most noble families of the city, with their loggias either external or above the inner courtyards. The lodgings for slaves were in low-roofed intermediate floors (entrepisos), hardly visible, while the high rooms of the wealthy owners continued above them.

Following the British invasion (1762), the city was enlarged and further market centers were developed, and the square increasingly lost its importance. In the 19th century, the square changed names several times (Plaza de Fernando VII and Plaza de la Constitución). In 1835, it received the name Plaza de Cristina. Its Persian windows (jalousies) and brightly painted window panes date from this time. When, in 1863, the city walls were gradually torn down and the urban aristocracy moved to other parts of the city outside the walls, the square received its name Plaza Vieja. This also marked a (spatial-temporal) division between the old and new cities.

At the beginning of the 20th century, the luxurious villas were abandoned to apartment speculators, so that the first multiple-family houses (cuidadeles) could appear on all sides of the square and in the surrounding neighborhoods. In the early-1940s, individual houses on the square were demolished and new ones built, for example, the Palacio Cueto, in art deco style, also an official building (Edificio de Correos). In the 1950s, two apartment houses and a movie theater were erected. The surface of the square was artificially raised and an underground garage was built beneath it. After the Revolution in 1959, new rental laws were introduced prohibiting small businesses. All the shops around the square were closed and the buildings used for residential purposes only. The buildings themselves belong to the state. All substandard houses were put at the disposal of anyone interested in living in them, without rental contracts. At the same time, there was further "wild building," illegal modifications of the houses around the square. As a consequence, there was an over-population and the conditions in the square and its surrounding neighborhood turned more and more into a slum.

The chosen model for the ongoing reconfiguration of the square was a copper engraving which the English traveler Durnford made in 1772 (cf. Juan 1980; Capablanca Rico 1993; Fornet Gil 1998; Delgado Acosta 2000). It shows an abundance of loggias, arcades, coaches, and merchants in self-important poses. Based upon the engraving, Plaza Vieja has been staged as Plaza Principal (cf. Juan 1980: 7). Many segments have been erased from its history. Similarly, what is striking about today's guided tours are the countless empty spaces; the slave labor which was used to construct the monuments, for example, goes entirely unmentioned. The simulated square tells a nostalgic tale of a white, aristocratic past.

One of the other houses on the Plaza Vieja became known as La Ratona (House of the Rats). When I visited the house for the first time in 1996, I found a desolate picture. Like all the many other ciudadeles around the square, it was completely over-inhabited. Thirty-five families lived in the rear of the building. The tenements usually present a quite respectable appearance from the street, not unlike that of a middle-class private residence. The difference becomes evident only 
when one passes the main entrance, looks down the long narrow lane of the interior, and sees a row of doors that face each other at ten- or twelve-foot intervals. Behind each door is a room of twelve square feet or more, accommodating a family. A woman friend led me to her room in the uppermost floor of the house. To get there, we had to climb broken stairs and, in the end, used a home-made ladder with broken rungs. From above, we could partially see into the niches below. One could speak of slum conditions with evident ethnic marginalization: Almost only black Cubans lived here. They shared a kitchen and a toilet in the courtyard and gathered their water from the fountain in the square; there were neither windows nor ventilation. There were 250 people lodged in this and the neighboring ciudadel on the Plaza. The residents paid no rent because of these substandard conditions.

When I visited the city again in 2000, my apartment in the Calle Mercaderes no longer existed and neither did La Ratona. There was now a bank in what had been the house of my former landlady. The ciudadel of my friend at the Plaza had been completely evacuated (as had the other one). The 35 families of the house described above had all been resettled in Alamar (a worker-constructed suburb eight kilometers from the center of Havana).

Some of them moved happily, relieved to find themselves with better livingconditions, but others were dissatisfied, as they had been waiting for years for construction materials promised to them which would have allowed them to remain where they were. It was not possible for the residents themselves to contribute anything toward the maintenance of the buildings. Now their zone was finally defined as a Priority Zone for Preservation (by Law 144 of 1993), but in the service of tourism.

The Old Town of Havana has been transformed over twenty years into a tourist attraction, unimaginable in 1959 and the 30 following years when tourism had been deliberately dethroned as the leading economic sector. Fidel Castro had often vowed that Cuba would not become an island of bourgeoisie-catering bartenders and chambermaids, as had other Caribbean nations (Burchardt 1999: 36). Accordingly, in 1975, only 25,000 non-military foreigners visited Cuba, while in 2000, the figure approached two million (Scarpaci 2000: 290).

Long-term Cuban resident of the Plaza Vieja reacted with some bitterness to the presence of ever increasing numbers of foreign tourists and business people in the city which resulted in the resettling of a high percentage of resettlement. The process started in 1978 when the former intramural Old Town was declared a National Monument. In 1982, the Historical Centre and its fortress system were listed as World Cultural Heritage by UNESCO. The Convention concerning the Protection of World Cultural and Natural Heritage was ratified in March 1981 and came into force in the same year. However, it took until December 1982 before UNESCO acknowledged the status of World Cultural Heritage of the historic centre of the City of Havana. 
The declaration of the historic centre of Havana and its systems of fortification as World Cultural Heritage and the fact that it is subject to the precepts of the Convention concerning the Protection of World Cultural and Natural Heritage has primarily implications for the State of Cuba. In addition to the commitment to protect, preserve, rehabilitate and transmit it to future generations, by its own means and to the utmost of its resources, the State of Cuba is also able to request international aid from the World Heritage Committee for the protection and preservation of this area.

(Oficina del Historiador 2002: 259f)

Salvaging the Old Town represented a virtually unmanageable financial problem. The economic crisis of the Cuban state made the collaboration with UNESCO attractive. The Cuban government justified the financing with foreign participation by pointing out that the upgrading of the quarter through renovation would result in an enormous flow of capital to the benefit of the Cuban people. The actual financial participation of UNESCO was relatively small, but its patronage opened new avenues. The Cuban government agreed to adopt a general policy of UNESCO,

ascribing to the defined area a function in the collective life of the city, integrating its protection into planning programs, developing and stimulating scientific, technical and methodological studies. They also adopted appropriate juridical, scientific, technical, administrative and financial measures to protect, preserve, revalue and rehabilitate the area. (Oficina del Historiador 2002: 259)

The government appointed the institution headed by Eusebio Leal Spengler, the official Historian of Havana, to manage important budgets to undertake this work with a new urban perspective. In the midst of the crisis experienced in the country in the 1990s, the City Historian was thus allowed to transform his institutions into income-generating entities in order to implement an ambitious social, economic and cultural project for the Historical Center of Havana.

The key challenges the city faces are to meet the needs of a fast growing destination for cultural tourism in the Caribbean and to use the economic benefits to promote urban restoration and social provision for residents, the revival of the economy, the welfare of the society, and cultural dignity, which are the main goals of the rehabilitation plan. The rehabilitation process taking place in Habana Vieja is a complex procedure: It is structured around the principal guidelines of economic, social and cultural development. These priorities have been part of the sociopolitical orientation since the collapse of the COMECON countries and the period of hardship that followed in Cuba, called the Periodo Especial. The first is a economic goal: The re-stabilization of the Cuban economy and to find an alternative to the sugar industry. Social goals are the welfare of the people and an increase in em- 
ployment. The third goal is cultural: To raise the awareness of Cuban culture through institutions and events.

The privileged position of the Office of the City Historian in Habana Vieja virtually a state within a state - with its unique status and international support, has made radical changes possible. The engine driving this massive transformation is tourism.

\subsection{Special Administrative Regime for Housing}

A series of legal administrative regimes were established to manage these plans, beginning with a special housing regime: The Territory of the Old Town of Havana was titled a Priority Zone for Preservation according to the Decree Law No. 148. This law extends the authority of the Office of the Historian of the City of Havana, making it directly responsible to the Council of State and strengthening its condition as a cultural institution with its own legal character and hierarchy. This is appropriate for obtaining the necessary financial resources for the restoration and preservation of the territory and for exercising the administrative powers related to development, town-planning and the management of taxes.

Decree Law No. 143 had far reaching implications:

That the occupation of the housing can only be realized by means of ownership or rent, reserving free usufruct for rooms only means establishing regulations with respect to the exchange of property with a residential function and other regulations with respect to granting authorization for work and the use of properties within the zone. (Oficina del Historador 2002: 263 ff.)

The system of control of state owned property situated in the zone allowed for the implementation of complementary norms to those already promulgated, those which emphasize even more the characteristics of the territory in relation to different aspects: renting, exchange, et cetera.

Furthermore, the Cuban interpretation of text of the convention specifies that:

if patrimony is not declared by the competent international organization as cultural heritage (as is the case with respect to some cuidadeles at the Plaza Vieja) and has been, as a result, included in one of the two lists of heritage held by this organization - while it does not in fact mean that the said heritage lacks exceptional universal value - by law it means it does have such "value" $[\ldots]$ for different purposes from those in the registration in these lists. This then is the reason why the Convention for the Protection of the World, Cultural and Natural Heritage is not directly applicable. However, this latter is the situation in which a portion of the territorial object of this analysis finds itself, but which in the light of Cuban legislation constitutes 
national heritage, although not protected by the Convention. (Oficina del Historiador 2002: 259; my translation)

This has consequences for the inhabitants of the square: What happens if residents claim ownership to National Heritage?

\subsubsection{The Case Study of La Casa Conflictiva:}

When I once again stayed for several months in Havana in 2005, there was only one house remaining on the square that had not yet been renovated. It was known as la casa conflictiva (the problematic house). A net had been hung over it, and from outside one saw only the two highest stories, with broken windows and roofing. It was impossible to overlook the need for renovation.

"We're not leaving here. We will wait for the materials to come. We have been living here for generations," Rita, a long-term resident, explained to me.

In the Cuban context, commercialization associated with revitalization and heritage preservation has produced conflicting claims concerning the ownership of a particular type of collective urban property known as "housing given in usufruct." The latter consists of dilapidated tenement housing, dating in some cases from the 18th century, which, until recently, has been considered to possess little if any value. Claimants to this property consist of residents, on the one hand, who claim ownership based on length of residency, payments to the state and socialist guarantees of tenure. The state, in contrast, also claims ownership by its entrepreneurial proxy in the Historic Center, and on the grounds that the buildings in question are national and global patrimony. Legally, this means that residents can be expropriated if need be in the interest of the nation, which implies their adaptive reuse for tourism purposes.

At the time of my last visit in December 2010, the facade of this house had also been renovated, and none of the people I had interviewed in 2005 were still living there. A grill restaurant had been installed on the ground floor, and construction of apartments for long-term foreign visitors to Havana who would pay rent in hard currency was underway in the upper stories.

The case of la casa conflictiva demonstrates the ambivalent and unequal consequences inherent to heritage processes elaborated by regimes: We have to debate curatorial and ethical choices in a given political environment. In the case of la casa conflictiva: The contradictions involved in "recovering" property from residents who claim ownership to it, and the state which seeks to relocate them to Soviet-style replacement housing on the urban periphery still goes on. It is taking on a new dynamic which will have to be studied in the future.

The specialists' aim is the preservation of houses and buildings of architectonic, historic and cultural value, all for finally commercial reasons. These buildings should be restored. Up to now, all the buildings around the Plaza Vieja have been exclusively used for commercial exploitation, as have many other buildings in the 
City core. Zone One has historically valuable buildings and luxury hotels, shopping malls, tea parlors, art galleries, restaurants, and museums, where consumption must be paid for in hard currency only (earlier in US dollars, today in convertible pesos known as CUC).

The exclusively functional exploitation of the historical core of the city is partly justified by strategies for reinvestment in less favored zones of the Old Town (cf. Law 144 1993).

The neighboring Barrio San Isidro is supposed to be shielded from the negative consequences of zoning. Here, the character of the neighborhoods and their milieus are to be, in many respects, preserved. The fragmentation introduced in this way to the Old Town (half-private and half-touristic) is impossible to overlook. Segregation defines space both for residents and for tourists.

\subsection{Administrative Regime of Development}

The Old Town became a zone given "highest priority," and a wide variety of contracts were signed with foreign partners who participated to a great extent in the renovations. The projection of the Office if the City Historian with regard to international cooperation is integrated into the policy outlined by the Cuban state through the Ministry of Foreign Affairs and Cooperation. The Office names strategic guidelines for international cooperation. The $\mathrm{OHCH}$ (Oficina del Historiador de la Cuidad de La Habana) creates its own fund to co-finance international cooperation.

Part of it, the collaboration between the UNDP (United Nations Development Program) and the Cuban Government for the period 1997-2001, is articulated in the declarations and conclusions of the Social Declaration of Copenhagen of March 1995. The cooperation agreement foresees the continuity of the strategy of sustainable human development in accordance with the mandate of the UNPD aimed at the prevention of poverty and the maintenance of fairness. ${ }^{5}$ It contributes to one of the projects that belong to the Strategy for International Cooperation promoted by UNDP and Italy through the Fiduciary Fund for sustainable Human Development, Peace, and the support to countries in special situations, founded by the PNUD in October 1995. UNPD values decentralized cooperation models between the local Italian and European Community at provincial levels. ${ }^{6}$ The governments of the countries and towns participating in the program cooperate

\footnotetext{
5 The UNPD is part of the international cooperation initiative of control and follow-up established to assist in the implementation of the agreements subscribed to by more than 110 countries in the Copenhagen Summit on Social Development in 1995.

${ }^{6}$ Eight cities in the regions of Toscana, Emilia Romagna, Umbria, Lazio Liguria, and Veneto in Italy formally participate in the program. In a joint Cuban-Italian project experts on social and economic matters try to initiate local development in the Cuban provinces of Gramma, Pinar del Rio and the municipality of Havana by, for example, specific training in craftsmanship and construction, .
} 
through the United Nations. The program foresees the co-funding of projects, even duplicating the resources provided by the cooperating city. The international funding includes investment in workshops and education and training in handcraft skills and construction. Many of these skilled workers contribute to different sectors of the reconstruction process. The Office of the City Historian is also responsible for the rehabilitation of housing (it saved close to 4,000 dwellings in the first ten years). From a material point of view, the main benefit has been the recovery of about $33 \%$ of the territory of the Historical Centre; the undertaking as a whole has also provided a significant boost to the local, state-based economy through the large-scale creation of jobs: More than 11,000 new jobs have been created, among them 3,000 for trained employers (Oficina del Historiador 1995, 1999).

The development project for the maintenance of Old Havana legitimized the founding of new companies and organizations, and laws were passed which allowed investment by foreign firms (joint ventures) for construction work. According to Coyula (2002: 66), $80 \%$ of the construction work is in the service of tourism. These accords enabled rapid processes of decisionmaking and planning freed from the normal limitations imposed by the $\mathrm{Cu}-$ ban state bureaucracy. The company Habaguanex, for example, part of the OHC, assumed the legal right to operate restaurants, museums, gift shops, and hotels in Old Havana, just as other state agencies do elsewhere. As such, the firm (and $\mathrm{OCH}$ ) is part builder-developer and part tourism promoter, a mediator between both sectors (Scarpaci 2000: 289 ff.).

\subsubsection{Impact of the Company Habaguanex}

By 2008, Habaguanex managed 25 hotels, including the four-star Santa Isabel and the Ambos Mundos (Hemingway's old haunt), 13 restaurants, 13 cafeterias, 10 openair bars, 22 shops, a bakery, 9 markets and a pastry shop. Among these are buildings on the Plaza de Armas, Plaza de la Catedral and the Lonja de Comercio (business market) on San Francisco Square, facing the new Italian-financed renovation of the ocean terminal at Sierra Maestra dock (UN Habitat La Habana 2007). As mentioned, the $\mathrm{OHC}$ has saved close to 4,000 dwellings in the first ten years of the operation (Scarparci 2000: 289 ff.).

The disadvantages of the far-reaching renovation (resettlement and the conversion of apartments to other uses) were explained to the population as a sacrifice required to meet "social necessities," in accordance with a social development model. Those who managed to stay would be compensated with building materials and improvements in the infrastructure. Today's residents of the quarter pay a high price for the privilege: As a result of the renovation activities, they can be asked at any time to leave their apartments, as they are living in a Priority Zone with national and international value. This is, indeed, what happened to the residents of the so-called "Rat House" described above. 


\section{Heritage Choice, Social Control and Unplanned Dialogs}

\subsection{Social control and Exclusion}

A friend repeatedly says that she always enjoys passing through Havana Vieja, because it makes her feel like a tourist in Cuba. This is what everyone enjoys, except that she then has to return to another reality, not Europe from where the real tourists come. "Cuba wouldn't be so bad," she says, "were it not a prison" (Interview Laura, 2011). In the first phase of its restoration (1996 to 2000), the paths of tourist groups crossed those of police patrols, who checked only Cuban passers-by. At night, "black berets" patrolled the tourist zone with dogs. Their mission was to protect wandering tourists from petty thieves. One consequence is a division which segregates tourist from residential districts. Entire neighborhoods have been fragmented into dollar and peso zones due to these measures, intensifying the dichotomy between tourists with US dollars-CUC and the peso population, and the creation of "no-go districts" with limited and controlled access for the population. The effect of these processes has been the rearrangement of the sociocultural structure of the neighborhood, and the establishment of a completely new spatial order.

In the first period under construction, I also hardly recognized Plaza Vieja itself. It seemed placid, without the typical Cuban activity so well-known to me from earlier visits. It resembled a modern "no-go district:" A cement wall had been constructed around the fountain, and on top of that a ten-meter-high iron fence served as protection against vandalism and for the safety of children playing. The streets that meet at the square were interrupted by gigantic iron chains, and no cars could enter it. Huge metal spheres, each a meter across, had been laid in all four entrance ways to also impede transit for bicyclists. The square was fenced in and made inaccessible to its former dwellers.

Children were no longer allowed to play there and no one could gather water from the fountain, although there were no functioning water lines in the courtyards. There were no longer any domino players, no children playing baseball, no women sitting in front of the house entrances interacting with life in the streets. Instead, a newly-constructed police station extended directly into the square, and police controlled any remaining unhindered crossings.

Ten years later, the square is the centre stage of the performance of a dream of a city, offering, with its newly constructed and (re)historicized backdrop, its tourists and local spectators and actors, a new form of urban quality for late-socialist Havana: Entertainment, consumption, drinking, and esthetic pleasure in clean and safe surroundings. Various levels of the repertoire of cultural and social-cultural signs and symbols have been used to achieve this within only ten years. Architectural references have, for example, been stretched to their limits to represent historical epochs of the square and its significance as a monument of material cultural 
heritage. The historical architectural legacy has been enriched with colorful "flower girls" in 19th century costumes and lively carnival groups, in addition to individual representatives of Afro-Cuban beliefs which decorate the scenery with immaterial images of Cuban colonial history.

\subsection{Regimes of Entertainment, New Forms of Sociability}

The square was a screened-off area, little animated and visibly sealed off in the first period following its renovation. However, in the years since then, new actors have set in motion a spatial appropriation and enlivenment. Artists, providers of religious services and tourists have collectively developed a life of their own which animates the square and expresses a new sociability: Local activities around a livelier square. Tourists are closer to what people do, and locals get used to tourists' habits: Shopping, drinking, sharing time together, looking at people. It appears to be a process of accepting of a new reality.

Many tourists stroll around the square and, along with many Cubans, they fill its restaurants. Women dressed in gaudy "gypsy-style" clothing mingle among the tourists, offering their services as card readers. There are also men and women dressed fully in white, with white caps, who claim to be diviners in the West African Yoruba-derived tradition of Ifá. Sometimes one can hear the rhythm of batá drums echoing from a nearby corner, or see a rowdy, carnivalesque troop of acrobats making its way through the inner city, a welcome colorful and extravagant diversion for tourists, who follow the troupe from the Calle Mercedes to the Plaza de Armas.

The square is no longer monotonous or empty, and many Cubans participate in these activities. When I want to go out with Cuban friends, they usually suggest the square. When we are sitting together, downing overpriced beer and pigs' knuckles, they say, "I wanted to come here, because the food is better than in the office canteen." The square provides them with the feeling of taking a break from the drudgery of the Cuban routine. "This is the way it should always be, and I can only hope that someday I will be able to invite you here" (Interview Lázaro 2010). The bill for the drinks and food corresponds to about a month's wages for my Cuban companions.

\subsection{Regime of Cultural Representation and the Impacts of the Heritage Format "Diversity"}

Beginning in 2003, the tourist industry, entertainment and consumption were linked with a heritage format of diversity and the promotion of intangible heritage in the public sphere. Afro-Cuban religious groups were allowed to enter the public scenery to represent "plurality and multi-vocal cultural heritage" (Prieto Abel, Minister of Culture in Cuba 2003) in late-socialist Cuba. One could observe new city 
life, a vibrant Plaza Vieja, active neighborhoods with the participation of both winners and losers of the transformations, different actors making use of the new possibilities of dialogue: Immaterial cultural heritage had taken on a specific new form, namely religious heritage tourism. A market for Afro-Cuban religions as a new expression of cultural diversity, wrapped into the form of cultural heritage, so that practices which, before the 1990s, had been a cause for exclusion, became a foreground aspect of national identity. Specialized institutions, such as the Yoruba Association founded in 2003, in the wake of the amplification of UNESCO's discourse on cultural diversity, ${ }^{7}$ have promoted African-derived cultural practices not only as reservoirs of national legacy, but also as merchandize in heritage tourism. The acceptance of long ostracized practices in public space is a particularly ambivalent counterweight to the "homogenization" and "simplification" of the Plaza.

\subsection{Cultural Administrative Regimes at Play}

Another important element of the Law 143, 1993, is that it defines two scopes of action and authority for the OCH: One cultural, throughout the entire city of Havana, the other cultural and administrative.

A special tax regime established for the territory designated as Highly Significant for Tourism and Priority Zone for Preservation must be particularly mentioned, "which has the particularity of including a new tax within the national taxation system, with the very special characteristic of having only territorial scope" (Oficina del Historiador 2002: 261). This new tax regulation applies to all cultural performers in the territory who are obliged to pay taxes when they work with tourists. ${ }^{8}$ It is managed and collected by the $\mathrm{OCH}$ and constitutes ordinary income in the budget of the Office.

Hearn (2004) goes on to discuss problems in the San Isidro neighborhood which developed in a project which was designed to sponsor a weekly performance of Afro-Cuban folkloric music, linked to a local health-education campaign. It was soon contested by local hustlers more interested in attracting tourists who could pay in hard currency (CUC). The OHC had to step in to ensure that the original objectives of the project were restored (Hearn 2004: 78 ff.).

Every single performer (card readers, Ifá priests, "gipsy" photo models, even book sellers) are selected characters who receive an identity card (carné) specifying that they are member of the OHC.

All these cultural scenarios meant to attract the tourists combine social contact with mechanisms of control, oriented by a strategic "imagineering", just as the

\footnotetext{
7 In 2005, UNESCO passed the Convention on the Protection and Promotion of the Diversity of Cultural Expressions.

8 The Ministry of Finance defines its current legal norms (in Resolution no. 38, 1997) by implementing a variable tax in the zone applied differently to income in the national currency. The tax must be paid in a freely convertible (hard) currency on legal entities that have premises located in the territory (Oficina del Historiador 2002: 261).
} 
buildings are a corporate blend of "imagination" and "engineering", whose standardized building blocks have been culled from the world of entertainment, the tourist industry and a specific idea of urban development (Baldauf 2008: 15 ff.; Kirshenblatt-Gimblett 2004). The newly invented square interlaces the rationalization and romanticizing of stage-managed urbanization.

\subsection{Unplanned Dialogs - Interlocution of Resistance}

As negative comments on the process are rarely published or studied, I will take the position of interpreting the ongoing manifestation of the "Cuban Ladies in White" (Damas de Blanco) as a specific contribution to the cultural heritage discourse in Cuban streets. The Ladies in White are an opposition movement consisting of wives and other female relatives of jailed dissidents. During the Spring of 2003 (later called Black Spring), the Cuban government arrested and summarily tried and sentenced 75 human rights defenders, independent journalists and independent librarians to terms of up to 28 years in prison. For its part, the Cuban government accused the 75 individuals of "acts against the independence or the territorial integrity of the state." The Ladies in White group was formed two weeks after the arrests. Relatives of the prisoners began gathering weekly to protest against the imprisonments, attending mass each Sunday wearing white dresses and then silently walking through the streets (Damas de Blanco 2012). The white clothing the damas wear is reminiscent of the Argentine Madres de Plaza de Mayo, who used a similar strategy to demand information about their missing children from the 1970s military junta. The Cuban government has attached the Ladies in White as a subversive association. Cuban law limits freedom of expression, association, assembly, movement, and the press. These women take an ethical stance and express a historical understanding in their struggle to address the alienation and absence of free speech in their country.

They have used the openness to alternative voices and diverse communities in Havana since 2003 in their own interpretive way. Wearing white clothes to call attention to the suppression of free opinion in Cuba, they perform a living heritage of contemporary Cuba. White dresses are also worn by iyawós (lit. "spouses of the god"), the adherents of Afro-Cuban religions who are obliged to dress in white during the year following their initiation. The Damas confuse Cuban police, who at first cannot distinguish between a forbidden demonstration of Damas de Blanco or a group of iyawós.

In my interpretation, these women embody the "alienated" part of the dominant Cuban heritage discourse, constructing a heritage of global justice through a process of cultural transmission. Interlocution works profoundly toward the extension of cultural and human rights and the enhancement of cultural agency. 


\section{Conclusion}

This late-socialist Cuban case-study demonstrates that an apparently rational approach to heritage exists which is enshrined in late-socialist ideology and in the administrative structures of the country. The socially empowered elites select and administer "cultural heritage." Although this approach is publicly not accepted nor unquestioned, resistance is rare (but exists) as there is no civil society in contemporary Cuba.

There are generally uncontested "norms" of what elements of the past carry value, and consequently, the government puts structures in place to regulate and manage heritage. The products of this approach are a blend of commercial value and politics, knowledge and power as has been said at the beginning of this paper. What are the implications of these "selections" in terms of what is prioritized for display within a multi-ethnic and multicultural society? Why is it necessary to name it "heritage" and not simply substitute the term with "invention of tradition" (Hobsbawm 1983)? It is difficult, of course, to imagine such guilelessness. The term "interpretational heritage choice" of Homi Bhabha (2006) defines the ongoing transformations and helps to identify how chosen heritage is attributed to scientific and cultural politics in a given political environment.

My starting point was to ask for the tacit link between heritage productionconsumption and the development of an entertainment city: The first implicit link is that we are dealing with heritage chosen for development according to economic criteria. UNESCO authorizes the choice and the local historians-cultural specialists interpret that heritage. The cultural specialist creates a narrative to assuage the public with respect to ongoing transformations, an "interpretational heritage choice."

The label "heritage" stabilizes the ongoing process. From the outset of UNESCO's declaration of Old Havana as World Heritage in 1982, Havana's City Historian Eusebio Leal Spengler prioritized the development of a popular awareness concerning the cultural, urban and architectural values of the Old City. $\mathrm{He}$ presented multiple lecture cycles on both radio and television and implemented programs ranging from sensitization to the promotion of the values of heritage. This initiative led to the creation of the television program Andar la HabanaStrolls through Havana (División de la Prensa Latina y la Oficina del Historiador de la Cuidad 2000), broadcast weekly for over 20 years and personally conducted by Leal, as a centerpiece of his "pacifying" discourse. Leal does not omit explaining and justifying the negative consequences of interventions in urban construction, but, in order to palliate the downside of these intrusions, he invents "assuagement formulas," attributing to these encroachments their own "beauty." This is an attempt, through the esthetization of horror, to mitigate and sublimate it (Wilhelm 2002).

The symbolic and spatial ordering of the city of Havana has been driven by two impulses: An aggressive impulse, proceeding from the marketing by regimes, 
and a pacific impulse, belonging to what I think of as a "prescribed" urban culture which wants to assuage the social divisions and discord which accompany economic development. Hand-in-hand with restoration, revitalization and symbolic renewal, there is a heritage discourse which serves to "pacify" the population. Following the process, teaches us to direct our view toward the double character of the city, which has taken on its form through discovery and foundation, destruction, construction, maintenance, and ongoing threats from enemies outside, or, as Max Weber expressed this, in the tension between peaceful trade and its political and military safeguarding (Weber 1976). With respect to present-day Cuba, one could sum up: Inner-city peacefulness is maintained on the basis of a calculated control of speech, a set of shalls and shall nots. A struggle within political circles as to who rules the control of speech is inherent to this socialization model.

It is, of course, not only the placating voice of the city-narrator Eusebio Leal Spengler which assures the peace in today's Cuba, but rather this unfolds hand-inhand with the intransigent declarations of the Máximo Lider Fidel Castro and the middle-of-the-road speeches of his brother and successor Raúl. The proximity of serenity to aggression in the discourses which accompany the transformation of urban space in the Old Town of Havana is permanently unsettling.

A further link between heritage choice and heritage regime is ethical (not only epistemological or symbolic). The Damas de Blanco take an ethical stance and express a historical understanding in their struggle to address the alienation and absence of free speech in their country. As choice is also a metaphor of dialogue, interrogation and interpretation, chosen heritage works to give voice to the "interstices" of cultural transmission. The process of cultural transmission - tangible or intangible - is, I believe, a critical practice of interlocution, a mode of conversation, dialogue and critical thinking. It has been shown that there is a tension between the choices made by cultural heritage regimes and those made by the inhabitants, and another between what is appropriated from cultural inheritance and what is alienated from it. The metaphor of choice addresses the tension between what we appropriate and what we alienate in the interest of our interrogations and revisions. There is a chance, in these debates, when we introduce choice into our analytical framework.

The Damas de Blanco's claim for free speech is placed in opposition to the highly state-controlled heritage discourse. This calls attention to the ethics of cultural transmission and to the reality that respect for cultural diversity and human creativity does not necessarily follow from the continuity of tradition constantly created by communities in response to their environment (as the ICH Convention declares). As such heritage choice is a metaphor for dialogue and interpretation against the grain of tradition and dominant hegemonic discourses, it opens a way to critical and alternative thought and diversity.

The notion of heritage choice helps to sharpen our sight with respect to unrepresented aspects of diverse cultures that do not fit into the revered meta-narrative of Cuban culture, and that continue to haunt its present. Cultural polyphony (in 
the sense of the ICH) undermines totalitarian co-optation. In today's Cuba, differing perspectives are set off against each other as opposing commentaries and reflections, making explicit ambiguities which would otherwise remain concealed.

Cultural respect requires confrontation and struggle with the ambivalent conditions and agonizing choices with which history and its heritage confronts us. Interlocution, interpretation and dialogue always work profoundly toward the extension of cultural and human rights and the enhancement of cultural agency. Cultural respect for diversity and creativity means, above all, to refuse political respect for exclusion and suppression (Bhabha 2006: XX). From this perspective the expansion of the concept of cultural heritage to include the "intangible" gives even late-socialist Cuba a chance to come to terms with itself.

\section{References}

Appadurai, Arjun (2002): Cultural Diversity: A Conceptual Platform, Sustainable Diversity: The Indivisibility of Culture and Development. UNESCO Declaration on Cultural Diversity. UNESCO Cultural Diversity Series No.1. Katérina Stenou, ed. Pp. 9-15. Paris: UNESCO.

Baldauf, Anette (2008): Entertainment Cities. Stadtentwicklung und Unterhaltungskultur. Vienna: Springer Verlag.

Bendix, Regina (2007): Kulturelles Erbe zwischen Wirtschaft und Politik: Ein Ausblick. In Prädikat HERITAGE. Wertschöpfungen aus kulturellen Ressourcen. Studien zur Kulturanthropologie/ Europäischen Ethnologie 1. Dorothee Hemme, Markus Tauschek, and Regina Bendix, eds. Pp. 337-356. Wien: Lit.

Bhabha, Homi (2006): The Texture of Heritage. Paper presented at the Conference Scope II. Sites and Subjects. Narrating Heritage. Vienna, September 28-29.

Burchardt, Hans Jürgen (1999): Kuba. Im Herbst des Patriachen. Stuttgart: Schmetterlingverlag..

Capablanca Rico, Enrique (1983): La Plaza Vieja: Propuesta de Restauración. Arquitectura Cuba 355-356: 22-31.

CENCREM-Centro Nacional de Conservación Restauración y Museología (1983): La Plaza Vieja. Ediciones Plaza Vieja. La Habana.

Coyula, Mario (2002): The Old, Havana Way. Theme issue, "Tourism in the Americas. Development Culture and Identity", Revista: Harvard Review of Latin America Winter: 66-69.

Csáky, Moritz, and Monika Sommer (2005): Kulturerbe als soziokulturelle Praxis. Bozen: Studienverlag.

Las Damas de Blanco (n.d.): Luchando por la Liberación de sus seres Queridos. http://www.damasdeblanco.com/ <accessed June 2, 2012>

Delgado Acosta, David (2000): La Plaza Vieja: El Edificio Gomez Vila: Un ejemplo de rehabiltatión. Centro Nacional de Conservación Restauración y Museología (CENCREM). La Habana. 
División de la Prensa Latina y la Oficina del Historiador de la Cuidad (2000): Andar la Habana. CD-Rom. Copyright Génesis Multimedia.

Fornet Gil, Pablo (1998): El Centro Historico en Transformacion. La Plaza Vieja (1982-1997). Centro Nacional de Conservación Restauración y Museología (CENCREM). La Habana.

Fox, Richard G., and Barbara J. King (2002). Toward a Richer Description and Analysis of Cultural Phenomena. Anthropology Beyond Culture. Papers from a Wenner-Grenn Conference. Richard G. Fox and Barbara J. King, eds. Pp. 23-36. Oxford: Berg 2002.

Hearn, Adrian (2004): Afro-Cuban Religions and social welfare: consequences of commercial development in Havana. Human Organisation 63(1): 78-87.

Hobsbawm, Eric, and Terence Ranger (1983): The Invention of Tradition. Cambridge: Cambridge University Press.

Joynt, Arthur (2006): Old Havana: Restauration and Utopia. Thesis submitted for the Postgraduate Diploma in Building Conservation. London: Architectural Association.

Juan, Adelaida de (1980): Pintura Cubana. Temas y Vaiaciones. Cuidad Mexico: Universidad Nacional Autónoma de Mexico.

Kirshenblatt-Gimblett, Barbara (2004): Intangible Heritage as Metacultural Production. Museum International 56(1-2): 52-64.

Oficina del Historiador (1995): Primerios Resultados. Censo de Población y Viviendas. Centro Historico de La Habana Vieja. Plan de Dessarollo Integral. Centro Nacional de Conservación Restauración y Museología (CENREM). La Habana: Oficina del Historiador de la Ciudad de La Havana.

- (2002): Plan Maestro. Desfío de una Utopia. Una estrategia integral para la Gestión de salvaguardia de La Habana Vieja. Cuidad Vol. 4. La Habana: Oficina del Historiador de la Ciudad de La Havana.

Pichler, Adelheid (2001): La Habana Bruja. Rituelle Geographie in der Altstadt von Havana. Lateinamerika im Globalisierungsstress. Innsbrucker Geographische Studien 21. Vienna.

- (2004): Havana a Neotraditional Urban Landscape? In Kultur Raum Landschaft. Zur Bedeutung des Raumes in Zeiten der Globalität. Elke Mader and Ernst Halbmayereds, eds. Pp. 52-70. Vienna: Aspes \& Brandes.

- (2005): Kuba - Die utopiemüde Insel. In Trauminseln? Reflexionen über Tourismus und Alltag in vermeintlichen Paradiesen. Margit Wolfsberger and Heidi Weinhäupl, eds. Pp. 211-232. Berlin: LIT.

- (2010): Havanna - Texturen und Bilder. Sozio-kulturelle Eigenlogiken der kubanischen Hauptstadt. Ph.D. dissertation, Department of Social and Cultural Anthropology, University of Vienna.

Pichler, Adelheid, and Fernand Kreff (2009): Zur Ambivalenz des Erbes bei Homo Bhabha. In Erb.gut? Das kulturelle Erbe in Wissenschaft und Gesellschaft. Buchreihe der Österreichischen Zeitschrift für Volkskunde. Karl C. 
Berger, Margot Schindler, and Ingo Schneider, eds. Pp. 335-344. Vienna: Selbstverlag des Vereins für Volkskunde in Wien.

Pichler, Adelheid and Gertraud Marinelli-König (2008): Kulturerbe Stadt. Stadtentwicklung und UNESCO Mandat in Spät- und Postsozialistischen Städten. Bozen: Studienverlag.

Pichler, Adelheid and Havanna Terzett (2007): Havanna ist Kuba. Der Rest die Insel. In Havanna. Vergangenheit - Gegenwart - Zukunft. Gerhard Drekonja-Kornat, ed. Pp. 93-104. Vienna: Lit.

Prieto, Abel (2003): Opening Speech at the 8th World Oricha Congress 2003 hosted by the Yoruba Cultural Association of Cuba, July 7th-13th. Cuba Arte La Habana.

Robinson, Mike (2009): Moving Heritage Forward. Tourism, the Popular and the Hypermodern. In Erb.gut? Das kulturelle Erbe in Wissenschaft und Gesellschaft. Buchreihe der Österreichischen Zeitschrift für Volkskunde. Karl C. Berger, Margot Schindler, and Ingo Schneider, eds. Pp. 75-88. Vienna: Selbstverlag des Vereins für Volkskunde in Wien.

Rodríguez Alomá, Patricia (1996): Viaje en la Memoria: Apuntes para un acercamiento a La Habana Vieja. Cuidad City 96(2). La Habana: Oficina del Historiador de la Ciudad de La Havana.

Scarpaci, Joseph (2000): Winners and losers in restoring Old Havana. In Cuba in Transition. Jorge Pérez Lópe, and José F. Alonso, eds. Pp. 289-299. Association for the Study of the Cuban Economy, 10. Washington D.C.

- (2002): Havana: The Dynamics of Mayoral Executive Power in Havana. In Capital City Politics in Latin America: Democratization and Empowerment. David J. Meyers, and Henry A. Dietz, eds. Pp. 163-192. Boulder: Lynne Reiner Publishers.

- (2007): Comment: GIS and Remotely-sensed Research on Habana Vieja and Jardines del Rey. In Cuba in Transition. Jorge Pérez-López, ed. Pp. 234-236. Association for the Study of the Cuban Economy, 16. Washington D.C.Taylor, Diana (2003): The Archive and the Repertoire. Performing Cultural Memory in the Americas. Durham, NC: Duke University Press.

UNESCO (n.d.): World Heritage List. Old Havana and its Fortifications. http://whc.unesco.org/en/list/204/documents < accessed June 4, 2012>

- (1972): Convention Concerning the Protection of the World Cultural and Natural Heritage.

http://whc.unesco.org/en/conventiontext < accessed June 4, 2012>

UN Habitat (2007): Habitat Scroll of Honour Award 2007 for Eusebio Leal Spengler.

http://www.unhabitat.org/downloads/docs/6554_5263_020-

Cuba\%20\%28Eusebio\%20Leal\%20Spengler\%29.pdf < accessed on June 6 . 2012>

Weber, Max (1976): Wirtschaft und Gesellschaft. Grundriss der verstehenden Soziologie. Tübingen: Mohr. 
Wilhelm, Karin (2002): Zwischen Krieg und Frieden. Sarajewo - Beispiel eines Stadträumlichen Zivilisierungsmodells. In Städte im Globalisierungsdiskurs. Helmuth Berking, ed. Pp. 285-303. Würzburg: Köningshausen \& Neumann.

Wolff, Katrin, Stefan Heerde, Irma Leinauer, Birgit Hunkenschroer, and Markus Stilo (1994): Stadterneuerung in Havanna. In Phänomen Cuba. Alternative Wege in Architektur, Stadtentwicklung und Ökologie. Karlsruher Städtebauliche Schriften 2. Kosta Matéy, ed. Pp. 63-82. Karlsruhe: Lehrstuhl für Städtebau und Entwerfen.

Zukin, Sharon (1995): The Cultures of Cities. Oxford: Blackwell Publishers. 



\title{
Castles Abroad. Nations, Culture and Cosmopolitanisms in African Heritage Sites of Portuguese Origin
}

\author{
Maria Cardeira da Silva
}

\section{Introduction}

"The power of heritage is precisely that it is curated, which is why heritage is more easily harmonized with human rights and democratic values than is culture," says Kirshenblatt-Gimblett (2004: 1). Thus, inscription on the authorized map of world heritage of the communities of nations constructs and exhibits a transnational map of allegedly shared values. However, it would be naïve to adhere to a perspective that views UNESCO as the hegemonic and normative source of the world landscape and cultural values, endowed with the power that produces a map overriding nations.

Alternatively, and testing the limits of an anthropology that is still excessively focused on the hegemonic power-local resistance axis, different ethnographies have found agency and autonomy in local actors. States and non-governmental organizations (NGOs), as well as individuals, negotiate a place, one way or another, through heritage-making processes in the shadow of a would-be cosmopolitan modernity - a modernity that is still being constructed according to the model of a system of nations. This is especially evident in postcolonial contexts.

This axis of analysis continues, however, to privilege in its verticality a view that obscures horizontal and transversal relations between different states and other organizations that often configure the nomination files put together for 
UNESCO and that institute the eventual success of such nominations in heritage regimes. In fact, although we come across an increasing number of studies about heritage in postcolonial and post-conflict countries, there are few that focus, in a comparative manner, on the historical and contemporary specificity of the countries in question and on the particular international relations involved in the processes of colonization that are staged in heritage-making operations.

I present case-studies within this transversal cut based on international networks and relations constructed around Portuguese-influenced heritage sites in Morocco and Mauritania. Through them, it will be possible to see how seemingly contradictory discourses link up with UNESCO rhetoric; I will argue that they seek new forms of cosmopolitanism or at least different types of engagement with modernity for each country and actor concerned, without encroaching upon their own models of nationhood. Although we can observe this kind of process in different contexts, the specificity of the historical, colonial and contemporary relations between Portugal and the countries involved provides a set of stable factors within the comparison.

\section{Portugal - Large Country, Small Country}

Portugal's oldest university, Coimbra University, dates back to the 12th century and it is now applying for World Heritage status. In November 2010, Coimbra University organized the 2nd International Meeting of WHPO (World Heritage of Portuguese Origin), in which 24 countries signed the Coimbra Declaration. The WHPO Network's main goal is essentially presented as:

to promote cooperation between countries with cultural heritage (tangible and intangible) of Portuguese influence so that the tools and knowledge that facilitate access to UNESCO's World Heritage and their management instruments are available to all as provided by the UNESCO's Global Strategy documents. (WHPO 2010)

A great deal could be said about this encounter, a sort of Portuguese display of the UNESCO regime, but I will merely describe the atmosphere in which the event took place and forgo ethnographical rigor here, in order to share later a few vignettes that might allow us to appreciate in loco the effects of the rhetoric developed and summarized there. To describe in a few words what happened in Coimbra - where, apart from Portuguese delegates, there were representatives ${ }^{14}$ from 24 other countries - we could speak of a "forum" of investment in a shared colonial past. This was a game in which everyone could take part on the same level, as Por-

\footnotetext{
14 These were official delegates from the Ministries of Tourism, head offices dealing with heritage making, museum curators, and local or regional representatives of UNESCO.
} 
tugal alternatively represents itself as a large-small country in a peripheral location but with a global vocation, which allowed each of the other participants to position themselves strategically without losing face. Although it is hard to follow this game, it is easy to imagine how in the case of Brazil, for instance, taking into account its economic and political position in the world today, there appears to be an inversion of colonial relations, with "the empire striking back." But the multiplicity of Portuguese rhetoric enables all the partners to make their move, and capitalize on it symbolically and financially.

There are many more World Heritage Sites of Portuguese origin or influence in the world (of which there are 22) than in Portugal itself (of which there are 13) ${ }^{15}$. Portugal is a country with few resources to invest in economic cooperation. In the name of Lusofonia, it prefers to channel them into its more recent former colonies $^{16}$. Cultural cooperation is, therefore, a way to lubricate diplomatic relations with other African countries with which it had more remote historical connections. This paper limits itself to African cases, but Portugal's indirect involvement in places on the UNESCO map of classifications extends to three continents - Africa, Asia and America.

Outside Portugal, World Heritage of Portuguese influence is of colonial origin, or as successive Portuguese governments like to put it, the result of the "first globalization" which was allegedly carried out by the Portuguese. This rhetoric is based on an assumption that simultaneously explains its heritage policies as well as its major forms of bilateral cultural cooperation.

Nearly all diplomatic speeches in this setting are rooted in the idea of Lusotropicalism. Lusotropicalism is an underlying rhetoric of Portuguese colonialism that praises the distinctively Portuguese soft form of colonialism, promoting racial and cultural miscegenation. This concept was proposed by Gilberto Freire - a wellknown Brazilian ideologist - to glorify the virtues of Brazilian hybridism and support multiculturalism. According to Freire, the historical roots of Lusotropicalism were to be found in the multicultural layers of Portugal's own national history: Since its origin, Portugal has known how to incorporate difference into its identity. It was this legacy of genuine tolerance and miscegenation that later on softened Portuguese colonialism and produced what he called Lusotropicalism (cf. Castelo 1998). This alleged Lusotropical distinctiveness of Portuguese colonialism was very useful during the final phase of colonialism and dictatorship - especially after the Bandung Conference, which once and for all stigmatized Portuguese colonialism in

\footnotetext{
${ }^{2}$ One among the latter is directly related to the period of colonial expansion. This is the Hieronymites Monastery in Lisbon built by King Manuel I in 1496 in honor of Henry the Navigator, the first paladin of the discoveries. It has been listed as a World Heritage Site since 1963.

16 There were different phases of Portuguese colonisation. Lusofonia applies to the so-called "Third Portuguese Empire" or return to Africa, when Portuguese colonialism took the shape of a modern project in the 19th century (Clarence-Smith 1985) and could be integrated with what Cooper (2005) calls "late colonialism."
} 
$1955^{17}$ - and still lasts today, deeply embedded and barely undisputed, in the construct of "the Portuguese way of being," and present either in institutional or individual rhetoric.

Cooperation and heritage-making projects at an international level are mainly undertaken in Portugal by the government and the Calouste Gulbenkian Foundation. This important foundation was designed and donated by Calouste Sarkis Gulbenkian in his will dated June 18, 1953. It is a private institution of general public utility and the largest provider of funds for projects within the area of heritage of Portuguese origin. It is part of the European Foundation Centre (EFC) and is involved in several artistic activities, development, science, and education. Its international services provide support for projects that aim - among other things at promoting and disseminating Portuguese culture within the areas of historical heritage and expressions of Portuguese culture through scholarships, subsidies for IT and audiovisual equipment, and donations of sets of works by Portuguese authors. The history of this foundation and the personality of its founder should be taken into consideration in order to understand the resilience of some cultural policies that have remained relatively uncontested in Portugal until today. It should be said (and this still needs further investigation) that in the last years of Salazar's fascist regime, the Calouste Gulbenkian Foundation (FCG) was the main provider of stages and performances for an exercise, albeit restricted, of cosmopolitanism among the Portuguese elites. Among the lower classes, too, the foundation promoted literacy and the arts in creative and effective ways, such as itinerant libraries, concerts and exhibitions throughout Portugal. This lent the FCG an aura of charismatic cosmopolitanism and might explain why - along with the population's gratitude for its generosity and the genuine excellence of its activities in times of a dearth of cultural and artistic events - its cultural policies are approved a priori by most within a civil society. The FCG is still looked upon as a supplier of social distinction, in Bourdieu's terms.

I would argue that governmental heritage-making projects together with those implemented by the FCG at an international level are configured by six fundamental factors. Together, they outline these endeavors' specificities with regard to the bilateral relations with former colonized countries:

1) The discourse of - and belief in - Lusotropicalism and its corresponding political performance;

2) the harmony between the rhetoric of Lusotropicalism and the "creative diversity" oratory of the UNESCO regime;

3) the distant past of Portuguese colonialism in many of the contexts involving this kind of cooperation;

\footnotetext{
17 "Portuguese colonialism can be said to have been in a subaltern position vis-à-vis other international and colonial powers; administered by a small semi-peripheral country with at best a weak economic centre, it was sustained by a dictatorial regime and it lasted until 1975, later than other European colonialisms." (Vale de Almeida 2008: 435)
} 
4) the fact that Portugal's political and economic power in global terms today is innocuous or irrelevant together with

5) its - nevertheless - strategic position in the European Union and its Atlantic vocation; and

6) the boom of colonial nostalgia (Werbner 1998) across the entire world.

It is within this framework that Portugal has been administrating its cultural and participative relations of cooperation, both real and symbolical, in promoting many heritage sites of Portuguese origin. These assumptions have allowed Portugal to replicate a model of nation strongly based on a romanticization of its colonial past, enhancing these global connections under the umbrella of UNESCO's heritagization projects.

Countries with whom Portugal has at times had less friendly relations, nonetheless permit the country to project into the past an idea of cultural co-existence and miscegenation. This sustains, today and internally, an undisputed image of a once great and now as always tolerant nation. This is in line with the vague but unquestionable principles of "creative diversity" that UNESCO broadcasts, possibly relieving the Portuguese people and their governments of the responsibility of having to comply with them in the present and within their national borders.

Nostalgia is both a way of remembering and forgetting. Although Portugal has based its image on miscegenation and cultural tolerance, it is careless about managing its cultural diversity politically. Such diversity increasingly characterizes Portugal as a result of the growing influx of immigrants. Unlike Great Britain or France, there is no clear historical continuity - colonial and postcolonial - in the political guidelines for handling immigration. Throughout its colonialist period, Portugal followed a case-by-case policy, oscillating between models of assimilation and segregation according to the different colonial contexts and moments (see Machaqueiro 2011). Portugal's somewhat casual attitude to its cultural integration policies is supported by the naturalist perception of the Lusotropical "tolerant Portuguese:" Portugal is a large country with a global vocation. The responsibilities in this domain, however, are more easily shrugged off by assuming the obligatory conformity with regard to the European directives on these issues: Portugal is, after all, a small and peripheral country.

The FCG strategy on heritage building seems to rely on the decisions of a restricted number of architects that worked for the Gulbenkian Foundation from the last quarter of the 20th century. Their names and memorials to their attendance can be found in most of the heritage sites of Portuguese influence, from Safi in Morocco to Ormuz in Iran. Prominent historians and archeologists participate in concomitant celebratory processes, as was the case in the publications of four huge and expensive volumes on the Património de Origem Portuguesa no Mundo (Mattoso 2011). The fact that the FCG interventions usually involve a great amount of money for structural rehabilitation might well explain why local agents do not complain about its general neglect of local participation. This might also be explained, espe- 
cially in the case of some impoverished citadels in Morocco, by the fact that the state (or the makzhen $n^{18}$ ) controls most of the heritage ventures.

Portuguese governmental investment on heritage building abroad relies on the national expertise of its ministry departments (especially the IGESPAR, the Institute for the Architectural and Archaeological Heritage, run by architects, historians and archaeologists $^{19}$ ). However, local specialists are also involved, for instance, in Mauritania where a local architect's atelier was hired. Heritagization processes of "Portuguese Discoveries" led by the government are usually developed under the scope of bilateral cooperation programs of development, which would, at least in name, suggest some kind of mutual participation. Nevertheless, these projects are random and subject to political alternation, and subject to the personal approaches and resolutions of the different experts involved. Contingent encounters, such as those resulting from occasional strategies and frail heritage policies, seem to allow for a larger role of local and informal participation in heritage building, even when the states are involved. This was, as we will see, the case in Mauritania where heritage and tourism enabled the emergence of unexpected actors.

\section{Morocco - Enhancing Creative Diversity in Lopsided Neighborhoods}

Despite an evident lack of cultural knowledge on both sides (greater on the part of the Portuguese), one can say that relations between Portugal and Morocco are diplomatically translated into a social terminology of contemporaneous "neighborhood" and genealogical "kinship." Shared Mediterranean cultural values are displayed and honored mainly in a convention significantly called the Treaty of Good Neighborbood, Friendship and Cooperation, signed on May 30, 1994. The common past between both countries is frequently highlighted either recalling the Arab presence in Portugal (8th to 12th centuries) or the Portuguese presence in North Africa (15th to 18th centuries). This is the substance of official speeches designed to embellish economic interests and investments with Morocco, for instance, in telecommunications, road construction and tourism infrastructures. The lopsidedness or asymmetry underpinning this discourses is, however, evident. On a political level, it translates into free circulation of Portuguese citizens in Morocco, while Moroccan citizens must have a visa to come to Portugal. On the symbolic level, heritage of Portuguese origin or influence (as it is diplomatically called) in Morocco is classified, but heritage of Islamic origin in Portugal is still not on the Portuguese list.

\footnotetext{
18 The Moroccan kingdom administrative machinery.

19 The IGESPAR has been recently merged with the Museums and Conservation Institute (IMC), responsible for Intangible Heritage.
} 
Morocco is one of the countries (together with Yemen and Albania) with a classified World Heritage list that includes only walled sites (Creighton 2007). These refer to kasbahs and medinas - Arab cities frozen in time largely as a result of a kind of urban apartheid (Abu-Lughod 1980) practiced by the French - as well as the old Portuguese citadels also preserved by the French with the same political objectives. Both reify a Western presence. Even if connected in colonial times in terms of rules of urban apartheid and cultural disjunction, these are completely different historical and cultural products. Yet it is interesting to note the similarity between the display models and forms adopted for both in terms of heritagization, commodification and consumption. Both also generated identical processes of gentrification and romantic residence tourism.

In 2004, AlJadida succeeded on its second attempt in having its application as UNESCO World Heritage accepted after its name was changed for the sake of its application from the "Portuguese City of AlJadida (Mazagan)" to the "Portuguese City of Mazagan (AlJadida)" - the pressure for the name change came from the Portuguese UNESCO delegation. What was highlighted most in UNESCO's final decision to include the site was the past Portuguese connection of AlJadida. Although the citadel underwent several phases of occupation, in particular as a Jewish quarter or mellah (as the whole site is still known today) until the early-20th century, these cultural connections were not foregrounded as a reason for heritagization. This obviously serves Portugal's purposes. However, from an economic point of view, it was also very much in Morocco's interest to gain UNESCO's approval given the concomitant development of a tourist project along the coastal area between AlJadida and Azamor ${ }^{20}$, a few kilometers to the north, where another citadel was being restored with the help of the Portuguese government. Moroccan officials involved in this process may for this reason have been moved to allow this form of territorial alienation leading to what has been termed dissonant heritage (Tunbridge and Ashworth 1996). As the phase of Portuguese colonization is historically increasingly distant, it is also less threatening in Moroccan memory. The management of heritage of Portuguese origin is in a privileged position in comparison to that of France or Spain, whose colonial past in Morocco is more recent and whose relations with Morocco are strained.

Whatever the case may be, Moroccan concessions to Portuguese requests about its heritage are underscored by the possibility of initiating another discourse, an alternative yet corresponding one in Portugal's favor: A discourse that also falls back on the military and architectural magnificence of the monuments in order not to sing the praises of those who built them but to glorify all the better those who managed to get rid of them.

In AlJadida, as in other sites of Portuguese influence in Morocco, such as Arzila or Essaouira, it is not so much the heritage criteria as advanced by UNESCO

\footnotetext{
${ }^{20}$ Significantly named Mazagan, the old Portuguese name of AlJadida, as well. This is a huge luxury "touristic enclave" mainly funded by South African investors.
} 
that are featured as a tourist attraction. In fact, the Portuguese citadels are in themselves, just as walled-in medinas are, features that are in line with the contemporary tourists' taste as a whole. They are framed and thus displayed for the gaze and enjoyment of tourists, enabling a view of the different strata of occupations following one another through the centuries inside a space that will not allow for large structural and urban changes - a result of "Arab urban structure" throughout centuries and "French cultural apartheid." Therefore, they are, as a rule, centers of huge historical and cultural density with a very active contemporary social life. This is why, in many cases, it is easy to insist on the notion of conviviality, which really only conceals and estheticizes a succession of historical events and frequently hides moments of conflict and "multiculturalist" policies of segregation. Churches that became mosques or synagogues reflect the presence of different religious groups at different times, but the synthetic and uncritical argument is that of a timeless fusion of a common heritage.

As in so many other historical centers, gentrification fluxes interfere with the residents' habitat and daily lives. In AlJadida, urban requalification processes set inflation and real estate speculation soaring. "Like in Palestine" say some young people of AlJadida seated at the entrance to the Portuguese cistern - which is the most important tourist attraction - as they see several houses being bought and restored by foreigners. However, this does not prevent these same young people from displaying a Barcelos rooster - a symbol of Portuguese popular culture as emblematized during Salazar's fascist dictatorship - in one of their tourist shops. They call it, ironically, Dom Sebastião, the king who in Portuguese legends disappeared one misty morning in Morocco and is to return to save Portugal, but whose tomb is well identified by the Moroccans near Alkasr alkibir, where the Portuguese army was vanquished. This is not only parody, or mimicry (Ferguson 2002), but engagement in colonial nostalgia, using different versions of the past, and "jumping scales" (Smith 1993) as a response to neoliberal policies of urban restructuring (Bissell 2005).

In fact, it is not only Portugal that has benefited politically from these heritage negotiations. When members of the Portuguese government visit Morocco, for instance, official committees are sometimes invited to visit Cape Bojador - a headland which is nowadays located in Saharaui territories and has become emblematic in narratives of Portuguese identity such as Lusiadas, Portugal's epic poem. Tacitly or inadvertently, this legitimizes Morocco's sovereignty in this contested region which is still waiting for a referendum on self-determination mandated by the United Nations to be carried out. One of the most recent processes of heritagization in which Portugal has been involved in Morocco is the restoration of a Portuguese cathedral in Safi, also on the Atlantic coast, that hopes to get a World Heritage nomination. The process has been slow and is regularly postponed. The CGF drew up and financed the project which involves evacuating people from about ten medina houses (funded by the Moroccan government) in order to set up an interpretation center close to the cathedral flanked by the mosque. The land on which 
this project is built is habus (waqf) ${ }^{21}$ property. The Moroccan ministry concerned has not raised any objection. Nevertheless, setting up this project involving evacuation for the restoration of the cathedral is obviously a delicate matter as it is located in such a strongly Muslim and poverty-stricken area.

On my last visit to Safi in June 2011, the guard at the cathedral (canyssa) proudly showed me this "Portuguese Jewel" and told me about the restoration plans. He replicated the rhetoric - as repetitive as that of the almuezin call to prayer - that one can hear in every medina that has undergone heritage work: One that echoes UNESCO's proclaimed creative diversity. Performing this, he pointed out the closeness between the minaret of the djema al kabira (the big mosque) and the cathedral's dome; but in this case, in order for the model to conform, the Jewish part was missing. Unlike most medinas (and also the Portuguese citadel in Aljadida), Safi has never had a mellah, probably because the number of resident Jews did not justify one. However, for the sake of conformity with the diversity model, the fact that it did not exist has been converted into an added value: The guard explained that over here, everyone lived together, they shared housing, food and marriages, with no walls to separate them. There had been no need for a mellah. In its rhetoric, the "assimilationist" model seems to be of greater value than the "multicultural" one ${ }^{22}$. Not all discourses on heritage of Portuguese origin in Morocco fall in line with this rhetoric. Space does not permit a thick description of all the political negotiations that are voiced apart from this one. The Safi discourse seems to be hegemonic and not always consensual, seeing that areas of competences and responsibilities often overlap in the labyrinth of administrative quarrels and quickly become competitive and contradictory. There was a time when a delegate from the Safi commune - a political opponent to the municipal council - wanted to bring down the walls of Portuguese origin, saying that they were strangling the city and urban flow. On the other hand, an online petition is underway in Safi that has already been signed by 1,537 people (not one of them is Portuguese) lamenting the abandonment of the Castle at the Sea (which is in danger of collapsing and is also of Portuguese origin). The petition asks to whom the responsibility of saving this "precious jewel" should be attributed. It says:

\footnotetext{
${ }^{21}$ Religious endowment, mainly property, for religious and charitable purposes.

${ }^{22}$ But then, he also seems to be repeating the Moroccan king's speech when he visited the kissayria of Safi two years ago, as reported on local media: "On that occasion, H.M. the King was given an explanation of the integrated plan for the rehabilitation of the old medina of Safi that exhibits all aspects of co-existence among civilisations and religions, characterized by its walls, gateways, a cathedral and Ksar Lebher (sea fortress), Dar Soltane (currently the Music Conservatory), etc." (Darnna n.d.)
} 
No to the collapse through negligence of Safi's Castle at the Sea, the hidden history of the city. The civil society of Safi wonders who is responsible for the safekeeping of this precious jewel: Is it the Municipal Council? The Regional Council? The Culture Delegation? The Tourism Delegation? The Group of Associations of the City of Safi? The Portuguese Embassy? (Société Civile Safiote n.d.)

It is true that the comments - in French - of most of the signatories suggest that they belong to what we could call the cosmopolitan educated class in the strict sense that Boaventura de Sousa Santos defines them: Transnational elites that make a "Utopia" of world "citizenship" viable, thereby making use of something else that he suggests makes this Utopia viable, namely the assumption that there is a world heritage (1997). However, this stance should not be applied to another emerging social group that endeavors to include more recent modern colonization in the heritage-making process: Drawing on the French colonial past, there is an effort to nominate Casablanca to be included among the UNESCO Tentative List. The debate is, in this case, necessarily more heated given the relatively recent end of French colonialism in Morocco and the enduring political tensions with France. The heritage vocabulary used in this case expresses more social strain and could pending further examination - be considered a process of reversed Orientalism (Hendry 2000), and, more significantly, a new form of sophisticated cryptocolonialism (Herzfeld 2002). In the case of Safi, neither the social framework nor the Portuguese origin of the heritage involved seem to lend themselves to these distinction games through the display of discrepant cosmopolitanism (Clifford 1997).

In its heritage regime, Morocco is aiming increasingly at a model of "cultural diversity" for reasons yet to be properly examined. They appear to be connected with the difficulties Muslim countries experience in attracting tourists kept away due to fears of terrorism. Furthermore, the directions outlined signal Morocco's committed efforts to recreate the kingdom within parameters that are not rooted in Islamism. An even more recent example of this involves the reformulation of the ongoing UNESCO nomination process for the capital, Rabat. The process began again by focusing on a walled city - the Oudayas kasba. After this application had been turned down, it was broadened to include a larger urban landscape that links Arab remains with others of Roman, Phoenician and French origin ${ }^{23}$ that can be found throughout the area, thereby playing the trump card of UNESCO's regime of "culture diversity" to manage to include the capital in the Tentative List.

In the land of colonial heritage, all narratives on coexistence became possible; like Orientalism, travelogues and other touristic narratives, they are often incapable of

\footnotetext{
23 This time the only remains of the "Portuguese" presence in the town was excluded: The Hotel Balima, which was designed by a Portuguese architect in the early-1930s and where Che Guevara once stayed. The Ministry of Habous, which owns it, declined to have it included for nomination (I would like to thank Romeo Carabelli for this piece of information).
} 
enlightening the past and thereness; but they are very eloquent in talking about the present and hereness.

\section{Mauritania: \\ Drawing New Maps in the Sand Where the Past is Buried}

If we now turn to Mauritania, the past is not only far away (even further than Morocco, where the Portuguese remained until the 18th century), but also buried in the desert sands. Relations with the Portuguese have a different profile. I experienced this myself when I was welcomed into the tent of the head of the community of Ouadane in the Adrar oasis (north-central Mauritania), where the Portuguese had allegedly built a trading post in the 15th century. I tried to break the ice with the usual performance learned in prior Moroccan experiences. I started the rigmarole of genealogical connections, the rhetoric that Portuguese and Moroccans regularly engage in for formal and diplomatic occasions. The head of the community replied rather skeptically that he did not know of any likely mixing with the Portuguese in his family tree which he certainly knew better than I know mine. I quickly understood that I had ineptly tried to carry out a cultural transfer. Genealogy in Mauritania is taken very seriously, to a much greater extent than in Morocco; it is too serious a domain to allow inventive and metaphorical games that legitimate political protocols. This does not mean that there are not tribes that acknowledge, even more so than in Morocco, that they have historical family connections with the Portuguese. But it is precisely the alleged reconstructive "rigor" of oral history that leaves no room for a metaphorical invention to create links in the present. Curatorship of the past becomes difficult.

Things are different with regard to built heritage. Mauritania provides a good contrasting context to concepts of heritage anchored to its materiality. Still strongly inspired by nomadism, the tangibility of heritage, whether individual or cultural, remains relatively irrelevant for most Mauritanians. It is this very irrelevance that allows such heritage to be commoditized to respond to tourist demands in a straightforward manner. Processes of intervention on heritage of Portuguese origin are also determined by this fact.

Mauritania is a poor, Islamic country with a political scenario that has favored dialogue with Europe and the United States. The Adrar in particular (the northcentral desert zone) is rich in archeological remains and other heritage, most of it yet to be explored. France cared less about this patrimony than, for instance, its Moroccan heritage. Mauritania and particularly the Adrar in the north of the country was seen mostly as a sandy and harsh military district among France's Central African (rhetorically less Arab) possessions. The entire north and central region of Mauritania is inhabited mostly by Arab nomads, and they were seen to possess a rather meager material culture that was more interesting to record on an ethnographic and pictorial level than to reproduce in an organized, commercial manner. 
This economic and political choice accompanied an Orientalist concept of the Bedouin (badyya) civilization as deeply rooted in honor, word and genealogy. They were seen as different from the Arabs of Morocco, who had benefited from the Al-Andalus splendor among other things, and had built a much more tangible and ostensible urban civilisation. The French occupation of what is now Mauritania thus took on administrative and cultural policies that converged more with "Blackness" and "Africanness."

In the postcolonial period, the desert, which the French had to a certain extent seen as a barrier that separated Central Africa from the Magreb, began to be presented as a bridge, a traffic route. While this stance was also determined as a reaction to previous French political and administrative plans, it cannot be explained only in the light of a reductive chronological, and in a way ethnocentric, binomial colonialism and postcolonialism.

In order to understand this change of perspective, from "Africanness" or "Blackness" to "Arabness," deeper domestic political tensions have to be considered. They historically separate the black population - the Pular, Wolof and Soninghé (freed from slavery or descending from former slaves, the Haratin), who make up the main population along the Senegal River - from the Beidan (white Moors), who are of Arab origin and live mostly in the more northern zone and desert areas. Other identity classifications with deep historical roots, such as those that separate the Beidan into warrior tribes (Hassan) and marabout tribes (Zaonia), together with their current links with those in power must be taken into account. They are important for understanding the strategy behind the new nation scenario which can only be sketched for the present paper's purposes.

However, the French colonial administrators, who were obviously determined in their mission civilisatrice, were the first to evince a great desire to find out about the history of Mauritania. Concerns about the conquest and the administration of the people produced regional monographs following consultations with local scholars and depositories of oral traditions. This positivist effort to compile and objectify Mauritanian history brought forth an official market of history, linked with the new government's educational programs after Mauritania gained independence in 1960. This complex series of events allow one to see the patrimonialization process in the light of an "imperial formation" (Stoler 2008). The state exploitation of the Arab Adrar region towns (centre-north), Ouadane, Chinguetti, as well as the more southern Tidjika and Oualata, was of special importance in the reconfiguration of Mauritania into a platform between Arabness and Blackness within a global context where culture was becoming an important resource all over the world. These towns had for centuries been important trading posts along the Saharan route connecting the present Moroccan territory with Timbuktu, a route on which caravans trading in gold, salt, slaves, and gum arabic travelled. They were nominated UNESCO World Heritage Sites in 1996, under the auspices of the Mauritanian Fondation Nationale pour la Sauvegarde des Villes Anciennes. 
In addition to their historical and economical value, the oasis towns of Ouadane, Chinguetti, Tidjika, and Oualata have accumulated the symbolic capital of knowledge and religiosity gathered throughout centuries of waves of pilgrims. They took advantage of the trade routes in travelling from the south on their way to Mecca. Nevertheless. this intangible, symbolic capital does have a tangible, material expression: The passageway for pilgrims, students and ulema ${ }^{24}$ led to a concentration of amazing libraries and collections of manuscripts that many families have kept for generations, some manuscripts dating back to the 11 th century (the 3rd century after $\mathrm{Hijra}^{25}$ ).

The great investment with regard to heritage of Portuguese origin in Mauritania was made in Ouadane, one of these cities. This was the construction of the walls around the ruins of the ancienne ville or old city subsidized under the scope of a bilateral cooperation agreement signed by the Portuguese and the Mauritanian governments. This government decision is difficult to understand according to the monumentalist concept typical of Portuguese cooperation, which is so very committed to raising the profile of Portugal's 16th century "Golden Age of Discovery." Why would Portugal invest a large sum of money in a place that is visited by so few tourists and in a country in which Portugal has no economic and political commitments of any kind? Only cautious ethnography - practically an indiscretion - provided me with an answer after some research. These funds were meant for Guinea Bissau - a member of the Community of Portuguese-speaking Countries which had embarked on a civil war at that time, hence eroding the diplomatic atmosphere for cooperation agreements. It was under this conjuncture and these casual contingencies that the cooperation agreement was advanced during a private meeting between a delegate of the Portuguese embassy in Senegal (since there is no Portuguese diplomatic delegation in Mauritania) and the head of the commune of Ouadane. Such cooperation was, in any case, warranted by the idea that the Portuguese had built a trading post there in the 15th century in order to intercept the caravans of Saharan merchants ${ }^{26}$.

The construction of the walls has played an important role in the touristic promotion of Ouadane, since it permitted a new reading of the landscape: Something which used to be a pile of stones became "ruins" and earned a symbolic density that enabled it to be transformed into a touristic attraction. Most tourist are

\footnotetext{
${ }^{24}$ Plural of alim, literally, sapient. Generally designates legal scholars engaged in Islamic studies.

25 The Muslim year during which the Hijra - the migration or journey of the Islamic prophet Muhammad and his followers from Mecca to Medina in $622 \mathrm{CE}$ - occurred was designated the first year of the Islamic calendar.

26 This still needs to be archaeologically confirmed. The lack of certainty together with the relative symbolic irrelevance of built heritage, allows for different locations of the old fort to be strategically mapped: While the mayor places it 15 kilometers outside Ouadane, the curator of the "Ouadane Museum" endeavors to place it right in the heart of the city to bring together the Portuguese with Jews and resident Arabs and build up layers of cultural tolerance and co-existence again according to UNESCO regimes on heritage and cultural diversity. The curator seeks to confront these regimes with the constant attacks on the heritage sites, for which he blames the mayor.
} 
not aware that, although Ouadane obviously has its own history that it strives to save and now to display as merchandise for tourists, the type of construction that the walls signal and preserve - a ksür - was not necessarily enclosed by walls (cf. Cheikh et al. 2002, Silva 2006, 2010). Consequently, preservationist worries that today are part of daily ideology and practices in Ouadane seem relatively recent and imported. The ruins (gharyba), nowadays circumscribed by the walls built with the help of Portuguese funding, testify to a much more recent and, therefore, from a semantic point of view, much more insignificant past than tourists can imagine. They possess, nonetheless, a fundamental value - rightly accrued by the circumscription that has improved its display. In the eyes of the visitor, they claim the need to preserve, or should I say, to salvage local heritage.

The ethnographies that we managed to carry out on emerging tourism in Ouadane (Silva 2006, 2010) show that what attracts most tourists to Ouadane is this sense of frailty and urgency expressed in the monumental enframing of the ruins and other areas of local touristified life and culture. The motive of safeguarding highlighted by UNESCO becomes a tourist attraction itself. Inadvertently, Portuguese cultural cooperation appears, for once, to have actually contributed to local development.

Part of the local population - frequently the youngest members, the haratin women and others with less symbolic capital and thus less social restrictions - has joined the process: They were the ones to have the "know-how" to participate without losing face and have found economic recourse in it; they also view it as a way to join "modernity" and set themselves free them from harsh social structures that do not concede them many opportunities. Embarking on the process with nothing to lose, they were perhaps the first to assume the "value" of heritage, and propel - and sometimes embody - the value of conservation in itself (see Silva 2006). In this case, and more significantly than what seems to be happening in Morocco, where the government has a greater presence in the whole process of heritagization and touristification, at least part of the local population here has reappropriated in an informal and creative manner the dramaturgy of safeguarding heritage as inspired by the UNESCO nomination and re-activated it by means of Portuguese cooperation.

\section{Conclusion}

Remains of the Portuguese Empire are being monumentalized in different places in North and Atlantic Africa. It is clear in each situation, that there is a mutual interest, both on the part of the Portuguese and local agents, to rehabilitate this heritage. For the Portuguese, it is seen as an economically viable way of attesting to a certain cultural visibility, permanence and materiality so as to reassure the allure of Lusotropicalism that "still" allows it to maintain privileged and peaceful relationships with these countries. For Moroccan makhzen (the governing elite in Mo- 
rocco), it might be used either as a way of legitimating its sovereignty over some parts of the territory or as an additional ingredient to season "cultural diversity," without danger of great political humiliation, while for other Moroccan elites, it can be played as a distinctive card on a cosmopolitanism playing field. Mauritanian authorities can use heritage so as to reinforce internal ethnic and tribal policies and to attract foreign investment. Local residents reinforce via heritagization a need of rescue, which becomes, in itself, an important touristic attraction, and draws external financing of international NGOs guided by the rhetoric of sustainable development.

The further away (geographically and historically) the land of colonial nostalgia is, the more different narratives of coexistence are permitted.

After a semi-peripheral euphoria that led to the careless importation of models of postcolonial studies produced in other academic contexts and spanning different colonialisms, Portuguese anthropologists have been cautious about ways to approach the Portuguese empire. Without whitewashing it as Lusotropicalism frequently does, they have sought to analyze it in its political and social specificities, putting aside analysis of other colonial encounters as they might well obscure different realities.

Portugal's cultural cooperation clearly utilized the heritagization of its colonial past and embarked in "romancing the colonial," even before the expansive growth of colonial nostalgia all over the world (Werbner 1998). As Pamila Gupta (2009) said, "romancing the colonial" can be a starting point for thinking analytically about the larger cultural and material spaces of colonial nostalgia that tourist and, I would add, heritage industries endorse.

This might be a good general outline to cultural insights into postcolonial heritagization processes. however, in order to make them eloquent here and now, one must engage in more specific approaches and take into account the specificity of historical and colonial encounters. As Bissell puts it, "we must pay greater attention to the specific geographies and particular histories of discourses and practices organized around logics of longing and loss" (2005: 225). This involves a comparative effort between different forms, different actors and different moments of colonialism and postcolonialism to which the present case studies contribute.

Portuguese colonialism can be said to have been subaltern to other international and colonial powers ${ }^{27}$. Due to the antiquity and specificity of processes of Portuguese history and colonization in the places examined, it is easier to deal with the politically sensitive meanderings of colonial memory and heritage here than in other contexts. Present relations between Portugal and its former colonies are economically and politically less asymmetrical, and the trajectories of these countries are often very troubled; both factors created very different historical and an-

\footnotetext{
27 Similarly, Portuguese tourism can also be said to have been subaltern and, in a way, subjected to the same "crypto-colonialism" that Herzfeld (2002) refers to in Italy or Greece. The most obvious proof of this is that Portugal itself has been - since the time of the romantic Grand Tour and visits to Sintra - more a tourist destination than a place of departure.
} 
thropological frameworks than those that inspired an anglophone idea of tourism and heritagization processes as a form of neo-colonialism, as formulated by Nash (1978) and de Kadt (1979) and others. Links between anthropology and colonialism have been over-explored, but little work has been done about anthropology's connection with specific forms of decolonization and postcolonial international relations. Following the processes of construction and progressive reformulation of heritage and tourist places during the postcolonial period and in the present are productive, not merely in the epistemological sense inspired by postcolonial studies, but also in the sense of history and political economy that allow for a reflection of the links between anthropology, heritage and tourism with specific forms of decolonization and with contemporary political and economic relations between nations. After all, even though UNESCO proclaims a universal ideal of ultimately transnational more than international proportions, it actually reinforces national projects and reproduces the classicism of 19th century European romanticism that is still embedded in "heritage formations."

We should withdraw our attention from an already exhausted focus on the vertical relations between UNESCO and its nominated sites, the greatest result of which has so far been the reification of the idea of UNESCO as the hegemonic disseminator of the heritage regime. This, together with essentialized reflections on colonial nostalgia, has influenced our academic gaze on cultural landscape too much and might obscure particularities and eloquent dialogues that are in danger of remaining concealed behind apparent conformity.

Acknowledgments. This research was carried out within the Project "Portuguese Castles abroad II. Heritage, Tourism and Portuguese cultural cooperation in African contexts," funded by the Foundation for Science and Technology (Portugal).

\section{References}

Abu-Lughod, Janet (1980): Rabat. Urban Apartheid in Morocco. Princeton: Princeton University Press.

Almeida, Miguel Vale de (2008): Anthropology and Ethnography of the Portuguese-speaking Empire. In A Historical Companion to Postcolonial Literatures. Continental Europe and Its Empires. Prem Poddar, Rajeev S. Patke, and Lars Jensen, eds. Pp. 435-439. Edinburgh: Edinburgh University Press.

Bissell, William Cunningham (2005): Engaging Colonial Nostalgia. Cultural Anthropology 20(2): 215-248.

Castelo, Cláudia (1998): O modo português de estar no mundo: O Lusotropicalismo e a ideologia colonial portuguesa (1933-1961). Porto: Edições Afrontamento. 
Cheikh, Abd El W.O. with Sylvain Estibal, Bruno Lamarche and Vincent Vernet (2002): Sahara. L'Adrar de Mauritanie sur les traces de Théodore Monod. Paris: Vents de Sable.

Clarence-Smith, Gervase (1985): The Third Portuguese Empire, 1825-1975: A Study in Economic Imperialism, Manchester: Manchester University Press.

Clifford, James (1997): Routes: Travel and Translation in the late Twentieth Century. Cambridge, MA: Harvard University Press.

Cooper, Frederick (2005): Colonialism in Question. Theory, Knowledge, History. Berkeley: University of California Press.

Creighton, Oliver (2007): Contested townscapes: the walled city as world heritage. World Archaeology 39(3): 339-354(16).

Darnna (n.d.): Forum du Communautes Originaires du Maroc. http://www.darnna.com/phorum/read.php?2,54537,page=3

$<$ accessed December 11, 2011>

Ferguson, James G. (2002): Of Mimicry and Membership: Africans and the New World society'. Cultural Anthropology 17 (4): 551-569.

Gupta, Pamila (2009): Romancing the Colonial on Ilha de Mozambique. Paper presented at the Conference on Emotion in Motion. The Passion of Tourism, Travel and Movement, Leeds Met University, July 7.

Hendry, Joy (2000): The Orient Strikes Back: A Global View of Cultural Display. Oxford: Berg.

Herzfeld, Michael (2002): The Absent Presence: Discourses of CryptoColonialism. South Atlantic Quarterly 101(4): 899-926.

De Kadt, Emanuel (1979): Tourism - Passport to Development? New York: Oxford University Press.

Kirshenblatt-Gimblett, Barbara (2004): From Ethnology to Heritage: The Role of the Museum. SIEF Keynote, Marseilles, April 28, 2004 http://www.nyu.edu/classes/bkg/web/SIEF.pdf < accessed 2 May, 2011>

Machaqueiro, Mário A. (2011): Islão Ambivalente: A construção identitária dos muçulmanos sob o poder colonial português. Cadernos de Estudos Africanos 22: 43-64.

Mattoso, José (ed.) (2011): Património de Origem Portuguesa no Mundo. Lisboa: Fundação Calouste Gulbenkian.

Nash, Dennison (1978): Tourism as a Form of Imperialism. In Host and guests. The Anthropology of Tourism. Valene L. Smith, ed. Pp. 37-53. Oxford: Basil Blackwell. Pp. 37-53.

Santos, Boaventura de Sousa (1997): Por uma concepção multicultural de direitos humanos. Revista Crítica de Ciências Sociais 48: 11-32.

Silva, Maria Cardeira da (2006): Hospedaria Vasque: Cultura, raça, género e expediente num oásis da Mauritânia. Etnográfica 10(2): 355-381.

- (2010): Mauritanian guestbook: shaping culture while displaying it. In Tourism and Visual Culture, vol. 1: Theories and Concepts. Catherine A. Palmer, Jo- 
Anne M. Lester, and Peter M. Burns, eds. Pp. 181-191. Oxfordshire: CAB International.

Smith, Neil (1993): Homeless-Global: Scaling Places. In Mapping the Futures. Local Cultures, Global Change. Jon Bird et al., eds. Pp. 87-119. London: Routledge.

Société Civile Safiote (n.d.): http://www.soschateaudemersafi < accessed December 11, 2011>.

Stoler, Ann Laura (2008): Imperial Debris: Reflections on Ruins and Ruination. Cultural Anthropology 23(2): 191-219.

Tunbridge, John E., and Gregory John Ashworth (1996): Dissonant Heritage: The Management of the Past as a Resource in Conflict. Chichester: John Wiley \& Sons.

Werbner, Richard (1998): Memory and the postcolony: African anthropology and the critique of power. London: Zed Books.

WHPO (2010): Rede WHPO formalizada na Universidade de Coimbra.

http://www.uc.pt/noticias/09_nl_2010/nuc04_102010

$<$ accessed December 9, 2011> 


\title{
Uneasy Heritage: Ambivalence and Ambiguity in Caribbean Heritage Practices
}

\author{
Philip W. Scher
}

\section{Introduction}

This essay explores the issue of public debates about history through the examination of controversial public monuments in the Caribbean. In addressing this concept, the idea of what constitutes historical debate immediately emerges. Debates about "what happened" in the life of a community, society or nation range from academic arguments all the way to violence and vandalism taken against historic sites, monuments and archeological digs. The stakes are often extraordinarily high and the results may be extraordinarily drastic. All of these things are concerned with history and are, as such, the rightful province of heritage studies, conceived as the present's use of the past. The stakes may be raised further as heritage becomes increasingly important as an economic activity and may lead to specific interventions into specific areas of a community's culture in order to secure viability into the future. Such interventions range from institutional oversight and protection of cultural forms to exploring legal protections. Justification for state or governmental involvement in the representations of historical events is often manifested through "nation branding" which makes a strong case for the preservation of history while at the same time positioning the nation-state as the only legitimate political entity because it has the ability to define, safeguard and promote that which is key in 
creating economic health and competitiveness. This essay focuses on the routine and seemingly seasonal debates about the fate of the statue of Horatio Nelson in Heroes Square in downtown Bridgetown, the capital city, as well as an earlier outcry over a statue raised to honor emancipation.

\section{The Heritage Landscape: Barbados}

Sarah Ann Gill is one of ten national heroes of Barbados. This distinction was bestowed upon her memory in 1998. Gill, a Methodist free colored woman of the early-19th century, was elevated to the status of national hero as a result of her outspoken resistance to religious oppression in the British colony and her persistence in preaching Christian doctrine to the enslaved population of Bridgetown. She was persecuted and threatened by representatives of the white planter class, who both opposed her attempts to convert slaves and her non-conformity to the Anglican Church. In the face of a violent mob she protected her home and land. In April of 2010, she was called the "mother" of the nation by noted University of the West Indies historian Henderson Carter in a lecture in the Parliament building. Dr. Carter, in the same speech, called for the re-introduction of the teaching of history to secondary school children in forms one to three (Barbados Advocate, April 25, 2010).

There are two noteworthy aspects to this lecture: Firstly, the home of Sarah Ann Gill, "mother" of the nation and defender of her house and land: The Methodist Church, to which she had willed her property, had had that very same structure demolished in February, 2009. Secondly, Dr. Carter's talk highlighted the fact that history as a subject is not taught to early secondary school students. It is also not taught to elementary school students. In the wake of the demolition of the Gill house, historian Karl Watson wrote: "the glittering process of modernization dulls our historical consciousness and the relevance of old buildings with historic associations is often questioned. New high rise buildings are equated with the notion of progress. Old structures seem symbolic of the past and of stagnation" (Watson 2009: 187).

In an essay in the same volume of Slavery and Abolition, Jamaican scholar Annie Paul details the debate that surrounded that country's decision to commemorate the abolition of slavery in 2006 and 2007. Paul notes that certain segments of the society (she cites the example of the parish councilors of St. Elizabeth, Jamaica) were unhappy with what they complained was the continual focus by Jamaican scholars on the issue of slavery, noting that they (the councilors) preferred to think more about the economic future of the island. At the same time, Paul quotes the Kingston and St. Andrew Corporation's resolution that: 
the government and the local authorities, as well as the Jamaica National Heritage Trust, should make plans "to renovate existing historical sites, and to erect additional statues and monuments to transform Kingston, Spanish Town and other towns, ahead of Cricket World Cup 2007. Thus making our city and towns of historical interest to the thousands of visitors expected to attend Cricket World Cup 2007. (cited in Paul 2009: 169-170)

According to Paul:

The St Elizabeth councilors, however, begged to differ. A newspaper article quoted: the comments of two senior councilors, Wright and Sinclair: "I do not wish to remember that kind of thing," said Sinclair. "Talking about the slave trade and slavery is just reminding ourselves that whites had domination over us. We need to leave slavery behind and forget it. All I want to know is how to develop this country. (Paul 2009: 170)

Indeed, there was a subdued reaction to the commemoration of the abolition of the slave trade all across the Caribbean region, except mainly in academic and some government circles. Often, as Watson notes, local residents in Barbados and elsewhere commented that "by focusing so heavily on the period of slavery, negative feelings and feelings of inferiority were strengthened rather than dissipated among the young" (Watson 2001: 180). Furthermore, the reminders of slavery contributed to the opinion that young people in Barbados could never "make it" and that it was better to focus on the future and on material gratification and success.

It would appear from this evidence (and this is only a small sample of such comments) that the focus on slavery in the Caribbean is frequently perceived as detrimental at the psychological level and ultimately a hindrance to the economic development and betterment of the nation and its population. The specific issue of the commemoration of the abolition of the slave trade in 2007 and the events surrounding the demolition of the Sarah Ann Gill house in Barbados are only two of many events in the past few years that highlight a deep ambivalence about the role history should play in the consciousness and public life of the nation. Just to enumerate some of these events:

- October 2008: A "slave hut" is demolished in Rock Hall Freedom Village.

- March 2009: Concert promoter Al Gilkes calls for the demolition of Farley Hill House, the remains of Barbados' "most magnificent plantation house."

- October 2010: Fire ravages historical landmark Sam Lord's Castle.

- Ongoing debate over the presence of Horatio, Lord Nelson's statue in the center of Bridgetown. 
A vocal portion of the population in the wake of these events was generally outraged, disappointed or cynically philosophical about the failure to preserve and protect heritage sites. However, it does not appear, on the whole, that such publically expressed sentiment is accompanied by any real political action. Overall, however, it becomes clear that the resistance to the focus on slavery and the slave trade in the Caribbean derives from wanting to move on, to leave the past behind and think about the future of the nation; primarily, the economic future. Yet the economic future of Caribbean nations is increasingly becoming dependent, at least in part, on developing heritage into a marketable commodity. Thus, the desire to leave the past behind and the desire to foreground the past in the expansion of a heritage-based tourist economy are increasingly coming into conflict. The expression of this conflict manifests in both public debate in the press, in parliaments and government agencies, in the university, and finally in public expression. These debates are not always clearly articulated in these specific terms and one must often read the silences and general ambivalences as voices in their own right. Nevertheless, a significant dimension to the global push to develop heritage tourism at both the tangible and intangible levels is a problem of what to do about heritage that makes a significant portion of the population uneasy, angry, hurt, and distressed.

\section{Background on Barbados}

For the purposes of this paper, I focus primarily on the nation of Barbados. Here, in this small Caribbean nation of 166 square miles, the legacy of British colonial power is perhaps most strongly felt. Barbados was settled by the British in 1625 and achieved independence in 1966 having never been the colony of any other European power. It is, in fact, the only Caribbean colony never to have changed hands. In that regard, it has some of the most enduring and impressive examples of English Caribbean colonial architecture. Furthermore, unlike many of its neighbors, the newly independent government of Barbados did not indulge in the usual post-colonial erasure of the monuments and buildings of the former colonizers. Whatever one's political views on the subject, many parts of Barbados look as they might have in the late-19th and early-20th centuries. In addition, many of the plantation houses are still privately-owned and inhabited, and although they are generally inhabited by whites, they are not always the descendants of the original owners. Outside of the plantation homes, Bridgetown, the country's capital, has many examples of churches, government buildings, former hospitals, and military structures from the 18th to the early-20th century that survive. The Bridgetown garrison, the subject of intense historic preservation activity, for example, contains some of the most impressive and contextually intact British military buildings in the Caribbean along with perhaps the most complete collection of early cannon in the world. 
Through this landscape, the population of Barbados, 95\% of African descent, moves on a daily basis. The structures that impose themselves on the visual experiences of the majority of "Bajans" is saturated with the history of how this colony came into being, how and why Africans were brought here and how they were treated for 350 years. The idea of "commemoration," whether it manifests in placing plaques on noteworthy buildings, sites of slave sales, locations of resistance and rebellion, having celebrations or ceremonies of remembrance is met with profound ambivalence by many Barbadians. Indeed, the general neglect for historic buildings and sites is itself testimony to the general lack of interest in highlighting "history" in Barbados, and where history is preserved, for instance, in museums and galleries, there is often the observation that slavery is downplayed or even erased (Price 2001, Watson 2009). The charge, for it often appears as such by artists and intellectuals, that the Caribbean is a place of "amnesia," of "pastlessness," of forgetting is an extremely common one in the Caribbean (Walcott 1974, Trouillot 1995, Reinhardt 2006), especially as it pertains to slavery. However now, as Walkowitz and Knauer indicate,

in the wake of deindustrialization and economic restructuring, everyone from grass-roots organizers to politicians and developers stresses history (or "heritage") as an element of the cultural or creative economy that they fervently believe (or hope) will serve as a magic bullet to revitalize sluggish local and regional economies. (Walkowitz and Knauer 2009: 5; see also Klak 1998)

There is increasing pressure to pursue diversification in the tourism market in Barbados. Citing falling revenues in other sectors, attributable, for instance, to the pursuit of neoliberal economic policy throughout the region and the devastation such policies have wreaked in manufacturing and agriculture, national governments are increasingly turning to those resources that are not subject to intense international competition. Even the more traditional sectors within the tourist economy, such as resorts, beaches, tropical landscapes, et cetera, are increasingly competitive and market share is harder and harder to come by.

The development of cultural and heritage tourism in the Caribbean comes as a result of distinct historical and economic pressures. The shaping of local economic strategies has most recently been by agents of neoliberalism, such as the World Bank, IMF, Inter-American Development Bank, World Trade Organization, and others. The influence of such powers as the United States and European nations is not, of course, new to the region. The Caribbean, as we know it, was created almost entirely by such "global" economic powers. What is somewhat newer is the elimination of whole economic sectors by the dismantling of colonial or postcolonial era protections and guarantees that has resulted, overall yet unevenly, in a massive tourism sector. Based originally on the foreign enjoyment of the natural attributes of the islands, Caribbean tourism and the landscapes promoted to for- 
eigners through travel advertisements very quickly became enmeshed with representations of the people themselves who inhabited the islands (Thompson 2006).

In Caribbean tourism, as far as many North American consumers are concerned, there may be little to differentiate one island from the next, or one allinclusive resort from the next. In the parlance of the tourism industry, this is the danger of substitutability. Transcending this "substitutability" by supplying comparative advantages has become a primary strategy in gaining market share. In that sense, seizing on that which differentiates one place from the next has meant commodifying cultural forms, such as Carnival in Trinidad and Tobago or "scratch music" in St. Croix. This strategy is not only imperative; it leads to specific interventions into expressive culture in order to, as mentioned above, secure the longevity of the festival into the future. Again, such interventions range from institutional oversight and protection of cultural forms to exploring legal protections (Scher 2002).

That being said, some amount of substitutability is clearly desired: For instance, in terms of Caribbean clichés that European and American consumers will readily recognize, a certain stability is required, especially in such areas as climate and landscape, vernacular architecture, music and festival, et cetera. I can recall a Trinidadian friend explaining to a visitor during carnival that Trinidad is not "typically Caribbean" in terms of its appearance. For that, he said, one must travel to Tobago, which has the classic appearance of a Caribbean island with its white sand and turquoise waters.

This brings up a continuing tension in marketing between that which all recognize as being fundamentally Caribbean, and that which differentiates one place from the next in such as way as to make it a specifically desirable destination. Striking that balance is not easy, especially when another dimension of neoliberal development is the opening up of markets to an influx of foreign businesses that threaten to homogenize the local.

The concept of "nation branding" is designed to solve some of these problems. Nation branding as an idea and practice has been pursued by such diverse countries as Taiwan, Jamaica, Poland, New Zealand, and Botswana. Briefly defined, nation branding involves "engaging the profit-based marketing techniques of private enterprise to create and communicate a particular version of national identity"(Aronczyk 2008).

With regard to Jamaica, nation branding has been a key strategy for economic development and national culture figures prominently in its implementation. Indeed, by its very definition, nation branding trades on the creative output of the people. Jamaica's Ministry of Industry, Investment and Commerce, through its agency Jamaica Trade and Invest (JTI), has pursued nation branding aggressively. In a recent speech given at the "Target Growth Competitiveness Committee's Minister's Forum" on "Competitiveness in Manufacturing," at the Hilton Kingston Hotel, Robert Gregory, the JTI president, said, "leveraging Jamaica's culture into high-value, globally competitive niche products and services for economic wellbe- 
ing and sustained prosperity, represents the next economic frontier for the "creative economy." He further stated, "that over the last 20 years, Jamaica has been transformed from a primary agricultural producer, to a predominantly servicesbased provider." Mr. Gregory contended that the only way the country's goods and services could achieve the competitive edge, is through the nation's culture, "which makes us different from the rest of the world."

Compare this, for instance, to Trinidad's National Carnival Commission's statement regarding its attempts to protect and preserve the traditional characters of carnival:

The characters in Trinidad's traditional Carnival are the repositories of very important features which distinguish Carnival Trinidad and Tobago style from other Carnivals. They add to the uniqueness of the national festivals which, with calypso, pan and, above all else, the spirit, create a differentiation of the product as Trinidad and Tobago Carnival claims a niche in the world economic market. (Cupid 1994: 3)

Or yet again, from Barbados' National Initiative for Service Excellence:

The national vision for Barbados is to be a fully developed society that is prosperous, socially just and globally competitive by the year 2025. The national strategic plan embodies the theme "Global Excellence, Barbadian Traditions", which conveys the message of a Barbados that is a successful and globally competitive society, fully integrated into the world economy, but at the same time capable of preserving and strengthening its own identity, enterprise, national sovereignty, and traditions. (NISE Website; accessed March 15, 2009)

Strongly evident in this kind of rhetoric is the idea that culture is the key to economic success because it creates clear product differentiation. In its conception, nation branding makes a strong case for the preservation of the nation-state as the legitimate political entity because it has the ability to define, safeguard and promote heritage, an idea implicitly sanctioned by the structure of such international bodies as UNESCO (Askew 2010: 39). Diversifying the tourism sector is seen by many economists as a way of capturing tourism dollars by capitalizing on other attractions, such as eco-tourism, cultural attractions, history and heritage, et cetera. In the case of Barbados the most obvious "untapped" resource is its historical attractions.

It may be taken as evidence of the economic potential for heritage tourism that state agencies as well as private sector interests came together for the purpose of a particular heritage project: The nomination of Historic Bridgetown and its Garrison for UNESCO World Heritage designation. A World Heritage Committee was created to advance the nomination process and create the nomination documents 
to present to UNESCO. A nearly 100-page document, the Historic Bridgetown and Garrison Management plan, was written which details, going forward, the management and development of the proposed site. In fact, the original dossier sent to UNESCO argued for the designation of a significant section of the city; a linking corridor, and the Garrison and Savannah, a former military base with historic buildings dating to the late-18th century, historic race track, cannon collection, and other items of significance. The site was officially declared a World Heritage Site in June, 2011.

The management plan gives a key insight into the collection of parties and organizations whose work must be coordinated and mobilized to ensure the nomination process is a success and to reassure UNESCO that the site will be wellmaintained. That so many governmental organizations are involved and seemingly supportive of the project gives some indication that heritage has increased in importance in Barbados in recent years. There are 14 distinct entities listed in the report that would play a part in the management of the sites. These range from the Heritage Committee itself to The Town and Country Development Planning Office, the Ministry of Culture, Sports and Youth, the Ministry of Tourism, the University of the West Indies, the Chamber of Commerce, et cetera. Interested parties in the private sector include religious organizations that control historic churches on the site to the National Trust, The Barbados Museum, The Barbados Defence Force, et cetera. In addition to the coordination of these various institutions and agencies, legislation has been passed recently with the specific aim of preserving cultural heritage. The Amended Physical Development Plan of 2003, for example, pays special attention to historic buildings and sites in ways that are clearly more detailed and far reaching than ever before. Even more recently, the proposed Antiquities Bill provides for much more stringent penalties for the destruction of heritage sites. Yet the mountain of documents, legislation, suggestions, and proposals is ultimately only as effective as the revenue stream, enforcement and public can make it. The increased attention that the World Heritage designation has garnered for heritage in Barbados is directly linked to the expansion of the tourism industry, as noted above. Whether or not a general interest in heritage can be maintained still remains to be seen. The following section of the paper gives a casestudy to underscore some of the issues faced by Barbadians with regard to embracing the heritage that would, ultimately, form the foundation of the heritage tourism industry itself.

\section{Public Monuments: Ambiguity Set in Stone}

I want to turn now to two statues and public monuments in Barbados. The purpose here is to examine two different sets of debates about two very different public monuments in order to show some of the attitudes that Barbadians have towards their own history and specifically about how it is represented to locals as 
well as foreigners. These attitudes about history are presented in order to gain some insight into a local ambivalence towards the active pursuit of a heritage-based tourism industry to complement existing tourism modalities (Macdonald, 2009: 93-104). I conclude with the suggestion that a particular kind of historical narrative that has dominated in the Caribbean region, the resistance narrative, may have necessarily, but unintentionally, limited the contemporary uses to which heritage may be put. This would seem to have important consequences for attempts to create a heritage-based tourism industry.

\subsection{Case 1: Redemption Song}

Public monuments in Barbados, and indeed throughout the Caribbean, are largely memorials to significant figures or events in the building of the nation. If they are monuments that were left by the colonizers, then they are often re-evaluated through the lens of whether or not they are appropriate objects for public contemplation in that regard. As Petrina Dacres has pointed out, many monuments in the Caribbean celebrate the moment of or the passage to independence and the birth of the modern nation (Dacres 2004). Overcoming slavery is a significant part of this story. She has also astutely noted that in the absence of "wars of liberation," some Caribbean states have focused their monumental displays on struggles of resistance, slave rebellions, et cetera. Indeed, this may be seen as a dominant trope in public sculptural displays in the region. However, unlike Jamaica, which makes up for a lack of a specific war of liberation with a rich history of slave and worker rebellions, maroon wars and the like, Barbados has very little to memorialize in this regard. Comparing the roster of national heroes between Jamaica and Barbados we find that although both share a dearth of female figures, and Jamaica has three fewer national heroes (seven as opposed to the ten of Barbados), more than half of Jamaica's are connected in some way to rebellion, maroon resistance or racial pride.

In Barbados the history of slave uprisings is complex. Slaves undertook three major rebellions in Barbados in 1649, 1675 and 1692. These were put down at great cost to human life. There seem to be no historical records of any armed slave insurrections occurring in Barbados between 1702 and 1815. This may have been due to the presence of a large military force on the island. The most visible slave rebellion in terms of public history was the 1816 Easter Rebellion, often known as Bussa's Insurrection.

Ultimately, in Barbados, the narrative of a struggle toward nationhood is placed within the workers' or trade union movement. In either case, the emphasis in national monuments reflects a general conflation between the origins of the nation through struggle and the freedom of the majority of the people through struggle; but these are not the same thing. To explain this position further, I would like to take a brief look at a public debate that has unfolded in Jamaica over the 
past few years concerning a contentious statue to Emancipation entitled Redemption Song by the artist Laura Facey Cooper. The decision to choose the work of an artist, albeit a Jamaican national, who is of predominantly European descent to depict an experience of deep importance to people of primarily African descent has been criticized or at least questioned in several quarters (Graham 2004, Paul and Thompson 2004). What is more salient, it seems to me, is the selection of emancipation as a theme for a national monument, and not because it is an illchosen theme. Monuments to the experiences of a portion of a community as representations of the history of a whole community are clearly widespread and not necessarily controversial. Moreover, where there has been controversy recently it has been found in the persistence of monuments to the achievements of elites over the subaltern or to the power of a dominant group to represent the histories of subordinate groups they have dominated (even if such representations are meant to communicate remorse)(Zimmerman 2007).

However, almost by definition, an "emancipation monument" in a multicultural nation with the descendants of slaves and slave owners, as well as those who had nothing to do with either historically, cannot be a national monument in the sense that it attempts to represent the experiences of the people as a whole. It must exclude those who were never emancipated. This is not simply the exclusion of whites, but also of other groups who may have been indentured laborers or more recent immigrants. A monument that represents the population as a whole should, theoretically, be an independence monument. However, this is rarely the case in the Caribbean. Furthermore, the ways in which emancipation can be represented are severely limited. Although cries against many public monuments charge that such monuments are elitist in design, execution and selection, the voices raising such cries are rooted in their own intellectual and creative traditions that one might more properly call a class fraction than a wholly separate class. Both sides of this debate tend to have an effect on the uses of history in public discourse and in public life. At the very least, such debates remind us that history is alive and meaningful for the members of any nation. They illustrate that the reason people argue over statues and buildings is that these are not mute features of an idle landscape.

The material presence that constitutes the built heritage of Caribbean societies continually speaks. It may, given the way it is contextualized and narrated, tell a people about themselves while also telling visitors what locals want them to know. As Peter Siegel has pointed out in his book Protecting Heritage in the Caribbean (Siegel 2011: viii), the Caribbean is faced with a difficult process in this regard. The fundamental idea is that by limiting the general conception of what slavery and emancipation mean to modern people - that is, that they should only be seen as sites of resistance - current narratives of heritage are preventing the creation of novel narratives of productivity, survival, innovation, and perseverance under slave conditions. This has a dramatic effect on 1: The desire even to construct a heritage industry and perform the requisite work of preservation and maintenance; and 2: The direction any such acts of construction, preservation and conservation may 
take. Buildings and landscapes are never merely "maintained," they are contextualized within a vision or several competing visions of history within society.

\subsection{Case 2: Lord Nelson vs. "Bussa"}

In the center of Bridgetown, Barbados, in a square formerly known as Trafalgar square, and renamed Heroes Square in 1999, stands a statue of Horatio, Lord Nelson. The square and statue were created and named in 1813 in honor of Nelson's victory over the combined French and Spanish fleets off Cape Trafalgar in 1805. The victory was a devastating blow to France's sea power and, whether accurately or not, was presented and commemorated as a significant factor in the preservation of the British West Indies from foreign invasion. In the intervening 196 years, the statue has been the object of celebration, lore, scrutiny, and ire. There have been scores of articles and letters written in the Barbados newspapers (primarily the Nation and the Advocate) debating the merits of its removal or destruction. There have been not one but two calypsos composed by The Mighty Gabby (Barbados' most famous calypsonian) endorsing its removal and quite a number of statements supporting its preservation.

Not far away from Heroes-Trafalgar Square, out on the major arterial highway that runs from the airport up to the West Coast of the island, stands another statue. This one, created in 1986, represents a slave in revolt, his arms up-stretched, broken chains hanging from his wrists. This too has been the object of much debate. There have been calls for the removal of both statues over the years, but Nelson has clearly earned the "lion's share" of the attention. The Emancipation statue was created by the Guyananese-Barbadian sculptor Karl Broodhagen and was placed (not without some controversy of its own) in a roundabout on the socalled $\mathrm{ABC}$ highway that runs through Barbados from the airport to the Industrial park of Warrens north of Bridgetown. It is not in a location that would be seen by visitors coming from the airport or near too many of the main tourist sectors. It was unveiled in 1985 as part of a memorialization of the 1834 emancipation of the slaves under Queen Victoria. The pedestal is inscribed on each side, including a popular song sung by the slaves upon hearing of the passing of emancipation in England:

Lick and Lock-up done wid,

Hurrah for Jin-Jin (the slaves nickname for Victoria)

Lick and Lock-up done wid,

Hurrah for Jin-Jin.

God bless de Queen fuh set we free,

Hurrah fuh Jin-Jin;

Now lick and lock-up done wid,

Hurrah fuh Jin-Jin. 
Another side of the pedestal contains text from the Abolition Act of 1833.

However, this statue of a man, naked to the waist, arms upraised with broken shackles on each wrist and chains dangling, is NOT intended to be a portrait of Bussa, the storied leader of the 1816 Easter time slave rebellion and one of the ten national heroes of the island as designated by the Order of National Heroes Act, passed by the Parliament of Barbados in 1998.

The assignment of that identity is purely apocryphal and, indeed, sometimes a source of some irritation for local scholars and artists. Many editorials were written at the time of the statue's erection. Some were celebratory while others were highly critical of the appearance of the slave himself. Indeed, many of my informants mentioned that he was originally intended to be totally naked, but a general outcry led the sculptor to add "shortpants." Terms such as "grotesque" and "crude" were used and some local residents called for the statue's removal until a more suitable one could be created (The Nation newspaper, January 20,1989). The editorial comments seemed generally to reflect an uneasiness not simply with depicting a slave or commemorating emancipation, but, as in the Redemption Song piece, depicting a person of African descent as a slave and in a kind of primal state. In both cases, this form of representation seems to have been read as "uncivilized" and a perpetuation of racial stereotypes.

The primary objection to Nelson is that he was a British colonial naval officer who, although a hero to the empire, despised Barbados and was a supporter of slavery. At the heart of the discussion over these two statues is ambivalence about the place and role of history and memory in Barbados. As such, it provides a sense of the way history becomes heritage, and further, how heritage in the Caribbean must always take account of both identity and the economy. From the economic perspective, heritage tourism is quickly emerging as something more than a luxury. As tourism increases exponentially in the region's economic profile, diversification into a range of tourism products, such as heritage and culture, gain in importance. The debate over statues and other public monuments may be about identity within the context of a post-independence, post-colonial state finding a voice for its people, but it must also balance such struggles with the idea of what kinds of identity are best suited to show to the hundreds of thousands of visitors who pour off airplanes and ships every year. I want to frame this debate from an anthropological point of view, that is, with an eye towards the contemporary cultural implications of the debate.

\section{Theorizing Heritage as Power}

Historian and philosopher Michel Foucault said in an interview with Lucette Finas in 1979 that, "One 'fictions' history starting from a political reality that renders it true, one 'fictions' a politics that does not yet exist starting from a historical truth" (Morris and Patton 1979: 74-75). Statements like these made by Foucault have 
often been taken and reduced to a kind of vulgar relativism, the gloss of which might be "historical truth is written by the victors." Received this way, the challenge of the post-colonial historian is to wrest control of the writing of history from the colonizer, the West, whomever. However, Foucault, by pointing out the relationship between political realities and history, was not saying merely that the powerful compose histories to suit themselves creating, thereby, a "truth-effect." Foucault was concerned with structures of power, recognizing that one does not free truth from power, but instead examines the production of truth in order to understand contemporary society. In exploring any historical debate, one gets a clearer picture of the political realities facing the participants. Certainly one might get a glimpse of the competing structures of power, all of which trust the persuasiveness of the idea that some histories are truer than others. History needs the backing of the science side of its social science status. Challenging historians to cite their sources and show their evidence is the prime example of this.

However, as such, I am not going to make a pronouncement on the figure of Nelson himself, although I will discuss what others have said about him. My object here is to broaden this discourse to a more general problem of history in Barbados itself. Indeed, my view is that Barbados has a relationship with history (its own, of course, but history in general too) that makes a relationship with heritage an issue. I say this not because historians there are not committed or uncertain, nor to imply that elsewhere history and heritage always have a cozy fit, but in many ways, ironically, it is a kind of certainty about history that has led, really, to an uncertainty about Heritage as an industry:

Against Nelson:

"Massa's day not done?"

Down with Nelson; up with Barrow! If Goddard and his ilk want to see Nelson, they are free to go to England.

Or,

Barbados has a long way to go to free her children's minds from the shackles of the slavemaster and one sure way to start this mission is to remove the marauder's statue, hereby remove that energy, that invisible chain from the minds of her children. Then you can address the miseducational system. I say to replace nelson with the labourers of the field.

Or,

Pull the statue down and put a Bajan born and bred hero in its place. Why not put one of Rihanna in its place, let's move forward with what's happening in Barbados in the 21st century not some ancient relic of the faded rule the world days of the English. 
For Nelson:

How would this generation that wishes to see Nelson removed feel about a future generation tearing down Sir Grantly, Sir Gary or The Emancipation Statue. We need to realise that we cannot change history by pulling down statues, they are there as reminders of our heritage, that we should see, ask questions and learn from the past.

And perhaps most tellingly to this discussion:

I think it is an important part of our history and also plays an important part in our tourism product and should stay where it is now. (Commentary cited from Barbados Free Press website. Accessed August 18, 2008)

Barbadians need to start thinking about what we are offering to visitors as our overall product, I think it is a shame that everything old is taken down and most new buildings with no hint of the past are put up instead. Yes we have to move forward but we have to keep that island-historical feeling in our back pocket at all times if we are to compete internationally in tourism.

\section{Plantation House vs. Chattel House: The Hegemony of "Resistance"}

Anita Waters in her book Planning the Past: Heritage Tourism and Post-Colonial Politics at Port Royal, (2006), lays out what for her is the enduring problem that has plagued Caribbean historiography. This problem is characterized by a kind of historical amnesia, a "loss of collective memory" as Glissant has said (1989). Michel-Rolph Trouillot (1995) has identified this absence of memory as, in actuality, a silencing of memory. That is, the history of the islands is not merely written by elites; they create an historiography founded upon their own prejudices, privileging not only documents and archives, personages and events that they have ultimately created but that these are the only kinds of "history" that are considered legitimate.

As a response, but working necessarily within this structure of power, stands the following general rejoinder: The laying claim and repossessing of history on the part of the marginalized. This is not, as in some spaces, a divide of classes or levels of education alone, but always one of color. Walcott has called the response to colonial history the "literature of revenge" which, he says, "yellows into polemic" (1998: 37) Both Walcott and William A. Green (1977) seem to find only a grim dichotomy available for writers of Caribbean history. On the one hand, the remorseful or arrogant imperial histories, on the other, a rather shallow history of resistance that sees all people of the Caribbean who are not white as African and 
whose actions stand as object lessons in opposition. I would argue that, given the course of Caribbean independence movements and identity politics from the late1950 s through the 1970s, the latter form of historiography has won out. Green adheres to neither of these two poles; nor do I. Indeed, there may be many historians in the region who do not, but the legacy of this polarization in the writing of history has become the power structure from which a Foucauldian "truth-effect" has emerged. This "truth-effect" emerges as the rather broad stereotype of the colonial world, the plantation house, et cetera. It derives, of course, from the plantation's very real role in the enslavement and oppression of generations of Africans, not to mention the indenture of poor whites, Asians and South Asians. However, the role of sugar and the plantation economy in the post-emancipation period and the cultural changes that can be traced through the society of the emancipated could provide a different kind of heritage.

Anthropologist Peter J. Wilson once wrote that Caribbean people have only the land and themselves with which to identify and that "until such time as a Caribbean culture is recognized with pride by the people themselves, much of the burden of their identity must be placed on land" (Wilson 1973: 224-225). This is enormously problematic in Barbados, although it may be somewhat true for other Caribbean spaces. As quite a few historians have noted, land in Barbados has never been readily available to free people without means. For free black and colored as well as poor white, gaining access to land was extremely difficult. Furthermore, the visible landscape of Barbados is a constant reflection and reminder of this state of affairs. Sugar-cane is no longer the economic engine it once was, but the land is absolutely dominated by it. Its presence is a continual reminder of the past. The cane fields themselves are heritage. Given that sugar-cane is still standing and that land is both difficult to get and expensive, it is no wonder that building a consistent identity, as Wilson has said, based on land, is more difficult than, say in Jamaica or Trinidad. A heritage industry based around monuments to those who did own the land, presented largely in a vacuum of not only the social consequences at the time, but also of subsequent developments in the history of the island is not going to resonate with the general public. Only public support can really sustain a heritage industry.

To reiterate: The legacy of Colonialism and the kind of historiography that was useful in the postcolonial moment has established a certain orthodoxy about slavery and the plantation that makes an industry based on heritage very difficult. There can be little flexibility in the narrative that continues to see sugar and slavery in only one light. Richard Hart, a strong example of the post-colonial historian of resistance, says quite clearly in his introduction to Slaves Who Abolished Slavery: Blacks in Rebellion (2002) that his impulses were political, growing out of the workers' movement in the 1930s. Yet the role of the workers in sustaining the sugar industry is a subject of far less public attention, even if there have been excellent histories of it. Similarly, investigations into how others saw the plantation house in the 20th century, how it was used, who else besides whites may have owned them, 
may lead to public exhibitions about the other side of the great house; not simply rooted in the era of slavery but well beyond it. As Joanne Melish (2006) has said in her study of problems in representing slavery in the United States: "Acknowledging the past presents the problem of reconciling dissonant but fully developed interpretations." Though this seems quite clear to historians and anthropologists working with the most "difficult" histories, in the case of Barbados and other parts of the Caribbean, it is compounded by the sense of urgency that comes from needing to expand and diversify the tourism economy. Why? It is because any heritage industry must be built on a notion of heritage that resonates with significant numbers in the society. The separation between those who control the reins of government and those who might control or stand to benefit from the industry of heritage is wide at critical points in Barbados, perhaps too wide at this time.

\section{$7 \quad$ References}

Aronczyk, Melissa (2008): 'Living the Brand': Nationality, Globality and the Identity Strategies of Nation Branding Consultants. International Journal of Communication 2: 41-65.

Askew, Marc (2010): The Magic List of Global Status: UNESCO, World Heritage, and the Agendas of States. In Heritage and Globalisation. Sophia Labadi and Colin Long, eds. Pp. 19-44. London: Routledge.

Barbados Advocate Newspaper. http:/ / barbadosadvocate.com/newsitem.asp?more=local\&NewsID $=10024$ $<$ accessed March 20, 2012>

Barbados Free Press. http://barbadosfreepress.wordpress.com/2008/07/24/barbados-nationaltrust-votes-to-leave-nelsons-statue-where-it-is/ <accessed August 18, 2008>

Cupid, John (1994): Trinidad Carnival Traditional Characters. Port of Spain: $1^{\text {st }}$ Carnival King and Queen of the World Magazine 1: 16-17.

Dacres, Patrina (2004): Monument and Meaning. Small Axe 8(2): 137-153.

Dreyfus, Hubert L., and Paul Rabinow (1983): Michel Foucault: Beyond Structuralism and Hermeneutics. Chicago: University of Chicago Press.

Glissant, Edouard (1989): Caribbean Discourse: Selected Essays. Charlottesville: University of Virginia Press.

Graham, Narda (2004): Whose Monument? The Battle to Define, Interpret, and Claim Emancipation. Small Axe 8(2): 170-178.

Green, William A. (1977): Caribbean Historiography, 1600-1900: The Recent Tide. The Journal of Interdisciplinary History 7(3): 509-530.

Hart, Richard (2002): Slaves Who Abolished Slavery: Blacks in Rebellion. Pp. i-ii. Jamaica: University of the West Indies Press.

Klak, Thomas, ed. (1998): Globalization and Neoliberalism: The Caribbean Context. Lanham, MD: Rowman and Littlefield. 
National Initiative for Service Excellence.

http:/ / nisebarbados.org < accessed March 15, 2009>

Macdonald, Sharon (2009): Unsettling Memories: Intervention and Controversy

Over Difficult Public Heritage. In Heritage and Identity: Engagement and

Demission in the Contemporary World. Marta Anico and Elsa Peralta, eds. Pp.

93-104. London: Routledge.

Melish, Joanne (2006): Recovering (from) Slavery: Four Struggles to Tell the Truth.

In Slavery and Public History: The Tough Stuff of American Memory. James

Oliver Horton and Lois E. Horton, eds. Pp. 103-134. Chapel Hill: University of North Carolina Press.

Morris, Meaghan, and Paul Patton, eds. (1979): Michel Foucault: Power, Truth, Strategy. Sydney: Feral Publications.

Nation Newspaper (1989). January 20: 8-9.

Paul, Annie (2009): Do You Remember The Days of Slav'ry? Connecting the

Present with the Past in Contemporary Jamaica. Slavery and Abolition 30(2): 169-178.

Paul, Annie, and Krista A. Thompson (2004): Special Issues on Caribbean Locales/Global Artworlds. Small Axe 8(2): v-ix.

Price, Richard (2001): Monuments and Silent Screamings: A View from

Martinique. In Facing Up to the Past: Perspectives on the Commemoration of

Slavery from Africa, the Americas and Europe. Gert Oostindie, ed. Pp. 58-62.

Kingston: Ian Randle Publishers.

Reinhardt, Catherine A. (2006): Claims to Memory: Beyond Slavery and

Emancipation in the French Caribbean. New York: Berghahn Books.

Scher, Philip W. (2002): Copyright Heritage: Preservation, Carnival and the State in Trinidad. Anthropological Quarterly 75(3): 453-484.

Siegel, Peter E., and Elizabeth Righter, eds. (2011): Protecting Heritage in the Caribbean. Tuscaloosa: The University of Alabama Press.

Thompson, Krista A. (2006): An Eye for the Tropics. Durham: Duke University Press.

Trouillot, Michel-Rolph (1995): Silencing the Past. Boston: Beacon Press.

Walcott, Derek (1998): What the Twilight Says. New York: Farrar, Straus and Giroux.

Walkowitz, Daniel J., and Lisa Maya Knauer (2009): Contested Histories in Public Space: Memory, Race and Nation. Durham: Duke University Press.

Waters, Anita (2006): Planning the Past: Heritage Tourism and Post-Colonial

Politics at Port Royal. New York: Lexington Books.

Watson, Karl (2009): Barbados and the Bicentenary of the Abolition of the Slave

Trade. Slavery and Abolition 30(2): 179-195.

Wilson, Peter J. (1973): Crab Antics: A Caribbean Case Study of the Conflict

Between Reputation and Respectability. Prospect Heights: Waveland Press.

Zimmerman, Larry J. (2007): Plains Indians and Resistance to 'Public' Heritage

Commemoration of Their Pasts. In Cultural Heritage and Human Rights. 
Helaine Silverman and D. Fairchild Ruggles, eds. Pp. 144-158. New York: Springer. 


\title{
A Policy of Intangible Cultural Heritage between Local Constraints and International Standards: "The Cultural Space of the yaaral and the degal""
}

\author{
Anaïs Leblon
}

\section{Introduction}

"The cultural space of the yaaral and the degal" in Mali was included on the UNESCO list of Masterpieces of the Oral and Intangible Heritage of Humanity on the initiative of the Malian government in November 2005. Based on the ethnography of the process of heritagization of these Fulbe pastoralists' transhumance festivals in the Inner Niger Delta, I follow the proposals of Ferdinand de Jong and Michael Rowlands. In the introduction to Reclaiming Heritage. Alternative Imaginaries of Memory in West Africa (2007), these authors invite researchers to focus on the local appropriations of policies of Intangible Cultural Heritage (ICH) in Africa, particularly of UNESCO, by studying local, national and international constructs of cultural heritage. UNESCO has become an international institution for heritage legitimization by recognizing and classifying certain cultural expressions under the label of "heritage of humanity." With the introduction of the concept of ICH, UNESCO imposes new standards for cultural heritage selection. Cultural heritage must, from now on, be defined in a dynamic view of culture (Hafstein 2004, Bortolotto 2006, Turgeon 2010), which involves the active participation of the communities con-

\footnotetext{
1 This article is based on data acquired during several field studies lasting a total duration of 12 months (2007-2010) in the context of research on the heritagization of Fulbe pastoral institutions for a doctorate in anthropology at the University of Provence.
} 
cerned in the nomination process (Blake 2009). Selection criteria emphasize interculturality and respect for human rights (UNESCO 2003). I seek to lay open the encounter between the normative logics of international selection procedures for ICH and the actual application of such criteria by representatives of the state and actors within affected communities with a detailed ethnography of the classification procedures, applications of programs for protecting cultural heritage, as well as forms of presentation of the past and identity.

Building on Revel's notion of scales of analysis (1996), I will look at the process of heritagization of the Fulbe pastoral festivals by the Mali State as an "arena" (Bierschenck and Olivier de Sardan 1998) within which the actors develop a pragmatic relationship with the patrimonialized object. This will allow me to describe how the patrimonial dynamics at work in the construction of the relationship to the past, to identity and to territory, held by different participants (pastoralists, heritage agents, mayors, politicians) interconnect, contrast, contradict, and/or join together. My analysis is situated within a broader study of contemporary sociopolitical dynamics that cultivate heritagization with all its transformative effects.

The institutional heritagization of these festivals by the establishment of a plan of action and protection under the National Directorate of Cultural Heritage (DNPC) takes place in a context of increasing instability of Malian pastoral activity. ${ }^{2}$ In the 19th century, the Fulbe Empire of the Diina of the Maasina organized the Delta in favor of pastoral activity and established precedence, shelters and transhumance routes. Several sociopolitical (abolition of slavery, transfer of ownership of livestock) and ecological (droughts, decrease in flooding levels) changes led to a loss of power of pastoralists, who were not always able to ensure the maintenance of their pastoral infrastructures (Turner 1992, Barrière and Barrière 2002, Marie 2002). In the mid-1990s, a new decentralization policy ${ }^{3}$ revived tensions over land (Fay 1998). While set in the background of heritage development, issues relating to ecology, economy, insecurity of pastoral activity, and political management of the territory reveal the reasons and policy stakes entangled with heritage matters. They are closely related to the management of different cultural identities which are connected with production sectors (Fay 1997), as well as to the development of the Delta territory in the context of political decentralization.

It is thus important to see how heritage agents combine the constraints of their own cultural policies with the normative demands of UNESCO. While heritagization now promotes a dynamic view of culture, we need to ask how socio-economic changes, re-creations of identity and the Fulbe pastoral practice will be treated in the different phases of the institutional program of heritage production (from candidacy to the implementation of the heritage protection program). Further questions to consider are how the involvement of the population in protection activi-

\footnotetext{
2 The plan of action was carried out from January 2007 to April 2009. The UNESCO-Japan Funds-in-

Trust for the Preservation and Promotion of Intangible Cultural Heritage funding was US $\$ 74,470$.

${ }^{3}$ This is the effective transfer of part of the powers at the village level organized by communities.
} 
A Policy of Intangible Cultural Heritage between Local Constraints and International Standards

ties has been promoted, and what role is given to endogenous concepts of heritage and to the measures proposed by the populations to promote them? Study of the candidacy dossier and the subsequent inventory enables one to compare UNESCO standards for a legitimate patrimonial production to its effective realization in a bottom-up approach constructed a posteriori. This reveals what is at stake in the heritagization of a cultural space which, before becoming a patrimonial good, was a place of demonstration of identity and a pastoral activity in crisis.

\section{The Context of Institutional Heritagization: The Candidacy Dossier and the Justification of Classification}

The National Directorate of Cultural Heritage (DNPC), organ of the Malian Minister of Culture, has led several survey missions in order to prepare the candidacy dossier for the "cultural space of the yaaral and the degal" since 2003. In that capacity, it benefited from the expertise of UNESCO-Bamako and the support of "resource persons" as much at local and regional as at national levels. The classification as proposed and adopted by UNESCO makes reference to the transhumance space of Fulbe pastoralists of the inner Delta of the Niger River and, more particularly, the spectacular festivities sprinkling the calendar of pastoral activities. Among these, the yaaral of the Jafaraabe and the degal of the Jallube, respectively the first point of entry to the Delta and the last event of the pastoral calendar, benefit from a program of heritage development. This choice is linked to the strategic position of these festivals in the regulation of animal movement between deltaic pastures during the dry season and Sahelian pastures during the rainy season. The choice is enhanced by the memory that at the end of the colonial period and during the first years of independence, a public composed of politicians, functionaries and administrators was present for the events. Public powers were present at the time in part to signal their desire to control one of the most important economic activities in Mali.

Yaaral designates the crossing of the Jaaka River at Jafaraabe in December with herds returning from the Sahel. The degal is the descent of herds at Jallube in April to the last pastures of the dry season north of the Inner Niger Delta (Figure 1). These two festivals validate pastoral activity through livestock parades, competitions for the fattest herd and the declamation of pastoral poetry.

These festivals are presented as emblems of Fulbe identity and culture in the UNESCO candidacy dossier prepared by the DNPC. The argument pays particular attention to Fulbe social and esthetic values in the pastoral way of life, attachment to cattle and the richness of the Fulfulde language expressed in the pastoral poetry and songs of the young girls. Such promotion of the Fulbe culture for itself is complemented by other arguments combining regional history, historical depth of the good to be patrimonialized and especially the promotion of cultural diversity ap- 
pealing to a new heritage standard supported by UNESCO (Leblon 2011a: 201202). To express this, the candidacy dossier promotes Fulbe traditions dating back to the founding of the Diina of the Maasina at the beginning of the 19th century that enabled different populations of the Delta to renew their intercommunity pacts and to live in harmony (DNPC 2004: 6, 11, 12). Each ethnic group of the region is thus associated with a professional activity and esthetic norms or standardized ways of dressing meant to identify them (Leblon 2011a: 203).

The identity metaphor of the richness of cultural diversity by serving a discourse on the cohesion between groups is a means of making reference to the regulations for the use of natural resources and to power relations between those exploiting them. The distribution of groups in this region "renvoie à un rapport réglé entre ethnicité, spécialité professionnelle et milieu naturel" (Fay 1989: 160, Gallais 1968). This justification of patrimonial value, taking recourse to a normative discussion on the intercommunity links and cohesion between groups, comes during a moment of tension: Access rights to "properties" - water, pasturage, land (Fay 1989) - and political decentralization are on the horizon. Resolving conflicts between the different actors in the Delta is presented as one of the most pressing challenges to achieve a plan for sustainable management of the 5th Region's natural resources (Mosely et al. 2002: 105, Barrière and Barrière 2002). The state appears thus to be less desirous of revalorizing pastoral activities in themselves; rather, the relationship of transhumance festivities and other activities regulating access to natural resources and land are focal. The institutional patrimonial rhetoric has, however, never made explicit reference to an ecology of peaceful and sustainable resource management.

The objective presented by the institutional program is to preserve the "cultural and environmental integrity of local communities," "to perpetuate in autonomy the cultural space and the pertaining traditions in order to ensure a future of knowhow," "to identify and group existing traditions in a common base," and also to "raise awareness of tourists of the fragility of the site" (DNPC 2006: 5). Protection activities thus essentially concern inventory, documentary collection, awareness raising, and educational activities. To this end, the population identified as holder of the good to be patrimonialized is invited to participate in "protection" practices: It is foreseen that certain people within the group will act as authority figures to set out what should be preserved. The elements retained will then provide the reflection of heritage awareness shared by the local populations. One of the paradoxes of this project is to insist on a "bottom-up" protection, although it is in a large part constructed a posteriori. The DNPC agents devised this project unilaterally - as a function of UNESCO's criteria for ICH; the population was brought in to participate only once the project was crafted.

This raises two main questions: Do the modalities of protection planned correspond to what is already in progress within the society? And how are the institutional concepts and procedures to be translated for the group concerned? 
A Policy of Intangible Cultural Heritage between Local Constraints and International Standards

The concept of ICH was translated from the first surveys in preparation for the candidacy dossier by the expression finaa-tawa, meaning "we are born, we have found." "This is a common utterance in the tradition considered, referring to cultural heritage received from preceding generations. This heritage is "older" (beccude) than the individuals who will "follow" (jokkude) it or not. It is considered to be an intergenerational transmission of utterances, goods, representations, knowledge, practices, activities, and rules. Finaa-tawa is thus used to justify the practices carried out during the festivals of yaaral and degal. However, its use is not limited to the festive domain. It covers different aspects of social life, such as professional specialization or respect for social hierarchies. ${ }^{5}$ For the latter, it refers to a value system and individual status defined by genealogical affiliation. This word thus covers a broad range of meanings. It can be applied to material goods which a person has inherited, to the natural environment, and it even serves as a definition of culture and identity. This social construction of tradition proposes a normative, immutable framework to elements deemed characteristic and indispensable for the maintenance of institutions and the collective identity of members of the group who claim this tradition (or who are assigned to it). However, because the found practice is attached to a specific place and time: "En naissant en un lieu, on y a trouvé," as Jacky Bouju has emphasized for the expression of the tradition in the Dogon context (1995: 105), it is necessary to take account of the context in which the practice claimed as "found in being born" is realized, since this condition forms part of the heritage received. By placing the accent on reception of the heritage, the tradition is open to transformations associated with developments in a given context. In other words, the expression of continuity is constructed by references and common access to a certain number of practices, symbols and values. However, this pronouncement of continuity authorizes and integrates changes in meaning depending on the generation or the status of the individuals who utter a claim. By insisting on a particular way of doing or saying something, the individual aims to conform to a practice for which he or she is recognized as being the heir, but he or she has a creative power over this practice. Each individual can potentially participate in the construction of festivals and in the selection of what will be retained or excluded as cultural heritage. The social actors' ability and capacity to negotiate and sometimes distort what is to be recognized as tradition or not while

\footnotetext{
4 The expression finaa-tawa is constructed from the verb finude, literally to wake up, to rouse (Seydou 1998: 188), but which also takes on the meaning of being born, and the verb tawude, which means to find one's traditional cultural heritage, to have something as a tradition (697). This expression is a common definition in the tradition of West Africa (Bouju 1995: 105, Lassibille 2003: 559, Andrieu 2009: 232).

5 The Fulbe society is a hierarchical society composed of several social classes: The Fulbe Rimbe, who are defined as free nobles - most herders are found in this class; the Jaawambe, free with non-noble status, most often merchants and livestock owners; the Nyeeybe are caste craftsmen (weavers, cobblers, blacksmiths, wood utensil makers, griots); and the Riimaybe are the descendants of the captives of the Fulbe, in general associated with agricultural activities. The community of Fulfulde speakers is called pulaaku in the Maasina (Region of the Inner Niger Delta) (Le Marcis 2001: 21-26, de Bruijn and Van Dijk 1995, Breedveld and De Bruijn 1996).
} 
the institutional process of selecting elements for UNESCO promotion is in progress, can produce points of rupture and conflict that have to be investigated.

In the reasoning of institutional heritagization, the choice of elements inventoried seems to have been the act of a small group of men influenced by heritage agents who entrusted them with this task. While the expression finaa-tawaa does not reproduce the distinctions between categories of material and Intangible Cultural Heritage, a series of examples separating the heritage constructed by personal ornamentation, poetry or festive practices have enabled heritage agents to indicate the categories of goods concerned in the heritage project. The action plan anticipated the establishment of several structures at different levels in the heritage sequence in order to inventory, document, collect, and finally validate the elements to retain.

The "management sub-committees" created in January 2007 at Jafaraabe and Jallube were composed at the village level, taking into account criteria defined by UNESCO and the DNPC. They were to include representatives of the community authorities, as well as local cultural and educational associations. Although UNESCO requires the involvement of the population as a whole, the people retained to execute patrimonial activities are primarily literate, male, herd owners, who did not themselves directly participate in Sahelian transhumance. A "regional coordinator," based in Sévaré, ${ }^{6}$ is responsible for maintaining relations between the two sub-committees and the DNPC. A young Fulbe with a degree in geography, he must type up the inventory forms processed by the sub-committees and send them to the DNPC. The Center of Information and Documentation on the yaaral and the degal that he was supposed to manage has never really existed. A "national coordination committee" was also set up to coordinate regional and local structures. It is composed of DNPC administrators, representatives of UNESCO-Bamako and some Malian political executives working in the area of Fulbe cultural promotion. ${ }^{7}$ These structures of supervision and execution of the action plan are composed of individuals who were consulted previously during meetings in preparation for the classification. At the local level, these new institutions extend the power of political authorities already in place and regular intermediaries of other development programs reaching the village level. The participants, in their role as village chiefs, communal councilors and chiefs of cattle herders, are involved in the official organization of festivals and have a reflexive view on the presentation of the tradition. Since their nomination as committee members, confusion has arisen between their task to execute the action plan and their assumed quality as "recognized practitioners of the tradition" or "resource persons." The action plan should

\footnotetext{
${ }^{6}$ City near Mopti, the regional capital.

7 These persons are all members of Tabital Pulaaku, an international Fulbe cultural association. Some offer news in the Fulbe language, aired by the ORTM (Office de Radiodiffusion et Télévision du Mali). They are all known by their activities in the cultural domain and have been considered as "resource persons" and intermediaries between the DNPC and village populations from the start of the DNPC initiatives.
} 
A Policy of Intangible Cultural Heritage between Local Constraints and International Standards

have been carried out by this pyramid of participants: Its base is formed by the sub-committees representing the "population" and also "tradition," and the top is symbolized by the DNPC as the principal link to UNESCO. These different actors all intervene, at different moments and levels, in the cultural heritage definition and selection; they hold different and often contradictory stakes.

\section{The Execution of the Protection Plan: Inventory of Intangible Cultural Goods}

Actors from the DNPC and UNESCO-Bamako trained the sub-committees and their coordinator in the use of standard UNESCO inventory forms for ICH. The choice of elements to inventory was, therefore, their responsibility, although certain themes or focus areas were mentioned during their training. Feminine esthetics, pastoral competitions, poetry, and festive events constituted the principal elements inventoried (Figure 1). Sub-committee members thus repeated the same elements already promoted by institutional heritage actors either in the candidacy dossier or in the missions carried out at Jafaraabe and Jallube. Some of these had already been the focus of promotion during official festivals for more than ten years; pastoral competitions had been re-created and clothing to symbolize Fulbe cattle herders or women modeled (Leblon 2011a). Only elements taking part in festive contexts are retained. In other words, the inventory reflected the spectacular view of pastoralism and the classic definition of the Fulbe identity contained in part in the candidacy dossier. The inventory does not, however, contain elements related to pastoral know-how or the particularities of raising transhumant livestock in the Delta. The dossier thus reduced the scope of patrimonial practices to those visible at the festivals, illustrating the difficulty of nominating a practice that extends across a territory and its transformations. The "cultural space of the yaaral and the degal" as a place for the expression of pastoral know-how, learning and the transmission of pastoral practice remains unconsidered. This is also true for changes in territorial organization and the role of festive events as institutions of seasonal regulation for access to pastures. Rules for pasture management, precedence of access, the transhumance route, and the mythico-historical recitations attached to them, however, constitute significant parts of the social and cultural knowledge related to these festivals. In effect, changes in the territorial organization of pastoralism (financial instability, precedence not respected) also condition the perpetuity of the festivals. Although the candidacy dossier stressed the ecological and organizational uniqueness of the Delta, this element has barely been taken into account. The dossier presented one of the arguments concerning the pastoral institution from the angle of the cycle of access to pastures, herd displacements and relationships between Fulbe cattle herders and the mainly Bozo and Marka sedentary populations at the return of the transhumance. Yet, in the end, the "cultural space" of transhumance is limited to the two moments of the yaaral and the 
degal, and to the associated esthetic, artistic and festive practices. The intangible, therefore, appears understandable only through the mediation of physical goods that render them more easily comprehensible (Ciarcia 2006: 5). Thus, it is difficult in the process of the institutional promotion of heritage to step some distance away from the spectacular and esthetic aspects of the heritage goods. However, this is necessary to propose an analysis of the real conditions for the production of cultural performances that takes into account the ordinary and conflicting aspects of pastoral practices.

\begin{tabular}{|c|c|}
\hline Domain & Elements \\
\hline Feminine esthetic & $\begin{array}{l}\text { Fatoumaji and Jalli braiding, lip tattoos } \\
\text { (tbioddi), small and large gold earrings } \\
\text { (kootone mawbé and kootoné pomoré), amber } \\
\text { beads (allubanaaje) }\end{array}$ \\
\hline Cattle herders' attire & The boubou kassa and the hat (tenngaade) \\
\hline Habitat and house decorations & $\begin{array}{l}\text { The grass hut (buguru), the jongui (set of } \\
\text { superimposed calabashes), the plastering } \\
\text { of floors and façades (withiougol) }\end{array}$ \\
\hline Musical instruments & $\begin{array}{l}\text { The flute (serendou), the drum (mbaggou, the } \\
\text { bumbutu (overturned calabashes in another } \\
\text { calabash filled with water) }\end{array}$ \\
\hline Dance & Noddi-noddi, lasaara degal, himbere \\
\hline Stages in the return of the livestock & $\begin{array}{l}\text { The Yontere Pondoori (week of Pondori at } \\
\text { Jallube), the woulliron (livestock parade at } \\
\text { Jallube) }\end{array}$ \\
\hline Pastoral competition & $\begin{array}{l}\text { Cola nut (goro), slaughtered beef (ngar } \\
\text { kirsamar), the coverage of honor (disare } \\
\text { ndanou), pastoral competition (danondiral). }\end{array}$ \\
\hline Poetry & $\begin{array}{l}\text { A poem in praise of cattle (not included } \\
\text { in the final inventory) }\end{array}$ \\
\hline History & $\begin{array}{l}\text { History of the Jaaral of Jafaraabe (not in- } \\
\text { cluded in the final inventory) }\end{array}$ \\
\hline
\end{tabular}

Figure 1: Summary of the goods inventoried

Source: DNPC 2007, Rapport final d'inventaire des biens liés à l'espace culturel du yaaral et du degal, Bamako Ministère de la Culture et DNPC, 62 p; DNPC 2008, Borderean d'envoi nº0003/ PPSECJD,

Sévaré, DNPC, 15 p.; DNPC 2009, Bordereau d'envoi nº0005/PPSECJD, Sévaré, DNPC, 23 p. 
A Policy of Intangible Cultural Heritage between Local Constraints and International Standards

However, the candidature dossier does list elements that threaten the realization of the festivals, such as the lack of succession or taking over the responsibility by younger generations, drought, rural exodus, and the "manque de discipline" among young herders (DNPC 2004: 10-13, DNPC 2007). While this shows awareness and consideration for the proper dynamics of the festivals, it thus breaks with an essentialist definition of pastoral heritage that is also contained within it. However, their role is particularly to legitimize the need for a safeguarding policy by UNESCO classification. Although local and national promoters of heritage are conscious of the real constraints affecting contemporary transhumant pastoralism, it is the esthetic and spectacular aspects that are chosen to meet the expectations of UNESCO regarding patrimonial protection. Finally, the inventory transforms the cultural space into a geographically circumscribed set of promotional elements.

Parameters of places and people consulted defined legitimate frameworks for the production of inventoried data. Sub-committee members consulted "resource persons" in order to document the themes that they themselves had beforehand decided to examine. They consulted cattle herders who had won several pastoral competitions and the best poets of their generation: These are exclusively elderly Fulbe. No young herder or young woman had been interviewed, although most of the art forms inventoried concerned their ongoing practices. It was thus the goods as practiced by the Mawbe (old, elders) and not those practiced today that interested the sub-committee members. The dances, pastoral competitions and the practice of transhumance that they are able to describe would present in this view, forms purportedly more stable or original than the forms actually performed. Moreover, although the candidacy dossier insisted on including all of the socio-professional categories in the region, only the Fulbe were consulted. No good inventoried directly concerns any other population in the Delta. The literate members of the subcommittees pointed to the knowledge of the "environment" and "customs" of this part of the population by only surveying the elderly. Thus the committee members placed themselves in a position of learners even though they already knew what they planned to find. Turning to the elders recognizes their pastoral know-how, the role that they may have played in the organization of festivals and their status as elders or notables within the village. Most of the sub-committee members speak and write in French - an ability that the elders lack, but is necessary to prepare the inventory ${ }^{8}$ - and in the process, translate a statement concerning the knowledge of a practice acquired by experience into a patrimonializable object to inventory. These actors chosen as surveyors due to their anchorage in the territory already share a large part of their knowledge with the inhabitants - and they share the social deference and honor given to elders. They are both "porteurs de tradition" 9

\footnotetext{
${ }^{8}$ The forms were not translated into Fulfulde and the language of communication with heritage agents is French.

${ }^{9}$ This expression is borrowed from Gaetano Ciarcia, who used it during the presentation "Imaginaire consensuel du patrimoine à l'épreuve de l'inventaire" at the meeting "Au-delà du consensus patrimo-
} 
and social-status-bound actors within the communities inventoried, which, in turn, also helps to explain why the up-to-date, changing pastoral performances carried out by active, young participants were also neglected by sub-committee members. They had, however, in their biographical journey and professional, political or associative activities, acquired skills that made them "cultural interpreters" (Bierschenk 1995) or "mediators in heritage."

The position of the coordinator further illustrates how contingent the legitimacy of heritage knowledge has become based on new standards promoted by UNESCO, as applied by the national executing agency. This can be illustrated with data from a workshop for the validation of the inventory held in the city of Mopti in December 2007. Present were members of the two sub-committees, the coordinator and agents from the DNPC, UNESCO-Bamako and "resource persons," intellectuals, and politicians working in the area of the promotion of Fulbe culture. The heritage inventory is designed to be produced at a local and rural level. During the workshop, the observation was made that some of the elements had been inventoried by the coordinator himself and not by the sub-committees. Both members of the two sub-committees and members of the national coordination committee expressed reservations regarding the quality of information that he could provide. The coordinator, stuck in the city of Sévaré since he had no means available to travel to work directly with the sub-committees, had held his own surveys with people typically recognized for their knowledge of the Fulbe world, notably his father, a radio broadcaster in Fulfulde, a member of the association for the promotion of Fulbe culture Tabital pulaaku, and a retired teacher.

Members of the sub-committees were frustrated by the corrections that the young coordinator made to their work. The coordinator, aged 27 , had not grown up with the herd and had gone to the city for his education early in his life. He had not been "born into" and had not "found" the herder's life that would have entitled him to be a legitimate voice within the festivals. Yet members of the subcommittees, even if born in Jallube and Jafaraabe to families of cattle herders, had not themselves, for the most part, led the livestock in transhumance either. They are wuronkoobe ${ }^{10}$ and, although a small number had had immediate pastoral experiences, most were teachers or merchants outside the village. ${ }^{11}$ Nonetheless, they had sufficiently internalized the notion that information gathered in situ was preferable.

nial. Anthropologie des résistances à la patrimonialisation" organized by Cyril Isnart, Julien Bondaz and Anaïs Leblon at MMSH of Aix-en-Provence, November 4-5, 2010.

10 This term designates the villagers, contrasting with the Fulbe Wodeebe, the herders who practice transhumance.

${ }^{11}$ Four of the six committee members at Jafaraabe are teachers or retired teachers and all have a political or associative responsibility. Only four of the six members at Jallube really participated in the inventory. These members included four who are literate in French, two who are teachers and one lawyer at the court of appeals in Mopti. Only one member of each committee has actually participated in transhumance. 
A Policy of Intangible Cultural Heritage between Local Constraints and International Standards

Heritage agents (DNPC and UNESCO) and the Fulbe intellectuals of the national coordination committee in going over the work of the coordinator emphasized the need for local production of heritage. The ICH relative to the classified space had to be inventoried at Jafaraabe and Jallube. Actual presence in the territory, and hence, direct experience of the festival was seen as enabling a more "authentic" basis of information than that collected in urban contexts from people sometimes originally coming from the area, but who were now distanced from it in their lives as functionaries or executives.

The "resource persons" of the national committee, not necessarily Fulbe, validated the inventory through what is considered their expertise of Fulbe pastoral tradition. They are engaged in a more distant reflection of Fulbe origins, tradition, history, and culture. Unlike the members of the sub-committees, they no longer live in the village and expound a discourse marked by an intellectualization of the tradition. Some of these participants have European university diplomas and have acquired their knowledge of the Fulbe by scholarly research. They often engage in promotional activities for the territory and its cultural identity for political or social ends. They are consulted at the last level of inventory validation in order to reorient the work of the sub-committees and the coordinator, and to advise them on new axes of work. So, after the workshop for the validation of the inventory, these experts asked members of the sub-committees to concentrate on the feminine esthetic, poetry and songs and to "record and transcribe oral traditions and expressions" (DNPC 2007), and also to complete the forms sent with photographs of the elements inventoried. These activities had not been done ${ }^{12}$ and the DNPC and the coordinator had countless times denounced the lack of involvement of the subcommittees.

The classification of the "cultural space of the yaaral and the degal" is the first experience of the DNPC in inventorying ICH entrusted directly to the population and not to technical agents. Some institutional agents in responsible positions experience this demand by UNESCO as a brake on the good success of the project. Part of the urban elite, they enumerate illiteracy, local actors' interest in financial compensation or even just recurrent stereotypes about a resistant rural context to explain the difficulties encountered in this process of "participatory heritagization." 13 Yet, an inventory can only be compiled by building on what festival participants - the very people these elite actors blame for the glitches in the process actually consider worthy of preservation.

The field observations thus demonstrate that, despite this discursive promotion of a participatory approach, the production of the inventory is highly influenced by international categories that require the participants to rethink their cultural heritage in terms of these categories (material, intangible, natural) and in for-

\footnotetext{
12 Only the coordinator and the Jafaraabe sub-committee provided additional forms regarding the feminine esthetic or the herders' material.

13 On this point, see Olivier de Sardan (1995: 59-69).
} 
mats (inventory form) that do not map onto the different meanings that the concept of finaa-tawaa covers. This logic of inventory, based on the exclusive consultation of the "elders," especially presents the risk of creating fixed definitions without taking into account the dynamic of transformations. The DNPC, voluntarily or not, involves a village elite while maintaining "l'apparence de la consultation et du consensus" (Le Marcis 2003: 637). The inventory is limited to a few, mostly emblematic aspects that have the merit of presenting easily shared symbols. However, it does not necessarily correspond to the practices and actions that the cattle herders consider as useful to "revive" (wurtude) the festivals and pastoralism. In effect, the latter, far from being passive, question the relevance of such an action and discuss what they would like to develop within the framework of this partnership with the DNPC or autonomously.

\section{Delays, Misappropriations and Patrimonial Contradictions}

The cattle herders have observed a decline in the festivals and pastoralism since the 1970s. The reduction in the number of herds presented in the parades, conflicts within the herder population and lack of respect for precedence of access to pastures are advanced as additional factors that disrupt the smooth running of the festivals. Cultural associations and local authorities, some of which are also members of the management sub-committees, have attempted to reinvigorate the festivals for about ten years by offering prizes to the best cattle herders. Moreover, the herders ask above all for better protection of pastoral activity. They often invoke a sentiment of political, economic or identity marginalization.

Patrimony is commonly perceived as an opportunity to revalorize marginalized territories or activities, particularly through the establishment of tourism. Since its independence in 1960, Mali has thus engaged in a policy of heritage valorization with the aim of promoting an independent state, breaking with the colonial past and ensuring the promotion of the Malian nation (Rowlands 2007: 131). With the advent of the Third Republic in the 1990s, the valorization of Malian heritage had the ambition more directly of reinforcing the program of political decentralization by providing economic resources to the communities (Ouallet 2003a: 69-74, 2003b: 302 and 311, Arnoldi 2006: 64, Doquet 2006). Patrimonial development then appeared as the result of political support for projects. The UNESCO candidacy dossier proposed by the DNPC sets out, in a double movement, the desire for revalorization of the Fulbe identity in itself and the inclusion of heritage in the global circuits of consumption of cultural goods. The yaaral and the degal are presented as being part of a group, adding to the already highly promoted delta of the Niger River and other classified sites in the region: Djenné and the cliffs of Bandiagara. ${ }^{14}$ As Gaetano Ciarcia identified for the Dogon Country, heritage in the rhet-

\footnotetext{
14 The Malian government proceeded with the inclusion of several sites to the list of World Heritage Humanity: The old towns of Djenné and Timbuktu in 1988 and the Cliff of Bandiagara (Land of the
} 
A Policy of Intangible Cultural Heritage between Local Constraints and International Standards

oric of institutional discourse becomes "a selection of elements deprived of exemplarity, responsible for leading communities into the future and well-being" (2003: 180-181) and a tool in the service of the socio-economic dynamics of the region. In fact, any patrimonial program then appears to be ambiguous in promoting both cultural valorization for itself and the use of culture for the dynamics of local development. Such ambiguities are perceived firstly at the level of the recipients of the patrimonial classification, through the interpretation that they themselves make of it. The question of the translation of the categories of heritage thus goes beyond the level of translating concepts, and reaches into the sphere of concrete expectations related to the development of pastoralism.

The real content of the action plan was presented to the members of the subcommittees and to the coordinator during their meetings with the DNPC, but they only have partial knowledge. They control neither projected action timetables nor the distribution of budgets. For several members of the sub-committees long involved in the organization of the festivals, the intervention of UNESCO via the DNPC had been conveyed as a solution to the difficult financing of the events, to housing problems for the official delegations and, over the long term, was viewed as a possibility to directly subsidize pastoral activity. These ideas were shared with the inhabitants of Jafaraabe and Jallube, for whom the intervention of an international organization most often meant concrete material productions. UNESCO is generally associated with many other international bodies that intervene in the region of Mopti. Local authorities, mediators and "development brokers" (Bierschenk; Chauveau; Olivier de Sardan 2000) know them, but their focal area, like their function, remains unclear for most of the participants (sub-committee members included).

The classification has brought expectations for the actors in the festivals, but also a certain number of recommendations. These are set out on the levels of project promoters or sub-committee members and of the herders: The latter translate this international awareness as a duty to present fat livestock during the festivals and to take care of the cattle. Patrimonial valorization leads here to an increased surveillance of the herd and responsibilities toward the young herders. This discourse precedes the classification. The change to institutional heritage results only in adding a new dimension to already existing strategies of valorization of pastoralism. While the discourse on the finaa-tawaa, held by festival participants and patrimonial agents, makes reference to events, poetry, jewelry, and hair, the discussion of raising awareness of the protection of the festivals comes back to better management of the herd.

Some of the cattle herders interpreted the announcement of classification as an opportunity to aid herding by activities of pasture regeneration, vaccinations and

Dogons) in 1989. The impact of heritage policies in the cities of Djenné and the challenges they raise have been reviewed by Michael Rowlands (2007) and Charlotte Joy (2007). Gaetano Ciarcia (2003) and Anne Doquet (1999) have analyzed the influence of anthropological discourses and tourism in the Dogon culture. 
materialization of pastoral infrastructures that UNESCO would directly finance. There is thus a mismatch between the expectations raised by the announcement, the program designed by heritage agents and the pastoralists own view of what should be done to promote their practice.

The goal put forward by UNESCO and the DNPC was, indeed, to reconcile the protection of the "integrity" of the heritage in which the people must be recognized while enabling local development to benefit this population. Up to that point, there is consistency between the DNPC agents, who think in terms of socio-economic development of the zone, and the expectations of the inhabitants of Jafaraabe and Jallube. It is the modes of realization that occasionally conflict. While festival organizers hope for real investment for the development of the village and pastoralism, institutional heritage promoters think in terms of inventories, documentary acquisition and preservation of knowledge and skills. Both parties are aware that it is the events, jewelry and the competition that interest the international organization, national spectators, some Western tourists, and also the herders, and thus understand the choice of elements targeted by the patrimonial action. Nonetheless, they feel that an intervention focusing on the promotion of the festivals should only concern the pastoral practice in itself. As such, an effective protection program should address security for land tenure, food and the health of transhumant pastoralists.

In other words, the actions promoted by the DNPC are considered inadequate, even incongruous, for most of the inhabitants of the villages involved. The actions of inventory, promotions of musical works or raising awareness by radio programs about the festivals (DNPC 2006) did not meet the expectations raised. This confusion between patrimonial project and development operation has been fostered by the promises made by the political leaders present at the festivities, including the President of the Republic, who announced the realization of a program for regeneration of pasturage or the construction of a vaccination park at the same time as they launched the classification procedure. In the strategies of local authorities, the festivities are already privileged occasions for the community to air grievances to political and administrative leaders present and to meet with potential donors. At Jafaraabe in 2008, for example, repair work on the river banks and river dredging were inaugurated during the yaaral. Many local cattle herders thus see the UNESCO classification in this logical series of actions aimed at developing the village or livestock breeding. Some point with pride to the international recognition of the festivals, but they remain skeptical as to its effects. Indeed, even the subcommittee members regard the achievements of the action plan as a failure. For them, UNESCO and the DNPC remain invisible institutions incapable of resolving the pastoral problems with which the local populations are confronted. 
A Policy of Intangible Cultural Heritage between Local Constraints and International Standards

\section{Conclusion}

My research has shown that the cattle herds have been able to divert the classification to evoke their own representations of contemporary pastoralism and to insert it into the interplay of local power and in their negotiations with the central government. Overall, the project as designed by heritage agents has been reworked by different actors once it passed to the actual implementation phase. Whether in institutional patrimonial discourse or in the work undertaken by the organizers of the transhumance festivals, the pastoral competition, the feminine esthetic and the livestock parades are promoted, recycled and reinterpreted. They are transformed into stereotypes that recover their different meanings in a patrimonial arena where the presentation and public reformulation of the tradition carries contradictory political or identity-related objectives. To take only one example of all the possible misappropriations, the patrimonialized festivals can be perceived as tools for the protection of the pastoral exploitation system of the Delta. The classification of the "cultural space of the yaaral and the degal" then appears as a label that could potentially further land and territorial claims when it is transformed into a symbol of pastoral exclusivity by the cattle herders (Leblon 2011b). Groups of cattle herders might claim rights to maintain pastoral spaces when faced with other cattle herders or other professional groups partaking of the resources the Delta offers. ${ }^{15}$ Even symbolic uses of the heritage label could enter into contradiction with other uses, identity-related or political, of the territory as they are operated by the institutional project brought in by the Malian state.

The heritage discourse is couched consensually and placed the accent on the spectacular aspects of pastoralism. In so doing, it avoids involvement in the more conflict-ridden issues concerning modes of management (of a space, a resource, a power). ${ }^{16}$ Elements related to the territorialization of pastoral activity, polemic in a context of climate change and redefinition of rights between the different users of the Delta, are neutralized or "camouflaged" behind a consensual presentation of the pastoral tradition. This corresponds both to the UNESCO classification procedure and the guidelines for heritage policy in Mali. Indeed, on the scale of a global patrimonial regime, institutional heritage promoters propose a peaceful

\footnotetext{
${ }^{15}$ Non-local herders and other socio-professional groups of the Delta have a figurative role in the festivities. Herders foreign to the leydi (pastoral territory), farmers and fishermen, even if they are livestock (most often entrusted to a Fulbe breeder who will include them in his own herd) owners, cannot participate in the livestock parades or the competition for the fattest herd reserved for the Fulbe herders of the locality. For non-local herders, the exclusion from the festive practice often corresponds to an exclusion from direct rights to the exploitation of the pastures open at the moment of the festivities. Only local herds enter the pastures at Lake Debboy during the degal at Jallube.

16 The resolution of conflicts between the different actors on the Delta is presented as one of the most pressing challenges to be met for a sustainable management of natural resources in the 5 th region by several observers of the Inner Niger Delta (Mosely et al. 2002: 105, Barrière and Barrière 2002).
} 
image of "traditional" society in which conflicts do not exist. With regard to building an architectural heritage classified on the UNESCO World Heritage List, Daniel Fabre has emphasized that:

dans tous les lieux qui seront exhaussés par cette inscription mondiale, nous assistons à une sorte de mise à nu des relations de pouvoir qui débouche, par la force des choses, sur une unanimité négociée puisque la suspension des polémiques, la fraternisation autour du monument est une des conditions de la sélection du dossier. (Fabre 2010: 43)

The harmony of the façade is initially necessary to the classification, since it must be maintained so as not to risk compromising the image of international classification and the benefits it might bestow.

At the Malian national level, the official promotion of ICH cuts across a political issue indirectly promoting sustainable management of natural resources and the different professional activities of the Delta: It defuses conflicting elements that condition, however, the perpetuity of the festivals. It is a rhetorical response brought to the question of sustainable management of natural resources.

The listing of the yaaral and the degal thus comes back to the international imperative of sustainable development and protection of cultural diversity, two themes joined together in the discourse of UNESCO (Stoczkowski 2009). The discourse on patrimony, therefore, offers the possibility for the Malian state to create a synthesis between international norms for patrimonial valorization and the local constraints of a policy of territorial management and development at a time when the state is beginning the transfer of powers to the communities.

My case study dwells on the uniqueness of ICH valorization in what Herzfeld has termed the "hierarchy of global cultural values" (2004). The focus on the involvement of populations concerned allowed me to question facets of heritage protection. The case illustrates the "participatory rhetoric" considered as a key to "good governing" by international organizations (Saint-Lary 2009: 16), while showing, on the ground, how a policy is implemented under the assumption that it opens up opportunities for international donations. The state has been able to implement this nomination while simultaneously withstanding the challenges that pastoral activity represents; they have long been neglected to the benefit of agriculture, though they hold a central economic potential. The state has implemented a heritage discourse here that does not promote herding for itself, but its relationship to the other socio-professional categories along the Niger Delta. Institutional heritagization thus seems to be closer to a short-term project of social development in the deltaic region than an action for promotion of the Fulbe culture. Agents entrusted with heritigization invest the past and the Fulbe tradition with a mission of ensuring improved living conditions for the people of the Inland Niger Delta. In this, they are joined by villagers who, furthermore, have an interest in the self- 
A Policy of Intangible Cultural Heritage between Local Constraints and International Standards

spectacularization of their culture. A specific use of natural resources and land is thus defined from one level to another of the patrimonial nomination ladder.

In a context of decentralization, the passage of the implementation of the project from national to local level also forms part of the process of involving populations at the smallest level of the administrative network. This "increasing localization of projects" (Bierschenk and Olivier de Sardan 1993) implies that actors serve as an interface between project recipients and heritage institutions. In the case studied, the process of involving the populations confirms once again the role of certain actors, political administrators and local associations. Despite the criticisms raised by members of the sub-committees concerning the relevance and utility of the heritage actions undertaken, these critics themselves are not immune to the promotion of the spectacular and esthetic aspects of the patrimonialized goods. They are, however, engaged at different levels in activities promoting pastoralism that have other meanings than simply cultural heritage protection. They can, from now on, extend the work in progress for the presentation of the tradition based in particular on the pastoral competitions and the feminine esthetic (Leblon 2011a). However, in this context, the production of heritage knowledge invokes the power relationships between the state and the pastoral world or between the different inhabitants and exploiters of the Inner Niger Delta.

\section{References}

Andrieu, Sarah (2009): Le spectacle des traditions. Analyse anthropologique du processus de spectacularisation des danses au Burkina Faso, Doctoral thesis presented under the direction of Professor Bruno Martinelli, 15 December 2010, Université de Provence.

Arnoldi, Mary Jo (2006): Youth Festivals and Museums: The Cultural Politics of Public Memory in Postcolonial Mali. Africa Today 52(4): 55-76.

Barriére, Olivier, and Catherine Barrière (2002): Un droit à inventer. Foncier et environnement dans le Delta intérieur du Niger (Mali). Paris: IRD.

Bierschenk, Thomas (1995): Rituels politiques et construction de l'identité ethnique des Fulbe au Bénin. Cahiers des Sciences Humaines 31(2): 457-484.

Bierschenk, Thomas and Jean-Pierre Olivier de Sardan (1993): Les courtiers locaux du développement. Le bulletin de l'AP $A D, 5$.

http://apad.revues.org/document3233.html. <accessed March 19, 2010>

- (1998): Les pouvoirs au village: le Bénin rural entre démocratisation et décentralisation. Paris: Karthala.

Bierschenk, Thomas, Chauveau, Jean-Pierre, and Jean-Pierre Olivier de Sardan (2000): Introduction. In Courtiers en développement. Les villages africains en quête de projets. Thomas Bierschenk, Jean-Pierre Chauveau and Jean-Pierre Olivier de Sardan, eds. Pp. 5-42. Paris: Karthala. 
Blake, Janet (2009): UNESCO's 2003 Convention on Intangible Cultural Heritage. The implications of community involvement in 'safeguarding'. In Intangible Heritage. Laurajane Smith and Natsuko Akagawa, eds. Pp. 45-73. London: Routledge.

Bortolotto, Chiara (2006): La patrimonialisation de l'immatériel selon l'UNESCO. Résumé de la communication présentée le 16 juin 2006, à la réunion des conseillers à l'ethnologie et des ethnologues régionaux, Mission à l'ethnologie (Dapa, Ministère de la culture).

http://www.iiac.cnrs.fr/lahic/sites/lahic/IMG/pdf/Bortolotto_juin_06.pdf accessed May 22, 2012>

Bouju, Jacky, (1995): Tradition et identité. La tradition dogon entre traditionalisme rural et néo-traditionalisme urbain. Enquête 2: 95-117.

Breedveld, Anneke, and Mirjam De Bruijn (1996): L'image des Fulbe: Analyse critique de la construction du concept de pulaaku. Cahiers d'Études africaines 36(4): 791-82.

Ciarcia, Gaetano (2003): De la mémoire ethnographique. L'exotisme en pays dogon. Cahier de l'Homme, 36. Paris: Éditions de l'EHESS.

- (2006): La perte durable. Étude sur la notion de "patrimoine immatériel", Les carnets du Lahic 1.

http://www.iiac.cnrs.fr/lahic/les-carnets-du-lahic/article/la-perte-durableetude-sur-la <accessed May 23, 2012>

De Bruijn, Mirjam, and Han Van Dijk (1995): Arid Ways. Cultural Understandings of Insecurity in Fulbe Society, Central Mali. Amsterdam: Thela Publishers Amsterdam.

De Jong, Ferdinand, and Michael Rowlands (2007): Reconsidering Heritage and Memory. In Heritage. Alternative imaginaries of memory in West Africa. Ferdinand de Jong and Michael Rowlands, eds. Pp. 13-29. Walnut Creek: Left Coast Press.

DNPC (2004): Proposition d'inscription de biens sur la liste du patrimoine oral et immatériel de l'humanité. Espace culturel du Jarral degal au Mali. République du Mali. Bamako: UNESCO.

- (2006): Plan d'action de sauvegarde du Yaaral et du Degal. UNESCO/Japan Funds-in-Trust For The Preservation and Promotion of the Intangible Cultural Heritage.

- (2007): Atelier de validation du rapport d'inventaire des biens lies à l'Espace culturel du Yaaral et du Degal. Rapport de mission, Bamako, Ministère de la Culture, DNPC. Mopti, December 11, 2007.

- (2008): Bordereau d'envoi nº0003/PPSECJD, Éléments inventoriés. Sévaré: DNPC.

- (2009): Bordereau d'envoi N00005/P.P.S.E.C.Y.D, Éléments inventoriés. Sévaré: DNPC.

Doquet, Anne (2006): Décentralisation et reformulation des traditions en pays 
A Policy of Intangible Cultural Heritage between Local Constraints and International Standards

dogon. Les manifestations culturelles des communes de Dourou et Sangha. In Décentralisation et pouvoirs en Afrique. En contrepoint, modèles territoriaux français. Claude Fay, Yaouaga Félix and Catherine Quiminal, eds. Pp. 303-319. Paris: IRD.

Fabre, Daniel (2010): Habiter les monuments. In Les monuments sont habités. Daniel Fabre and Anna Iuso, eds. Pp. 17-52. Paris: Éditions de la maison des sciences de l'homme.

Fay, Claude (1989): Sacrifices et prix du sang: fondation des territoires de pêche dans le delta central du Niger. Cahiers des Sciences Humaines 25(1-2): 158 176.

- (1997): La ruralité revue et corrigée par l'État: représentation et traitement du paysannat dans le delta central du Niger (Mali). In La ruralité dans les pays du sud à la fin du 20ème siècle. Jean-Marc Gastellu and Jean-Yves Marchal, eds. Pp. 53-76. Paris: ORSTOM.

- (1998): Genèse et enjeux de l'organisation communale au Maasina. In Pouvoirs locaux, pouvoir d'État, démocratie et décentralisation au Mali, Rapport d'étape. ISH, EHESS, Ministère de la coopération, fond documentaire de l'ORSTOM: $55-75$.

Gallais, Jean (1968): Le delta intérieur du Niger, Étude de géographie régionale. Tome 1. Thèse principale pour le doctorat d'État. Paris. (Première édition: 1967, Mémoires de l'Institut fondamental d'Afrique noire. Dakar. IFAN. n 79, 2 tommes).

Hafstein, Valdimar (2004): The Making of Intangible Cultural Heritage: Tradition and Authenticity, Community and Humanity. Unpublished Ph.D. dissertation. Berkeley: University of California.

Herzfeld, Michael (2004): The Body Impolitic. Artisans and Artifice in the Global Hierarchy of Value. London: The University of Chicago Press.

Joy, Charlotte (2007): Enchanting Town of Mud: Djenné, a World Heritage Site in Mali. In Reclaming Heritage. Alternative imaginaries of memory in West Africa. Ferdinand De Jong and Michael Rowlands, eds. Publication of the Institute of Archeology, University College London. Pp. 145-159. Walnut Creek: Left Coast Press.

Lassibille, Mahalia (2003): Danses nomades. Mouvements et beauté chez les WoDaaBe du Niger. Tome I et II., Doctoral thesis in Anthropology under the direction of Jean-Loup Amselle. Paris: EHESS

Leblon, Anais (2011a): La sélection paradoxale. La patrimonialisation des fêtes de transhumance peules au Mali. In La sélection patrimoniale DROUIN. Martin Drouin and Anne Richard-Bazire, eds. Pp. 195-214. Montréal: Cahiers de l'Institut du patrimoine de l'UQAM.

- (2011b): Le patrimoine pastoral au prisme de la décentralisation politique. Les fêtes du yaaral et du degal au Mali. Géographie et cultures (in Press). 
Le Marcis, Frédéric (2001): Des maux ordinaires. Une anthropologie de la santé au quotidien dans le Maasina (Mali). Doctoral thesis in Anthropology under the direction of Didier Fassin. Paris: EHESS.

- (2003): Le développement à l'épreuve des systèmes locaux de relation. Conflits et pouvoir autour de la construction d'une maternité dans le Maasina (Mali). Cahiers d'Études africaines 171(3): 629-656.

Marie, Jérôme (2002): Enjeux spatiaux et fonciers dans le Delta intérieur du Niger (Mali). Delmasig, un SiG à vocation locale et régionale. In Gestion intégrée des ressources naturelles en zones inondables tropicales. Didier Orange et al., eds. Pp. 557-586. Paris: IRD.

Mosely, William G. et al. (2002): La décentralisation et les conflits entre agriculteurs et éleveurs dans le Delta intérieur du Niger. In Gestion intégrée des ressources naturelles en zones inondables tropicales. Didier Orange et al., eds. Pp. 101-118. Paris: IRD.

Olivier de Sardan, Jean-Pierre (1995): Anthropologie du développement: essai de socio-anthropologie du développement. Paris: Karthala.

Ouallet, Anne (2003a): Perceptions et réutilisations patrimoniales en Afrique. Quelques exemples maliens. In Regards croisés sur le patrimoine dans le monde à l'aube du XXIe siècle. Maria Gravari-Barbas and Sylvie GuichardAnguis, eds. Pp. 59-75. Paris: Presse de l'université de Paris-Sorbonne.

- (2003b): Affirmations patrimoniales au Mali: logiques et enjeux. In Patrimoines et développement dans les pays tropicaux. Pp. 301-312. Pessac: DYMEST et CRET (Espaces tropicaux, 18).

Revel, Jacques (1996): Jeux d'échelles. La micro-analyse à l'expérience. Paris: Le seuil.

Rowlands, Michael (2007): Entangled Memories and Parallel Heritages in Mali. In Reclaming Heritage. Alternative imaginaries of memory in West Africa. Ferdinand De Jong and Michael Rowlands, eds. Pp. 127-144. (Publication of the Institute of Archeology, University College London) Walnut Creek: Left Coast Press.

Saint-Lary, Maud (2009): Introduction: des entrepreneurs entre rhétorique et action sur le monde. Bulletin de l'APAD 29-30: 9-17.

Seydou, Christiane (1998): Dictionnaire pluridialectical des racines verbales du Fulbe: Fulbe - français - anglais. Paris: Agence de la francophonie.

Stoczkowski, Wiktor (2009): Unesco's Doctrine of Human Diversity: A Secular Soteriology. Anthropology Today 25(3): 7-11.

Turgeon, Laurier (2010): Du matériel à l'immatériel. Nouveaux défis, nouveaux enjeux. Ethnologie française XL(3): 389-399.

Turner, Matthew D. (1992): Living on the edge: Fulbe herding practices and the relationship between economy and ecology in the Inland Delta of Niger. A dissertation submitted in partial satisfaction of the requirements for the degree of Doctor of Philosophy in Energy and Resources, Berkeley: University of California. 
A Policy of Intangible Cultural Heritage between Local Constraints and International Standards

UNESCO (2003): Convention pour la sauvegarde du patrimoine culturel immatériel. Paris: UNESCO. 

Layers of Preservation Regimes and State Politics 



\title{
Unity Makes...Intangible Heritage: Italy and Network Nomination
}

\author{
Katia Ballacchino ${ }^{1}$
}

\section{Introduction}

This article seeks to outline the process that began in Italy in 2011 to submit a network nomination that would include four cities in the Representative List of the Intangible Cultural Heritage of Humanity on the basis of their shared tradition of feasts with large "festive machines." Before analyzing this process of constructing a sort of "shared heritage" among multiple cities, I would like to introduce the analytical work I have carried out in relation to one of these feasts.

Since 2006, I have been conducting ethnographic research on the feast of the Gigli in Nola, a town in Campania, and its processes of patrimonialization ${ }^{2}$. My work has concentrated on a detailed analysis of the festive practices surrounding the Gigli in the Nolan area and other locations, engaging with the "community of practice" concept ${ }^{3}$, as well as the dynamics triggered in Nola by UNESCO-style discourses. As a matter of fact, recent Gigli history has been marked by four differ-

\footnotetext{
${ }^{1}$ Translated from the original Italian by Angelina Zontine and Chiara Masini.

${ }^{2}$ For a deeper analysis of the Nolan Gigli feast, which I am not able to address in this context, please see the following: Ballacchino 2008, 2009, 2011; the following publications are forthcoming: a monograph based on my complete research, and an article about the ties between the Gigli and Watts Towers in Los Angeles, a tower construction listed among the heritage of the state of California which, according to some scholars including myself, may have been influenced by the Nolan Gigli feast as they were constructed by a migrant from Campania.

${ }^{3}$ For a deeper review of the literature on the "community of practice" concept, see the following: Lave and Wenger 1988, 1991, Wenger 1998, Wenger; McDermott; Snyder 2002.
} 
ent nomination attempts and their associated processes of valorizing and sponsoring the feast according toa "UNESCO logic."

In the multiple attempts to nominate this ceremonial complex to the UNESCO Representative List of the Intangible Cultural Heritage of Humanity (2003 Convention, ratified by Italy 2007), its trans-local practice has been treated in different ways. Between 2000 and 2005, an association based in Nola put forward three nominations of the Gigli feast as a Masterpiece of the Oral and Intangible Heritage of Humanity, all of which failed ${ }^{4}$. The dossiers underlined the originality and uniqueness of the Nolan feast without mentioning its having spread to other regional, national and international localities, such as the multiple copies of the Gigli found throughout the Campania region and the secular re-staging of the Giglio in Williamsburg, Brooklyn, NYC, that I myself investigated as part of my ethnography. The nominations made use of the feast's history to underline its mythical origins, linkage to Christianity and religious values, somewhat obscuring any element of complexity linked to modernity or to social systems of connectedness to local territory and culture. In presenting this element of heritage at the international level, nominators sometimes concealed such references to the feast's exclusive bond with the local territory or its geographic replications. Links to the local territory were thus mentioned but not in a way that was strategic for each nomination attempt.

Building on these earlier nomination attempts, the local administration became aware of the potential value the feast could assume at the supra-local level and gradually activated local and non-local mechanisms of exploitation and political strategy aimed at promoting an increasingly spectacular version of the ritual to outside audiences. The link with local territory was thus utilized to assert the authenticity of this piece of heritage by designating the origins of the Gigli in the early nominations in Nola or, vice versa, to use the heritage to claim ownership rights over a specific territory - with the associated problems of imitation or falsification of the good represented by the feast ${ }^{5}$.

These complex procedures thus produced changes and activities that are intrinsically connected to UNESCO and the new opportunity this international agency offers to local sites in an era when local cultures may be experiencing a powerful pressure from the larger society to homogenize.

This has led to the focus of this article, the latest nomination attempt in the shape of a "network" nomination. A first experience for Nola, this is also the only

\footnotetext{
${ }^{4}$ See the undergraduate thesis D’Uva 2010 for an outline of the various attempts to nominate the Gigli feast.

${ }^{5}$ I address this specific question in an essay titled "I Gigli di Nola 'in viaggio verso l'UNESCO': autenticità, serialità ed eccellenza di un patrimonio immateriale e del suo territorio" presented at the international seminar "Atelier de recherche en sciences sociales et humaines, Allemagne, France, Italie»: Institutions, territoires et communautés - Perspectives sur le patrimoine culturel immatériel translocal, PREMIER ATELIER, L'inscription territoriale du patrimoine immatériel," DFG,Villa Vigoni,Maison des Sciences de l'Homme - Forschungskonferenzen in den Geistes- und Sozialwissenschaften, held March 23 to 26, 2010.
} 
occurrence of its kind in Italy thus far ${ }^{6}$. This latest nomination focuses on the serial character of the larger Italian festive practice of carrying large festive "machines"7 on the shoulders.

As a result, whereas in previous years I was engaged in investigating the dynamics surrounding UNESCO discourse and the local effects they produced in my field sites, during the last nomination I found myself playing a direct role in that the Nolan town hall commissioned me as a scholar of the Gigli feast to work on cataloguing the event as required by the Italian UNESCO commission. Although UNESCO does not specify what shape the inventory must take, Italy has implemented the UNESCO directives by implicitly requiring anthropologist involvement in the work of cataloguing intangible heritage. This is also due to the fact that anthropological functionaries conceived of and manage inventorying forms at the ministerial level and thus their specific professional expertise continues to be required for cataloguing activities.

In the specific process established in Italy, any locality wishing to present a nomination is required first of all to begin an inventory of the good in question: Specifically, this involves documenting the various elements that are to be nominated as intangible heritage. In the Italian context, this consists of compiling an undefined number of cataloguing forms, usually produced following the BDI format (Beni Demoetnoantropologici Immateriali or Immaterial Demo-ethnoanthropological Goods) ${ }^{8}$. The BDI format has a long national tradition ${ }^{9}$ that cannot be neglected even though no clear rules exist regarding the protocols that must be followed in inventorying for the nominations. Following Article 12 of the 2003 convention, it became necessary to create inventories of the heritage being nominated. As a result, a process of documentation was implemented at the national level, requiring the municipalities involved in the network to commission and finance cataloguing activities. The coordinating committee of the "festive machine" network nomination, therefore, employed cataloguing anthropologists, including myself, to carry out research on the territories involved. In some cases, the anthro-

\footnotetext{
${ }^{6}$ However, Italy has been involved in the Intangible Cultural Heritage ( $\mathrm{ICH}$ ) trans-national nomination of the Mediterranean diet, discussed by Broccolini in this volume.

7 In Italian, just as in English, the term "machine" is generally associated with industrial production, but here I refer to the meaning that this term has taken on in the Italian festive vocabulary, according to which "festival structures carried on the shoulders" can be described as "big wooden constructions." Please see the two illustrations included in the article.

8 The ICCD, Istituto Centrale per il Catalogo e la Documentazione (Central Institute for Cataloguing and Documentation) of MiBAC, the Ministero per $i$ Beni e le Attività Culturali (Ministry of Cultural Goods and Activities), defines the standards for cataloguing various types of cultural goods. There is a set of norms, rules and methodologies that must be followed in order to acquire the most homogenous and standard information possible at the national level. To better understand some aspects of Italian Ministerial cataloguing using the BDI form, please see the following: Tucci and Bravo 2006, and the second volume of the folder Scheda BDI Beni demoetnoantropologici immateriali (Istituto centrale per il catalogo e la documentazione 2006).

${ }^{9}$ For an additional analysis of cataloguing activity in the Italian tradition, please see the article by Alessandra Broccolini in this volume.
} 
pologists were selected through mediation by the participating cities; in other cases, selection occurred through recommendations made by the local cataloguing institutions or through external evaluation by the network coordinating committee.

From this premise, I seek to highlight the way that, by crossing multiple analytical levels, my study was enriched by a close-grained ethnographic perspective on the internal and external patrimonialization processes of a specific city; this allowed me to consider the enlargement of the idea of a "heritage" form that we could say is "shared" among multiple, apparently similar, localities, outlining the opportunities and limits posed by the process of granting institutional visibility to the tradition on the crest of the opportunity offered by UNESCO.

I will thus outline the efforts of an Italian committee that has coordinated a twin-city network among multiple municipalities in order to construct a network nomination bringing together feasts characterized by large, shoulder-carried "machines." The category of "festive structures carried on shoulders" is interesting because it is internally diverse and yet provided the nucleus around which the homogenizing idea of an Italian network nomination was formed.

\section{The Italian Experience of a Network Nomination}

In 2006, five cities in South-Central Italy (Palmi in Calabria, Gubbio in Umbria, Nola in Campania, Sassari in Sardinia, and Viterbo in Lazio) reached an agreement protocol at the local level for a project of cultural exchange titled "La Varia e le Macchine a Spalla Italiane"10 (The Varia and Italian Shoulder-carried Machines). During the preparation of the UNESCO nomination project that the original coordinating committee ${ }^{11}$ developed between 2009 and 2010, the network grew smaller when the city of Gubbio voluntarily chose to leave it. On the other hand, the protocol's very title expresses the central place given to Palmi's festive "machine," the Varial1. Indeed, the effort of coordinating the network originated in the Calabrese city of Palmi thanks to a local historian at the University of Messina who was interested in this area and its traditions ${ }^{13}$. The objectives expressed in

\footnotetext{
${ }^{10}$ See the text of the protocol, signed June 30, 2006, and published at http://www.conteanolana.it/protocollo-finale-NOLA.pdf < accessed July 4, 2012> to understand the objectives and aims of the project.

11 The coordinating entity in charge of the network nomination was composed of the University of Messina historian who initiated the agreement protocol among the cities, a University of Rome anthropologist who has been studying local traditions for years, and an expert who analyzed the Gigli of Nola nomination in his undergraduate thesis, supervised by an advisor who was also the president of the Italian National UNESCO Commission.

12 The initial project was proposed alongside another one titled "I Percorsi della Fede. La Varia di Palmi nello scenario delle grandi Macchine lignee a spalla italiane" (Itineraries of faith: the Varia of Palmi among the large, Italian, wooden, shoulder-carried machines).

${ }^{13}$ It might also be hypothesized that personal reasons also motivated the network coordinator to take on this role, which went beyond her specific professional expertise. She might have been motivated mainly by a desire for civic involvement and local pride, seeing that she comes from one of the cities
} 
project documents and press releases of the time included the aim of using the circuit of twin-cities to promote research seminars "to establish actual touristic and commercial relationships, with the creation of special packages to promote tourism in the city." The project, therefore, appeared to aim at channeling a shared objective of promoting touristic and economic development in the local areas involved through the idea of uniting these similar festive spheres. The UNESCO opportunity thus represented a catalyst for implementing local objectives that can certainly be seen as valid.

Through my ethnographic monitoring of the processes involved in making the Nolan Gigli feast into heritage, I observed instances of hostility break out among the four cities and three other towns with their own feasts: the Ceri of Gubbio in Umbria, the Misteri of Campobasso in Molise ${ }^{14}$, and the Carro of Ponticelli in Campania. These cities were identified as subjects that deserved to be included in the protocol; however, due to a great deal of contention between the network coordinators and the individual municipalities, they were excluded or chose not to participate. In relation to this, there is a very interesting document that illustrates the highly problematic nature of the procedure through which this network nomination was constructed and the direction it took, including the contested forms it assumed in each of its local replications and in particular in Calabria ${ }^{15}$.

This circuit of large shoulder-carried machines was subsequently defined as an "Italian folklore network" that also referenced the idea of the union of the Mediterranean in addition to the idea of the four cities in the network. The network nomination was guided by UNESCO-style discourses ${ }^{16}$; it was based on a positive relationship between the various "communities" and did not call into question the territorial and heritage-based authenticity of the individual material goods, but

included in the project. Another hypothesis is that this visibility might have granted her some "authority" in terms of public recognizability within local political or academic dynamics. At any rate, this role allowed her to construct a certain level of profile, with the result that she is currently coordinating, for example, the nomination attempt for Italian Opera.

${ }^{14}$ See Bindi (2009) for more information about the patrimonialization processes linked to the Misteri feast in Molise. During the 2007 edition of the feast, the town hall of Campobasso made a request to enter into the Italian shoulder-carried machine circuit. Their entrance appeared to be officially recognized in 2008, but was blocked immediately after the application due to personal conflicts with the circuit coordinators.

15 The document, published in a Palmi newspaper, was ironically titled "UNESCO o DIVIDESCO? Quali verità?" (UNite-ESCO or divide-ESCO? What is the truth?) and included an article by the network coordinator alongside an article by the mayor of Palmi representing a counter-argument. The two arguments asserted two different interpretations of the confused and highly contested events surrounding the network nomination activities, characterized by marked inclusions and exclusions, and of the coordinating committee's selection procedures, which caused problems at local and national levels.

Please see http://www.madreterranews.it/public/upload/120720112034_716959_1.pdf < accessed July 4, 2012>.

16 These involve highlighting (after the fact) positive relations, harmony and authenticity, but also specifying which different kinds of actors were participating in the discourse. 
rather capitalized on the effectiveness of similar instances of immaterial excellence at the national level.

The common elements defined as shared among the four cities with shouldercarried machines were quite diverse and generic: identity, the use of shoulders, physical effort, the carriers' corporate groups, emotions, the sense of belonging, historical markers, community memory, artisanal skills, et cetera. These elements are present in countless religious ceremonies in Italy. At the beginning, indeed, network administrators and promoters - that is to say, not only the festival practitioners themselves, but also and especially administrators or other local political actors - used their rhetoric and public discourse to express the idea that the recognition of this network nomination on the part of UNESCO would have represented a step forward, underlining the importance of local community and dialogue among different communities as a currency for the future. In this sense, the feast was used as a bridge for the transmission of culture, a common denominator and a wider framework for local identity. This is in contrast to the representation of the Gigli feast in its nominations as a Masterpiece of the Oral and Intangible Heritage of Humanity, which stresses the unique and irreproducible element of a feast risking extinction.

Still under the management of the same nomination organizing committee, the project was successively denominated "UNESCO prospective ${ }^{17}$," in line with the idea of a dangerous weakening of local identity. In fact, the nomination was presented as a grass-roots effort that originated in the communities involved, although in reality it was carried out mainly by institutions and external intellectuals.

One can already note a short-circuit in the very hypothesis of a network built according to what UNESCO hoped would become a means of preventing conflict, namely dialogue between multiple diversities and the sharing of common heritage. This short-circuit in some ways invalidates the relationship between what Bortolotto defines as "the spirit of the convention," that is, the objectives contained in the international UNESCO legal regulations, and the reality of local policies ${ }^{18}$. To reflect on the uses of territory and heritage forms that are "serial" or "shared," it makes sense to focus on an analysis of the national processes of implementing international UNESCO policies, alongside the more local processes observed at moments of dialogue and of outright conflict surrounding these festive communities and their institutions. Following the 2003 UNESCO convention governing inclusion in the Representative List of the Intangible Cultural Heritage of Humanity, the concepts of "territories" and "local communities" or "heritage communities" are strategically and instrumentally used by ad hoc committees and local and national institutions in nominating certain heritage forms.

\footnotetext{
17 "Cultura Immateriale e prospettiva UNESCO: La Rete delle grandi Macchine a spalla italiane." Please see http:/ / www.rivistasitiunesco.it/articolo.php?id_articolo $=438<$ accessed July 4, 2012>.

${ }^{18}$ For further analysis of some of the delicate questions linked to heritage and UNESCO policies, see, among others, the following: Palumbo 1998, 2001, 2003 and 2007, Matsura 2002, Risse 2003. Bortolotto 2008, Zagato 2008, Bendix and Hafstein 2009, Pietrobruno 2009.
} 
Let us thus look more closely at the four connected feasts, underlining their common features in view of the network nomination defined under the general category of "large festival structures carried on shoulders." The Macchina di Santa Rosa of Viterbo, the Varia of Palmi, the Candelieri of Sassari, and the Gigli of Nola were selected from among many similar "ceremonial machines" in Italy. The coordination group proposed this project to the individual municipalities or local committees involved, which agreed to finance it in the hopes of "bringing together Italian situations that are geographically distant but close in terms of the values they represent: collective participation, sharing and openness to dialogue."

This network, conceived as a "bottom-up" nomination project according to UNESCO logics, generated a series of institutional and community-level patrimonialization processes that are quite interesting from an anthropological standpoint. I therefore examine in more detail the development of the individual cataloguing activities in the four cities involved in the network. These details show how the cataloguing process was quite detached from the network coordination. It also reveals how conflictual elements within the institutions or between the heritage communities and local institutions emerged.

The Santa Rosa feast in Viterbo, catalogued by anthropologists Alessandra Broccolini and Antonio Riccio, consists of transporting a tower illuminated by torches and electrical lights and made from light and modern materials such as fiberglass (which in recent years has replaced iron, wood and papier mâché). The tower is approximately 30 meters tall, and every year on the evening of September 3 , it is carried on the shoulders of 100 men, called facchini (porters), for about a kilometer between the walls of the city's historic center ${ }^{19}$. The origins of this "machine" date to the period after 1258, when Santa Rosa's body was transferred from the Church of Santa Maria in Poggio to the sanctuary dedicated to her, which took place on September 4 by order of Pope Alexander IV; this event was subsequently commemorated by repeating the procession, carrying an illuminated image or statue of the Saint on a canopy which reached ever greater dimensions over the centuries. The work of cataloguing the Feast of Santa Rosa was, therefore, commissioned by the municipality of Viterbo. For the inventorying, Antonio Riccio dealt with the porters and the Santa Rosa machine itself, while Alessandra Broccolini oversaw the elements related to the mini-machines (for the training and transportation of children) and the mini-porters, as well as the Cult of Santa Rosa and the Historical Procession. Altogether, 21 BDI forms were produced.

In terms of participating in the inventorying, the involvement of the various communities (the city in its official role, and the Sodalizio dei Facchini di Santa Rosa, the porters' society) was quite limited; the involvement of the media, which often reported on the inventorying work on the pages of local newspapers, was more significant. This imbalance led to a lack of control and sharing, and produced very

${ }^{19}$ In relation to the Santa Rosa feast of Viterbo, please see the following literature that Broccolini used in her cataloguing work: Piacentini 1991, Arduini 2000. I would also like to thank my colleague for the data provided. 
little in terms of feedback and repayment of the work on institutional and administrative levels (for example, the city did not initially provide employment contracts for the cataloguers). In addition to the municipality, the heritage subjects (heritage communities) in Viterbo included the Sodalirio dei Facchini di S. Rosa and the two mini-porter and mini-machine committees (one from the historic center and the other from the Pilastro neighborhood). These entities predate the UNESCO nomination and had little knowledge of the nomination project, the inventorying work or relations with other entities in the network. The committees and the porters' society did not oversee the inventorying work, which reveals the specific arrangement of these local heritage communities in relation to local institutions.

The Varia feast in Palmi, catalogued by anthropologist Tommaso Rotundo, takes place over the course of 15 days but at irregular intervals - once, twenty years passed between celebrations of the feast. It culminates in the transportation of the Varia, a massive, 16 meter tall scenic float carried in procession through Palmi in the Province of Reggio Calabria on the last Sunday in August ${ }^{20}$. The feast is linked to the cult of the Madonna della Sacra Lettera of Messina. Varia means coffin or bier, a term that alludes to the reliquaries of the Madonna but which actually references the entire votive float representing the Virgin's Assumption into the heavens. The structure is set into motion (the so-called scasata) by approximately 200 Mbuttaturi, the carriers who belong to five historic corporate groups: the Farmers, the Artisans, the Carters, the Drovers, and the Sailors. Through the gathering of oral testimony and archive material, and the production of photographic and video documentation, $16 \mathrm{BDI}$ forms were completed to create the inventory. The cataloguer operated in a context where multiple actors - belonging to various institutional and associational groups - competed for the role of valorizing and protecting the feast. ${ }^{21}$ Unlike the other feasts, in Palmi it was not the municipality who commissioned the heritage cataloguing, but rather a citizens' committee (the January 11, 1582 Varia Pro-UNESCO Citizens' Committee) comprised of young people who launched numerous initiatives to cover the costs of cataloguing 22 . The municipality of Palmi vacillated in relation to the network nomination project, at times showing support for the proposals made by the coordinating committee and at other times hampering the nomination process. According to the cataloguer, the presence of the committee, which represents a form of active citizenship, seems to

\footnotetext{
${ }^{20}$ For a more extensive investigation of the issues connected to the Varia feast of Palmi, please see the following publications cited in the cataloguing work of Rotundo, who is to be thanked for the data provided by his work: Lacquaniti 1957, Ferraro 1987, Grillea 1990, Galluccio and Lovecchio 2000, Marino 2000.

${ }^{21}$ In relation to this point, see the presentation La Varia di Palmi: dal lavoro sul campo al documento. Rilevamento, documentarione e schedatura made by Rotundo at a Palmi-based conference La Calabria verso l'UNESCO. La Varia di Palmi nella Rete Italiana delle Grandi Maccbine a spalla, held November 26, 2010, on the topic of the network nomination.

22 For example, they set up stands in the piazzas as information points and sold t-shirts and gadgets to publicize the initiative, alongside the distribution of collection boxes in various commercial sites, or the fundraising campaign, called "un'euro per UNESCO" (a Euro for UNESCO). Their promotional activities were conducted even through social networking platforms.
} 
constitute for Palmi an opportunity for mediation aimed at evaluating cultural heritage as an economic resource in a realistic and sustainable way, though within the guidelines of the external network coordinating committee.

The Candelieri feast in Sassari, catalogued by the anthropologist and ethnomusicologist Chiara Solinas, is called the Faradda di li candareri, which in the Sassari dialect means "the descent of the candlesticks." It takes place in Sassari on August 14th, the day before the Feast of the Assumption of Mary, and consists of a dancing procession of large wooden columns resembling candlesticks or candleholders (li candareri) ${ }^{23}$. It is also called the Festha Manna, meaning Big Feast. According to local literature, it derives from a votive candle lit in honor of the Madonna Assunta that reportedly saved the city from the plague in 1582. The Candelieri or festive machines belong to ten different professional associations, called gremi, each with a team of eight carriers who carry a richly decorated column in the procession. The task of cataloguing was commissioned by the City of Sassari, Department of Local Development and Cultural Policy. Facing a general lack of information on the part of the network coordinating committee, the cataloguer consulted with the ICCD ${ }^{24}$ and subsequently identified three main heritage forms: the Candelieri vestments, the descent of the Candelieri and the entrance into the St. Mary of Bethlehem Church. Overall, 33 BDI forms were produced for the feast as a whole, accompanied by audiovisual documentation. The cataloguing anthropologist maintained excellent and highly collaborative relations with the commissioning entity. Relations with the network coordinating committee, on the other hand, were irregular and never seemed to be completely clear.

Finally, we have the Gigli feast in Nola, which I documented on behalf of the Cultural Heritage Commissioner's Office for the City of Nola. I completed 25 BDI forms, generating an inventory shared with the ICCD and additionally collaborating with the Superintendency of Naples. The Nolan Gigli feast is celebrated annually the Sunday after June 22, a day dedicated to Saint Paulinus, who was the Bishop of Nola at the beginning of the 15th century. It is celebrated with a procession of eight, 25 meter tall obelisks called Gigli that local artisans build from wood and papier mâché, and a boat that commemorates the legend of the Saint's return over the sea ${ }^{25}$. The contemporary form of these obelisks, which became fixed between the 18th and 19th centuries, resembles the spires of Naples in the ephemeral Baroque period. A musical team, playing and singing "traditional" and local festive marches, gathers at the base of each Giglio, which is made to dance for approximately 24 hours on the shoulders of the men - called "collatori" or "cullatori" (literally, cradlers) - who comprise the paranza, a group of about 128 for each machine.

\footnotetext{
${ }^{23}$ For a bibliography on the Candalieri feast of Sassari that was also used in the cataloguing work of Solinas, see the following publications: Pittalis 1912, 1921 and 1988, Spanu 1994, 2007, Campanelli and Mereu 2006, Luiu 2007, Cau and Saba 2008, Brigaglia and Ruju 2009. Solinas is also to be thanked for the data provided by her work.

${ }^{24}$ See note 7.

${ }^{25}$ See Manganelli 1973, Avella 1993 and my own contributions listed in the bibliography.
} 
Relations between the cataloguer and the local institutions and community were extremely positive, thanks to my extensive understanding of the territory gained over the years. This allowed me to reach agreement with the "heritage community" itself - by which I mean the feast practitioners rather than local institutional representatives - about the content of the forms and the elements of the community to be valorized. The network coordinating committee did not affect the inventorying work except at the purely bureaucratic level; however, the procedure was funded entirely by the municipality. Due in part to the extensive media coverage that the previous nomination attempts had received in the area, the numerous associations connected to the feast in the Nola case were very collaborative and present in the initiatives connected to the nomination project. However, they did not participate significantly in the network's attempts to organize events outside the city. This suggests that some participants did not display any strong "sense of belonging" in the network, which was the main aim of the project.
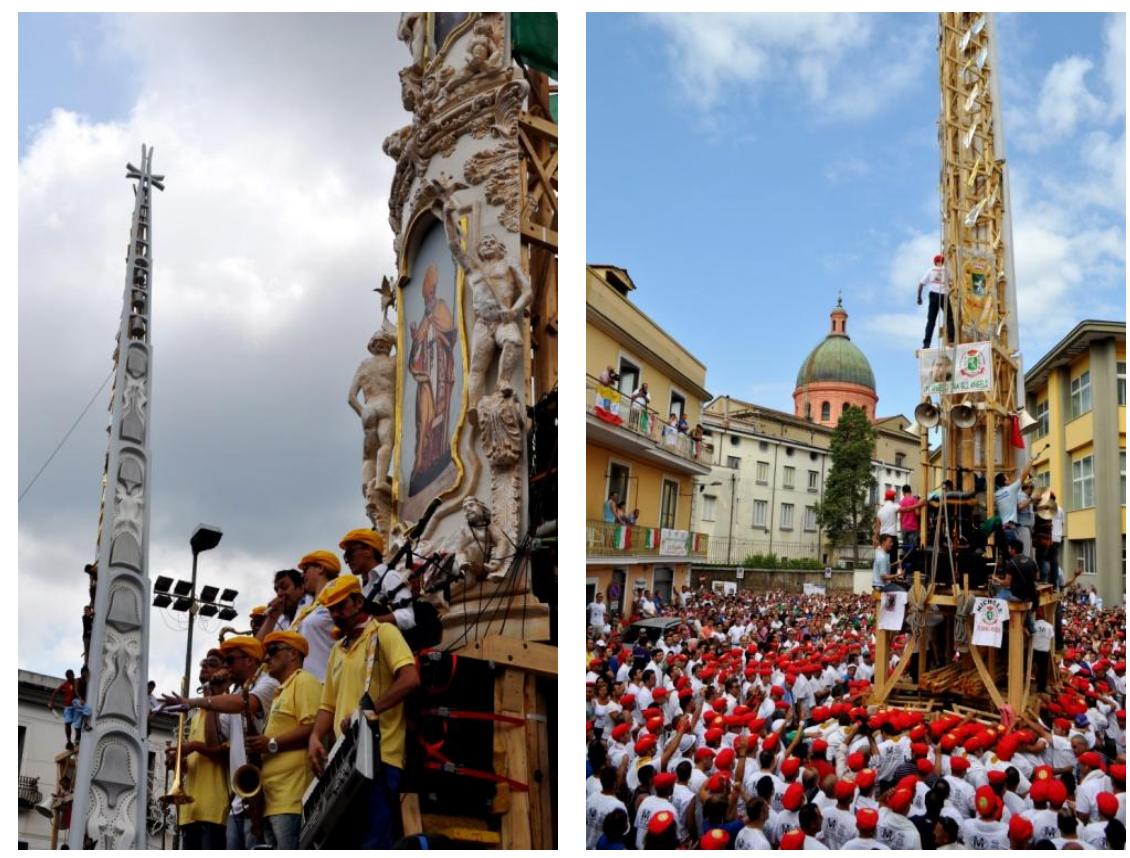

Figure 1: Giglio "festive machines”, Gigli feast in Nola [Photograph by Sabrina Iorio 2011, reproduced courtesy of the author].

The actors responsible for coordinating this collective nomination are external intellectuals and experts who often act on behalf of local administrations, exploiting the opportunities UNESCO might offer localities in terms of touristic development and economic profit; in turn, they impact local actors who, motivated by a 
deep passion for their feast, tend to pursue any project that valorizes their local traditions. As a matter of fact, a distinctive feature of the Nolan context is that feast practitioners and enthusiasts fully participate in the activities promoting and valorizing the feats that various administrations have organized over time ${ }^{26}$.

Retracing the path that led from initial interest on the part of individuals and, later, local administrations ${ }^{27}$, to the construction of the network nomination, one thing is clear if implicit: The activity of network coordination might conceal an idea of intangible culture aimed at rendering it progressively more "material," so that it can be more easily managed as "merchandise" to be valorized for touristic and economic ends. A clear example of this dates from the period directly following the submission of the network nomination. The local association called "La Contea Nolana" designated by the municipality of Nola to supervise the nomination process, "from the bottom up" in accordance with UNESCO recommendations, promoted the event in question. They presented a new food product, promoted on websites and through local newspapers: A Nolan Gigli feast-shaped pasta called precisely "Il Giglio Nolano: sapori e tradizioni della pasta campana" (The Nolan Giglio: Tastes and traditions of the pasta from Campania) and referenced a patent for the idea, already submitted (GIGLIOLA di D’Apuzzo Stefania 2012). Many local areas, especially in Campania, where cultural creativity is especially notable, have always used the symbols of their own traditions to create attractions, as well as souvenirs and gadgets based on these symbols, in order to stimulate the local economy. The interesting thing here, however, is the emergence of what we might call a "festive trademark" that can be exported to promote a local territory that is often complex or economically depressed. Even before the invention of the Giglishaped pasta, in the period when the network nomination was moving forward, there was also a public announcement that the municipality of Nola was going to pursue the patenting of the Gigli themselves with the help of a board of jurists. Here are some extracts from the press release about this event:

In fact, the municipality of Nola has submitted the logo and slogan "city of Nola - the Gigli feast" with the office of patents and trademarks of the Ministry of Productive Activities in order to hold an exclusive right to it and prohibit unauthorized third parties to use it or similar symbols. According to a note from the municipality, "the act of safeguarding the trademark was carried out, on one hand, as an investment, seeing as the costs required for registering the trademark will be widely reimbursed through a careful exploitation of the exclusive rights granted; on the other hand, it represents a preventive protection from any unfair competition by others." The mayor, Fe-

\footnotetext{
${ }^{26}$ In relation to the "passion" that Nolan locals feel for the Gigli feast and its implications in daily practices, please see one of my recent articles: Ballacchino 2011.

${ }^{27}$ Initially, this interest was based on a desire to promote local areas in terms of culture and tourism, which was often subordinated to efforts to attract financing for activities like these that are aimed at developing the local economic system.
} 
lice Napolitano, who is also president of the Gigli Feast Agency, declared that "with this action, we have ensured the protection of our feast, which over time will become ever more a symbol and trademark of quality recognized and appreciated throughout the world." (Fantastic Team 2006)

The example illustrates how the promotional activities originate in an exclusive and closed idea of one's own heritage, in opposition to the principles of dialogue and solidarity among cultures; these promotional activities suggest a change in the way one's own intangible culture is transmitted that is reminiscent of some aspects already outlined by scholars of popular tradition in the $1970 \mathrm{~s}^{28}$, but which today are re-invented in an international perspective under the UNESCO banner. The level of tension I observed between various local actors and the cities involved during my fieldwork highlights how the "opportunity" offered by the UNESCO convention can produce alliances, agreements or disagreements. We must, therefore, ask whether or not it is really necessary to institutionalize heritage according to these logics or if, in some cases, it risks becoming nothing more than a manipulation of community-based passions by various actors within and without the local context in the pursuit of economic gains, local power or professional career advancement.

\section{Local Powers and Strategies: Conflict and International Opportunity}

Parallel to the cataloguing work, which turned out to be non-cohesive and varied from case to case, the network coordinating committee also organized a series of public events in 2010 aimed at documenting and demonstrating the high level of ongoing participation that local institutions and, above all, the "heritage communities" involved had in the project. In some cases these events were organized in collaboration with the Italian Pro Loco associations ${ }^{29}$, in other cases they were part of the broader sphere of national cultural policy. Several conventions, for instance, were organized in the individual cities, and one in the central headquarters of the Rome city government; there was collaboration with the project Abbraccia l'Italia Antichi saperi e nuovi linguaggi (Embrace Italy - Old Knowledge and New Languages) that was aimed at spreading, at the national level, "a message promoting social inclusion through culture and activating a deep awareness among local communities" (Patrimonio Culturale Immateriale 2012) about the valorization of their intangible heritage. According to the same article: "This project currently represents, in

\footnotetext{
${ }^{28}$ See Lombardi Satriani (1973) for a discussion of the Italian debate in that period about popular tradition and the concept of "folklore" which was linked to a process of developing and commercializing local areas that involved a redefinition of popular culture.

29 Pro Loco are associations connected to individual Italian municipalities that carry out activities related to various touristic, social, cultural, and sport-related spheres.
} 
Italy, the only functional response to what should be achieved under the UNESCO guidelines: safeguarding, archiving and spreading the intangible cultural heritage forms of nations around the world" (Patrimonio Culturale Immateriale 2012).

In contrast to the original intentions of the network coordinators, however, these events received only sporadic and irregular participation by the entirety of the various "heritage communities:" Mainly the carriers of the heritage, but also to some extent, civil society, experts, the intangible heritage commission, et cetera. The following is an extract from one of the many articles published in local Nolan newspapers about the network nomination project; though the project was still in an initial phase, the atmosphere surrounding its realization is already clear:

\section{UNESCO puts its seal on the Gigli}

[...] Unity makes strength, it is known, and the locally rooted and recognized traditions of the individual events suddenly come together, erasing the geographic distance separating the cities. Not even the competition with the Palio of Siena and the Mediterranean Diet, potential adversaries in the race for recognition, is able to frighten the network - on the contrary, it only raises the stakes. (Napolitano 2010)

Here we see the idea of a union among different cities that is also fueled by "competition with" the other cities running in the race for intangible heritage nomination in Italy, thus exacerbating some conflictual elements among the groups of local actors involved. However, this competition broke out even during the course of the individual feasts in 2010, parts of which I observed firsthand. An exemplary illustration is the case of the Nolan cullatori, the Gigli carriers, during their visit to Viterbo to see the facchini feast of Santa Rosa. The Nolan carriers displayed a great deal of antagonism toward the porters of that solitary votive machine that, in their opinion, was not in any way comparable to their eight Gigli. Various informal discussions conducted during this visit to Viterbo reminded me of similar issues I had read about in the newspapers the year before about the Ceraioli of Gubbio who, for various reasons, actually ended up withdrawing from the network and presenting their own separate nomination.

An episode that occurred in Nola on April 1, 2011 is also emblematic. One of the most widely read of local Nolan newspapers literally "invented" a replica of a letter from the Cultural Heritage Ministry publicly announcing that the Gigli had won out over the other nominations. The letter, intended by the editors as an April Fool's Joke, succeeded magnificently; it produced an uproar among institutional actors, who feared the project would collapse due to this false piece of news, as if it might have drawn the suspicion of the hypothetical local "overseers" governing the UNESCO nomination process. The administration responded to this joke through a back-and-forth with the newspaper, which took the opportunity to at- 
tack the political work of the office that was carrying the nomination forward. There was already an idea that UNESCO was "checking" on the localities presenting the nomination due to the constant presence in recent years of a Mexican UNESCO representative sent by the network coordinators. This representative was invited to watch the network feasts in their respective cities and, in view of his presence, the communities were urged to put on a "healthy" and "positive" edition of the ritual, almost as if to suggest that each heritage form was faultless, tidy, conducted in accordance with local rules, and perfectly managed. A local article published online in connection with the edition of the Gigli feast reads:

[...] the illustrious Mexican World Heritage representative present in Nola during the feast days warns us of the importance of an honest and essential collaboration and dialogue among the political institutions and all the other local entities, with no one excluded. The danger is the inevitable manipulation of a process that, if it were to risk the distortion of its authentic nature through the construction of an empty touristic display, would lose sight of its own aim: "The construction of a lasting peace through the sharing of unifying values," according to the canons laid out by UNESCO. (Autiero 2010)

Even before the emergence of the UNESCO project, the network counted on an idea of shared values and dialogue among the different localities; from 2010 onwards, in the wake of UNESCO discourses, the network claimed to enjoy an intense and lasting relationship among the various "communities." However, my ethnographic observation revealed that this relationship was not as linear as it was represented to be in local newspapers and in the public speeches organized to illustrate the work of the coordinating network, work that pursued aims different from those established through the rhetoric surrounding the nomination.

Intangible heritage thus becomes a construct with a broader scope than local identity. The network nomination project presented itself as a "bottom-up" process arising from the "communities" and, in some cases, even tried to improve the community's level of "literacy" in the UNESCO values of dialogue and multiculturalism. It failed to take into account, however, the competitive and conflictual energy, both internally and externally oriented, that is a primary characteristic of the local contexts involved and which often represents the animating essence of intangible heritage forms that are as contradictory, dynamic and complex as the cultures they represent. In addition, it is possible that an attempt to demonstrate at all costs that internal conflict (which is not always as destructive as it is represented to be) has been ironed out, might actually serve to reduce the intensity of the very sense of belonging and pride in culture and values that renders intangible heritage so unique.

According to the nomination agents' calculated interpretation of UNESCO rhetoric, the element of conflict was opposed on the grounds that it would ob- 
struct dialogue among diverse cultures; however, in the case I observed, it was clear that conflict could be exacerbated by the very processes of patrimonialization carried out according to UNESCO logics. The numerous human-powered machine feasts excluded from the network (the Sicilian ones, for instance), or the abovementioned case of the Ceri of Gubbio and other feasts that were not able or willing to enter the network (such as the Misteri of Campobasso or the Carro of Ponticelli) are all examples of how UNESCO theory and local practice often follow tracks that are seemingly parallel but not entirely the same.

However, if we focus on the translation of the UNESCO regime at the state level in Italy, my analysis suggests that the adaptation of this logic involved a great deal of "simulated" grass-roots interest in the network nomination; indeed, the actors promoting it are institutionalizing a practice of patrimonialization that owes more to the logics of Italian administrative and academic spheres than it does to the logics of UNESCO heritage.

An additional example emerged during one of the meetings I had with some of the "carriers" from the cities involved, which took place at the Gigli feast in Nola in 2010. On the website of the La Contea Nolana (the Nolan County) association, which internally oversaw the nomination for the city of Nola, interesting captions accompanied several of the photos. A caption reading "you can't do it alone" accompanied an image of a small group of carriers attempting to lift a Giglio off the ground, followed by the caption "but together we can do it" referring to the same scene but involving a larger number of carriers, from multiple cities (La Contea Nolana n.d.). This example shows how the carrying of the Giglio (and metaphorically also the UNESCO recognition project) can only take place through a common effort by all parties involved, as if the heritage form might become such only by being "shared ${ }^{30}$." In the network case, the union of cities creates intangible heritage according to a UNESCO logic. However, at the local level the content of heritage remains likely distinct, dynamic, conflictual, processual, variable, and often even, we might say, self-referential and completely localistic, as the case of the Nolan cullatori and their "Gigli-based" criticisms of the facchini from Viterbo illustrates so well.

\section{Conclusions}

In view of the data I analyzed, I tried to present some concluding remarks on the distortion of the reading of Italian UNESCO Convention and its consequences.

Conflict in the sphere of intangible heritage is inevitably endogenous and necessary, as long-term ethnographic fieldwork in local Italian contexts thoroughly demonstrates; nonetheless, there is often a tendency in public discourses and representations of the processes of constructing nomination dossiers to eliminate

${ }^{30}$ See Sassen (2002) for an interesting take on this issue. 
conflict in order to conform to what might be defined as the "spirit of the convention." In doing so, however, we may risk thoroughly distorting the local meaning and vitality of the heritage forms to be valorized, according to a centralist and coercively harmonious approach dictated by the effort to achieve the aspired-to international recognition.

An article recently published in Nolan newspapers shows even more clearly how the logic of international or national "heritage" recognition is considered to be an essential value for the local context, the clear outgrowth of a specifically Italian tendency to strategically use local territories and their traditions at the level of local and supra-local politics.

\section{With Minister Brambilla, the Gigli Feast Becomes "Italian Heritage"}

"For an expression of the ability to promote tourism and national image as well as valorize local history and culture through a perspective suited to contemporary times."

In the words of Minister of Tourism Michela Vittoria Brambilla this morning, this was the motivation for recognizing the Nolan Gigli Feast as "Italian Heritage" as part of the public presentation of the project by the same name.

This is an important "mark" of recognition, granted to 34 municipalities that represent just as many prestigious celebrations (including cities twinned with Nola, such as Sassari and Viterbo, with their respective Candelieri and Macchina di Santa Rosa); it is reserved for examples of national excellence that contribute to valorizing the image of Italy and consequently generating touristic flows.

As Minster Brambilla declared, "Italy has a unique and extraordinary heritage. Our country has always been a guiding light in the world thanks to its history, tradition, art, culture, creativity, and style. These forms of excellence constitute an enormous resource that only Italy holds. This is why I wished to create a new and prestigious mark: "Italian Heritage" symbolizes the recognition that I will grant every year to these wonderful specimens which have concretely stepped forward to take on the role of representing our country to the world and which will enjoy special visibility, especially abroad, as a result of their ability to generate positive effects on both national touristic flows and the appeal of Italy and our brand, Made in Italy [...]. (Il meridiano on line 2011)

Is institutionalized patrimonialization, therefore, really necessary or does it, in some cases, become nothing more than a manipulation of community-based passions on behalf of various subjects both inside and outside given territorial contexts? And as for the communities, are they aware of these complex and ever more frenetic activities that often impact on the actors themselves as they pursue the 
illusion that the recognition they so yearn for will resolve all the problems of a complex territory? During my web-based ethnography on the Nolan Gigli feast, which I carried out parallel to the field research, I came across multiple statements by and debates involving feast practitioners in recent years; they have spoken out to oppose the feast's endogenous tendency to reproduce clientelistic or politically defective logics, as if it were a mirror image of the local system. In some cases, these criticisms represented the UNESCO stamp as a possible means of liberating the city and its feast from a provincial and defective logic ${ }^{31}$.

In this interesting and complex frame constituted by systems of power, anthropologists must continue to monitor patrimonialization processes and their implications through daily, close-grained ethnographic research in the local areas involved in these processes. In addition to carrying out documentary-style cataloguing, let us not forget to critically address the political strategies connected to the local sites and their affect on the individuals. These local actors are the carriers of the specific traditions that are defined from the outside as "heritage," but which should be recognized and prized in any case on the basis of their value, a value attached to them by local communities but constructively and critically "mediated" with the outside. As De Varine warns us, nature and culture die rapidly when they are made into the objects of appropriation and codification by specialists who do not belong to the local population; when they belong to the population and constitute its heritage, however, they live and thrive ${ }^{32}$.

\section{References}

Arduini, Marcello (2000): Aspetti antropologici in alcune azioni rituali del culto di Santa Rosa. In S. Rosa, tradizione e culto. Atti della seconda giornata di studio 10 settembre 1999: "La città, la macchina, il rito. I nuovi supporti." Silvio

Cappelli, ed. Pp. 111-124. Manziana: Vecchiarelli Editore.

Autiero, Annamaria (2010): I Gigli di Nola e l'Unesco. In dialogo XXV (7),

September: 21.

http://www.diocesinola.it/web/files/07.pdf < accessed July 4, 2012> Avella, Leonardo (1993): La festa dei gigli. Nola: Scala.

Ballacchino, Katia (2008): Il Giglio di Nola a New York. Uno sguardo etnografico sulla festa e i suoi protagonisti. Altreitalie. Revista Internazionale di studi sulle migrazioni italiane nel mondo 36-37: 275-289.

- ed. (2009): La Festa. Dinamiche socio-culturali e patrimonio immateriale.

Antropologia e Patrimonio, 1. Nola: L'arcael'arco.

\footnotetext{
${ }^{31}$ In relation to this point, see the numerous discussions posted in the guest section of a Nolan paranza's website, which for years has been collecting the most significant debates about the city of Nola's social life and its Gigli feast. See http://www.fantasticteam.it/PRIMAPAGINA.htm <accessed July 4, 2012>.

32 See De Varine 2005.
} 
- (2011): Embodying devotion, embodying passion. The Italian tradition of La Festa dei Gigli" in Nola. In Encounters of body and soul in contemporary religiosity. Anthropological reflections. Anna Fedele and Ruy Llera Blanes, eds. Pp. 43-66. Oxford, New York: Berghahn Books.

- (in Press): Towers of Memory: Images and Visual Community Symbols between Italy and the United States. In Sabato Rodia's Towers in Watts: Art, Migrations, Development. Luisa Del Giudice, ed. New York: Fordham University Press.

Bendix, Regina, and Valdimar Hafstein, eds. (2009): Culture and Property.

Ethnologia Europaea 39(2).

Bindi, Letizia (2009): Volatili misteri. Festa e città a Campobasso e altre divagazioni immateriali. Rome: Armando.

Brigaglia, Manlio, and Sandro Ruju, eds. (2008): Sassari: Gremi e candelieri. Sassari: Delfino.

Bortolotto, Chiara, ed. (2008): Il patrimonio immateriale secondo l'UNESCO: analisi e prospettive. Rome: Istituto poligrafico e Zecca dello Stato.

Cau, Paolo, and Marcello Saba (2008): I candelieri, Sassari: Composita.

Campanelli, Ricardo, and Angelo Mereu, eds. (2006): I candelieri: una festa lunga 500 anni. Sassari: Edizioni R\&R.

De Varine, Hugues (2005): Le radici del futuro. Il patrimonio culturale al servizio dello sviluppo locale. Daniele Jallà, trans. Bologna: CLUEB.

D'Uva, Francesco (2010): I Gigli di Nola e l'UNESCO. Il patrimonio culturale immateriale tra politiche internazionali e realtà territoriali. Nola: Extra Moenia.

Fantastic Team (2006): La festa dei Gigli di Nola diventa marchio registrato. http:/ /nx.fantasticteam.it/newsgigli/view.php?id=45 <accessed July 4, 2012>

Ferraro, Domenico (1987): La Varia di Palmi. Palmi: Edizioni Metauro.

Galluccio, Teresa, and Francesco Lo Vecchio (2000): La Varia. Storia e tradizione. Palmi: Rem Edizioni.

GIGLIOLA di D'Apuzzo Stefania (2012): Il Giglio Nolano. Sapori e Tradizioni della Pasta Campana: il Giglio di Nola.

http:/ /www.giglionolano.it/it/formati/ilgiglionolano-pasta < accessed July 11, 2012>

Grillea, Elisabetta (1990): La Varia di Palmi. In Folklore della Calabria: Volume I - Rivista di tradizioni popolari diretta da A. Basile - Soc. Calabrese di Etnografia e Folklore. Palmi: Nuove Edizioni Barbaro.

Istituto centrale per il catalogo e la documentazione (2006): Scheda BDI, Beni demoetnoantropologici immateriali, seconda parte. Roma: ICCD. http:/ /www.iccd.beniculturali.it/getFile.php?id=353 < accessed July 11, 2012>

La Contea Nolana - Libera Associazione Culturale e di Volontariato (n.d.): Le Città delle Macchine da Festa ed il rionoscimento. http://lnx.conteanolana.it/Riconoscimento\%20UNESCO.htm <accessed July 4, 2012>

Lacquaniti, Luigi (1957): La Varia di Palmi. Palermo: Tipografia G. 
Lave, Jean (1988): Cognition in Practice: Mind, Mathematics and Culture in Everyday Life. New York: Cambridge University Press.

Lave, Jean, and Etienne Wenger (1991): Situated Learning: Legitimate Peripheral Participation. New York: Cambridge University Press.

Lombardi Satriani, Luigi Maria (1973): Folklore e profitto. Tecniche di distruzione di una cultura. Rimini: Guaraldi Editore,

Luiu, Antonio, ed. (2007): Suoni e visioni dei candelieri di Sassari. Soprintendenza B.A.P.P.S.A.E per le province di Sassari e Nuoro.

Manganelli, Franco (1973): La festa infelice. Napoli: LER.

Marino, Filippo (2000 [1977]): Le feste patronali palmesi e il culto della Sacra Lettera Mariana. Gioia Tauro: Tauroprint.

Matsura, Koichiro (2002): Preface. In Cultural Diversity: Common Heritage, Plural Identities. UNESCO, ed. Pp. 3-5. Paris: United Nations.

Il meridiano on line (2011): La festa dei Gigli di Nola diventa "Patrimonio d'Italia" con il Ministro Brambilla. Il meridiano on line, July 28.

http:/ /www.ilmeridiano.net/index.php?option=com_content\&view=article\&i $\mathrm{d}=4837$ :la-festa-dei-gigli-di-nola-diventa-patrimonio-ditalia-con-il-ministrobrambilla\&catid=76:primo-piano\&Itemid $=551<$ accessed July 4, 2012>

Napolitano, Autilia (2010): Sui Gigli il sigillo dell'Unesco. Il Nolano.it, III (74). http: / $/$ www.ilnolano.it/index.php?page $=0 \&$ news $=9802 \&$ cat $=2<$ accessed July 4, 2012>

Palumbo, Berardino (1998): L'UNESCO e il campanile. Riflessioni antropologiche sulle politiche di patrimonializzazione osservate da un luogo della Sicilia orientale. Ėupolis 21/22: 118-125.

- (2001): Campo intellettuale, potere e identità tra contesti locali, 'pensiero meridiano’ e ‘identità meridionale’. La Ricerca Folklorica 43: 117-134.

- (2003): L'UNESCO e il campanile. Antropologia, politica e beni culturali in Sicilia orientale. Rome: Meltemi.

- (2007): Località, 'identità', patrimonio. Melissi 14/15: 40-51.

Patrimonio Culturale Immateriale (2012): Abbraccia l'Italia: il patrimonio immateriale una risorsa per il Paese.

http://www.patrimonioimmateriale.it/index.php?option=com_content\&task= view\&id=93\&Itemid=35< <ccessed July 4, 2012>

Piacentini, Ernesto (1991): Il libro dei miracoli di Santa Rosa da Viterbo. Viterbo:

Basilica di S. Francesco alla Rocca.

Pietrobruno, Sheenagh (2009): Cultural Research and Intangible Heritage. Culture

Unbound: Journal of Current Cultural Research 1: 227-247.

Pittalis, Salvatore (1912): I candelieri. Note storiche. Sassari: Chiarella.

- (1921): I candelieri e la caratteristica processione dei candelieri che si celebra in

Sassari, in Nulvi e in Ploaghe, la sera del 14 agosto. Note storiche. Sassari:

Gallizzi.

- (1988): Gremi e candelieri. Sassari: Chiarella. 
Risse, Thomas (2003): European Identity and the Heritage of National Cultures. In Rethinking Heritage. Cultures and Politics in Europe. Robert Shannan Peckham, ed. Pp. 74-89. London: I.B. Tauris.

Rotundo, Tommaso (2010): La Varia di Palmi: dal lavoro sul campo al documento. Rilevamento, documentazione e schedatura. Paper presented at the workshop "La Calabria verso l'UNESCO. La Varia di Palmi nella Rete Italiana delle Grandi Macchine a spalla," held at the Palazzo Arnone in Cosenza and organized by the Soprintendenza per i Beni Storici, Artistici ed Etnoantropologici of Calabria, November 26, 2010.

Sassen, Saskia, ed. (2002): Global Networks, Linked Cities. New York: Routledge. Spanu, Gian Nicola (1994): Sonos. Strumenti della musica popolare sarda. Nuoro: Ilisso.

- (2007): Piffaru e tamburu. Considerazioni storico-organologiche. In Suoni e visioni dei candelieri di Sassari. Antonio Luiu, ed. Soprintendenza

B.A.P.P.S.A.E per le province di Sassari e Nuoro.

Tucci, Roberta, and Gian Luigi Bravo (2006): I beni culturali demoetnoantropologici. Milan: Carocci.

Wenger, Etienne (1998): Communities of Practice: Learning, Meaning and Identity. Cambridge: Cambridge University Press.

Wenger, Etienne, Richard McDermott, and William M. Snyder (2002): Cultivating Communities of Practice. A Guide to Managing Knowledge. Boston: Harvard Business School Press.

Zagato, Lauso, ed. (2008): Le identità culturali nei recenti strumenti dell'UNESCO. Padua: CEDAM. 


\title{
Heritage Regimes and the Camino de Santiago: Gaps and Logics
}

\author{
Cristina Sánchez-Carretero
}

\section{Introduction}

The pilgrimage to Santiago de Compostela, together with the sites along the routes, the monuments and landscape, have been rendered into heritage in a process carried out at various levels. There are thus several heritage regimes, deployed by different sets of actors. This article will explore the strategies used by actors representing these regimes and the controlling forces and logics underneath a given heritage enterprise. In the case of Galicia, two of these heritage regimes are related to nations: the Spanish national level and the Galician national level; another level is related to the church, as the Catholic church is an essential part of the heritage endeavor surrounding the pilgrimage; a fourth heritage regime is linked to municipal governance. Finally, the capacity - or lack thereof - of actors on the local level to participate in heritage decision-making processes involved in all these levels of heritage production will be explored.

"Regimes" in the plural are particularly important in this case-study as there is no single regime controlling the governance of heritage initiatives. The lack of a heritage vocabulary at the local level, as will be explored in the second part of this article, illuminates the silences that heritage regimes produce and the gaps between institutional policies and grassroots understanding of what is valuable and deserves to be maintained. The analysis presented here seeks to illustrate these gaps and is based on ethnographic fieldwork conducted along the Camino de Santiago route to 
Fisterra as part of the research project Procesos de patrimonialización en el Camino de Santiago: tramo Santiago-Fisterra-Muxia, a three-year research project (2010-2012) developed at the Spanish National Research Council (CSIC) that focuses on the effects that this route is having on the local populations. A central component was the inclusion of institutional as well as local actors in the research.

Two aspects will be explored: (1) The mechanisms developed by various social actors to include other routes in the UNESCO nomination; and (2) the heritagization processes - or the heritage formation processes - that are being developed in the Camino de Fisterra and how the logic of the market and the logic of the politics of identity are in play in this case. To do so, this chapter is structured in two parts: The first is dedicated to the Camino de Santiago as a World Heritage Site, the participation of the regional and central state and the lack of participation of other local actors. In particular, I will concentrate on the on-going nomination process aiming to include the Caminos del Norte in the UNESCO World Heritage List, as well as the demands filed by local organizations to include the Camino in the List of World Heritage in Danger. For this part, I conducted interviews with representatives of the Galician government, ICOMOS-Spain and Galician grassroots organizations such as The Galician Association of Friends of Camino de Santiago (AGACS).

In the second part, I concentrate on how the logic of the market and the logic of the politics of identity are employed by different social actors in another, Camino-related case: The route of the Camino that leaves Santiago and arrives at Fisterra. This part is not included in the UNESCO List but the implementation of the "heritage regime" has modeled institutional policies for this route as well, however, they stand in contradiction to local ideas of what is valued most within "their heritage."

\section{The Camino de Santiago as a World Heritage Site}

Spain ratified the World Heritage Convention in 1982 and the Intangible Heritage Convention in 2006. The route to Santiago de Compostela was proclaimed the first European Cultural Itinerary by the Council of Europe in 1987, and in 1993 it was included in the UNESCO World Heritage List. Not all the constituent routes of the Camino are part of this designation; rather, it is the part known as the French Camino. The other routes are not on the list, including the route that reaches the coast in Galicia, the Camino de Fisterra to be discussed later in this article. The main routes, in addition to the French Camino, are the Via de la Plata (from Seville), the Northern Routes (along the north coast of Spain), the English Route (from the town of A Coruña, in Galicia), and the Portuguese Route (from Porto).

The institutional actors who are part of the management of the Camino are represented in the Council of St. James, created in 1999 as a cooperative body between the Spanish central administration and the regional administrations. It includes representatives from the Comunidades Autónomas (the regional governments 
of Galicia, the Basque Country, Catalonia, Asturias, Cantabria, Aragón, Navarre, La Rioja, and Castilla y León), representatives from the Spanish Ministry of Culture and other ministries, such as Economy, Foreign Affairs, Education, and the Ministry of Industry, Tourism and Commerce. ${ }^{76}$ Other social actors, such as cultural associations, academics or religious representatives, can be invited to attend meetings of this Council to speak but without voting rights.

\subsection{The Nomination Process of the Caminos del Norte}

Since its inclusion in 1993 in the World Heritage List, the Camino de Santiago, the pilgrimage to Santiago, has been one of the main tourist attractions in Galicia, and various Comunidades Autónomas along other routes have also prepared dossiers seeking to be included in the World Heritage List. Since 2006, the regional governments of Galicia, Asturias, Cantabria, the Basque Country, and Navarra have worked on the technical file to justify the inclusion of the Caminos del Norte in the List.

The process for any UNESCO candidature in Spain is as follows: ${ }^{77}$

A. The heritage site needs to be on the Spanish Tentative List (TL), which consists of an inventory of the goods and sites that might become part of the List in the future. The TL is approved in the following way:

a. Each Comunidad Autónoma selects heritage goods that they want to see included in the TL.

b. The suggestions from the regional governments are taken to the Spanish World Heritage Commission of the Board of Historic Heritage (Consejo del Patimonio Histórico). The Board includes representatives of the Spanish Ministry of Culture (MEC) and the regional governments. This Commission proposes the final TL.

c. The Spanish Ministry of Culture sends the approved TL to the UNESCO World Heritage Center.

B. Preparation of the file: The World Heritage Commission of the Board of Historic Heritage (Consejo del Patimonio Histórico) selects one or two items each year from the TL to be prioritized and asks regional governments to prepare the file for the nomination process. The MEC coordinates the process, but the regional governments are in charge of contacting experts and grassroots organizations to prepare the file. The selected file is sent to the Spanish World Heritage Center each year.

C. After this phase, the nomination process takes place within UNESCO and it is the same for all countries.

\footnotetext{
${ }^{76}$ For more information on the Council of St. James see http://en.www.mcu.es/cooperacion/MC/ConsJacobeo/Index.html < accessed June 5, 2011>.

77 For more information on this process see the Spanish Ministry of Culture web page at http://www.mcu.es/patrimonio/MC/PME/ProcesoCandidaturas.html < accessed May 30, 2011>.
} 
In relation to this standard procedure, the case of the Caminos del Norte, or Northern Routes, is quite peculiar, because it is not a straightforward candidature. Rather, the application consists of the extension of the nomination of the Camino de Santiago - currently including only one route (the French Camino) - to also include the Northern Routes: Camino Primitivo, Camino Costero along Asturias, Camino del Baztán in Navarra, the Camino inside the Basque Country, and the route Lebaniega. The Caminos del Norte is thus already on the TL. Therefore, no specific procedure needs to be taken in phase A. Phase B is the same as in any other candidature, as a file needs to be produced.

When asked about each of the phases for the case of the Caminos del Norte, actors involved made a clear distinction between phases $\mathrm{A}$ and $\mathrm{B}$ in terms of procedure, although not in terms of grassroots participation. The decision to be part of the TL was taken by the autonomous (regional) and central governments, without any participation of local agents. As one of my ICOMOS informants explains, it was a decision made "at the highest institutional level." 78

In phase B, theoretically, more possibilities are open for local participation and regional governments might contact various social actors for the elaboration of the technical file. However, in the case of the Caminos del Norte, no collaboration from local associations was requested. Indeed, the main Galician Friends of Camino de Santiago Association, AGACS, completely opposes the candidature. According to its president, AGACS is against the inclusion of the Caminos del Norte on the World Heritage List for two reasons, both of them related to being coherent with the previous history of the Camino as a World Heritage Site: Firstly, "if the inclusion of the French Route of the Camino did not have effects in terms of protection of the Camino, what is the point of protecting it?" and secondly, because the route does not have a fixed delimitation: "How can you protect it if its delimitation hasn't been established?"79

The technical file of the Caminos del Norte was approved by the MEC to be presented to UNESCO in February 2011, and a decision will be made in 2012 about its inclusion.

The lack of participation of local actors in the process is explained by the president of AGACS with the "logic of the market" argument: "Politicians see the Camino as a resource and they want to attract tourists; that is their only purpose." Linked to the previous inclusion of the Camino in the World Heritage List, and the current official demarcation of the French Route, the Xunta (Galician government) hosted a meeting to present the delimitation of the Camino to various social actors in 2011. According to a delegate of ICOMOS from Galicia who prefers to remain anonymous, "these meetings are meant to be participative, but they are only in-

\footnotetext{
${ }^{78}$ Interview conducted by Cristina Sánchez-Carretero with an ICOMOS representative on May 27, 2011.

79 Personal communication, May 25, 2011.
} 
formative. Politicians don't care about our suggestions." 80 This representative considers the entire process - both the preparation of the Caminos del Norte file and the previous general Camino de Santiago nomination - to have been prepared without participation at the local level.

Comparing the description of the nomination process made by the Spanish Ministry of Culture and the data gained from interviews about the nomination process related to the Caminos del Norte allows for various conclusions: Firstly, the inclusion in the TL does not involve any grassroots participation (phase A) either in the administrative process or in its application. The preparation of the file (phase B), as described by the Ministry of Culture, should include local participation. However, my analysis of the Caminos del Norte file revealed no grassroots participation. In short, in the case of Spain, the heritage implementation structure foresees very limited participation; when this plan is applied, the participation is even more limited. Two levels hold strict control of the nation-state heritage: the central Spanish state and the autonomous nation-state.

\subsection{The List of World Heritage in Danger; the "List of the Embarrassment"}

There have been two complaints regarding the Camino de Santiago directed at UNESCO in the last months of 2010: A complaint presented by ICOMOS-Spain and a complaint coordinated by AGACS and signed by 60 local associations. In both cases, a list was included of the dangers that the Camino has been facing over the last few years. AGACS wants the Camino to be included in the "List of the Embarrassment," as they call it, and removed from the list of World Heritage Sites. For ICOMOS, the reason for the complaint is as follows: "At least the state and the regional governments will realize that having a site declared World Heritage has also a counterpart: It needs to be taken care of." ${ }^{11}$ An international commission will be created by UNESCO in the next few months to study the case.

A Galician representative of ICOMOS-Spain locates the grounds for the conflict in the instrumentalization of the UNESCO label and the lack of protection: "Everybody wants to place a UNESCO World Heritage label at their sites; and once they get it, the other side is forgotten; 'we want to build an industrial compound, no problem!' And afterwards, they tell you there is no way to stop it. In the middle of the Camino de Santiago, in La Rioja, a golf course has been built!" 82

Compared to the candidature process described above, the application to include the Camino in the List of World Heritage in Danger can be located at the

\footnotetext{
${ }^{80}$ Interview conducted by Cristina Sánchez-Carretero with an ICOMOS representative on May 27, 2011.

${ }^{81}$ Interview conducted by Cristina Sánchez-Carretero with an ICOMOS representative on May 27, 2011.

${ }^{82}$ Interview conducted by Cristina Sánchez-Carretero with an ICOMOS representative on May 27, 2011.
} 
grassroots level: It began with complaints made by AGACS. This association produced a video denouncing incidents along the route where the Camino had been destroyed. In a meeting of the International Committee of Cultural Itineraries that took place in November 2010, a member of ICOMOS-Spain showed the video made by AGACS. After seeing it, the members immediately decided to write a manifesto and it was signed and sent to UNESCO the following day. Some of the examples of destruction included in the complaints are: Construction of an industrial area in the middle of the Camino in Logroño (Rioja), and another in O Pino (Galicia); construction of a golf course in the middle of the Camino in Ciriueña (Rioja); destruction of a hospital for pilgrims "bospital de Gran Caballero" in Cervatis de la Cueza (Palencia); and a project to construct windmills in the middle of the Camino in Triacastela (Galicia).

The complaints can be interpreted as a reaction against the unidirectionality of control in the realm of heritage policies. The conflict between a regional association, such as AGACS, and the regional governments related to the management of the Camino shows a case in which local actors find a UNESCO solution to a UNESCO-related problem. Although it is not openly expressed by the AGACS president or by the members of ICOMOS, one can suggest that the lack of local participation in the implementation of Camino policies made local actors find alternative solutions. What is interesting here is the use of the same tools employed by those who generated the conflict: According to AGACS, the UNESCO nomination created the problem in the first place, and AGACS used a UNESCO tool, the List of World Heritage in Danger, to try to stop the destruction of the Camino.

\section{The Logic of the Market and the Logic of the Politics of Identity in Play in the Camino de Fisterra: The Heritagization of the Camino}

Discourses about heritage show two main logics: The logic of the market, linked to the use of heritage as an economic resource, and the logic of the politics of identity, linked to the idea that heritage belongs to "a group" and reflects and reproduces its identity. In this part, I will exemplify both logics with the case of the Camino to Fisterra. The two logics generate different regimes which, in turn, lay open the gaps between how various actors understand heritage.

Heritagization is a term for the process which bestows value on "something" it could be any practice or "heritage good" - that a group of people considers their property. Building on the dynamic perspective entailed in heritagization (patrimonialización), including its political and symbolic dimensions, engendered in scholarship in the 1990s (Kirshenblatt-Gimblett 1998, Prats 2004), I follow Mexican anthropologist Victoria Novelo's definition of heritage as "something that somebody or some people consider to be worthy of being valued, preserved, catalogued, exhibited, restored, admired (etc.); and others share that election - freely or by vari- 
ous mechanisms of imposition - so that an identification takes place and that 'something' is considers ours" (Novelo 2005: 86). As Fernández de Paz and Agudo argue, the goods that are heritagized are those that have special meaning for a community and are particular to a given cultural context (1999: 7). Other authors, such as Pereiro, define "heritagization" as the activation of cultural heritage and its promotion (Pereiro 1999: 98, 104). Kevin Walsh was one of the first authors who used this term in English (1992: 4). However, Walsh employs it in a pejorative manner in the context of the "heritagization" of space, to refer to "the reduction of real places to tourist space, constructed by the selective quotation of images of many different pasts which more often than not contribute to the destruction of actual places" (1992: 4), very much in line with Greenwood's idea of "culture by the pound" (1977). Although some authors continue using Walsh's take on the term in a pejorative way, that is not the meaning of the word in other languages and it is used more frequently now as an English equivalent to the Spanish patrimonialización or the French patrimonialisation.

\subsection{The Camino de Santiago to Fisterra, "The End of the Earth"}

Instead of ending in Santiago, as the rest of the Caminos, this route reaches the cape of Fisterra on the Galician Atlantic coast. In Latin, Fisterra means "the end of the earth." Fisterra's cape is located in the north-west of Spain in Galicia. It is considered the western-most point of continental Europe, although geographers have demonstrated that the capes of Roca in Portugal and Touriñán - very close to Fisterra, also in Galicia - are situated further to the west. Other European mythical "ends of the world" include Land's End in Britain, Finistère in Brittany, France, and Dingle in Ireland. The end of the world is linked to the idea of conquering territories and expanding the limits of the known world; using the words of Spanish anthropologist Nieves Herrero, "these places have been frequently the objects of symbolic elaborations; aspects such as their frontier character or the braveness and dangerousness of the sea allowed for an interpretation as liminal spaces, associated to the unknown, to the más alla' (Herrero 2009: 166).

The existence of pilgrims continuing their journey to Fisterra after their arrival in Santiago was already documented in the 12th Century. Pilgrims visited the sanctuaries dedicated to the Santo Cristo de Fisterra and the Virgen de la Barca in Muxía (Vilar Álvarez 2010). However, the links between the cult developed in these two places - Fisterra and Muxía - and the cult to Saint James are not so clearly established. There are two types of mainly historical explanation linking Fisterra and Muxia with Santiago: On the one hand, there are studies that explain the pilgrimage to Fisterra and Muxía as a medieval construction of the cult and a unifying Christian strategy against Muslims; on the other hand, there is the sun cult explanation of pre-Christian origin, mostly followed by 19th Century Galician nationalists. There are several legends that establish the relationship between these places, and the use of legends to establish links among sanctuaries was a common 
strategy employed by the Catholic church to redirect the large number of pilgrims that the major sanctuaries attracted to the less popular ones (Herrero 2009: 168).

In the 20th century, the recuperation of the Caminos started as an initiative of the Associations of the Camino de Santiago and, afterwards, various administrations added to the project. In 1993, the year of the inclusion of the Camino in the World Heritage List, the Government of Galicia initiated the program called "Xacobeo." The Camino Fisterra-Muxía was then included as one of the Caminos de Santiago (Vilar Álvarez 2010). This part of the Camino de Santiago is not officially recognized by the Catholic church and the route does not count in order to get the Compostela, the recognition granted by the Catholic church to those pilgrims who have walked at least $100 \mathrm{~km}$. For this reason, as well as its relationship with the sun cult, many pilgrims call this route "the Camino of the atheists."

In fact, the Catholic church is a strong heritagization force for the rest of the Caminos, and maintains a clear ignoratio strategy in relation to the Fisterra route: Officially, the church does not oppose this route, but it also does not recognize it.

\subsection{Changes in Olveiroa: A Youth-Hostel Village}

After leaving Santiago and on the way to Fisterra, many pilgrims spend the second night in Olveiroa, a small town with two hostels and a hotel. By shifting the focus from pilgrims to the local population, I want to bring to the fore questions such as: What does it mean to live in a town with less than 100 inhabitants that hosted, in 2010, more than 8,000 pilgrims who slept in its public hostel and in two private accommodations? How does it affect the daily routine of Olveiroa's inhabitants? What processes emerge next to the heritagization? What are the logics underneath these processes in order to heritagize certain practices and not others? Who initiates, decides and controls? This section of my paper lays bare the logics that are behind the various heritage-making endeavors related to the Camino de Santiago.

The youth hostel of Olveiroa, inaugurated in 2001, was built as a municipal initiative rehabilitating four different stone houses in the middle of the village. The hórreos - grain deposits on top of columns - of the village have also been restored and illuminated from below and the transformations in the village have been marked by the inauguration of the public hostel. A bar, a hotel-restaurant and a private hostel have also been built since 2001. The center of the village was largely abandoned, as new modern houses were built in the 1970s and 1980s next to the main road. Therefore, one of the first impacts of the Camino in Olveiroa has been the restoration of the old stone houses, which is - using the mayor's own words "the first step to value our heritage." 83

The initiative started at the municipal level and the mayor, an architect, shaped the esthetic decisions for this "hostel-village." The mayor controlled decision-making

\footnotetext{
${ }^{83}$ Interview conducted by Paula Ballesteros-Arias and Cristina Sánchez-Carretero with the mayor of Dumbría on February 7, 2011 (the project code of the recording is GR011).
} 
processes in what kind of architectural vision was to be followed, although the resources came from the Galician Government.

The village of Olveiroa does not have a mayor of its own; it is part of the Dumbría municipality in the Galician province of A Coruña. Olveiroa went through a process of abandonment similar to the process many other villages in Galicia have undergone in the last decades. After the 1960s, the abandonment became more visible. Many inhabitants migrated to Northern Europe, particularly Switzerland, and also to large Spanish cities, mainly in the Basque Country, where a growing industry needed workers (Río 2009). When these migrants returned, either for vacation or permanently, they built a different style of houses in a different space. Instead of restoring the old houses, new ones were constructed next to the roads. At the beginning of the 21st century, Olveiroa thus consisted of an old semi-abandoned village center. As Puri, the hospitalera (youth hostel assistant) of the public hostel, born in Olveiroa, explains: "When migrants coming back from Switzerland returned, they built another house and abandoned the village one (...). They said 'it's more in to live next to the road, rather than in the middle of the village' and now it's just the opposite!"84

Heritage does have a role in these changes, and it can be made palpable by focusing on the presence and absence of both heritage practices and heritage terminology in discourse, looking at who is controlling what. The analysis is based on ethnographic fieldwork that Paula Ballesteros Arias, a member of the research team, and myself, the coordinator of the project, conducted in Olveiroa during the autumn of 2010 and the first months of $2011 . .^{85}$

I will analyze the spheres of discourses and practices in relation to how the term "heritage" is used. I want to see if the notion of heritage that various administrations employ have permeated both the discourses and practices of the daily life of Olveiroa inhabitants. Among them, the word "heritage" is not used in either conversations among villagers nor when we asked about aspects of Olveiroa that are valued most. The absolute absence of the word "heritage" in the discourse of the people from Olveiroa is even more evident when compared to the use of the term by José Manuel Pequeño, their mayor. He has an elaborate narrative on the importance of heritage for the promotion of his municipality. The promotional work is concentrated along three lines, and two of them are related to heritage: The promotion of their cultural heritage through the promotion of the Camino de Santiago in their territory; and the promotion of their natural heritage through the promotion of the activities at the river Xallas. In addition, the municipal employment plan is linked to their heritage sites. The political strategy of the municipality is to promote cultural tourism as their most important economic strength. In fact, the

\footnotetext{
84 Interview conducted by Paula Ballesteros-Arias and Cristina Sánchez-Carretero with the youth hostel assistant on October 20, 2010 (the project code of the recording is GR005).

85 This part of the research was presented by Paula Ballesteros-Arias and Cristina Sánchez-Carretero at the Spanish Anthropology Conference (FAAEE 2011).
} 
same characteristics that made people migrate in previous decades - for instance, inaccessibility - is what preserved their landscape and rural life (Aguilar 2003, Herrero 2005). Now it has turned into a value to be consumed by pilgrims and tourists.

The use of the term "heritage" in the discourses of the institutional social actors, such as the mayor, shows the logic of the market and the logic of identity politics taking place simultaneously. The logic of the market understands heritage as a resource for the area's economic development and targets, in this case, tourists and pilgrims; the second logic focuses on the creation of a sense of belonging and targets the local community. Both logics can be exemplified in the following excerpt from an interview with the mayor of Dumbría:

Regarding the Camino de Santiago, our first decision consists of the recupera-
tion of the heritage of the Camino $[\ldots]$. to do so, two things needed to be
done: Actions from the municipality and actions from other institutions. We
talked about how interesting it would be $[\ldots]$ to create a public hostel, as we
need pilgrims to stop here, we also need to recuperate our churches, to re-
cuperate the Camino; and, on the other hand, how do we do it? Well, let's see
if we can prepare an employment plan so our people participate in the recu-
peration process; so the inhabitants themselves take care of it, so they feel
that it belongs to them. And that was our biggest success. The success is
that, in that moment, people recognize that something belongs to them, and
take care of it, because they participate. (Interview February 7,2011$)^{86}$

The two logics are clearly present in this quote. The mayor explains how pilgrims are a resource and, in order to attract them, two things need to be done: Make pilgrims sleep in the township through the construction of a public hostel; and secondly, heritage needs to be taken care of. To the mayor, heritage needs to be preserved as a resource. The logic of the market is reflected in the emphasis on the development of rural tourism. The promotion of the sector of tourism in rural areas reduces, as a consequence, resources dedicated to other options, such as agrarian development.

The logic of belonging seeks the participation of Olveiroa's inhabitants in the construction and maintenance of "their heritage." The mayor actively tries to make Olveiroans proud of, value and, more importantly, take care of the elements that are rebuilt and linked to the Camino de Santiago: hórreos, houses, the common washing space (lavadeiro) and the gardens. In order to create a sense of belonging attached to "something" (which is called "heritage"), civil society needs to take part in the process and participate in the recuperation of heritage. The rate of unemployment is very high in rural areas in Galicia, and the public employment plan of

\footnotetext{
${ }^{86}$ Interview conducted by Paula Ballesteros-Arias and Cristina Sánchez-Carretero with José Manuel Pequeño on February 7, 2011 (the project code of the recording is GR011).
} 
the municipality of Olveiroa gives three months of contract per year to most of the unemployed people of the village. Instead of having a quarter of them working the whole year, the mayor prefers to distribute the work among all the unemployed inhabitants, offering them a few months a year of municipal contracts. The mayor's control of the municipal heritage processes is evident in his depiction of the top-down mechanism; the population figures as passive recipients of heritage.

In sum, the institutional discourse of Olveiroa features heritage vocabulary, but it is missing in the discourse among the inhabitants. In the next section, I will concentrate on the practices related to heritage activations in the area.

\subsection{Heritage Activations in the Area}

The promotion of Olveiroa as an overnight stop for pilgrims is linked to the activation of various heritage elements: The rehabilitation of the buildings of the public hostel in the center of the village; the restoration and maintenance of the route of Santiago, and the other paths in the village; and the restoration of the borreos.

The houses used to build the public hostel were bought by the municipality for very little money. Again, I quote the mayor:

We bought it for 400,000 or 500,000 pesetas [...] almost for nothing because they were in ruins. My idea from an architectural point of view was to recuperate the old houses... the rural houses; to have them rehabilitated instead of a new building. After that rehabilitation, the people realized that they could live in the old houses as comfortably as in the new houses they were building. This was like a procession. When we had a funeral, people from the area came and visited the restoration "how could those houses be so nice and at the same time be so comfortable?' $[\ldots]$ and that was the beginning of the recuperation of the center of Olveiroa. (Interview February 7, 2011) $)^{87}$

Even though the funding agency for the restoration was the Xunta (the Galician Government), the municipality bought the houses and had complete control to decide the style of the hostel.

The hostel was built by rehabilitating the stone houses' architecture. This activated the valorization of the village center and triggered new private initiatives to restore other houses. Among the motivations, the word "pride" appears frequently both in the narratives of the representatives of institutions and in the narratives of Olveiroans.

In addition to the houses and the paths, the bórreos along the Camiño in the village of Olveiroa and next to the hostel have been "monumentalized" using two strate-

\footnotetext{
${ }^{87}$ Interview conducted by Paula Ballesteros-Arias and Cristina Sánchez-Carretero with José Manuel Pequeño on February 7, 2011 (the project code of the recording is GR011).
} 
gies: Restoring them and placing lights underneath the bórreos to illuminate them at night. The rest of the hórreos have not been restored. The illumination gives the whole village a touristic sheen. Most of the neighbors we interviewed consider the illumination is a "sign of modernity" and like it, but some of them, such as Clara, who works cleaning the restaurant-hotel, think that "this illumination is made for pilgrims, not for us." ${ }^{88}$ None of them were asked about the style of restoration or any other related issue. The villagers have thus far not had any agency in terms of heritage preservation.

\section{Conclusions: Heritagization and Controlling Forces}

The heritagization processes in Olveiroa do not include bottom-up initiatives of the type described by Iñaki Arrieta (2010: 13). Spanish anthropologist Arrieta insists on the importance of communicating the modus operandi and not only the opus operatum in the heritage actions initiated by institutions, so the local communities can be also agents in the modus operandi, rendering the processes of heritagization also a bottom-up endeavor.

The analysis of the relationship between the absences and presences of the term "heritage," on the one hand, and the level of discourse and practices, on the other, allow for some conclusions. Narratives about heritage, for instance, are largely employed by local administrators and are absent among the inhabitants of Olveiroa. However, the latter have a clear idea of what they value the most in Olveiroa and what they would like to see preserved and taken care of: In addition to their church, houses and hórreos, they unanimously point to their festivals and the idea of the "rural life" and "being able to work our land."

No performative practices, such as festivals, are promoted by the municipality in their heritage policies, yet conversations with the inhabitants of Olveiroa reveal that they are considered valuable. Institutional discourse and practice have naturalized the notion of heritage as objects; this definition has, however, not permeated the discourse of Olveiroa inhabitants, who have a more holistic vision, adding not only built elements, such as hórreos or houses, but also performative practices, such as festivals.

A double objective in the heritage mobilization in Olveiroa can be pointed out: The first objective is related to the goal of promoting identity markers to legitimate feelings of belonging among the population of Olveiroa; secondly, tourism and heritage are to be promoted as a resource (Jiménez de Madariaga 2005: 25-27). In the case of Olveiroa, the logic of the market - the second objective - is meant to increase the arrival of pilgrims, and, as the words of the mayor show, the logic of the politics of identity is also present. Both logics are integrated in the employment

\footnotetext{
88 Interview conducted by Paula Ballesteros-Arias and Cristina Sánchez-Carretero on October 19,
} 2010. 
plan of the municipality and also in the overall design of the Camino de Santiago policies. Tourists and pilgrims are the same thing for the promotion of the area. In terms of policies, it is not a question of tourists being half-pilgrims or if pilgrims are half-tourists (Turner and Turner 1978), but a question of both being rural development resources.

The "touristic mono-crop" is the unquestioned basis of the rural development of the area among institutional representatives. There are no plans to develop the agricultural sector, even though it is the economic activity that occupies a greater percentage of the active population in the municipality of Dumbría (Río 2009: 108). The economic promotion of the area for the local administration is synonymous with the promotion of tourism: The pilgrimage to Santiago being the priority in the local development plans. However, these priorities are far from being shared by the inhabitants of Olveiroa. The focus on tourism (and by that I include the services offered to pilgrims) leaves aside other possibilities that are voiced by the inhabitants of Olveiroa, who repeated "if I could make a living by working the land, I'd have stayed here." Working the land is one of the aspects of the life in Olveiroa that is valued the most. Therefore, according to the working definition of heritage proposed at the beginning of this paper, working the land is the most important aspect of their heritage for the inhabitants. However, the policies and resources dedicated to heritage in Olveiroa are related to the Camino de Santiago. This research project thus makes visible the gap between state heritage policies and the local scale of heritage values. While the latter includes the possibility of linking heritage with the development of the agricultural sector (among others), the former closes off this possibility by naturalizing the assumption that heritage is linked exclusively with the touristic sector.

Various heritage regimes affect the daily life of the inhabitants of Olveiroa. Decision-making at the national level (nation meaning Galicia and also Spain) affects decision-making at the municipal level. In addition, the ignoratio tactic of the Catholic church contributes to this amalgamation of layers of controlling forces. The bidirectionality between institutions and civil society needs to be further explored, as these processes of heritagization do not only take place top-down. The main conclusion thus far is, however, that the local population in the area examined absolutely lacks control over heritage policies and heritage-related initiatives.

Acknowledgements. We thank the Xunta de Galicia for their assistance to the research project "Heritagization Processes along the Camino de Santiago: Route Santiago-Fisterra-Muxía" (INCITE-09PXIB-606181PR). 


\section{References}

Aguilar Criado, Encarnación (2003): La cultura como recurso en el ámbito de la globalización: la nueva dinámica de las industrias artesanas. In Las expresiones locales de la globalización: México y España. Carmen Bueno and Encarnación Aguilar, eds. Pp. 405-423. Ciudad de México: CIESAS, Universidad Iberoamericana, Ed. Porrúa.

Arrieta, Iñaki (2010): Comunidades, científicos y especialistas en los proyectos patrimoniales y museísticos. In Activaciones patrimoniales e inciativas museísticas: ¿por quién? y ¿para qué?. Iñaki Arrieta, ed. Pp. 11-19. Bilbao: Universidad del País Vasco.

Fernández de Paz, Esther, and Juan Agudo Torrico, eds. (1999): Patrimonio cultural y museología. Santiago de Compostela: FAAEE-Asociación Galega de Antropoloxía.

Greenwood, Davydd J. (1977): Culture by the Pound: An Anthropological Perspective on Tourism as Cultural Commoditization. In Hosts and Guests: The Anthropology of Tourism. Valene L. Smith, ed. Pp. 129-138. London: Blackwell Publishers.

Herrero, Nieves (2005): La Costa de Morte (Galicia): Localización de un modelo de turismo cultural. In Encuentros del turismo con el patrimonio cultural. Augustín Santana Talaverea and Llorenç Prats Canals, eds. Pp. 117-130. Sevilla: FAAEE-Fundación El Monte.

- (2009): La atracción turística de un espacio mítico: peregrinación al cabo de Finisterre, Pasos. Revista de Turismo y Patrimonio Cultural 7(2): 163-178. Jiménez de Madariaga, Celeste (2005): Patrimonio etnológico e instrumentalización política. In Patrimonio cultural: politizaciones y mercantilizaciones. Xosé Carlos Sierra Rodríguez and Xerardo Pereiro Pérez, eds. Pp. 25-36. FAAEEFundación El Monte.

Kirshenblatt-Gimblett, Barbara (1998): Destination Culture. Tourism, Museums, and Heritage. Berkeley: University of California Press.

Novelo, Victoria (2005): El patrimonio cultural mexicano en la disputa clasista. In Patrimonio cultural: politizaciones y mercantilizaciones. Xosé Carlos Sierra Rodríguez and Xerardo Pereiro Pérez, eds. Pp. 85-99. Sevilla: FAAEEFundación El Monte.

Pereiro Pér, Xerardo (1999): Patrimonialización, museos e arquitectura: o caso de Allariz. In Patrimonio cultural y museología. Esther Fernández de Paz and Juan Agudo Torrico, eds. Pp. 97-110. Santiago de Compostela: FAAEEAsociación Galega de Antropoloxía.

Prats, Llorenç (2004 [1997]): Antropología y Patrimonio. Barcelona: Ariel.

Río Barja, Francisco Javier, ed. (2009): Diccionario Xeográfico Ilustrado de Galicia. La Coruña: Xeogal Publicacións, S.L. 
Turner, Victor, and Edith Turner (1978): Image and Pilgrimage in Christian Culture. Anthropological Perspectives. New York: Columbia University Press.

Vilar Álvarez, Manuel (2010): El camino al fin de la tierra. Santiago de Compostela: Cámaras Caminos Jacobeos.

Walsh, Kevin (1992): The Representation of the Past. Museums and Heritage in the Post-Modern World. London: Routledge. 



\title{
Heritage Politics and Neglected Traditions: A Case-Study of Skellig Michael
}

\author{
Máiréad Nic Craith
}

This essay explores a case-study of World Heritage in the southwest of Ireland from an anthropological perspective with particular reference to changing relationships between local stakeholders, the Irish state party and UNESCO. It examines the impetus for change in cultural practices at a local level and reactions to such impulses at national and international levels. Changing heritage practices at Skellig Michael reflect greater community involvement in the protection of heritage at local levels, as well as an evolving understanding of heritage in an international context. Moreover, the case-study illustrates the strong impact of ICOMOS (International Council on Monuments and Sites) in continuing to guide the state party in Ireland and its willingness to listen to local actors and experts.

\section{World Heritage Sites in Ireland}

World Heritage status is highly prized. Apart from the international legitimacy and universality it confers on the value of a site, it is also viewed as a guarantor of authenticity or "global cultural currency" (Kaschuba 2008: 37). Since it is anticipated that World Heritage status will attract foreign tourists, it is also perceived as a source of economic potential. At the time of writing, 936 properties form part of the cultural and natural heritage on the World Heritage List - that is, they are deemed to have "Outstanding Universal Value." These include 725 cultural, 183 
natural and 28 mixed properties in 153 states. Two sites are located in the Republic of Ireland.

Ireland ratified the 1972 World Heritage Convention in 1991. Following this ratification, it successfully sought World Heritage status for two sites. Brú na Bóinne in County Meath (entitled the Archaeological Ensemble of the Bend of the Boyne on the list) was designated a World Heritage cultural site in 1993. Three years later, the World Heritage Committee conferred World Heritage status on Sceilig Mbichil (more widely known as Skellig Michael). There is one other site on the island of Ireland with World Heritage status. The Giant's Causeway in County Antrim was inscribed as a natural site on the World Heritage list in 1986. Politically, this site is part of the United Kingdom.

Skellig is an Anglicization of the Gaelic word Sceillic which translates as a steep rock. The site is an island or a ridge of rock jutting 200 meters out of the Atlantic Ocean. It is located some 12 kilometers off the coast of County Kerry in the southwest of Ireland. The island is primarily promoted as the site of a 7th century Celtic monastery which was dedicated to St Michael in the 10th century, but has many other remarkable attributes. An important lighthouse tradition is associated with the island, which is now uninhabited. The site is noted for its wealth of seabirds. "The steep rocky slopes and cliffs provide nesting places for species such as Fulmar, Kittiwake and Guillemot, while Storm-Petrel, Manx Shearwater and Puffin nest in burrows and other holes throughout the island" (DoEHLG and OPW 2008: 5).

\section{The Nomination Process}

The nomination of Skellig Michael for World Heritage status in 1996 followed the passing of the Heritage Act in Ireland in April of the previous year. The 1995 Irish Heritage Act was designed to promote public interest in and knowledge, appreciation and protection of the national heritage. It established a new state body (an Chombairle Oidhreachta, the Heritage Council) to deal with Ireland's national heritage. It was Ireland's first formal Heritage Act but followed other legislation dealing with heritage, such as the National Monuments Acts (1930, 1954, 1987, and 1994), the Holycross Abbey (County Tipperary) Act (1969) and the Canals Act (1986). Although the Heritage Act provided a definition of terms, such as "archaeological object," "architectural heritage" or "heritage objects," it offered no definition of cultural heritage. In fact, the concept of culture does not appear at all. While this may surprise readers today, it is important to place the Heritage Act in the context of its time. In previous decades, heritage was largely perceived in terms of material culture, and the concept of Intangible Cultural Heritage had not yet come to the fore - in the English-speaking world at least.

Following the passing of the Heritage Act, the Republic of Ireland submitted a proposal for the acquisition of World Heritage status for Skellig Michael. They 
justified the nomination of Skellig Michael on the basis of criteria i, iii and iv, which require that a nominated site should:

(i) Represent a masterpiece of human creative genius;

(iii) bear a unique or at least exceptional testimony to a cultural tradition or to a civilization which is living or which has disappeared; and

(iv) be an outstanding example of a type of building or architectural or technological ensemble or landscape which illustrates (a) significant stage(s) in human history.

The Irish state argued that Skellig Michael was "an outstanding example of a perfectly preserved Early Christian settlement" (Advisory Body Evaluation 1996: 47). They also suggested that conservation and repair works on the island had provided an opportunity "to examine the structures in detail" and enabled them "to work out a relative chronology" for the cell structures on the island. The Irish Government proposed that Skellig Michael could be considered "a group of buildings in terms of the categories of property set out in Article 1 of the 1972 World Heritage Convention." However, as the entire island was covered by the nomination, the Irish State hypothesized that it should also be considered as "a cultural landscape" as set out in paragraph 39 of the Operational Guidelines for the Implementation of the World Heritage Convention (Advisory Body Evaluation 1996: 47).

In June 1996, an expert mission of ICOMOS, the lead body in the case of cultural landscapes, visited Skellig Michael. Subsequently, ICOMOS recommended that the property be inscribed on the World Heritage List on the basis of criteria iii and iv, stating that:

Skellig Michael is an outstanding, and in many respects unique, example of an early religious settlement deliberately sited on a pyramidal rock in the ocean, preserved because of a remarkable environment. It illustrates, as no other site can, the extremes of a Christian monasticism characterizing much of North Africa, the Near East, and Europe. (Advisory Body Evaluation 1996: 50)

In December 1996, the World Heritage Committee awarded World Heritage status to the site.

\section{A Cultural Landscape of "Outstanding Universal Value"}

While the concept of "cultural landscape" has been used by geographers, it is relatively more recent in the World Heritage context (Graeme 2007). In December 1992, the World Heritage committee formally recognized the concept of "cultural landscape" and three categories emerged in paragraph 39 of the Operational Guidelines for the implementation of the World Heritage Convention. The first 
refers to a landscape "designed and created intentionally by man" and includes, for example, gardens or parklands. The second is "the organically evolved landscape." In this instance, the landscape "results from an initial social, economic, administrative, and/or religious imperative and has developed its present form by association with and in response to its natural environment." The final category, "associative cultural landscape," places great emphasis on "the powerful, religious, artistic, or cultural associations of the natural element rather than the material cultural evidence, which may be insignificant or even absent" (UNESCO 1996: 11). The quality of the landscape itself remains highly significant, with a strong emphasis being placed on the notion of "Outstanding Universal Value."

Since the category was new in 1992, there were no official cultural landscapes on the World Heritage List at that time. The first cultural landscape inscribed on the World Heritage List in 1993 was Tongariro National Park in New Zealand. Interestingly, this was deemed to be an associative cultural landscape and is a significant sacred space for the indigenous Maori people (Rössler 2008: 50). Technically, Skellig Michael is inscribed on the World Heritage List in terms of the categories of property as set out in the first Article of the 1972 World Heritage Convention, that is, as "a group of buildings." However, since the entire island is included in the nomination, it is also considered to be a cultural landscape (UNESCO 2008: 3). At the time of its application, the Irish Government identified Skellig Michael as an organically evolved landscape, which had been connected with a Celtic monastic community. A strong emphasis on the monastic dimension is also reflected in the Skellig Experience, the heritage centre on the nearby Valentia Island. "It is inspired mainly by the extraordinary saga of the cloistered life of a community of monks who inhabited the unpromising, steep-sided pinnacle of Skellig Michael between the 6th and 12th centuries" (Royle 2003: 25).

While the precise date of the establishment of the island monastery is unknown, tradition suggests that it had been set up by St Fionan in the 6th century AD. Some early written records about the monastery date from the end of the 8th century, and it appears that the monastery was formally dedicated to St Michael around the turn of the first millennium. The monks remained on the island until late in the 12th century when harsh environmental conditions forced them to move to the mainland (Advisory Body Evaluation 1996: 47). The remains of the monastery on the island are a great source of fascination and many of the rock formations have religious connotations, such as "the Needle's eye" or "Christ's saddle." One prominent rock formation, commonly known as the "Wailing Woman," is deemed "to represent one of the stations of the cross on the old pilgrim circuit" (McNally 1978: 122).

In drawing specific attention to the material remains of the monastic settlement, the Irish Government were firmly placing the site in category 2a, which refers to relic or fossil landscapes "which came to an end at sometime in the past," but whose distinguishing features are still visible (UNESCO 1996: 11). This was reaffirmed in the management plan of 2008, which stated that Skellig Michael "rep- 
resents a unique cultural achievement, illustrating a significant period of history and a civilisation that has disappeared" (DoEHLG and OPW 2008: 5).

In accepting the nomination for inscription, ICOMOS also gave prominence to the monastic remains (i.e. the group of buildings), emphasizing not just the exceptional state of preservation of the buildings on the island, but the significance of those buildings in universal terms. It noted that the monastic cells and other remains on the island are highly significant since they:

symbolize both the conquest by Christianity and literacy of lands so remote that they were beyond the frontiers of the Roman Empire and the ultimate reach of organized monasticism which spread from Egypt by land and sea through Italy and Gaul to Britain and Ireland in a mere two centuries (the 5th and 6th). (Advisory Body Evaluation 1996: 49)

The ICOMOS report described Skellig Michael as a small "desert" on the ocean. "All the physical components of the ideal small monastery [...] exist here in dramatic and unique settings." Unlike many other monasteries of the time, Skellig Michael had not been plundered by invaders, making it "the best preserved, and the most impressive of monastic settlements on Atlantic islets" (Advisory Body Evaluation 1996: 50).

The magnetism of the Celtic monastic narrative is highly significant - as therein lies the appeal to universal relevance. The ruins of the island point to the widespread movement by Celtic monks in the Middle Ages to Christianize the island of Ireland and further afield. From the island of Iona in Scotland, the Donegal-born Colum Cille (also known as Columba) played a leading role in the Christianization of many Britons (Sharpe 1995; Herbert 1988, 1999; Broun and Clancy 1999). St Aidan established the See of Lindisfarne in Northumbria in the 7th century.

Irish monks traveled well beyond Ireland and Britain and established monasteries across Europe. St Columbanus is reputed to have founded a number of monasteries on the continent at the turn of the 6th century. Most notable are the monasteries in Luxeuil (France) and Bobbio (Italy), where there is now a cathedral honoring his memory. The 7th century Celtic Saint Fiachra set up a hospice for travelers in France, in what is now Saint-Fiacre, Seine-et-Marne. (The Fiacre cab, a horse-drawn, four-wheel cab, is named after him.) St Gall is associated with Switzerland. St Killian was martyred at Würzburg in Germany in 689 AD and St Dymphna is linked with Gheel in Belgium. Latin Christian manuscripts with Old Irish glosses are located in libraries all over the continent, in places such as Karlsruhe, Leyden, Milan, Munich, St Gallen, Turin, Würzburg, and Vienna (Stokes and Strachan 1903; Nic Einrí 1971). The ruins of Skellig Michael point to the international profile of the Celtic "golden age" and hence its significance beyond the Island of Ireland. Moreover, they remind us that migration is not a new phenomenon. Instead it has been a regular feature of the human condition since the begin- 
ning of time (King 2007; Castles and Miller 2009; Harzig and Hoerder 2009; Nic Craith 2012).

\section{Isolation, Integrity and Authenticity}

As well as universality, the notion of integrity is very significant for the concept of World Heritage and has been defined as referring to the "physical and/or contextual and/or environmental integrity." All of these matters are easily confused or blurred with the notion of authenticity, and development on or around a site which could be deemed to be at odds with its intrinsic nature is perceived as diminishing its authenticity (Fowler 2003: 16). In the case of Skellig Michael, the island's isolated position seems to have served as the key guarantor of authenticity.

During the initial application process, the Irish state placed great emphasis on the remote position of the island. The state party argued that Skellig Michael was "the most spectacularly situated of all the Early Christian island monastic sites, particularly the isolated hermitage perched on narrow, man-made terraces just below the South Peak." Moreover, the state party suggested that "its isolation in the Atlantic has helped preserve it. This seclusion has protected it from alteration and adaptations, other than those of the lighthouse builders, who were in occupation for a brief period in the 19th century" (Advisory Body Evaluation 1996: 47). Isolation was the key guarantor of the site's authenticity. "Because the level of authenticity is so high, it makes this site of immense and immeasurable importance to the archaeologist, the architectural historian, the anthropologist, and the ethnologist" (Advisory Body Evaluation 1996: 47).

ICOMOS had been impressed with the remote location of the island. They noted its position at "the extreme north-western edge of European civilization in the 1st millennium AD." Although there were some twenty island monasteries off the Irish coast, and more around the Hebridean Islands off north-western Scotland, the ready accessibility of the Scottish islands meant that they have been constantly modified, altered or plundered over the centuries. In contrast:

the extreme remoteness of Skellig Michael, where the monastic settlement may have begun in the 7th century earlier than the Hebridean and Northern Isles sites, has allowed an exceptional state of preservation and, until recently, hardly any visitors[...]. Skellig Michael must be claimed among the earliest, certainly the best preserved, and the most impressive of monastic settlements on Atlantic islets. (Advisory Body Evaluation 1996: 50)

However, the integrity of the conservation work on the island soon became problematic. From 2005 onwards, concerns were addressed formally to the UNESCO World Heritage Centre by Michael Gibbons, an independent Irish archaeologist, by An Taisce (The National Trust for Ireland) and by some anonymous commentators 
regarding the restoration work. Concerns were raised about the lack of transparency in the decision-making process which led to the conservation work. In a direct submission to ICOMOS, Michael Gibbons suggested that stonemasons were frequently "left unsupervised and unmonitored for long periods of time." He criticized the dismantling of sites "without proper archaeological supervision or record keeping." He argued that the "conservation programme to date has been characterised by the destruction of original features and the over-restoration of monuments" (Gibbons 2007b).

The lack of evidence and transparency regarding original versus reconstructed material was a crucial element in the complaints regarding the principle of authenticity. In his submission to UNESCO, Gibbons protested that "works undertaken as part of the conservation programme in both the Main Monastic Complex and on the South Peak have seriously compromised the authenticity of the site" (Gibbons 2007b). Gibbons made the case that the authenticity of monuments was "further compromised by the fact that no indication is given, either on site or in the draft management plan, of the extent of the reconstruction work involved." Instead, "much of the stonework now visible to visitors is not original but the best approximation of the original work that 21 st century masons, architects and archaeologists could conceive of' (Gibbons 2007b). The lack of distinction between the original buildings and the reconstructions had seriously compromised the authenticity of the site since "there is no way of telling which portions of monuments are original and which are replicas" (Gibbons 2007b).

Interestingly, the issue of isolation, which was initially regarded as a key component in the maintenance of authenticity, was now identified as a crucial factor in damaging that same authenticity. In October 2006, the Tara Foundation uploaded a YouTube video for public consumption on the Internet. The YouTube video is entitled "Skellig Michael: The Fabrication of History" and is described as "a short film about unauthorised reconstruction on one of Ireland's only World Heritage Sites - the spectacular Skellig Michael." This description is interesting as it implies that the award of World Heritage status effectively removes authority from the national state party to undertake rebuilding on the island without appropriate permission from ICOMOS. At the time of writing, some 25,384 viewers have accessed this YouTube video which highlights the natural isolation of the island and the consequential difficulty in access. In this YouTube presentation, the Tara Foundation concludes "that the damage done to the site under the stewardship of the Office of Public Works (OPW) has gone unnoticed by the rest of the world." The Tara Foundation accused the OPW of a lack of integrity and suggested that the restoration was in contravention of the Venice Charter (1964), which states in Article 9: 
The process of restoration is a highly specialized operation. Its aim is to preserve and reveal the aesthetic and historic value of the monument and is based on respect for original material and authentic documents. It must stop at the point where conjecture begins, and in this case moreover any extra work which is indispensable must be distinct from the architectural composition and must bear a contemporary stamp.

The Tara Foundation accused the OPW of the fabrication of history. "Conjecture has replaced evidence and investigation. Our present is now only understandable in terms of modern fundamentalist mentality. What we do not bother to understand, we erase. What we are left with is packaged, chocolate-box history" (The Tara Foundation 2006). This is in accord with Michael Gibbon's accusation (2007a: 5) that " $[\mathrm{g}]$ enuine archaeological remains have been replaced by faux-monastic twenty-first century imitations."

The Irish Government refuted the allegations made by various bodies and largely relied on a case of urgency in defense of their restoration process. They highlighted the fragility of surviving structures on the island; deeming it necessary to deal with such structures before further damage was inflicted by the harsh environment and increasing visitor numbers. From their perspective, the team in charge of the conservation was experienced and responsible and included a range of appropriate expertise. The Irish Government requested an independent monitoring mission to review the controversy and evaluate whether the restoration had impacted on the "Outstanding Universal Value" of the site. The World Heritage Centre referred the issue to ICOMOS.

A mission, headed by Tom Hassall (former President of ICOMOS-UK) took place in late November 2007 and their report thanks the Government of the Republic of Ireland for the invitation to consider the case. Members of the mission considered evidence from official bodies such as the Department of the Environment, Heritage and Local Government and the National Monuments Service. Evidence was presented in person by Ian Lumley from An Taisce (The National Trust for Ireland) and by Michael Gibbons (independent contract archaeologist). Joe Roddy, Joe Feehan and other Skellig boatmen also had an opportunity to meet with members of the mission, who also visited the island.

Overall, the ICOMOS evaluation noted the complaints, while also taking account of the oral, documentary and photographic evidence that the Irish Government presented in its rejection of the criticisms (UNESCO 2008). ICOMOS largely accepted the Irish Government's argument for the urgency of the conservation project required, but highlighted problems with the recording of changes. Detailed documentation of any alteration is regarded as crucial to maintaining the authenticity of a site. At the time of the ICOMOS mission, only "short descriptive interim publications and annual summary articles have been published" (UNESCO 2008:8). (Some additional dissemination had occurred at various lectures and conference presentations.) ICOMOS further observed "that site sieving and metal 
detector scanning of spoil, which might have been appropriate in view of the paucity of finds, had not been employed." Moreover, "walls were recorded in the plan, without individual top courses being recorded." In order to redress this issue, it suggested photographs of all the conserved external elevations should be taken from a helicopter overhead. These images would serve "to distinguish the original from the new stonework" (UNESCO 2008: 8).

While largely endorsing the Irish Government's approach, the mission made some harsh criticisms of the procedures followed. The ICOMOS report suggested that "the authentic, original structures on the South Peak have been conserved and reconstructed, and as a result they are dramatically different from how they appeared before work started." In particular, they noted that these structures "now look more like conjectural reconstructions published after the original survey." Damningly, they argued that: "the new work is in its own way almost as remarkable as the original work" (UNESCO 2008: 11). The Economist described this as a "Solomonic judgment" (Anonymous 2009).

Opportunities to engage with experts in the field were lost and the lack of public consultation was problematic. "The process of conservation and reconstruction, including the controversy surrounding these activities, has now become a part of the history of the property" and the reconstructed monument "will become the popular vision of Skellig." The mission noted that:

"the cumulative effect is that a series of structures now exist which are totally different in appearance from what had originally survived before conservation. At present areas of old and new work can be distinguished, but in time the appearance of old and new work will be undifferentiated as the stonework weathers and lichens grow on all the surfaces." (UNESCO 2008:7)

ICOMOS urgently requested the full publication of changes during the reconstruction process, so that "the new work should be distinguishable from the old in all future publications." This was not just "an added extra" but an essential component of the process of restoration and the maintenance of authenticity. "Until the works are published at an academic and a popular level the conservation works cannot be said to have been completed" (UNESCO 2008: 12). This is a key issue, as the original operational guidelines stress that reconstruction is "only acceptable if it is carried out on the basis of complete and detailed documentation on the original and to no extent on conjecture" (UNESCO 1996: 7). While some of the conservation works had dramatically altered the appearance of the surviving remains, ICOMOS concluded that the "Outstanding Universal Values" had remained intact. However, the site's authenticity was reliant on open and detailed reporting of the scale of the restoration works.

ICOMOS regretted the lack of public consultation during the entire process and noted concerns regarding the issue of publications. While the Irish authorities 
"recognize that full publication, at both a scholarly and at a more popular level, of the archaeological investigations and the conservation works undertaken from 1978 to 2007 is essential," only "short descriptive interim publications and annual summary articles have been published," although there had been "some additional dissemination of the results through lectures and presentations" (UNESCO 2008: 8). The mission received assurances that "a programme for ordering the records of the site stratification is about to commence, and specialists have been identified to contribute to the final report" (UNESCO 2008: 8). The mission further recommended the appointment of an Academic Advisory Committee, as suggested by the Heritage Council of Ireland, the Institute of Archaeologists of Ireland and the Royal Irish Academy. The World Heritage Committee endorsed the conclusions of the ICOMOS advisory mission and requested copies of a new management plan from the Irish Government. It also asked for an interim progress report.

In 2008, the Irish Government published a formal management plan, which had previously been circulated in draft form. This ten-year plan had been prepared by the Department of the Environment, Heritage and Local Government (DoEHLG), in conjunction with the OPW. The management plan defined its mission as the protection, conservation and promotion of an appreciation of the Skellig Michael World Heritage Site "by putting in place a management framework that will ensure its Outstanding Universal Value is preserved for present and future generations." The plan re-affirmed the Irish Government's commitment to the site as a cultural landscape, suggesting that it exhibits the "combined works of nature and man and [...] which are of outstanding universal value from the historical [and] aesthetic [...] point of view" (DoEHLG and OPW, 2008: 19).

The plan addressed the issue of authenticity and integrity, noting again that the island's isolation has "helped preserve and protect it from agents of destruction that have adversely affected most other sites of the period" (DoEHLG and OPW 2008: 22). It commented on the program of preservation on the island since the 1970s suggesting that the philosophy underpinning this work was that "all original features are retained and conserved in situ." It also referred to the concept of integrity which had not been mentioned at the time of inscription. Defining integrity "as a measure of the wholeness and intactness of the natural and/or cultural heritage and its attributes," it suggested that Skellig Michael exhibited two types of integrity: (a) Structural-historical integrity, "in that the structures have evolved over time; and (b) visual-aesthetic integrity, in other words, the iconic image that has been retained" (DoEHLG and OPW 2008: 22). 


\section{A Neglected Narrative}

Apart from the issue of conservation, further concerns related to the neglected narrative of lighthouse-keeping on the island. From an archaeological perspective, there was a sense of unease that the restoration works had concentrated primarily on the evidence for the early Christian period to the neglect of the island's later history as a pilgrimage centre. Michael Gibbons lamented the focus on the monastery to the neglect of the more recent lighthouse-keeping tradition in an independent submission to UNESCO. The original application by the Irish Government had briefly noted the building of two lighthouses on the Atlantic side of the island, which were manned for some time but had gone automatic by the time the current process of conservation had begun in 1978. The decision to inscribe the island with World Heritage status did not focus on the lighthouse-keeping tradition.

Perhaps such concerns have been taken into account as more recent official publications have made some reference to the import of the lighthouse buildings. The 2009 Annual Progress Report noted that "Skellig Michael is important not just for the famous early medieval remains - its importance is enhanced by the more modern buildings and other structures associated with the development of the two light-houses" (Skellig Michael Implementation Group 2009: 9). These lighthouses were crucial for the safe passage of ships around the southwest coast of Ireland for many decades and one unmanned lighthouse continues to operate today.

There are potentially a number of reasons for the downgrading of the lighthouse tradition in favor of the monastery buildings. In the first instance, the state does not actually own the lighthouse buildings on the island. While it bought the island from the Commissioners of Irish Lights in 1989, the working lighthouse and ancillary areas did not form part of the purchase. Much more likely, however, is the national and international appeal of the narrative of Celtic Christianity as an icon of Irishness. The era of Celtic monasticism is often regarded as the "golden age" of Irish history. It is in keeping with the image of Ireland as a "land of saints and scholars" and reminds us of a few centuries when Ireland achieved international significance. Ireland "held and prized the bequest of Christianity and Rome [...]. When the chance came, she carried her possessions to continental Europe, willingly restoring a tradition to places where it had been neglected and exiled" (Lehane 1968: 2).

Lighthouse building and keeping is more associated with Britishness. Ireland was under British control at the time that Sir Maurice Fitzgerald requested permission for approval for a lighthouse on the island in the early 19th century. The site was subsequently purchased from the Butlers of Waterville who requested that the monastery buildings be treated with care. However, it subsequently transpired that the builders of the roads and the lighthouses were living in some of the monastery cells and storing explosives in others (Lavelle 1976: 54). The lighthouses were 
completed by 1826 with two semi-detached houses nearby as residences for the keepers and their families. Des Lavelle (1976), a fisherman and the "son, grandson and great-grandson of a lighthouse family on one side" tells the story of "the lighthouse and its men" in his memoir, The Skellig Story (Lavelle 1976: 54-67).

There is some folk memory of the lighthouse keeping on the Skelligs in the Irish tradition which has recently been highlighted in a publication by Biddy Jenkinson. In Duinnin, Bleachtaire ar an Sceilg, she imaginatively re-creates the narrative of a song collected by Muircheartach O hAogain in the early decades of the 20th century in southwest Ireland (Jenkinson 2011). The song refers to the folk memory of two lighthouse keepers on the island. Napier was probably from the Protestant tradition, while his working colleague, Cárthach, was Catholic. For a short period, Napier disappeared from the island and it was assumed by the police that his Catholic colleague had murdered him. However, no body was found and the Catholic priest, lexicographer and detective, an tAthair Peadar Ua Duinín, was hired to investigate. It transpired that Napier had temporarily escaped the drudgery of lighthouse keeping in favor of a life more in tune with nature.

\section{Fractured Relationships}

Central to the story of Skellig Michael is the role of the local fishermen. At the time of the original nomination, the management structure on the site was largely informal. The Advisory Body Evaluation document noted that an agreement regarding permits was reached with the local boatmen and a "finite number of nontransferable permits" (1996: 49) was issued to those already established on the route. Only one trip a day was permitted with a maximum of twelve visitors. It was assumed that the informal management structure would suffice, but with time, problems began to emerge and relations became fractured. The boatmen, who regarded themselves as "spiritual guardians" of the island, expressed their concerns.

Although they had been issued with permits for bringing visitors to the island, the boatmen were not willing to accept their terms and sign them. In the first instance, the boatmen felt that access to the island should be allowed throughout the entire tourist season (weather permitting). They were unhappy with the timing of permit issues, which occurred on an annual basis. This did not help the boatmen when endeavoring to secure longer-term bank loans for new boats and equipment. Moreover, the boatmen resented what they considered to be the preferential treatment given to cruise ships. They pointed out that unauthorized boats landed unannounced on the island both in and out of season, and were not regulated by permits or any other procedures. In particular, the boatmen were aggrieved with the non-transferrable status of their landing permits and were strongly of the view that these should be transferable to other family members. They pointed to the 
Killarney National Park where the jarvies (horse-drawn-vehicle drivers) were issued with transferable permits to carry passengers (UNESCO 2008: 9).

The ICOMOS mission to the site in November 2007 met with some of the local boatmen and noted their difficult relationships with management. Although some attempts had been made in 1994 to reach a resolution, the lack of written records was problematic. "The authorities and the boatmen differ in their perceptions of what was agreed at that time and there are no formal agreed minutes of the discussions that took place" (UNESCO 2008: 8). The mission recommended the establishment of a "durable agreement with the passenger boatmen" which would "be reached through negotiation and compromise." They noted "a degree of pragmatism on both sides" of the controversy "which could provide a foundation for a future agreement, provided that a constructive dialogue is maintained" (UNESCO 2008: 13). As a first step, they advised the OPW to establish an annual meeting with the respective boatmen to look at practical arrangements, and stipulated that formal minutes of these meetings be maintained. They recommended revisiting the issue of the non-transferability of permits and that the OPW should establish and make known "the future criteria for the issue of permits, once permits become available as present holders cease to operate" (UNESCO 2008: 13).

In accordance with these recommendations, the 2008-18 management plan proposed annual meetings with the local boatmen in advance of the tourist season (DoEHLG and OPW 2008: 51). It also advocated written minutes of all meetings to help curtail future conflict. Permits would continue to be renewed on an annual basis, as the annual cycle was necessary to monitor visitor numbers to the island. However, management undertook to review the criteria for the granting of future permits for boats. To the concern of the World Heritage Committee, no meeting occurred in 2009 (SMIG 2009: 2). The Committee requested that the State Party "give higher priority to liaising with stakeholders who transport visitors in order to put in place formally agreed arrangements for landing and timetables" (SMIG 2010: 10). A series of meetings took place in 2010.

Apart from the controversial issues involved here, there is a further dimension to the story that needs exploration. The original Advisory Body Evaluation document contains few references to the boatmen. This reflects the understanding of heritage at the time, which focused primarily on material culture. Since then, and especially with the adoption of the UNESCO Charter for Intangible Heritage in 2003, a more holistic approach has been adopted internationally towards heritage. Were the nomination to be made today rather than some two decades ago, it is highly likely that the narrative of the boatmen, and in particular the notion of these boatmen as "spiritual guardians" of the site, would be much more central to the application. 


\section{Skellig's Intangible Heritage}

Skellig Michael's heritage narrative has focused to date on primarily archaeological, architectural and restoration issues and these clearly point to built heritage as a particular sub-section of the heritage regime. As previously noted, this reflects the timing of the application almost two decades ago, and conflict between state representatives and the boatmen may in part reflect tensions between tangible and intangible heritage, between the built environment and the human factor.

Since the initial application was made, there has been a gradual shift in emphasis in international legislation towards an appreciation of the wealth of intangible heritage associated with Skellig Michael. The 2008 management plan, for example, highlighted the significance of the island as a place of pilgrimage. "The presence of the monks on the island for such a long period of time has bequeathed us with more than just physical remains. They have imbued the place with a strong sense of spirituality, which is palpable to anyone who has had the opportunity and privilege of spending time there" (DoEHLG and OPW 2008: 20). However, there is much more to the island's intangible heritage which remains a vastly underresearched resource. For the purposes of this essay, I would like to draw attention to the Skellig Lists, which represent a unique aspect of this island's intangible heritage and can be accessed at the National Folklore Collection at University College, Dublin.

The Skellig Lists refer to matchmaking customs during the season of Lent on Skellig Michael and should be set in the context of tensions between the Roman and the Celtic Church concerning the timing of Easter. A conference took place at St Hilda's monastery in Whitby in 664 which decided that the Celtic church should adopt the Roman timing. Apparently the monks at Skellig Michael continued with the Celtic calendar. In consequence, Lent began later on the little island than it did on the mainland of Kerry. As Lenten weddings were not permitted, folk memory suggests that single men and women traveled to the island during its pre-Lenten period to pray for good partners, repent of their sins and/or get married. "When the monks were in Skellig long ago they used to marry people later than their own priests. I think they could be married there the first week of Lent. It was said, anyway, and I don't know was it true" (National Folklore Collection (NFC) 1592: 208). This folk memory is confirmed in manuscripts in the National Folklore Collection in University College, Dublin:

When the Church Laws concerning Easter and Lent were first adopted in Ireland, they did not extend to the monastery in the rocky island of Sgeilg, west of Kerry for some time. Marriages could take place there on Ash Wednesday. There was an extra day in Shrove. So people who made up their mind to get married and hadn't managed to do so by Shrove Tuesday need not wait till Easter. (NFCS 282: 40) 
However, folk memory also suggests that these proceedings were often more fun than prayer, and the "pilgrimages" were gradually curtailed.

Verses were composed in parishes of Cork and Kerry to celebrate this Lenten anomaly and the opportunity it represented for un-married men and women. These rhymes were written in English and the poets usually remained anonymous. The verses were designed to scorn bachelors and single women who had not "found" a spouse before the season of Lent began and frequently ridiculed their unmarried status. "People didn't like to be mentioned in these things at all. You may be sure tisn't praised they'd be in it atall" (NFC 1592: 209).

Examples of these rhymes abound in the National Folklore Collection in University College, Dublin. The first extract is from Schools Manuscript Collection (NFCS 413: 103) and is the one of several verses written by Eilís Ní Aodhagáin, who heard them from her father:

First came Eillen Buckley,

That small and red-faced girl.

She is courting Eddie Glavin

Who's [sic.] face is like a squirrel.

Next comes Danny Slattery

That tall and saintly boy,

He's all in love with Nora Callaghan,

He says for her he'll die.

Most of the rhymes were distinctly unkind and although the names were often changed, people could easily identify to whom they referred. The following is an example from the schools manuscript collection (NFCS 435: 232):

Pat Lyons I fear another year,

Is left to grind the bit,

Since Ganndal's daughter from Clahan,

Cares not for him a bit,

He dresses in his toffee style,

And makes a gallant show

He is only a ladys' gent, me, boy,

No matter where he go [sic].

The rhymes often referred to the "pilgrimages" to Skellig Michael and the purpose of these journeys. The following account is related in NFCS 282 (p. 40) in the schools manuscript collection:

It is still a joke in this parish to send the unmarried people "to the Sgeilgs" on Shrove Tuesday night. 
"Are you going to the Sgeilgs?" is a common question asked on the evening of Shrove Tuesday. And on Ash Wednesday morning, "You look worn out. Had you a good crossing to Sgeilgs?”

In some areas, there was a custom of "sending people to the Skelligs" which was accompanied by a lot of noise and buffoonery:

On "the night of the Sgeilgs" the children of Bantry town get a long rope and tie on all the tin cans they can find. Two are "harnessed" at one end. They run making an awful noise - the following tin cans. The crowd runs after them. The noise represents the noise of cars - full going to Sgeilgs. The youngsters shout "Come on to Sgeilgs." (NFCS 282: 40)

Crofton Croker also notes the level of noise that accompanied such rituals. In 1832, he received a Skellig List from a friend in Cork, telling him that "the tumult in the streets, last Tuesday night, was extreme. Bodies of five hundred men and boys paraded the town, blowing horns, firing, breaking lamps et cetera; and all on the occasion of the Skellig Lists" (Crofton Croker 1839: 127).

There is no doubt that these rhymes were extremely popular at one stage in southwest Ireland. Thomas Crofton Croker writes that a ballad publisher in Cork printed 13 different Skellig Lists in 1836. As his average presswork amounted to 300 impressions a day and his press was fully occupied for 12 days, he produced 3,600 impressions, which ultimately generated 15,000 Skellig Lists (Crofton Croker 1839: 126).

\section{Conclusion}

With hindsight, it is amazing that greater prominence is not given to these unique sets of rhymes in relation to Skellig Michael as a World Heritage Site. However, these rhymes represent a fraction of the wealth of intangible heritage relating to the site which is yet to be researched and fully documented. There is much about Skellig Michael that remains to be told. The lack of interest in the Skellig's List is symptomatic of the general neglect of the intangible heritage related to this site. This includes the neglect of the fishermen's tradition or the narrative of the lighthouse tradition. One might ask why the monastery buildings attract such great attention whereas recent oral traditions, such as the Skellig Lists, or living traditions, such as the narratives of the boatmen, are neglected. However, the answer probably lies in the changing context of heritage. Interest in the intangible dimension of heritage is relatively recent and emerged subsequent to the award of World Heritage status to Skellig Michael. 
Overall, the Irish Government appears to be adopting a more proactive approach in general to the issue of World Heritage. In 2009, the then Minister for the Environment, John Gormley, suggested that Ireland's "World Heritage programme has been in abeyance for a number of years," a situation he was now rectifying. Since the establishment of an Advisory Group in 2008, the Irish Government has published a list of tentative World Heritage Sites. This rather extensive list demonstrates an enthusiasm for the acquisition of World Heritage status which is not necessarily matched by action on the ground - all of which must be set in the context of extensive cuts to the budget of the Heritage Council of Ireland which were announced in November 2010. Moreover, the focus appears solidly on elements of material culture. In a country like Ireland where the collection of folklore and oral tradition has such a long "heritage" itself, it is surprising that the Irish Government has not yet approved or ratified UNESCO's Charter for Intangible Heritage. The story of Skellig Michael is unfinished and must now be set in the context of a country that is struggling economically and a government that may have neither the inclination nor the resources to finally achieve the targets set out by the ICOMOS mission.

Acknowledgments. I am grateful to the National Folklore Collection at University College, Dublin, for permission to research their archives in relation to the Skellig Lists. I would like to acknowledge permission to publish material from the following manuscripts in particular:

NFC 1592, 208-210. Jerry Buckley, 78, Labourer, Cluain Droichead, Collector Seán Ó Cróinín, February, March 1961.

NFCS 282, 39-42. Kathleen O’Sullivan, 1938.

NFCS 413, 103-105. Eilís Nic Aodhagáin, school pupil in Scoil Mainistir ó dTórna, County Kerry, heard from her father (aged 39), January 1938.

NFCS 435, 230-33. Áine Ní Chlubháin, Fearannteóirín, Kilorglin, 1938.

I also wish to acknowledge the help of Dr. Michael Gibbons who forwarded me a copy of his original submission to UNESCO along with other relevant material. I would like to thank Dr. Catherine Swift of Mary Immaculate University College, Limerick, who was most helpful with my initial inquiries on the subject. Finally I would like to thank the peer reviewers for their helpful comments and suggestions. 


\section{References}

Advisory Body Evaluation (1996): World Heritage List, Skellig Michael. No. 757. http://whc.unesco.org/archive/advisory_body_evaluation/757.pdf $<$ accessed April 21, 2012>

Anonymous (2009): Skellig Michael, An Irish riddle wrapped in a mystery. The Economist, Sep 10.

http://www.economist.com/node/14401046?story_id=14401046 <accessed April 21, 2012>

Aplin, Graeme (2007): World Heritage Cultural Landscapes. International Journal of Heritage Studies, 13(6): 427-446.

Broun, Dauvit, and Thomas O. Clancy (1999): Spes Scotorum: Hope of the Scots, Saint Columba, Iona and Scotland. Edinburgh: T \& T. Clark.

Castles, Stephen, and Mark J. Miller (2009): The Age of Migration: International Population Movements in the Modern World. 4th edition. Palgrave: Macmillan.

Crofton Croker, Thomas, ed. (1839): Popular Songs of Ireland. London: Coldburn.

Department of the Environment, Heritage and Local Government (DoEHLG) and The Office of Public Works (OPW) (2008): Skellig Michael World Heritage Site: Management Plan 2008-2018. Dublin.

http://www.kerrycoco.ie/en/allservices/heritage/skelligsmanagementplan/the file,2411,en.pdf < accessed April 21, 2012>

Fowler, Peter J. (2003): World Heritage Cultural Landscapes 1992-2002. World Heritage Papers 6. Paris: UNESCO World Heritage Centre. http://whc.unesco.org/documents/publi_wh_papers_06_en.pdf < accessed April 21, 2012>

Gibbons, Michael (2007a): Restored to death? Skellig Michael's World Heritage Status threat. History Ireland 15(3): 5-6.

- (2007b): Some Notes on the Draft Skellig Michael World Heritage Management Plan. Unpublished Report submitted to ICOMOS.

Harzig, Christiane, and Dirk Hoerder (2009): What is Migration History? Cambridge: Polity Press.

Herbert, Máire (1988): Iona, Kells and Derry: the History and Hagiography of the Monastic "Familia" of Columba. Oxford: Clarendon Press.

- (1999): The legacy of Columba. In Celebrating Columba: Irish-Scottish Connections 597-1997. Tom M. Devine and J.F. McMillan, eds. Pp. 1-14. Edinburgh: John Donald Publishers.

Heritage Act, Ireland (1995): Number 4 of 1995. The Irish Statute Book. http://www.irishstatutebook.ie/1995/en/act/pub/0004/index.html $<$ accessed April 21, 2012>

Jenkinson, Biddy (2011): Duinnín ar an Sceilg. In Duinnín Bleachtaire ar an Sceilg. Pp. 7-45. Binn Éadair: Coiscéim. 
Kaschuba, Wolfgang (2008): Cultural Heritage in Europe: Ethnologists' Use of the Authentic. Anthropological Yearbook of European Cultures 17(2): 34-46.

King, Russell, ed. (2007): The History of Human Migration. New Holland Publishers.

Lavelle, Des (1976): The Skellig Story: Ancient Monastic Outpost. Dublin: O’Brien Press.

Lehane, Brendan (1968): Early Celtic Christianity. London: Constable.

McNally, Kenneth (1978): The Islands of Ireland. London: B.T. Batsford.

NFC 1592, 208-210 Jerry Buckley, 78, Labourer, Cluain Droichead, Collector Seán Ó Cróinín, February, March 1961.

NFCS 282, 39-42. Kathleen O’Sullivan, 1938.

NFCS 413, 103-105 Eilís Nic Aodhagáin, school pupil in Scoil Mainistir ó dTórna, County Kerry, heard from her father (aged 39), January 1938.

NFCS 435, 230-33, Áine Ní Chlubháin, Fearannteóirín, Kilorglin, 1938.

Nic Craith, Máiréad (2012): Narratives of Place, Belonging and Language: an Intercultural Perspective. Basingstoke: Palgrave Macmillan.

Nic Einrí, Úna (1971): Stair na Teanga Gaeilge. Baile Átha Cliath: Folens agus a chuid ta.

Rössler, Mechtild (2008): Applying Authenticity to Cultural Landscapes. APT Bulletin 39(2/3): 47-52.

Royle, Stephen A. (2003): Exploitation and celebration of the heritage of the Irish islands. Irish Geography 36(1): 23-31.

Sharpe, Richard, ed. (1995): Adomnán of Iona: Life of Saint Columba. London: Penguin.

Skellig Michael Implementation Group (SMIG) (2009): Annual Progress Report 2009.

http://www.worldheritageireland.ie/fileadmin/user_upload/documents/Annu al_Report_on_Skellig_Michael_SMIG_2009.pdf < accessed April 21, 2012>

- (2010): Annual Progress Report 2010.

http://www.worldheritageireland.ie/fileadmin/user_upload/images/Gallery_I mages/Skellig_Michael/skellig\%20michael/Annual_Report_on_Skellig_Micha el_SMIG_2010.pdf < accessed April 21, 2012>

Stokes, Whitley, and John Strachan (1903): Thesaurus Paleohibernicus: a Collection of Old-Irish Glosses Scholia Prose and Verse, Vol 2. Cambridge University Press.

The Tara Foundation (2006): Skellig Michael: The Fabrication of History. http://www.youtube.com/watch?v=GpXgBveqnjY < accessed April 21, 2012>

The Venice Charter, International Charter For the Conservation and Restoration of Monuments and Sites (1964): http://www.icomos.org/fr/component/content/article/116-englishcategories/resources/publications/308-sj-the-venice-charter < accessed June 3, $2012>$. 
UNESCO (1996): Intergovernmental Committee for the Protection of the World Cultural and Natural Heritage: Operational Guidelines for the Implementation of the World Heritage Convention.

http://whc.unesco.org/archive/opguide96.pdf < accessed April 21, 2012>

- (2008): Convention Concerning the Protection of the World Cultural and

Natural Heritage, Convention Concernant La Protection Du Patrimoine

Mondial, Culturel Et Naturel World Heritage Committee / Comite Du

Patrimoine Mondial (Report on the Mission to SKELLIG MICHAEL,

IRELAND 26- 28 November 2007), Thirty-second session / Trente-deuxième session Quebec, Canada / Québec, Canada 2-10 July 2008 / 2-10 juillet 2008. http://whc.unesco.org/en/documents/10056 < accessed June 3, 2012> 


\title{
The French Journeymen Tradition: Convergence between French Heritage Traditions and UNESCO's 2003 Convention
}

\author{
Nicolas Adell
}

\section{Introduction}

When France ratified the 2003 UNESCO Convention on Intangible Cultural Heritage $(\mathrm{ICH})$ in 2006 , this hardly entailed a new and unfamiliar set of practices. On the contrary, the ICH Convention complements and reinforces a complex set of historical measures concerning the protection and conservation of heritage. The focus on historical monuments, dating from the French Revolution, was complemented in the 1930s by attention to local languages, folk representations and skills. These are the themes that would be identified seventy years later by the ICH Convention. A taste for the Arts et Traditions Populaires (folk arts and traditions) has been supported by the state, first through the Front Populaire policy (1936-1939), and then by the Vichy government during the Occupation period (1940-1944). During this time, ethnology began to develop as a discipline, breaking in part with the perspectives of folklorists, although ethnology was initially largely based on folklorists' earlier research (Bromberger 2009).

A look at institutions clarifies the rift between ethnology and folklore further. While folklorists worked well away from academia, research centers and universities (regard Arnold van Gennep, who was never able to obtain the institutional recognition he sought), the young discipline of ethnology began to fill sites of cultural and political power. By the late-1930s, the ethnology of France dealt inten- 
sively with heritage and heritage policy. Until the early-1980s, its place of expansion and fulfillment was the Musée des Arts et Traditions Populaires created by Georges-Henri Rivière in 1937 (Gorgus 2003: 95-98). From the start, Rivière wanted to realize a "living museum" (similar to the heritage conceptions held by Konrad Hahm in Berlin at the same time). The key concern of the museum was the presentation of objects in context.

From this approach was born, in the 1970s, the notion of patrimoine ethnologique (ethnological heritage), whose importance alongside other types of heritage (historical, artistic, natural) was quickly recognized. In 1980, the Mission du Patrimoine Ethnologique (Ethnological Heritage Service), later to become the Mission Ethnologie, was created within the Ministry of Culture. With a goal of conservation, the Mission was tasked with the identification and study of vernacular languages, systems of representation, and folk beliefs and knowledge related to the environment. Again, one recognizes categories that will be featured within the ICH Convention. Thus, this concern for safeguarding has found in the Mission Ethnologie, a privileged state department of interpretation and implementation of $\mathrm{ICH}$, as well as a national equivalent, the notion of patrimoine ethnologique able to articulate goals at local and global levels.

The specificity of the French interpretation of the convention can be seen particularly well in particular cases. One of them is the compagnonnage, registered on the ICH Representative List in 2010. The following chapter will examine this case because it also affords an opportunity to look at an institution that has been maintained in France over two centuries, not least due to its close ties with the French idea of heritage.

\section{Compagnonnage and Heritage in France}

The compagnons are divided into several craft communities that train young craftsmen through a temporary tramping system (called the Tour de France). Journeymen and corresponding organizations exist in various states and have attracted a considerable amount of scholarly attention (e.g. Hobsbawm 1965, Bohnenkamp and Möbus 1989, Wadauer 2005) as well as popular interest. Dating from the middleages, this institution has followed the transformation of the heritage idea and policy since the early-19th century, following (but adapting it to their own specifications and requirements) the general French trend of heritage conceptions. Three stages can be distinguished, termed "heritage spirits" by Jean-Louis Tornatore (2010): beritage, heritagization and heritagity. I will briefly present the first two stages that constitute the cultural and historical context onto which the last state - which contains the ICH program - is built. 


\subsection{Heritage}

The first stage is that of compagnons as builders of monuments. It fits into the general framework of the Monuments Historiques (Historical Monuments), which is the first step in the constitution of French heritage. Compagnons are conceived as builders of monuments, in particular historical monuments; they are supposed to have been the main builders of cathedrals as well as modern constructions of import, such as the Statue of Liberty or the Eiffel Tower. They also produce their own monuments, which mark their own history at the community and individual level: These monuments are called chefs-d'oeuvre (masterpieces). There are collective and individual masterpieces. The collective chef-d'oeuvre is more common, as one is more inclined to attribute monumental achievements to a group than to an individual. Thus we find chefs-d'oeuvres that represent specific compagnon trades, such as carpenters, joiners or stonecutters - crafts that also pursue rivaling rites of initiation. These chefs-d'oeuvres were sites of identification; they served as emblems and could also mark events of collective significance, such as the great chef-d'oewure of the Charpentiers du Devoir (Carpenters of Duty) built in honor of the lawyer who defended journeymen in Paris in the great strike of 1845 (Illustration 1). One could also find masterpieces to represent a city of compagnonnage. This was the case, for example, for the cities of Angers and Bordeaux. In Angers' masterpiece, it is the First World War that has deeply marked the memories, including that of the main builder, Auguste Bonvous, who lost his son during this war and honored this sad event with an inscription on the work he crafted.

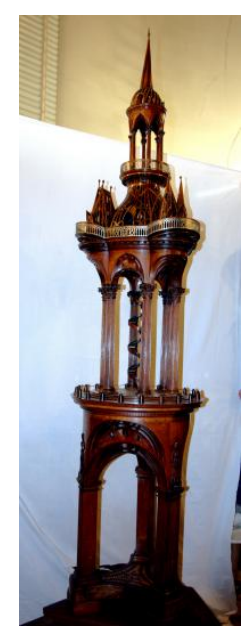

Figure 1: The collective masterpiece of carpenters called "Le Berryer," offered to their lawyer Pierre-Antoine Berryer during the great strike of 1845 in Paris (Jean-Paul Chapelle 2011. Reproduced courtesy of the Author). 
When the concern for training and technical excellence became distinctive elements of the compagnonnage, the individual masterpiece gained in significance. This went hand-in-hand with an increase in the discourse of "bad workers" and "dangerous classes" in the age of mechanization of crafts. Henceforth, it was required for a craftsman to gain access to compagnon status, a rule which remains to this day. New types of masterpieces emerged where the technical process is dominant and reference to the past falls away (it was no longer valued or seen as useful to build a "historical monument" in miniature). New points of reference were technique, skills and secret knowledge.

Although "historical monuments" served as a starting point in the construction of heritage sentiment, they gradually became lost. To understand the shift from the early-19th century where the idea of historical monuments was closely intertwined with compagnonnage, the contemporary individual masterpieces as heritage require a look not at the shape, but rather at its opposite: In the gradual stripping of the actual appearance, the focus shifts to journeyman customs and traditions. From this vantage point, a collectively built historical monument and an individual masterpiece reflect the same logic.

When heritage focused on historical monuments, time ruled the heritage logic. The monument encapsulated a moment in time, solidifying an event or an era: Thus, a series of stones in Brittany represented the time of the last Druids; a church in Roussillon embodied the beginnings of Romanesque art. In 1796, Alexandre Lenoir founded the Musée des Monuments Français (Museum of French Monuments). It was to bring together works of art removed from buildings destroyed during the French Revolution. The museum organized artifacts chronologically, with rooms devoted to individual centuries. Ultimately, this system shelters time from itself. Wanting to show the passage of time through changes in art forms, the change is simultaneously brought to a halt, as each century must be immortalized in a series of monuments. The course of time and the succession of ages must be deciphered in the alternation of styles and not be seen or felt by the impact of a (too visible) degradation. It is a time measured by "art-historical value" an intellectual time, to use Alois Riegl's typology (1984 [1903]). ${ }^{1}$

Journeymen's masterpieces also reflect this accounting of time. They encode, date and represent events, and thus represent time. In terms of craftsmanship, also, there is an accounting of how much time was necessary to complete the masterpiece: Two hundred hours for a small model, and 500-800 for a travail de réception that granted access to a journeyman's status (Illustration 2). The great masterpieces naturally required great amounts of time, such as the Angers chef-d'oewvre clocking in at 3,771 hours of work. Accounting of time spent also is also, of course, owed to the industrializing context within which journeymen worked. However, such accounting - which did not receive any compensation - was also consistent with the essential conjunction of masterpieces celebrating heritage of a time past.

${ }^{1}$ For a general view of Riegl's works, for example, S. Scarrocchia (1995). 


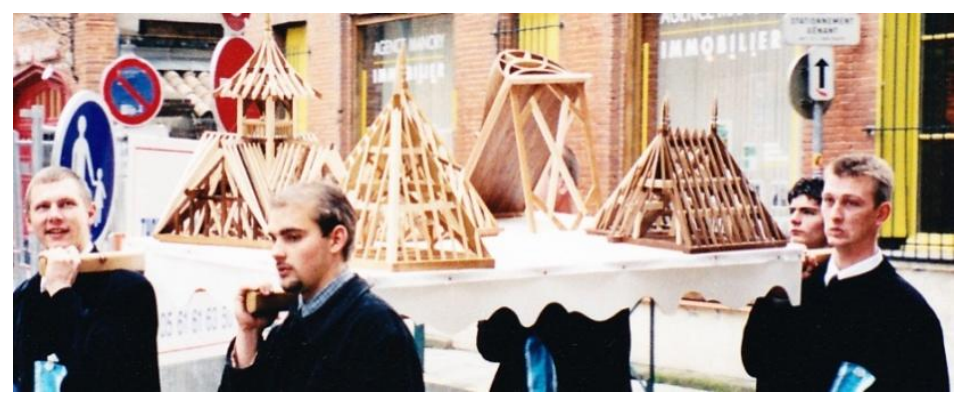

Figure 2: Small models of apprentice carpenters (Adell 2004)

Compagnons have an additional means of sheltering aspects of their work from time. While they have no museums, they have shaped spaces or objects where time and its passage are made visible, if only to those in the know. These are the secrets boxes, the boites, where the compagnons collect those objects that embody the time that is not spent on the masterpieces. This is the sensitive time, the time that results in "ruins." It does not get counted but is simply there for its "age-value," although it is largely invented. Most of the ritual practices and texts, presented as very ancient, were actually developed or written a few years earlier. The boxes contain books and other records, such as correspondence, that contain the history of the journeymen's community, its legends and its rules. Sometimes all the material was bound in one volume, giving it even more unity to the past.

These two representations of time have different audiences. Time in "ruins" is for internal use, reserved for insiders; the counted and monumental time can be shown to the public and is for outsiders. The collective masterpieces were largely made to fulfill this function as public representations. During trades' feasts in compagnonnage, a parade, dating from the 17 th century and still practiced today by some compagnon trades, such as the carpenters in Toulouse or the bakers in Tours, was planned in which the great chef-d'oeuvre was paraded through the city. The carpenters of Toulouse have retained this practice, engaging with their parade - much as do monuments and museums of the 19th century - in a display of "deposits of values" (Poulot 2001: 30). For the compagnonnage of that era, these were values connected with technical skill, the quality of journeymen's works and the educational value inherent in the compagnonnage. When the compagnons participated in industrial exhibitions in the second half of the 19th century, especially from 1870-1880, it was explicitly because their masterpieces were "teaching models."2

These exhibitions and participation in parades featuring the unity of the community and its spirit contribute to a new heritage regime, using new tools and fulfilling new functions. While in the heritage stage, the masterpiece, the technique and

2 According to a carpenter (quoted in Bastard 2008: 74), about an exhibition in Lyon in 1882. 
its pedagogy, and the time represented were central; in the new heritagization stage, people (not monuments), identity and its performance, and the self (not time) increased in importance.

\subsection{Heritagization}

The transition from technical competence to identity, and from monuments to individuals in the fields of culture and heritage occurred in the early-20th century. The World's Fair in Paris of 1900 announced the shift. Indeed, compagnons of Paris had wanted a pavilion devoted to compagnonnage, built to face the "chefs-d'oeuvre of [their] ancestors" (Bastard 2007: 51). It was neither a single trade, nor a simple technique, but a compagnon identity on which they focused. The project did not succeed.

This failure is significant. At the turn of the 19th and 20th centuries, compagnonnage was in a very bad condition: Trade unions and the rise of associations had made the institution irrelevant, and out of step with the times. A historian wrote in 1901 that compagnonnage was taking its last breaths (Martin Saint-Leon 1977). There were indeed only a few dozen journeymen left in the early years of the 20th century. The sense of being the last was probably never stronger, lending urgency to the reflection of the specificities of compagnonnage: Thus the wish for a compagnon pavilion in the World's Fair; thus, ten years earlier in 1889, the establishment of a compagnon organization which brought together various compagnon trades. This meant that the ritual-symbolic peculiarities of each trade were abandoned; instead, there was the Union Compagnonnique des Devoirs Unis (Journeymen's Union of all Crafts).

Reflecting about one's endangered self took many forms. Among the compagnons, it began with a reflection of journeymen history, legends and symbols. Interest in the legends was never as powerful as during those times of institutional crisis. There were reports about the (desired or dreamt of) past and the wealth of resources that were no longer present. History and fiction were mixed in novels and plays. A taste for the esoteric grew. One looked for the relationships between the origins of compagnonnage and the building of Solomon's Temple, between compagnons and Templars, and so on. Some compagnons undertook research into these topics, and the results were published in the compagnon papers of that time as well as in their contributions to esoteric papers such as Le Voile d'Isis (The Veil of Isis). The low number of actual compagnons made the community more accepting of some "intellectual" people 3 in order to thicken the meaning of compagnonnage, drawing from traditions such as traditional Catholicism, mysticism, esotericism, masonry, and so forth. Compagnons contributed to the crafting of their identity in plays

\footnotetext{
3 "Intellectuals" were mostly artists or writers who were curious about journeymen's customs, which they often knew because one of their family members had been in the compagnonnage. Such is the case of Jean Bernard, a painter who became a stonecutter compagnon and founded the Association Ouvrière in 1941.
} 
and novels (Adell 2011: 46-7), and through this work of re-presentation and selfreflection, the interest in a "past self" contributes to the heritagization of the self. Journeymen took the opportunity to present themselves as heritage to others and endeavored to become - as people and as a community - heritage at the state level. From the 1930s, compagnonnage was the subject of specific heritage attention, profiting also from a public interest in craftsmen folklore. In May 1939, an exhibition called Les compagnons du Tour de France was organized in Paris. It emphasized a common past embodied in the old ways of the craft and the sociability involved in the work. Journeymen represented a quasi "exotic" otherness through practices such as customs, festivals and initiation rites, as well as their vocabulary. Like other groups (peasants, mountain dwellers), they became a topic of ethnography. However, unlike other "candidates" for ethnography, journeymen early on guided the ethnographic knowledge production about themselves and the reflection of cultural institutions, such as museums, where they might be represented. The journeymen practiced a kind of "auto-ethnography" in their narratives, their autobiographies or their compagnon newspaper articles, that influenced scholarly studies. Moreover, as a society with secrets (more so than a secret society) and scenery (e.g. for the initiation rites, the distinction between the sacred and the profane), the compagnonnage was led to reflect on what could be said or not, shown or hidden. Compagnon museums especially elaborated on this aspect.

In 1968, the Musée du Compagnonnage was established in the city of Tours. It did not satisfy all compagnons. In the late-1970s and in the 1980s, compagnon museums (sometimes just a room in compagnons' houses takes this title) appeared. The museum had become so essential that heritage and compagnonnage seemed to go "naturally" hand-in-hand. Compagnons were living heritage. Sometimes this happened literally: Historical monuments, such as the Maison des musiciens italiens at Versailles where the castrati invited by the court were housed in the early-18th century, became compagnons' houses.

\section{The New Age of Compagnonnage Heritage: Toward a Dossier for UNESCO}

Space and place grew in importance to perform compagnons' relationship to the past. The other dimensions (time, identity) did not disappear, but they were increasingly subjected to the rules of place and submitted to a new type of materialization.

In this regard, the "compagnon thought" met the UNESCO ideology in the implementation of the 2003 Convention. Indeed, making visible intangible heritage required materialization by pointing out the major objects, the spaces in which it takes place, and people and actions that embody it. The museums of compagnonnage also worked toward an account for journeymen's "invisible culture." How could one show the production of attachment that occurs within a secret initiation rite? How could one highlight the importance of the idea of transmitting knowledge in 
the group? How, in short, could one communicate the compagnons' esprit de corps? These questions and the solutions proposed reflect a new age of heritage which I call heritagity; it is a phase that overlaps and fuses with the new interpretation of heritage that UNESCO proposed in the ICH Convention.

\subsection{Heritagity, or "living well"}

This "spatial turn" in heritage politics, with its effort to materialize the immaterial, indicates the beginning of the heritagity regime. The two previous regimes (heritage, heritagization) were marked by a concern for dissociation between the heritage subject and heritage itself. Heritagity rather advocates the idea of a resubjectivation concerned with the who of heritage, not just with the what. Among compagnons, this deleting of the gap is marked by living in historical monuments. Heritage, that is life; and there is the belief that "living well" in the Aristotelian sense is living with heritagity, that is to say, a life whose relationship to the past is intimate, emotional, and not just, as in previous regimes, intellectual, calculated, and at a distance. This emotional approach favors "place" because this allows for the establishment of a real proximity to the diversity of past expressions. Among compagnons, this takes on various forms.

One of them is the project born of a Centre de la Mémoire (Center of Memory). This institution, based in Angers and opened in December 2009, combines several histories and several memories: It is an exhibition of journeymen objects, a resource centre on the history of compagnonnage, and also the place where all the archives of the Association Ouvrière, a compagnon group, are kept. All of this refers to the past and gives substance to this serious joke by the historian Henry Rousso (2003: 375) who imagined the creation of a "Ministry of the Past" or of a "State Secretary for Lost Time" after he had assessed the outbreak of new heritage and heritage policies.

The Centre de la Mémoire was conceived in honor of a former baker compagnon, René Edeline (1914-2005), who had assembled a collection of over 1,000 objects, which forms the basis of the new institution. Heritage value thus goes through a few exceptional men who relay and implement it; "heroes" who represent something better than rules, the duty to transmit and to embody "living well" in compagnonnage. To give to this heritage the space it claimed, it had to get out of the small private collection and "break with the show still reserved for the happy few, in 187 Grenelle Street, Paris." These were the words of Michel Guisembert, president of the Association Owrriere, in his inauguration speech, and these words echo the idea of a "heritage for all" which fuels so many UNESCO's speeches.

Indeed, in compagnon speech, future generations are the first recipients of these materializations and this new places of heritage. "Fair heritage" is a key notion and solidarity in heritage is, first of all, intergenerational solidarity. This requirement for a new relationship between the generations explains the "madness of conservation:" We must keep everything. Previous heritage regimes, focusing on time and 
identity, were built on "distance" (to the masterpieces, on the one hand, and between ancient and present journeymen, on the other hand) and this distance helped to choose them. Now that the gap between past and present is closing, there is an end to selecting from the past. If heritage and life converge, how can one select something to be heritage?

This new heritage awareness is also the seed-bed for a new and strange idea: One might call it a covert heritage, an ignored heritage just waiting for the appropriate circumstances to be revealed. All manifestations from the past are kept, as one does not know what the heritage of future people will be. Michel Guisembert told me that one has to develop "good habits" of conservation: On the one hand, one should not assume that what is heritage in the present will be the heritage of future generations; on the other hand, one has to live in the awareness that "every day that passes is a historic day." What better way is there to describe the idea of a living heritage?

\subsection{Toward UNESCO}

France ratified the 2003 ICH Convention in 2006. This provided the context for this covert heritage - the idea that journeymen's lives are heritage - to come to fruition. To many journeymen, the concept of Intangible Cultural Heritage provided an opportunity to openly show this life-heritage. In 2007, the numerically largest compagnon group (over 10,000 individuals), the Association Ouvrière des Compagnons du Devoir du Tour de France (AOCDTF), proposed itself spontaneously as eligible for ICH. The demand, addressed to the Ministry of Culture and UNESCO, did not receive a response. Without knowing the precise contents of the first dossier submitted, it is difficult to explain the failure of the first meeting between compagnonnage and the Ministry of Culture. In France, compagnonnage was among the first to offer an open application for the Representative List of ICH. While it was largely in line with the spirit of the Convention, it disregarded the way the French State had seized on it. France was implementing a top-down logic in line with its established, national logic of heritage, with a policy drawn up by a group of experts and representatives of the State (curators, inspectors, and so on) responsible for selecting heritage and safeguarding it by including elements on national lists. ${ }^{4}$

The initiative thus had to come from the top. The publication of my own book on the anthropology of compagnonnage (Adell 2008) opened the door for such an initiative. It was partly funded by the Ministry of Culture within the collection "Ethnologie de la France." To my own surprise, the work hit a nerve almost from its publication in April 2008, and the compagnons as well as the Ministry took possession of it, each in their own way. The compagnons found in it the scholarly language to express their "sense of identity and continuity," which is a fundamental

\footnotetext{
${ }^{4}$ For a detailed and recent description of these processes of heritage implementation in France, see Heinich (2009); cf. also Bortolotto, Fournier and Tornatore, all in this volume.
} 
criterion of the 2003 Convention for any ICH element. The compagnons suspected that their unsolicited, spontaneous application had been ignored because they had not mastered the scholarly language. In this book, they recognized their much needed interpreter. For the Ministry of Culture, the book became a "measure for safeguarding," offering scientific essays relating such measures according to the 2003 ICH Convention.

This double interpretation of the book by the "top" and the "bottom" resulted in very concrete initiatives that allowed for the preparation of an application dossier for the compagnonnage application for the ICH Representative List. A few weeks after the book's publication, I was contacted by Christian Hottin, head of the Ministry service in charge of ICH for France at the Mission Ethnologie, informing me of the Ministry's intent to support a compagnonnage application for the ICH lists. To do this, one needed not only someone who knew the world of compagnonnage, but someone who was simultaneously able to make the link between the Mission Ethnologie, the administrative requirements of a dossier for UNESCO and the "field." I seemed to be the best person. So the task fell to me to get in contact with representatives of different compagnon communities to suggest the idea of such an application. At the time, I did not know that the journeymen's association had attempted such an application the previous year. A few days after this administrative contact, some compagnons joined me after the publication of my Hommes de Devoir, expecting me to attend a conference they had organized in Paris on the issue of learning and skills' transmission. At this conference, I was informed of the open application that had been made the previous year. I was thus contacted separately by "both sides."

\section{From Writing to Registration: The Story of a French Dossier for ICH}

\subsection{Polyphony}

Aside from a lack of mastery of the appropriate language, the failure of the first dossier submission was also attributed to the lack of dialogue between the different compagnon communities. Alongside the AOCDTF, there are several other groups of compagnons. The two main ones are the Fédération Compagnonnique des Métiers du Bâtiment (FCMB, nearly 5,000 members) and the Union Compagnonnique des Devoirs Unis (UCDDU, 2,000 members). Occupying most of the French compagnon landscape both in terms of geographical location and institutions (such as agreements with the state to provide training, award degrees, and so on), it was necessary for these communities to be involved in the application project. In addition, one of the compagnonnage features is the fact that "being companion" is subject to multiple interpretations. That creates tensions which repeatedly lead some compagnons to part from a group and join another or, more often, form a new one. Thus, in 2000, the 
stonecutters of the AOCDTF decided to form a separate group, called the Alternative. In 2007, saddlers, tapestry makers, fine-leather-workers, shoemakers, and cobblers seceded to form an independent community. Finally, in 2011, bakers and pastry cooks of the AOCDTF undertook to separate from the other trades and take the title of Fédération des compagnons boulangers et pattissiers restés fidèles an Devoir. The ICH dossier had to be able to manifest the unity of the community while preserving the diversity of the compagnonnage.

It was important that the dossier would not become an instrument that would allow any subgroup to claim more "true" compagnonnage than another. Rather, the dossier had to highlight the diversity of involvement in its creation. The required paragraph "identification and definition of the element" opened as follows: "The compagnonnage movement, mainly represented by the three communities, the AOCDTF, FCMB and UCDDU, constitutes a unique way of transmitting trade knowledge and know-how, which is both rich in traditions and open to technical developments, and has its roots in the crafts brotherhoods of 13th-century Europe" (emphasis added). This allowed for the inclusion of different compagnonnage spirits and was sufficiently discreet for none of the three groups to see a downside. A number of smaller and greater concerns among the groups demonstrate that the act of registration on the ICH Representative List was not trivial to them; one group expressed to me the concern that they might have to claim the UNESCO label on their own. Being on the list was to them, at the cultural level, the "placeto-be" in the early-21st century.

After discussing the group boundaries for the registration process, the central issue of the dossier had yet to be identified. The first meetings in the fall of 2008 mainly concentrated on this point. Which practice(s), value(s), use(s), and custom(s) should the dossier focus on so that most of the compagnons' distinctive characteristics would appear? A first meeting specifically devoted to this issue was held between representatives of the Mission Ethnologie and myself. We had concluded that the Tour de France, the distinctive tradition to learn crafts and customs, could serve as a means to "crystallize" compagnon traditions; it also showed the materialization of the immaterial. I decided to present this approach at the first "ICH Meeting" about compagnonnage without members of the Mission Ethnologie where I met for the first time all the representatives of the different compagnon groups. As a sign of their interest in the matter, they had traveled to Toulouse, where I teach anthropology. We met in the lodge of the FCMB. The moment this November 2008 meeting began, I realized that the representatives present were not just there to understand the requirements of the application dossier, but to evaluate me as the person designated to carry the responsibility of the dossier. To my surprise, the first part of the meeting was thus devoted to a debate about passages from my study Hommes de Devoir, about which the compagnons showed reservations, as they felt themselves to be incorrectly described. I had to provide explanations, clarify my intentions, and to open myself to their point of view. Writing an ICH application is thus clearly not a job like any other. On the one hand, it is not paid (alt- 
hough this was suggested to me by some compagnons). On the other hand, aside from the skills it requires, one needs to establish a relationship of both trust and "fair distance" as one becomes simultaneously a public writer, historian, ethnologist, and representative of the research community and of all cultural institutions involved in the process (not only the Ministry, but also UNESCO, because the guidelines for the completion of the dossier were transmitted only by my voice).

My answers seemed to be satisfactory, likely also due to the multiple positions that were attributed to me (writer, representative of cultural national and international institutions, and so on). Thus, after having tested me well beyond what is reasonably my sphere of competence, the compagnons charged me with writing the file, but without entering into a discussion with me on the approach to take. The Tour de France perspective was heard, evaluated and rejected. While I had succeeded in introducing myself as competent and trustworthy, the dossier strategy planned with the Mission Ethnologie failed, at least partially. By focussing on the Tour de France, we had relied on an interpretation of the ICH Convention that would then also allow one to select elements for registration - as we had understood there to be a need to present objects easy to define, localizable and describable by some narratives. I was puzzled at the journeymen's rejection of this approach: Why would they first recognize my skills, including realms I was not competent in, but then not follow recommendations regarding the interpretation of the Convention? Recommendations which officials of the Mission Ethnologie (whose voice I also represented) were certainly competent to express, whereas most compagnons were not, at least from the Mission's point of view. The journeymen acknowledged that their self-started application in the previous year had failed because they had not fully read the ICH Convention. Nevertheless, they had grasped the most important concern: The success of the dossier was primarily based on a deep and broad commitment of the community membership. The dossier had to reflect a desire for representation, which an application focused on Tour de France did not satisfy. Instead, the compagnons wanted the whole institution of compagnonnage to be at the application's core. The Tour de France is an important part of the organization, but not the only one. There is a compagnon life after and emerging from the Tour de France: The making of a compagnon identity and its maintenance through life - this is what the compagnons wanted to highlight. The project was beautiful and aroused the enthusiasm of compagnons. However, it was also complex, and made the task of the newly appointed writer difficult, not least because the formulations of the compagnons' themselves was quite far from the guidelines provided by UNESCO for applications to the Representative List.

The perspective chosen to guide the writing of the dossier focused now on the notion of transmission that crossed all compagnon practices from the Tour de France to initiation rites. The compagnons also put this notion at the core of most of their legends, autobiographies, and songs. The title of the dossier submitted reflects this dimension: "Compagnonnage, network for on-the-job transmission of knowledge and identities." To strengthen the dossier, research was commissioned to formulate the 
role of the act of transmission into the heritage concept (Adell and Pourcher 2011). Two meetings were held in 2009 with the Mission Ethnologie at the Ministry of Culture to discuss the first version of the dossier that had been submitted in February 2009. In the process, I discovered that the contents of the dossier were at my discretion: Very little had been changed of my original wording. The main part of these meetings focused on how the "community consent" could be expressed beyond the participation of some representatives at the meetings. Thus, in addition to the representatives' speeches presented in writing and through videos, questionnaires were sent to all community members asking for their views on $\mathrm{ICH}$ and on the current dossier. Several hundred responses were collected, indicating a significant mobilization that the Mission Ethnologie and I thought would be crucial to the success of the application.

\subsection{Being Registered on the Representative List}

In November 2010, at the fifth meeting of the Intergovernmental Committee for the Safeguarding of ICH held in Nairobi, the "Compagnonnage, network for on-thejob transmission of knowledge and identities," file 0441, was registered on the ICH Representative List. ${ }^{5}$ The representatives of the Ministry informed me immediately since I was officially the "contact person" for the case. As soon as they were told, the compagnons broadcasted the information widely within their groups and their professional network.

Among the key elements for this success, the contribution of the general context, including the national framework, and the specific elements in the dossier of compagnonnage need to be distinguished. The very strong and systematic attention that has been paid to folk knowledge and skills in France since the early-1980s assisted in the constitution of the patrimoine ethnologique. Compagnonnage fits perfectly into the logic established by the Ministry of Culture. Moreover, the strength of the idea of community, supported by a special, shared idiom, local roots and specific customs, increases a group's visibility and self-awareness in fields such as trades, as well as village life. This facilitates fulfilling UNESCO's requirement for "community consent."

Similarly, the interest for heritage place developed by the ICH Convention and the crystallization effect it provides to make gestures, values and ideas visible, could, in France, be based on heritage-making drafts that focused on the concept of place. Thus, the project of Lieux de mémoire (Places of memory), a three-volume book initiated in early-1980 by the historian Pierre Nora (1997a), resulted in the 1990 s in the return of historical memory, and reduced place improperly to its topographic dimension, which has strengthened, according to P. Nora (1997b), the concern with celebration.

\footnotetext{
${ }^{5}$ The dossier is available online: http://www.unesco.org/culture/ich/index.php?lg=fr\&pg=00011\&RL=00441.
} 
The experience of Lieux de mémoire has also contributed to the reading and implementation of the 2003 Convention. It allowed for the development of the idea of moving places, of non-rooted places; authenticity has ceased to be the fundamental criterion for the heritage value of these places; rather, it is the sincerity of those who recognize themselves in such places that permit the intense appreciation of heritage. This sincerity is expressed in actions, claims and feelings of belonging. ${ }^{6} \mathrm{It}$ is these very emotional manifestations that individuals, groups or communities are encouraged to demonstrate according to the ICH Convention.

The success of compagnonnage as heritage in France can be linked to its ability to produce a sincere place by the practice of the Tour de France, the experience of mobility, and the need to do and undo steps according to job opportunities. Compagnon places, which may be displaced, abandoned and invented, cannot abide in the luxury of authenticity, and must find other ways to indicate the compagnon identity.

There are also the peculiarities of the compagnon organization that have made the dossier particularly attractive. Compagnonnage has been a priority of French cultural policy for ICH. Indeed, when Mission Ethnologie had to reduce, on UNESCO's request, the number of dossiers to be submitted to the Representative List, the application of the compagnonnage was not even discussed. From the Ministry's point of view, this dossier embodied well the new category of intangible heritage while ensuring continuity with the old categories of French heritage: From the age of historical monuments to the age of patrimoine ethnologique, compagnonnage was involved at all levels. The application emphasizes this aspect, reserving a paragraph in item 2 "Contribution to ensuring visibility and awareness, and to encouraging dialogue" to show that compagnonnage is a "structure representative of ICH." Moreover, in an assessment made by the Ministry about the first French applications on the ICH lists, the compagnonnage dossier is among those quoted in full as an example (Hottin and Grenet 2011: 292-214).

The success did not happen without moments of tension, which had sometimes appeared more clearly at three levels: 1) within compagnonnage itself; 2) between the national logic (compagnonnage and Ministry together) and the UNESCO logic; and 3) between compagnonnage and the State. Firstly, within compagnonnage, the compagnon communities, the differences among whom had been smoothed over in the context of the application, immediately reactivated these differences at the time of registration. The temptation to find one's own group more closely associated with the UNESCO label than the others was great. Thus, suspicions about any appropriation of the dossier arose, and a climate of reciprocal mistrust has developed between the communities, though there does not seem to be any bitterness.

UNESCO was concerned that the diverse ways of living and performing compagnonnage were, nonetheless, adhering to national law. During the pre-application review by the Secretariat of the Convention for the Safeguarding of Intangible

${ }^{6}$ The couple authenticity-sincerity, though diverted here, refers to the essential works of L. Trilling (1972). 
Cultural Heritage, the Secretariat wished to draw the attention of the dossier's writers to:

the definition of intangible cultural heritage in the Convention which states that only the intangible cultural heritage will be taken into consideration which is in accordance with the international system relating to human rights. In this sense, I [Cecile Duvelle, in charge of the Secretariat; N.A.] invite you to make clear that compagnonnage is in accordance with the various legal measures that prohibit discrimination in employment and training, including the Convention concerning Discrimination in respect of Employment and Occupation, adopted by the General Conference of the International Labour Organisation in 1958 (Convention 111). From my understanding, among the three networks of compagnonnage, there is only one that welcomes girls and this since 2000. Therefore, it seems to me important to demonstrate that compagnonnage is in accordance with the measures and the principles relating to human rights. (Letter of November 30, 2009)

The Ministry of Culture, the anthropologist and the compagnons themselves were surprised that the traditional elements, having an historical depth, should be in line with current legal issues. Such limits would be extremely problematic for several western and even more non-western traditions. It turned out that even though only AOCDTF admitted girls in the compagnonnage course, the other groups had begun for several years a discussion of this use which was apparently sufficient to the Secretariat to see "human rights" as respected.

After the official registration on the Representative List, a final focus of tensions surfaced between compagnonnage and the State. While compagnons were expecting a national celebration to mark their "promotion" to the list, nothing happened. "The gastronomic meal of the French" (registered on the ICH List at the same time $^{7}$ ) enjoyed the limelight and state representatives spoke amply about it; only the local or craft-specialized papers relayed the compagnonnage registration. Some journeymen now struggle with regard to how the $\mathrm{ICH}$ registration may be used for advertising, on the one hand, and on the legal field, on the other. How may one use the UNESCO and ICH Convention logos? Will it be possible to use the UNESCO registration and dossier as means to confine the name compagnons to those who meet the dossier's definition of compagnonnage? The ICH Convention can be read on many levels, but it would appear that the interpretation and appropriation of the $\mathrm{ICH}$ title by the communities concerned is the most important. It shows the actual reception on the part of groups or individuals who project onto the UNESCO listing their intentions and desires, that is to say, the affective part of a culture which is generally so difficult to grasp.

${ }^{7}$ Cf. The contribution by Tornatore in this volume. 


\section{$5 \quad$ References}

Adell, Nicolas (2008): Des hommes de Devoir. Les compagnons du Tour de France (XVIIIe - XXe siècle). Paris: Editions de la Maison des sciences de l'Homme.

- (2011): Transmettre, verbe intransitif. La marche vers la patrimonialité. In Transmettre: quel(s) patrimoine(s)? Autour du patrimoine culturel immatériel. Nicolas Adell and Yves Pourcher, eds. Pp. 39-56. Paris: Michel Houdiard. Adell, Nicolas, and Yves Pourcher, eds. (2011): Transmettre: quel(s) patrimoine(s)? Autour du patrimoine culturel immatériel. Paris: Michel Houdiard.

Bastard, Laurent (2007): Concours et défis chez les compagnons d'autrefois. La serrure de Marseille. Fragments d'histoire du compagnonnage 9: 7-73.

- (2008): Chefs-d'œuvre de compagnons. Sayat: De Borée.

Bohnenkamp, Anne, and Frank Möbus (1989): Mit Gunst und Verlaub!

Wandernde Handwerker: Tradition und Alternative. Göttingen: Wallstein Verlag.

Bromberger, Christian (2009): L'ethnologie de la France, du Front populaire à la Libération: entre continuités et ruptures. In Du folklore à l'ethnologie. Jacqueline Christophe, Dominique-Marie Boëll, and Régis Meyran, eds. Pp. 110. Paris: Editions de la Maison des sciences de l'Homme.

Gorgus, Nina (2003): Le magicien des vitrines. Paris: Editions de la Maison des sciences de l'Homme.

Heinich, Nathalie (2009): La fabrique du patrimoine. De la cathédrale à la petite cuillère. Paris: Editions de la Maison des sciences de l'Homme.

Hobsbawm, Eric J. (1965): Laboring Men: Studies in the History of Labor. London: Weidenfeld and Nicolson.

Hottin, Christian, Sylvie Grenet et al. (2011): Le Patrimoine culturel immatériel. Premières expériences en France. Paris; Arles: Maison des cultures du monde; Actes Sud.

Martin Saint-Léon, Etienne (1977 [1901]): Le compagnonnage. Son histoire, ses coutumes, ses règlements et ses rites. Paris: Librairie du Compagnonnage.

Nora, Pierre, ed. (1997a [1984-1992]): Les Lieux de mémoire, vol. 3. Paris: Gallimard; Quarto.

- (1997b [1992]): L'ère de la commemoration. In Les Lieux de mémoire, vol. 3. Pierre Nora, ed. Pp. 4687-4719. Paris: Gallimard; Quarto.

Poulot, Dominique (2001): La morale du musée: 1789-1830. Romantisme 31(112): 23-30.

Riegl, Aloïs (1984 [1903]): Le culte moderne des monuments. Paris: Le Seuil.

Rousso, Henry (2003): Conclusion générale. In Le regard de l'Histoire.

L'émergence et l'évolution de la notion de patrimoine au cours du XXe siècle en France. Henry Rousso, ed. Pp. 365-376. Paris: Fayard; Editions du Patrimoine. 
Scarrocchia, Sandro (1995): Alois Riegl: teoria e prassi della conservazione dei monumenti. Antologia di scritti, discorsi, rapporti, 1898-1905, con una scelta di saggi critici. Bologna: Accademia Clementina-Clueb.

Tornatore, Jean-Louis (2010): L'esprit de patrimoine. Terrain 55: 106-127.

Trilling, Lionel (1972): Sincerity and Authenticity. Cambridge, MA: Harvard University Press.

Wadauer, Sigrid (2005): Die Tour der Gesellen. Mobilität und Biographie im Handwerk vom 18. bis zum 20. Jahrhundert. Frankfurt; New York: Campus Verlag. 



\title{
The Bureaucratic Texture of National Patrimonial Policies
}

\author{
Markus Tauschek
}

\section{Introduction}

Heritage is not only a "project of ideology" (Kuutma 2007: 178), but also a project of bureaucracies. The broad ethnographic literature on heritage production and heritage consumption documents the various dimensions of bureaucratic logics and constraints that influence, for example, the ways traditional culture, transformed into heritage, is used and managed (e.g. Hafstein 2007, Bortolotto 2008, Smith and Akagawa 2009). Discussing the results of patrimonial interventions, Dorothy Noyes underlined the bureaucratic power of heritage regimes that create tensions in the understanding of culture and that change the uses of traditions (Noyes 2006: 35f.). Heritage as an ideological process is "a regime in rapid expansion" (Hafstein 2007: 76). However, this expansion cannot only be explained by the plausibility of the different cultural values that are reified in concrete heritage practices: democracy, cultural diversity, human rights, et cetera. Rather this expansion, one could assume, also depends on the specific institutional nature of heritage regimes that are organized according to western bureaucratic logics (cf. Bendix 2009: 184). 
"Once created, bureaucracies notoriously expand" (Noyes 2006: 35; cf. Herzfeld 1993). ${ }^{1}$ Consequently, bureaucratic institutions permanently legitimize their existence and their search for new fields of action (cf. Douglas 1986). In addition, expansion is accompanied by the need for money and requires legitimation: Bureaucratic budgets expand accordingly with the bureaucratic institutions themselves. The cultural biography of UNESCO's various heritage programs and conventions illustrate this claim - just within the realm of tangible heritage there has been an expansion of types of sites and attendant bureaucratic measures (both on the international level and the steps necessary and different for each ratifying nationstate), from cathedrals and castles to industrial landscapes, underwater heritage, memory of the world, digital heritage, and so forth. National patrimonial traditions for the protection of historical monuments show the same expanding character of bureaucratic institutions. These institutions, too, are in search of new patrimonial fields that legitimize their institutional existence and that are often inspired by international interventions. The present essay contextualizes the more recent paradigm of Intangible Cultural Heritage by focusing on an older heritage regime: The protection of historical monuments on the national or even state level. I will ask which actors shape national policies for the protection of tangible heritage, and in which bureaucratic and political contexts they are moving. Such a perspective is especially important as many member states that have ratified the 2003 Convention for the Safeguarding of Intangible Cultural Heritage combine this new category with former legislation concerning monuments or archives. As a result, national heritage policies can be seen as assemblages of different patrimonial paradigms, as creative contact zones between different heritage logics that compete against one another or that are combined in synergetic ways.

UNESCO's 2003 Convention for the Safeguarding of Intangible Cultural Heritage led to enormous anthropological interest in this new category (cf. Kirshenblatt-Gimblett 2004, Hafstein 2007, Hemme; Tauschek; Bendix 2007, Bortolotto 2008, Smith and Akagawa 2009). The ethnographic literature discussing questions concerning the protection of material heritage and the birth of a politics of tangible and natural heritage is comparatively sparse; but there is a plenitude of researchers focusing on the (institutional) emergence of UNESCO's intangible heritage concept that resulted from international negotiation (e.g. Schmitt 2009). In his research of UNESCO's intangible heritage regime, Valdimar Hafstein also focused on the institutional agency and bureaucratic power in the process of installing a new concept (Hafstein 2007). This new key concept within the basket of global heritage conventions is, however, pre-structured by different patrimonial forerunners (cf. Tauschek 2010a: 89ff., Hemme 2007). If we want to understand the complex nature of today's heritage interventions and the bureaucratic structures connected with them, we have to take into account that the cultural life of heritage

\footnotetext{
${ }^{1}$ It was in 1957 that sociologist and historian Cyril Northcote Parkinson published his reflections on the expanding nature of western bureaucracies. Bureaucratic structures grew and grew and grew even if their workload did not grow in the same way or even if this workload was on the decrease.
} 
bureaucracies is shaped by national traditions devoted to the interpretation of history in general. One of these national traditions is the protection of historical monuments that also shaped the semantic field of heritage (cf. Swenson 2007).

One of the central characteristics of UNESCO's heritage operations is the fact that the member states choosing to ratify a given convention have to translate the internationally binding legal instruments into concrete national heritage policy. This transformation has different impacts: States have to define legal parameters and create responsible governmental authorities and bureaucratic institutions. UNESCO's program addressing natural and tangible heritage could build on existing legal frameworks at national levels; the implementation of the new concept of intangible heritage required that new frameworks be established. An analysis of this complex process delivers insights concerning national heritage policies, as well as the embedding of these national policies into the global heritage system. In this context, it is not only important to ask how an internationally negotiated concept such as intangible heritage is implemented on a national level, but also how this implementation is brought into being in bureaucratic ways. From a cultural anthropological perspective, it is methodologically relevant to pursue the path of this unfolding implementation through concrete actors, taking in account what range of agency is allotted to them. Heritage interventions on international as well as national levels are realized by different institutional actors, such as ministries on a higher level and museums, for example, on a lower level; individual actors outside of or within different institutional settings may, depending on the political context, contribute as well. Ethnographic research on heritage as a practice, policy and concept thus has to consider concrete actors and their options and paths of action. Who, for example, represents governmental authority in the context of national heritage policies? Who are individual or institutional actors that deal with heritage issues in the context of national bureaucracies? From which perspective do they argue? What is their professional background? How does their often quite personal understanding of heritage influence professional definitions? What are the bureaucratic and political contexts that shape these dimensions?

A first step into this direction is an understanding of patrimonial bureaucracies as cultural practices in their own right. In her reflections on the metacultural nature of Intangible Cultural Heritage, Barbara Kirshenblatt-Gimblett identified differences between bureaucratic heritage interventions and the traditional practices these interventions seek to protect (Kirshenblatt-Gimblett 2004: 55). Whereas traditional culture - or folklore - is dynamic, vibrant, creative, and, through its performative character, constantly remade, heritage bureaucracies can be circumscribed as persistent, slow or unidimensional. In the context of the circumscribed heritage regimes, these bureaucracies are situated in national or international legal and political frames of reference which may explain their persisting character. Hence, these frames - laws or lists concerning heritage - produce sustainable effects and realities that can only be reformed very slowly. In my case-study focusing on nominations in Northern Germany, I will argue that even within these persist- 
ing systems, conflict-laden negotiation processes unfold and show which concepts of cultural heritage are articulated within these conflicts.

\section{Competing Competences: the Protection of Historical Monuments}

If heritage is always dissonant (cf. Tunbridge and Ashworth 1996), different actors that produce and use heritage in the context of the state may also act in a dissonant way. Even if the result of state interventions - materialized in texts, laws and so forth - can be described as an "authorized heritage discourse" (Smith 2006: 29), a more detailed look at the various actors shaping patrimonial fields in the context of the state is helpful. Within an authorized heritage discourse, actors can struggle for different interpretations of heritage. These interpretations emerge on different levels as ethnologist Beate Binder showed in her detailed analysis of Berlin's "Schlossplatz" debate (Binder 2009). Here, it was a political, national decision to demolish the Palast der Republik as an important monument of the German Democratic Republic in order to reconstruct the baroque castle in Berlin's city center. As Binder demonstrated, the negotiation process was about the nature and look of Germany's capital, but it was also about the relationship between the two German states during the Cold War, about collective memory and, finally, about divergent representations of history. Different actors were involved in the discussions about the reconstruction of the castle: politicians, members of local initiatives, curators of monuments, scientists of different disciplines, and so forth. All these actors produced urban textures of meanings. Binder understands the production of heritage as a cultural performance that reproduces significance and, at the same time, has an enormously transformative power. In Binder's case-study, the negotiation process was shaped both by political actors and actors of the civil society.

This was also the case, when in 2008, parts of Kiel's university campus built in the postwar period were declared a historical monument of outstanding value. ${ }^{2}$ This incident caused a short but intense conflict among the different actors involved. In Germany, the protection of historical monuments is organized according to the federal structure of the state: The Bundesländer (states) are responsible for cultural policy. Therefore, a wide field of bureaucratic institutions and legal regulations exist. In Schleswig-Holstein, the state where Kiel is located, the authorities responsible for the protection of historical monuments are the Federal Historic Preservation Office and, at a lower level, Regional Preservation Offices: Each holds different competences. ${ }^{3}$ The ministry responsible for these executive authori-

\footnotetext{
${ }^{2}$ Kiel is the capital of the Bundesland Schleswig-Holstein in the north of Germany on the shore of the Baltic Sea. Almost $80 \%$ of the historic city was destroyed during World War II. Today, Kiel has nearly 240,000 inhabitants.

${ }^{3}$ The different competences are defined in operational guidelines that complete Schleswig-Holstein's preservation act: Ministerium für Bildung, Wissenschaft, Forschung und Kultur 2002.
} 
ties is the federal Ministry of Science, Economy and Transport - which provides an important frame within which cultural policy is set on the federal level. The ministry is supervised by the prime minister of the state. In Schleswig-Holstein, the protection of historical monuments is organized as a constitutive system, which means that the law defines the qualities of historical monuments and the executive institutions concerned have to declare these monuments officially in an administrative act. ${ }^{4}$

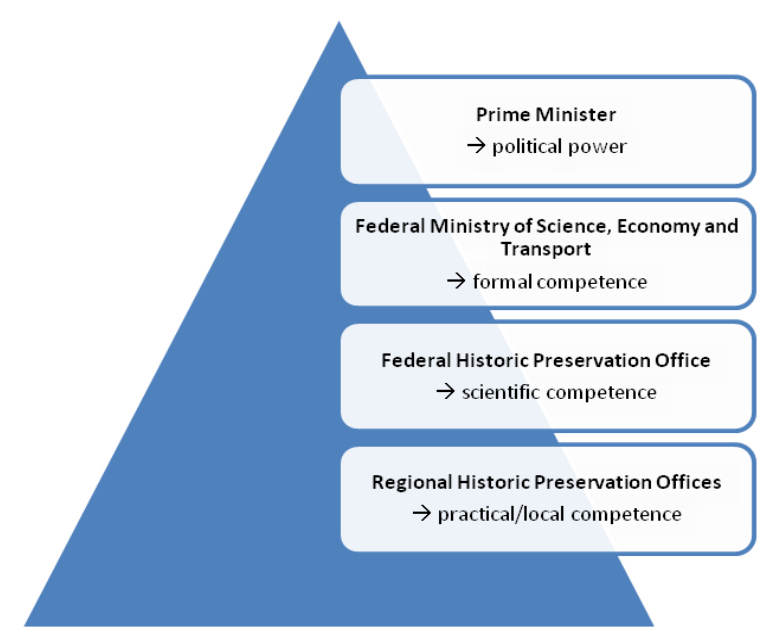

Figure 1: Bureaucratic hierarchies in Schleswig-Holstein's heritage system (Tauschek 2012). Each institution is part of the executive power of the state.

The Federal Historic Preservation Office is the main bureaucratic institution responsible for the identification of future historical monuments as well as for the "scientific" documentation. ${ }^{5}$ In the case of Kiel's university campus, it was an art historian of this office who pushed the idea of putting the buildings on the list of valuable monuments. She defined the patrimonial space using art historical expertise for her arguments. Her patrimonial intervention was motivated not simply due to her professional background as an employee of the Federal Historic Preservation Office; postwar university architecture had been her dissertation topic and

\footnotetext{
${ }^{4}$ In contrast to this bureaucratic system, a declarative system exists in which the law also defines patrimonial qualities of a building, for example, and the executive institution only informs owners of historical monuments. Additionally, there are also mixed forms of both systems.

${ }^{5} \mathrm{I}$ put the word scientific in quotes as most of the employees of the Federal Historic Preservation Office have a scientific training in disciplines such as art history, archeology or even European ethnology. From this disciplinary background, they interpret historical materiality often in quite reflexive ways. However, their expertise is framed by legal prescriptions that - to a certain degree - contradict actual scientific approaches to heritage as they are, for example, based on the idea that cultural values simply exist as such.
} 
thus an important aspect of her scholarly biography, adding an element of personal motivation in casting the Kiel campus as an important monument.

A conflict arose surrounding the legal protection of the campus within which one can identify three dimensions characteristic for the making of cultural heritage more generally.

\subsection{Negotiations about Esthetic Values}

Arguments articulated in the debate about the cultural values of the campus focused on its symbolic nature. The question was whether the campus buildings were outstanding examples of esthetic, architectural qualities that symbolize a certain period in Germany's university architecture - a period that bears testimony to the introduction of democratic structures in academia. The debating parties sought to represent "factual arguments" and the actors involved tried to objectify their interpretation of the future monument. Arguments that were elaborated in that context were based on scholarly knowledge focusing on art history or on the history of architecture. An important discursive strategy was legitimization of interpretations of the buildings concerned through a comparative perspective. The art historian compared the buildings - which is a typical approach in art history - with other universities built after World War II in order to underline their outstanding quality. Different opponents used comparisons to shape their argumentation, stating that the university buildings were simply functional mass products that could be found a hundred or a thousand times in similar form all over Germany.

\subsection{Competing Authorities}

The nomination process delivered grounds for social conflict: The university's chancellor and president protested, as they felt ownership of the campus: They both responded with anger as the art historian responsible, representing the Federal Historic Preservation Office, visited the campus without having informed the university's administration beforehand.

One could argue that this dimension of the conflict was based on different notions of property: The representatives of the Federal Historic Preservation Office interpreted the campus as a public space accessible to everybody. That is why they visited the buildings in order to prepare a nomination dossier. The university representatives held a different notion of "their" university and expected to be asked whether the buildings could be examined or not. These two concepts clashed when the university administration was informed that the representatives of the Federal Historic Preservation Office would visit different buildings. All the actors involved reacted quite emotionally instead of discussing the question whether the university was a public space or not. 


\subsection{Competing Imaginations}

Different concepts of preservation, finally, brought the crisis to a climax. Different actors held equally different images in their minds for what constitutes preservation practices. The university's administration was afraid that the campus, as a consequence of the transformation into a monument, would be fossilized, that it would become a museum and that this would prevent future developments of the university (cf. Tauschek 2010b). These paradigms of conservation practices were not based on concrete experiences, but rather presumed uncompromising preservation instructions. The university's chancellor, especially, expected that the Federal Historic Preservation Office would embark on realizing restoration issues in a quite radical way, for example, concerning the usage of specific building material. However, the monument conservators involved underlined that compromises are a daily occurrence in their conservation practice and that even legal instructions had to be interpreted case by case.

The amalgamation of these three dimensions formed the basis of another important aspect of the conflict: Activated by the university's president, the Mayor of Kiel wrote a firm letter to the Prime Minister of Schleswig-Holstein as the highest political authority in order to cancel any heritage intervention at the university campus. The prime minister's reaction is not documented in any of the records available but, as a direct consequence of this letter, a state secretary of the federal Ministry of Science, Economy and Transport protested against the protection of the campus. He argued with both legal and quite personal arguments that went as far as attacking the art historian responsible whose interest, in his perception, had lead to a choice overreaching her power of office. ${ }^{6}$

All three actors in this conflict - the prime minister, the state secretary and the art historian - represent the executive power of the state: That is, all three enact the same bureaucratic, institutional logic even if their agency is quite different. Thus, the results of the negotiation processes in the context of heritage regimes are all but coherent; rather they result from different scopes of action and different interpretations. That also means that national institutions of the state are heterogeneous formations. In the case of Kiel's university campus, the actors mentioned argued and performed within the same bureaucratic system which constitutes a frame and structures and organizes bureaucratic, formal interventions (e.g. the formal declaration of a building as a historic monument) and the symbolic function of these interventions (e.g. codification in preservation acts). At the same time, all the actors in this system compete relying on their competences and authority, causing the multivocal conflict described.

This conflict can be further explained by drawing on the differentiation of the state's executive power discussed by social philosopher Johannes Heinrichs (2003). Heinrichs differentiated two forms of executive power, both depending on the

${ }^{6}$ The conflict is documented in the Historic Preservation Office's archive; register no. 16080. 
relationship between authorized actors and the law. The first will execute laws in a formal bureaucratic - one could also say objective - way. The interventions of the Historic Protection Offices follow this path in transforming legal provisions into concrete conservation practices. The second variant of executive power draws on a wider scope of interpretation and acts more subjectively: This is the case with the ministry responsible whose interventions are directly influenced by the actual political will. The ministry's interventions are framed by scholarly or factual arguments only in a minor way, as the ministry needs to enact a particular political agenda. Consequently, heritage decisions that are influenced by the ministry are dependent on the given political landscape, which may change more rapidly (in particular after elections), whereas the executive institutions are charged with transforming heritage policy in a more enduring fashion.

The Kiel university conflict led to a legislative discussion within the federal parliament - as a governing body - whether the legislation concerning the protection of historical monuments should be reworked. Buildings of the postwar period, so ran the proposition, should only be protected if the federal Ministry of Science, Economy and Transport agreed. Before, it had been the subordinated Federal Historic Preservation Office that decided which building was to be declared an important monument, legitimizing its decisions with the federal Preservation Act. The proposed shift in the definition of cultural heritage implies a shift in competence from the Federal Historic Preservation Office to a more politically determined executive branch in the case of postwar buildings. One must assume that in this new context, different types of arguments will be articulated, as the decisionmakers depend to a greater degree on decisions of political actors. Scholarly arguments may recede as actors from outside institutions devoted to preservation shape the discourse. Earlier decisions, of course, had also been achieved within specific political contexts; the new legislation simply codifies and legitimizes new governmental interests. ${ }^{7}$

This small episode illustrates that different representatives of the state can hold different notions of cultural heritage, depending on various criteria. The Kiel campus further shows the social conflict potential inherent in heritage production: Individual social actors may represent a given institution, but they may also fight over individual competences. The conflict between the art historian, on the one hand, and the state secretary, on the other hand, was not only based on factual arguments, but also carried a very strong personal dimension. Finally, two bureaucratic institutions claimed hegemony with regard to determining whether the cam-

\footnotetext{
${ }^{7} \mathrm{~A}$ further and still broader context within which the management of the heritage status of the Kiel campus is to be understood is the composition of the federal government at the particular juncture in time: The government consisted of a coalition of the conservative Christian Democrats and the Liberal Democratic Party. Their members sought to protect the interests of house owners. The change in the preservation act thus had intended consequences far beyond Kiel university's potential heritage status.
} 
pus was to be declared a historical monument or not. The making of heritage is thus a bureaucratic operation, but it is also a social process. ${ }^{8}$

\section{Legal Frames of a Federal Heritage Policy}

In my first example, actors that were part of the governmental executive power competed for predominance in the definition of cultural heritage. The case of Rantzau castle widens the focus by asking which powers of the state are involved in heritage production and heritage management in general. Rantzau castle is part of the same "heritage-scape" (Di Giovine 2009) as the Kiel campus; both are located in the north of Germany. ${ }^{9}$ The castle is a renaissance monument rebuilt in the 18th century. The structure was originally built as a manor house by an aristocratic family who experienced a period of prosperity in the 16th and 17th centuries. After World War II, the house served as a refugee camp and was transformed into a hotel in the 1960s. Gradually, the condition of the house worsened; it was sold in 2009, at which point the story about its patrimonial status began. As is so often the case, the conflict began with rumors.

In June 2010, the Federal Historic Preservation Office heard about dramatic reconstruction work in Rantzau castle for the first time. Representatives of this office tried to get access to the privately-owned building in order to see whether these rumors were based on fact. Even before the preservation office officially asked to gain access, the castle's owner took legal action in order to forbid the authority concerned from entering the building. The lawyer entrusted with the case based his argument on article 13 of the German Constitution, which guarantees the privacy of the home. The legal institution responsible in this case was the higher administrative court. In its judgment, the court argued that article 13 could not be applied as the building was in such poor condition that one could not live in it. At this level of the conflict, the court thus did not argue with the federal heritage preservation act, but rather employed the legal frame concerning questions of privacy and the accessibility of the home.

As a consequence of this judgment, employees of the Federal Historic Preservation Office could visit the castle during the summer of 2010 in order to see what had been done. A mountain of rubble in front of a window immediately announced what was to be expected inside: Ninety percent of the stucco walls and ceilings had been removed. Eventually, this incident stipulated reactions in another legal context; defined by the federal Preservation Act, questions of public interest

\footnotetext{
8 This is also one the main results from my research about the production of intangible heritage in Belgium (Tauschek 2010a). If one looks at the processes of the implementation of UNESCO's 2003 convention in the French-speaking part of Belgium, one can observe that single actors shaped a federal heritage policy. Their motivation was not only to protect popular culture, but also to strengthen their own political position - heritage policy as a kind of personal biographical resource.

9 Since 1982, Rantzau castle has been officially listed as an important historical monument of Schleswig-Holstein.
} 
were brought into play. If properties of public interest, protected under article 13, are destroyed or damaged, this is a punishable act under criminal law. Responsibility for judgment thus migrated to a criminal court of law (see Fig. 2).

\section{competing legal contexts}

German Constitution
art. 13: privacy of the home
higher administrative court
(access to the privately-owned
building)

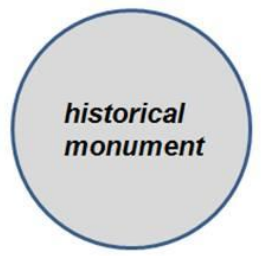

Federal Monuments Act

$\S 1$ "public interest"

$\S 13$ duty to give information

court of first instance (criminal law) damaging property which is harmful to the public

\section{responsible legal institutions}

Figure 2: Legal and judiciary frames (Tauschek 2012).

A core issue in this case thus concerns public and private property. If an owner of a historical monument destroys, for instance, protected historical decorations, this action can be punished, as the historical monument is of public interest even if the property is privately-owned. To understand this differentiation in the context of the protection of historical monuments, one has to turn to deeper historical dimensions: At the turn of the 20th century, German legislation concerning the protection of historical monuments, for the first time, also included private properties.

When a systematic interest in historically important buildings and objects started in the second half of the 18th century in different German principalities, the sovereigns concerned tended to underline and legitimize their claims to power by dint of historical monuments (cf. Schmidt 2008). During the 19th century, the preservation of historical monuments became an important issue for the nationstate. Firstly, laws that were intended for the preservation of monuments were elaborated after 1900 (1902 in Hessen-Darmstadt, Hamburg in 1920, SchleswigHolstein in 1958 as the first German state that ratified a preservation act after 1945). In 1880, the term "Denkmalpflege" - protection of historical monuments was used for the first time in the context of Prussian bureaucracy. In the same context - the emergence of the modern nation-state - concepts for the protection of monumental heritage had to be rethought with regard to the state's relation to privately-owned properties. When monuments served to demonstrate absolutist power in the 18th century, this relation was irrelevant as conservation interventions only concerned properties of secular or ecclesiastic sovereigns. Later, however, 
states employed cultural logics to legitimize their symbolic appropriation of private property by evoking public interest of esthetic and historic values, a realm which requires further research (cf. Holtorf 2007: 35).

Apart from the question of national legal regulations, in both cases - Kiel campus and Rantzau castle - concepts of property are legally defined but, nonetheless, required negotiation. In the case of Rantzau castle, it was the court that had to articulate and to assert the public interest.

The case of Rantzau castle is paradigmatic for heritage conflicts as it demonstrates clearly which actors may declare a patrimonial field within governmental structures of the nation-state. Here, there were two important actors who influenced the evaluation of the castle as cultural heritage: Courts, as institutions of judiciary power, and bureaucratic institutions - the Federal Historic Preservation Office - as executive authorities. Both argue within different frames of reference and both shape their arguments by different bureaucratic and legal logics even if the object of negotiation is the same. It is quite clear that the employees of the Federal Historic Preservation Office employ scientific reasoning drawn from disciplines such as archeology, (art) history or architecture. Yet, how do judges discuss patrimonial qualities that lead to a public interest in a building? How do these actors define historical values as circumscribed in preservation laws, but which elude strict legal definitions? How do they weigh public and private interests?

It would be a worthwhile enterprise to analyze the jurisdiction concerning historical monuments in a diachronic perspective. ${ }^{10}$ The field of tensions between public interest and private matters is in flux much as is the interpretation of monuments.

\section{Patrimonial Contact Zones: From Tangible to Intangible Heritage}

What is the relevance of these two cases in the context of the concept of intangible cultural heritage? In the second half of the 19th century, one of the founding fathers of the modern preservation movement in Germany, Alois Riegl, had already differentiated two forms of monuments: Monuments that were, in a thought through manner, built for future generations and made to transport a distinct message, perhaps with the aid of statuary, and monuments that only achieved status in the course of subsequent history. The value of these monuments - "Denkmalwert" - is based on a process of attributing values and meanings, ${ }^{11}$ a process which

\footnotetext{
10 An excellent example of the value of such source material is a judgment of the Saxonian higher administrative court dating from 2007. The court had to decide whether plastic windows in a 19th century building had to be removed and replaced by wooden windows. Beside the question if this change was economically reasonable, the court discussed whether the building was an outstanding representative monument or not. See the judgment in detail: Sächsisches Oberverwaltungsgericht 2007.

${ }^{11}$ Riegls most important theoretical and programmatic texts are reprinted in Huse (2006).
} 
is inherently intangible. That is one reason why Laurajane Smith argues that all heritage is intangible in a certain sense (Smith 2006: 54). Intangibility is one of the central characteristics of heritage and contributes to the flexible nature of the heritage concept: Its intangible attributes allow for continual re-interpretation.

The linkage between the two cases and the concept of intangible heritage also unfolds on an institutional and organizational level. State policy concerning the protection of intangible heritage is in many instances pre-structured by the legal structure of tangible heritage. As Germany has still not ratified the 2003 Convention for the Safeguarding of Intangible Heritage of Humanity, my last examples are based on Belgium's official national, or better federal, heritage policy. Germany and Belgium can be compared insofar as both nations are federal states.

In Belgium, the federal structure depends on three linguistic communities: the German-speaking, French-speaking and Flemish community; each community has its own cultural policy, as do the Bundesländer in Germany. In 2007, the Flemish community adopted a draft version of a law concerning cultural heritage - tangible as well as intangible - that was based on a former decree for the protection of popular culture dating from 1998 and a law concerning the organization and function of public archives. This reshaping of a national heritage policy was motivated by Belgium's ratification of UNESCO's Intangible Heritage Convention.

The French-speaking community had already adopted a decree concerning mobile cultural goods and Intangible Cultural Heritage in 2002.12 The two legal texts reflect the different contexts of their emergence and are situated within different legal frameworks - both have their own cultural biography. The reason why the French-speaking community had re-organized its heritage policy earlier than the Flemish community has to do with the role this community played within UNESCO's program "Masterpieces of the Oral and Intangible Heritage of Humanity." The French-speaking community identified this program as a means to get symbolic recognition within an international heritage landscape by supporting the new concept of intangible heritage. However, the transfer of the international discourse on intangible heritage into federal heritage policy shows that the political authorities used existing legal frameworks.

The result of this process is an innovative amalgam of different approaches codified in the context of federal legal systems. Ratifying an internationally negotiated convention, such as the one centered on the concept as intangible cultural heritage, on a national or federal level is a step requiring further analysis. One could argue that the circumscribed federal strategies to adopt the concept of intangible heritage created what one could call patrimonial contact zones. These contact zones are relevant in two different ways: Firstly, and quite practically, intangible heritage law is not a completely new legal field in the Flemish or the French-speaking commu-

\footnotetext{
12 Décret relatif aux biens culturels mobiliers et au patrimoine immatériel de la Communauté française. Centre de documentation administrative: Secrétariat général (2002).
} 
nity. Rather, both communities tried to combine the new concept with existing laws. ${ }^{13}$ This contact zone is thus related to the textual representations of heritage concepts. A second contact zone refers to the concrete realization of these legal representations: Concrete heritage interventions also need to be brought into life. For this issue, federal authorities in Belgium had to install - as was already the case in the protection of historical monuments - commissions and offices that create forms and lists in order to manage the intangible heritage (cf. Hafstein 2009).

The Belgian French community, for example, inspired by UNESCO's masterpieces program, decided to install a federal list of intangible heritage masterpieces. UNESCO's interpretation of outstanding value thus endured within this part of the Belgian context, even though it had been abandoned on the international level. The last Belgian federal nominations for that list date from 2011.14 The body responsible for the nomination of possible candidates is a federal scientific commission whose members are denominated by the federal minister of culture.

Earlier, I argued that heritage bureaucracies and relevant legal frames persist in their character. Within the federal scientific commission of the French-speaking community responsible for the proclamation of federal masterpieces, different members critically discussed the proof of outstanding value by arguing that on the international level too, the idea of masterpieces had been replaced by other criteria. However, the director of the heritage section responsible in the ministry of culture explained that the federal legislation could not easily be reworked. He pointed to the complexity of legislative processes that complicates the change of existing legislation. The bureaucratic and legal structures, one could argue, complicate the transfer of scientific negotiations on the nature of intangible heritage into concrete heritage interventions. ${ }^{15}$

The protection of tangible monuments in Western states has a long bureaucratic history. Bureaucratic experts have developed concrete practices and discursive strategies to transform objects into valuable monuments. The most relevant practice in that context is the listing of heritage, which is also a persisting practice (in the context of UNESCO's world heritage program, the cases of delisting heritage items are very rare). I also consider the instrument of "the list" as a patrimonial contact zone. It proved itself in the protection of historical monuments and was simply taken over for the task of safeguarding intangible heritage; this has been broadly discussed in the historical (Schuster 2002) and ethnographic literature (Hafstein 2009: 105). Listing heritage is an important bureaucratic and symbolic tool; it renders heritage manageable and translates it into bureaucratic organiza-

\footnotetext{
${ }^{13}$ Silke von Lewinski discusses the integration of new concepts into existing legal frameworks in the context of the protection of cultural property (Lewinski 2004). From the perspective of the law, she shows how existing intellectual property laws can be interpreted in a different way due to changes in the concept of property. Similar processes can be described in the realm of intangible heritage.

${ }^{14}$ Chefs d'œuvre du Patrimoine oral et immatériel de la Communauté française (Fédération Wallonie-Bruxelles 2011).

${ }^{15}$ Cf. field notes, April 2010.
} 
tional language. No wonder that bureaucratic experts, who during their whole professional life have dealt with such instruments, also try to make these instruments work in the context of the protection of intangible heritage on the international as well as on the national level: Listing heritage is a traditionalized practice itself, which may explain that the experts of the Belgian French community decided to safeguard their intangible heritage by making a list.

More comparative and micro-level research is needed to understand these bureaucratic logics and practices and their meaning for heritage preservation and construction. How, for example, do federal civil servants responsible for the protection of historical monuments react to expansion of their professional field of action due to changes in the legislation (which actually happened in Belgium)? Do states and governments that changed this legislation also change the bureaucratic structures linked to laws, decrees and operational guidelines? What new expertise emerges and on what scientific and administrative grounds is it built? What is the role of bureaucratic practices and materialities - forms, registers, inventories, dossiers, et cetera - in the production and powerful management of heritage (cf. Tauschek 2009)?16

\section{Conclusion}

Talking about national heritage policy is tricky. The implementation of UNESCO's Intangible Heritage Convention on the level of the nation-state is, first of all, a political project. However, this project has to be realized by concrete actors who move in bureaucratic or political webs of meaning. A central task of anthropological heritage research consists - as Kristin Kuutma stated - of complicating simplicities. ${ }^{17}$ Without a consideration of the political background, where strong individual and partisan interests emerge, one might perceive the process of nominating a heritage site as completely arbitrary. The Kiel case demonstrates, most of all, how utterly unpredictable the results of a heritage nomination process are.

What is predictable, however, is the fact that international and national heritage regimes bureaucratize the management and also the interpretation of tangible and intangible heritage. National heritage policies result from very different heritage interventions with various bureaucratic institutions and actors involved. Whereas the products of this process unfold long-lasting effects - once legislation is constituted, it cannot easily be changed; once heritage lists are installed, they will be constantly replenished - concrete nomination procedures as well as the concrete handling of heritage depend on constant negotiation processes.

\footnotetext{
${ }^{16}$ Cf. contributions by Ballachino, Bodolec, Broccolini, and Fournier in this volume.

${ }^{17}$ Cf. Kuutma, this volume. See also Dorothy Noyes' paper entitled "Traditional Culture: How does it work," where she discusses central terms of heritage policy as community, tradition or folklore (Noyes 2010).
} 
Cultural anthropologists usually hesitate to voice predictions. Yet the example of the implementation of UNESCO's Intangible Heritage Convention in Belgium suggests that similar processes will follow the same pattern when Germany ratifies this convention. In this case, the legislation concerning tangible heritage and monuments will serve as the legal and bureaucratic model that will be conferred on the concept of intangible heritage. In her feasibility study concerning the implementation of UNESCO's Intangible Heritage Convention in Germany published in 2011, Marie-Theres Albert, UNESCO Chair in Heritage Studies (university of Cottbus), underlined that Germany's tradition in the protection of historical monuments has established a well functioning bureaucratic system. Hence, a national committee for Intangible Cultural Heritage should be organized analogous to the "German National Committee for Monument Preservation."

Albert's recommendations show that power, hierarchies and different interests will play a crucial role, as discussed in my two examples. If Albert suggests having representatives of all German UNESCO chairs, as well as representatives of all heritage studies programs in Germany, in the aforementioned commission, this proposal might be understood as the inscription of disciplinary interests in the proclamation and management of future intangible heritage. This will eventually cause new conflicts.

It is evident that the ratification of UNESCO's Intangible Heritage Convention initiates debates about the relevance and the nature of popular culture. In contrast to the protection of historical monuments, this debate is not only about the esthetic or historical values of castles or other types of buildings, but is also about cultural identity and the value of performative culture. "Intangible" culture may be less easy to destroy than the historical interior of a castle. Perhaps popular culture considered for protection might, in its colorful, dynamic variety, mitigate the conflict potential inherent to the protectionist and managerial processes.

\section{References}

Albert, Marie-Theres (2011): Feasibility Study: Implementation of the UNESCOConvention for the Safeguarding of Intangible Cultural Heritage (2003) in Germany. BTU Cottbus. http://www-docs.tu-cottbus.de/gradschool/public/Fachklasse_5/feasibility _study.pdf < accessed June 6, 2012>

Bendix, Regina (2009): Heritage between Economy and Politics. An Assessment from the Perspective of Cultural Anthropology. In Intangible Heritage. Key Issues in Cultural Heritage. Laurajane Smith and Natsuko Akagawa, eds. Pp. 253-269. New York: Routledge.

Binder, Beate (2009): Streitfall Stadtmitte: Der Berliner Schlossplatz. Alltag \& Kultur, 13. Köln: Böhlau. 
Bortolotto, Chiara, ed. (2008): Il patrimonio immateriale secondo l'UNESCO: analisi e prospettive. Rome: Istituto poligrafico e Zecca dello Stato.

Centre de documentation administrative: Secrétariat général (2002): Décret relatif aux biens culturels mobiliers et au patrimoine immatériel de la Communauté française.

http://www.patrimoineculturel.cfwb.be/fileadmin/sites/colpat/upload/colpat _super_editor/colpat_editor/documents/Decrets/Decret110702.pdf $<$ accessed August 4, 2011>

Di Giovine, Michael A. (2009): The Heritage-scape. UNESCO, World Heritage, and Tourism. Lanham: Lexington Books.

Douglas, Mary (1986): How Institutions Think. London: Routledge and Kegan Paul.

Fédération Wallonie-Bruxelles (2011): Chefs d'œuvre du Patrimoine oral et immatériel de la Communauté française.

http:/ /www.patrimoineculturel.cfwb.be/index.php?id=7301 <accessed August 4, 2011>

Hafstein, Valdimar (2007): Claiming Culture: Intangible Heritage Inc., Folklore(C) Traditional Knowledge ${ }^{\mathrm{TM}}$. In Prädikat HERITAGE. Wertschöpfungen aus kulturellen Ressourcen. Studien zur Kulturanthropologie/Europäischen Ethnologie, 1. Dorothee Hemme, Markus Tauschek, and Regina Bendix, eds. Pp. 75-100. Berlin: Lit.

- (2009): Intangible Heritage as a List. From Masterpieces to Representation. In Intangible Heritage. Key Issues in Cultural Heritage. Laurajane Smith and Natsuko Akagawa, eds. Pp. 93-111. New York: Routledge.

Heinrichs, Johannes (2003): Revolution der Demokratie. Eine Realutopie für die schweigende Mehrheit. Berlin: Maas.

Hemme, Dorothee (2007): „Weltmarke Grimm“ - Anmerkungen zum Umgang mit der Ernennung der Grimmschen Kinder- und Hausmärchen zum „Memory of the World“. In Prädikat HERITAGE. Wertschöpfungen aus kulturellen Ressourcen. Studien zur Kulturanthropologie/Europäischen Ethnologie, 1. Dorothee Hemme, Markus Tauschek, and Regina Bendix, eds. Pp. 225-251. Berlin: Lit.

Hemme, Dorothee, Markus Tauschek, and Regina Bendix, eds. (2007): Prädikat HERITAGE. Wertschöpfungen aus kulturellen Ressourcen. Studien zur Kulturanthropologie/Europäischen Ethnologie, 1. Berlin: Lit.

Herzfeld, Michael (1993): The Social Production of Indifference: Exploring the Symbolic Roots of Western Bureaucracy. Chicago: University of Chicago Press.

Holtorf, Cornelius (2007): What Does Not Move Any Hearts - Why Should It Be Saved? The Denkmalpflegediskussion in Germany. International Journal of Cultural Property 14(1): 33-55.

Huse, Norbert, ed. (2006): Denkmalpflege. Deutsche Texte aus drei Jahrhunderten. München: C.H. Beck. 
Kirshenblatt-Gimblett, Barbara (2004): Intangible Heritage as Metacultural Production. Museum International 56(1-2): 52-65.

Kuutma, Kristin (2007): The Politics of Contested Representation: UNESCO and the Masterpieces of Intangible Cultural Heritage. In Prädikat HERITAGE. Wertschöpfungen aus kulturellen Ressourcen. Studien zur Kulturanthropologie/ Europäischen Ethnologie, 1. Dorothee Hemme, Markus Tauschek, and Regina Bendix, eds. Pp. 177-195. Berlin: Lit.

Lewinski, Silke von (2004): Protecting Cultural Expressions: The Perspective of Law. In Properties of Culture - Culture as Property. Pathways to Reform in Post-Soviet Siberia. Erich Kasten, ed. Pp. 111-127. Berlin: Reimer.

Ministerium für Bildung, Wissenschaft, Forschung und Kultur (2002):

Durchführungsvorschriften zum Denkmalschutzgesetz (DSchGDV) des Landes Schleswig-Holstein.

Noyes, Dorothy (2006): The Judgement of Solomon: Global Protections for Tradition and the Problem of Community Ownership. Cultural Analysis 5: 2756.

- (2010): Traditional Culture: How Does It Work? CP101: Concepts and Institutions in Cultural Property Working Paper 1/2010.

http://www.uni-goettingen.de/de/publikationen/213471.html < accessed August 3, 2011>

Sächsisches Oberverwaltungsgericht (2007): Urteil (Aktenzeichen 1 B 324/06). http://www.justiz.sachsen.de/ovgentsch/documents/1B324_06u.pdf $<$ accessed August 3, 2011>

Schmidt, Leo (2008): Einführung in die Denkmalpflege. Darmstadt: Theiss.

Schmitt, Thomas M. (2009): Global Cultural Governance. Decision-Making concerning World Heritage between Politics and Science. Erdkunde 63(2): 103-121.

Schuster, Mark J. (2002): Making a List and Checking it Twice: The List as a Tool of Historic Preservation. Working Paper, 14. Chicago: Cultural Policy Centre at the University of Chicago.

http://culturalpolicy.uchicago.edu/papers/workingpapers/Schuster14.pdf $<$ accessed August 5, 2011>

Smith, Laurajane (2006): Uses of Heritage. New York: Routledge.

Smith, Laurajane, and Natsuko Akagawa, eds. (2009): Intangible Heritage. Key Issues in Cultural Heritage. New York: Routledge.

Swenson, Astrid (2007): "Heritage", "Patromoine" und "Kulturerbe"; Eine vergleichende historische Semantik. In Prädikat HERITAGE.

Wertschöpfungen aus kulturellen Ressourcen. Studien zur Kulturanthropologie/Europäischen Ethnologie, 1. Dorothee Hemme, Markus Tauschek, and Regina Bendix, eds. Pp. 53-74. Berlin: Lit.

Tauschek, Markus (2009): „Writing Heritage“ - Überlegungen zum Format Bewerbungsdossier. In Erb.gut? Kulturelles Erbe in Wissenschaft und Gesellschaft. Referate der 25. Österreichischen Volkskundetagung vom 14.- 
17.11.2007 in Innsbruck. Karl C. Berger, Margot Schindler, and Ingo Schneider, eds. Pp. 437-448. Wien: Selbstverlag des Vereins für Volkskunde. - (2010a): Wertschöpfung aus Tradition. Der Karneval von Binche und die Konstituierung kulturellen Erbes. Studien zur

Kulturanthropologie/Europäischen Ethnologie, 3. Berlin: Lit.

- (2010b): Denkmal wider Willen? Kulturanthropologische Perspektiven auf einen Kieler Konflikt. Kieler Blätter zur Volkskunde 42: 5-22.

Tunbridge, John E., and Gregory John Ashworth (1996): Dissonant Heritage: The Management of the Past as a Resource in Conflict. Chichester: John Wiley \& Sons. 


\title{
The Role of UNESCO and the Uzbek Nation Building Process
}

\author{
Gabriele Mentges
}

\section{Introduction}

In February 2010, French newspapers announced that the Uzbek government had forbidden rock and rap music because of the dangerous connections perceived with drugs and loose morals (Libération Network 2011). This measure seems less surprising when we look at Uzbek cultural policies and modern nationhood narrative, both of which are marked by an extremely national rhetoric. I will ask if this is perhaps unintentionally favored and encouraged by UNESCO's involvement in Uzbekistan.

Within the framework of the research project "The Modernity of Tradition, Uzbek Textile Culture as an Economic and Cultural Resource,"1 I investigate practices and discourses regarding the traditional Uzbek textile culture in a globalized fashion market. How does global fashion consumption exercise an impact on local actors? What kinds of cultural and social differences are created by global fashion for example, differences in social status, differences between the older and younger generations, the creation of new ideas of ideal women coming from new body images broadcast by the media, and social stratification between globally orientated elites and groups within the local population. The Uzbek government pays great attention to its national image and presentation abroad; an image in which the

\footnotetext{
${ }^{1}$ Research project, 2010-2012, grant by VW-Stiftung.
} 
ethnic variety of traditional textile cultures of the Central Asian population are fused into a coherent Uzbek identity via modern fashion design.

While UNESCO initiatives and policies are not at the center of my research, I saw traces of UNESCO in all of the places I visited. In fact, handicrafts, in particular textile handicrafts, are counted among the main focuses of UNESCO engagement in Uzbekistan. Markedly, many designers and craftsmen - the players on the lowest level - mentioned UNESCO as their in ways unknown, mysterious supporter. I have been carrying out ethnographic research among designers, craftsmen and fashion consumers (mainly in Namangan in the Fergana Valley). Drawing from this material, I try to analyze the results and effects of UNESCO's programs. The realms of craftsmen and designers in Uzbekistan are closely intertwined. At this point in my research, I can only try to answer some of the questions put forward by this volume's focus on heritage regimes. I will mainly consider the political layout and the ideological perspectives on culture. Along with the ethnographic material drawn from interviews with designers, and visits to workshops, craft centers, and bazaars, I consulted internet sources about UNESCO activities in Uzbekistan. The official website only provides very rough and basic information. ${ }^{2}$ This information was full of confusing hints and tracks, some leaving me with the impression of an intentional cover-up - an issue I will return to later. My task consisted of deconstructing this puzzle of information in order to reconstruct a somewhat more coherent concept of UNESCO's actions and intentions in the country. In the end, I am left with more questions than answers!

\section{The Case of Uzbekistan}

The commitment of UNESCO to Uzbekistan goes back to Soviet times when the project Silk Road was started in 1988:

UNESCO launched a ten-year project entitled "Integral Study of the Silk Roads: Roads of Dialogue". As part of the project, several expeditions were organized to retrace, by land and by sea, some of these routes, with the participation of experts from all the countries involved. The purpose of the project, which uses a multidisciplinary approach, was to carry out field studies of the scientific, technological and cultural exchanges which took place between the East and the West along these routes with a view to stimulating further research at the international and national levels and promoting the concept of multiple identities and a common heritage. (UNESCO 2002: 1) ${ }^{3}$

\footnotetext{
${ }^{2}$ For advice concerning websites, I would like to thank Philipp Socha for his instructive remarks. See also the article of Sue Williams: Sur les routes de la soie (Williams 1996: 15).

${ }^{3}$ According to Frederico Mayor, former Director-General of UNESCO, the first UNESCO initiative on the Silk Roads Project tended "to shed light on the common heritage [...] that links the people of Eurasia” (UNESCO 2002: Introduction).
} 
Since then, political changes have made these intentions outdated. Instead of claiming the common cultural heritage of the Silk Road, the five nations (Uzbekistan, Kazakhstan, Kyrgyzstan, Tajikistan, and Turkmenistan) each emerged with wishes for separate support, insisting on focusing on cultural differences rather than what is shared in common. Hence, an analysis of UNESCO's role must take into consideration the particular historical and political situation from which these new Central Asian nations emerged.

Uzbekistan obtained national independence in 1991 together with the four other Central Asian countries after the breakdown of the Soviet Union. However, differently from the countries of Northeastern Europe, Uzbekistan was not prepared for the new status of sovereignty nor had there been a real struggle for independence. Instead, some parts of the population would have preferred to stay under the great, protective roof of the Soviet Union. The romantic and Western idea of nationhood conveying a distinct entity connected with a fixed territory was alien to the population of Central Asia.

This seems surprising, but a closer look at history can explain the different attitudes. Uzbekistan, along with the other states of Central Asia, was an invention of the Soviet government. It defined new regional areas with provincial governments during the 1920s in an effort to create clear administrative structures. These were partly based on ethnolinguistic borders or on the political structures of the former principal feudal territories (Khanat) (Baldauf 1991; Hiro 2009). Demarcated and officially founded in 1925 (Bell 1999: 2), the newly created national republic of Uzbekistan faced the problem of inventing its own nationhood inside the former Soviet frontiers. ${ }^{4}$

\section{UNESCO's Initiatives in Uzbekistan}

What role can UNESCO play in this new geopolitical layout and what goals are to be implemented? The following goals concerning Central Asia were proclaimed in a 1996 issue of Sources UNESCO, and each of the goals was also elaborated in separate articles:

UNESCO a été appelée à la rescousse pour préserver l'environnement ${ }^{5}[\ldots]$, rénover les systèmes éducatifs ${ }^{6}[\ldots]$, développer des médias indépendants ${ }^{7}$ $[\ldots]$, faire renaitre l'identité de cette région à travers son héritage culturel ${ }^{8}$

\footnotetext{
${ }^{4}$ Nevertheless, the concept of nation was not alien to Soviet ideology but a basic category in their conception of collectivities. Concerning Uzbek nation formation, see Eckert 1996; Melvin 2000. For the conception of Eurasia, see Kaiser 2004.

5 Akimbekov 1996: 9.

${ }^{6}$ Kukushkin 1996: 10.

${ }^{7}$ Hadlow 1996: 11.

${ }^{8}$ Boccardi and Williams 1996: 14; Williams 1996: 15.
} 
[...] ou aider à la découverte de ces pays de la Route de la soie qui servirent jadis - et veulent servir à nouveau - de pont entre l'Occident et l'Orient [...]. ${ }^{9}$ (Starr 1996: 7)

Between 1992 and 1993, all five states had joined UNESCO, which first opened an office in Uzbekistan in 1996 which was headed by Michael Barry Lane until 2007.

Uzbekistan has four cultural sites on the World Heritage List: The historic districts of Bukhara, Samarkand, Khiva, and Shahrisabz. UNESCO's interests here concern the safeguarding of historical architecture. The first, enormous scientific project was installed in the regional district of Boysun as part of the intangible and immaterial cultural heritage. Boysun district was proclaimed a Masterpiece of the Oral and Intangible Heritage of Humanity in 2001. Boysun was "submitted by the National Commission of the Republic of Uzbekistan for UNESCO [...]: Surkhanddarya Region" in January 18, 2008.10 A year before, on December 12, 2007, the Uzbek Republic edited a law on the "ratification of an international convention on protection of immaterial cultural heritage of 2003."11

One goal of UNESCO is to encourage regional identities. Therefore, a good portion of the initiatives revolves around supporting traditional handicraft activities, in particular in the textile sector, with the concrete intention of revitalizing and restoring old techniques and handiwork items. This protection of folklore and ethnic features was also a concern of the Soviets in former times. Thus, Laura Adams argues that: "Soviet institutions, far from destroying traditional culture, acted to preserve traditional culture even as they transformed it, not just in a socialist way, but also by participating in the establishment on international cultural norms [...]" (Adams 2010: 106). She goes on, adding that, in the case of Uzbekistan, we deal with a special Central Asian version of post-colonialism not comparable to other post-colonial situations. To the question how Soviet discourses and practices shaped the ways Uzbekistan's elite conceive culture, Adams answers that "the contemporary public expression of national identity in Uzbekistan gives us evidence that a Soviet version of Uzbek ethnic identity was successfully institutionalized and remains hegemonic among cultural and political elites" (Adams 1999: 356).

Adams' study (2010) refers to the national holiday Navro'z (the Persian New Year) - an institution of particular continuity and popularity which has enjoyed UNESCO status as Intangible Culture Heritage since 2009. By taking on this case study, she has furnished proof of the restorative cultural policy which confirms and reinforces the assuredness and identity of the old and new cultural elites which had already been in existence during the Soviet period. The situation regarding textile handicrafts seems to be more varied and complicated. Uzbekistan is not

\footnotetext{
9 Otchet 1996: 16.

10 Boysun UNESCO Heritage Centre 2011.

11 Aviabrok-CONSAUD Co. Ltd., accessed May 13, 2012.
} 
only counted among the world's most important producers of cotton (currently it is number five), ${ }^{12}$ but can look back on a rich history of textile handicrafts, including the colored Ikat textiles (made of silk or cotton, or both), Bukhara golden embroidery, the abundantly embroidered wall carpets Suzani, and the Karakalpak embroidered handbags and accessories. Modern Uzbek fashion design refers to these traditions by using traditional handicraft techniques, but above all, by citing and applying ornaments, colors and fabrics of Central Asian traditional dress cultures.

This phenomenon of revitalization is often addressed as "re-orientalization," i.e. adopting and playing with old oriental stereotypes which, in the case of Uzbekistan, date from the time of the Tsarist colonialism (Leshkowich and Jones 2003). Thus, actual textile crafts, as well as new fashion design, have become strong markers of the new Uzbek national identity. ${ }^{13}$

During the Soviet period, certain traditional textile handicrafts were actively practiced but only for official, industrial or private purposes, whereas some crafts, such as the golden embroidery of Bukhara, were considered to belong to the feudal past and excluded. The Soviet government never allowed Uzbeks to exercise a handicraft profession on their own and for personal profit. One of my interviewees in Margilon reported that his father was punished with a five-year prison sentence for attempting to work independently.

It was difficult to find out what types of handicrafts UNESCO is encouraging and in what ways the development of textile handicrafts is being forwarded. There are only tentative answers to some questions. UNESCO provides no financial means, but mostly material and technical support instead. At times, UNESCO assistance is dependent upon the personal interests and preference of UNESCO actors in the field - an opinion which is confirmed by other studies. ${ }^{14}$

The official aim is to encourage craft-workers to use traditional skills and materials. The establishment of the Seal of Excellence program (referred to as the Seal ${ }^{15}$ ), initiated in 2001 and expanded to Central Asia in 2004, aims to ensure the continuation of traditional knowledge and skills and the preservation of cultural diversity in the region. It is based on the following key criteria:

\footnotetext{
${ }^{12}$ However, Uzbekistan is number two for cotton export. See Battes 2007: 29-53, 36 (production), 32 (export).

${ }^{13}$ For a good survey, see also Zernickel 1995; Rezvan 2006.

${ }^{14}$ For example, by a study from 2010 entitled ИИскусство Узбекистана на современном этапе социо-культурного развития (Eng. Arts of Uzbekistan at the present stage of social-cultural development), which was funded by the Swiss Agency for Development and Cooperation. http://cultureuz.net/analitica/coll/1/first.html < accessed 13 May, 2012>.

15 The SEAL of Excellence for Handicraft Products in Central Asia 2004 was jointly established by UNESCO and CACSA (Asian Crafts Support Association) in order to establish quality standards and to enhance regional and international awareness of traditional and innovative handicrafts; UNESCO 2004.
} 
- Creative and successful alliance of traditional skills and innovation in material, form or design;

- Expression of cultural identity and traditional aesthetic value;

- Respect for the environment in materials and production techniques; and

- Marketability of the craft products with potential for the world market.

(UNESCO Office Bangkok, accessed May 13, 2012)

The following centers have profited from UNESCO support:

- Bukhara Artisan Development Center is an association of artisans' "everlasting heritage" whose main goal is to receive and develop ancient handicrafts. ${ }^{16}$ Bukhara belongs to the Central Asian Crafts Support Association (CACSA) which has been a partner with the Seal program in Central Asia since 2004.

- Marg'ilon (Margilan) Craft Center is supported by UNESCO (silk Ikat weaving center). ${ }^{17}$ A private, successfully working silk factory is also located in Margilon.

It was only by word of mouth that I became acquainted with a center of designers who have constructed a workshop for traditional handicraft, in this case block-printing, and modern design in Tashkent's old city. This center, Human Wear, was founded in 2000. Only the architecture of the building in which the center is housed (a 19th century house) was sponsored by UNESCO in 2006-07. The aim was to restore the historical district and make modern usage of its buildings - in this case as both a handicraft workshop and an educational center for young women who are willing to learn a special handicraft. In this way, the designers concerned were able to provide employment and, at the same time, attract tourists to the old city. There are plans to open an exhibition hall. The design and craft center stimulated the creation of a designer marketing organization and shop called $\mathrm{Hu}$ man Wear inside Tashkent where designers can show and sell their own products with relative success and strikingly modest appearance and advertising campaigns. ${ }^{18}$

The craft center in Margilon is quite impressive: It was supported by UNESCO between 2003 and 2007 with material equipment rather than financial support in an effort to ensure sustainability. The proclaimed goal was to encourage the development of all the traditional crafts of Uzbekistan and to reunite them in the center of Margilon. The director stressed in a personal communication the

\footnotetext{
16https://signin.wiserearth.org/openid/v2/signin?token_url=http $\% 3 \mathrm{~A} \% 2 \mathrm{~F} \% 2 \mathrm{Fwww}$.wiserearth.org \%2Fsingle_sign_on $\% 2$ Freferer $\% 2 F$,slsh,organization,slsh,view,slsh,fe3582a41f5f546d5f84569021b9c 0eb>000 < accessed May 5, 2011> (Website has been closed, content downloaded as pdf).

17 http://www.tashkent.UNESCO.org/en/tentativelists/5300 and the website of the UNESCO office in Tashkent; UNESCO 2011.

18 The founders of Human Wear were Lola Sajfi, Jurij Pak und Dina Malkova. At the beginning, the shop was organized as a Limited Liability Company (LLC) called Kischilar libosi. Today, the business is privately owned by Natalja Kim (Field research, November 2010). Since recently, the shop has concentrated more on internet marketing due to several reasons. For further information, see: Человеческая одежла < accessed May 13, 2012>.
} 
individual efforts of Michael Barry Lane, former director of the Tashkent UNESCO office, who, according to my source, confessed a strong personal interest in carpet weaving. Today, the center appears to be functioning well with 45 employees ranging from students to master craftsmen. Only highly skilled craftsmen are hired. Some, like the block printer, can look back on an old family tradition within their chosen craft. The center has also organized folklore festivals with the help of UNESCO. The carpets can be ordered via the internet. The craftsman I interviewed stated that the employees are able to earn a living as well as make a small profit. Another silk carpet workshop was successfully initiated in Chiva, one of the most touristic places in Uzbekistan, with the help of UNESCO and marketed via the Internet. Due to the suggestion of UNESCO, the weavers have developed a different design similar to that of the traditional wooden doors (field research October 2011).

One of the main concerns of UNESCO in Uzbekistan appears, therefore, to be the encouragement of textile handicrafts which, according to UNESCO (UNESCO 2007), provide a central element in sustainable development. In fact, textile handicrafts and fashion design are very popular among the Uzbek population and refer to old traditions, knowledge, values, and symbolic representation. ${ }^{19}$

UNESCO's strategic support goes hand in hand with the Uzbek government's efforts to develop a handicraft economy with decrees in favor of the producers (i.e. exemption from taxes). The same is valid for Bukhara, where the association Hunarmand, comprised of national foremen, handicraftsmen and painters, is based on a particular decree of the president. ${ }^{20}$ The association has as its target "the preservation of centuries-old national art traditions, development rich in both diverse and applied art of Uzbekistan, support it not only on a home market, but also progress in the external world [global] market."21

The purpose of the association is the coordination of activity and the protection of the rights and interests of the national foremen, handicraftsmen and experts in applied art.

In some areas, such as the Fergana valley, the reinforcement and consolidation of handicraft industries seem to diminish the high degree of unemployment and, at the same time, encourage women in particular to become more economically independent. This was illustrated by a country woman I met near Namangan who specialized in the production of the traditional headgear Tubetejka. She had established a small, functioning and successful manufacturing plant with one hundred female

\footnotetext{
${ }^{19}$ Field research in handicraft centers confirmed that Uzbeks interested in handicrafts prefer to learn textile or fashion over other handicrafts techniques.

20 The association of handicrafts, Hunarmand, is a non-governmental, non-commercial, public organization set up according to the decree of the President of Uzbekistan from 1997. Resolution of the President of Uzbekistan (Body of legislation of Uzbek Republic 2006 г., № 46-47, ст. 456ic). See "UZINFOINVEST" accessed May 13, 2012 or Uzbekistan Today 2011.

${ }^{21}$ Fourteen regional managements and ten departments in various regional areas are currently operating: More than 16,000 handicraftsmen and -women in 33 different fields of applied creativity are employed there and produce more than 1,000 brand products (field research October 2010).
} 
employees. Another good working example was a small workshop comprised of two women who produced the very rare and expensive velvet, Ikat bakhmal, which has become fashionable. There are several other successful examples which improve the situation at the local level, such as bringing golden embroidery to the Bukhara folk market. In most cases, work is distributed on a "take home" basis and female family members provide labor. The products are targeted mostly at domestic consumers within the small middle class who still wear traditional dress on festive occasions, family gatherings, weddings, and so on.

\section{Broader Impact of UNESCO Initiatives}

However, the measures, in the long run, reinforce a resurgence of traditional practices and discourses within Uzbek community life which can be compared with the process of malhallization in Uzbek society. Thus, the old neighborhood institution malhalla - which existed even throughout the Soviet era and represents an interface between state and local communities - is more or less instrumental as a new organizational unit of political control, using old patterns of social practices: Family, kinship and patriarchal structure organize the life of citizens on a local level (Massicard and Trevisani 2000: 206-208). The term malhallization is used in research to refer to a discourse that claims the natural emergence of the Uzbek state out of Uzbek traditions, fostering particular hierarchical structures. It is a system based on patriarchy and family, with elders holding a high position and the individual coming after the family, the bokim (mayor), the city, and finally the president, who is considered the natural head of the nation (Massicard and Trevisani 2000: 217). In fact the project's interviews about consumer attitudes towards traditional textile consumption indicate an increase of patriotic rhetoric and a gradual incorporation of national discourses. ${ }^{22}$

The situation becomes more complicated when looking at the fashion sector because of the diversity of the UNESCO support programs, the number of suborganizations and their connections with a multitude of competitors, such as the Seal program which organizes fashion shows for Central Asian participants - a welcome opportunity for Uzbek designers to go abroad. The Seal program was initiated in 2001 by the UNESCO Asia-Pacific Regional Office in Bangkok and the ASEAN Handicraft Promotion and Development Association (AHPADA), and has expanded into Central Asia. The Seal program's explicit intention is to raise the quality control and marketing of traditional crafts and allows Uzbek fashion designers to participate in international platforms (UNESCO, accessed May 13, 2012).

Thus, the different programs also support efforts to build an independent fashion industry which is of vital interest for Uzbekistan's government.

22 Interviews in Namangan during field research in November 2010. 
Fashion shows offering platforms for Uzbek designers operate on an international level and allow the representation of Uzbek fashion as a national brand. Fashion design is the particular concern of the fashion house Dom Stilya (House of Style) under the direction of the President's daughter, Gulnara Karimova. She also acts as a chairperson of the Board of Trustees of the Fund Forum which cooperates directly with UNESCO through joint projects.

Gulnara's importance for fashion design and to the country is proved by the fact that until recently, she was considered as a successor to her father as president. The other daughter, Lola Tillyaeva, was nominated a Permanent Delegate of UNESCO in 2008. Gulnara, above all, is serving as an effective interface between different networks of fashion, fashion designers and the global Asian fashion market. She seems to thus be slowly gaining control of the fashion design sector, which also implies a strong influence in the educational sector, particularly within the design departments of universities. As director of the famous internationally known Dom Stilya, she organizes exclusive fashion shows. Small labels, in contrast, have difficulty surviving and competing successfully; perhaps this is the reason why small labels are concentrating more and more on internet marketing.

UNESCO cannot bypass this organization of fashion design. Uzbekistan, as a so-called "presidential democracy," is marked by a particular organization and conception of state institutions in which kinship affiliation plays an important role (Collins 2006). ${ }^{23}$ Thus, unwillingly or not, UNESCO's interventions are involved in state interests and strategies.

Handicraft development and design are closely linked to each other, ${ }^{24}$ but they serve different interests and markets: Consumers from the Uzbek middle classes and tourists, on the one hand, and the upper class as a global player in the realm of fashion design, on the other. The Uzbek fashion industry seems to be, as argued by Lise Skov (2011) in a study about small national fashion labels, more "orientated towards international validation rather than domestic power" (Skov 2011: 139). In the case of Uzbekistan, it helps to not only construct a new national image, but also to strengthen the nation's claim as the natural heir to the Silk Road. For this reason, it does not matter anymore that the fashion design industry is based on a successful fashion market.

Meanwhile, as a result of globalized fashion competitions, the link with media and communication has become more vital in selling a national image via fashion. It is all about being included or excluded. ${ }^{25}$

\footnotetext{
${ }^{23}$ Collins' definition of clan: "[...] clans are rooted in the informal kin-based communities, tribal or non-tribal, of traditional society organized around extended family units that engage in social, economic, and political activities" (2006: 68). See also her remarks on the current situation in Uzbekistan (2006: 256).

${ }^{24}$ The strong connection between craft and design is also confirmed by Yurkova 2004. See also the recent study by Krebs 2011 .

25 This argument is put forward by Lise Skov on the basis of her research on national fashion designs operating on the global market (2011: 139).
} 
The trend for the working classes to wear cheap print textiles with traditional oriental ornaments and colors from China or sometimes Arabian countries is completely excluded from this cultural policy. This reinforces and widens the already existing social and cultural gap between educated and non-educated parts of the population.

The actors on the lowest level are the craftsmen, who are looking at UNESCO as a deus ex machina promising help and future, without any understanding of the mechanism of UNESCO procedures. They were surprised by the sudden interruption of UNESCO support to handicrafts which cut them off from new relations with festivals and exhibitions abroad (e.g. Santa Fe, Mexico).

Last but not least, it seems that personal relationships and the personal tastes of UNESCO principals play a role in the strategies of support. This was apparently the case during the time of the former head of the Uzbekistan office, Michael Barry Lane, who was honored several times by Uzbek officials for his great commitment to Uzbek culture (Uzbekistan National News Agency 2007). ${ }^{26}$

\section{Conclusion}

UNESCO's strategies to revitalize traditional crafts are, in some cases, also accompanied by intensive scientific research, as in the case of ethnographic field research in the Boysun district or the founding of the International Institute of Central Asian Studies in Samarkand (IICAS), which "was established under the aegis of UNESCO in 1995" (UNESCO 2009). UNESCO initiatives aim to forge a cultural identity through the exact historical knowledge of regional variety and to meet economic expectations and needs. However, these efforts remain ambiguous because they reinforce the tendency of present-day Uzbek society which is dominated by a dual mentality: "Uzbekistan's traditionalism and modernity" (Dadabaev 2004: 141-142).

Given the actual political structures, regional networks combined with kinship affiliations, one can conclude with certainty that the major part of UNESCO initiatives within Uzbekistan are organized from the top and are kept under strict state control. This explains the lack of transparency which is reflected in the opinions of the craftsmen.

The same impression is also shared by members of the cultural elite. In an interview with Laura Adams, a woman responded to the questions about her feelings on the new cultural politics: "Yes, I feel I'm part of a larger movement toward [sic] cultural renewal [...] but it comes from the top [...]" (Adams 2010: 113).

\footnotetext{
26 Another example for the relationship between UNESCO and Uzbek President Karimov is his decoration with UNESCO medals Avicenna and Borobudur. The awarding was accompanied by the protest of human rights organizations, such as Human Rights Watch (Silverstein 2009; Carter 2006).
} 


\section{References}

Akimbekov, Sultan (1996): La mer qu'on voit mourir. L'aide internationale est décisive pour limiter les dégâts engendrés par la plus grave catastrophe écologique du XXè siècle. Sources UNESCO, Asie Centrale: À la Recherche du Temps Perdu 83: 9. http://unesdoc.unesco.org/images/0010/001041/104122f.pdf < accessed February 12, 2012>

Aviabrok-CONSAUD Co. Ltd. (n.d.): PRAVO Legal Information System. http:/ / www.pravo.uz/eng/get_data.php3?topic $=36213 \&$ sub $=0 \# 0<$ accessed May 13, 2012>

Baldauf, Ingeborg (1991): Some thoughts on the making of the Uzbek nation. Cahiers du Monde russe et soviétique 32(1): 79-95.

Battes, John (2007): Cotton-Dependant Countries in the Global Context. In The Cotton Sector in Central Asia. Economic Policy and Development Challenges. Deniz Kandiyoti, ed. Proceedings of a conference held at SOAS University of London, 3-4 November, 2005.

Bell, James (1999): Redefining National Identity in Uzbekistan. Symbolic tensions in Tashkent's official public landscape. Ecumene 6(2): 183-213.

Boccardi, Giovanni, and Sue Williams (1996): Des joyaux en ruine ou sans âme. La richesse et la diversité du patrimoine culturel de l'Ouzbékistan sont exceptionnelles. Mais le restaurer, et plus encore lui redonner vie, est ardu. http://unesdoc.unesco.org/images/0010/001041/104122f.pdf < accessed May 13, 2012>

Boysun UNESCO Heritage Centre (2011): Boysun Description. http://whc.unesco.org/en/tentativelists/5300 < accessed May 13, 2012>

Bukhara Artisan Development Center.

https://signin.wiserearth.org/openid/v2/signin?token_url=http $\% 3 \mathrm{~A} \% 2 \mathrm{~F} \% 2 \mathrm{~F}$ www.wiserearth.org $\% 2$ Fsingle_sign_on $\% 2$ Freferer $\% 2 \mathrm{~F}$,slsh,organization,slsh, view,slsh,fe3582a41f5f546d5f84569021b9c0eb>000 < accessed May 5, 2011> (Website has been closed; content downloaded as PDF)

Carter, Holly (2006): HRW letter to protest UNESCO award to Uzbek Presi-dent Islam Karimov. Human Rights Watch.

http://www.hrw.org/news/2006/09/12/hrw-letter-protest-unesco-awarduzbek-president-islam-karimov < accessed February 21, 2012>

Collins, Kathleen (2006): Clan Politics and Regime Transition in Central Asia. Cambridge: Cambridge University Press.

Dadabaev, Timur (2004): Post-Soviet realities of society in Uzbekistan. CentralAsian Survey 23(2): 141-166.

Eckert, Julia M. (1996): Das unabhängige Usbekistan: Auf dem Weg von Marx zu Timur. Berliner Studien zur Internationalen Politik, 1. Münster: Lit.

Hadlow, Martin (1996): Relais et témoins du changement. L’essor des médias prouve et accélère l'évolution des républiques nouvellement indépendantes. 
Mais il est jalonné d'obstacles et de périls, que l'UNESCO aide à surmonter. Sources UNESCO, Asie Centrale: Á la Recherche du Temps Perdu 83: 11. http://unesdoc.unesco.org/images/0010/001041/104122f.pdf < accessed February 12, 2012>

Hiro, Dilip (2009): Inside Central Asia. A political and cultural history of Uzbekistan, Turkmenistan, Kazakhstan, Kyrgyzstan, Tajikistan, Turkey and Iran.New York/London: Overlook Duckworth.

Искусство Узбекистана на современном этапе социо-культурного развития. [Arts of Uzbekistan at the present stage of socio-cultural development]. http:/ / cultureuz.net/analitica/coll/1/first.html < accessed 13 May, 2012>

Kaiser, Markus (2004): Auf der Suche nach Eurasien. Politik, Religion und Alltagskultur zwischen Russland und Europa. Bielefeld: Transcript.

Krebs, Melanie (2011): Zwischen Handwerkstradition und globalem Markt. Berlin: Karl Schwarz.

Kukushkin Andrey (1996): Autres Temps, autres fins, autres moyens. Commentréformer un système éducatif quand ses moyens sont divisés par deux etque la demande change du tout au tout? Le cas du Kazakstan.

SourcesUNESCO, Asie Centrale: Á la Recherche du Temps Perdu 83: 10.http://unesdoc.unesco.org/images/0010/001041/104122f.pdf < accessed February 12, 2012>

Leshkowich, Ann Marie, and Carla Jones (2003): Introduction: The Globalization of Asian Dress: Re-Orienting Fashion or Re-Orientalizing Asia? In ReOrienting Fashion. The Globalization of Asian Dress. Sandra Niessen, Ann Marie Leshkowich and Carla Jones, eds. Pp. 1-49. Oxford, New York: Berg. Libération Network (2011): Le rock et le rap, «musique de Satan» pour le pouvoirouzbek. Libération Next, February 22, 2011.

http:/ / next.liberation.fr/musique/01012321520-le-rock-et-le-rap-musique-desatan-pour-le-pouvoir-ouzbek <accessed February 25, 2011>

Massicard, Elise, and Tommaso Trevisani, (2000): Die Usbekische Mahalla zwischen Staat und Gesellschaft. Anthropos 95: 206-218.

Melvin, Neil J. (2000): Uzbekistan. Transition to authoritarianism on the silk road. Amsterdam: Harwood Academic Publishers.

Otchet, Amy (1996): Chronique de l'Asie centrale. En six volumes, dont trois déjà parus, l'Histoire des civilisations de l'Asie centrale est le premier ouvrage à couvrir toute la région. Sources UNESCO, Asie Centrale: Á la Recherche du Temps Perdu 83: 16.

http:/ / unesdoc.unesco.org/images/0010/001041/104122f.pdf < accessed February 12, 2012>

Rezvan, Efim A. (2006): Oriental Dreams. Russian Avant-Guard and Silks of Bukhara. Saint-Petersburg: Engelska.

Silverstein, Ken (2009): Pay to Play at UNESCO. Harper's Magazine, January 6. http:/ /www.harpers.org/archive/2009/01/hbc-90004139 < accessed February $21,2012>$ 
Skov, Lise (2011): Dreams of Small Nations in a Polycentric Fashion World. Fashion Theory 15(2): 137-156.

Starr, Frederick S. (1996): Asie centrale: À la recherche du temps perdu. Sources UNESCO, Asie Centrale: Á la Recherche du Temps Perdu 83: 7-8. http://unesdoc.unesco.org/images/0010/001041/104122f.pdf < accessed February 12, 2012>

UNESCO (2002): The Silk Roads Project. "Integral Study of the Silk Roads: Roads of Dialogue" 1988-1997.

http://unesdoc.unesco.org/images/0015/001591/159189e.pdf < accessed February 10, 2012]

- (2004): Handicraft products which received the 2004 UNESCO/CACSA Seal of Excellence (SEAL) were announced during the Crafts Fair in Almaty, Kazakhstan. http://www.unesco.kz/new/en/unesco/news/1102/ <accessed May 13, 2012>

- (2007): UNESCO presents the results of its 4th annual Handicraft pro- gramme in Central Asia http://www.unesco.kz/new/en/unesco/news/2089 <accessed May 13, 2012>

- (2009): International Institute for Central Asian Studies, Samarkand, Uzbekistan. http://portal.unesco.org/culture/en/ev.php URL_ID=35410\&URL_DO=DO_TOPIC\&URL_SECTION=201.html $<$ accessed May 13, 2012>

- (2011): Tashkent, Training on Improvement of quality and design of handicrafts in Uzbekistan http://www.tashkent.unesco.org/en/events/282- < accessed May 13, 2012>

- (n.d.): UNESCO. Building peace in the minds of men and women. http://www.unesco.org/new/en/unesco/ <accessed May 13, 2012>

UNESCO Office in Bangkok (n.d.): UNESCO Bangkok Culture in the News. UNESCO - AHPADA Seal of Excellence for Handicraft Products in Southeast Asia.

http://cms2.unescobkk.org/culture/resources/culture-asia-pacificresources/unesco-bangkok-culture-press-kit/seal-of-excellence/ <accessed May 13, 2012>

Uzbekistan National News Agency (2007): President Islam Karimov receives head of UNESCO office in Uzbekistan, August 10, 2007. http://uza.uz/en/politics/9/ < accessed February 12, 2012>

Uzbekistan Today (2011): Advancing Sericulture. http://www.ut.uz/eng/business/advancing_sericulture25.mgr < accessed May 13, 2012>

UZINFOINVEST the Information Support \& Foreign Investments Promotion Agency (n.d.): Syrdaryo province. http://www.uzinfoinvest.uz/eng/investment_opportunities/by_province/syr da $<$ accessed May 13, 2012> 
Williams, Sue (1996): Sur les routes de la soie. L'Asie centrale s'ouvre au tourisme culturel. Un moyen pour les cinq pays d'ancrer leur futur dans leur histoire ... et de relancer leur économie! Sources UNESCO, Asie Centrale: À la Recherche du Temps Perdu, 83: 15.

http://unesdoc.unesco.org/images/0010/001041/104122f.pdf < accessed February 12, 2012]

Человеческая одежАа. (n.d.)

http:/ /www.humanhuman.net/ < accessed May 13, 2012>

Yurkova, Irina (2004): Der Alltag der Transformation. Kleinunternehmerinnen in Usbekistan. Bielefeld: Transcript.

Zernickel, Maria (1995): Textile Kultur in Usbekistan. In Usbekistan. Erben der

Seidenstraße. Johannes Kalter and Margareta Pavalo, eds. Pp. 211-262.

Stuttgart: Meyer. 


\title{
Borders, European Integration and UNESCO World Heritage: A Case Study of the Curonian Spit
}

\author{
Ullrich Kockel
}

\section{Landscape Management and Human Ecology}

The Curonian Spit is a unique cultural landscape - an elongated "finger of sand" of about 98 kilometers, separating the Baltic Sea from the Curonian Lagoon (Figure 1) - which received World Heritage status in 2000. Its unique character is the result of human intervention into natural processes of geomorphological change. The southern part of the Curonian Spit, 46 kilometers long, belongs to the Zelenogradsk District of the Kaliningradskaya Oblast, which is part of the Russian Federation. Here, the Spit is connected with the mainland.

The northern part, approximately 52 kilometers long, belongs to the Republic of Lithuania. This northern part is administered by the Municipality of Neringa, formed from the four villages of Nida, Juodkrante, Preila, and Pervalka with some 3,400 inhabitants, and the City and Municipality of Klaipeda, of which the village of Smyltine near the tip of the Spit, with about 100 inhabitants, is a suburb. Both areas together make up the Kuršiuc Nerija National Park, established in 1991. On the Russian side, the Kurshskaya Kosa National Park was established in 1986; it encloses the villages of Rybachy, Lesnoye and Morskoye, with a combined population of about 1,530, but the villages are not formally part of the national park. Nearly a third of registered inhabitants on the Lithuanian side are using their homes on the Curonian Spit primarily as second homes, and thus the number of full-time residents is actually much lower than statistics suggest. The Kuršiu Nerija National Park comprises 26,461 hectares, of which 9,761 hectares are land; the 
remainder covers the adjacent waters of the Baltic Sea and the Curonian Lagoon, including the coast of Šilute District. The Kurshskaya Kosa National Park covers some 16,421 hectares, of which 6,621 hectares are land.

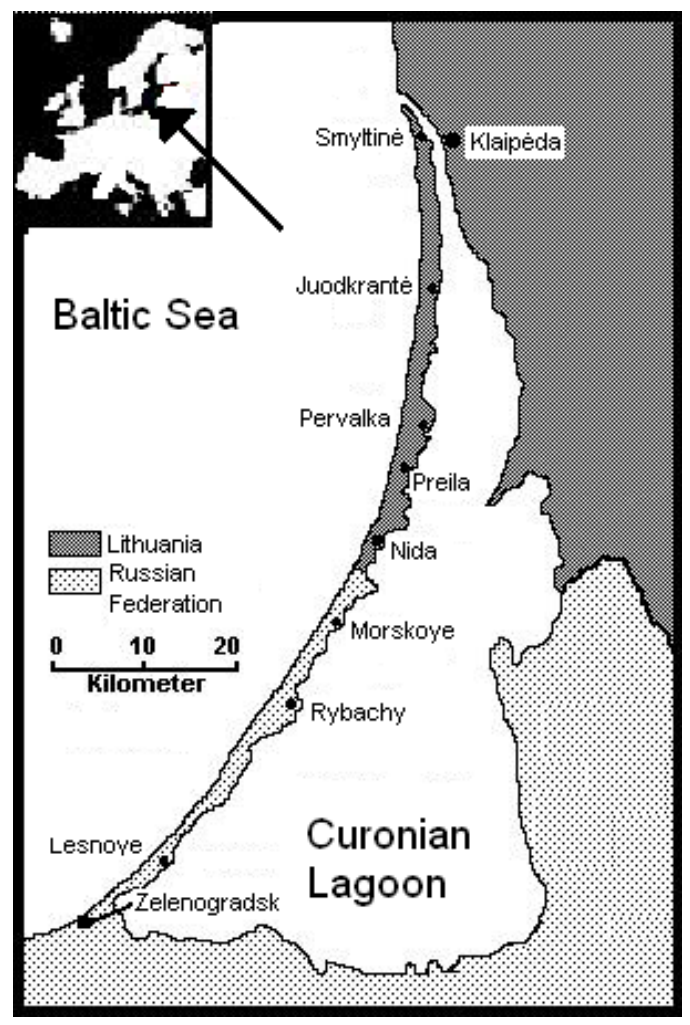

Figure 1: Map of the Curonian Spit (C) Kockel 2012).

Along the entire length of the Baltic Sea side of the Spit runs a sandy beach, accompanied by an engineered protective dune. On the eastern side, towards the Curonian Lagoon, a range of higher dunes stretches for some 72 kilometers, rising to nearly 70 meters, and in some locations a littoral plain extends along the shore. The width of the Spit varies from less than 400 meters near Lesnoye, to almost four kilometers at the Cape of Bulvikis, and covers a territory of some 180 square kilometers. Nowadays more than 70 percent of the Spit is covered by forests, with varieties of pine dominating the landscape. The protection of this environment in its present form raises broader issues of landscape management and human ecology, not least the questions of whether, to what extent and at what cost the envi- 
ronment in its current form can and should actually be protected against the "forces of nature."

In 2000, the year the Curonian Spit received UNESCO World Heritage status, the European Landscape Convention (ELC) was launched by the Council of Europe as the first supra-national instrument devoted to the protection, management and planning of all the landscapes of Europe. This convention does not merely add yet another type of heritage to the catalogue, but offers a fresh outlook by emphasizing the cultural significance and societal value of landscape across different contexts while leaving actual policies, methods, and procedures of implementation to individual countries that have ratified it. In the convention's preamble, its signatories sum up this new approach, stating that landscape has "an important public interest role in the cultural, ecological, environmental and social fields, and constitutes a resource favorable to economic activity and whose protection, management and planning can contribute to job creation." It "contributes to the formation of local cultures and is a basic component of the European natural and cultural heritage, contributing to human well-being and consolidation of the European identity." Landscape is "an important part of the quality of life for people everywhere: in urban areas and in the countryside, in degraded areas as well as in areas of high quality, in areas recognized as being of outstanding beauty as well as everyday areas." This makes landscape "a key element of individual and social well-being and [...] its protection, management and planning entails rights and responsibilities for everyone" (Council of Europe 2000).

For anthropologists, cultural heritage is primarily a cultural construction that happens in the present and refers to the past (Kirshenblatt-Gimblett 1995, Peleikis 2006b). Such constructions of heritage can be described against the background of changing national attachments (Peleikis 2008). Landscape, as defined by the ELC, is such a construction, but it is also material reality with substantive impacts on, and thus relevance for, people's everyday lives and well-being. Historically the most northerly part of successive Germanic polities since the Middle Ages, the Curonian Spit has in the course of the 20th century changed hands several times, and is currently divided between the Republic of Lithuania and Kaliningradskaya Oblast, which forms part of the Russian Federation. A military restriction zone during the Cold War, the Oblast now seeks to develop tourism, with the unique landscape of the Spit viewed as a major asset. On the Lithuanian side, too, tourism development is an important strategy, building also on the artists' colony at Nida and the legacy of the German-Baltic ethnic frontier as heritage resources. With the break-up of the Soviet Union, already existing differences in the approach to the landscape on either side of the Russian-Lithuanian border were exacerbated, and Lithuania's EU membership has created further complexities. While the physical frailty of the cultural landscape has been well recognized on both sides of the current border, political and practical responses have differed markedly. The present essay is a first attempt to survey the present situation in terms of a human ecological perspective on cultural heritage and belonging (see Kockel 2012), drawing on 
an initial period of fieldwork in the Lithuanian part of the region, informed by a recent comprehensive study of governance in the two national parks involved (Albrecht 2008), as well as a range of UNESCO documents and secondary sources.

\section{The State and the Curonian Spit}

Historically, the Curonian Spit in its entirety was for a long time governed by a single authority, the Prussian state. In Prussian times, the protection of the environment started in 1908 with legislation against non-traditional buildings and other impacts on the landscape; thus a set of protective measures has already been in place for over a century. The northern area of the Curonian Spit became a part of Lithuania in 1923. In 1939, the Spit, as part of the Memelland, came under German rule again, but was occupied by the Soviet Union in 1945. From that point on, although the Spit belonged to the same state until Lithuania gained independence in 1990, the two parts were managed separately. Kavaliauskas (2010: 69) contends that already

in the Soviet years, the status of environment protection and formation of cultural landscape in the Lithuanian part of the spit traditionally was considerably better. Even the development plans for the National Park "Kurshskaja Kosa" were worked out following the Lithuanian standards and in close cooperation with the Lithuanian experts.

Moreover, according to Kavaliauskas there is a distinctly different attitude to planning and environmental management in the two jurisdictions, to the extent that "projects regarded as absolutely unacceptable, impermissible and harmful in the Lithuanian part of the spit are rather easily realized in the southern part without any fear to lose the status of the site of World Heritage," for example, "new recreational constructions on the sea shore (Šarkuva/Lesnoje), radical reconstruction of older buildings (Rasyté/Rybatchij), intensive construction of new recreational buildings (Pilkopa/Morskoje), etc" (Kavaliauskas 2010: 69).

The wider Klaipeda region and Kaliningradskaya Oblast are participating in activities associated with the Euroregion Baltija, established in 1998 by representatives of Lithuania, Denmark, Poland, Latvia, Russia, and Sweden. The Euroregion agreement provided a platform for joint projects in a range of fields including environmental protection and tourism, although progress has been slow and it has been noted since that "the nascent Russian-Baltic Euroregions lack substance" (Kononenko 2005: 25). Initiatives for incorporation of the Curonian Spit into the UNESCO World Heritage List (WHL) were already under way, and on May 7-8, 1998, the final declaration of an international conference recommended that the Republic of Lithuania and the Russian Federation submit a joint application to that effect. The application recommended that the Spit be "considered an area of natu- 
ral and cultural value" (Lopata and Sirutavičius 1999: 7). Accordingly, in 1999, both national parks, supported by both national governments and a number of NGOs, prepared a joint nomination for the Curonian Spit to be included in the WHL as a site of outstanding features according to several UNESCO criteria (Lithuanian National Commission for UNESCO 1999), and in 2000, the Spit was finally inscribed on that list as cultural heritage under criterion $\mathrm{C} v$, characterized as

an outstanding example of a landscape of sand dunes that is under constant threat from natural forces (wind and tide). After disastrous human interventions that menaced its survival the Spit was reclaimed by massive protection and stabilization works begun in the 19th century and still continuing to the present day. (UNESCO World Heritage Centre 2000)

This process nominally united the two parts of the Spit once again as a single entity, although there are no policy tools for enforcing unified management structures or even only approaches, and despite repeated attempts to facilitate such integration, not least following UNESCO pressure since 2005 to devise a detailed management plan, progress has been slow. Following inscription of the Curonian Spit on the WHL, Lithuania signed up to the European Landscape Convention (ELC) in October 2000, ratifying it in April 2002. The ELC, which "promotes the protection, management and planning of European landscapes and organizes European co-operation on landscape issues" (Council of Europe 2000), entered into force on March 1, 2004, after ten signatories had ratified it; the Russian Federation has yet to sign up to this treaty. Moreover, the situation of the Curonian Spit has become more complex since Lithuania joined the European Union (EU) in 2004 and has had to adapt to EU environmental policy regulations and projects such as Natura 2000 (Keilbach 2006: 7), designed to protect the most valuable wildlife areas in Europe. The Baltic States had woven the planning and implementation of these measures into their preparations for EU accession. This effectively gave them an edge over many of the older member states, which are struggling with the EU's ambitious environmental policy. In the Baltic States, "whole teams were created to work on the legislative approximation process and, because new laws need to be enacted, the Baltic States chose verbatim transposition and implementation of EU laws" (Keilbach 2006: 8).

The political category of "the state" can refer to any one of a number of levels, from the local to the supra-national, and in practice "the state" refers to a combination of levels and factors as they affect a particular constellation. Theories of multilevel governance, frequently applied in analyzing such constellations, distinguish co-operation networks in terms of a "vertical dimension" and a "horizontal dimension" (Paraskevopoulus 2006: 6). The former refers to co-operation between stakeholders from different levels of authority, for example, between local actors and a state government, whereas the latter refers to co-operation on a comparable level, for example, between local government and other local public agencies. EU 
integration, to some extent, opens up formerly fixed national structures to facilitate a range of multilevel governance relations; the degree of progress with these structural changes depends on the learning ability of national governments, thus determining the success or failure of EU policy (Paraskevopoulus 2006). For Lithuania, these adaptations are also affecting relations with the non-EU part, the Russian side, of the Curonian Spit, where the interplay and interaction between local, national and international levels appears to be characterized by a considerable level of confusion, and accompanied by a somewhat condescending attitude of protagonists on both sides towards one another. This may be a reflection of the very different perspectives that Russia and the EU seem to have with regard to how crossborder co-operation should be organized (cf. Kononenko 2005).

Co-operation and communication between stakeholders in the Kuršiu Nerija, as in other protected areas of Lithuania, is increasingly seen as important:

The new age presents us with new opportunities that can help with the conservation of our most valuable territories. Their management is becoming less centralized, information and education is becoming publically available, and society is being given the chance to participate in the planning and decision making process. (Baskyte et al. 2006: 322)

However, beyond the rhetoric, evidence of notably improved communication between stakeholders or other forms of local community involvement in protected areas remains sparse. The frequently overlapping responsibilities due to poorly defined structures of responsibility between local authorities and other administrative bodies, and a perception of policy of protected area administrations as consisting primarily of restrictions, which leads to conflicts between these administrations and local communities are particularly problematic. The Kuršiu Nerija participated in research evaluating the relationships between local inhabitants, especially entrepreneurs, and governmental and non-governmental authorities towards its administrative practice to identify problems in relation to communication. The study formed part of an international EU-funded program on "Coastal Sustainability as a Challenge" (Grönholm and Berghäll 2007). According to the data presented in that report, over 80 percent of local entrepreneurs in Kuršiu Nerija claim co-operation with the National Park administration as non-existent. Moreover, only 37 percent of other stakeholders report organized co-operation, mostly in the form of information rather than joint activities. However, 83 percent of the Kuršiu Nerija personnel mention examples of co-operation other than the mere exchange of information (Grönholm and Berghäll 2007: 29). Some 58 percent of local inhabitants, and indeed 88 percent of local entrepreneurs, see the restrictions imposed by the Kuršių Nerija administration in a negative light (Grönholm and Berghäll 2007: 70). Judging by these statistics, co-operation between stakeholders is low. This contradicts the observation of increased support for protected areas by local stakeholders, noted by Baskyte et al. (2006: 325). 


\section{Aspects of Implementation}

The Kuršiu Nerija and Kurshskaya Kosa both fall under the responsibility of their respective government ministry for environmental affairs. In Lithuania, the Ministry of the Environment (MoE) has a Protected Area Strategy Division, charged with developing laws and regulations for the protection of natural heritage in Lithuania. The agency responsible for implementation of any conservation-related policies is the State Service for Protected Areas (SSPA; Baskyte et al. 2006: 28). This Service controls environmental protection measures and activities in Lithuania's four national parks. Furthermore, the SSPA is responsible for managing protected areas, assigns administrations to individual areas and implements planning decisions (Baskyte et al. 2006: 28f.). In theory, therefore, the Kuršiu Nerija follows the directions of the SSPA.

In the case of the Kurshskaya Kosa, the Russian Federation Ministry of Natural Resources (MNR) has overall responsibility (Oldfield 2005: 83). The MNR develops and implements legislation with regard to protected areas and conservation, which are managed by a state service subordinated to the ministry. The Natural Resources Management Service (NRMS) implements legislation introduced by the MNR. Unlike the Lithuanian SSPA, which has a more local-regional policy remit, its duties are limited to areas considered of federal significance (Baskyte et al. 2006: 28).

\subsection{Stakeholders}

A wide range of stakeholders are at play on the Curonian Spit (Figure 2): Different government bodies; other public as well as private and voluntary organizations; and, indeed, interested individuals. Among the main stakeholders at a national level are the state institutions, such as the MoE and MNR, with their respective state services, the SSPA and NRMS, as primary institutions with the power of legislation and implementation. A number of further stakeholders with legal powers exist on both sides of the border. 


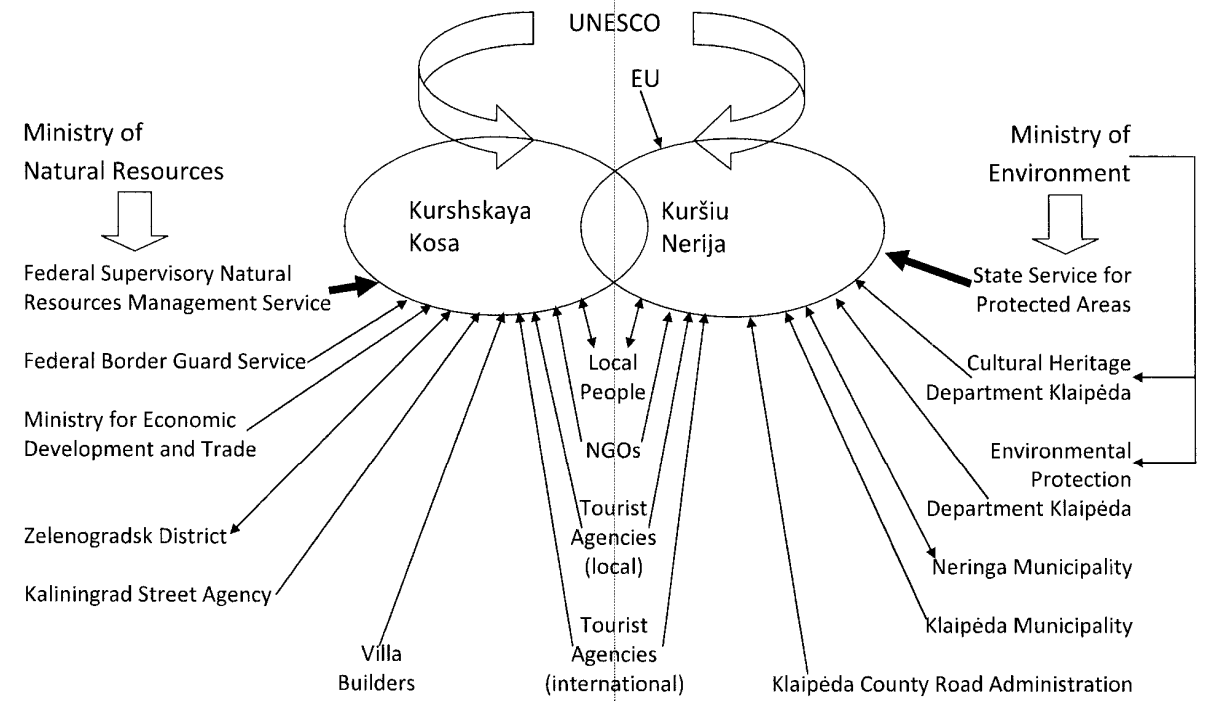

Figure 2: Stakeholders in the Curonian Spit (adapted from Albrecht 2008)

On the Lithuanian side, these are the municipalities of Neringa and Klaipeda, and the regional offices of national agencies, the Cultural Heritage Department and the Environmental Protection Department, both based at Klaipèda, as well as the state forest service. All of these state services are subordinated to the MoE. In the Kuršiu Nerija, unlike elsewhere in Lithuania, responsibility for the state forests lies with the national park administration. On the Russian side, bodies comparable to the regional offices in Lithuania are absent and local government functions differently. Zelenogradsk District's role is not the same as that of Neringa Municipality because its settlements are not included in the Kurshskaya Kosa's territorial definition and remit. Due to these differences in territorial governance, the local population in the Kurshskaya Kosa area is less involved with and affected by the management of the national park than the population in the Kuršiu Nerija, which is directly affected in its everyday life by decisions made in the interest of the national park management.

Other authorities that play an insignificant part in Lithuania have a major role to play in the management of Kurshskaya Kosa. The border guards are one example. Whereas in Lithuania they are almost invisible, in Kaliningradskaya Oblast the service effectively controls the area along the Russian-Lithuanian border to a depth of two kilometers. Another stakeholder whose role and influence is likely to be significant in future years is the Ministry for Economic Development and Trade of the Russian Federation, which has been planning a large-scale tourist development on the Curonian Spit, although this particular project had to be abandoned under 
pressure from the Lithuanian government and UNESCO (Ostpreußenblatt 2011), at least for the time being.

Among the international stakeholders, UNESCO clearly has a dominant role as the institution that controls the World Heritage List. A second key stakeholder is the $\mathrm{EU}$, with various policies and environmental directives that Lithuania is expected to follow. While EU influence extends to both Kuršiu Nerija and Kurshskaya Kosa, it is obviously much stronger on the former as long as Kaliningradskaya Oblast remains outside the EU. The EU offers project funding under a number of schemes, such as TACIS (Technical Assistance for the Commonwealth of Independent States) and INTERREG, which shape initiatives in border regions such as the Curonian Spit (Kennard 2010). Various NGOs, such as the World Wildlife Fund (WWF) or Greenpeace, are involved in such projects, and Greenpeace Russia was involved in the World Heritage List nomination of the Curonian Spit. However, these NGOs are not considered important partners when it comes to managing the World Heritage Site.

The "stake" foreign tourists and companies hold in the Curonian Spit relates primarily to having particular standards and expectations which the World Heritage Site is supposed to meet, and this has an obvious influence on the managers in charge of the national parks. The number of foreign and local tourists differs significantly between the Kuršiu Nerija and the Kurshskaya Kosa, which has considerably smaller numbers of especially foreign visitors.

\subsection{Co-operations and Constellations}

Co-operation between the Kuršiu Nerija and the Kurshskaya Kosa commenced in 1997-98. The chief reason was the nomination of the Curonian Spit as a UNESCO World Heritage Site straddling the border between the two jurisdictions (Kvietkus 2005: 59f.). Albertas Kvietkus, former Deputy Director for Natural and Cultural Heritage at the Kuršiu Nerija, outlines the key stages of co-operation between the two administrations over the period 1998-2004. The co-operation agreement between the Kuršiu Nerija and the Kurshskaya Kosa of May 1, 1998 is identified as the first stage. The agreement set out measures for a joint action required to meet the standards of a World Heritage Site, especially collaborative research and the safeguarding of human-made heritage landscape features. Through staff training and the provision of information for visitors, the image of a unified territory and full communication with stakeholders at all levels was being projected. The second stage, between 1998 and 2000, was the preparation of the nomination document (Kvietkus 2005: 60), with applications for joint projects under IINTERREG and TACIS forming the third stage (1999-2004), and the fourth stage was envisaged as full-blown co-operation between administrators and specialists of Kuršiu Nerija and Kurshskaya Kosa, in accordance with the co-operation agreement (Kvietkus 2005: 61). 
There have been few agreements at state level concerning governance or development of the Curonian Spit, although the Lithuanian Ministry of Environment had declared this as its primary aim for international co-operation during the period 2005-2007 (Ministry of Environment of the Republic of Lithuania 2005). The only major agreement related to a joint environmental impact assessment of a Russian oil rig located 22 kilometers off the Curonian Spit (UNESCO World Heritage Centre 2005b).

Some stakeholders have been involved in active conflict in both national parks. The conflicts in the Kuršiu Nerija have been between the national park administration, Neringa Municipality and local inhabitants or their representatives. The Kurshskaya Kosa has seen different conflicts between the authorities of the three settlements and wealthy entrepreneurs, supported by their political connections, who are building illegal residences (Russland aktuell 2007). In both cases, a key issue is the desire of the local authorities to expand the areas available to them for further construction and to improve tourist infrastructure. The conflicts in Lithuania are mainly clashes of opinion over interpretations of the specific points in the law, whereas in the Kurshskaya Kosa, strictly illegal building work, both within and outside the settlements and even in the protected dunes, is a major problem.

A related issue arises over the further development of existing settlements. Private building plans must be approved by the municipality in accordance with their socioeconomic policies and goals, and Neringa municipality has occasionally approved proposals that have later been turned down by the Kuršiu Nerija administration. Both bodies are charged with agreeing joint general development plans, but the process is fraught as the question of legal superiority has not been sufficiently clarified.

In the Kurshskaya Kosa, the lack of a general planning document means disputes often end up in court, especially where illegal construction is concerned. The national park administration frequently comes into conflict with Zelenogradsk District over the issue of tourist infrastructure. The situation of the settlements, which remain outside the remit of Kurshskaya Kosa, continues to be problematic. Interestingly, the Kuršiu Nerija's Deputy Director for Economic and Forestry Development, Viktoras Kolokšanskis, sees most of the conflicts in the Kuršiu Nerija as due to the fact that the settlements are within the national park area and managerial remit.

Co-operation between the Kuršiu Nerija and Neringa has been hampered by conflicting sets of aims and objectives. Whereas Neringa, as a municipality, has to look after the local inhabitants, Kuršiu Nerija deals with natural and cultural heritage. One issue raised by Kuršiu Nerija staff is the absence of local people involved in the original culture of the region. The Curonian Spit was resettled with new inhabitants after the Second World War, so that 
most of the adult inhabitants living on the spit are in the first generation and the community's common collective memory of the region only reaches back 50 years. Local identity has no roots in the history and culture of the spit. This lack of identification with the surrounding cultural landscape reinforces the [...] negative tendencies of regional development, especially at the social level. (Pluhařova-Grigiene 2006: 4)

Arguably, these new locals lack a real understanding of the cultural and natural heritage and values around them - a point I will pick up again toward the end of this discussion.

While Neringa officials may accuse Kuršiu Nerija staff of acting contrary to local needs, staff of the Kuršiu Nerija sometimes see local inhabitants as being interested only in quick income, careless about tradition and heritage, and unsupportive of the Kuršių Nerija administration's attempts to develop sustainable tourism.

With regard to co-operation, the Kuršiu Nerija staff mentioned the agreement of 1998, but this seems to have had little practical effect in terms of engendering co-operation between the two administrations. The World Heritage Committee, in its Decision 34COM7B.91 regarding the state of conservation of the Curonian Spit, had requested the Russian Federation and Lithuania to invite a World Heritage Centre-ICOMOS-IUCN monitoring mission, and to review their draft Statement of Outstanding Universal Value for the property. A joint report on the state of conservation on the Spit and implementation of the various actions requested was due to be submitted to the World Heritage Centre by February 1, 2011, for examination by the World Heritage Committee at its 35th session (UNESCO World Heritage Committee 2010). The visit of the monitoring mission to both parts of the Curonian Spit took place in December 2010 (Lithuanian National Commission for UNESCO 2011). At the time of writing, Kuršiu Nerija staff were still drafting the joint "Statement of Outstanding Universal Value of the Curonian Spit," but there had been limited input from the Russian side.

The main co-operative activity both administrations appear to engage in regularly is the exchange of information. The two administrations also support a scientific co-operation project, and co-operative meetings have been increasing. However, the two administrations entertain different priorities with regard to cooperative efforts; whereas the Kurshskaya Kosa favors development of a unified tourist information system, the Kuršiu Nerija seeks broader co-operation and mutual learning. Kuršiu Nerija staff, for example, holds the ecological education activities of Kurshskaya Kosa in high regard and would like to improve their own provision through co-operative ventures, offering, in turn, to support their colleagues at Kurshskaya Kosa in matters that may be of interest to them.

Since Lithuania is expected to comply with EU environmental policies and receives funding for this, the Lithuanian state has expected the Kurshskaya Kosa to apply the same standards in the context of the cross-border UNESCO World Heritage Site. However, there have been political and administrative obstacles to this. 
Co-operation projects, such as a tourist boat line between Klaipeda and Rybachy, for example, could not be developed despite the availability of EU funding, owing to the Russian Federation's regulations concerning border controls for sea traffic. While the UNESCO World Heritage Centre has high-lighted the demand for joint planning schemes in its Annual Reports, there does not seem to be much pressure by UNESCO to implement more co-operative ventures. An exception to this has been the environmental impact assessment which UNESCO required, in response to an initiative by the Lithuanian government, in order to keep the Curonian Spit off the List of World Heritage in Danger (UNESCO World Heritage Centre 2005b).

Vertical as well as horizontal co-operation between the stakeholders at various levels is required to achieve multilevel governance (Paraskevopoulus 2006: 6). EUfunded projects are often required to involve different levels of authority. One such project was the aforementioned boat line between Klaipeda and Rybachy. This included the two national park administrations along with Kaliningradskaya Oblast, Zelenogradsk District and the municipalities of Klaipeda and Neringa, with Klaipeda being the lead partner. Moreover, Neringa Municipality co-operates with Zelenogradsk District under a long-term agreement involving local entrepreneurs in tourist development, and the Kuršiu Nerija administration, for example, cooperates with the Kaliningrad-based NGO Ecodefense, and has organized school exchanges between Rybachy and Juodkrante to engage children in the cleaning up and strengthening of dunes.

\subsection{Economic Development}

There has been a shift towards a greater focus on economic and social issues in the Kuršiu Nerija. Since the municipality earns most of its revenue through tourism, developing the tourist business through unique recreational resources is of key importance. Settlements in the Kuršiu Nerija are part of the national park, which is effectively divided into two distinct but overlapping spheres of managerial responsibility, unofficially described by Lina Dikšaitè, Deputy Director of Natural and Cultural Heritage as the "city zone," managed by the Neringa and Klaipeda Municipalities, and the "forest zone," managed by the Kuršiu Nerija administration (interview, May 2, 2011). The overlap results from the existence of cultural protection areas in the settlements, and the municipalities support the Kuršiu Nerija administration financially. Beyond this, the local population or community groups play no significant role in the management and governance of the Kuršiu Nerija. The municipalities regard themselves as representing the people of the area, but the Kuršiu Nerija does not see the local population as stakeholders responsible for management decisions of their own.

Since the Curonian Spit has been inscribed on the UNESCO World Heritage List, the World Heritage Committee (WHC) has published several reports on its regular meetings, containing recommendations and discussions concerning current 
issues. At one such meeting, both states concerned with the Curonian Spit were asked to co-operate in a risk assessment of a Russian off-shore oil rig (UNESCO World Heritage Centre 2002). Subsequently, Lithuania complained that the Russian Federation had failed to share information and was obstructing co-operation, while the Russian Federation insisted that all relevant information was readily available (UNESCO World Heritage Centre 2003: 56). The World Heritage Committee then urged both states to make progress on the environmental impact assessment, cautioning the Russian Federation against commencing oil extraction before the required assessment had been carried out; the Committee also requested

a joint UNESCO/ICOMOS/IUCN mission to be undertaken to the site in full collaboration with the Russian and Lithuanian authorities, and a detailed report by the State Party of the Russian Federation to be prepared on the state of the project, by 1 February 2004, for examination by the 28th session of the World Heritage Committee. (UNESCO World Heritage Centre 2003:56)

The subsequent report noted efforts to improve the management of the site. Lithuania had by then requested that the Curonian Spit be added to the List of World Heritage in Danger, as Russia was proceeding with oil exploration and the environmental impact assessment remained outstanding. The World Heritage Committee responded with an ultimatum to both states to come to an agreement by the committee's next meeting (UNESCO World Heritage Centre 2004). Under pressure, the two governments finally managed to communicate on the environmental impact assessment and a number of other common projects, and the Curonian Spit was saved from inclusion on the List of World Heritage in Danger (UNESCO World Heritage Centre 2005a: 91), but the committee requested a detailed report on progress with co-operation between the two national parks, as well as jointlyprepared documentation on the current state of the property, for its next session (UNESCO World Heritage Centre 2005a: 91). The 2006 report of the committee noted that the required joint documentation had not been submitted, and the two states were given an extension until February 2007 (UNESCO World Heritage Centre 2006: 220). This episode reflects the slow progress towards co-operation at state level and the persistent need for UNESCO, through the World Heritage Committee, to seek compliance with agreements by exerting international pressure. Lithuania quasi forced the committee to act by nominating one of their designated heritage sites for the List of World Heritage in Danger. This indicates greater willingness to co-operate on the part of Lithuanian state authorities, compared to their Russian counterparts, at least in this instance. 


\subsection{Culture vs. Nature}

The differences in the development directions and priorities between the two national parks need to be kept in mind with regard to natural and cultural heritage. Problems of natural heritage exist, with dune erosion being an issue on both sides of the border. The Kurshskaya Kosa sees the problem as a minor one that can be managed, whereas Kuršiu Nerija staff express concern about different problems related to the dunes that need to be tackled urgently, in particular the natural succession of grey dunes, and the coastal erosion on the shores of both the Baltic Sea and the Curonian Lagoon. The Kuršiu Nerija staff sees no solution to this problem and believe it is only a matter of time until the grey dunes disappear. With good management, they hope to delay this process for as long as possible. Further to the landscape impact of natural forces, the negative impact of tourist developments can be noted. Obviously, the much higher number of visitors in the Kuršiu Nerija, compared to the Kurshskaya Kosa, causes considerable pressure there. A related concern is the danger of forest fires potentially ignited by a discarded cigarette or an illegal camp fire. Coniferous forests dry out in summertime and the risk of fires is high; the big fire of 2006, for example, devastated some 230 hectares of forest and shrubs.

Natural problems have little regard for human boundaries; problems of cultural heritage seem, however, to be non-existent on the Russian part of the Spit. Traditional buildings tend to be in poor condition, or have been restored in a nontraditional manner. Cultural heritage in the Kurshskaya Kosa exists today primarily in the form of the cultural landscape, and the strategic impetus for its consistent management appears to be lacking, whether for want of resources or due to other, more systemic, cultural reasons, as some Lithuanian observers suspect: "The reality of the Kaliningrad oblast is that strategies will never be clear, always chaotic" (Lopata and Sirutavičius 1999: 9).

The Kuršiu Nerija, in contrast, has strict regulations concerning traditional buildings, and maintains a more or less "authentic" atmosphere, although critics note that most of the "traditional" houses are in fact copies and can only barely be considered traditional. Nevertheless, protecting and preserving this cultural heritage is a major concern for the Kuršiu Nerija. Given a relative paucity of traditional buildings on the Russian side, it is surprising that UNESCO seems to have taken little notice of the discrepancy, and there is no reference to the problem in any of the World Heritage Committee reports.

As a historical cultural landscape straddling a multifaceted international border - one that separates an EU from a non-EU member state, a former Soviet republic from its one-time superpower, and the northern tip from the rest of a once German province - the Spit is exposed to multiple stakeholder interests that try to navigate the parameters established by bodies such as UNESCO, and frameworks such as the European Landscape Convention, that seek to regulate heritage. The UNESCO World Heritage Committee, at its 2010 meeting in Brasilia (UNESCO 
World Heritage Committee 2010), chastised the Kaliningradskaya Oblast for its ambitious plans to develop tourism on the Russian part of the Curonian Spit. The threat of the Spit's inclusion on the Danger List, averted in 2005 after assurances were given by both governments with regard to off-shore oil production in the region, was back on the horizon, although this now seems to have been averted once more (Ostpreußenblatt 2011).

The genesis of different visions of heritage and their utilization for the purposes of national identity formation is an issue that cannot be explored in depth here, given the focus of the essay on more technical questions, but some observations should be noted. Anja Peleikis has studied the local context extensively, especially on the Lithuanian side, for a number of years (Peleikis 2006a, 2006b, 2008). Her work highlights different heritage discourses at the grass-roots level that have significance for the present topic even if the groups involved are not among the most potent stakeholders and their influence is felt rather indirectly. In both parts of the Curonian Spit, the majority of the normally resident population are immigrants from other parts of the jurisdiction (or former jurisdiction), who have often come to their new home from a considerable distance. Hence the sense of rootedness and ownership of whatever cultural heritage outside agencies, including one's own state government, may perceive in the locality is generally limited. Having not yet carried out fieldwork in Kaliningradskaya Oblast, I can only comment here on the Lithuanian part of the Spit. In this region, there appears to be an intriguing process - or rather, a set of processes - of re-rooting at work, involving a handful of very different groups. One of these are returning refugees and expellees who left the Memelland at the end of the Second World War and who, since the collapse of the Soviet Union, have been returning to their former homeland, mainly to reconnect with their memories and a particular construction of what constitutes "their" heritage. Most of these are ethnically German, although there are also ethnic Lithuanians among this group, exiled during the Nazi or Soviet periods. Another group are internal migrants from different parts of Lithuania who have settled on the $\mathrm{Cu}$ ronian Spit since 1945. Many of these take a keen interest in a cultural heritage that was not theirs until they came here, but which they are now trying to appropriate in a respectful manner. There is little or no precedence for such cultural practice and many analysts would be quick to point out the constructedness of it all. While acknowledging that they do have a point, I have discussed elsewhere (e.g. Kockel 2012) why I am not inclined to follow their analysis. Peleikis (2008) has argued that what we are witnessing here are discourses of cultural property rights that relate to different epochs, and which, therefore, can co-exist in relative peace. In formal, legal terms, local and national actors have the power of definition over the locality and any heritage representations connected with it. However, as Peleikis points out, tourists - including cultural heritage tourists - are a major source of income and the Spit depends on this income. Therefore, German lieux de memoire are acceptable if they bring tourists to the region. This means, however, that the same places may be interpreted entirely differently by different groups, and different 
heritage representations may exist side by side. Peleikis wonders whether, in time, these might be replaced by a common European heritage discourse. Such a common discourse is, arguably, already emerging, although the range of "commonality" depends largely on where and how one draws the boundaries of "Europe" (Kockel 2010). There is a certain postmodern cosmopolitanism that regards the existence side-by-side of sometimes highly divergent heritage claims as evidence of a new "European" heritage discourse transcending the old animosities between different peoples sharing the European space. Ideas of mutual tolerance, underlying a vision of "unity in diversity," are evident in this interpretation. On the Curonian Spit and in many other border regions, stakeholders frequently include groups who may have historical roots but no contemporary basis in the region. The challenge of creating a shared European heritage discourse is all too often perceived rather restrictively in terms of metanarratives - primarily that of reconciling the European credentials of the three monotheistic religions. At the local, everyday level, a " $\mathrm{Eu}-$ ropean" heritage discourse is conceivable but likely to remain, at least for some time, a matter of practical negotiation and largely pragmatic circumnavigation of the obstructions created by different local, regional and national actors. However, as opportunities for interregional networking and experience exchange increase, the interpretations by different groups of their historical and environmental circumstances as singular may well be expected to shift towards shared narratives, out of which a common heritage discourse may, in time, emerge.

\section{Summary and Conclusion}

This essay is a first attempt to compare and contrast approaches to landscape conservation in the two jurisdictions sharing - at least nominally - a UNESCO World Heritage Site. A particular emphasis has been on aspects of cultural import, and raising some questions for ethnographic research.

The SSPA sets the framework for management and decision-making for the Kuršiu Nerija. Thus the national park's general management plan is shaped primarily by a national authority. Moreover, the local municipalities, as stakeholders in the planning process, but often overruled by the Kuršiu Nerija administration, are not always able to affect the situation of their inhabitants and other public stakeholders to the extent and in the ways they would like. There is a division of responsibilities between the Kuršiu Nerija administration and Neringa and Klaipèda municipalities as the main players at a local level, with a large set of bodies representing other stakeholders. However, there is also on-going tension between Neringa municipality and the National Environmental Protection Agency, which constitutes

a serious obstacle in finding best land management solutions. In the current situation, it would be best to return to the integrated planning of the $\mathrm{Cu}$ ronian Spit. [...] It is necessary to reach closer cooperation with the admin- 
istrative institutions of the southern part [...] and to develop a common vision for the future of the whole Curonian Spit. (Kavaliauskas 2010: 71)

The Russian part has been divided into three administrative zones, with the settlements and the restricted border area taken out of the remit of the national park management and each of the three zones following its own planning directions. This makes the sustainable management of the World Heritage Site difficult. In the absence of appropriate legislation, and with the three settlements excluded from the protected area, local residents and newcomers show little or no interest in protective measures.

The border remains a major problem for the development of the region, not only because of the Russian customs regime, but also because of the EU's reinforcement of border controls in the context of the Schengen Agreement, which creates conflicts with other EU policies. While external borders of EU member states were initially seen as channels for co-operation, following the $2004 \mathrm{EU}$ enlargement "the prevailing discourse in the Baltic states tends to view the EU's external border more cautiously as a line protecting the EU's internal stability against external risks" (Kononenko 2005: 24). Moreover, as Kononenko (2005: 25) notes, "border regions have their own place in the border discourse. This is something that often tends to be overlooked if one focuses on such aspects of border regime as Schengen, visas, migration and so forth." This wider significance of the Curonian Spit, not least as a multi-layered lieu de memoire for different stakeholders, is only beginning to be explored in the work of Peleikis (2006a, b, 2008) and others.

It seems from the reports of the World Heritage Committee, corroborated by interviews with Lithuanian officials, that communications relating to the Curonian Spit are primarily conducted by the SSPA and the NRMS with UNESCO rather than directly with each other, and the lack of motivation on the Russian side, as noted in those reports $(2003,2004,2005 a)$, appears to have been a major impediment to the establishment of common management structures and procedures. At the time of writing, there are on-going discussions on the Russian side with regard to the new recreational zoning, with conflicting signals being sent across the border concerning the progress with or rejection of specific proposals, such as the large-scale tourism development mentioned above (4.1). A meeting between the main stakeholders on both sides of the border to discuss cross-border cooperation concerning issues raised by UNESCO was due to take place at Nida in late 2011. 
Acknowledgments. I would like to thank Ms Lina Dikšaitè, Kuršiu Nerija national park administration, and Prof. Rimantas Sliužinskas, Institute of Baltic Sea Region History and Archaeology, University of Klaipeda, for sharing their extensive knowledge of the Curonian Spit with me during my fieldwork in May 2011, and for their very helpful comments on an earlier draft of this essay.

Thanks are also due to the reviewers for a number of useful suggestions.

\section{$5 \quad$ References}

Albrecht, Moritz (2008): Governance of the National Parks on the Curonian Spit: Applied Management, Conflicts and Stakeholder Co-operation. Joensuu: Department of Human Geography, University of Joensuu.

Baskyte, Ruta, Vidmantas Bezaras, Paulius Kavaliauskas, Algimantas Klimavicius, and Gediminas Rascius (2006): Protected areas in Lithuania: State Protected Areas Service under the Ministry of the Environment. Kaunas: Lutute Publishing Company.

Council of Europe (2000): The European Landscape Convention.

http://www.coe.int/t/dg4/cultureheritage/heritage/landscape/ < accessed May 31, 2011>

Grönholm, Sam, and Jonna Berghäll (2007): Cooperation between Coastal

Protected Areas and Surrounding Societies: From Experiences to

Recommendations. Vantaa: Metsähallitus.

Kavaliauskas, Paulius (2010): Sustainable and Balanced Development of Lithuanian Curonian Spit and Neringa Municipality: Planning and Political Aspects.

Technological and Economic Development of Economy: Baltic Journal on Sustainability 16(1): 58-74.

Keilbach, Patricia M. (2006): Governance or Government? Explaining Pathways of

Nature Protection in the New EU Member States. In 2006 Meeting of the

Central and Eastern European International Studies Association, Tartu,

Estonia June 24-27. Tartu: CEEISA.

http://www.ceeisaconf.ut.ee/orb.aw/class=file/action=preview/id=169191/

Keilbach.pdf < accessed May 30, 2011>

Kennard, Ann (2010): Old Cultures, New Institutions: Around the New Eastern

Border of the European Union. European Studies in Culture and Policy, 8.

Berlin: LIT Verlag.

Kirshenblatt-Gimblett, Barbara (1995): Theorizing Heritage. Ethnomusicology 39(3): 367-380.

Kockel, Ullrich (2010): Re-Visioning Europe: Frontiers, Place Identities and

Journeys in Debatable Lands. Basingstoke: Palgrave-Macmillan.

- (2012): Being From and Coming To: Outline of an Ethno-Ecological

Framework. In Radical Human Ecology: Intercultural and Indigenous 
Approaches. Lewis Williams, Rose Roberts, and Alastair McIntosh, eds. Pp. 57-71. Farnham: Ashgate.

Kononenko, Vadim (2005): New departures on the EU- Russian Border?

Assessing discourses and policy practices. Journal of Borderlands Studies 20(2): 13-29.

Kvietkus, Albertas (2005): Kursiu Nerija National Park (Lithuania) -Kursskaja

Koja National Park (Russian Federation): Cooperation between 1998 and

2004. In World natural heritage and cultural landscapes in Europe: The

potential of Europe's World Natural Heritage. Andrea Burmester, Barbara

Engels and Birgit Scheuerbrandt, eds. Pp. 59-63. Bonn: Bundesamt für

Naturschutz.

Lithuanian National Commission for UNESCO (1999): UNESCO - World

Heritage Nomination Curonian Spit.

http://unesco.lt/uploads/file/failai_VEIKLA/kultura/Pasaulio_paveldas

Lietuvoje/nerija_dok/curonian_spit_nomination_EN.pdf < accessed May 31, 2011>

- (2011): Activity Report 2010.

http://unesco.lt/uploads/file/failai_APIE/Nackomisija/ataskaitos_EN/repor t_2010.pdf < accessed June 1, 2011>

Lopata, Raimundas, and Vladas Sirutavičius (1999): Lithuania and the Kaliningrad

Oblast: a Clearer Frame for Cooperation, Lithuanian Foreign Policy Review

No. 3.

http://www.lfpr.lt/uploads/File/1999-3/Lopata_Sirutavicius.pdf < accessed

May 31, 2011>

Ministry of Environment of the Republic of Lithuania (2005): Priorities of

International Cooperation in Environment Formation and Protection in 20052007.

http:// www.am.lt/VI/en/VI/index.php\#a/84 < accessed May 31, 2011>

Oldfield, Jonathan (2005): Russian Nature: Exploring the Environmental

Consequences of Societal Change. Farnham: Ashgate Press.

Paraskevopoulos, Christos J. (2006): EU Enlargement and Multi-Level

Governance in European Public Policy-Making: Actors, Institutions and

Learning. In Adapting to EU Multi-Level Governance: Regional and

Environmental Policies in Cohesion and CEE Countries, Christos J.

Paraskevopoulos, Panagiotis Getimis, and Nicholas Rees, eds. Pp. 3-24.

Farnham: Ashgate.

Peleikis, Anja (2006a): Tourism and the Making of Cultural Heritage: The Case of

Nida (Curonian Spit), Lithuania. Acta Historica Universitatis Klaipedensis Vol.

XII, Studia Antropologica Vol. I: 101-114.

- (2006b): Whose Heritage? Legal Pluralism and the Politics of the Past. A Case

Study from the Curonian Spit (Lithuania), Journal of Legal Pluralism 53-54: 209-237. 
- (2008): Recht und die Konstruktion von Kulturerbe: Das Fallbeispiel Kurische Nehrung (Litauen).

http://www.mpg.de/373422 <accessed May 28, 2011>

Pluhařova-Grigiene, Eva (2006): The Curonian Spit: Identity and Cultural Heritage.

Paper presented at the Forum UNESCO University and Heritage 10th

International Seminar "Cultural Landscapes in the 21st Century". Newcastle-

upon-Tyne, April 11-16, 2005.

Preußische Allgemeine Zeitung (2011): Pläne für Touristenparadies verworfen. Die

Kurische Nehrung soll nun doch geschützter Nationalpark bleiben. No. 14,

April 9: 13.

Russland aktuell (2007): Kurische Nehrung - Schwarzbauten und

Massentourismus.

http://www.kaliningrad.aktuell.ru/kaliningrad/im_gebiet/kurische_nehrung_s chwarzbauboom_und_massentourismus_118.html < accessed May 31, 2011>

UNESCO World Heritage Centre (2000): Curonian Spit.

http://whc.unesco.org/en/list/994 < accessed May 31, 2011>

- (2002): Decision - 26COM 21B.57 - Curonian Spit (Lithuania/Russian

Federation).

http://whc.unesco.org/en/decisions/899 <accessed May 31, 2011>

- (2003): 27COM7B.70.

http://whc.unesco.org/archive/2003/whc03-27com-07be.pdf < accessed May

31, 2011>

- (2004): Decision - 28COM 15B.75.

http://whc.unesco.org/en/decisions/247<accessed May 31, 2011>

- (2005a): WHC-05/29.COM/7B.Rev.

http://whc.unesco.org/archive/2005/whc05-29com-07BReve.pdf < accessed

May 31, 2011>

- (2005b): Agreement between Lithuania and the Russian Federation keeps

Curonian Spit off List of World Heritage in Danger.

http://whc.unesco.org/en/news/107 <accessed May 31, 2011>

- (2006): WHC-06/30.COM/7B. http://whc.unesco.org/archive/2006/whc06-

30com-7bE.pdf < accessed May 31, 2011>

UNESCO World Heritage Committee (2010): Curonian Spit (Lithuania - Russian

Federation) (C 994), WHC-10/34.COM/20. Paris: UNESCO.

UNESCO World Heritage Nomination Curonian Spit (1999)

http://www.unesco.lt/documents/Paveldas/Kursiu\%20nerija/curonian\%20s

pit_nomination.pdf < accessed December 15, 2011> 
States and their 'Thing': Selection Processes, Administrative Structures, and Expert Knowledge 



\title{
The Chinese Paper-Cut: \\ From Local Inventories to the UNESCO \\ Representative List of the Intangible Cultural Heritage of Humanity
}

\author{
Caroline Bodolec
}

\section{Introduction}

On December 2, 2004, China became the sixth country to ratify the 2003 UNESCO Convention for the Safeguarding of Intangible Cultural Heritage. In 2011, the country held the largest number of elements on the Representative List of the Intangible Cultural Heritage of Humanity (29 of a world total of 232) and on the List of Intangible Cultural Heritage in Need of Urgent Safeguarding (7 of 27). ${ }^{1}$ This can be seen as another expression of the international cultural "Soft Power" of China (Huang 2006, Kurlantzick 2007, Li 2009), but it would miss the national impact of the UNESCO Convention. The translation of the concepts into the Chinese cultural laws has had profound consequences for all the elements now called Intangible Cultural Heritage (ICH). The first part of this article presents the modifications of the Chinese administrative structure subsequent to the ratification of the 2003 Convention (Wang 2010). This highlights some of the ideological concepts mobilized by the government to integrate the previous cultural policies. In the same way, it is important to see how the convention principles were read and interpreted through actual national ideology, as, for instance, the bexie shebui 和谐社会, the "harmonious society." In the second part, the example of the Chinese paper-cut practice, a form of popular art performed predominantly by wom-

1 cf. UNESCO 2011a. 
en, is considered in order to reveal the compiling of the files, starting with a local survey to the inscription on the UNESCO Representative List. Based on information gathered during my ethnographic researches in Shaanxi province since 1995 (Bodolec 1999, 2005, 2010a, 2010b, 2012) and the study of provincial and national ICH lists, the analysis aims at presenting the channels of communication and the role of the actors at every step of the process. The purpose is to examine how the new international concept of ICH can affect local cultural policy.

\section{The Popular Republic of China and Intangible Cultural Heritage}

Only four months after the ratification of the UNESCO Convention on March 26, 2005, the Chinese State Council decreed a Recommendation to Intensify the Protection of National Intangible Cultural Heritage. ${ }^{2}$ This document also announced the government projects of national inventories and of a National Representative List of Intangible Cultural Heritage which constitute the core of the Chinese action plan for the implementation of the 2003 Convention. Until this date, cultural heritage was associated with the National Bureau of Cultural Heritage, ${ }^{3}$ but in order to show the importance given to the new concepts, a special organization was established.

\subsection{Modifications of the Administration of Culture in China}

The recommendation created the Interdepartmental Meeting for the Protection of Intangible Cultural Heritage, ${ }^{4}$ a temporary organization directly responsible to the State Council. It was composed of vice-directors of important administrations, such as the Ministry of Culture, the Ministry of Education, the Ministry of Planning, the National Board for Reforms and Development, the National Board for Minority Affairs, the National Bureau of Religious Activities, the National Bureau of Tourism, and the Ministry of Budget. A centralized management was intended which is clearly linked with the difficulties of administrative divisions for the Chinese sites of the World Heritage List. The management of these sites is the responsibility of local government but they are also subject to regulations of the various ministries (Ministry of Planning, Ministry of Environment, Ministry of Culture, and sometimes National Bureau of Religious Affairs). The dialogue between the various administrations is not regulated and can lead to difficulties in site manage-

\footnotetext{
2 Guowu yuan baogongting guanyu jiaqiang, woguo feimushi wenhua yichan baobu gongzuo de yijian 国务院办公厅关于加强我国非物质文化遗产保护工作的意见 ${ }^{\circ}$ guoban 国办 [2005] 18, March 26, 2005, published in Guowu yuan gongbao 国务院公报, $\mathrm{n}^{\circ} 4,2005$.

${ }^{3}$ Guojia wепши ju 国家文物局.

${ }_{4}^{4}$ Feiwuzbi wenhua yichan baobu gongzuo bu jïlianxibui yizhidu 非物质文化遗产保护工作部际联席会议制度。
} 
ment. This is clearly the case when the touristic interest takes precedence over cultural integrity at the risk of displeasing UNESCO (Xie 2004: 35-37). Funding came primarily from local government and the national guidelines are not always considered. The establishment of an Interdepartmental Meeting as a single manager aims to avoid the problems of split jurisdiction. It also expressed that the Central Government put considerable importance on this issue, looking for the most effective solutions.

When it was created, the Interdepartmental Meeting was associated with an existing department of the Ministry of Culture, the Department for Social Culture and Library Administration, ${ }^{5}$ which is in charge of popular culture and ethnological research through an extensive network of cultural centers. ${ }^{6}$ Each district in China has a cultural center with one or more official state ethnologists. They are usually native to the region, fully aware of the local culture and have close contacts with the population. This had great importance in the rapid development of inventories of cultural practices as of the third quarter of 2005.

In March 2008, the Interdepartmental Meeting for the Protection of Intangible Cultural Heritage was officially replaced by a permanent organization: The Intangible Cultural Heritage Division. ${ }^{7}$ Established within the Ministry of Culture, it is no longer connected with the Department of Social Culture and the local cultural centers. Its main partners are now the provincial cultural administrations.

\footnotetext{
5 Shehui wenhua chu 社会文化处.

6 Wenhua guan 文化馆.

${ }^{7}$ Feiwuzhi wenhua yichan si 非物质文化遗产司. This name was added to the Social Heritage Bureau in 2007 but without a special budget and without the creation of positions (Wang 2010: 187).
} 


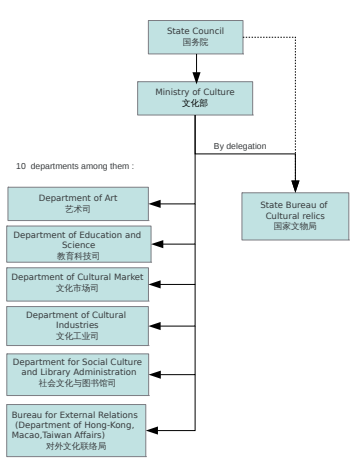

Figure 1, left: The Organization of the Chinese Ministry of Culture before 2008

(Chinese Government n.d.).

Figure 2, right: The Organization of Chinese Ministry of Culture since 2008

(Chinese Government n.d.).

The new institution has three sections: Management, Protection and the General Secretariat, ${ }^{8}$ to meet its numerous missions. In line with UNESCO requirements, the ICH division manages the safeguarding of projects and the National Repre-sentative List of ICH (file evaluations and elections); it also prepares the national protection policies and the legislative regulations. More surprisingly, the division deals with "the transmission and popularization of elements of excellence of national Chinese culture." The definition of this "national culture," as well as the elements included in it, have been constantly modified since the end of the 19th century in order to match the current political situations (Wang 1997). By this decree, the newly created division is now responsible for this aspect, which is important for the harmony of the country. Furthermore, for the first time, the term "excellence" appears in official policy papers. It is meant to - in contradiction of the UNESCO Conventions' principles - sort among the cultural and social practices of China. Only some of them will be worthy of being considered part of the Chinese national culture.

${ }^{8}$ Guanli chu 管理处, baobu chu 保护处, bangong shi 办公室. 


\subsection{From the Study of Folk Culture to the Recognition of Intangible Cultural Heritage Elements}

The Chinese government did not wait for the UNESCO Convention to take an interest in local cultures. Since the foundation of the People's Republic of China in 1949, rural practices were set as an example for the new socialist society. In addition, as of 1953, the Central Ethnic Affairs Commission began to organize anthropologists, ethnologists and, more generally, researchers on minority areas to do fieldwork on minority languages and practices. This project, called Ethnic Groups Recognition, ${ }^{9}$ led to the establishment of the 55 minority designations in China (7\% of the population in $60 \%$ of the territory) and permitted the publication of numerous books and documentaries (Fei 1980, Wang 1997, Liu 2003). This large investigation was, however, marred by the political ideology of the time: Studying these populations, "the other ones," was to lead them to socialism and modernity (Baptandier 2001). By studying and popularizing the minorities' cultural practices, the Chinese scholars participated in the creation of a "new united nation" after 1949. However, they also contributed to the construction of the Han Chinese majority discourse of modernity and progress by focusing the researches on the most "primitive" and "colorful" costumes (Gladney 1994, Liu 2012). The minorities have played the role of an "internal orientalism" (Schein 1997, Allès 2011). During this period, studies of popular practices concentrated almost exclusively on minorities, neglecting the incredible diversity of practices of the Han nationality $(95 \%$ of the population).

The Cultural Revolution during the 1960s and early-1970s rejected cultural and popular practices: Numerous artifacts, objects and instruments were destroyed. Some knowledge owners also suffered the throes of this period as representatives of the old culture to be eliminated (Clark 2008, King 2010). It was not until the 1980 s that some intellectuals and, thereafter, cultural authorities developed renewed interest in these issues. A new program of investigation was organized as of 1980 , based on the 1950s' inventories, but rather focused on music and literature. In 2006, the 298 volumes of Collection of ethnic and popular art and literature ${ }^{10}$ were published under the supervision of the Central Ethnic Affairs Commission and the National Confederation of Art and Literature Associations. This collection was one of the most important cultural projects since the foundation of the People's Republic of China (Wang 2010).

Since the 1990s, in addition to those national actions, China has been involved in international reflections on popular culture. China has closely followed the debates with the World Intellectual Property Organization (WIPO) and UNESCO since the late-1970s and early-1980s (Wang 2010). China was particularly interested

${ }^{9}$ Minqu shibie 民族识别.

${ }^{10}$ Zhongguo min₹u minjian wenyi jicheng zhi 中国民族民间文艺集成志. 
by the 1989 "Recommendation on the Safeguarding of Traditional Culture and Folklore," which was the first legal instrument of its kind oriented towards the safeguarding of ICH. Reacting quickly, from 1990 onwards, the Chinese government prepared several legal projects; some were presented at the Popular National Assembly, entitled "Law for the protection of ethnic and popular cultures," "Law for the protection of oral and intangible heritage" and "Law for the protection of popular cultures." The proposals mingled elements of the UNESCO regular reports and recommendations, and Chinese national principles of heritage protection. A regulation was promulgated, for example, to define what practices should be safeguarded (a historical tradition of 100 years needed to be proven) and how to protect them (such as the measure for the transmitters of knowledge ${ }^{11}$ or the creation of a label of excellence ${ }^{12}$ ) (State Council 1997).

It was only in August 2002 that the Ministry of Culture introduced an official law project to the National Popular Assembly. It was about to be approved in November 2002 when the UNESCO Convention was passed. The project was taken to incorporate the new principles of the Convention but without giving up certain items such as excellence which will be discussed below.

\subsection{The Chinese Law to Protect the National Intangible Cultural Heritage of China}

The new law project was completed in March 2006 and was submitted to the State Council for approval in 2007, but it was not promulgated until February 25, 2011, and came into force on June 1, 2011.13 Between the two dates, an interim law was enacted on November 26, 2006..$^{14}$ The texts present the essence of what are, for the Chinese government, the values of ICH. They provide information about the Chinese interpretation of the UNESCO convention, especially the first and fourth articles ${ }^{15}$. They translate as follows:

Article 1. In order to carry forward the excellence of Chinese cultural traditions, to promote the spirit of the Chinese nation, to encourage the building of socialist spiritual and material civilization, to reinforce the protection of Intangible Cultural Heritage and preserve it, this law is formulated. ${ }^{16}$

\footnotetext{
${ }^{11}$ Measures for the Transmitters of Intangible Cultural Heritage at the National Level guojia feinushi wenhua yichan xiangmu daibiao xing chuangcheng ren 国家级非物质文化遗产项目性传承人.

${ }^{12}$ Chinese Arts and Crafts Treasury Zhongguo gongyi meishu zhenpin 中国工艺美术珍品.

${ }^{13}$ Zhonghua renmin gonghe guo feiwur bi wenbua yichan $f a$ 中华人民共和国非物质文化遗产法. The entire text of the law is available on the WIPO site http://www.wipo.int/wipolex/fr/text.jsp?file_id=215504 < accessed December 20, 2011>.

${ }^{14}$ Ministry of Culture of the People's Republic of China (2006).

15 The fourth article of the 2011 law was the third article of the Temporary Measures. 16 为了继承和弘扬中华民族优秀传统文化促进社会主义精神文明建设，加强非 物质文化遗产保护、保存工作, 制定本法.
} 
Article 4. The protection of Intangible Cultural Heritage should respect its authenticity, its completeness and transmission; it is conductive to enhancing the Chinese national cultural identity, to safeguard national identity and national unity and to promote social harmony and sustainable development. ${ }^{17}$

The terms of the two texts are almost exactly the same, but it is worth noticing that some parts of the sentences were put in a different order. In the first article of the law, for example, the words "carry forward the excellence of Chinese cultural tradition" were moved to the beginning of the paragraph in order to shift the emphasis. Chinese ICH would have the primary responsibility to promote what is the "excellence" of the Chinese culture. This concept of excellence or of outstanding value which was highlighted on the Proclamation of Masterpieces of the Intangible Cultural Heritage (2001-2003) was left out in the Convention of 2003 (Bortolotto 2008 , 2011), so as to place emphasis on the equal recognition of expressions and traditions with no hierarchical distinctions among them. The concept of "outstanding universal value" embodied in the 1972 Convention does not, therefore, apply to the safeguarding of ICH. China emphasizes the excellence, and this has consequences for practices less consistent with the state ideology. A report of the XVIth General Meeting of the Chinese Communist Party in October 2007 provides us with clues. While the $\mathrm{ICH}$ is seen as a way to participate in the construction of a "Spiritual Home of Chinese Nation,"18 this heritage also has to reactivate the principle of distinction between "the essence and the scrap." This sentence came from a Mao Zedong speech of 1940 on culture at Yan'an (Zedong 1940). ${ }^{19}$ Originally concerning the Communist Party's attitude in the face of occidental culture and Chinese popular culture, the distinction between the essence (excellence) and scrap (the other practices) has now been updated. Actually, no public document describes the criteria for distinguishing an "excellent" ICH practice from the others. A careful examination of the files elected on the Chinese (provincials and national) and UNESCO lists allows us to gradually extract those criteria and understand where the break between "excellence" and "scrap" occurs. ${ }^{20}$

ICH also holds great importance for the national unity and identity, as stated in article 4 of the law. One expression is particularly accurate on this subject: the promotion of "social harmony." Obviously, this can be related to the important ideological concept of "harmonious society," developed by President Hu Jintao in 2005 and, since then, ubiquitous in political speeches. This corresponds to an ideal

\footnotetext{
17 保护费物质文化遗产，应当注重其直实性、整体性和传承性，有利于增强中 华民族的文化认同, 有利于维护国家统一民族团结, 有利于促进社会和谐和可持续发展。 18 Jingshen jzayuan 精神家园.

${ }^{19}$ Many thanks to Wang Li for this reference.

20 This examination of the files is one of the task of the research group "Techniques et Patrimoine culturel immatériel en Chine (XVIe-XXIe siècles): formation, tradition, transmission" of the Centre d'études sur la Chine moderne et contemporaine (CECMC), UMR 8173 Chine, Corée, Japon (http://cecmc.ehess.fr/ <accessed June 25, 2012>).
} 
society where conflicts are absent and harmony reigns among all individuals. It is a discursive instrument in the construction of the Chinese nation, intended to unite all the nationalities around the idea of a large Chinese power (Frangville 2007, Boutonnet 2009). ICH is thus seen as a way to gather the entire Chinese population around its culture, and more precisely around its most remarkable elements.

\section{The Paper-Cut File: An Example of the Selection Process of a Particular Intangible Cultural Heritage Element}

The paper-cut file is one of those elements of excellence. It was, indeed, chosen to be one of the Chinese practices on the Representative List of ICH of Humanity in 2009. However, before that, the file passed through several steps of selection. To reveal the compiling of the files, I chose the examples from the districts of Yanchuan 延川 and Ansai 安赛 in the north of Shaanxi province.

\subsection{From the Status of Popular Art to the Inscription on the Provincial List of Intangible Cultural Heritage}

The paper-cut of Shaanxi province, especially of the northern Shaanbei, was one of the first popular art forms valued by the government in the 1940s. The Communist Party took refuge there after the Long March in 1935 and was particularly interested in this type of art. However, the first inventories made during the 1950s revealed that farmers in every part of the country cut paper for decorative or ritual purposes with quite different techniques (scissors or knife) and designs. Exhibitions stopped during the Cultural Revolution, but the practice was never prohibited. The patterns changed and became more political.

In the districts mentioned above, the situation changed in 1973 with the arrival of Jin Zhilin 靳之林 (born in 1928) at the head of the Cultural Center of Yan'an prefecture (Bodolec 2012). ${ }^{21}$ He made inventories of the artist-farmers of the thirteen districts of the area and organized some exhibitions in Xi'an, capital of the province. In 1978, with the economic reforms and a new interest in popular arts and practices, matters grew to a different scale. The state officers in every district made inventories of local artists especially in paper-cut and embroidery. The results are impressive: In the district of Ansai, 20,000 women declared that they were engaged in paper-cut activity and about 5,000 could be qualified as experts. ${ }^{22}$ Among them, forty were ceremoniously designated to transmit their technique.

\footnotetext{
${ }^{21}$ Yan'an diqu wenhua guan 延安地区文化馆.

22 ianzhi nengshou 剪纸能手.
} 
They were named "artist-farmer chosen to be the seeds" 23 and were encouraged to transmit the oldest patterns of paper-cut that tell the myths of their villages.

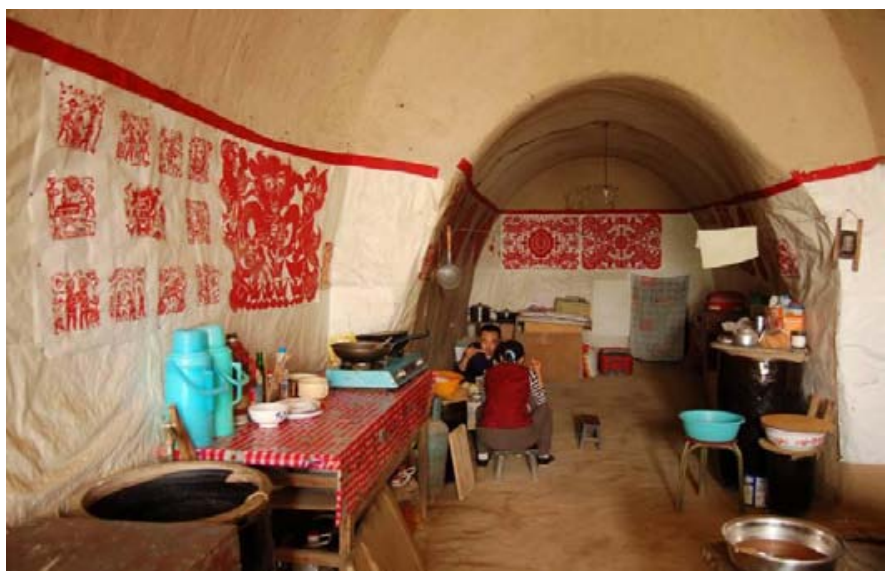

Figure 3: Paper-cut in a yaodong house, Xiaocheng village, Yanchuan district, Shaanxi province (Bodolec 2009).

The first national and, thereafter, international exhibitions were organized at the beginning of the 1980s. In 1986, Jin Zhilin was appointed to the head of the Popular Art Chair at the Central Academy of Fine Arts at Beijing. He was also the first director of the Popular Art Research Center.

Less than 20 years later, this very same Central Academy of Fine Arts was in charge of the application of Chinese Folk Paper-Cutting for the UNESCO Masterpieces of Oral and Intangible Heritage of Humanity list. The Masterpieces program was established between 2001 and 2005 in order to draw attention to the most outstanding examples of ICH. There were three proclamations (2001, 2003 and 2005) and 90 elements were elected. This program of Masterpieces was stopped in 2005 and all the elements were integrated in the Representative List and the Urgent Safeguarding List in 2008. Four Chinese practices were elected as Masterpieces of Oral and Intangible Heritage of Humanity and several other applications presented, like the Chinese paper-cut, were rejected. However, the preparation of the case took four years and the Yan'an region, particularly the population of Yanchuan district, was involved in it. A book containing the collective actions and many articles from local and national experts on paper-cut were even published to support this application (Qiao 2005). After the failure, the application file was completely revised and had to follow the procedures put in place by the Minis-

${ }^{23}$ Nongmin yishu jia de zhongzi xuanshou 农民艺术家的种子选手.

http://www.trshw.com/art_show.asp?nameid=63\&id=111 <accessed June 6, 2011>. 
try of Culture: In particular, the organization of a new survey of the practice. From that time, artists and local experts were no longer involved in the case.

Indeed, by ratifying the Convention of 2003, nation-states agree to establish a survey of all the practices within the ICH field in its territory. In China, the Circular of June 9, 2005, ${ }^{24}$ was sent by the Ministry of Culture to the provincial administrations. We learn that the survey was meant to be completed by the end of 2008 and aimed at establishing a general database and a cartography of Chinese ICH. ${ }^{25}$ The provincial plans for safeguarding and protection were to be based on the survey results (Wang 2010).

The first step was the sending of an Operational Manual ${ }^{26}$ to the provincial administrations. The cultural division of Shaanxi issued a work program in May $2006^{27}$ and organized a first training course for the district's cultural center officers and experts (folklorists, ethnologists, local historians, art experts, etc.) in August of the same year. The courses were led by the experts who drafted the manual. Offered throughout the regions, this training ensured a unified methodology in every district.

The district team planned a survey schedule and field studies in villages were organized. The investigators conducted interviews following the manual and according to the categories defined by the previous inventories (1953 and 1980). Nonetheless, it seems that it was possible to add elements not mentioned in the earlier inventories. The information gathered was used to write reports for the provincial administration. As the Operational Manual and the survey contents are not accessible to the public, ${ }^{28}$ only a few indications by local informants allow one to know that video and audio records, photographs and sometimes artifacts and ancient documents were added in the reports. However, a website was created to make visible the provincial actions for the $\mathrm{ICH} .{ }^{29}$

\subsection{From the National List of Intangible Cultural Heritage to UNESCO Recognition}

The Shaanxi website presents all the official information available on ICH practices in every district of the province. The two proclamations on the Shaanxi ICH

\footnotetext{
${ }^{24}$ Circular from the Ministry of Culture on the Way to Carry out the Survey of Intangible Cultural Heritage Wenhua bu gongting guanyu kaizhan feimuzhi wenhua yichan pucha gongzuo de tongzhi 文化部公厅关于开展非物质文化遗产普查工作的通知, no wenbanshetu fa 文办社图法 [2005] 21. 25 In November 2008, only 40\% of the provincial inventories were finished; but it is said that all of them were finished by the end of 2009 (Wang 2010).

${ }^{26}$ Zhongguo feiwushi wenhua yichan pucha shouce 中国非物质文化遗产普查手册. Operational Manual was the official translation provided by Chinese delegation to UNESCO (Wang 2010).

27 Shaanxi sheng feiwurbi wenbua yichan pucha gongzuo shishi fangan

陕西省非物质文化遗产普查工作实施方案 [Shaanxi province survey work program for the Intangible Cultural Heritage], May 26, 2006. Shaanwenshe 陕文社 [2006] 22.

${ }^{28}$ It is said that, ultimately, a general database should allow access to the survey data.

${ }^{29}$ http://www.snwh.gov.cn/feiwuzhi/index.htm < accessed December 22, 2011>.
} 
List are published, in addition to an interactive map. Those lists are the result of a choice made by a comittee of experts among the hundreds of reports sent in by the districts. The criteria of choice were not public and no element was given to justify the ranking. The first proclamation, made in 2007, selected 165 practices, and the second, in 2009, 165 more. Six different files were elected for the art and techniques of the paper-cut (jianshi 剪纸): one in $2007^{30}$ and five in 200931 gathered from all parts of Shaanxi province.

The description of each paper-cut practice is, however, very succinct. In the case of Yanchuan district, the file contains ten pages and a movie. ${ }^{32}$ There were no photographs to present the patterns and it is obvious that the text sought to place paper-cut techniques into a story that would make them as old as China itself and incorporate the recent election onto the UNESCO ICH list with the previous cultural policies for popular art. The practice is not seen in its social and ritual environment. According to the file, the only people - essentially women - involved in the technique are the "transmitters of knowledge" (chuancheng ren 传承人) who must be mentioned in the ICH program. In addition, a five-year plan for safeguarding and development is presented. This file seems very thin compared to the very rich artistic activity in Yanchuan district and the richness of the survey made in the villages. There is no reference to the events linked with the UNESCO Masterpieces of Oral and Intangible Heritage of Humanity application in 2005.

The provincial administration then made a selection of practices to apply for the National List. The shortlist was forwarded to the national authority in charge of ICH and each file was considered by an expert committee for each domain of ICH. The committies made a provisional list to be discussed. The last step before publication on the website was the approbation by the State Council. ${ }^{33} \mathrm{Up}$ to now, three announcements have been made: 2006 (518 practices), 2008 (510 practices) and June 11, 2011 (191 practices). ${ }^{34}$ In 2006, Shaanxi province succeeded in electing 21 elements including the paper-cut, but at the expense of its local specificities. Indeed, the national file named "paper-cut" is, in fact, the accumulation of different techniques and patterns from nine places: four in the North of China and three in the South;35 a national minority is involved with three of them (Mandchous and

\footnotetext{
30 Dingbian jianshi yishu 定边剪纸艺术 [The art of paper-cut in Dingbian district].

31 Xunyi caitie jian₹ $b i$ 旬邑彩贴剪纸 [Paper-cut with color inclusion of Xunyi district]; Yanchuan jian₹bi 延川剪纸 [Paper-cut of Yanchuan district]; Yongshou minjian jianそbi 永寿民间剪纸 [Popular papercut of Yongshou district]; Luochuan jian₹bi 洛川剪纸 [Paper-cut of Luochuan district] and Huangling jianz $h i$ 黄陵剪纸 [Paper-cut of Huangling district].

32 http://www.snwh.gov.cn/feiwuzhi/sjep/mjms/5/201112/t20111208_124620.htm

As far as we know, the video space exists but no link with a video < accessed December 22, 2011>.

33 Temporary Measures for the Protection and the Management of the Elements on the National List, 2006, op. cit. art. $9,12,13,16$ and 17.

34 http://www.ihchina.cn/main.jsp < accessed December 22, 2011>.

35 District of $\mathrm{Yu}$ 蔚县in Hebei; Mandchous autonomous district of Fengning 丰宁满族自治县 in Hebei; District of Zhongyang 中阳 in Shanxi; Yiwulü shan Mandchous region 医巫问山满族地区
} 
Dai). Shaanxi province was then only one example among others chosen to represent the "Chinese Paper-Cut" in the National List. The selection criteria for this list are very specific and follow the general policy for the ICH: ${ }^{36}$ Notably, to be of outstanding value (criterion 1). Surprisingly, the Shaanxi province case concerns the district of Ansai whose paper-cut practice is not in the Shaanxi list of ICH. We can only speculate on how a file never inscribed in a provincial list was able to be elected in the National List and, moreover, as we will see, in the prestigious Representative List of Intangible Cultural Heritage of Humanity. The main reason is probably due to a problem of schedule: In order to apply for the first proclamation of Chinese National List of ICH, the provinces had to send the files before September 2005 when the survey had not yet begun (Wang 2010). As the Ansai district was well-documented, its well-known paper-cut practices could help to fill in the gap quickly.

The Chinese applicants for the two UNESCO lists were chosen from among the elements of the National List and only among them. The exact procedures and criteria are not public. No reasons are given for why particular elements were chosen, and the decisions are final. In 2009, a nomination of the Chinese Paper-Cut was presented for inscription on the Representative List of ICH. The file is based on the National List with the same nine places described, including the Ansai district. However, the groups and transmitters of knowledge are more visible. It should be noted that the majority of the safeguarding measures and actions with the communities described happened in Shaanxi province and especially in Yanchuan district, which was not mentioned as a special paper-cut place. ${ }^{37}$ At the time of the UNESCO nomination, the Shaanxi survey was finished, two provincial list proclamations were made and Ansai still did not appear on a list. Field research indicates that this was ill perceived by Yanchuan people who had been involved in the survey as well as in the exhibitions and symposium organizations since at least 2001 (Bodolec 2012). The benefits of the UNESCO nomination (safeguarding program supports, artistic events and international recognition) are then reaped by another district which may have discouraged some members of the local elite to invest in cultural activities.

\section{Conclusion}

As shown by the case-study of paper-cut, the ICH practices have to pass through several filters from the district surveys to the provincial and national commissions

Liaoning; City of Yangzhou 扬州 in Jiangsu; City of Leqing 乐清市 in Zhejiang; Province of Guangdong 广东; Dai nationality 傣族 in Yunnan; and District of Ansai 安塞, Shaanxi.

36 Temporary Measures for the Selection of Candidates on the National List of Representative Works of ICH Guojia ji feiwuzi wenbua yichan daibiao zuo shenbao pingding zanxing banfa

国家级非物质文化遗产代表申报评定暂行办法, March 26, 2005, Art. 6.

37 Particularly the actions for the UNESCO Masterpieces applications that were mentioned above (UNESCO application). 
in order to be enhanced. The political and ideological importance of ICH concepts within the national policies were particularly taken into account at every stage. With the implementation of the 2003 Convention, the legal apparatus and administrative organization of the Chinese state have been modified, an extensive survey was made, and many events were organized to publicize and enforce the political importance of this new cultural concept. A big effort is actually being provided to study, publicize and promote the cultural and social practices of the whole country. This is not only to show the world that China holds important cultural resources, but also to strengthen the notion of unity and national culture within its own society.

In recent years, the concept of $\mathrm{ICH}$ has become a very important paradigm in the cultural life in China. The prospect of having a practice elected in the provincial, the national or even in the UNESCO list underlies every cultural activity. It is certain that a choice is made when certain practices are more in the political line than others. The creation of the Department of Intangible Cultural Heritage within the Ministry of Culture in 2008 follows this direction. This department does not have any further connection with the district cultural centers and local ethnographers. However, one of its main functions is to steer the work of inheriting and disseminating the essence of national culture. ${ }^{38}$ Recently, the focus on the "excellence of Chinese cultural traditions" in the 2011 law on ICH may produce a sort of cleaning among the cultural and social practices of China.

Although it is still too early to realize all the impacts of this new concept in the field, some aspects are to be carefully observed. Indeed, for the moment, the communities and groups are only superficially involved in the investigation and local development of the ICH practices. It is sometimes difficult to find information in the files presented for the UNESCO inscriptions on how the communities have participated in the nomination process and how customary practices governing access to specific aspects of the elements would be respected. Information is lacking to identify the bearers, practitioners and community concerned more clearly and to explain its current social functions, transmission methods and cultural significance to that community (UNESCO 2011b). The files available on the provincial and national websites do not put the practices back in the social, cultural and ritual context. The social interaction and tensions between the community members are not described nor are the divergences on practice interpretations.

Another aspect that deserves to be watched carefully is how the practices are valued by provincial authorities, in particular by the tourism industry. In China, where the domestic tourism is the main source of tourism revenue $(70 \%$ of the total in 2004 with 1 billion visitors) (Goi 2007), the development of festivals and cultural

38 http://www.mcprc.gov.cn/English/jgsz/bjg/200904/t20090428_62711.html < accessed March 20, 2012>. 
theme parks is a reality. The main question is how the ICH practices are presented to the public.

Acknowledgments. I would like to sincerely thank Wang Li for her help in understanding the Chinese legal apparatus.

\section{References}

Allès, Elisabeth (2011): Un orientalisme intérieur. Les nationalités minoritaires en Chine. In Après l'orientalisme. L'Orient créé par l'Orient. François Pouillon and Jean-Claude Vatin, eds. Pp. 245-252. Paris: IISMM/Karthala.

Baptandier, Brigitte (2001): En guise d'introduction: Chine et Anthropologie. Atelier 24: 9-27.

Bodolec, Caroline (1999): Current Tendencies in Yaodong, Shaanbei. In

Proceedings of the 8th Conference of ACUUS. Associated Research Centers for Urban Underground Space. Pp. 232-242. Xi'an, China.

- (2005): L'architecture en voûte chinoise: un patrimoine méconnu. Paris:

Éditions Maisonneuve et Larose.

- (2010a) : Ershiyi shijie de yaodong: Shaanbei Yanchuan xian gongjiang chuantong jianzao jishu de xuexi yu chuancheng 二十一世纪的窑洞:

陕北延川县工匠传统建造技艺的学习与传承 [Building yaodong Houses in the XXIth Century: Craftsmen Training and Transmission of Knowledge in Yanchuan County, China]. In Jishu, zhishi yu zhongguo jin xiandai xingye de shanbian 技技艺、知识与中国近、现代行业的嬗变 [Transformation of the Craft, Knowledge and Professions in Modern and Contemporary China].

Christian Lamouroux 蓝克利, ed. Pp. 3-19. Beijing: Guojia tushuguan chubanshe.

- (2010b): Houses as Local Culture Identity: The Case of Yanchuan District, Shaanxi. In Along the Great Wall. Architecture and Identity in China and Mongolia. Erich Lehner, Alexandra Harrer, and Hildegard Sint, eds. Pp. 223232. Vienna: Institute for Comparative Research in Architecture (ICRA).

- In press (2012): Décider ensemble du développement local: Le cas du musée des Arts et Traditions populaires de Nianpan (Shaanxi). In Agir ensemble en Chine contemporaine. Isabelle Thireau, ed. Paris: Éditions de l'EHESS.

Bortolotto, Chiara (2008): Les enjeux de l'institution du patrimoine culturel immatériel. Compte rendu du séminaire organisé au Lahic (2006-2008). Culture et Recherche 116-117: 32-34.

- (2011): Le patrimoine culturel immatériel. Enjeux d'une nouvelle catégorie.

Paris: Editions de la Maison des sciences de l'homme. 
Boutonnet, Thomas (2009): Vers une "société harmonieuse" de consommation? Discours et spectacle dune Chine "civilisée" (1978-2008). Ph.D. dissertation. Etudes transculturelles, Institut d'Etudes Transtextuelles et Transculturelles, Université Jean Moulin, Lyon 3.

Chinese Government (n.d.): Chinese Government Public Information Online. http://govinfo.nlc.gov.cn/jlsfz/zfgb/200816/201010/t20101009_443108.htm ?classid=443< accessed June 20, 2012>

Clark, Paul (2008): The Chinese Cultural Revolution: A History. Cambridge: Cambridge University Press.

Fei, Hsiao-tung (1980): Ethnic identification in China. Social Sciences in China 1: 94-107.

Frangville, Vanessa (2007): Construction nationale et spectacle de la différence en République Populaire de Chine. Ph.D. dissertation, Institut d'Études Transtextuelles et Transculturelles, Université Jean Moulin, Lyon 3.

Gladney, Dru C. (1994): Representing Nationality in China: Refiguring Majority/Minority Identities. The Journal of Asian Studies 53(1): 92-123.

Goi, Isabelle (2007): Tourisme. In Dictionnaire de la Chine contemporaine. Thierry Sanjuan, ed. P. 257. Paris: Armand Colin.

Huang, Yanzhong, and Sheng Ding (2006): Dragon's Underbelly: An Analysis of China's Soft Power. East Asia 23(4): 22-44.

King, Richard, ed. (2010): Art in Turmoil: The Chinese Cultural Revolution 19661976. Toronto: University of British Columbia Press.

Kurlantzick, Joshua (2007): Charm Offensive: How China's Soft Power is Transforming the World. New Haven: Yale University Press.

Li, Mingjiang (2009): China's Emerging Strategy in International Politics. Lanham: Lexington Books.

Liu, Lydia H. (2012): Translingual Folklore and Folklorics in China. In A Companion to Folklore. Regina Bendix and Galit Hasan-Rokem, eds. Pp. 190210. Malden: Wiley-Blackwell.

Liu, Mingxin (2003): A Historical Overview on Anthropology in China. Anthropologist 5(4): 217-223.

Ministry of Culture of the People's Republic of China (2006): Temporary Measures for the Protection and the Management of the Elements on the National List. Guojia ji feiwuzhi wenhua yichan baobu yu guanli zanxing banfa 国家级非物质文化遗产保护与管理暂行办法. Edict No. 39 of November 26, 2006.

- (2009): Department of Intangible Cultural Heritage. http://www.mcprc.gov.cn/English/jgsz/bjg/200904/t20090428_62711.html $<$ accessed March 20, 2012>

Qiao, Xiaoguang, ed. (2005): Guanzhu Muqing he. Zhongguo feiwuzhi wenhua yichan. Minjian jianzhi Guoji xueshu yantaohui wenji

关注母亲河。中国非物质文化遗产。民间剪纸国际学术研讨会文集 
[Keeping A Close Eye on Our Mother River. Collection of Essays from the International Symposium of the Intangible Cultural Heritage of China and Chinese Paper-cutting]. The text of China Folk Paper-Cutting for Applying for UNESCO's Masterpieces of the Oral and Intangible Heritage of Humanity. Taiyuan, Shanxi: Renmin Chubanshe.

Schein, Louisa (1997): Gender and Internal Orientalism in China. Modern China 23(1): 69-98.

UNESCO (2011a): Intangible Heritage List.

http:/ /www.unesco.org/culture/ich/index.php?lg=en\&pg=00011\#tabs

$<$ accessed December 5, 2011>

- (2011b): Report of the Subsidiary Body on its work in 2011 and evaluation of nominations for inscription in 2011 on the Representative List of the Intangible Cultural Heritage of Humanity. http:/ / www.unesco.org/culture/ich/doc/src/ITH-11-6.COM-CONF.206-13EN.pdf < accessed June 27, 2012>

Wang, Jianmin, ed. (1997): Zhongguo minzu xue shi 中国民族学史 [The History of Ethnology in China], 2. Kunming: Yunan Jiaoyun Chubanshe

Wang, Li (2010): La convention pour la sauvegarde du Patrimoine culturel immatériel et son application en droits français et chinois. Ph.D. dissertation, Droit public, Université Paris-Sud 11.

Xie Ninggao 谢凝高 (2004): Shijie yichan guanli tizhi zhi zheng de shizhi 世界遗产管理体制之争的实质 [Realities in the Management of World Heritage Sites]. Lüyou xuekan 旅游学刊 [Tourism Tribune] 5: 35-37.

Zetong, Mao (1940): Qiqi zaopo, quqi jinghua 弃其糟粕取其精华. In Xin minzu zhuyi lun 新民主主义论 [The new democracy]. Speech on January 9, 1940. Jiefang 解放 [Liberation], Yan'an, February 20: 198-199. 


\title{
The French Inventory of Intangible Cultural Heritage: Domesticating a Global Paradigm into French Heritage Regime
}

\author{
Chiara Bortolotto
}

\section{Introduction}

How does the global-politique (Abélès 2008) concretely affect national heritage policies? What is the effect of UNESCO on state heritage regimes? Is it enforcing a UNESCOization (Berliner 2012) of heritage theories and practices or are national institutions resisting the homogenization of heritage criteria and procedures? In order to understand how global norms are articulated in national policies, I consider the case of the French implementation of the 2003 UNESCO Convention for the Safeguarding of the Intangible Cultural Heritage. I will focus on the Intangible Cultural Heritage $(\mathrm{ICH})$ inventory system and investigate how the key idea of the 2003 Convention, namely the "participation" of "communities," is understood and applied in the identification of ICH at the national level. My aim is not to underline the possible gap between international norms and their local implementation, or to oppose "good" and "bad" interpretations of the idea of participation, but to understand how a global paradigm can concretely affect national heritage practice.

\section{UNESCO and Global Standards}

Cultural globalization has been a growing UNESCO concern for almost two decades; it has made cultural diversity a key policy priority for UNESCO. Several initiatives have addressed this issue: From the 1982 World Conference on Cultural 
Policies (Mondiacult), the 1996 report Our Creative Diversity prepared by the World Commission on Culture and Development, to the 2009 UNESCO world report Investing in Cultural Diversity and Intercultural Dialogue. Since the 2001 Declaration on Cultural Diversity, this concern has been put at the core of UNESCO action and addressed using the tools of international law. The UNESCO Convention for the Safeguarding of ICH is one of UNESCO's weapons in this crusade since, as stated in its preamble, it is intended to maintain and foster cultural diversity.

To the outside observer, the very fact that this organization engages in this battle at a global level paradoxically makes this agency itself a major actor in the very globalization process that it aims to control (Turtinen 2000). UNESCO core action lies in setting standards to be implemented at the world level by its member states. Such instruments establish common rules in the form of agreements between states (recommendations, declarations or conventions) and, by "coordinating the ethical, normative and intellectual issues of our time," these instruments "define benchmarks" (UNESCO n.d.) which, in the case of conventions, are legally binding. The World Heritage Convention (1972), as the most longstanding and wellknown heritage convention, is a good example of this procedure. According to those who commented on its local impact, this instrument endorses a particular kind of "protection" of heritage, which may be different or contrast with local cultural and social values, as well as with local strategies for the transmission of culture (Owens 2002, Ciarcia 2003, Shepherd 2006, Scholze 2008, Berliner 2012). William Logan (2002) assesses the globalizing intrinsic characters and unintended effects of this convention, and points to several homogenizing aspects of the assistance provided by UNESCO with a view to improving international practice in the protection of heritage. He perceives this, for example, in the establishment of codes of international best practice for cultural heritage professionals, the provision of training programs and the funding of consultants to assist developing countries in preparing nominations to the World Heritage List according to the set of rules and principles established at the intergovernmental level. Being based on a global grammar, the very praxis of the UNESCO heritage system thus imposes "a common stamp on cultures across the world and their policies creating a logic of global cultural uniformity" (Logan 2002: 52).

In other words, while UNESCO celebrates the diversity of content (the elements of heritage to be safeguarded), it enforces common codes, categories and values because it operates through a common scheme or, as Berardino Palumbo puts it, a "global taxonomic system" (Palumbo 2010). This procedure echoes similar homogenizing processes criticized for establishing a "global hierarchy of values" (Herzfeld 2004) through the very use of standard procedures. Like World Heritage $(\mathrm{WH})$, the more recent global institution of ICH is another example of what Richard Wilk calls the "global structures of common difference" (Wilk 1995). The 2003 Convention for the Safeguarding of ICH, ratified by more than 140 States in less 
than ten years, departs from its forerunner by addressing a different field of cultural expressions (the domains listed in art. 2.2) and by delegating its recognition to the "bearers" of this heritage (art. 2.1).

Despite this substantial difference, the $\mathrm{ICH}$ Convention inherits its main mechanism from the WH Convention: international listing. This choice was discussed at length during the 2003 negotiations (Aikawa-Faure 2009) and was criticized as a tool that itemizes, folklorizes, touristifies, and ultimately globalizes culture (Kirshenblatt-Gimblett 2004, Hafstein 2008). The use of standard formats and procedures in the implementation of UNESCO's conventions frame the heritage elements into a common syntax thus organizing and arranging cultural diversity. Diverse and geographically disconnected groups, such as the Senufo communities of Mali and Burkina Faso, the Buddhist Drametse community in eastern Bhutan, the jaguar shamans of Yuruparí (Colombia), the followers of Saint Blaise, the patron of Dubrovnik, the Ainu people of northern Japan, to name just a few, have had to deal with the same nomination forms and guidelines. They all received letters from the UNESCO secretariat intended to help them in presenting their culture in a way that would match the UNESCO criteria in order to submit the "strongest possible nominations." Staging local cultural elements in the global heritage system thus implies the adoption of global standards. According to this analysis, what is normalized in this process are not the elements themselves, whose diversity is safeguarded and displayed, but the structures, criteria and principles underpinning the heritagization process in all states' parties.

In the following, I will challenge these conclusions reached in anthropological research through the presentation of the establishment and concrete production of the inventory of ICH in France. Can we still observe the same globalizing outcomes if we consider their impact on national institutions, rather than the effect of UNESCO's standards on particular cultural elements?

\section{Inventories of ICH According to the Spirit of the Convention}

In order to understand the French interpretation of ICH inventory-making, we need to consider how UNESCO presents this measure. The UNESCO ICH Convention compels the states to establish inventories of ICH present in their territory. Even if the states have room to decide whether to have only one or several inventories and how to design them, the Convention establishes that such inventories are draw up "with a view to safeguarding" (12.1) and "with the participation of communities, groups and relevant nongovernmental organizations" (art. 11). 
If one wants to understand what these terms mean in the framework of the Convention, the text itself does not help very much: Neither the term of "participation" nor that of "community" is defined. In order to grasp them, it is necessary to observe UNESCO at work: The meeting of the organs of the Convention, the expert meeting or the capacity-building workshops organized by the secretariat allow one to seize their actual meaning and follow its evolution. The tools of pragmatism turn out to be very useful in these situations: The observation of embedded actions, as well as of the performative discourse that they generate, allows for an understanding of the practical reasons that produce international standards (Akrich; Callon; Latour 2006).

The last ICH committee, held in Bali in November 2011, referred several nominations that did not provide convincing information on the actual participation of communities in the inventories. ${ }^{1}$ The subsidiary body appointed by the committee to examine the files stressed that "communities are central to each of the five criteria," and insisted on the importance of active involvement of community members at all stages of the nomination process, in particular that of identification of the element and design of safeguarding measures "not only as targets or beneficiaries of such measures but as their instigators and implementers."' The debate stirred up on this issue demonstrates how participative identification is gaining importance in the evaluation of nominations to the international lists. On one hand, the committee deemed that the proof of the consent of the communities concerned cannot be considered as evidence of their participation in the nomination process; on the other hand, the committee is not offering explicit wording on what the intent of this "active involvement" is (Bortolotto 2012).

More information on UNESCO's actual understanding of "participation" comes from the UNESCO secretariat. Even if the ICH section does not provide state parties with standard formats for inventories, it organizes capacity-building workshops intended to present possible inventory methods matching UNESCO's requirements. The very name of the workshop "community-based inventory" is chosen on the assumption that community members will constitute a substantial proportion of the participants. The secretariat also explains that every inventory must be community-based in the sense that community members provide the necessary information to the researchers. By training community members in research

\footnotetext{
${ }^{1}$ Out of the 32 nominations that did not receive a favorable recommendation for inscription on the Representative List, 17 did not satisfy criterion R4 ("The element has been nominated following the widest possible participation of the community, group or, if applicable, individuals concerned and with their free, prior and informed consent" Unesco 2008). For ten nominations, this was the only criterion that was not satisfied.

${ }^{2}$ Intergovernmental Committee for the Safeguarding of the Intangible Cultural Heritage, sixth session Bali, Indonesia, November 22 to 29, 2011. Item 13 of the Provisional Agenda: Report of the Subsidiary Body on its work in 2011 and evaluation of nominations for inscription in 2011 on the Representative List of the Intangible Cultural Heritage of Humanity: 18.
} 
techniques, the message is communicated that they are now to be actively involved in the identification process with a new and different role, namely that of researchers whose expertise, though different from that of scientifically-trained researchers, is legitimate and recognized.

Fostering the cooperation between heritage professionals or institutions and social actors, and emphasizing collaborative, bottom-up approaches to the recognition and safeguarding of cultural expressions, the spirit of the ICH convention ultimately entails a new definition of expertise in the heritage field and entrusts communities with key responsibilities in the safeguarding process. This principle is controversial: NGOs and other advocacy activists interpret this shift as a triumph of cultural democracy, while the majority of academic or heritage experts and professionals regard it as a dangerous hyper-relativistic and populist instrument. From this perspective, "participation" of "communities" is a value-laden idea that makes consensus among international bodies and a key notion of global advocacy discourse, but it is founded on a romantic idea of community idealization of supposed natural solidarity (Noyes 1995); "the magic word around which consensus can take shape in international tensions over the uses of tradition [... and which] speaks to the moral concerns of the larger publics to whom policymakers must answer, indexing both the metropolitan romance with authenticity and subaltern demands for justice and agency" (Noyes 2006: 31).

Whatever its premises and effects, is the global norm of "participation of communities" really homogenizing local ways to deal with heritage? This question is particularly challenging for French institutions, which are neither designed to consider the concept of community nor to deal with communities in public action. French governmental policies are not intended to establish any difference between the citizens, and the principle of the indivisibility of the Republic is opposed to the recognition of collective rights for groups. Community is more often associated with an ethnocentric degeneration, a communautarisme disruptive of republican social cohesion (Wieviorka 2001). This approach has an effect on the heritage field and has been recently discussed following the opening of the Musée du quai Branly, where the absence of "native voices" has been criticized as a further example of the institutional reticence to officially recognize ethnic identity (Price 2007).

This framework can help us to understand the challenge faced by the ministry officials in charge of the implementation of the 2003 Convention in rendering the UNESCO community-based perspective in French and in establishing a French inventory of ICH. 


\section{The French Inventory: Resistance against UNESCOization?}

\subsection{The Establishment of the Inventory}

Following the French ratification of the 2003 ICH Convention in 2006, a committee composed of members from various departments of the French Ministry of Culture (music, dance, archives, museums, and libraries) was established to implement the ICH policy and to select the elements to be submitted for inscription on the UNESCO lists. The Mission Ethnologie, 3 a section of the Ministry of Culture devoted to French ethnology, was delegated to assist this committee and to be in charge of ICH programs. This choice was made on the basis of an equivalence established between the field of "intangible cultural heritage" and that of "patrimoine ethnologique:"4

The ethnological heritage of a country includes the specific modes of material existence and social organization of the groups that compose it, their knowledge, their representation of the world, and, generally speaking, of the elements that form the basis of each social group and makes it different from the other ones. The following will, therefore, be included:

- Agents: individuals, social groups, institutions;

- Material and immaterial goods, potential or completed works;

- Organized knowledge: technical, symbolical (magic, religious, based on games), social (etiquette, group traditions), aesthetic...

- Means of communication: languages, idioms, systems of signs. (Benzaïd 1979) ${ }^{5}$

According to the priorities of the Convention, the Mission Ethnologie was asked first of all to draw up inventories of ICH. Firstly, an "inventory of inventories" was drawn up collecting all the available information on already existing archives and repertoires covering the fields of ICH (Grenet 2008). This inventory had the major inconvenience of including elements of ICH which are no longer practiced. For this reason, the Mission Ethnologie decided "to draw up another inventory, based on fieldwork, and involving the communities" (Grenet 2008). ${ }^{6}$ The Inventaire des

\footnotetext{
${ }^{3}$ During the reorganization of the Ministry in 2009, the Mission ethnologie was merged into the Département de Pilotage de la Recherche et de la Politique Scientifique, part of the Direction Generale des Patrimoines. Since the section in charge of the implementation is the same in the new structure, I will use the term "Mission ethnologie" to refer to its intervention even if this is no longer the official name.

${ }^{4}$ As explained in 2006 to the Assemblée Nationale by, the deputy, M. Bruno Bourg-Broc (2006), in the Rapport fait au nom de la Commission des Affaires Etrangères sur le projet de loi $n^{\circ} 2605$, autorisant l'approbation de la convention internationale pour la sawvegarde du patrimoine culturel immatériel.

${ }^{5}$ Translated by Sylvie Grenet (2008).

${ }^{6}$ In order to compare existing systems in other countries, a conference was organized at the l'Institut National du Patrimoine: "Le patrimoine culturel immatériel de l'Europe: inventer son inventaire," November 30, 2007.
} 
Ressources Ethnologiques du Patrimoine Immateriel (IREPI) developed in Québec (Turgeon 2009) was chosen as a model both for its technical tools, such as the inventory form, and for its main moral principles: Turn to the public, internet diffusion, action research, meaning research that aims to return to their "owners" the collected data after they have been studied and organized by the researcher. This restitution is made in the form of exhibitions, conferences, articles in local newspapers, et cetera (Grenet 2011).7 An inventory form has thus been designed and a team of local partners has been identified and charged to test the form in their respective fields.

As we have seen, "participation" is the key idea of the 2003 UNESCO Convention. In order to evaluate the impact of the global ICH paradigm on the French inventorying system, it is necessary to consider how "participation" translates into the operators of the inventory (i.e. the tools designed by the Mission Ethnologie) and the operations of the inventory making (i.e. the praxis of the actors of the French inventory). In order to discuss this translation, I will draw on my participant observation of the inventorying process. From 2008 to 2010, I was involved in the program as a research partner of the Ministry of Culture and Communication with the assignment of making inventory forms to be included in the national inventory. This insider position also gave me access to the reflexive discourse of the different actors of this program through informal discussion with other researchers involved in the project and participation in two assessment meetings. ${ }^{8}$

\subsection{Participation in the Tools and Design of the Inventory}

The inventory is a list of forms accessible on the website of the Ministry of Culture and organized into seven categories. ${ }^{9}$ The visitor can download the forms corresponding to the items inscribed as pdf files. According to the officer in charge of the inventory, this choice was made in order for the visitors to easily print the form and take it with them as an information handout if they decided to visit or attend the ICH element in question. The website does not feature any web application allowing the visitors to add information or edit the content nor to interact with the inventory in other ways. The interaction with the communities is delegated to the partners of the project, associations or research centers specialized in different fields. These consultants are contracted for specific inventory campaigns and pro-

\footnotetext{
7 The organization of data is nonetheless very different in the two cases: IREPI is a database; the French inventory is a list of individual forms.

${ }^{8}$ No programmatic or methodological directives have been drawn up by the institution in charge of the inventory so far. However a presentation of the project has been published (Grenet 2011, Hottin 2011b) A PhD thesis in public law focuses on the French inventory comparing it to the Chinese one (Li Wang (2010): La convention pour la sauvegarde du patrimoine culturel immatériel et son application en droits français et chinois).

9 http://www.ethnologie.culture.gouv.fr/index-immat.html < accessed April 30, 2012>.
} 
vided with the tools designed to contribute to the inventory: an inventory form and a consent form.

The inventory form is a word document composed of five sections (identification and localization; description; history; heritage interest and valorization; safeguarding measures) and includes a section where the name and data of the heritage stakeholders have to be filled in. These actors - called "communities" by the UNESCO Convention - are here referred to as "persons met" and presented, therefore, more as a plurality of individuals than as a collective entity. What kind of participation is intended for them? The consent form gives some explanations on that point:

\section{Conduct of participation}

The participation to this research consists of a recorded and/or filmed interview, of approximately 60 minutes. The interview is about the description of practices and knowledge of the participants, the apprenticeship of their practice and the transmission of their know-how. It may involve the taking of photographs and their use for illustrating the practice on the website of the Ministry of Culture. A copy of recordings and photographs may be sent to the participants, should they wish it. ${ }^{10}$

According to this document, the participation of heritage stakeholders is intended as strictly linked to the documentation process: They provide information to the researcher. The expression used to designate these individuals - "persons met" indicates that they are providers of information to be used by the researchers appointed by the Ministry; it is the researcher who presents the element in the form. The idea of participation underpinning the structure of the inventory is, therefore, the classic ethnographic relationship established between a researcher and an informant.

A pragmatic study of the heritage inventory system has demonstrated (Heinich 2009) that institutional systems, categories and tools have a performative effect in heritage authorization (Smith 2006). How do the structure and the principles of the inventory affect the modes of production of such heritage? How did the partners of the project interpret their role in this assignment and how did they interpret the idea of participation?

\subsection{Participation in the Practice of Inventory Making}

The partners of the Ministry of Culture are research centers or associations involved in the study, protection and valorization of heritage. They may focus on specific cultural elements or on geographic regions. They are contracted on the

10 Translated by the author. 
basis of a thematic project established in collaboration with the Ministry of Culture. The specialization of each partner and their possible territorial focus or jurisdiction establish the choice of a research field: The Institut des Métiers d'Art worked on the inventory of rare craftsmanship in France; the Institut Occitan focused on Occitan practices in Aquitaine; the Centre des Musiques Traditionnelles in Corsica started research on cantu in paghjella; ${ }^{11}$ the Direction Régionale des Affaires Culturelles in Normandy, in cooperation with the Centre Régional de Culture Ethnologique et Technique, prepared an inventory on practices and representations of the "vegetal world" in that region; and the Centre Permanent d'Initiatives pour l'Environnement of the Basque littoral worked on fishing practices. Two projects converged on the ICH of immigrants in France: The first, coordinated by the Association Trajectoires, focused on immigrant communities in the tenth arrondissement in Paris; the second one, carried out within the Laboratoire d'Anthropologie et d'Histoire de l'Institution de la Culture, identified practices associated with Italian immigration in France and Mexican communities in Paris. When the associations did not have people with research skills, they contracted young researchers to work on the inventory project; fieldwork was then distributed to experts on the different subjects. All partners could enjoy a high degree of autonomy in their work and each of us developed his or her own interpretation of the inventory-making process, as is evident from the diversity of the results obtained: While some of us adapted the structure of the form in order to write monographic articles, others chose a more schematic approach. Despite this diversity, we all adopted a common perspective, which was made explicit during an assessment meeting in July 2010. The discussion made clear that the ultimate end of the inventory was, for many partners, doing research: "To us, what was interesting in this research was [...]," "what we wanted to dig out is [...]." The scientific approach is claimed openly and is evident in the working method adopted and presented at the meeting: Figure out how the different research fields "could be studied as intangible heritage," conduct bibliographic research and finally carry out fieldwork with interviews.

This scientific standpoint is clear from the choice of the object of the enquiry ("The subject was suggested by the director of the department. Being an ethnologist, this has been going through his mind for a long time."). The point of view of the researcher not only influences how an element is observed and described ("the practice conveys a set of representations that is interesting to study [...] this is what we were interested in"), but can also have an impact on the definition of the element ("when we got interested in the practice of $[. .$.$] we changed the name of$ the form"), meaning that research priorities can influence the identification of ICH elements.

\footnotetext{
11 The cantu in paghjella is a male Corsican singing tradition that combines three vocal registers. It was inscribed on the List of Intangible Cultural Heritage in Need of Urgent Safeguarding in 2009.
} 
The scientific ambition of this work was openly endorsed when some researchers explained that, given the poor elaboration allowed by the form, they conceived this work as a preparatory step toward further and deeper research ("not making an article, but keeping the form as a first step toward [the construction of] a scientific object"). This limitation was considered somewhat frustrating for them and they expressed the hope that in-depth research would follow the inventory ("the form is a starting point for in-depth ethnologic studies, $\mathrm{PhD}$ thesis for example, $[\ldots]$ this is the meaning of the form, finding research tracks").

Finally, the presentations and the discussion at the assessment meeting made clear that the inclusion in the inventory depends on the evaluation of the researcher ("the intern selected a few practices which may match with the definition of ICH" or "the dynamism of the practice is crucial for us to choose what we could include or exclude from the inventory").

Far from exploiting the "persons met," the partners of the ministry are sometimes very involved in their fieldwork and try to show this in their research results; the Mission Ethnologie encourages this "coupling of scientific research and diffusion of information among the public" (Grenet 2011). This proves to be a real challenge for the researcher: In the case of the organization of an exhibition on traditional Basque maritime practices in the harbor of Soccoa, the researcher described the difficult task of explaining to local heritage stakeholders (in this case the fishermen of the Basque littoral) why their ordinary everyday activities are considered as heritage and listed in the inventory. When it comes to recognizing heritage, the criteria of the fishermen and those of the researcher differ and "gaps" between the different actors involved became evident. Heritage experts interpret this gap as "lack of awareness" and classic heritage policies are first and foremost intended to raise this awareness. However, in the framework of the ICH UNESCO paradigm, this gap takes on a completely different meaning, which is considered controversial from the juridical perspective. According to Li Wang (2010), author of a comparative analysis of the French and Chinese inventory, in both cases there would be a "problematic balance between the actors of inventory-making with a major role of state institutions, a limited participation of communities and an ambiguous and questionable position of the researchers." From this perspective, thematic projects entail a top-down selection, which makes heritage out of scientific criteria and the inventory a corpus of ICH items intended as "mere objects of ethnologic research" (Wang 2010: 290). The Mission Ethnologie see its independent researchers as best qualified: They have no stakes in the promotion of one particular element, as do many NGOs, and can evaluate, for instance, if the element is the result of an artificial revitalization for commercial uses. The intervention of researchers may, furthermore, counter-balance the hyper-relativism that a community-driven heritage selection might imply. The researchers would thus be sufficiently neutral to withstand militant claims and able to evaluate the real nature of the elements to be 
inscribed. The researchers involved in this project sincerely planned for their approach to involve the "persons met" in the identification project. To them, the fact that locals are consulted by the researcher and have the opportunity to provide information from which heritage elements are identified means their involvement. By making their work available to the subjects of their study through action research, researchers see themselves as pushing even further the involvement of their informants.

\section{Democracy and the French Heritage System}

Guided by their academic background and goals, the partners in the French inventorying process put the scientific perspective at the core of their approach. The tools designed by the Ministry of Culture do not invite them to negotiate a new role and to share their expertise with heritage stakeholders. Action research involves a public with a pedagogical rather than an advocacy potential, and "participation" is understood as the involvement of informants in ethnographic research. According to the analysis of the chief of the Mission Ethnologie, the Convention would force the team to work in new ways, but at the same time ICH programs in France draw from the preexisting, research-conditioned work of the Mission Ethnologie (Hottin 2011a). This research-based approach has proven to be instrumental in legitimizing the Mission's service, as well as the role of anthropology within the Ministry of Culture. A research-based inventory is, in fact, an essential tool for dealing with tangible heritage, archives or museums, and thus associates ethnologic heritage with heritage domains and institutions with longer traditions enjoying state and society appreciation. In order to be upgraded to the board of legitimate national heritage, ICH has to be processed according to longstanding authorization procedures and to adjust to the logics underpinning heritage policies within the Ministry of Culture.

The inventory of tangible heritage is a good example for understanding the reasoning behind French heritage. Research and scientific know-how of highly specialized officers are at the very core of the process of inscription in the longstanding Inventaire general (Heinich 2009), established in 1964 to identify French heritage. The political perspective underpinning this program is intended as "generously democratic" in that it is meant to "arouse in every citizen the perception of a meaningful local and material heritage" (Balsamo 2003: 414). In this perspective, a corpus of heritage elements established on the basis of scientific criteria by highly specialized professionals is made available to the largest possible number of people, intended as a public that is educated and sensitized in order to develop "heritage awareness." This standpoint has shaped French museum policy since the 1930s (Poulot 2005) and is consistent with the founding program of the Ministry of Culture: "Make masterpieces of humanity, and firstly of France, accessible, to the greater 
possible number of French $[\ldots]$ and ensure to our cultural heritage the larger attendance." 12 This ideal of cultural democratization underpinning the establishment of the French Ministry of Culture under the aegis of André Malraux in the late1950s still affects French cultural policies (Dubois 2010).

According to the reflexive analysis conducted by the regional correspondents of the officers of the Mission Ethnologie on the actions of this agency, the ideal of cultural democratization also shapes the model of patrimoine ethnologique (Barbe 2009, Tornatore 2011). The founding, historical institutional mandate of the Mission Ethnologie rests on this perspective and emphasizes the role of research entrusting professional anthropologists - who are supposed to be objective - in order to counter the subjectivity of "wild ethnology." The original principles of patrimoine ethnologique ban amateurish ethnology, considered a "pseudoscientific illusion." In this perspective, "self-study" is to be avoided, because only professional ethnologists are seen to be competent to do research objectively (Benzaïd 1979).13 This approach has undergone an evolution at the central and regional level, and regional projects are often based on a different understanding of participation (Lebovics 2005, Barbe 2009, Hottin 2011b). Yet, as we have seen, it informs the campaigns of the inventory of ICH. The inventory is, in fact, expressly intended to be the result of a research process, as well as a tool for further research (Hottin 2011a), similar to other heritage inventories drawn up within French cultural agencies.

\section{Conclusion}

Founded on the idea that culture provides an identity to affirm rather than a body of knowledge to democratize, and aiming to change the roles of heritage actors,

\footnotetext{
12 Décret du 24 juillet $1959 \mathrm{n}^{\circ}$ 59-889. The text of the decree is available in Eléments d'histoire administrative. Ministère de la culture 1959-1996, Paris, La documentation française, 1997.

13 The Mission du patrimoine ethnologique, founded in 1980 and re-named Mission Ethnologie in 2003, played a key role in the development of French Anthropology in France (Langlois 1999) by way of the regular funding of thematic research and its diffusion through the journal Terrain. Anthropology of contemporary western societies, which was not developed in France at that time, also gained its legitimacy thanks to this institution. The role of this institution in the political arena has been studied both by historians and by its own members. The establishment of patrimoine ethnologique as an institutional category is presented by its initiator as an attempt to pay attention to social dynamics in the otherwise very traditional French heritage approach dominated by art history (Chiva 1990). The historian Herman Lebovics considers its creation as political strategy aiming at protecting French anthropology weakened by the postcolonial turn. This strategy would build on regionalist movements (in particular in Brittany, Occitania and New Caledonia), as well as on the re-launch of salvage ethnography justified by the rapid sociocultural change in the modernizing economic and urbanistic boom of the Three Glorious Decades (Lebovics 2005). According to Pierre Nora (Barbe 2009), the Mission du patrimoine ethnologique would ride the wave of the rising local interest in heritage expressed by the establishment of countless regional heritage associations. This would allow the Ministry of Culture to organize their intervention and control its militant fringes at the same time (Lebovics 2005).
} 
the UNESCO ICH paradigm is far from overturning the preexisting French patrimoine ethnologique model, which has its own experts (professional anthropologists) and is a matter of knowledge and study.

The French domestication of ICH is particularly interesting for evaluating the globalizing effect of the ICH Convention. While UNESCO introduces into the global arena a common vocabulary and promotes specific values, their translation into a French institutional framework domesticates them to the preexisting available institutional structure and skills. In this case, global policies do not spread uniform structures framing local heritage according to a standard code; rather, they are twisted by local bureaucratic, administrative and scientific interventions and institutional structures. The French inventory of ICH, with its emphasis on ethnographic research and its aim for cultural democratization, does not passively adapt to global standards but ultimately represents a form of resistance against UNESCOization.

Is this an example of French exceptionalism? Is it a consequence of the internationally recognized authority of the French heritage system; of the "model" status of French cultural policies, akin to the model status of Scandinavian welfare policies, or US educational and research policies (Dubois 2010)? Comparative analysis on the establishment of ICH inventories in other countries (ASPACI 2010, Broccolini, this volume) shows that each state translates key terms of the UNESCO Convention in different ways, resulting in different safeguarding approaches. Rather than being a French exception, the domestication of global standards results in a constant negotiation between the spirit of an international convention and the institutional categories, structures and tools that shape national administrative and scientific treatment of heritage. In this respect, the domestication of the UNESCO ICH Convention seems to parallel that of the fastfood chain McDonald's, the quintessential symbol of cultural homogenization and imperialism. Like UNESCO, McDonald's is a global system, which depends on highly standardized procedures and exports them all over the world (Ritzer 1993). Ethnographic accounts of the impact of McDonald's in Asia have, nonetheless, demonstrated how local interpretations of this global system turn it into a local institution (Watson 1997). Not only are menus adapted to different tastes, but the social appropriation of McDonald's also addresses particular needs and habits: "Fast" comes to refer to the delivery of food, not to its consumption, and restaurants are turned into leisure centers and after-school clubs. In the beginning of the 1990s, eating in Beijing's McDonald's was not casual dining but an exclusive experience reserved for upper-class society and enjoyed by young couples for romantic dinners (Yan 1997). Much as experiencing McDonald's in non-western and urban societies is, or at least was in the beginning of the 1990s, a way to access to global modernity (Watson 1997), framing heritage elements into the UNESCO system is a modern way to deal with the past. 
While in the case of McDonald's, the global(-izing) effect is compensated by social and cultural forces, the "local translations" of the UNESCO programs are governmental ones. Global governance is thus counterbalanced by nation-based institutions, the key actors who are entrusted with the capacity for heritage authorization (Smith 2006). The example of the French inventory of ICH confirms what has been already been argued for World Heritage; it is "as much, and probably more, a creature of its member states and their agendas as it is an instrument of UNESCO's specialists, intellectual apologists and affiliated professional bodies of conservation specialists" (Askew 2010).

The impact of the UNESCO paradigm on French ICH policies is not to be minimized. Though domesticated to local taste, social habits and needs, McDonald's had real effects on Asian foodways: In Japan, for example, the habit of eating while standing was previously not an acceptable mode of dining (Ohnuki-Tierney 1997). Similarly, even if in the first years of its implementation, the French inventory interpreted the UNESCO Convention's idea of participation in a very specific way, the nominations submitted for the inscription on the international lists are more influenced by the UNESCO paradigm, because they are put forward and prepared by heritage stakeholders. This resonates with the passionate domestic debate on what role different actors should have in the recognition of heritage and what alternatives might be possible to the leading model of cultural democratization (Poirrier 2007). More concretely, French cultural institutions are internally confronted with a growing heritage production developed without the state and its experts. They are the result of flourishing local associations over at least twenty years (Leniaud 1992). While effective participation of communities is still mostly limited to nominations for international lists and is not an explicit, funding principle of the inventory system, the Mission Ethnologie is engaging in a debate on heritage emotions and social values of heritage. At present, this is but a scholarly argument that benefits from the expertise of state and academic institutions. However, it is worthwhile asking and observing whether the involvement of new actors in this debate will eventually lead to the UNESCOization of French ICH cultural policies.

Acknowledgements. I would like to thank Regina Bendix, Aditya Eggert, David Berliner, and Christian Hottin for their comments on the manuscript of this article. This research is the result of a broader research project (ICHEUROPE) funded by a Marie Curie fellowship (FP7-PEOPLE-2009-IEF) and conducted at the Laboratoire d'Anthropologie des Mondes Contemporains in the Université Libre de Bruxelles. 


\section{References}

Abélès, Marc (2008): Politique et globalisation. Perspectives anthropologiques. L'Homme 185-186: 133-143.

Aikawa-Faure, Noriko (2009): La Convention de l'UNESCO pour la sauvegarde du patrimoine culturel immatériel et sa mise en œuvre. In Le patrimoine culturel immatériel à la lumière de l'Extrême-Orient. Internationale de l’imaginaire - Nouvelle série, 25. Maison des cultures du monde, ed. Pp. 13-45. Paris: Babel.

Akrich, Madeleine, Michel Calon, and Bruno Latour (2006): Sociologie de la traduction. Textes fondateurs. Paris: Les presses de l'École des Mines.

Askew, Marc (2010): The Magic List of Global Status: UNESCO, World Heritage and the Agenda of States. In Heritage and Globalisation. Sophia Labadi and Colin Long, eds. Pp. 19-44. New York: Routledge.

ASPACI (2010): Identificazione partecipativa del patrimonio culturale immateriale transfrontaliero. Research report for Archivio di Etnografia e Storia Sociale, Regione Lombardia.

Balsamo, Isabelle (2003): Les enjeux politiques de la création de l'inventaire general. In Pour une histoire des politiques du patrimoine. Philippe Poirrier and Loïc Vadelorge, eds. Pp. 411-420. Paris: Éditions de la Maison des sciences de l'homme.

Barbe, Noël (2009): La mission du patrimoine ethnologique comme instrument de gouvernementalité. HAL - Science de l'Homme et de la Société. http://halshs.archivesouvertes.fr/docs/00/35/38/08/PDF/MPEInstrumentdegouvernementalite.p df $<$ accessed July 12, 2012>

Benzaïd, Redjem (1979): Rapport sur l'ethnologie de la France. Besoins et projets. Paris: La Documentation Française.

Berliner, David (2012): The politics of loss and nostalgia in Luang Prabang (Lao PDR). In Routledge Handbook of Heritage in Asia. Patrick Daly and Tim Winter, eds. Pp. 234-246. New York: Routledge.

Bortolotto, Chiara (2012): L'idéal participatif du patrimoine immatériel à l'épreuve du réel: le cas de la flèche des Huachipaire du Pérou/The participatory ideal of intangible heritage put to the test by reality: the case of the Huachipaeri arrow. In Masques d'Europe. Patrimoines vivants. Binche : Musée international du carnaval et du masque. Pp. 17-21. Bruxelles: Renaissance du Livre.

Bourg-Broc, Bruno (2006): N² 2875 - Rapport fait au nom de la Commission des Affaires Étrangères sur le projet de loi $n^{\circ} 2605$, autorisant l'approbation de la convention internationale pour la sauvegarde du patrimoine culturel immatériel. Document put into circulation March 13, 2006. Paris: Assemblée Nationale. 
Ciarcia, Gaetano (2003): De la mémoire ethnographique. L’exotisme du pays dogon. Paris: Éditions de l'EHESS.

Chiva, Isac (1990): Le patrimoine ethnologique: l'exemple de la France. In Encyclopaedia Universalis 24: 229-241.

Dubois, Vincent (2010). Le "modèle français" et sa "crise": ambitions, ambiguités et défis d'une politique culturelle. In Tendances et défis des politiques culturelles. Cas nationaux en perspective. Diane Saint-Pierre and Claudine Audet, eds. Pp. 17-52. Québec: Presses Université Laval, INRS.

Grenet, Sylvie (2008): Les inventaires en France. Culture et Recherche 116-117: 27-28.

- (2011): Les inventaires en France. In Le patrimoine culturel immatériel: premières expériences en France. Internationale de l'imaginaire - Nouvelle série, 25. Christian Hottin, ed. Pp. 77-92. Paris: Babel.

Hafstein, Valdimar (2008): Inviting a Noisy Dance Band into a Hospital: Listing the Intangible. In Il patrimonio immateriale secondo l'UNESCO: analisi e prospettive. Chiara Bortolotto, ed. Pp. 95-113. Rome: Istituto poligrafico e Zecca dello Stato.

Heinich, Nathalie (2009): La fabrique du patrimoine. De la cathédrale à la petite cuillère. Paris: Éditions de la Maison des sciences de l'homme.

Herzfeld, Michael (2004): The Body Impolitic. Artisan and Artifice in the Global Hierarchy of Value. Chicago: University of Chicago Press.

Hottin, Christian (2011a): Patrimoine culturel immatériel et recherche ethnologique. In Le patrimoine culturel immatériel: premières expériences en France. Internationale de l'imaginaire - Nouvelle série, 25. Christian Hottin, ed. Pp. 129-158. Paris: Babel.

- (2011b) : Entre ratification et inscriptions: la mise en œuvre d'une politique du patrimoine culturel immatériel en France (2006-2010). Terrain 57: 145-157.

Kirshenblatt-Gimblett, Barbara (2004): Intangible Heritage as Metacultural Production. Museum International 56(1-2): 52-65.

Langlois, Christine (1999): Recent Developments in French Anthropology of France and the Role of the Mission du Patrimoine Ethnologique. Cultural Anthropology 14(3): 409-416.

Lebovics, Herman (2005): On the origins of the Mission du patrimoine ethnologique. Ethnologies comparées 8. http:/ /alor.univ-montp3.fr/cerce/r8/h.l.htm < accessed August 23, 2010>

Leniaud, Jean-Michel (1992): L'Utopie française. Essai sur le patrimoine. Paris: Mengès.

Logan, William Stewart (2002): Globalizing Heritage: World Heritage as a Manifestation of Modernism, and Challenges from the Periphery. In Twentieth Century Heritage: Our Recent Cultural Legacy: Proceedings of the Australia Icomos National Conference 2001. David Jones, ed. Pp. 51-57. Adelaide: University of Adelaide and Australia Icomos, Adelaide. 
Noyes, Dorothy (1995): Group. The Journal of American Folklore 108(430): 449_ 478.

- (2006): The Judgement of Solomon: Global Protections for Tradition and the Problem of Community Ownership. Cultural Analysis 5: 27-56.

http://socrates.berkeley.edu/ caforum/volume5/pdf/noyes.pdf < accessed April 10, 2007>

Ohnuki-Tierney, Emiko (1997): McDonald's in Japan: Changing Manners and Etiquette. In Golden Arches East: McDonald's in East Asia. James L. Watson, ed. Pp. 161-182. Stanford: Stanford University Press.

Owens, Bruce McCoy (2002): Monumentality, Identity, and the State: Local Practice, World Heritage, and Heterotopia at Swayambhu, Nepal. Anthropological Quarterly 75: 269-316.

Palumbo, Berardino (2010): Sistemi tassonomici dell'immaginario globale. Prime ipotesi di ricerca a partire dal caso UNESCO. Meridiana 68: 37-72.

Poirrier, Philippe (2007): Le politiche del patrimonio in Francia nella Quinta Repubblica: da una statale a una politica nazionale, 1959-2005. In Il patrimonio culturale in Francia. Maria Luisa Catoni, ed. Pp. 95-114. Milano: Electa.

Poulot, Dominique (2005): Une histoire des musées de France. Paris: La Découverte.

Price, Sally (2007): Paris Primitive. Jacques Chirac's Museum on the Quai Branly. Chicago: University of Chicago Press.

Ritzer, George (1993): The McDonaldization of Society: An Investigation into the Changing Character of Contemporary Social Life. Thousand Oaks: Pine Forge Press.

Scholze, Marko (2008): Arrested Heritage. The Politics of Inscription into the UNESCO World Heritage List: The Case of Agadez in Niger. Journal of Material Culture 13(2): 215-231.

Shepherd, Robert (2006): UNESCO and the Politics of Heritage in Tibet. Journal of Contemporary Asia 36(2): 243-257.

Smith, Laurajane (2006): The Uses of Heritage. New York: Routledge.

Tornatore, Jean-Louis (2011): Du patrimoine ethnologique au patrimoine culturel immatériel: suivre la voie politique de l'immatérialité culturelle. In Le patrimoine culturel immatériel. Enjeu d'une nouvelle catégorie. Chiara Bortolotto, ed. Pp. 213-232. Paris: MSH.

Turgeon, Laurier (2009): Building an Integrated Multimedia Digital Database of Quebec's Tangible and Intangible Religious Heritage. In Spirit of Place:

Between Tangible and Intangible Heritage. Laurier Turgeon, ed. Pp. 411-428. Québec: PUL.

Turtinen, Jan (2000): Globalising Heritage - On UNESCO and the Transnational Construction of a World Heritage. SCORE Rapportserie, 12. Stockholm:

Stockholm Center for Organizational Research.

UNESCO (2003): Convention for the Safeguarding of Intangible Cultural Heritage. Paris: UNESCO. 
- (2008): Operational Directives for the implementation of the Convention for the Safeguarding of the Intangible Heritage. Adopted by the General Assembly at its second ordinary session. Paris, France, June 16 to 192008.

http://www.unesco.org/culture/ich/index.php?lg=en\&pg=00026<accessed July 25, 2012>

- (n.d.): Standard-Setting Instruments. http://portal.unesco.org/en/ev.phpURL_ID $=12024 \& U R L$ DO=DO_TOPIC\&URL_SECTION=201.html $<$ accessed April 30, 2012>

Wang, Li (2010): La convention pour la sauvegarde du Patrimoine culturel immatériel et son application en droits français et chinois. Ph.D. dissertation, Droit public, Université Paris-Sud 11.

Watson, James L. (1997): Introduction: Transnationalism, Localization, and Fast Foods in East Asia. In Golden Arches East: McDonald's in East Asia. James L. Watson, ed. Pp. 1-38. Stanford: Stanford University Press.

Wieviorka, Michel (2001): La Différence. Paris: Balland.

Wilk, Richard (1995): Learning to Be Local in Belize: Global Systems of Common Difference. In Worlds Apart: Modernity Through the Prism of the Local. Daniel Miller, ed. Pp. 110-133. New York: Routledge.

Yan, Yunxiang (1997): McDonald's in Beijing: The Localization of Americana. In Golden Arches East: McDonald's in East Asia. James L. Watson, ed. Pp. 3976. Stanford: Stanford University Press. 


\title{
Intangible Cultural Heritage Scenarios within the Bureaucratic Italian State
}

\author{
Alessandra Broccolini
}

\section{Introduction}

With the Italian ratification of the UNESCO Convention for the Safeguarding of Intangible Cultural Heritage in 2007, and the subsequent creation of the Representative List ${ }^{1}$ as a central ministerial practice, significant changes occurred in the scenario of local and national cultural policies in relation to the sphere of Intangible Cultural Heritage (ICH). Prior to the convention, ICH held a marginal position in national cultural policies and was mainly left to the purview of local initiatives and the study of popular traditions within folkloristics. Italy has a long history of folklore studies and strongly marked regional cultures; these have enjoyed only periodic moments of visibility in the cultural policies of the Italian state at the national level. There was a moment of increased interest in 1911 when the state organized a large "Exhibition of Italian Ethnography" (Mostra di Etnografia Italiana) meant to represent Italian regional cultural diversity as part of the celebration of the 50th anniversary of Italian Unification. In the following period, public interest in regional cultural production decreased due to the two World Wars, the fascist period and an unfavorable intellectual climate. With the exception of some specific spheres, such as cataloguing and the museography field that gave rise to two important national museums (the L. Pigorini Prehistoric and Ethnographic Museum and the National Museum of Popular Arts and Traditions'), the sphere of ICH after World War II

\footnotetext{
1 The UNESCO Representative List of the Intangible Cultural Heritage was established with the creation of the 2003 Convention for the Safeguarding of Intangible Cultural Heritage (article 16).

2 Museo Preistorico ed Etrnografico L. Pigorini and Museo Nazionale delle Arti e Tradizioni Popolari.
} 
was mainly addressed through local and regional initiatives in connection with the university system. ${ }^{3}$

In this article I seek to explore the implications of the entrance of the Italian state into an international global arena such as that produced by UNESCO through the 1972 convention $^{4}$ and, above all, the subsequent 2003 Convention for the Safeguarding of Intangible Cultural Heritage. How did the latter shape the complex national scene, compelling a multiplicity of local actors and institutions to engage with a new global scenario built up around the sphere of heritage, a scenario that produces national and local identity-oriented claims, political interests, conflicts, negotiations over meaning, and significant efforts of manipulation? 5

\section{UNESCO and Intangible Cultural Heritage in the Organization of Italian Bureaucracy}

How does the Italian ministerial sphere function in relation to the 2003 Convention? How does the Italian state implement this convention? These are not easy questions to answer. ${ }^{6}$ It is difficult for common citizens and local entities to understand the functioning and purview of the various state offices managing the commonweal in the highly bureaucratized Italian state. The implementation of the 2003 Convention was entrusted to various state bureaucratic apparatuses that operate according to frequently obscure political and governmental modalities and do not engage in dialogue with the citizenry; most of the appointments and decisions are made through political and governmental channels that are not accessible or visible to the public.

There are multiple bureaucratic structures in Italy for the implementation of UNESCO conventions: The most "dated" is the Italian National Commission for UNESCO (Commissione Nazionale Italiana per l'UNESCO), an agency of the Foreign Affairs Ministry, where the executive employees are appointed on a political basis. This entity was established in 1950, the same period as the founding of UNESCO itself, and, up to a few years ago (with the advent of the 2003 Convention), it was in charge of both World Heritage and the Masterpieces program. This work was conducted by a specific committee, the Committee for Intangible Heritage and

\footnotetext{
${ }^{3}$ Current Italian legislation dating from 2004 recognizes "demo-ethno-anthropological" resources as a form of cultural heritage, but does not recognize intangible forms, restricting this recognition to the sphere of tangible heritage. The professional figure of the anthropologist is similarly not present among the Italian state's cultural heritage personnel (Clemente 1982-1983, Clemente and Candeloro 2000).

${ }^{4}$ Convention Concerning the Protection of the World Cultural and Natural Heritage (UNESCO 1972).

5 In relation to cultural heritage policies and specifically UNESCO and world heritage issues, Berardino Palumbo's ethnographies deserve the lion's share of credit for introducing a critical analytical approach to the dynamics surrounding heritage policies in Italy (see, for instance, Palumbo 1998, 2003, 2006, 2010).

${ }^{6}$ Regarding the implementation of UNESCO policies in the Italian state, see Mariotti 2008a, 2008b, 2008c.
} 
Living Human Treasures (Comitato per il Patrimonio Immateriale e $i$ Tesori Umani Viventi). It included representatives from the Foreign Affairs Ministry, the Ministry of Cultural Heritage and Activities (MIBAC) and various anthropological professions (Mariotti 2008a). By 1995, the Foreign Affairs Ministry had already established an unwritten agreement protocol with the MIBAC that entrusted to the latter all technical responsibility for overseeing World Heritage registration procedures. As a matter of fact, the constituency of the Italian National Commission included representatives of both the Foreign Affairs Ministry and MIBAC. Following the agreement protocol between the two ministries, a Permanent Interministerial World Heritage Workgroup (Gruppo di Lavoro Interministeriale Permanente per il Patrimonio Mondiale) was instituted in 1997. This overtly political and strongly bureaucratized inter-ministerial organ included multiple ministries and was tasked with making decisions about the implementation of the 1972 Convention and, later, the 2003 Convention. Alongside this, an office called the UNESCO World Heritage Office was created within MIBAC in 2004, which currently oversees ICH nominations. The president of the inter-ministerial workgroup is the minister's Undersecretary and the vice-president is the minister's General Secretary. This is one of the highest administrative ranks within the ministry and also the person who signs nomination applications. The remaining membership of the workgroup is similarly a concentration of bureaucracy and politics: There is the minister's Diplomatic Counselor, the Director of the World Heritage Office and the General Directorate for Cultural Heritage Promotion (also part of MIBAC), the Counselor of the Foreign Affairs Ministry's Commission for the cultural sector, and the Directors of the General Directorate for Culture and of the General Directorate for Cooperation and Development, both of which belong to the Foreign Affairs Ministry. Lastly, there are representatives of the Ministry for the Environment, the Ministry for Agricultural Policies and the Education and Research Ministry. The workgroup's political composition and existence is thus subject to the vicissitudes of the government; when an administration collapses, the workgroup must be reformed and, every time it is re-constituted, it is subject to new regulations. This means that a new minister may simply decide that the presence of a certain ministry within the workgroup is no longer necessary. These few details alone illustrate how difficult the management and implementation of the UNESCO conventions might be, considering the complexity of bureaucratic apparatuses and the conflicts over purview that can arise among them, as well as the workgroup's overtly political rather than technical character. 


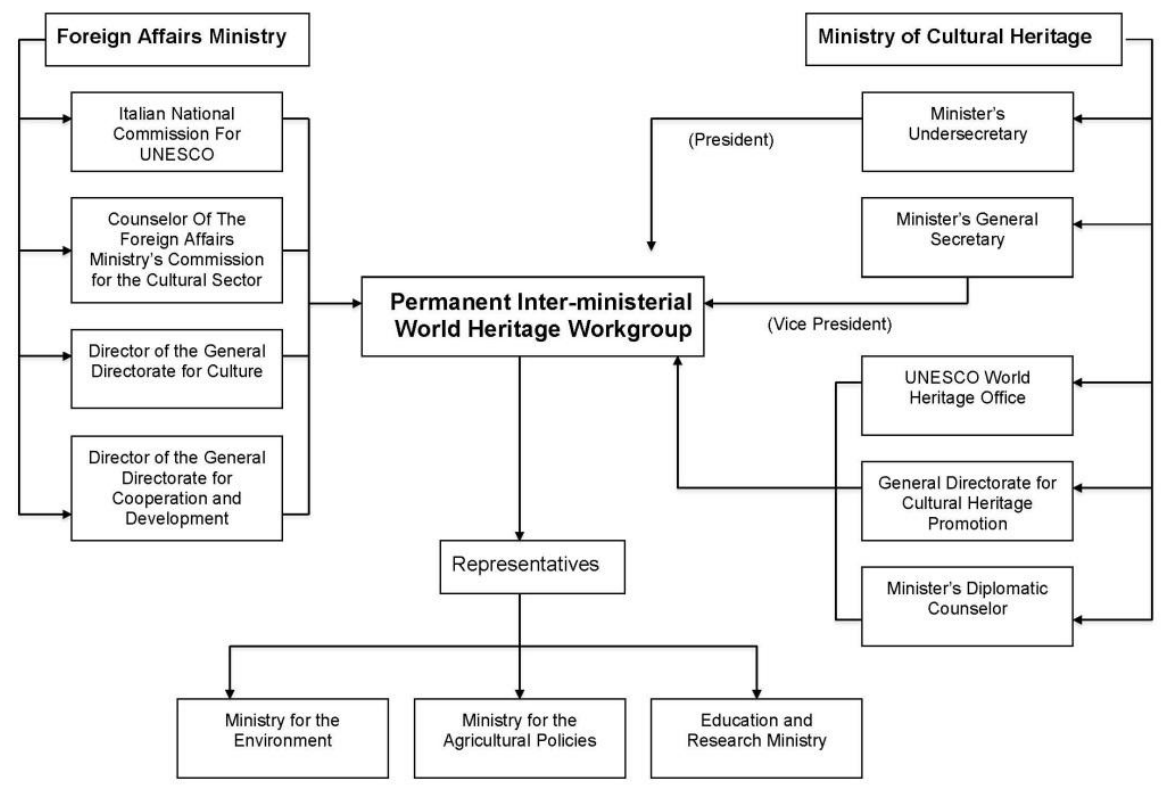

UNESCO and Intangible Cultural Heritage in the Organization of Italian Bureaucracy

Figure 1: (Broccolini 2012).

Starting in 2010, the workgroup began to define the forms through which the 2003 Convention would be implemented and the norms of its application. The situation is, therefore, characterized by emergent norms which have not yet been well defined. As a matter of fact, this organ has only made a few decisions thus far: The creation of a national list of $\mathrm{ICH}$ that would effectively account for the Italian situation; the possibility of presenting theme nominations bringing together multiple localities; and, finally, the decision to limit the number of applications presented each year in Paris to two, in contrast to the numerous applications presented the year before.

Seeing as the workgroup is political in nature and does not include any recognized anthropological expertise, ${ }^{7}$ it is easy to image how the execution of the 2003 Convention in Italy has more to do with the sphere of politics than that of culture. In fact, the interpretation of the Convention that prevails in the bureaucratic practices differs from that of UNESCO and focuses, above all, on visibility and prestige in the sphere of Italian "culture," forms of "excellence," and the appeal of "great Italian culture" and intangible "Made in Italy" products in relation to tourism. Through statements by its directors, the National Italian Commission for

\footnotetext{
7 Since the Ministry of Cultural Heritage and Activities has not yet granted concrete recognition to the professional figure of the anthropologist on its staff, any anthropological expertise that may be present in the inter-ministerial workgroup appears to fulfill other functions.
} 
UNESCO has repeatedly demonstrated that it interprets the 2003 Convention politically rather than, according to the UNESCO intentions of "giving voice," to community, individuals and non-elite forms of cultural diversity originating in local areas.

Giovanni Puglisi, president of the National Italian Commission for UNESCO, interpreted and presented ICH and the work of the Commission (and thus of the Italian state) for a large audience at a public event dedicated to artisanal production that was recently held in Rome. Puglisi's speech is characteristic of the kind of interpretation of ICH and the UNESCO Convention that prevails among bureaucratic state actors:

I am pleased to express my own personal greetings and those of the National Italian Commission for UNESCO at today's event, which celebrates the deep and enduring bond our country enjoys with every form of artistic and cultural expression. [...] The relationship between artisan and artist constitutes a deeply rooted element of Italy's history: In the Renaissance, one of our civilization's moments of greatest magnificence, this relationship was so close that the two figures nearly overlapped, especially within that magical space of the artistic or artisanal "workshop". [...]

Among the various manifestations of intangible heritage, forms of knowledge and crafts connected to traditional artisanal production, the characteristic traditions of Italian artistic trades can and should be recognized as part of this category of heritage. These include, to name only a few, the lute-making tradition of Cremona, Murano glass-making, Florentine leather-working, and the extraordinary food and wine-making traditions that live on in every Italian region. [...] In Italy, the creative craftsmanship that has combined technique and creativity, rigor and talent, precision and imagination at all levels has given life to the outstanding excellence of Made in Italy that forms the foundation of the whole of Italian exportation as well as our national market. In a country that cannot compete in terms of natural resources or heavy industry with global giants, with German steel mills or Arab and Norwegian oil, with African mines or the Chinese workforce, the population's industriousness and creative genius have produced a form of excellence that is recognized throughout the world. For all its economic significance, this excellence goes beyond economics to simultaneously incorporate and express the main facets of Italian identity. In the Italian city of Florence, there is a certain way of producing shoes because this country has a specific aesthetic taste and a specific history; it is the home of Michelangelo and Raphael. To say "Made in Italy" means to define Italian production as a form of production capable of incorporating a highly aesthetic dimension into materials and products that then leads to the perception of a high quality of life. 
Today, preserving, valorizing and promoting Made in Italy involves training a new generation of artisan-artists capable of maintaining, transmitting and developing forms of Italian excellence [...] it means using the valorization of artistic and monument-based heritage as well as the cultural and creative industries to create a culturally and creatively fertile ground throughout the country that is capable of re-awakening a passion for beauty and good craftsmanship, which have always been the fruit of hard work and patient dedication rather than superficiality and rough approximation. Believe me, there is nothing ephemeral or degrading about considering the love of beauty to be the foundation of our identity. ${ }^{8}$

The very decision to reduce nomination attempts to two per year has the effect of "selecting" and more closely "scrutinizing" what is nominated, thus augmenting competition among the various prospective localities and between these localities and the organs of the state. In this way, the Representative List becomes a "display window" highlighting the best examples of "great Italian culture," of an elite selection; it becomes a form of cultural property that the state proudly displays to the world but in relation to which, local communities fade into the background. An exemplary case of this was the "ministerial" nomination of the Mediterranean Diet, which was included in the UNESCO list in $2010 .{ }^{9}$ This process is especially visible in the field of cataloguing, where tensions between the state's various bureaucratic apparatuses and its interpretation of the convention appears most clearly and overtly.

\section{Cataloguing Intangible Cultural Heritage According to the Italian State}

In the field of Italian national cultural policies, much of the state's interest in ICH has been focused on inventories (catalogazione in Italian). This interest is not a product of the Italian ratification of the UNESCO convention but, rather significantly, preceded it: Its emergence coincided with the gradual, laborious process beginning in the late-1970s, through which the Italian state began to grant recognition to local and regional cultures within the sphere of cultural heritage. This recognition led to the development of a new type of national heritage called (tangible and intangible) "demo-ethnoanthropological" heritage. The phrase "demo-

\footnotetext{
${ }^{8}$ Speech by the president of the Italian National Commission for UNESCO, Giovanni Puglisi, inaugurating the section dedicated to ICH at Vivere di Cultura: Le giornate del lavoro culturale (Living off culture: the days of cultural work), held June 24-25, 2011, Auditorium, Rome (http://www.viveredicultura.it/patrimonio_culturale < accessed 19 July, 2012>).

9 The Mediterranean Diet nomination was presented by Spain, Italy, Greece, and Morocco, and headed by Spain. The nomination was strictly state-initiated in Italy, wholly concentrated on the international promotion of Italian cuisine and put forward on the initiative of the Ministry for Agricultural Policies without any grass-roots involvement by the communities (see Broccolini 2010).
} 
ethnoanthropological" emerged in the mid-1970s thanks to the anthropologist Alberto Mario Cirese (1973), who used it to convey the plurality of Italian academic traditions: "demologic" studies of folklore and popular culture, ethnological research on cultures outside of Europe, and cultural-anthropological approaches in the North American tradition. This form of the expression, "demoethnoanthropological," was adopted by the Italian state at the moment when cultural resources were first defined and recognized at the legislative level. This occurred firstly in the Legislative Decree of $1998^{10}$ and subsequently in the 2004 Code of Cultural and Landscape Heritage (Codice dei Beni Culturali e del Paesaggio) released by the Ministry of Cultural Heritage and Activities (Bravo and Tucci 2006). ${ }^{11}$ In reality, the legislation does not specifically define what is meant by "demo-ethnoanthropological resources" and only makes vague reference to something that "betokens civilization." ICH is similarly not yet formally recognized in legislation; however, cultural heritage cataloguing (including intangible ethnoanthropological forms) has a noteworthy history in Italy prior to the UNESCO convention.

Although the Italian state shows less interest in ICH cataloguing than it does in cataloguing more traditionally consolidated heritage forms (artistic or archeological works, etc.), the state's interest in cataloguing ICH does reflect a more general investment in cataloguing every type of cultural heritage recognized as cultural property. In 1975, immediately after the formation of the Ministry of Cultural Heritage and Activities, this interest gave rise to a special institute (the Central Institute for Cataloguing and Documentation, or Istituto Centrale per il Catalogo e la Documentazione [ICCD]) established especially to catalogue the state's cultural heritage. All types of cultural heritage that the state currently recognizes (historical-artistic, archeological, landscape, demo-ethno-anthropological assets, etc.) are, therefore, theoretically subject to a systematic process of cataloguing carried out by this institute.

The cataloguing of "demo-ethno-anthropological" heritage, therefore, has a specific history within national cultural heritage policies, and over the years, has produced two forms for cataloguing: A form for tangible demo-ethnoanthropological heritage (Beni Demoetnoantropologici Materiali or BDM) and one for intangible demo-ethno-anthropological heritage (Beni Demoetnoantropologici Immateriali or BDI), both of which were introduced in 2000 and are still currently in use.

These national forms were developed according to a classificatory and bureaucratic conception of cultural heritage that was applied in the same way to all types

\footnotetext{
${ }^{10}$ Legislative Decree of March 31, 1998: "The phrase 'cultural resources' refers to [...] those resources that comprise the historical, artistic, monument-related, demo-ethnoanthropological, archeological, archival, bibliographic and other forms of heritage that constitute a testament to the values of civilization thusly identified on the basis of law."

${ }^{11}$ Legislative Decree number 42 of 2004: "According to articles 10 and 11, cultural resources are those fixed and movable assets that hold artistic, historical, archeological, ethnoanthropological, archival or bibliographic value as well as other assets identified by law or on the basis of law that betoken the possession of civilizational values."
} 
of resources and all cultural heritage cataloguing activities. As a matter of fact, with the necessary modifications to reflect the kind of heritage in question, the same type of form was used for the entirety of Italian cultural heritage in order to produce consistency (read: standardization) among the various kinds of heritage and the language used in the cataloguing forms. Different types of heritage were thus "translated" into types of forms that were different yet standardized. Through the technical and administrative language used in the forms, the process of cataloguing ICH in Italy has produced a domestication of the heritage and "appropriation" at the national level.

The introduction of these forms marked an institutional acknowledgement of anthropological expertise in that the state recognized the professional proficiency of anthropologists for the first time. Only those anthropologists holding certified academic qualifications and experience in the field of ethno-anthropological documentation are eligible to do cataloguing work at either ministerial or regional levels. At the regional level, the procedure for recruiting anthropologists has varied from region to region. In Lazio, for example, public rankings were developed that were only open to degree-holding anthropologists with a specific background.

However, these forms were strongly contested by the anthropologists who displayed a more critical approach in relation to questions of heritage. ${ }^{12}$ For this reason, the forms have retained a marginal position and never enjoyed widespread support within the Italian anthropological community.

In its design, the BDI form appears to be a distant bureaucratic tool, reminiscent of the "bank-style census" that De Varine (2002) discusses in relation to the various types of cataloguing forms. The BDI form not only forces cataloguers to objectify a complex event by reducing it to a standard that shares the same homogenous language with other types of heritage (each asset has its own general cataloguing number that is unique at the national level), but it also functions to fragment complex events, such as rituals, into multiple separate forms (kinetic behaviors, songs, specific forms of knowledge, individual ritual moments, etc.). Each of these elements is to be considered a single "asset;" for instance, if a feast takes place over several days and consists of multiple moments and various ritual subevents (the blessing of animals, food preparation, proxemic behaviors, etc.), the form forces cataloguers to produce one form for each "asset" represented by these individual elements, although they are then reunited in a form field in which all sub-events can be identified as components of a single main event. ${ }^{13}$ Another element that illustrates the strongly bureaucratic character of the form is the fact that

\footnotetext{
12 The BDI forms are highly elaborate and complex in terms of conceptual organization; they are powerfully regulated and grant significant attention to audio-visual ethno-anthropological documentation; see Tucci 2002, 2005, 2006, Vasco Rocca 2002, Mariotti 2004.

13 The form includes a specific field, indicated with the code ROZ, that allows cataloguers to connect the various different forms pertaining to the same "fragmented" event. This has given rise to a new "bureaucratic" verb used among cataloguers: the verb rozzare, "to roz," meaning a cataloguing operation in which multiple forms are connected. The use of this verb clearly illustrates the power that bureaucratic procedures exercise in shaping communication.
} 
each field in the form ${ }^{14}$ is identified with a specific code; this literally codified language contributes to making the form into a bureaucratic tool detached from any concrete cultural practice.

As a matter of fact, the BDI form enjoyed only a very marginal relationship with the communities who are the bearers of these instances of heritage until very recently. This marginality is due in part to the communities' lack of interest in this technical-bureaucratic instrument. In part, however, it is due to the fact that "cataloguing" anthropologists have, throughout their research, habitually maintained a relationship with these communities that can be defined as "withdrawn," considering it sufficient to simply obtain the subjects' consent for interviews or to allow their ceremonies to be documented. BDI forms do not require any "participation" by the community (apart from the role of "informant") in the definition of heritage or the management of inventories, and the state has yet to produce any form of direct "restitution." Communities are not informed about the final product of cataloguing activities and the audiovisual materials collected through fieldwork are not returned except by direct request and with significant bureaucratic difficulty. The ICH inventories produced by the Italian state have, for the most part, been stored, either digitally or in hardcopy, in the archives of the institutions without any move to give them back, share them within the communities or with the heritage bearers themselves, even in the sense of returning audiovisual materials. ${ }^{15}$

This "absence" of the community in the practice of cataloguing is linked to the theoretical assumptions that produced the form. The BDI ministerial form is based on an objectivistic conception of "heritage" (that heritage "objectively" exists). The form thus pursues objectivistic analytical aims that are not in dialogue with either reflexive paradigms or the shared or participatory practices through which these forms of heritage are defined. This cataloguing model suffers from a "semiotic" cultural approach that was popular in Italy in the 1980s: documenting, collecting and sequentially ordering "data" to identify codes and languages. However, it is also reminiscent of the attention granted to documents and "texts" within Italian folkloric studies of the second half of the 19th century, which were markedly connected to the "text" and the production of "collections" of traditional folkloric extracts (songs, fables, popular poetry, etc.). ${ }^{16}$

\section{Bureaucratic Interpretations of Heritage in "the UNESCO Era"}

Until the current moment, these ICH inventories have been produced in Italy by the ministry (ICCD) or by local (regional or provincial) agencies without any at-

\footnotetext{
${ }^{14}$ The form is divided into paragraphs, fields and subfields.

${ }^{15}$ For an article regarding ICH cataloguing in Italy, see Broccolini 2010.

${ }^{16}$ Es. Bianco and Del Ninno 1981, Mazzacane 1985.
} 
tempt to share or give back to the individual communities involved. Over the last few years, any project the state wished to finance on this subject has been carried out without interference: The state decides on a cataloguing campaign and sends "its" own "bureaucrats," anthropologists, to "withdraw" samples of "heritage" in order to preserve the memory of a piece of cultural property for posterity in its own national archives, according to a conservation-oriented conception of heritage.

However, this bureaucratic scenario has changed in recent years, becoming more complex and dynamic than the relations the state was accustomed to maintaining with individual communities in the cultural heritage field, bringing with it consequent conflicts and forms of manipulation. With the arrival of UNESCO nominees vying for inclusion in the Representative List of ICH, the individual communities have begun to produce nominations and to actively work on the preparation of dossiers. ${ }^{17}$

The arrival of the Representative List instrument within national policies has triggered a great deal of commotion at the local level and interest on the part of those who saw these lists as a potential global display window to grant visibility to the community and build political consensus. This instrument has also led the state (through its various ministries represented in the inter-ministerial work group) to enact a process of filtering and inspecting the nominations, thanks to a national right to cultural property. ${ }^{18}$ This dynamic found expression first of all, in the bureaucratic field of cataloguing, and secondly, in the field of preparing and presenting the nomination dossiers.

Along with the emergence of these nominations and in compliance with Article 12 of the 2003 Convention, that required the state to catalogue intangible heritage, the inter-ministerial workgroup and the MIBAC World Heritage Office forced the "communities" proposing the nominations to fill out the inventory for their own nominated heritage as a preliminary requisite for presenting the dossier. The state did not, however, allow the individual communities to choose how to fill out the cataloguing forms but rather, following the Italian bureaucratic tradition of

\footnotetext{
17 Powerful patrimonialization processes affecting local policies and identity-related claims had already begun at local and supra-local levels many years before, with the institution of UNESCO World Heritage and the creation of the list of UNESCO World Heritage Sites. For a critical ethnographic approach to patrimonialization processes in the field of UNESCO World Heritage nominations, see Palumbo 1998, 2003, 2006, 2010.

18 The Italian Code on Cultural and Landscape Resources (Legislative Decree number 42 of January $22,2004)$ does not address the delicate issue of cultural ownership of "ethnoanthropological resources" and makes no mention of "intangible heritage," limiting itself to "movable" and "fixed" resources. As a result, as far as intangible heritage (which also includes UNESCO nominations) is concerned, none of the code's more than 180 articles mention the equally delicate issue of relations with local communities. In article 10, as well as multiple other passages, it ambiguously mentions the role of the state as "possessor" of ownership, equating works of art, archeological sites and "ethnoanthropoligical resources:" "Cultural resources are fixed and movable assets owned by the state, regions, and other local public agencies as well as any other public agency or institution and private legal persons not engaged in profit-seeking, and which hold artistic, historical, archeological, or ethnoanthropological value." [emphasis added]
} 
cataloguing, dictated that the inventories be created according to the national cataloguing standard, that is, using the BDI forms.

The state's bureaucratic choice illustrates an interesting interpretation of the convention. On one hand, it reflects the will to comply with the requirement established by UNESCO's article 12, which requires that inventories be filled out; on the other hand, with this choice, the state retains its controlling function over the local communities. ${ }^{19}$

This function becomes evident if we examine the bureaucratic dynamics surrounding the process these inventories must go through before the communities can move forward with their nomination applications. First of all, even though these inventories are promoted, commissioned and financed by the communities, they must be created by professional anthropologists trained in cataloguing; actors who are competent but often outsiders to the community in question. Secondly, all the procedures related to filling out the forms involve numerous obligatory steps that must be checked by the state (the ICCD must provide the general cataloguing numbers for each form and the codes for supporting audio-visual documentation). Above all, it is the state that holds the authority to check the forms and the progress of the nominations. In fact, the nomination must be reviewed and approved by functionaries of the state, which can approve or block a nomination and thus retains ultimate authority over the cataloguing process.

The state with this bureaucratic procedure retains control over a great deal of the nomination process; however, the individual communities have, nonetheless, been able to enter into the heritage arena, as had previously occurred in relation to World Heritage. As a result, during the past year (2010-2011), every one of the towns presenting nominations (there were 11 nominations in Italy in 2010) was required to inventory the heritage in question. Thanks to the fact that the communities specifically commissioned the work and were directly interested (in the validation of their nomination and a UNESCO recognition of their heritage form), for the first time in national history, cataloguing has begun to move "downhill:" From the ministry and regions to the municipalities and individual nominating subjects, who became both commissioners and owners of the inventories, as well as of the audio-visual documentation supporting the forms. Paradoxically, however, this democratic process of cultural appropriation was triggered by the way that the nominating subjects were forced to adapt to a bureaucratic procedure imposed by the state and its interpretation of the convention.

As one might imagine, in moving between a bureaucratic state-based centralism and the beginning of a grass-roots participatory process, this entire procedure expresses both the state's need to adapt to "global values" of participation and democratization in cultural policy and its discomfort with and efforts to manipu-

19 The ministry's decision to grant authority over heritage cataloguing to one of its institutes (the ICCD) is due to the fact that MIBAC is the ministry with the most authority over nominations (the dossiers are signed by the minister's General Secretary) which, therefore, has the power to make decisions about inventories. 
late these same values. This ambiguity is clearly illustrated by the ethnographic exploration of a specific nomination (and inventory) case, that of the Palio of Siena (par. 7), for which I directly oversaw the cataloguing component.

\section{Intangible Cultural Heritage in Italian Civil Society: the Role of Associations and NGOs}

In response to the centralization of governmental policies about ICH and the often ambiguous way they have been interpreted by some state apparatuses, in recent years Italy has also witnessed the development of a movement of nongovernmental organizations (NGOs) with UNESCO ICH accreditation that are connected to local territories and communities. They have emerged in response to the excessive politicization and bureaucratization of the cultural heritage policies developed to implement the 2003 UNESCO Convention and to the lack of appropriate scientific and local geographical expertise within the ministry. Encouraged by guidelines from UNESCO itself, this movement is beginning to build an intermediary network with the state to manage and promote ICH policies along UNESCO lines.

This movement has its roots in a fertile ground of associational activity, as well as cultural and political militancy that since the late-1960s has been connected to the folk revival movement and the cultural and political activism of leftist groups guided by popular culture and folkloric values (music, performative rituals, collective memory, oral sources). ${ }^{20}$ On the one hand, this marked pluralism was produced and stimulated by the state's lack of interest in popular culture (which was later defined "demo-ethnoanthropological heritage"), while on the other hand, it revolved around countercultural and anti-hegemonic political aims. This pluralism continued to exist locally even in subsequent years, during the 1980s and 1990s, and gave rise to numerous efforts to valorize and document popular culture as well as museography and research projects.

Later, when the UNESCO Convention, ICH and nominations for the Representative List started to attract local communities and enter onto the Italian cultural scene, there was already a fertile ground rich in associations of both experts and militants who were prepared to implement the logic of the convention in dialoguing with local communities and territories and to give life to a movement in reaction to governmental policies, although, nonetheless, in engagement with them.

The first association to appear on the scene was founded in 2001 by the name of SimbDea (Società Italiana per la Museografia e i Beni Demo-etnoantropologici - Italian Society for Museography and Demo-ethnoanthropological Resources); it currently works to put the academic world and anthropological expertise into dialogue with the sphere of cultural operators, museographers and local territories. In 2010,

20 See Clemente and Candeloro 2000. 
SimbDea's work gave rise to the need for a closer dialogue with state organs and the Ministry of Cultural Heritage and Activities about the policies used to implement the 2003 convention. Thanks to its recognition by UNESCO in 2010 as an NGO certified in the field of safeguarding and valorizing ICH, in 2012, SimbDea established a network (Rete Italiana per la Salvaguardia del Patrimonio Culturale Immateriale - Italian Network for safeguarding of intangible heritage) comprising six nongovernmental associations, together with ANCI (Associazione Nazionale Comuni Italiani - National Association of Italian Municipalities), several universities, and institutions such as the Lombardy Region. This network has produced a document aimed at drafting a convention with MIBAC and, in particular, with the UNESCO World Heritage Office. ${ }^{21}$

The network seeks to address the need for more significant dialogue between the central organs of the state and local territories, as well as more anthropological expertise in implementing UNESCO Convention policies in accordance with the convention's own orientation, which grants the communities a central role in defining ICH, by developing the following objectives to guide its projects: ${ }^{22}$

- To identify and monitor ICH on a regional and provincial level. They appear to be most concerned with locating cataloguing procedures implemented by the state alongside forms of "participatory inventories" built through dialogue with the communities and which complement the national inventorying projects regulated by the ICCD system.

- To offer support to MIBAC's World Heritage Office in handling the nomination applications in a way that engages with the network and grants each region knowledge "from the ground up," in dialogue with the local communities.

- To plan and test out documentary analysis procedures that follow international standards based on the language of the web and which complement the already existing national catalographic documentation systems (ICCD).

- To launch a multinational nomination pilot project dedicated to improvised poetry. This project seeks to develop the process of intercultural dialogue that began with the maritime Transborder France-Italy IN.CON.T.R.O project, an initiative that puts into dialogue several communities holding this form of oral heritage (Tuscany, Lazio, Sardinia, Corse, Cataluña, Balearic Islands, Tunisia, Morocco, and Brazil).

\footnotetext{
${ }^{21}$ Network participants include the national association "Città della Terra Cruda," the Comitato per la promozione del patrimonio culturale immateriale-ichnet, the Associazione per la Salvaguardia del Patrimonio Culturale Immateriale (ASPACI), SimbDea, the Scapoli-based Associazione Culturale Circolo della Zampogna, the Associazione Extra Moenia from Nola $(\mathrm{Na})$, the Venetian Università $\mathrm{Ca}^{\prime}$ Foscari, Università Roma 3, and the Lombardy Region.

22 Project document: Patrimoni culturali Immateriali tra Comunità locali, territori e musei: verso una Rete italiana per la salvaguardia del Patrimonio Culturale immateriale (Zingari 2012).
} 


\section{Local Conflict Arenas and Global Regimes: the Case of the Palio of Siena}

The nomination for including the Palio of Siena in the UNESCO Representative List of ICH was prepared over the course of 2010 and followed a bottom-up path in that it originated in the multiplicity of "heritage communities" in the Siena urban area. ${ }^{23}$ Siena represents a textbook case in terms of community participation and awareness of heritage in relation to its collective expressions. In fact, the nomination of the Palio was initiated by the municipality of Siena, the official organizer of the race, thanks to a direct interest on the part of the mayor. However, it was also supported by the Magistrato delle Contrade, the organ that represents the 17 city wards, and by the Consorzio per la Tutela del Palio di Siena, a consortium created in the 1980s to preserve the image of the Palio. Although the actual motivations that led the municipality of Siena to nominate its famous Palio to the UNESCO list were not generated by strictly "cultural" factors but rather (as we will see) political factors, this nomination was, nonetheless, characterized by extensive community participation following the spirit of the 2003 Convention.

In addition to exploring the complex internal events that motivated this nomination, I am interested in analyzing how the local community interpreted the state's bureaucratic policies. In fact, this nomination produced conflicts among different bureaucratic state apparatuses that ended up leading to a political crisis, prompting the Ministry of Cultural Heritage and Activities to block the nomination and sparking heated debates in the local community. The Siena case thus reveals the strongly political nature of the bureaucratic procedures surrounding heritage and the overtly conflictual character of the state's bureaucracies.

Firstly, the ministry's obligatory requirement that an inventory be produced using the BDI forms filled out by an external anthropologist was received with some suspicion by nomination supporters, especially given that there is already a truly enormous literature and store of audiovisual documentation about the Palio. Siena residents are highly aware of the heritage value of the Palio; the "cataloguing" anthropologist imposed on them to carry out a bureaucratic task thus represented an intrusion. The entire work of cataloguing was, therefore, necessarily shared with a strong "heritage" community. These were not simply passive informants; they were active heritage agents.

\footnotetext{
23 The Palio of Siena is a historical event consisting of a horse race in which ten horses represent the wards (contrade) of which the urban territory of Siena is comprised. The urban territory of Siena is divided into 17 contrade, but, through a complex procedure, only 10 are selected for each race. The race takes place twice a year during the summer in the city's main square (Piazza del Campo). The first time, on July 2, it is staged to honor the Madonna of Provenzano; the second time, August 16, it is to honor the Assumption of Mary. The race consists of three laps around the track of the square and lasts approximately one and a half minutes, but the preparations and the process of selecting and distributing the horses according to a rigorous public ceremonial is very lengthy. The victorious ward receives the Palio from the town hall; the Palio is a rectangular, painted silk flag that is different every year and which displays religious elements and scenes from Siena's history. For an anthropological interpretation of the Palio of Siena, see Dundes and Falassi 1975.
} 
What most significantly shaped the Siena nomination was the particular political moment in which it was prepared. This moment was characterized by a strategic and conflictual use of "global" values, such as heritage, but also other discourses, such as animal rights and intercultural dialogue.

We must take a few steps back in time to better understand this case. Several years before the nomination, animal rights movements targeted the Palio on Italian media platforms, repeatedly accusing the event (and the authorities promoting it) of not paying sufficient attention to the health of the horses. According to animal rights activists, the particularly dangerous urban course of the Siena race threatens the horses' welfare to such a degree that the race should be abolished. Over the history of the Palio there have in fact been several accidents involving the horses, some of which were fatal. In order to address this issue and ensure the continued occurrence (and existence) of the city's most prestigious public event with its high degree of local identification, the municipality developed over the years a rigorous training and evaluation program for the horses chosen to run in the race, aimed at reducing any possible risk.

It is not surprising that the UNESCO Palio nomination arrived in precisely this climate of debate and weakness on the part of the administration in relation to the subject of animal rights. International heritage recognition from UNESCO (an occurrence which many Siena residents considered inevitable) would have permanently silenced the debates and erased any doubt or conflict surrounding the health of the horses. By becoming an example of UNESCO-recognized ICH, the Palio (and the mayor) hoped to break out of the tangle of debates that had enveloped them in recent years.

With this in mind, the "political" motivation that led the municipal administration to present the nomination is easy to deduce: They sought to use a global regime like that offered by UNESCO, with its equally global values, to overcome national debates which were themselves fueled by equally global values (those of animal rights). It is similarly no coincidence that, during the staging of the event that coincided with the nomination preparation, the town hall hired a Lebanese painter to make the traditional silk flag, called the Palio, which is awarded to the winning contrada (ward-based group). This painter created a "transgressive" flag featuring various symbols from the Middle Eastern Islamic tradition ${ }^{24}$ alongside the traditional Catholic symbols (the race is run in honor of the Virgin Mary) and symbols of Siena's history, thus provoking anger among the conservative audience members. This was a clear call for inter-religious dialogue, but it also contained a powerful political message from the administration: A clear reclaiming of authority over a territory that has historically been governed by the political left. The deployment of these global values (world heritage and inter-religious dialogue) was

\footnotetext{
24 The painting features Saint George in the guise of a Saracen archer, holding a keffiyeh (traditional Arabic head covering) in the place of a helmet; furthermore, on the Virgin's crown, there is a Sura from the Koran, with the half-moon symbol together with the Star of David and the Christian cross.
} 
intended to symbolically contest and oppose the equally global values claimed by the animal rights activists (animal rights).

While disputes over the health of the horses in previous years had been marginal to the national debate and limited to the animal rights movement, during the year that Siena was preparing the nomination, these disputes were re-ignited by the Minister of Tourism who had been appointed by a right-wing government opposed to the local administration in Siena. ${ }^{25}$ The Minister once again raised the issue of the health of the horses running in the Palio on national media platforms, thus provoking a crisis in government relations between two ministries. Following these disputes, the Ministry of Cultural Heritage and Activities decided to block Siena's nomination without any official justification, even though the dossier did not contain any formal mistakes. In this way, they sought to ensure that the Palio nomination, which had become so highly exposed in the media, did not damage governmental relations.

The Siena case clearly illustrates how the issue of intangible global heritage in "the UNESCO era" can become the source of conflict between various local and national bureaucratic apparatuses. Local actors defend their interests within the arena of global heritage. In so doing, they must engage in the national arena with other global values and the filter of the state, all of which are factors which may negatively influence the nomination attempts and require that the communities defend themselves in any way they can. The state bureaucracies also display discomfort in the face of community participation and local interpretations of the heritage in question, and respond by enacting bureaucratic centralism as a way of reclaiming authority over heritage policies and over the "cultural property" of the nation, thus hampering local actors and communities whenever possible in their attempts to gain direct access to the global heritage regime.

Local and national interpretations of the UNESCO convention highlight a dense articulation among contemporary heritage arenas that emerge and develop between local and national settings but within global frames. These arenas oblige communities to locate and make a space for themselves between, on the one hand, the bureaucratic and standardizing language of UNESCO required for presenting a nomination and, on the other hand, the equally standardizing language of national cataloging.

\section{$7 \quad$ References}

Bianco, Carla, and Maurizio Del Ninno, eds. (1981): Festa. Antropologia e semiotica. Florence: Nuova Guaraldi Editrice.

Bravo, G. Luigi; and Roberta Tucci (2006): I Beni Demoetno-antropologici. Rome: Carocci.

25 The Minister of Tourism at the time was Maria Vittoria Brambilla. 
Broccolini, Alessandra (2010): L'UNESCO e gli inventari del patrimonio immateriale in Italia. Antropologia Museale (28-29): 41-51.

Cirese, Alberto Mario (1973): Cultura egemonica e culture subalterne. 2nd edition. Palermo: Palumbo.

Clemente, Pietro (1982-1983): Folklore studies and ethno-anthropological research in Italy: 1960-1980. Ethnologia Europaea 13(1): 37-52.

Clemente, Pietro, and Ilaria Candeloro (2000): I beni culturali demo-etnoantropologici. In Manuale dei Beni Culturali. Nicola Assini and Paolo Francalacci, eds. Pp. 191-220. Padova: CEDAM.

De Varine, Hugues (2002): Les racines du futur. Le patrimoine au service du développement local. Chalon-sur-Saône: ASDIC.

Dundes, Alan, and Alessandro Falassi (1975): La Terra in Piazza. An Interpretation of the Palio of Siena. Berkeley: University of California Press.

Mariotti, Luciana (2004): Storia dei processi catalografici. In Arti e Tradizioni: Il Museo Nazionale dell'EUR. Stefania Massari, ed. Pp. 157-180. Rome: De Luca Editori.

- (2008a): Capolavori del Patrimonio Orale e Immateriale dell’Umanità.

L'esperienza italiana: 2000-2005. Voci. Semestrale di Scienze Umane 5

(Gennaio-Dicembre): 90-104.

- (2008b): La Convenzione per la Salvaguardia del Patrimonio Culturale

Immateriale. Un'analisi. Antropologia Museale (18): 51-54.

- (2008c): Prospettive italiane della Convenzione sul Patrimonio Culturale Immateriale. Ipotesi di analisi tra antropologia e norme giuridiche. In La convenzione per la salvaguardia del patrimonio immateriale. Un'analisi. Chiara Bortolotto, ed. Rome: Poligrafico.

Mazzacane, Lello (1985): Struttura di festa. Forma, struttura e modello delle feste religiose meridionali. Milan: F. Angeli.

Palumbo, Berardino (1998) : L'UNESCO e il campanile. Riflessioni antropologiche sulle politiche di patrimonializzazione osservate da un luogo della Sicilia orientale. Èupolis (21-22): 118-125.

- (2003): L'UNESCO e il campanile. Antropologia, politica e beni culturali in Sicilia orientale. Rome: Meltemi.

- (2006): Il vento del Sud-Est. Regionalismo, neo-sicilianismo e politiche del patrimonio nella Sicilia di inizio millennio. Antropologia (6-7): 43-91.

- (2010): Le alterne fortune di un immaginario patrimoniale. Antropologia Museale (28-29): 8-23.

Tucci, Roberta (2002): Beni Demoetnoantropologici Immateriali. Antropologia Museale 1(1): 54-59.

- (2005): La catalogazione dei Beni demoetnoantropologici immateriali: le schede dell'Istituto Centrale per il Catalogo e la Documentazione. Voci (1): 51-64.

- (2006): Il patrimonio demoetnoantropologico immateriale fra territorio, documentazione e catalogazione. In Beni Demoetnoantropologici Immateriali, Scheda BDI, 2. I.C.C.D., ed. Pp. 20-29. Rome : I.C.C.D. 
Vasco Rocca, Sandro (2002): Beni culturali e catalogazione. Principi teorici e percorsi di analisi. Rome: Gangemi.

UNESCO (1972): Convention Concerning the Protection of the World Cultural and Natural Heritage. Paris: UNESCO.

Zingari, Valentina (2012): Le arti dell'improvvisazione poetica come patrimonio dell'umanità. Antropologia Museale, (28-29): 96-100. 


\section{Scheda BDI - Beni demoetnoantropologici Immateriali}

Modello per la registrazione dei dati

\begin{tabular}{|l|l|l|}
\hline CD & CODICI & \\
\hline TSK & Tipo di scheda & \\
\hline LIR & Livello di ricerca & \\
\hline NCT & CODICE UNIVOCO & \\
\hline NCTR & Codice Regione & \\
\hline NCTN & Numero di catalogo generale & \\
\hline NCTS & Suffisso numero di catalogo generale & \\
\hline ESC & Ente schedatore & \\
\hline ECP & Ente competente & \\
\hline EPR & Ente proponente & \\
\hline
\end{tabular}

\begin{tabular}{|l|l|l|}
\hline RV & RELAZIONI & \\
\hline RVE & STRUTTURA COMPLESSA & \\
\hline RVEL & Livello & \\
\hline RVER & Codice bene radice & \\
\hline RVES & Codice scheda componente & \\
\hline RSE & RELAZIONI DIRETTE & \\
\hline RSER & Tipo relazione & \\
\hline RSET & Tipo scheda relazionata & \\
\hline RSEC & Codice bene & \\
\hline ROZ & Altre relazioni & \\
\hline
\end{tabular}

\begin{tabular}{|l|l|l|}
\hline DB & DEFINIZIONE BENE & \\
\hline DBL & Denominazione locale & \\
\hline DBD & Denominazione & \\
\hline DBC & Categoria & \\
\hline
\end{tabular}

\begin{tabular}{|l|l|l|}
\hline RD & REDAZIONE & \\
\hline RDM & Modalità di redazione & \\
\hline
\end{tabular}

\begin{tabular}{|l|l|l|}
\hline LA & $\begin{array}{l}\text { ALTRE LOCALIZZAZIONI } \\
\text { GEOGRAFICO- } \\
\text { AMMINISTRATIVE }\end{array}$ & \\
\hline TLC & Tipo di localizzazione & \\
\hline PRV & LOCALIZZAZIONE GEOGRAFICO- & \\
& AMMINISTRATIVA & \\
\hline PRVS & Stato & \\
\hline
\end{tabular}

Figure 2: The first page of the BDI, the 17-page form for classifying and cataloguing ICH in Italy. 



\title{
Identifying "Living Traditions" in Switzerland: Re-enacting Federalism through the UNESCO Convention for the Safeguarding of Intangible Cultural Heritage
}

\author{
Florence Graezer Bideau
}

\section{Introduction}

A recent headline in a national French-language newspaper, "Yodeling or multimedia: which culture does Switzerland need?"(Fournier and Dufour 2011), is interestingly emblematic of what has happened since 2008, the year Switzerland ratified the 2003 UNESCO Convention for the Safeguarding of Intangible Cultural Heritage. During this period, federal and cantonal officials worked with experts and advisors to prepare the public launching, on September 2, 2010, of a national program for identifying "living traditions," the official translation of the technical term "intangible cultural heritage" ( $\left.\mathrm{ICH}^{1}\right)$. The process of identifying Swiss ICH is still under way and, through participant observation, I have had the opportunity to investigate the mechanisms and repercussions of Switzerland's ICH inventory. ${ }^{2}$

The newspaper article cited above clearly reflects the current political debate over the new law for funding culture, scheduled to come into force at the beginning of 2012; but by defining Swiss culture ("yodeling or multimedia") as a choice between the dichotomous terms of tradition and modernity, and by proposing a functionalist approach to culture ("which culture does Switzerland need?") it ob-

\footnotetext{
${ }^{1}$ This substitution was effectuated in order to promote better understanding amongst the media, the government officials involved and the population.

2 This research was carried out within the framework of a larger project entitled "Intangible Cultural Heritage: the Midas Touch?," funded by the Swiss National Science Foundation and coordinated by Professor Ellen Hertz, University of Neuchâtel, Switzerland.
} 
scures what is really at stake in the federalist context. I argue here that the question should be rephrased as "who is deciding?" (the federal government or the 26 cantons), rather than "what is decided?" (traditional or modern expressions of Swiss culture), with the sub-question, "who are the legitimate experts" on questions of culture? Or, more generally, what role does expertise play in the constitution of Switzerland's relations to its "living traditions?"

This paper explores the political and bureaucratic mechanisms of Swiss federalism that have played a key role in shaping the national program to constitute an inventory of Swiss ICH, and analyzes the making of ICHat the federal, cantonal and local levels. Specifically, the actors I will be examining include the federal government and its administration, national institutions, such as Pro Helvetia (the Swiss Arts Council), the 26 cantons' cultural administrations, and finally, the collection of experts of various stripes who have contributed to these procedures. In a first section, I will briefly introduce Swiss cultural policy for a better understanding of the particular federalist context within which it operates, notably, the subsidiarity principle. Next, I will examine the mechanisms for identifying ICH, designed to operate in three steps over a period of two years. ${ }^{3}$ At the end of this process in 2012 , three different types of lists will have been produced, covering the whole country: 26 cantonal inventories listing 387 propositions; an indicative list of 167 cantonal propositions of national interest (see Appendix); and a final selection of 6-12 items to be submitted to the UNESCO Representative List of the ICH of Humanity. The first steps in this process having recently been completed, we can already see certain key issues and tendencies emerging. Thus, in the final part of this paper, I will address questions about the artificiality of territorial divisions and historical cultural differences, famously called the "Röstigraben," 4 the sensitive place of culture within a federal state, and the role of experts in the process. My conclusion will emphasize the praxis of federalism and its reaffirmation through cultural expertise.

\footnotetext{
3 Cantonal propositions were first submitted to the federal administration (September 2010-March 2011); the Federal Office of Culture (FOC) then made its recommendations to the cantons (MarchSeptember 2011); and, at the time of this writing, the federal administration is selecting a list of national representative items (September 2011-March 2012) (Office fédéral de la Culture et Haute Ecole de Lucerne 2010).

4 "Rösti" is the Swiss dialect term for hash browns, historically eaten as a breakfast food in GermanSwiss areas. The "Röstigraben" (Rösti-ditch) metaphorically refers to the cultural division confirmed through cultural-geographic atlas documentation between the German and French Swiss area; it runs along the Saane river, through the bilingual canton Fribourg (Centlivres 1996, Büchi 2001).
} 


\section{Federalism in Action: the "Subsidiarity Principle"}

The separation of powers in the area of culture - between the 26 cantons that form the Swiss Confederation and the federal government - is inscribed in the Federal Constitution (see Article 69, also called the "cultural article," Clottu 1975). This article gives full responsibility in cultural affairs to the 26 cantons. The federal government is responsible only for national aspects of culture, such as guaranteeing the respect of cultural and linguistic diversity or subsidizing the Swiss film industry, national library, national archives, and national museums. Its principal organ, the Federal Office for Culture (FOC) $)^{5}$ is charged with the task of formulating cultural policy (for example, by drafting the proposed federal law governing the funding of culture) and of promoting culture through federal, cantonal and local institutions, both public and private. ${ }^{7}$ For their part, the principal actors, the 26 Swiss cantons, are responsible for promoting, funding and managing culture within their respective territories.

As applied to heritage policy, the Swiss Constitution and the subsidiarity principle imply that the FOC establishes a framework for the application of the UNESCO Conventions while leaving their actual implementation to the cantons. However, as can be expected, the task of establishing this framework involved many other actors, and gave the federal government a considerable degree of discretion in defining its content. Adopting the "participative principle" that has become virtually mandatory in international institutions today (Gradis 2008, Renz 2008, Vitali 2008), the FOC began its work by assigning the task of organizing meetings between parties concerned (administrators, cultural associations and other "bearers of ICH," scholars, journalists, politicians, etc.) to the Swiss UNESCO Commission. The institutional name given to these meetings was the "Swiss Forum for Intangible Cultural Heritage." Some initiatives from NGOs wellestablished in several UNESCO commissions were proposed (Leimgruber 2010). However, these methodological propositions for constituting the national invento$\mathrm{ry}^{8}$ were not accepted, although they were useful for reflecting on the process by

\footnotetext{
5 "Office fédéral de la Culture" in French, "Bundesamt für Kultur" in German.

${ }^{6}$ Assemblée fédérale de la Confédération suisse (2009): Loi fédérale sur l'encouragement de la culture (LEC).

7 The Swiss Arts Council, Pro Helvetia, a federally funded cultural foundation, also plays a key role in supporting original creation in theater, dance, literature, music, and the visual arts. Pro Helvetia has also participated in the protection and promotion of ICH since the beginning of 2012 within the frame of the revision of the LEC.

8 See in particular http://www.culturaldiversity.cioff.ch/index_suisse.html, initiated by the International Council of Organizations of Folklore Festivals and Folk Art (CIOFF), an NGO founded in 1970 that enjoys formal consultative relations with UNESCO. The Swiss branch was established in 1985 (see http://www.cioff.ch/) with the help of Traditions for Tomorrow, an NGO which has been supporting cultural initiatives by indigenous communities in Central and South America since 1986 and very active in Switzerland (see http://tradi.info/) <all accessed July 20, 2012>.
} 
raising questions about the notion of authenticity (Bortolotto 2007, Gonseth and Hertz 2008) and about the length of time necessary to qualify as a "bearer" of Swiss ICH (Camp 2006, Leimgruber 2008). Parallel to this participative procedure and in conformity with the Swiss legislative process, the Federal Council ${ }^{9}$ issued a statement on the promotion of culture, addressed to the federal legislature and relevant cultural institutions (Message relatif à la Convention pour la sauvegarde du patrimoine culturel immatériel, Conseil fédéral suisse 2007). It emphasized the leadership of the FOC in decision-making around norms and procedures for the drawing up of inventories and the responsibility of the 26 cantons for identifying the relevant items and submitting them to the FOC (Graezer Bideau 2010).

\section{The Mechanisms for Constituting Inventories}

According to this federal system, the 26 cantons were free to invent their own methodologies for the construction of their inventories, while respecting the framework of a centralized inventory project throughout the country. Following the division of labor imposed by the Constitution, the FOC had the role of assisting the 26 cantons by developing relevant selection criteria. The guidelines ${ }^{10}$ describing how to carry out this common project were discussed in meetings involving both the federal and cantonal levels (the FOC and a group of experts made up of cantonal officials, experts engaged by the cantons, some of whom were academics or members of civil society). Following what has been identified as the "spirit of the Convention" (Bortolotto 2008a, 2008b), the FOC emphasized the need for bottom-up procedures in the constitution of these cantonal inventories, the aim being to come up with a final list of approximately 160 Swiss items supported by "civil society."

The FOC, however, was also responsible for establishing the "indicative list" of Swiss ICH (the official name for the national inventory), taking into account those elements of ICH that the cantons proposed in their inventories (around 15 propositions each, giving a total of 390). In order to follow the spirit of the Convention (once again!) and to emphasize the participative principle of Swiss democracy, the FOC created an open website in September 2010 where citizens were encouraged to make their own propositions, to be discussed and taken into account as appropriate. ${ }^{11}$ In reality, as became apparent just after the public launching of the program, in order to accelerate the process and come up with a list by February 2011 (i.e. five months later), top-down procedures also became neces-

\footnotetext{
9 The Swiss Federal Council represents the executive branch of the federal government. It is composed of a college of seven ministers, elected by the Parliament, with a rotating presidency.

10 "Guidelines for establishing a list of living traditions in Switzerland," adopted by the FOC steering committee, June 2, 2010.

11 As of April 2011 (closure of the website), 102 propositions were posted on the website by Swiss citizens. See http://www.lebendige-traditionen.ch < accessed July 20. 2012>.
} 
sary. The tight deadline, the need for a coherent and comparable methodology between the 26 cantons, and the "respect for cultural diversity," a fundamental value in the Swiss Confederation, were finally major arguments put forward by the FOC for encouraging a top-down procedure.

Based on my participant observation of this procedure, especially in Frenchspeaking Switzerland, ${ }^{12}$ I will focus on some aspects of the bottom-up and topdown mechanisms that regularly entered into conflict with each other. Three issues will illustrate the particularities and complexities of the Swiss system.

\section{Artificial Territorial Divisions and the Reality of the "Röstigraben"}

The first question raised by this inventory process concerns the artificial territorial divisions imposed by the fact that the federal administration was obliged to respect the subsidiary principle and general cultural sensitivity to intercantonal "balance." Each canton was asked to propose the same number of items for its inventory, regardless of its size, demography, landscape, or economic profile. As has already been mentioned, cantons had the choice of a civil-society "participative" approach or an expert-based methodology. Unsurprisingly, the 26 cantons proceeded in different ways with the result that the data collected were quite heterogeneous in nature, reflecting a variety of methods (bottom-up and top-down) and understandings.

One major distinction to emerge from this process was between collective and individual approaches: Some cantons joined together to create their regional lists (collective inventories $)^{13}$ while others took independent measures for identifying local items (individual inventories). ${ }^{14}$ This difference was often translated into a difference between "traditional" and "modern" communities, and was regularly observed and commented on. As one French-speaking cultural affairs person put it: "No wonder the German-speaking cantons work together; they have done so since the creation of our country," referring to the historical (and mythical) founding of the first Swiss confederacy by the three "original cantons"15 uniting to com-

\footnotetext{
12 The German- and Italian-speaking parts of Switzerland were covered by colleagues, respectively Karin Janz and Andrea Jacot-Decombes.

13 These collective inventories are circumscribed in geographical areas, such as central Switzerland (Luzern, Nidwalden, Obwalden, Schwyz, Uri, and Zug) or eastern Switzerland (Appenzell Ausserrhoden, Appenzell Innerrhoden, Glarus, Graubünden, St-Gallen, Schaffhausen, Thurgau, and Zürich). In addition, Aargau and Solothurn, and Basel-Stadt and Basel-Landschaft decided to work in collaboration.

${ }^{14}$ Individual inventories were submitted by Bern, Fribourg, Genève, Jura, Neuchâtel, Ticino, Vaud, and Wallis.

${ }^{15}$ Note that the French expression for "original cantons" is "cantons primitifs."
} 
bat the domination of the Habsburgs in 1291. This discourse is noteworthy in that it simplifies the Swiss cultural landscape, which has conventionally been described as a system of cross-cutting ties (Lipset 1959); it operates to overdetermine the differences between French- and German-speaking areas, while muting those between urban and rural, Catholic and Protestant, elite and popular, industrialized and artisanal, as if these different forms of social affiliation all worked in an isomorphic fashion.

After discussions between cantonal and federal experts, more flexibility on the number and location of items was introduced into the guidelines, with the following results:

- The number of propositions allowed per canton tripled (from 5 to 15);

- the size of linguistic areas became more relevant than the 26 units (with more items from the French and German regions, and fewer from the Italian region (80 versus 30$) ; 16$ and

- items could be located on the border of cantons, such as paper-cutting (Vaud and Fribourg) or the Fête-Dieu (Fribourg, Wallis and Appenzell Innerrhoden), or over a larger area including two countries, such as woodcarving crafts (Wallis, Ticino and the Aosta Valley in Italy).

Nonetheless, studying the cantonal propositions from the first round, ${ }^{17}$ one can observe that these amendments did not really reduce the differences and discrepancies between cantons. On the contrary, the logics of distinction that historically made up Switzerland were re-formulated and even reinforced.

Of these, the most significant was the cultural difference between the French- and German-speaking regions of Switzerland, emblematized by the "Röstigraben." The participants in the expert meetings I observed regularly called attention to the differences they perceived between Swiss-German and Swiss-French cantons, especially regarding the use of scientific expertise. The French-speaking cantons were perceived as adopting both a more radical and a more bureaucratic approach, composed of both critical distance and compliance with the guidelines laid down by the federal government. ${ }^{18}$ The German-speaking cantons seemed to reflect a perception based on "participative democracy," characterized by a strong desire for independence from federal instances combined with a high level of participa-

\footnotetext{
${ }_{16}$ Romansh, the fourth national language, was included within the German-speaking part of Switzerland due to the existence of only three working languages in the federal administration.

${ }_{17}$ This first round of cantonal propositions applied the second version of the "Guidelines" published on February 18, 2010 (a first version was established on January 16, 2010). A third version was then produced (May 27, 2010) and discussed by cantonal and federal experts. It was finally adopted by the steering committee on June 8,2010 , see footnote 8 .

${ }^{18}$ In the minds of some commentators, the Napoleonic conquest (that created the short-lived Helvetic Republic lasting only a couple of years after the defeat of certain regional armies by the French revolutionary army in 1798) has left a mark on the French-speaking part of Switzerland.
} 
tion, symbolized by the institution of the "Landsgemeinde."19 Cantonal attitudes regarding the number of items submitted to the FOC also varied: French-speaking cantons basically respected the federal guidelines (Geneva 9; Vaud 14; Neuchâtel 8) while the German-speaking cantons less so (Schwyz 43, 9items specific to the canton and 34 representative of the regional inventory; Uri 36, 3 specific to the canton and 33 of the regional inventory) (Bundesamt für Kultur and Hochschule Luzern 2011; Graezer Bideau 2012).

Other important divisions related to landscape, economy and religion; for instance, urban, industrialized or Protestant cantons proposed fewer traditions than rural or Catholic ones. These "less touched" areas tended to be those with elaborate religious practices (the carnivals, processions, celebration days, and rituals studied by Swiss folklore specialists since the 19th century [Geiger and Weiss 1962, Hugger 1990, Waldis and Wendling 2002]), or with a higher exposure to tourism. They provided items more in accordance with a shared notion of folk tradition than the Calvinist or Zwinglist cities (Geneva or Zurich), which proposed more conceptual and unusual items (the "Spirit of Geneva," for example, or newspaper caricatures and comics, joke culture, contemporary dance [Ballet Béjart] and political cabaret [Dadaism], etc.).

A further interesting division concerned demography and a focus on indigenous versus exogenous populations. Very few cantons made proposals mentioning immigrant groups who also contribute to Switzerland, although the federal guidelines made specific reference to these communities. An exception that proves the rule: Wallis proposed inscribing "Italianità" on its list to acknowledge the active presence of Italians in this canton since the 13th century. In the final lists, only a few categories of "outsiders" were proposed in some areas (big cities close to an international border or in a circumscribed region) ${ }^{20}$ while others were conspicuously absent: for example, stigmatized and unrecognized former Yugoslavian and African communities.

Finally, although flexibility allowed finding ad hoc solutions to reflect present realities and attested to the efficiency of the federal system, this national inventory also simply demonstrated the highly conventional notion of ICH that this exercise inherited. Apparently, heritage carries with it its own heritage!

\footnotetext{
19 The "Landsgemeinde" is a popular assembly of eligible men and, since 1971, women that directs the affairs of cantonal government. Although it has been abolished in all cantons except for Appenzell Innerrhoden and Glarus, in everyday discourse, it remains an icon of direct democracy.

${ }^{20}$ For instance, Italian tradition (San Giuseppe-Tag in Laufenburg) and Jewish heritage are also proposed in Aargau, while Jenisch culture is mentioned as a national item.
} 


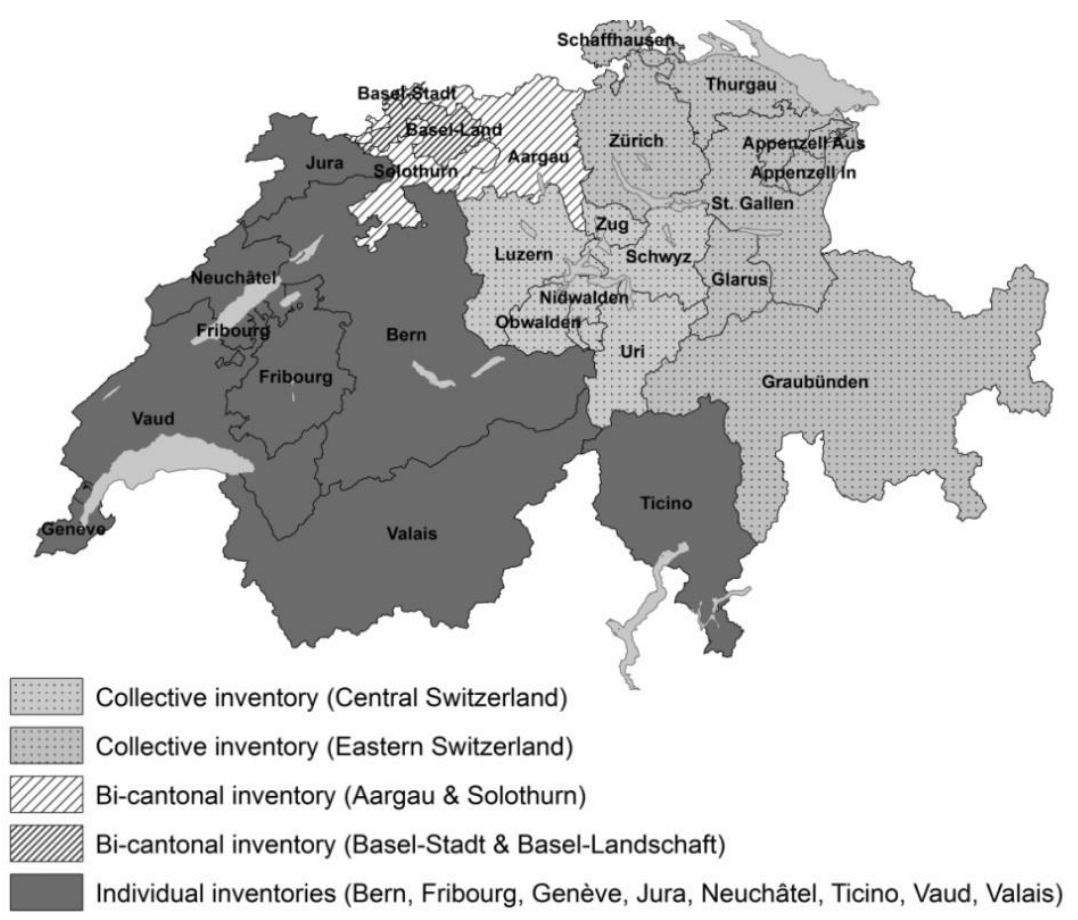

Figure 1: Map of inventories in Switzerland (Graezer Bideau and Munafò 2012)

\section{Which "Culture" for which Switzerland?}

The sensitive place of culture in a federal state is the second issue I wish to discuss here. Culture is sensitive in all national contexts, of course, but the federalist framework, based on the right to cultural difference within a single national territory, formats underlying tensions in particular ways. To whom does culture belong (the cantons or federal institutions, the elite or so-called "civil society," urban or rural communities, industrialized populations or artisans) and who is defining it (federal, cantonal and local institutions, or "bearers of tradition")? These are the two key questions this process of inventorization inevitably forefronts. Several national French-language newspapers did not hesitate to raise them. ${ }^{21}$

By deciding to call ICH "living tradition in Switzerland" (N.B. not "of Switzerland"), the federal administration emphasized the political connotation of such items, while producing a national list that thousands of Swiss communities could identify with. They were also aware of the very high percentage of citizens belonging to cultural associations (ten percent of the population), a significant factor for

${ }^{21}$ See Bourget 2011, Dufour 2011a, 2011b, Stevan 2011. 
analyzing the perceived need to encourage a "balanced" inventory. The notion of "balance" translates a worry on the part of federal and cantonal officials that an enormous and chaotic flow of propositions from so-called "civil society," even political initiatives to introduce amendments to the Constitution, ${ }^{22}$ would arrive at their doorsteps, demands that they would be in a difficult position to refuse in the name of "cultural peace." 23 A compromise was reached to resolve this potential problem by sorting items into three types. A very selective list of 6-12 items for international purposes (UNESCO), ${ }^{24}$ a "representative" but exclusive list of around 160 items to be used as a national platform, and numerous residual cantonal "portraits" of the 387 propositions on which local items excluded from the national or international lists could figure, satisfying, it is hoped, the "bearers of tradition" who proposed them. ${ }^{25}$ In addition, for those really "left out," there remains the opportunity to post their propositions on the official website of the national program!

Establishing three types of lists is one thing, selecting items for each list (through inclusion and exclusion) is another (Khaznadar 2004, Hafstein 2009). Indeed, this tension reflects the permanent overlap between technical and political tasks inherent in Swiss cultural policy. In the second step of the process, for instance, on June 15,2010 , the FOC steering committee sent an official letter to the 26 cantons to inform them of the recommended items retained for the indicative list. Items were organized in three categories: of local/cantonal, of regional or of national importance, for each list proposed by the cantons. For the cross-cantonal items, the FOC steering committee instructed the cantons concerned to negotiate and find a "well-balanced" solution to satisfy all cantons concerned within a deadline of three weeks. Thus, the canton of Wallis had to enter into a discussion with the cantons of Appenzell Innerrhoden and Luzern in order to find a solution to the fact that these three cantons proposed exemplary representations of a Corpus Christi occasion called "Fête-Dieu à Savièse." Following this brief period of negotiation, federal recommended items were approved by the cantonal administrations, which were then charged with producing complete files for the national data bank by September of the same year, and in accordance with the criteria defined by the guidelines (Graezer Bideau 2011).

\footnotetext{
22 Initiatives (100,000 signatures) allow citizens to petition for introducing amendments to the Constitution and referenda (50,000 signatures) to challenge any law passed by Parliament.

23 The notion of "social peace" ("paixsociale") is central to the Swiss political imaginary. It refers to the system for regulating conflicts between unions and management around wages and working conditions.

24 At the present time, very little discussion has occurred over the question of how this procedure will take place, particularly with respect to political and economic interest groups.

25 In May 2011, the steering committee decided to change the use of these cantonal "portraits." Nearly every canton produced a website to publicize their inventory and published the first results. The FOC steering committee, therefore, asked each of them to write a brief introduction to the cantonal propositions and a short methodology of the particular process used.
} 
Another example demonstrates well the entanglement between scientific and political tasks. During the second step of the process, experts from the FOC steering committee decided to reorganize the 367 cantonal propositions. Originally listed in alphabetical order with a short argument for its location and its exclusion or inclusion in the national list, each item was sorted into one of the five domains of the ICH UNESCO scheme (Art. 2): oral traditions and expressions, performing arts, social practices, ritual and festive events, knowledge and practices concerning nature and the universe, or traditional craftsmanship. These categories were to serve as guides for those items that had not been unanimously accepted in the first examination. They were also to help guide the expert committee in making recommendations to the cantons for further information they were to submit (more precision, historical documents, consent from the "bearers of culture") and for the constitution of intercantonal or regional items.

It quickly appeared to the FOC expert group that in order to better represent Swiss cultural and social realities, this list of a few hundred items needed to be reorganized by including new categories of practice and tradition that did not fit within the limits of the five UNESCO categories. In their eyes, creating a new classification of items would allow them to highlight relevant patterns of practice that disappeared in the standardized UNESCO overview of Swiss living traditions. ${ }^{26}$ They thus put forward Swiss particularities such as "Alpine culture," "wine-making and harvest festivals," "medicinal plants," "popular instrumental music," "popular music performance," "children's parades and festivities," "political institutions," "corporations and associations," and "local annual festivals." The group then proceeded to classify troublesome items in such a way as to highlight their "representativeness" in relation to Swiss culture in the light of these finer categories of "living tradition." This was particularly the case for activities regarding children, teenagers or young adults. Most of them were selected by cantons to confirm the importance of this category of the population for nation-building (graduation ceremonies, for example, in Geneva, Vaud and Fribourg; youth ritual festivities [Vaud] or festivals [Aargau and Solothurn]; the Saint-Nicolas parade in Fribourg; or the St-Gallen children celebrations).

Some propositions required re-arrangement within the process framework:

- Twelve elements related to alpine culture (from cheese-making to Alpine transhumance to religious rituals) were combined to compose a category entitled "alpine economy." But in order to better represent the different parts of the territory and different exemplary practices, this global category was then reworked into three local propositions: Gruyère alpine economy (Fribourg), Alpine festivities during the summer ("älplerschilbli" in Central Switzerland) and Alpine lotteries for the right to organize transhumancerelated festivities ("Alpverlosung" in Obwald); and

\footnotetext{
${ }^{26}$ See the internal document of this meeting entitled Eingaben der Kantone (May 10, 2011).
} 
- seven practices related to textiles (artisanal or industrial lacework, silk, cross-stitch, embroidery) finally produced, after reorganization for the national list, just three items: lacework (Neuchâtel); embroidery (St-Gallen) and silk ribbon production (Basel-Stadt, Basel-Landschaft and Aargau, Solothurn).

Other attempts to bring together local proposals into an overarching category were not as successful, however. This is particularly the case of two traditions with a significant symbolic importance to the Swiss.

- "Carnival festivals," practiced in many regions ${ }^{27}$ across the country, were not grouped into a general category. Arguments affirming the particularity of each of these expressions - the Basel city's carnival, the Carnival in Central Switzerland and in the Jura, the Rabandàn (Ticino), the Tschäggättä in Lötschental (Valais) - were convincing enough that the expert group decided to include each of these local expressions separately in the representative list of Swiss living traditions.

- Experts also failed in combining different kinds of popular musical performance together into a single category of "yodeling." Instead of becoming a large, dominant item in the final Swiss inventory, two distinct categories resulted from negotiations between the FOC and cantonal experts: Popular music performance and yodeling ("juuz") in central Switzerland, and popular music performance and natural yodeling in Appenzell (Appenzell Innerrhoden and Aargau) and in Toggenburg (St-Gallen).

In sum, we can observe a double logic in this Swiss mechanism of inventory production: Some items emerged smoothly from the cantonal propositions, often related to cantonal territories, while other items did not appear spontaneously or were simply forgotten because no national category had been invented into which to fit them - "the ritual of eating cheese fondue," for example, or playing "Jass" (card game), ${ }^{28}$ taking part in associative life, participating in consensual culture and direct democracy, innovating in the area of graphic design and typography, practicing target-shooting, et cetera. Thus, to enrich the list in relation to these realities, and reflecting what the expert group imagined to be expectations amongst the general public, the experts themselves were asked to produce a certain number of items that had not been submitted by the cantons individually or in groups.

More importantly, however, and somewhat ironically, the invention of new categories thought to be more useful in capturing the particularities of Swiss culture as a whole allowed for a better apportioning of items between the various cantons according to criteria such as "representativeness" or "exemplarity." Here again, the overlap between technical and political tasks resulted in a wide range of actors having to work together to produce, with the help of cantonal experts and local

\footnotetext{
27 Almost all of these festivities are Catholic.

${ }^{28}$ "Jass" is a trick-taking card game and is played in most Alemanic-speaking areas of Europe.
} 
bearers of traditions, data about ICH that reflected neither the point of view of the cantons, nor that of the federal government, but a kind of compromise in the name of abstract notions, cultural stereotypes and an imagined community invented by the expert group for the purposes at hand.

\section{The Making of Cultural Expertise}

As appears from this example and has been attested in the literature on Switzerland's cultural policies (Moeschler 2003, Surdez and Pidoux 2007), Switzerland lacks a tool that many neighboring states have at their ready disposition: centralized expertise for cultural matters. While the history of this state of affairs is complex and goes beyond the purview of this paper, its consequences in this instance are clear: "Swiss culture" is characterized by heterogeneity, reflecting the socioeconomic and historical conditions of each of its cantons.

More importantly for our purposes here, this heterogeneity translates directly into institutional configurations. To demonstrate this, one needs only to examine the spectrum of experts involved in the creation of the cantonal lists of ICH: from archaeology (tangible heritage) to ethnology ${ }^{29}$ (ICH), through media studies and including a wide range of professional statuses (from independent scholar to museum curator) and commitments (academic, bureaucratic, ideological). In contrast to most of its European neighbors, Switzerland does not possess a uniformly trained and socialized group of cultural experts, such as those who people the halls of the French or Italian Ministries of Culture. As the procedures and professionals involved in the collecting of cantonal ICH were heterogeneous, it is hardly surprising that the resulting lists were as well.

From a bureaucratic point of view, the heterogeneity of the data could be seen as a limit of the process. One could argue, for example, that this heterogeneity does not allow coherent comparisons between the 387 cantonal propositions and the 160 items selected for the indicative list. This incoherence could resurface as a problem during the third and final stage of the process, the selection of 6-12 "representative" items of Swiss culture to be submitted to UNESCO. From a political point of view, however, this same heterogeneity can be characterized as a specificity: One could argue that it proves how successful the process has been, as it faithfully reflects the cultural and linguistic diversity that is preserved by the Swiss federalist system.

It is clear from what proceeds that neither of these normative judgments accurately reflects the complicated interactions between actors and representations of

\footnotetext{
${ }^{29}$ For a better understanding of the Swiss case, I decided to choose the term of "ethnology" to identify disciplines studying societies, cultures and their collective expressions. I am aware of the fact that using this term "ethnology" could cast a shadow over other disciplines, such as social and cultural anthropology (in which I was originally trained) and folklore studies (which has concentrated on documenting the native culture of the nation within which the researchers work) that have different traditions and sometimes conflictual implementations in all parts of the country.
} 
Swiss culture that have produced the current situation. Rather, these judgments are themselves part of the data that must be taken into account in our understanding of the process. Indeed, this on-going process reveals that finding common selection criteria for the three types of lists according to the traditional and symbolic Swiss motto, "One for all, all for one," 30 is part of the performance of a federal system.

That being said, we must also account for the ways in which, despite the lack of uniformly trained cultural civil servants and unified cantonal procedures, a great deal of consensus was in fact produced through this procedure and around its results. One of the reasons for this clearly lies in the disciplinary training and professional activities of the diverse cultural experts called to the table. Social-cultural anthropology remained the dominant discipline and most of the experts shared institutional language through their professional positions or their academic publications. ${ }^{31}$ Thus, expert knowledge played a major role in this process of inventorying Swiss "living traditions" and stabilizing them within a "regime of truth" (Foucault 1969). UNESCO ICH categories were reworked to fit the Swiss situation through a transfer from the political and administrative to the scientific domains that could subsequently be passed down to the interested actors. This making of intangible heritage discourse was rarely questioned and tended to be hegemonic among the social actors concerned (from bureaucrats to civil society representatives, through media and cultural arenas). In reality, this production of knowledge acquired meaning through the operation of power within social practices: The 167 selected "living traditions" generate the production of files, whose description strengthens the representation of practices among stakeholders (see Appendix).

Even more interesting, no doubt, despite the key role played by cultural experts, the process made virtually no recourse to the notion of "authenticity" in order to legitimize the decisions taken by the federal expert group. Indeed, a large number of those "living traditions" finally selected are highly commercialized, radically "unauthentic" cultural productions, generously subsidized by the Swiss tourist lobby and local leisure industry; ${ }^{32}$ examples would include carnival, yodeling, costume-making, and wine festivals. Rather, based on a consensual model of "diversity" and "representativeness," they reflect "nice" culture, "good" practices and "positive" traditions that are perceived as emanating from all of the linguistic,

\footnotetext{
30 "Unus pro omnibus, omnes pro uno." This slogan has been used to symbolize the form that national solidarity and unity is thought to take in Switzerland, generally associated with the original myth of the founding of Switzerland through the union of its three original cantons in 1291. It circulated largely in 1868 during a campaign to raise money for alpine dwellers after massive flooding that year. It was inscribed in the cupola of the Federal Palace in Bern in 1902. Readers might, of course, also know it as the motto of Alexandre Dumas' Three Musketeers!

31 Of 12 inventories submitted by the 26 cantons, 8 were directed by anthropologists and 3 by anthropologically trained museum curators. Collective projects engaged a couple more anthropologists to cover large and diverse areas gathered within a geographical region (Antonietti; Meier; Rieder 2008).

32 For further reading regarding issues of the entanglement of economic, political and cultural interests, see Kirshenblatt-Gimblett 2006, Hemme; Tauschek; Bendix 2007.
} 
religious and geographical regions of Switzerland. The effect of including such "living traditions" enacts and reinforces a gap between these romanticized categories of "Swiss tradition" and other elements of culture, history and tradition in this country, leaving all manner of expressions in the shadows, and this despite a high degree of community involvement in the continuity and transmission of these practices.

\section{Conclusion}

Therefore, the in-depth study of this complex process raises new questions for our understanding of the role of heritage and tradition in the Swiss socio-political field. Does the implementation of the 2003 Convention re-enact federalism? Do experts really produce common knowledge? What are the repercussions of this process on Swiss culture as a whole if indeed we can still give credence to this notion after this exercise? This chapter demonstrates that the difficulty inherent in the enterprise of defining a homogenous notion of Swiss culture is compounded in a federalist system where cantons play a major role. Yet, paradoxically, the process becomes part of the outcome, and its very incoherence and "diversity" comes to stand in for a certain kind of legitimacy. This can be noticed, for example, in the reactions of non-Swiss observers when they learn of the procedures described in this paper. Generally, experts are both surprised and impressed by the fact that all of the 26 Swiss cantons worked together to produce their inventories simultaneously and in dialogue with one another. The consensual nature of the procedure seems to overshadow the ad hoc and contestable nature of the outcomes, such that a vague and largely intangible aura of "Swissness" seems to float over the entire enterprise.

The process of inventorization, of course, is still on-going, as the final decision on the items for inclusion in the national and international lists will only be made in the fall of 2012. One of the questions left wide open for our study is the role that the approximatelytwenty ethnologists engaged as experts have played in the process. Will they manage to create opportunities to emphasize less reified, more dynamic and reflexive, even controversial expressions of Swiss culture, such as Swiss banking secrecy, or will the entire exercise finally reflect highly commercialized stereotypes of Switzerland's "living traditions" with which the population is presumed to identify simply because they reproduce popular stereotypes of the popular? The question at this stage remains open! 


\section{References}

Antonietti, Thomas, Bruno Meier, and Katrin Rieder (2008): Retour vers le présent. Culture populaire en Suisse. Baden: Hier + jetzt.

Assemblée fédérale de la Confédération suisse (2009): Loi fédérale sur

l'encouragement de la culture (LEC), FF $2007-0244$ (December 11, 2009). http://www.admin.ch/ch/f/ff/2007/4607.pdf < accessed September 26, $2010>$

Bortolotto, Chiara (2007): From Objects to Processes: UNESCO's Intangible Cultural Heritage. Journal of Museum Ethnography 19: 21-33.

- (2008a): Les inventaires du patrimoine culturel immatériel. L'enjeu de la "participation". Rapport de recherche pour le Ministère de la Culture et de la Communication. Charenton-Le-Pont: IIAC/Lahic.

- (2008b): Les enjeux de l'institution du patrimoine culturel immatériel. Compterendu du séminaire organisé au Lahic (2006-2008). Culture et Recherche 116-117: 32-34.

Bourget, Albertine (2011): La Suisse, patrie des quilles, du chiffre 11 et des autostoppeuses fantômes. Le Temps, June 9.

Büchi, Christophe (2001): Mariage de raison. Romands et Alémaniques: une histoire suisse. Geneva: Editions Zoé.

Bundesamt für Kultur (BAK) (2012): Sélection définitive pour la liste des traditions vivantes en Suisse, adoptée le 5 septembre 2011 par le groupe de pilotage du projet, modifiée le 5 avril 2012.

Bundesamt für Kultur (BAK), and Hochschule Luzern (2011): Liste der lebendigen Traditionen in der Schweiz: Eingaben der Kantone (April 18, 2011). Document for internal use.

Camp, Marc-Antoine (2006): Die UNESCO-Konvention zur Bewahrung des immateriellen Kulturerbes.

http://www.gvs-smps.ch/html/img/pool/UNESCO-Konventionimmaterielles_kulturerbe.pdf < accessed July 10, 2012>

Centlivres, Pierre (1996): A propos des frontières intérieures de la Suisse. In L'Europe entre cultures et nations. Daniel Fabre, ed. Pp. 175-189. Paris: Editions de la Maison des sciences de l'homme.

Clottu, Gaston (1975): Eléments pour une politique culturelle en Suisse. Rapport de la Commission fédérale d'experts pour l'étude de questions concernant la politique culturelle suisse. Bern: Office central fédéral des impriméset du matériel.

Conseil fédéral suisse (2007): Message relatif à la Convention pour la sauvegarde du Patrimoine culturel immatériel du 21 septembre 2007: 07.076, FF 20071146.

http://www.admin.ch/ch/f/ff/2007/6837.pdf < accessed October 3, 2009> 
Dufour, Nicolas (2011a): La Suisse dresse le répertoire de ses traditions vivantes:

Un sanctuaire culturel. Le Temps, May 31.

http:/ /www.letemps.ch/Page/Uuid/e0877680-8bc4-11e0-b47e-

9f06196f1c28/Un_sanctuaire_culturel < accessed July 17, 2012>

- (2011b): 387 fragments d'une Suisse en son miroir. Le Temps, May 31.

http://www.letemps.ch/Page/Uuid/e178bf68-8bc4-11e0-b47e-

9f06196f1c28/387_fragments_dune_Suisse_en_son_miroir < accessed July 17, 2012>

Fournier, Anne, and Nicolas Dufour (2011): Yodel ou multimédia, de quelle culture la Suisse a-t-elle besoin? Le Temps, April 1.

Foucault, Michel (1969): L'archéologie du savoir. Paris: Gallimard.

Geiger, Paul, and Richard Weiss (1962): Atlas der Schweizerischen Volkskunde.

Atlas de folklore Suisse. Basel: Société des Traditions Populaires.

Gonseth, Marc-Olivier, and Ellen Hertz (2008): Quelques réflexions anthropologiques sur unterritoire émergent. Bulletin SAGW/ASSH

Immaterielles Kulturerbe - Patrimoineimmatériel 08 (2): 38-41.

Gradis, Diego (2008): Une mission en Suisse pour les acteurs du patrimoine vivant. Bulletin SAGW/ASSH 08 (2): 28-29.

Graezer Bideau, Florence (2010): Et après la ratification de la Convention de l'Unesco pour la sauvegarde du patrimoine culturel immatériel? Entretien avec David Vitali. Museums.ch 5: 22-25.

- (2011): La Svizzera: una buona allieva nel processo di inventorio del PCI? [La Suisse: bonne élève du processus d'inventaire du PCI ?] In Identificazione partecipativa del patrimonio culturale immateriale transfrontaliero. P. Odi Cooperazione Transfrontaliera Italia Svizzera 2007-2013, (rapporto di ricerca per Regione Lombardia/Archivio di etnografia e storiasociale, 2010). ASPACI (Associazione per la salvaguardia del patrimonio culturale immateriale) and Chiara Bortolotto, eds. Pp. 124-138. Milan: Progetto E.C.H.I - Ethnografie Italo-Svizzere per la valorizatione del patrimonio immateriale.

- (2012): Inventorier les "traditions vivantes". Approches du patrimoine culturel immatériel dans le système fédéral suisse. Ethnographiques.org

24 ("Ethnographies des pratiques patrimoniales: Temporalités, territoires, communautés").

http:/ /www.ethnographiques.org/2012/Graezer-Bideau < accessed July 26, 2012>

Hafstein, Valdimar (2009): Intangible Heritage as a List. From Masterpieces to Representation. In Intangible Heritage. Key Issues in Cultural Heritage. Laurajane Smith and Natsuko Akagawa, eds. Pp. 93-111. New York: Routledge.

Hemme, Dorothee, Markus Tauschek, and Regina Bendix, eds. (2007): Prädikat HERITAGE. Wertschöpfungen aus kulturellen Ressourcen. Studien zur Kulturanthropologie/Europäischen Ethnologie, 1. Berlin: Lit. 
Hugger, Paul (1990): Histoire et situation actuelle de l'ethnologie de la Suisse. Terrain 15: 125-134.

Khaznadar, Chérif (2004): Patrimoine culturel immatériel: les problématiques. In

Le patrimoine culturel immatériel: Les enjeux, les problématiques, les pratiques. Internationale de l'imaginaire - Nouvelle série, 17. Maison des cultures du monde, ed. Pp. 51-58. Paris: Babel.

Kirshenblatt-Gimblett, Barbara (2006): World Heritage and Cultural Economics. In Museum Frictions: Public Cultures/Global Transformation. Ivan Karp, Corinne A. Kratz, Lynn Szwaja, and Tomás Ybarra-Frausto, eds. Pp. 161-201. Durham NC: Duke University Press.

Leimgruber, Walter (2008): Was ist immaterielles Kulturerbe? Bulletin SAGW/ASSH 08 (2): 24-25.

- (2010): Switzerland and the UNESCO Convention on Intangible Cultural Heritage. Journal of Folklore Research 47(1-2): 161-196.

Lipset, Seymour Martin (1959): Some Social Requisites of Democracy: Economic Development and Political Legitimacy. The American Political Science Review 53(1): 69-105.

Moeschler, Olivier (2003): Enquêtesur les publics de la culture à Lausanne: chronique d'un mal entendu productif. In Le(s) public(s) de la culture: politiques publiques et équipements culturels. Olivier Donnat and Paul Tolila, eds. Pp. 51-63. Paris: Presses de Sciences Po.

Office fédéral de la Culture et Haute Ecole de Lucerne (HSLU) (2010): Guide pour l'établissement de la Liste des traditions vivantes en Suisse (June 2, 2010).

Document for internal use.

Renz, Cyril (2008): Quefaut-il identifier par un inventaire pour assurer la viabilité du PCI?: Synthèse d'un concept opérationnel global. Bulletin SAGW/ASSH 08 (2): 32-35.

Smith, Laurajane (2006): Uses of Heritage. New York: Routledge.

Stevan, Caroline (2011): La Suisse en listes. Le Temps, June 1. http://www.letemps.ch/Page/Uuid/e0a55bd2-8bc4-11e0-b47e9f06196f1c28/La_Suisse_en_listes < accessed July 17, 2012>

Surdez, Muriel, and Jean-Yves Pidoux (2007): Expériences d'acteurs et expériences d'experts: antagonismes et proximités lors de l'évaluation d'une politique culturelle. In Les constructions de l'action publique. Fabrizio Cantelli, ed. Pp. 135-156. Paris: L'Harmattan.

Vitali, David (2008): Immaterielles Kulturerbe erfassen und sichtbar machen. Über die Vorarbeiten zur Erstellung einer Schweizer Inventarliste. Bulletin SAGW/ASSH 08 (2): 30-31.

Waldis, Barbara, and Thierry Wendling (2002): La Suisse, ses ethnologies et ses ethnologues. Ethnologie française 32(2): 197-207. 
9 Appendix: List of Living Traditions in Switzerland compiled by the Federal Office for Culture

(Bundesamt für Kultur [BAK] 2012) 
Umsetzung der UNESCO-Konvention zur Bewahrung des immateriellen Kulturerbes:

Erarbeitung einer Liste der lebendigen Traditionen in der Schweiz

Finalisierte Auswahl für die Liste der lebendigen Traditionen in der Schweiz von der Projektsteuerungsgruppe verabschiedet am 5. September 2011

Anmerkung: Die Titel sind teilweise noch Arbeitstitel.

Mise en œuvre de la convention de I'UNESCO pour la sauvegarde du patrimoine : rédaction d'une liste des traditions vivantes de Suisse

Sélection définitive pour la liste des traditions vivantes de Suisse adoptée le 5 septembre 2011par le groupe de pilotage du projet

Remarque: Dans quelques cas, les titres sont encore de titres de travail.

Attuazione della Convenzione dell'UNESCO per la salvaguardia dei beni culturali immateriali: elaborazione di una lista delle tradizioni viventi in Svizzera

Selezione finale delle tradizioni viventi in Svizzera da inserire nella lista approvata il 5 settembre 2011 dal gruppo di coordinamento del progetto

Osservazione: In alcuni casi, i titoli sono ancora provvisori.

\begin{tabular}{|l|l|}
\hline Titel / titre / titolo & Kanton(e)/canton(s) / cantone/i \\
\hline Aarauer Bachfischet & AG \\
\hline Abbayes de tir & VD \\
\hline Albanifest & ZH \\
\hline Almanach romand Messager boiteux & VD \\
\hline Alphorn und Büchel & CH \\
\hline Älplerchilbi & LU-UR-SZ-OW-NW \\
\hline Alpverlosung & OW \\
\hline Anna Göldi & GL \\
\hline Appenzeller und Toggenburger Alpfahrten & Al-AR-SG \\
\hline Appenzeller Witz und Satire & AR-AI \\
\hline Auffahrtsumritt in Beromünster & LU \\
\hline Automates et boîtes à musique & VD \\
\hline Bärensymbolik & BE \\
\hline Basler Fasnacht & BS \\
\hline Basler Herbstmesse & BS \\
\hline Basler Trommeln & BS \\
\hline Bauerngarten in Osterfingen & SH \\
\hline Bauernmalerei rund um den Säntis & Al-AR-SG \\
\hline Bechtelistag in Frauenfeld & TG \\
\hline & \\
\hline
\end{tabular}




\begin{tabular}{|c|c|}
\hline Titel / titre / titolo & Kanton(e) / canton(s) / cantone/i \\
\hline Bénichon & FR \\
\hline Berner Bauernkeramik & BE \\
\hline Betruf in der Zentralschweiz & LU-UR-SZ OW-NW \\
\hline Blasmusikpraxis & $\mathrm{CH}$ \\
\hline Bochselnacht & TG \\
\hline Bootschnen & $\mathrm{CH}$ \\
\hline Brienzer Holzschnitzerei & BE \\
\hline Bruder-Klausen-Fest & OW \\
\hline Brunnensingen der Sebastianibruderschaft Rheinfelden & AG \\
\hline Carnaval jurassien & JU \\
\hline II carpentiere-muratore (teciatt) & TI \\
\hline Castagne, caldarrostai e castanicoltura & TI und GR \\
\hline Chalandamarz & GR \\
\hline Le chant du Ranz-des-vaches & FR \\
\hline Chienbäse & BL \\
\hline Chlauschlöpfe im Bezirk Lenzburg & AG \\
\hline Chröpfelimeh & ZG \\
\hline Les consortages en Valais & VS \\
\hline Cortège de la Fête des vendanges de Neuchâtel & NE \\
\hline La cueillette et la culture des plantes sauvages & VS \\
\hline Découpages du Pays-d'Enhaut & VD \\
\hline Dentelle de Neuchâtel & NE \\
\hline Dreikönigs- und Sternsingen in Graubünden und Tessin & GR und TI \\
\hline Economie d'alpages en Gruyère & FR \\
\hline Eidgenössisches Feldschiessen & $\mathrm{CH}$ \\
\hline Eierleset & AG-SO und $B L$ \\
\hline Elevage du cheval de race Franches-Montagnes & JU \\
\hline L'Escalade & GE \\
\hline L'Esprit de Genève & GE \\
\hline La Fabrique & GE \\
\hline Fasnacht in der Zentralschweiz & LU-UR-SZ-OW-NW-ZG \\
\hline Fekker-Chilbi & $\mathrm{CH}$ \\
\hline Fête des Fontaines de Môtiers & NE \\
\hline Fête des Vignerons & VD \\
\hline Fêtes des Jeunesses campagnardes & VD \\
\hline La Fête-Dieu à Savièse & VS \\
\hline Le Feuillu & GE \\
\hline Fiera di San Provino e di San Martino & TI \\
\hline Fifres et tambours du Valais & VS \\
\hline Flössen auf dem Ägerisee & ZG \\
\hline
\end{tabular}




\begin{tabular}{|c|c|}
\hline Titel / titre / titolo & Kanton(e) / canton(s) / cantone/i \\
\hline La fondue comme repas & FR und ganze Schweiz \\
\hline Fronleichnamprozession in Appenzell & Al \\
\hline Gansabhauet & LU \\
\hline Gebetsheilen & Al und Deutschschweiz \\
\hline Geistergeschichten aus der Zentralschweiz & LU-UR-SZ-OW-NW-ZG \\
\hline Gelebte Zweisprachigkeit in Biel & BE \\
\hline La gestion des risques d'avalanches & VS und Alpenraum \\
\hline Glarner Landsgemeinde & GL \\
\hline Glarner Orchester- und Chorwesen & GL und Deutschschweiz \\
\hline Graphik-Design und Typographie & $\mathrm{CH}$ \\
\hline Greiflet & SZ \\
\hline Groppenfasnacht & TG \\
\hline Le guet du beffroi de la cathédrale de Lausanne & VD \\
\hline Hallauer Herbstsonntage & SH \\
\hline Haute horlogerie & VD und GE, NE, JU, BE, SO, SH \\
\hline Historische Befreiungsmythen & LU-UR-SZ-OW-NW-ZG \\
\hline Hornussen & BE und AG-SO \\
\hline Hürnen und Mazza Cula & GR \\
\hline L'illustration, la bande dessinée et l'affiche genevoises & GE \\
\hline Innerrhoder Landsgemeinde & Al \\
\hline Innerrhoder Weihnachten & Al \\
\hline L'Italianità en Valais & VS \\
\hline Jassen & $\mathrm{CH}$ \\
\hline Jeu de quilles neuchâtelois & NE \\
\hline Jüdisches Kulturerbe im Kanton Aargau & AG \\
\hline Jugendfeste in den Kantonen Aargau und Solothurn & AG-SO \\
\hline Kirschenanbau & ZG \\
\hline Köhlern & LU \\
\hline Konsenskultur und direkte Demokratie & $\mathrm{CH}$ \\
\hline Kräuterwissen in Zentralschweizer Frauenklöstern & LU-OW-NW-UR-SZ-ZG \\
\hline Laientheater in der Zentralschweiz & LU-OW-NW-UR-SZ-ZG \\
\hline Lesegesellschaften und Dorfaktivitäten & AR \\
\hline Luzerner Herrgottskanoniere & LU \\
\hline Maibaum in Baselland & BL und ganze Schweiz \\
\hline Maiensässfahrt & GR \\
\hline Mani Matter und die Berner Mundartmusik & BE \\
\hline Marche commémorative de la Révolution du $1^{\mathrm{er}}$ mars 1848 & NE \\
\hline Maskenschnitzen und Fasnacht im Sarganserland & SG \\
\hline Meitlizyt in Fahrwangen und Meisterschwanden & AG \\
\hline Le Milizie Storiche della Valle di Blenio & TI \\
\hline
\end{tabular}




\begin{tabular}{|c|c|}
\hline Titel / titre / titolo & Kanton(e) / canton(s) / cantone/i \\
\hline Murailleurs & $\mathrm{CH}$ \\
\hline Näfelser Fahrt (Fährtlen) & GL \\
\hline Naturheilkunde in Appenzell Ausserrhoden & AR \\
\hline Nünichlingler & BL \\
\hline Obstbau und Obstproduktion & TG \\
\hline Operettentradition im Kanton Aargau & AG und LU \\
\hline Patinage sur le Doubs & NE \\
\hline Patois du Valais romand en scène & VS und FR \\
\hline Pfingstblütter & BL und Region \\
\hline Poya & FR \\
\hline Pratiques chorales dans le canton Fribourg & FR \\
\hline Pratiques des patois jurassiens & JU \\
\hline Processioni storiche di Mendrisio & TI \\
\hline Les promotions & GE und VD, NE, FR \\
\hline Pschuuri in Splügen & GR \\
\hline Rabadán & TI \\
\hline Räbeliechtli & ZH \\
\hline Rheinfallbeleuchtung mit Feuerwerk & SH \\
\hline La Saint-Nicolas à Fribourg & FR \\
\hline San Giuseppe-Tag in Laufenburg & AG \\
\hline Sarganserländischer Alpsegen & SG \\
\hline Scheibenschlagen & GR \\
\hline Schwimmen im Rhein / Rheinschwimmen & BS \\
\hline Schwingen & $\mathrm{CH}$ \\
\hline Sechseläuten & $\mathbf{Z H}$ \\
\hline Le secret & JU und FR \\
\hline Seidenbandindustrie & BL-BS und AG-SO \\
\hline Silvesterchlausen & AR \\
\hline Solothurner Fasnacht & so \\
\hline St. Galler Kinderfest & SG \\
\hline St. Galler Stickerei (Maschinenspitzen) & SG \\
\hline St. Nikolaus-Brauchtum & LU-UR-SZ-OW-NW-ZG \\
\hline Stäcklibuebe & AG-SO \\
\hline Stierenmarkt in Zug und Viehschauen in der Zentralschweiz & LU-UR-SZ-OW-NW-ZG \\
\hline St-Martin en Ajoie & JU \\
\hline Stoss-Wallfahrt & Al \\
\hline Stroh-Kultur, Geflecht- und Hutindustrie im Freiamt & AG und $\mathrm{TI}$ \\
\hline Tavillonnage & FR und VD \\
\hline Töfftreff Hauenstein & so \\
\hline La torrée & NE und JU \\
\hline
\end{tabular}




\begin{tabular}{|l|l|}
\hline Titel / titre / titolo & Kanton(e) / canton(s) / cantone/i \\
\hline Touristische Landschaftserschliessung & LU-UR-SZ-OW-NW-ZG \\
\hline La tradition botanique genevoise & GE \\
\hline Traditionen um den Munot & SH \\
\hline Troccas & GR \\
\hline Les Tschäggättä au Lötschental & VS \\
\hline Übernamen & LU-UR-SZ-OW-NW-ZG \\
\hline Uhrencup in Grenchen & SO \\
\hline Unspunnenfest & BE und ganze Schweiz \\
\hline Vereinswesen & CH \\
\hline Viehzucht und Kuhkämpfe im Wallis & VS \\
\hline Vogel Gryff & BS \\
\hline Volksmusikpraxis und Juuz in der Zentralschweiz & LU-UR-SZ-OW-NW-ZG \\
\hline Volksmusikpraxis und Naturjodel im Appenzell und Toggen- & Al-AR-SG \\
\hline burg & \\
\hline Volkstanzpraxis in der Nordwestschweiz & BL und ganze Schweiz \\
\hline Volkstanzpraxis in der Zentralschweiz & LU-UR-SZ-OW-NW-ZG \\
\hline Voyage Belle-Epoque & VD und VS, GE \\
\hline Wallfahrt nach Einsiedeln & SZ \\
\hline Wallfahrt nach Mariastein & SO \\
\hline Wässermatten & BE \\
\hline Weidlingfahren und Weidlingsbau & SH und ganze Schweiz \\
\hline Wetter- und Klimawissen & LU-OW-NW-UR-SZ-ZG \\
\hline Wilderergeschichten & NW \\
\hline Wildheuen & OW-NW-UR-SZ \\
\hline Woldmanndli & UR \\
\hline Zahl 11 in Solothurn & SO \\
\hline Zibelemärit & BE \\
\hline Zürcher Knabenschiessen & ZH \\
\hline Zürcher Textil- und Seidenindustrie & ZH \\
\hline & \\
\hline
\end{tabular}





\title{
Intangible Cultural Heritage in France: From State Culture to Local Development
}

\author{
Laurent-Sébastien Fournier
}

\section{Introduction}

The nature of the state has an impact on heritage nomination and implementation. France is the classic case of a centralist nation-state, and this paper will trace this state's heritage approach, including more recent problems faced by the French state in trying to regulate the nominations in the context of the 2003 UNESCO Convention on intangible cultural heritage (ICH). Since the 1980s, French decentralization has allocated a greater role to local and regional administrations, especially at the economic and financial levels. In this context, the selection of the cultural elements fit to be acknowledged as ICH in the terms accepted by UNESCO often leads to struggles between the local and the national levels. Local tradition bearers who seek state acceptance of their proposals have to show that these proposals are compatible with the universalistic ideals of the French nation. If the proposed cultural elements look too specific or too local, they might not be accepted by the state. However, if they do not appear sufficiently special, UNESCO might reject them. Accordingly, the decisions concerning the definition of intangible cultural heritage in France are compromises between local and national views.

Building on my fieldwork on the "Processional Giants and Dragons in Belgium and France," I will demonstrate how issues concerning ICH change the interactions between the state and the local economy in France. These festivities were first introduced as a "Masterpiece of the Oral and Intangible Heritage of Humanity" in 2005 and incorporated in the "Representative List of the Intangible Cultural Heritage of Humanity" in 2008 (Fournier 2009, Fournier 2011). 


\section{Heritage and the State: the French Doctrine}

To understand French policies in the realm of ICH, one needs to pay attention both to the history of cultural heritage in general and to the administrations in charge of the UNESCO policies in particular. Notions such as universalism and centralism have to be carefully looked at to understand the administrative situation of ICH in France.

\subsection{Cultural Heritage and Universalism}

Broadly speaking, the notion of cultural heritage is deeply anchored in the French universalistic doctrine introduced with the Revolution of 1789 (Chastel 1986). When the castles and the cathedrals were abandoned by the aristocracy and destroyed by the revolutionaries, the left-wing constitutionalist priest Abbé Grégoire pleaded that they should be preserved and protected for the nation's sake. Such valuable goods had to be considered as common goods, "res publica" in Latin, bringing together the ideas of cultural heritage and the Republic itself. However, at that time, the French word for cultural heritage, "patrimoine", was still mainly used by solicitors to inventory the material goods inherited inside families: Heritage was then both a matter of material culture and of private inheritance. It was the 1789 Revolution which led to the idea of preserving a cultural heritage within the building of a modern French nation-state. During the 19th century, a list of noteworthy cultural goods was established, and inspectors were appointed by the state to inventory the cultural heritage in the different regions and to reinforce the new central nation-state's eminent hold, with a special emphasis on monuments and the fine arts.

In this context, a never-ending struggle took place between the different French provinces and the central nation-state. Some local intellectuals in different places tried to valorize their regional cultural heritage, often insisting on the cultural value of the dialects or on the folklore. In Brittany, for instance, the so-called "Académie Celtique" aimed to revive the regional folk culture of the modern Brittons as a survival from the ancient Celts (Belmont 1995). In Provence, the "Félibrige" movement, founded in 1854 by the great poet and folklorist Frédéric Mistral (1830-1914), enhanced the Latin cultural heritage and the local "langue d'oc" (Martel 1986). However, such attempts to valorize the regional cultural heritage in France were frowned upon, in most cases, as secessionist, regionalist or merely romantic. As of 1870, the French national educational system imposed shared values on all French citizens and the main stake of the Third Republic was the unification of the national territory (Chanet 1996, Thiesse 1997). During the same period, the train system developed and helped the French state in its unification project. Furthermore, after Napoleon III was defeated by the Germans in Sedan in 1870, the idea of national unity was considerably reinforced, which also had a vital impact on the definition of a national cultural heritage. 
At the end of the 19th century, however, the political left began complaining about the criteria according to which the cultural heritage was inventoried in France. They did not really complain about the absence of regional references within cultural heritage, but about the hierarchies between the different items acknowledged as heritage. The avant-garde painters, for instance, began to argue that modern and contemporary paintings were as important as those from the Renaissance. Struggles broke out at the painters' annual salon in Paris where it became fashionable to valorize the outsiders. For their part, the factory workers said that the industrial buildings were sometimes more valuable than the old ruins or chapels; and the regionalists were still asking for regional folklore artifacts to be put into the museums. At this time, several regional folklore museums were founded in spite of the strong centralist and nationalist feelings.

In this context, the esthetic views commanding cultural heritage were dramatically changed. Heritage was becoming a matter of taste. It had to be discussed instead of being accepted as a standard. In the 1930s, the anthropologist Marcel Mauss said that "a tin-box tells us more about our society than the most precious jewel" (Jamin 1989). Connections between anthropologists and surrealist poets led to a definition of the new field of arts et traditions populaires (popular arts and traditions) and to a renewal of the accepted definitions of cultural heritage. French anthropologists clearly participated in this shift when bringing back African artifacts from the colonies. In the case of African masks, for instance, cultural heritage could be connected with social or symbolical values more than with the intrinsic value of the objects. Insights from such African cases could thus be utilized for generating a new understanding of cultural heritage in France. The discussion of cultural heritage entered a new era.

\subsection{Cultural Heritage and Centralism}

As of this point in time, cultural heritage was slightly divided in France. Historians, art historians and architects insisted on maintaining the old, accepted definition, encompassing the monuments and the fine arts; they valorized the museums. Whereas anthropologists and folklorists developed the notion of patrimoine ethnologique (anthropological heritage), including industries, crafts, popular culture, et cetera, which had to be preserved in situ. As head of the International Council on Monuments and Sites (ICOMOS), Georges-Henri Rivière, the founding curator of the Musée national des arts et traditions populaires in Paris, had a leading role in this reflection after World War II (Segalen 2005).

However, this new trend represented a real schism regarding the universalistic doctrine of the French nation-state. Emphasizing cultural diversity instead of national unity is often considered as a threat by the national French elites; the French doctrine of cultural heritage is thus still a significant place for political struggles. On the one hand, historians and specialists of fine arts carry on with the traditional vision of cultural heritage. The training of the museum curators in the national 
École du Louvre in Paris reflects their position quite well. Here, art forms are legitimated through their ability to encapsulate universal values. On the other hand, more and more people want to extend cultural heritage to everyday life. Local NGOs often insist on the fact that cultural heritage can help the identification and the valorization of local communities, which is highly problematic in a state where the notion of "community" does not even appear in the constitution.

Today, the implementation of ICH in France still reflects some of these historical features. Concerning the 2003 UNESCO Convention, there is ambiguity particularly connected with the fact that it is the civil servants from the central nationstate who should sort out and accept the proposals coming from the different French regions. In a country where all the different political and administrative elites need to train in the most prestigious Parisian schools, the provinces are still very much seen as peripheries. In such a context, nobody could seriously think that the national genius would burst forth in some remote countryside resort, when the eyes of international art critics are systematically turned towards the Louvre and the Parisian artistic milieu. This is also a reason why the word folklore is rather despised and laughed at in France. The word "folklore," being almost synonymous with "weird" or "kitsch" in the French language, is broadly perceived to be connected with narrow-minded parochialism, with cultural traditions in the countryside, which totally cuts it off from the universalistic commitments of the French elites.

\subsection{The Case of Intangible Cultural Heritage}

ICH in France is administered as follows: The French Commission for UNESCO is a branch of the Ministry for Foreign Affairs. As such, it does not really need to bother with French internal affairs. Indeed, the French Ministry for Foreign Affairs is not interested in the national internal cultural diversity but in international diplomacy. The French Commission for UNESCO is, therefore, only concerned with the fact of France being a UNESCO member state. This commission looks to the outside, at the international level, but not to the inside, except for advertising the UNESCO values in France through some conferences and meetings. Its members may raise discussions at an international level but are not fit to look at the cultural phenomena at the sub-national level. Furthermore, this commission is in charge of all the different aspects of the dialogue between France and UNESCO, which means that ICH is only a minor part of its activities. According to its representatives, there is no need to worry about French ICH as there are no diplomatic conflicts which could threaten cultural heritage in France. Since there are no such conflicts, there is no need to help the different communities involved with the UNESCO policies in France. This is even more understandable as the term community, as already mentioned, has no legal existence in the frame of the universalistic doctrine of the French nation-state. In this context, the French Commission for UNESCO acts more as a consultative body than as an executive one. Some representatives of this commission, together with other representatives in charge of 
museums, the fine arts, languages, culture, and international affairs in the Ministry of Culture, take part in a special committee called the "Comité interdirectionnel de suivi de la Convention" (Inter-Branch Committee for the Monitoring of the Convention). This committee is informed of the candidatures and submits them to the "Délégation permanente de la France auprès de l'UNESCO" (Permanent French Delegation to UNESCO), which is the French embassy at the UNESCO headquarters in Paris and the only body able to sign the candidature files.

It is a special branch of the "Direction générale des patrimoines" (General Branch for Heritage) in the Ministry of Culture, the Mission ethnologie, which is appointed to deal with the UNESCO policies and with the implementation of ICH in France. This Mission ethnologie was founded in 1980 under the name Mission du patrimoine ethnologique. After nearly thirty years of research on the notion of patrimoine ethnologique (anthropological heritage), this Mission ethnologie has begun since 2006, to inventory possible candidates for the UNESCO ICH lists. Its team in Paris is composed of three people including one art historian, one specialist in cultural studies and one secretary. Their job is to manage the implementation of the convention in France, with the help of a dozen anthropologists, the "Conseillers sectoriels à l'ethnologie" (Sectorial Councilors for Anthropology), who work in twelve different "Directions Régionales des Affaires Culturelles" (Regional Branches for Cultural Affairs), which are the regional administrations under the control of the Ministry of Culture. These regional councilors, working "in the field" both as anthropologists and as civil servants in charge of local cultural development, select cultural elements in the geographic regions they are in charge of and propose them to the central body, which discusses the opportunity of handing them over to the "Comite interdirectionnel de suivi de la Convention" and then to UNESCO.

The regional councilors, together with the three members of the central body of the Mission ethnologie, also have the task of proposing special files and guidelines to NGOs, local practitioners and associations interested in the nomination process in the field (Hottin 2011). The files proposed by the Mission ethnologie are principally inspired by the Quebec experience at Laval University (Turgeon 2010), which means they are simple enough to be filled in by local practitioners with the help of undergraduate students. The files describe the cultural practices, mention the places where they can be observed, the material elements connected with them, and the ways they are learned and handed down from generation to generation. They also document the history of the cultural practices and the efforts already undertaken to protect and valorize them, including a selective bibliography. Pictures and soundtracks of film footage can be added to the files, which contribute to establish a national repertoire of French cultural elements suitable to answer UNESCO criteria. Furthermore, several academic anthropologists have been asked to imagine common methods concerning the implementation of the elements already nominated, as well as the future nominations: The workshop, "Intangible Cultural Heritage," held in Paris from 2006 to 2008, was supposed to play this role (Bortolotto 
2011), but several French scholars have reflected in a critical way on the differences between the idea of filling in files and the importance of long-term fieldwork in the anthropological tradition. In spite of such critiques, the Mission ethnologie action plans expect more and more files to be completed over the next few years in order to build up a database of ICH practices in France.

However, the action of the Mission ethnologie is limited to the field of culture, which means that ICH is still strongly dependant on the universalistic doctrine of culture in France. Furthermore, this connection with the notion of culture does not allow any cooperation with the fields of local development or tourism, which deeply concerns the local actors. In this context, where only the national institutions are involved in the implementation of the UNESCO convention, no proper relations with local actors and "tradition bearers" have been built up yet.

\section{Combining the Global and the Local}

This historical and administrative background enables one to understand better some of the general issues involved in the implementation of the UNESCO policies in France. In the following section, I suggest that the principal problem lies in the combination of the new UNESCO global frame and the status of the local communities in the French universalistic nation-state.

\subsection{Decentralizing the Nation-state}

Since the 1980s, through French decentralization, administrative regions and departments have been pushed to the front of the scene, especially at the economic and financial levels. This was desired by the central state but did not open any real discussion of the old French universalistic doctrine. Decentralization in France was an initiative of the social democrats and was presented as a means to give some power back to the locals. However, it can also clearly be interpreted as a consequence of the oil crisis in the 1970s. At some point, the central state thought it better if local administrations could collect taxes themselves and finance different public policies in their own territories. Consequently, decentralization laws were introduced in the 1980s and led to a considerable gain of power for the different local governments, nearly one hundred Départements and about twenty Régions, which attained a relative autonomy.

However, some of the regions in France are more attractive than others. A lot of people, for instance, settle every year in the Mediterranean parts of France, but nobody settles in the northern and the central parts due to unemployment or bad climate. In the Languedoc-Roussillon region on the Mediterranean coast, the population increases by about 10\% per year, while in Picardy, a lot of people had to leave the region and seek work in Paris. These objective differences between the different regions are never taken into account in the French political system. On a 
legal and on an administrative basis, all the different regions are considered equal, and, in spite of this decentralization process, there is nothing like federalism in the French political system.

The role of the central nation-state has become mainly symbolical. It has no federal power, but also has no real political power on its own either. The local administrations in the Départements and the Régions - the so-called Conseils généraux and Conseils régionaux - pay for the roads, the schools and all the other public expenses. It is not a surprise then if the fields where the French central state remains most active are the ones with the greater symbolical value. This is why culture is still an important issue in France at a national level, but this also explains why culture in France is, in most of the cases, associated with the central state and, therefore, with universalism and with the global perspective.

\subsection{Selecting the Cultural Elements}

In this French context, the selection of the cultural elements to be nominated as ICH by UNESCO often leads to some struggles between the local and the national level, as I suggested in the introduction. It is difficult for the local administrations to present local or regional cultural elements as legitimate in the eyes of the universalistic national doctrine. ICH is spontaneously connected with the local milieu, with patrimoine ethnologique (anthropological heritage) or folklore, whereas the national level only supports the fine arts and more accepted cultural heritage items.

The local tradition bearers or local administrations who want to get their intangible heritage proposals accepted by the state usually have to show that they are compatible with the universalistic ideals of the French nation. However, it is interesting to note that such compatibility will not formally be asked for by the people of the Mission ethnologie, the section in charge of the ICH in the French Ministry of Culture. It will often surface as informal criteria when discussing the legitimacy of the different proposals. In some cases, the files are correctly filled in, but some evidence shows that the people who filled them in belong to a regionalist milieu. Their proposal will then be considered as political action, and it would be denied legitimacy as a genuine cultural initiative. In some other cases, the proposals come from unidentified people. In these cases, the civil servants in the Ministry of Culture will postpone the proposals in order to get more information on the different stakeholders involved in the candidature. Some investigations will be carried out to test the seriousness of the proposal. In short, proposing a cultural element as ICH in France requires firstly some competence in self-presentation. As a result, the most endangered or marginal cultural elements hardly manage to be accepted as $\mathrm{ICH}$ as the bearers of these traditions are too few in number and not sufficiently versed in dossier compilation. Several dozens of village carnivals in Mediterranean France, for instance, have processional giants, but only Pézenas and Tarascon, the two bigger towns where the people are most aware of their cultural value, have 
asked for the ICH label. As a consequence, the French nation-state will not even mention the variety of these local traditions at an international level.

The French selection of ICH ultimately appears as a dilemma: If the proposed cultural elements look too specific or too local, they might not be accepted by the state at a national level. However, if they do not look special enough, they might be rejected by UNESCO at the international level. Accordingly, the decisions concerning the definition of ICH in France are generally compromises between the local and the national views. The centralist and universalistic doctrine of the French state often operates as a means of selection and prevents the most marginal cultural elements from being inventoried.

\subsection{A Double-Bind System}

Tradition bearers who want to promote their local culture as ICH always need to combine the global and the local, because they face different sorts of logic which might appear contradictory to them. At a local or regional level, cultural diversity is usually clearly encouraged, whereas at a national level, it would be better to select elements emblematizing the national unity. Interestingly, the idea of cultural diversity fits well with the requirements of the UNESCO policies at a global level, even if cultural diversity and communities are frowned upon at a national level as possible threats to the unity of the central state. UNESCO policies emphasizing cultural diversity in a way seem to feed the critiques coming from the local or regional levels within the most centralist nation-states.

In such a system, however, candidates are caught in a double-bind, because on administrative grounds, all the candidatures are examined at a national level. The candidates then have to be at once special and universal; they have to look "authentic," but not too deeply entwined with the expression of local identities; they have to be local, but not closed to otherness, et cetera. Such a double-bind system compels the candidates to negotiate and to find a way between the opposite ideals of diversity and unity. In many cases, this situation can be problematic when it leads local traditions to change into a more "acceptable" cultural form for the guidelines of national or international authorities. In this way, sometimes the will to get the UNESCO ICH label leads to a standardization of the cultural elements. Studies in other countries have already critically addressed this idea of standardization. In the case of the Binche Carnival in Belgium, for instance, it has been suggested that the people were considerably impacted by the UNESCO label and that they changed their Carnival habits in order to meet the tourists' gaze (Tauschek 2010). In the case of the Patum festival in Berga, Catalonia, it has been claimed that the UNESCO policies were synonymous of a new era in public cultural management and in the festival itself (Noyes 2006). Looking at the role of the nationstate comparatively in the implementation of the UNESCO ICH policies in a centralist country like France helps one to grasp how the transformations can be 
framed by the national political systems within which the UNESCO cultural policies are implemented.

\section{The Example of the "Processional Giants and Dragons"}

The case of the "Processional Giants and Dragons" in France illustrates the importance of fieldwork for understanding better the role of the different nationstates in the implementation of the UNESCO convention. I will first describe my data and then propose a general overview of the French heritage regime in connection with the case of the "Processional Giants and Dragons."

\subsection{Traditional Processions as Intangible Cultural Heritage}

On the official UNESCO website, one finds under the link "Processional Giants and Dragons in Belgium and France," traditional processions of huge effigies of giants, animals or dragons encompassing an original ensemble of festive popular manifestations and ritual representations. These effigies first appeared in urban religious processions at the end of the 14th century in many European towns and continue to serve as emblems of identity for certain Belgian (Ath, Brussels, Dendermonde, Mechelen, and Mons) and French towns (Cassel, Douai, Pézenas, and Tarascon), where they are still practiced traditions. The giants and dragons are large-scale models measuring up to nine meters in height and weighing as much as 350 kilos. They represent mythical heroes or animals, contemporary local figures, historical, biblical or legendary characters or trades. The performances often mix secular procession and religious ceremony; they vary from town to town, but always follow a ritual sequence in which the giants relate to the history, legend or life of the town. Although these expressions are not threatened with immediate disappearance, UNESCO suggests that they do suffer from a number of pressures, such as major changes to town centers and increasing tourism, leading to the detriment of the popular, spontaneous nature of the festival.

The "Processional Giants and Dragons in Belgium and France" were first introduced as a "Masterpiece of the Oral and Intangible Heritage of Humanity" in 2005. The proposal was supported both by France and Belgium. The 90 masterpieces proclaimed before the 2003 Convention entered into force were incorporated in 2008 in the "Representative List of the Intangible Cultural Heritage of Humanity." The Convention was adopted in 2006 by the French state. Since then, several new elements have been acknowledged as $\mathrm{ICH}$ and appear either on the representative or on the safeguarding list. However, the "Processional Giants and Dragons" remain the oldest element on the lists. They have now been on the list for six years, which means that the people organizing or simply attending the processions may have had some time to learn about the convention and its general scope. 
The combination of ethnographic fieldwork, interviews among the administrators and questionnaires distributed to the tourists since 2007 have enabled me to reach some significant results concerning the impacts of the nomination of the "Processional Giants and Dragons" as ICH in France (Fournier 2009, Fournier 2011). The data allows one to compare the views of the different actors, the impact of the UNESCO label on the different towns, and the differences between the initial project and its transformations five years after the nomination. They also enlighten the role of the French state in the implementation of UNESCO's global policies.

\subsection{The Local Impact of Intangible Cultural Heritage}

In the nominated sites, a small number of activists willingly take part in the process, mainly through associations and other local networks, without looking too much at the state's role. These actors use the new label to experiment with strategies regarding the local implementation of cultural policies in general. In this respect, the UNESCO policies are only a pretext to discuss other local issues. As in each innovative process, there is local polarization, in this case between those who strongly believe in the benefits the label will bring and those who criticize it and think of the new policies as a new means of domination used by the local elites against the people. However, there is no clear consciousness here about the role that the state should play in the whole process. When asking the people at higher levels in charge of the implementation of the UNESCO policies, the positions differ. According to a local museum curator, for instance, the main issue is the management of the new label without any special financial support from either UNESCO or the state. For the people in the local tourist boards of the towns where the UNESCO label has been granted, the core question lies in the competition between the new and the old: In the interviews, several actors were concerned with the problematic articulation of the existing monumental and artistic heritage and the new ICH. For the elected representatives, ICH becomes something valuable in the marketing of the town's image; as such, it is used as a motto in almost all the public planning discourses and projects. At this local level, however, the French state is often criticized, as people are used to receiving some subsidies in a centralist state and they hope that the UNESCO label will convince the state to provide some financial support for their local festivals.

The comparison of the impacts of the UNESCO policies on the different towns where the "Processional Giants and Dragons" appear yields further results. There are definitely some differences between the four French towns of Cassel, Douai, Pézenas, and Tarascon. In Cassel, the new label has become a significant part of the local touristic development program and a new museum has been created. In Pézenas, new partnerships have brought together different local NGOs, including the local rugby club, whose members usually carry the local processional giant. Comparatively, very little has been done in Douai, where the people in charge of the giants seem rather skeptical regarding the impacts of the new 
UNESCO label. Focusing on the case of Tarascon, the main change is the visibility of the processional dragon. The Tarasque dragon was traditionally hidden at all times except for the time of the procession; it is now exhibited in a special showcase in the center of the medieval town. Moreover, a monumental stone sculpture is now on display in front of the local castle. The Tarascaires, the Tarasque-pushers, are invited to more and more other festivals throughout the year, both in France and abroad. Accordingly, they feel they have to become more professional in performing their traditions. Meanwhile, the people in charge of the cultural heritage have launched several exhibitions on the topics of dragons, the medieval times and on the fantastic. Shopkeepers have begun selling books, mugs and key-rings featuring the Tarasque dragon. The UNESCO listing has thus been adapted to the local development policies. The French central state's position, only being concerned with the symbolic value of the cultural elements, deeply contrasts with these practical considerations aiming at economic gain.

Lastly, the initial project has been transformed considerably. Before the nomination, all candidates were asked to plan previsions for the coming five-year term. In the case of the "Processional Giants and Dragons," the 2005 candidature file mentions that several meetings were to be held between 2006 and 2010 between the people in charge of the processions, and an itinerant exhibition was supposed to move from one town to another every two months to reinforce the connections between the different places involved in the nomination. A catalogue of this exhibition was to be published and emphasis was to be put on the giant- and dragonmakers as well. In 2009, a meeting of all the giants and dragons was supposed to prepare for the five-year term evaluation by UNESCO. Five years later, the report shows that only the first point - the 2006 meeting - was realized. All the other events did not happen. Sometimes this was due to the lack of financial resources. Sometimes the people in charge of the implementation of the convention were transferred to other cities; some of them died and new people were elected, et cetera. Such a comparison clearly shows that the UNESCO policies are suggestions rather than prescriptions. However, at the same time, the people involved in the organization of the festivals often consider that the role of the state would have been to accompany this valorization program. In a centralist state, people tend to ask the state to take on the prescriptions that UNESCO refuses to give.

\subsection{From State Culture to Local Development}

The data suggest that the candidature of the "Processional Giants and Dragons" was paradoxically reinforced by its very weaknesses. One of the most significant features here is the territorial heterogeneity of the different cultural elements concerned by the nomination: In France, at least, the four cities involved belong to three very different regions, which means they do not have very much in common at a historical or at a cultural level. At the same time, giants and dragons incorpo- 
rate universal features which can be found worldwide, including India and China. In this respect, they were fit to meet both the national and the global requirements.

At a local level, however, these considerations are far from being the most important. In a country where the nation-state was traditionally strong but where decentralization has recently made it weaker, people tend to consider the new UNESCO cultural policies as a handy tool for local development. In the context of a post-industrial economy, the UNESCO ICH label contains a lot of hopes. First of all, it is hoped that the UNESCO label will move the central state to give financial support to the local UNESCO festivals. Unfortunately, France sees its UNESCO membership as relevant only for matters of international diplomacy. Accordingly, the French UNESCO commission does not have the power to help locals with their cultural affairs. Neither the French Commission for UNESCO in the Ministry for Foreign Affairs nor the Mission ethnologie in the Ministry of Culture have the means to give subsides to local administrations in the cities where ICH is listed.

Another hope concerns tourism. In Tarascon, people in charge of this sector are especially keen to know whether the UNESCO policies will attract more tourists. This is understandable because Tarascon suffers from the excellent cultural reputation of several neighboring towns: Avignon, Arles, Nîmes, and Aix-enProvence attract most of the tourists in the famous area of Provence and they are all located less than 50 kilometers from Tarascon. A lot of visitors just head for the Mediterranean Sea and miss Tarascon entirely. In this context, the town of Tarascon dreams that her processional dragon could attract more people. However, at the same time, there is also some fear that tourism will cause harm to the cultural heritage, which makes the Tarascon people uneasy about advertizing the new UNESCO resource as a touristic one. ICH eventually asks questions which are determined by a post-industrial and post-national context: Are the labels able to bring in tourists as possible alternatives to the crisis faced by the local industries? Will the regions be able to make profit out of the new category of ICH when the central nation-state becomes weaker due to decentralization?

\section{Conclusion}

The case of the "Processional Giants and Dragons" in France is a very useful one to enlighten different aspects of the relations between the heritage regime and the state. Firstly, this example shows the different impacts that the UNESCO policies can have in the field, where local festivals are combined with tourism and other economic development. Secondly, the example illustrates the ways in which ICH issues change the interactions between the state and the local economy. The locals are encouraged to valorize their $\mathrm{ICH}$, but, in the process, they have to learn how to do things by themselves as this new sort of heritage does not receive any funding from the central nation-state, as was usually the case with material cultural heritage. 
Thirdly, the case offers a perspective on how an only half-heartedly lessened centralist state implements the global ICH doctrine.

Concerning the French example, I would suggest that a global cultural policy never erases the past. In the case of ICH, UNESCO wanted to propose a global frame to accompany the preservation and safeguarding of a new sort of heritage, but this new frame is interacting with the previous generations of national cultural policies. It would be naive to study the UNESCO policies without studying the diverse regional and national contexts where they are implemented. In some cases, the preservation faces a popular refusal, because the tradition bearers do not want to get into the ICH nomination process; they feel the transmission would become artificial if they were to rely on global protectionism instead of carrying on themselves with their traditional skills or practices. In other places, the UNESCO policies are considered as a means to boost the local economy and the development of cultural tourism; they generate projects and have a true influence in the ways the actors consider their own cultural practices.

As a conclusion, I would like to emphasize three main features of heritage studies that are also relevant for cultural anthropology in France. ICH enables one to scrutinize the transformations of local traditions in a globalized world. Investigating the field contributes to global comparative projects aiming to understand how different local cultures react to contemporary changes. Finally, heritage developments enable one to grasp how politics, economics, esthetics, laws, et cetera, interact and thus build up a holistic approach to societies and cultures. Comparative research in the different UNESCO member states helps us to better understand the complexity of the different heritage regimes in contemporary globalized contexts.

\section{References}

Belmont, Nicole (1995): Aux sources de l'ethnologie française: l'Académie Celtique. Paris: Comité des Travaux Historiques et Scientifiques.

Bortolotto, Chiara (2011): Le patrimoine culturel immatériel. Enjeux d'une nouvelle catégorie. Editions de la Maison des Sciences de l'Homme, 26. Paris: Maison des sciences de l'homme, coll. Ethnologie de la France.

Chanet, Jean-François (1996): L'école républicaine et les petites patries. Paris: Aubier.

Chastel, André (1986): La notion de patrimoine. In Les lieux de mémoire (II, 2). Nora Pierre, ed. Pp. 405-450. Paris: Gallimard.

Fournier, Laurent Sebastien (2009): L'impact de l'appellation “Chef d'œuvre du patrimoine oral et immatériel de l'humanité" en France: le cas des géants et dragons processionnels. Rapport de recherche remis à la Mission à l'ethnologie, Ministère de la Culture et de la Communication. 
- (2011): La Tarasque métamorphosée. In Le patrimoine culturel immatériel. Enjeux d'une nouvelle catégorie. Editions de la Maison des Sciences de l'Homme, 26. Chiara Bortolotto, ed. Pp. 149-166. Paris: Maison des sciences de l'homme, coll. Ethnologie de la France.

Hottin, Christian (2011): Sept ans, l'âge de raison. Dynamique et enjeux du patrimoine culturel immatériel. In Le patrimoine culturel immatériel. Premières expériences en France. Internationale de l'imaginaire nouvelle Série, 25, Pp. 27-56. Paris: Babel - Maison des Cultures du Monde.

Jamin, Jean (1989): Le musée d'ethnographie en 1930. In La muséologie selon Georges-Henri Rivière. Cours de muséologie, textes et témoignages. Georges Henri Rivière, ed. Pp. 110-121. Paris: Dunod - Bordas.

Martel, Philippe (1986): Le Félibrige. In Les lieux de mémoire (III, 2). Nora Pierre, ed. Pp. 566-611. Paris: Gallimard.

Noyes, Dorothy (2006): The Judgement of Solomon: Global Protections for Tradition and the Problem of Community Ownership. Cultural Analysis (5): 27-56.

Segalen, Martine (2005): Vie d'un musée. Paris: Stock.

Tauschek, Markus (2010): Wertschöpfung aus Tradition. Der Karneval von Binche und die Konstituierung kulturellen Erbes. Berlin: Lit Verlag.

Thiesse, Anne-Marie (1997): Ils apprenaient la France: l'exaltation des régions dans le discours patriotique. Paris: Maison des sciences de l'homme.

Turgeon, Laurier (2010): Le patrimoine immatériel de l'Amérique française. Ethnologie française XL(3). 


\title{
Anthropology's Payback: \\ "The Gastronomic Meal of the French" The Ethnographic Elements of a Heritage Distinction $^{247}$
}

\author{
Jean-Louis Tornatore
}

\section{Introduction}

The fifth session of the Intergovernmental Committee for the Safeguarding of Intangible Cultural Heritage of the United Nations Educational, Scientific and Cultural Organization (UNESCO), which was held in Nairobi in November 2010, inscribed "The gastronomic meal of the French" on its Representative List. "The gastronomic meal of the French" (GMF) is the official designation for the certified item. According to the definition taken from the nomination dossier and given on UNESCO's website (UNESCO 2010), it is variously "the art of good eating and drinking" enjoyed on the occasion of a "festive meal;" a "customary social practice" involving "togetherness," "the pleasure of taste," and "the balance between human beings and the products of nature;" and a custom whose celebration in the form of this UNESCO inscription is presented as contributing to the fight against the standardization and increasing uniformity of ways of life around the world. The nine-minute documentary included in the dossier is quite remarkable in that it constructs this sort of meal, this art of entertaining - from the "careful selection of dishes from a constantly growing repertoire of recipes" to the meal itself, which unfolds according to a "fixed structure" - as a cultural unit in which $95 \%$ of a

\footnotetext{
247 This article appears in French in Ethnographic.org, 24, summer 2012. Translated from French by
} Marie Deer (mariedeer1961@gmail.com). 
particular community, namely the French people, can recognize itself. ${ }^{248}$ It then goes on to set up that cultural unit as a subject for anthropological inquiry, in that it includes the classical themes of anthropology, such as the relationship between nature and culture, customs, social spheres, material culture, and transmission. It is quite an experience to watch this documentary and feel the surprise of seeing oneself, as a Frenchman, "objectified" in this way: To feel a sense of familiarity - "they are talking about me!" - while, at the same time, feeling imperfectly captured. It is both "right" and "not quite right;" "we don't do it like that!" This terrain is of course a minefield for the 21st-century anthropologist faced with the phrase "of the French," a category that invites debate as soon as it is put forward. And yet that is exactly what the Intangible Cultural Heritage (ICH) apparatus has done in including this category in its list as a substantial entity; inscribing it as an object in the marble of its list. I believe that this is the first time that anthropological objectification has struck, if I may put it that way, so precisely at this level: At an entire Western national entity. At the very least, it is the first time that it has designated and affected our national community. What we owe this "anthropological payback" to is a politics of heritage; this, in turn, suggests that the anthropological themes that I listed above, which are by definition scholarly, have, to a certain extent, become heritage themes, destined now to become political. I should add that this has surely always been the case, but no one has ever said so out loud, or at least not in those terms. What we have here is heritage exacerbating the political dimension of anthropological concepts.

I wanted to understand how we had come to the point where scholarship and politics are tied together within and for the sake of this heritage object, the GMF. This is a central question in my research on heritage, but in this case, my line of inquiry took on a particular shade: The act of eating holds almost no interest for me; the obsession with talking endlessly about what one is eating, while eating it, which is considered very French, has, to be honest, always annoyed me; and as for the typically jingoistic way in which France is made out to be the country of food and cookery par excellence, I find that completely unbearable. It is one thing to enjoy cooking up little dishes at home or among friends, but making a cultural trait out of this pleasure, duly circumscribed and labeled as such, could be seen as one more step towards the reification of culture. In fact, at first glance, and when the first newspaper accounts of UNESCO's decision came out, the reactions to the heritage choice seemed to confirm my fears.

As a result of these reactions, I began this research project. It would have been easy to develop a substantial monograph on the project of heritagization. However, I decided to confine myself to a quick investigation instead, one which I may never

\footnotetext{
248 According to a quantitative survey commissioned by the Research Center for the Study and Observation of Ways of Life (Centre de Recherche pour l'étude et l'observation des modes de vie, CREDOC) and carried out with a representative sample of 998 subjects (CREDOC 2009).
} 
follow up on at all or develop into anything larger. ${ }^{249}$ Establishing the boundaries of a project also means setting out the scope of its significance: Here is how I see that scope as it follows from the boundaries of my "blitz ethnography." I make no claim to have reconstituted the process that culminated in the Nairobi decision; at the very most, I may have been able to get a sense of its uncertainties and the adjustments that were required of the decision makers. This uncertainty was heightened by the novelty of the process, which was intended to define an object in such a way that the object would fit the parameters of a category and be eligible to fit into an apparatus - that is to say, the apparatus established by the 2003 ICH Convention - which had not only very recently come into effect (in April 2006) but had also only even more recently been ratified by France (in July 2006): The system was new and untested both for UNESCO and for the French state. I was also able to appreciate the very political dimension of the system, or rather that the political dimension is a particularly flagrant dimension of the ICH apparatus and informs the entire process. The political dimension is what completely motivates the actions of some of the players within the system, and this was visible in their reluctance to play the "ethnographic interview" game, or at least in the carefulness in their speech which could be seen in the almost complete lack of success I had in attempting to gain access to the minutes of the meetings that were held throughout the process. ${ }^{250}$ If I cannot "say everything" - or anyway, everything about the interactions that I see - I have, at least, in examining this political dimension and its interaction with the issues that follow from it, been able to arrive at a general reflection on the politics of the ICH. I submit this look at the situation with no greater claim for it than that it is a first step, a partial analysis: As the expression, completely up for debate, of an uncertain thought process..$^{251}$

\section{The ICH "Refrain"}

The modern profusion of ways of creating memorials and celebrating heritage (which are also often castigated, at least in France, for their very proliferation) can be understood as adaptations to the modern conditions of life (mobility, vulnera-

\footnotetext{
${ }^{249}$ I do not share the view generally agreed upon among anthropologists, which was recently solemnly reaffirmed in a manifesto (Saillant; Kilani; Graezer Bideau 2011), believing unlike them that it is possible to free oneself of the methodological dogma of the long-term research project - which is seen, unfortunately, as the minimum precondition for an "engaged presence" (Saillant; Kilani; Graezer Bideau 2011: 18) - and that it is possible, likewise, to liberate oneself from that wonderful "critical distance." From the point of view which I am espousing here, the work of the social sciences neither requires nor implies the perspective of an outsider, nor does it inevitably turn on the length of the research project: Like the "quick game" of chess, the quick research project is perfectly conceivable as long as it does not attempt to provide a "view from on high" or a divine perspective (something that, I should point out, not even a long-term research project can guarantee).

250 The materials to which I had access consisted of four interviews and a few status reports, along with one substantial press release and the files submitted to UNESCO.

${ }^{251}$ For a different and complementary approach to the UNESCO inscription, see Csergo 2011.
} 
bility and uncertainty) in a world that is taken to be globalized. The profusion itself could be seen as a result of globalization. One of the characteristics of globalization is said to be transforming the people-nation-territory relationship or at least calling the naturalness of this relationship, taken over from the construction of the European nations, into question (Thiesse 1999). If we look at it this way, we can imagine that these practices could provide a way for scattered individuals or communities to produce an adapted kind of village, in other words, one that suspends, relativizes, nuances (or does who knows what else to) the idea of being rooted in a territory; but then again, the new politics of heritage could be a way of reconsidering the relationship between territory and sovereignty. So then, all the activity around heritage nowadays is creating new territorialities and new kinds of territorialization in a constant game of territorialization, deterritorialization and reterritorialization. It is probably scarcely possible to overestimate the political inflection of all of this activity, but at the same time, we should also not underestimate the ability of nation states to use the idea of heritage for their own ends.

The possibilities inherent in the international and national ICH apparatus must be seen from this perspective, which will mean emphasizing its basic ambivalence: The apparatus allows for the best and the worst possible outcomes. Gilles Deleuze and Félix Guattari have developed a dynamic (rhizomatic) conception of territory: It is the branding - the quality, the material of expression - that makes the territory (Deleuze and Guattari 1980: 388) and the territory is always in the process of deterritorialization, moving towards other arrangements that will create a reterritorialization (Deleuze and Guattari 1980: 402). To describe this marking of territory, they have developed the metaphor of the "refrain" or "incantation," which can be territorial, indicate new arrangements, or involve absolute deterritorialization. It is tempting to see something like an incantation - or a potential incantation - in any move to make the ICH concrete, in the sense that such a concretization can happen on several different levels of territorial arrangement: international, national, translocal, or local. The story of the song "El condor pasa" told by Vladimir Hafstein (2007) is relevant and telling: ${ }^{252}$ It involves a history of colonial expropriation that has been taken by the Bolivian state as a reason for mobilizing to defend the integrity of national cultures, but that very mobilization has then actually been the occasion for a muzzling of Bolivia's Indian populations. In fact, Hafstein concludes that "the lessons to be drawn from this episode go well beyond the problem of transnational cultural fluidities" (Hafstein 2007: 339). The episode reveals that there are several territorialities involved which are intertwined but not necessarily convergent, all of which are organized around the same refrain, the same incantation, in this case Andean folklore, but with purposes which are by no means always beneficial to the communities themselves. The politics of ICH can be a hell paved

252 "El condor pasa" is a traditional Andean song, adapted in 1913 by a Peruvian composer and folklorist, that tells the story of a revolt by Indian minors who were exploited and despised by Yankee imperialists. (Simon and Garfunkel, collaborating with the group Los Incas, released a version that made the song world famous.) 
with better or worse intentions; at any rate, they take away with one hand what they claim to offer with the other (Hafstein 2011). Looked at within the reality of the story of "El condor pasa" - in other words, looking at how it actually works the ICH apparatus could be seen as the epitome of a contrôlat, a tool characteristic of "control societies" (monitor societies?), the new type of society which, according to Gilles Deleuze (1990), followed the "disciplinary societies" that Foucault described. The institution of an "ICH community," 253 therefore, would have more to do with monitoring populations than with managing them. Its main aim would not be to discipline them but to keep a watch over them by occupying them; we could say, therefore, that "occupying," as much in the sense of possessing and invading as in the sense of filling, saturating, or directing time, is the goal of the politics of ICH.

However, we cannot stop there. "There is no reason to ask," Deleuze says about the different kinds of societies, "which regime is the most onerous or the most tolerable, because it is within each one that liberation and bondage confront each other" (Deleuze 1990: 241, emphasis added). The question is, then, to understand how the pairing of territorialization and deterritorialization is worked out within the various national implementations of the politics of $\mathrm{ICH}$ : To what ends and who profits from it? Let us look at some possible scenarios, taking them as strictly delineated hypotheses that we can test empirically, noting that scenarios 1 and 2 are from the point of view of the state and scenarios 4 and 5 are from the point of view of communities, and they can, therefore, be looked at in connection or in dialogue with each other.

1. The ICH reterritorializes, allowing for a resistance to the deterritorialization (in the sense of a move towards uniformity) that follows from the changes brought by globalization. This is the first reasoning, which appears in the reasons given for the convention. It allows us to see the state as a protector (from forces such as global capitalism) - or at the very least, it allows the state to develop a rhetoric of protection - along the model of the Bolivian state in the example cited by Hafstein.

2. The ICH reterritorializes (or nationalizes), allowing for resistance to the deterritorialization (in the sense of liberation) that follows from the exchanges, circulation and creations of the free flow of information and of cultural motifs (for example, in the long-distance networks of the "creative industries"). This allows us to see the state as a controller or regulator - for example, in the name of the protection of cultural diversity.

3. The ICH reterritorializes (in other words, promotes the formation of social and cultural mediating entities), allowing for a resistance to the deterritorialization caused by the state and accentuated by the machinery of capitalism.

4. The ICH is a response to deterritorialization (in the sense of the disintegration of communities due to globalization) and is seen as a way to ensure the integ-

253 As Hafstein writes, "the intangible heritage is the community" (2011: 86). 
rity of communities and to reaffirm their integration into the nation. This allows us to see the community as a protected entity.

5. The ICH is a result of deterritorialization (in the sense of the "denationalization" of communities or of communitarianism) and a means of resisting the state's reterritorialization. This allows us to see the community as "liberated" and autonomous in its cultural choices.

The first scenario is consistent with the fourth, and the fifth one is a response to the second one. Communities and states can use $\mathrm{ICH}$ as a way to fight against the negative effects of globalization (scenarios 1, 2 and 4), but that does not mean that globalization has only negative effects (scenario 5) nor that states have no common cause with globalization (scenario 3). Ultimately, the only point of this outline of hypothetical scenarios is to emphasize the fact that, first of all, the capacity to territorialize or deterritorialize is not a property attached to collective entities: Thus, the state can be seen as either territorializing or deterritorializing, and it can just as easily resist liberalism as it can promote it or work towards it. We can, therefore, see the state (or whatever collective entity is at issue) as containing antagonistic forces, and we have to see the politics that it promotes, including that of ICH, in that context. Secondly, even though one can say that the most important principle of $\mathrm{ICH}$ is not territory but the community - and that, in this way, it breaks with how European states have traditionally viewed the idea of heritage in order to promote the recognition of cultures on an international level, the implementation of the UNESCO 2003 Convention rests with the states. The state remains an inescapable player in the promotion of heritage, and so we can say that $\mathrm{ICH}$ is still the state.

\section{The "Take"}

In order to understand what tune ICH is playing (and on what level), we first need to look at how each individual state - which is of course the first and primary level on which the politics of ICH is carried out - takes hold of the convention and puts it into practice. In other words, what their "take" is. ${ }^{254}$ Here, I would like to adapt an idea about expertise on objects - whether they be brand-name watches, socalled traditional foie gras, paintings by the masters, archeological sites, or holy relics - developed by Christian Bessy and Francis Chateauraynaud (1995). The "take" that experts have on objects sends us back to the work of mediation which, in the process of expert evaluation, organizes connections among materials, modes of perceptions, networks of people and objects that are more or less arranged in collectives or institutions, and descriptive conventions (Bessy and Chateauraynaud 1995: 234). In this case, it is cultural phenomena that are objectified (named, designated, embodied, labeled) within scientific, cultural and administrative institutions

\footnotetext{
254 See Tornatore 2011.
} 
that organize similar mediations: ad hoc museums, state services, a contingent of conservationists, and also clubs, groups and associations. Systems of classification, inventories and lists work to establish cultural entities and transform them into "heritage" entities. The nation, as we know, is a great producer of such entities.

Understanding that the convention is subject to "national takes" also means taking into account the history of public action on the management of the past and on this sort of inventory taking, as well as the way in which a tradition of heritage expertise can influence the interpretation of the means available for bringing to light the entities defined by the convention. Without going into detail on heritage institutions, which tend to exist at the intersection of knowledge and power, suffice it to say here that in the French tradition, cultural phenomena have been vetted by two historically-based politico-scientific institutional configurations, both of which also involve obvious government involvement. First of all, there is folklore. Here, we should note that its development, from the 19th century to the Second World War, is tied to cataloguing and mapmaking methodology; in France, folklore has never been truly established among the sciences and was lastingly discredited by the "cultural decline" orchestrated by the French state during the Second World War. Then, more recently, there is the institution of ethnological heritage, a specifically French invention which found itself at the junction of the development of ethnology in France and the politics of a heritage-based celebration of culture in its anthropological sense (Fabre 1997, Rautenberg 2003, Tornatore 2004).

The French "take" on the convention ought to be measured against one of these two configurations, both of which are part of the national tradition; in addition, this "take" needs to be imagined not only on the level of the state, but also on the level of associations and groups, of segments of civil society, of the communities to which the UNESCO language refers and those who have appointed themselves as the representatives of those communities. This, in turn, brings up two questions. On the one hand, there is the question of the degree of agreement or complicity among these various groups. In this context, we should note that it is only in France that ethnology rejects, or is at least suspicious of, the idea of "folklore." Elsewhere the divisions are much less clear-cut and terms, such as tradition, folklore, customs, heritage, and of course culture, are used less rigorously and more flexibly. On the other hand, we have the question of the performative quality of the take. This understanding is framed by the culture's traditions of objectification or celebration of culture, but it is no less constructed in the very "take" on the convention. Seen this way, to "take" the convention is to bend it to one's own tradition in bending oneself to it in turn: It is to adapt oneself to it. This notion of "take," I reiterate, connects material with perceptions and descriptive conventions and brings all those elements into play. If we only consider the perceptions and the descriptions, we are not doing justice to what the material does and causes to be done in the process of the "take." The material, in this case, is a political mechanism that induces a particular mode of apprehension. The taking engages and defines the one who takes; if it is informed, it also informs; and we can postulate that 
the taker does not emerge unmarked from the taking. Can the French take on the convention mold, or even shake up the culture's traditions of politicization? Can the convention force those who take it on to adjust their actions with respect to the convention's project as well as their idea of heritage, of the principles that inform the ways in which heritage value is assigned? In this analysis of the recording on the gastronomic meal of the French, the GMF, as an ICH, I will attempt to answer these questions.

\section{How to Make French Gastronomy into a Matter of State}

Let us try, first of all, to describe the process or at least to set out its major steps, in order to gain some understanding of the project.

\subsection{A Political and Scientific Assembly Process}

To begin with, we find one person who was actively involved in championing and promoting food cultures and heavily engaged in cultural politics. Francis Chevrier ${ }^{255}$ was the director of cultural affairs for the city of Blois when Jack Lang was its mayor. 256 In that capacity, he founded the "Meetings of History" festival, which in its second year was devoted to "Foods of the World." Most of all, though, for our purposes here, in 2001, while Lang was the French national Minister of Education and also of Higher Education, Chevrier was behind the creation of a European institute devoted to research on food, the European Institute for the History and Culture of Food (IEHCA), of which he is currently the director. The organization is a foundation hosted by the Institute of France and, therefore, also under the auspices of the Ministry of Higher Education. Closely connected with the François Rabelais University in Tours, the institute is defined as an "agency for scientific development" (IEHCA, accessed May 16, 2012) or as a "network of researchers," (Interview Chevrier 2011) whose activities, then, revolved around research, training and the organization of seminars and symposia. It was within the context of his activities for the institute that Chevrier happened, "fortuitously," as he says, to read the new UNESCO ICH Convention, soon after it was developed. Reading that text, and especially Article 2 which defines the entities covered under the convention, was decisive for Chevrier: "I said to myself, you'd think that this was written to be about cuisine" (Interview Chevrier 2011). From there it was but a short step to imagining the inclusion of French cuisine, or gastronomy, or some

\footnotetext{
${ }^{255}$ Since the record is public and the people involved are known, I did not see any reason to hide their identities.

256 Jack Lang is a leftist French politician (member of the Socialist Party) known for having put a strong French stamp on cultural politics during his two terms as Minister of Culture, both of them under François Mitterrand (1981 to 1986 and 1988 to 1993). He was also the national Minister of Education (1992 to 1993 and 2000 to 2002), a representative, and mayor of the city of Blois from 1989 to 2000.
} 
aspect of that cultural reality, on one of the lists (the Representative List or the preservation list) set up by the convention.

What becomes clear from his own words and from what he has told me about how the application process began ${ }^{257}$ is that Chevrier set himself to carrying out this project, or one might say projection, with a very sure political sense, the sense of someone who was used to navigating in decision-making spheres. He began by trying out his idea on UNESCO, whose headquarters are in Paris, first meeting with the person in charge of the Intangible Cultural Heritage Section, who told him that the idea was viable. That official invited him to convince the French government to take on the case. Chevrier then went on to propose the project to the various relevant ministries, one after the other - the Ministry of Agriculture, and then the Ministry of Culture - but he ran into strong resistance there, which he attributes to what he calls "the administration's splendid stalemate" (Interview Chevrier 2011). The Ministry of Agriculture found the project uninteresting because it had no European dimension; the Ministry of Culture was uninterested because they could not see what gastronomy had to do with culture (and I will come back to this very important point). Chevalier's strategy was, as he put it, to "keep on knocking where the decisions are made." For that reason, he never considered taking his case to the ethnology division of the Ministry of Culture, which was at that time in decline (and which is now trying to find some administrative legitimacy in promoting the agenda of the 2003 Convention): "If we had gone that route," he says, "we would still have been at it twenty-five years from now!" (Interview Chevrier 2011). Not getting anywhere with the ministries, therefore, he took his case higher up, right to the President's office. Chevrier approached the President via his special adviser for culture and audiovisuals, Georges-Marc Benamou, a well-known leftist journalist who had taken part in Nicolas Sarkozy's 2007 presidential election and whom Sarkozy had then appointed to his cabinet. ${ }^{258}$ Over the second half of 2007, a number of meetings were held with members of the presidential cabinet (the final meeting was presided over by the cabinet director), first to determine the technical feasibility of the project, after consultations with the relevant ministries (of culture, agriculture and foreign affairs), and then, finally, to endorse it. This was what led to Sarkozy's official announcement of the project at the opening of the first International Agricultural Exhibition held during his presidency, on February 23, 2008.

Before we return to this crucial episode, I would like to finish describing the inaugural process, or line of attack, imagined by Chevrier. He said that he had quickly realized that the IEHCA could not be in charge of the case because it was not set up to do that sort of thing. In other words, it is an organization with scientific and cultural aims and not suited to the political needs of the project, all the

\footnotetext{
257 The following paragraph is based on my interview with Chevrier.

${ }^{258}$ Benamou was a special adviser to the President from the presidential election, in May 2007, to March 2008.
} 
more so because the institute's scientific council was not entirely in agreement on the project. The solution that Chevrier saw was to create an ad hoc structure, a voluntary nonprofit association (under France's Law 1901), to be presided over by someone substantial, well-known and influential, and the ideal person for this position was Jean-Robert Pitte, "an old friend" (Interview Chevrier 2011) of Chevrier's. Pitte, a geographer and university professor, had several advantages. First of all, he was a specialist in gastronomy and had written several books on the subject, in particular one entitled "French Gastronomy. The History and Geography of a Passion" (Pitte 1991). Furthermore, at that point, he was the president of Paris-Sorbonne University (Paris IV), which was seen as very good for name recognition outside of France. Finally, he was "very well connected in rightist political circles" (Interview Chevrier 2011). Therefore, he was truly ideal because, just like Chevrier himself in his way, Pitte was at the intersection of science and politics, at the junction of the two worlds. In fact, both men have hybrid personalities and complement each other politically, being on opposite sides of the left-right spectrum.

Pitte and Chevrier started working together very quickly in 2007, and in the wake of the presidential declaration, they efficiently set up an ad hoc structure, the French Commission for Heritage and Food Cultures (Mission française du patrimoine et des cultures alimentaires, MFPCA), whose statutes declared its purpose to be to "contribute to the inclusion of French gastronomy" and to "work towards the recognition of cuisine in general and French cuisine in particular as an important component of heritage" (MFPCA 2011). The commission's financing was largely provided in the form of services: Its operational premises and its secretariat were provided by the Ministry of Agriculture and its director was a cultural operative hired on contract by the same ministry, while the project's lead scientist was an academic temporarily transferred to the Ministry of Research and Higher Education for the duration of the project (more on that below). In 2008, the system was in place, summed up as follows by one of the people involved:

There is the IEHCA, which is the scientific network for the business, on the left. The IEHCA created the MFPCA, which is its enforcer, its 'military wing,' on the right. The president of the IEHCA is Pascal Ory, ${ }^{259}$ from the Socialist Party, and the president of the MFPCA is J.-R. Pitte, from the UMP. ${ }^{260}$

\footnotetext{
259 Ory is a Professor of Modern History, a specialist in cultural history, and a very media-savvy intellectual. He is a regular contributor to print and audiovisual media (especially French Culture on Radio France).

260 The UMP (Union pour un mowvement populaire; Union for a Popular Movement) is the main rightist party in France, established by former president Jacques Chirac. The political assembly of this cast of characters owes much to the involvement of Catherine Dumas, a UMP senator and the author of a report (June 2008) that would ultimately clarify the process; see Csergo 2011.
} 


\subsection{Sponsorships: People Mobilizing and Being Mobilized by Gastronomy}

So what was at stake in this beginning stage when the project was starting to take shape? Simply put, it was French gastronomy, as set out in the MFPCA's purpose statement: International recognition for a specifically French art and way of eating and drinking well. The list of the people who were involved and who took up the cause, in other words the list of people who were mobilized by gastronomy, is a good indicator of the stakes. Without even going into an analysis of the support committee for the "inclusion of France's food heritage," set up between 2006 and 2007, a simple look at the list of the founding members of the MFPCA is telling enough: Aside from the founding duo, this group included two leading chefs, ${ }^{261} \mathrm{a}$ representative of the Paul Bocuse foundation, the president of the Hotel Trade and Industry Union, the founder of the Institute for Taste, ${ }^{262}$ the president of Slow Food France, the chairman of the joint chambers of agriculture, the executive head of the Sèvres National Porcelain Factory, ${ }^{263}$ a food critic, a former ambassador to UNESCO, and three academic historians. Agriculture, the hospitality sector, the restaurant industry, and high cuisine were all well represented here, along with a reference to the traditional art of entertaining - to eat well one must also eat from high-quality tableware - and a reference to a probably more recent quality of French cuisine and entertaining that implicitly involves striking back against the Americanization of food. Including a representative of food criticism was essential; that genre is considered an art form in France. ${ }^{264}$ The vitally necessary presence of the historians reminds us that, in the words of Philippe Joutard (2000), history is a "French passion" and that the historian is the favorite intellectual figure of the French. Finally, the strategic inclusion of the former ambassador shows that it was crucial to the project's sponsors to make sure that the commission had a sound understanding of the institution that had introduced and was sponsoring the category of ICH, as well as privileged access.

\footnotetext{
${ }^{261}$ In other words, starred chefs, chefs étoilés, the star being the hallmark of excellence awarded by the Guide Michelin, the famous and the oldest (early-20th century) French restaurant guide.

262 The Institute for Taste, created in 1999 (and originally called the French Institute for Taste), is an organization devoted to training and research which is interested in the sensory perceptions and in dietary behaviors. It is involved in the education of taste, especially in young people (Institute du Gout, accessed May 16, 2011)

263 One of Europe's main porcelain manufacturers.

${ }^{264}$ We should point out that the critic on the commission worked for the daily newspaper Le Monde, which is seen as the most impartial newspaper in France or, at any rate, the one with the least identifiable political orientation (although there is a recurrent suspicion that the newspaper is on the center left).
} 


\section{3 "The Best Food in the World"}

Aside from a reading of the definition of the category, which anyone could do, the crucial question for us here is whether French gastronomy is an eligible entity for the label of ICH, according to the letter and the spirit of the convention. The official announcement of the application, therefore, is a key moment in the process, because it allows us to gauge how well the project is aligned with its targeted aim and to gain an appreciation for the fine-tuning required: How to adjust the idea of French gastronomy to fit the category? And, at the same time, how flexible is the category; is it flexible enough to accommodate the French entry?

The French president's speech announcing the project showed right from the beginning that it had the government's blessing. In the account - as the ethnomethodologists say - of the selection process that seems to have become formalized and established in reports in the press, that inaugural speech was also a moment that was noted for the presidential style of the announcement, which was annoying to people from the outset. The agricultural exhibition, the Salon de l'agriculture, which is held every year in Paris, is a required stop on the political circuit. Even though less than $4 \%$ of the workforce is involved in agriculture, everyone courts and lavishes attention on the rural, agricultural world because it is seen as a sort of privileged location for the essence of Frenchness and, therefore, also for French heritage. Sarkozy's predecessors knew how to cultivate the image of the France that is rooted in villages and the soil, and Jacques Chirac was perfectly at home at the agricultural exhibition, but Sarkozy enjoyed no such popularity in the agricultural community, so he wanted to find a connection and to make a point of appearing at the first exhibition of his five-year term. He started right off with an inaugural speech that was unusual for the exhibition in its solemnity; in it, he laid out the main foundations of his agricultural policy and announced measures to be phased in. At the very beginning of the speech, he spoke about the project to get the French contribution included in UNESCO's list:

I am very happy to be here among you to mark the inauguration of this 45th International Agriculture Exhibition, and I would like to welcome all the foreign ministers who have honored us with their presence. I want, of course, to welcome all of France's farmers, but also everyone - the industrial leaders, the employees and the craftspeople - thanks to whom France is at the forefront of the world in the agricultural and agri-food sector. Dear Christian Patria, ${ }^{265} \mathrm{I}$ am perfectly aware that this Agricultural Exhibition is an extraordinary showcase for France's trades and products. It is a global meeting place, an opportunity for discoveries and pleasure. For centuries, agriculture has been part of France's identity and tradition. Today, even be-

265 UMP politician and the president of the agricultural exhibition. 
yond its cultural dimension, agriculture carries a double charge. It has an economic component, to which I will return, but it is also a bearer of civilization. Agriculture has shaped our landscapes. It gave our Fatherland a soul and to this day, it is agriculture that allows France to have the second-largest surface area of any country in Europe. If it weren't for agriculture, our country would be a desert. Agriculture and the trades and occupations that shape it are also the source of our country's gastronomic diversity. I have taken the initiative for France to become the first country to submit an application with UNESCO, in 2009, to have our gastronomic heritage be recognized as part of the world's heritage. We have the best food culture in the world - anyway, from our point of view [...] well, of course we want to compare ourselves with everyone else - and we would like to have this recognized as part of the world's heritage. (Sarkozy 2008)

In fact, the president made many more headlines that day by insulting a visitor who refused to shake his hand. It is the infamous "Get out of here, you pathetic schmuck!" ("Casse-toi, pawv'con!") that history will remember from that agricultural exhibition. But even though it only came in second in that day's news, the way that Sarkozy announced the French application also got its share of negative reactions and especially managed to annoy the foreign observers as well as the UNESCO representatives in charge of the convention. Indeed, departing from his prepared speech as he often did, in one small phrase praising the excellence of France's food culture - even though he also acknowledged that his point of view was of necessity subjective and that that was why France was willing to put its "title" on the line and to enter the competition - he appeared to run roughshod over the criterion of representativeness that the UNESCO had so painstakingly developed. In other words, France was entering the field of the "heritagization" of culture based on its own idea of heritage. France's idea of heritage was primarily based on its uniqueness and excellence, not at all on typicality or representativeness. ${ }^{266}$

That one ad lib sentence about the best food in the world, repeated over and over, along with the many comments on it that appeared in the press, show the difficulties involved in the application process and its sensitive nature, even though the project's sponsors persisted in the position they had established. It was now February 2008, and it was quickly becoming clear that the application would not be ready by the summer, in time to be presented to UNESCO's intergovernmental committee in 2009. Extra time would be needed in order to work out the contours of the entity the group was proposing so that it would in fact fit the convention's parameters. The project's actors, then, were attempting to adjust the convention's "take." The French state was involved in this on two fronts: As a party, that is, a signatory to the convention, a role that imposed obligations on the state; and as a

\footnotetext{
${ }^{266}$ For an anthropological approach to the debates within the UNESCO on the criteria and on the
} principle of differentiation and classification of the elements of heritage, see Hafstein 2008. 
stakeholder, involved in the construction of a heritage value that would engage the entire nation.

\section{Identification and Purification: From French Food Culture to the "Gastronomic Meal of the French"}

Compiling the application ${ }^{267}$ took fourteen months, from September 2008 to January 2010, which was when the first version of the application dossier was submitted to UNESCO. The first half of 2010 was spent on fine-tuning the file after it had been returned by UNESCO, and the final submission was made in the August of 2010. This phase can primarily be characterized by the way in which it was steered by governmental agencies. The steering was carried out on two levels: The first level was the work done on the nomination dossier, determining the direction it would take, which consisted of inter-ministerial meetings, conducted approximately every month and a half under the auspices of the Ministry of Agriculture and including representatives from the ministries of culture, agriculture, national education, higher education and research, foreign affairs, and later also health and tourism; at these meetings, the MFPCA reported on the progress of the debate. The second level involved setting guidelines and consisted of meetings at the Élysée Palace involving the President's advisers.

\subsection{Purification as Popularization and as Anthropologization}

This phase was also marked by the arrival on the scene of Julia Csergo, a historian specializing in food ${ }^{268}$ who was temporarily liberated from her duties at the University of Lyon (where she was on the faculty) and given the responsibility for the scientific component of the application. Not only did her work as a historical anthropologist provide the necessary scholarly support for the project; she also acted as a purifying agent, in the sense that her input mitigated the very blatant political dimension of the project. In metallurgy, purification is synonymous with enrichment: When a mineral is enriched, the sterile and unproductive parts of it are gotten rid of and the mineral is made productive. To understand how Csergo acted as a purifying agent, it is important to understand the terms of scholarly productivity within an application process that is highly politically charged.

Csergo was not unknown to the network of people involved in the project; she had been involved in the preparatory discussions when the IEHCA was founded and she was a member of its scientific advisory board. She was one of the people

\footnotetext{
267 In 2010, the application had five components: I. Identification and definition of the entity; II. Contribution to visibility and awareness; III. Protective measures and governmental commitment; IV. Participation and consent of the community, groups and individuals concerned; V. Inclusion of the entity in an inventory. (UNESCO 2010)

268 Among other publications, we note Csergo 2001 and Csergo 2004.
} 
on the council who supported the agenda set out by Chevrier, convinced as she was that the UNESCO convention represented a genuine opportunity to gain recognition for food cultures and, indeed, that there was something in the area of food culture to be put forward as representative of a "French essence" and, therefore, to be established as a heritage:

This convention seems totally revolutionary to me: It should help us think of heritage differently, think about social practices, etc. differently, and so we have to seize it. And this applies to food as well, knowing that the attempts that Jack Lang made in the area of food tended to privilege both chefs and products. I tell myself that here we have an extraordinary tool that means that one day we may finally be able to think differently about heritage. (Interview Csergo 2011)

Csergo saw the convention as offering a way to develop her concept of food and eating as a social practice. In short, she was keen to restore the popular dimension of the practice, in both senses of "popular:" Involving all French people and of not being confined to the most often inaccessible realm of haute cuisine. In order to carry out her mission, she surrounded herself with a scientific council which was, one should note, made up of people who did not necessarily share her conviction about the opportunity offered by the convention. She organized or helped to organize working groups and retreats. And most of all, she initiated a qualitative survey on the question of "what does gastronomy mean to you?" specifically for the purpose of emphasizing the popular aspect of gastronomy. ${ }^{269}$ An article in the daily Le Monde, giving the history of the application process, did a very good job of describing the challenge:

Carefully avoiding coming at the issue from the angle of know-how, which would mean it's only about cooks, or of products, which implies business and marketing - which the UNESCO abhors - the historian undertook a series of interviews throughout 2009. She set her students to work on the subject and discovered a wonderful nugget that came from a 67 -year-old grandmother: "Gastronomy belongs to everyone as long as everyone puts in a little bit of themselves." (Ribaut 2010)

\footnotetext{
269 The survey was carried out by students and consisted of interviews with about seventy people who made up a representative sample of French society.
} 
Csergo's objective was to define, or redefine, the entry (the element) being nominated, since the reactions to the presidential announcement had clearly shown how necessary this was. The entry could not consist of gastronomy alone, though the word could and maybe should appear in it. According to Christian Hottin, ${ }^{270}$ the change from "gastronomy" to "the gastronomic meal of the French" happened rather late in the process: He says it was a few months into 2009, at a meeting of experts, organized under the auspices of the UNESCO, on the subject of food cultures. ${ }^{271}$ Since I do not have access to the minutes of all the meetings, it is hard for me to have a precise picture of the trial and error of the process and the progressive adjustments that were made. However, it is safe to assume that the fall and winter of 2008 were a pivotal period. The minutes of the inter-ministerial meeting of November 13, 2008, give us an interesting insight into the issue of what to call the entry: They mention that in her scholarly status update, Csergo emphasized the value of the term "gastronomy," being the "historically constructed cultural expression of a relationship to eating and drinking that is specific to French society." A month earlier, she had also laid out this idea in an article in the daily Libération:

Of course, France is not alone in having a tradition of meals and hospitality (...) Nevertheless, and surely because of this culture of a discourse of food and eating which is characteristic of France and which can, let's admit it, become excessive, gastronomy has historically been constructed as one of the representations of France and its culture. ${ }^{272}$ (Csergo 2008)

However, in order to be consistent with the spirit of the convention, Csergo suggested focusing on the notion of tradition. As a title for the entry, she proposed "France's gastronomic traditions" with the subtitle "Table knowledge, knowhow, and rituals." Referring to gastronomy as a tradition was a way to anchor it historically and to link it with an ethno-anthropological point of view.

This was still not the final title. At the end of March 2009, Csergo made a first official proposal: "The traditions of the gastronomic meal." This proposal was followed by debates refining the proposal and sharpening the various points of view: Should it be "the meal" or indeed "the traditions of the meal?" Should it be called the meal "of the French" or "à la française?"273 In the conversations that fol-

\footnotetext{
${ }^{270}$ Christian Hottin was the head of the Ethnology Commission in the Ministry of Culture at that time and was involved in the process in that capacity.

271 Workshops on food practices, Vitré, France, April 3, 2009. These meetings were mandated by the third session of the Intergovernmental Committee for the Safeguarding of the Intangible Cultural Heritage (Istanbul, November 2008) following a request by Peru, supported by France, "to organize meetings of experts on very specific questions and to begin with a meeting on knowledge about food systems and the practices associated with them" (Oral Report).

${ }^{272}$ Readers will not be surprised to learn that the title of the article ("Patrimoine et pot-au-feu," "Heritage and Stew") comes from the newspaper's editorial staff and not from the author.

273 This last option was championed by the project's sponsors. The debate took on a particular significance because French identity was a favorite theme of the political right in power at that time and a
} 
lowed from my questions and research, Csergo described herself as having been behind the shift in terminology and as having invented the concept of the "gastronomic meal of the French." She acknowledged having introduced a division among the players involved in the application process, a division that she saw as deriving, on the one hand, from her status as a scholar and, on the other, from her "anthropological academic culture." The first, her status as a scholar, is what informed her position and allowed her to maintain a distance which is the basis of the difference between herself and the others; to put it according to a classical topos, she relied on scientific reason, attempting to distance herself from passion and feeling, precisely because such things were what she studied. In the same way, taking a classical position that is reminiscent of the Weberian principle of Wertfreiheit, ${ }^{274}$ she distinguishes herself from researchers who work on food without any critical distance:

My object of study is something I totally distance myself from. That, by the way, is what bothers me very much about the relationship that French researchers have to gastronomy: They don't distance themselves from it and they tend to use elements of a sort of ideology of gastronomic culture. As for me, I try to see it in a totally cool way, to analyze it and to make my analysis objective. (Interview Csergo 2011)275

The second reason for the division, her anthropological academic culture, was what allowed her to define the entity more closely, on the basis of the research that she was overseeing:

I say that what seems to define gastronomy and the place where it is implemented the best is precisely festive meals, celebratory meals, et cetera. Therefore the question is not at all about knowing whether we have the best [cuisine]; it doesn't matter what we're eating. Because at the same time I realize that in France, we no longer have specific well-defined dishes that must be served at particular occasions, aside from the Christmas turkey. Ultimately, we no longer have the kinds of food traditions that can be seen in many other countries, where there are a certain number of holidays that are organized around traditional dishes and rituals. (Interview Csergo 2011)

theme that was on display in the very controversial Ministry of Immigration, Integration, National Identity and Cooperative Development, under whose auspices a grand debate on national identity was being planned, to be held from November 2009 to February 2010 (Csergo 2011: 4).

274 The "non-imposition of values" (non imposition des valeurs), according to Isabelle Kalinowski's translation; see Kalinowski 2005.

275 In the article mentioned above (Csergo 2011), Csergo explicitly repeats this stance, which consists of her putting herself in the position of an observer of "a practice as familiar as gastronomy" "in the same way in which an ethnologist who was discovering the habits and customs of a faraway population would have done it." 
The object of Csergo's research, then, is a cuisine that is de-singularized, inasmuch as it is not connected to specific products or dishes, but singular nevertheless, as the implementation of the social practice of the "shared meal."

It was obvious that this definition involved a break with what had gone before in the nomination project, and the proposal was very badly received by the project's sponsors. It was seen as a significant reduction in what the project covered and as having little to do with its original ambition. "At that point I realized that there was really a disconnect between the thinking of [the two groups]" (Interview Csergo 2011). ${ }^{276}$ And yet the historian's point of view would eventually carry the day, with the Ministry of Foreign Affairs asserting its authority: Political reasoning prevailed, in that France was interested in distinguishing itself not by subverting the convention but rather by respecting it and adhering to its spirit.

\subsection{Compromise}

As a proof of this political realism, we can see the uniqueness and hence, also the difficulty of the French application, in terms of the 2003 Convention and the kind of heritage that it was intended to promote and the rebalancing of North and South for which it aimed. ${ }^{277}$ This was clearly spelled out in a remarkable document, a note dated from this same critical period, namely mid-December 2008, from the French delegation to UNESCO and addressed to the MFPCA and to the ministries involved in the application process. This note explicitly detailed four pitfalls that "must be carefully avoided" if the application was to be successful, "regardless of the designation [of the proposed entity] that is finally agreed on:"

Pitfall number 1: subservience to the economy. "The experts must be convinced that the project is completely free of any commercial or economic angle:" In other words, the agro-food industries and the stakeholders in baute cuisine should not be the beneficiaries of the project and the entity should not be identified either with manufactured products or with the cuisine of restaurant chefs.

Pitfall number 2: too much self-assurance, "an ostentatious approach," or an "overly active marshaling of resources." A low profile is recommended instead, "choosing a relatively modest mode of presentation and discretion about the resources that have been mobilized." In the spirit of the convention, the project should originate from a "grass-roots community" and not from "well-known professional organizations or organizations with substantial resources."

Pitfall number 3: an elitist image, such as that associated with the cuisine of restaurant chefs, which is "famous but not very accessible." Instead, "the popular and familial aspect of gastronomy" should be stressed.

\footnotetext{
276 While Csergo's proposal was taken up by the Ministry of Culture, the Ministry of Agriculture and the MFPCA continued to champion cuisine and specific products (Interview Csergo 2011).

277 See Bortolotto 2008.
} 
Pitfall number 4: a museum-like ossification of the entry into one single tradition. Intangible cultural heritage is a living heritage, and gastronomy, too, should be presented in the image of modern French society, a fusion culture at the intersection of a variety of influences. The theme of cultural diversity should be the guiding principle in the presentation of the application.

A warning against prestigious or too obvious sponsorships, a concern with playing down the fact that the project was supported by the state and started life with the President's blessing; It is clear that there was a desire to change the initial project's direction. Contrary to what the note says (diplomatically), the question of nomenclature was anything but irrelevant. It was clear that the focus on festive meals, celebratory meals and Sunday dinners, seen as both a social and a cultural entity, was going to be the way to avoid the pitfalls that had been laid out. This echoes the conclusions reached by UNESCO experts at the end of the workshops in Vitré in March of 2009, particularly that, even though they are completely eligible to qualify as an intangible cultural heritage, "food practices cannot be reduced to one or more actions or steps of a process, but should, instead, be seen as a structured and complex process that stretches from the acquisition of the raw materials through the act of consumption" (Hottin 2009).

\subsection{Folklore versus Ethnological Heritage}

Does it make any sense to contrast the perspectives of folklore and ethnological heritage? Csergo, the historian, as we have seen, built her position from an anthropological perspective, based not on objects but on practices, and not professional practices but ordinary everyday ones. The original developer of the project, for his part, comes from a more global perspective of protecting gastronomy as culture. That, by the way, is the title of a slim volume that he published in June 2011 laying out his point of view (Chevrier 2011). And in spite of what he says in the book's opening pages, he actually does not retrace - or even refer to, except very superficially - the process that finally led to the inscription of the GMF in the ICH list. What the book does is to celebrate the GMF's inclusion on the list as a cultural recognition of gastronomy. Chevrier explains how he thinks this inscription along with the battle that was led and the resistance that had to be overcome to achieve that recognition should be understood. The first battle was against an elitist conception of culture, which Chevrier calls "Louis-Quatorzian or Jacobin," that the Ministry of Culture brought to the process. According to Chevrier, that ministry had usurped the title and should have been called the "Ministry of Fine Arts." Here was an institution - the Ministry of Culture - that was beholden to powerful corporations which dictated to the ministry the politics it should pursue on matters of cultural activity as well as heritage; and an institution that was jealous of its monopoly "on the enunciation of the principles governing the Beautiful that are worthy of being instilled in the masses" (Chevrier 2011: 98). Set against this double dictate, both institutional and symbolic, what is the message conveyed by the in- 
scription of the GMF on the ICH list? That cuisine, or gastronomy, is a cultural reality that transcends social divisions (it is both scholarly and popular) and political divisions (witness the team that Chevrier formed with Pitte).

Even though Chevrier defends his point of view with implicit references to the contrast between the democratization of culture and a cultural democracy, ${ }^{278}$ what he reflects is a unifying and neutralizing concept of heritage. Csergo, on the other hand, pushed the social aspect of culture, which made her sensitive to practices that were less centered on the actual food than they were on the act of sharing a meal: On tiny, humble, popular practices, on the side of the ordinary. This leaves us with the question: What tradition of celebration of cultural events was each of them drawing on? Let us propose the following hypothesis: Chevrier does not seem to have any prejudices about folklore - that is just another name for intangible cultural heritage and the place for the celebration of a people's culture. Csergo, in contrast, is on the side of ethnological heritage - a scholarly and critical approach to cultural pluralism. This tension can only be understood in the light of the French situation as regards the political treatment of culture and what has happened to those two traditions, one scientifically discredited because it was politically compromised and the other politically devalued because of its scientific distance. ${ }^{279}$ The paradox is that the adjustments to fit the convention were made based on the second tradition, while the politics of ICH could also, or perhaps especially, be read as a form of rehabilitation of folklore. UNESCO, in allowing two traditions, which - in France - are usually seen as irreconcilable, to share the field in this application, has opened the Pandora's box of heritage.

\subsection{What's Bred in the Bone...}

"Cock-a-doodle-doo!" The French press did not fail to comment on or crow over the success of the French entry. Here is a selection of titles (taken from the press reports available on the IEHCA's website): "France Offers Its Gastronomy to Humanity" (La Tribune); "The World Is Envious of Our Meals" (Aujourd'bui en France); "UNESCO Crazy for French Gastronomy" (20 minutes); "Cock-a-doodledoo, Our Great Food Is Classified at UNESCO" (Ouest France); "French Hospitality Is Already Universal" (La Nowvelle République); "UNESCO: Battle of the Chefs' Hats" (L'Express); "The Duty of Heritage. French Gastronomy Enters UNESCO's Heritage. This Coronation Will Give It a New Momentum.” (Le Monde Magazine); "French Hospitality Becomes Part of World Heritage" (Paris Match). Without looking at the articles, which may well have scrupulously reported what part of French heritage it was that received the UNESCO stamp, we can say that the headline the hook, and therefore what the reader would remember - was always something

278 This debate concerned cultural politics which have now more or less died down in France, at least in those terms. About this debate, see Bellavance 2000.

${ }^{279}$ See Tornatore 2004. 
to do with gastronomy and France's excellence in the matter. Csergo (Interview 2011) noted that "the declarations, whether by the commission, the ministry, or whoever, always come back to the same thing: The heritage, the products, the know-how, the AOC [registered designation of origin], the labels, et cetera, until finally you just end up with 'so good so French.' Which also gives one the sense that finally, the French politicians ended up exploiting the UNESCO convention for their own purposes."

It would appear that for the sponsors of the project, the GMF, the "gastronomic meal of the French," was a compromise and a starting point. It represented the vanguard of a reconnaissance mission sent out by France's food culture stating what a "home for gastronomy" - one of the projects listed in the application under the list of measures to which the state has committed itself - would be fully devoted to. Little phrases here and there in Chevrier's activist book suggest that once the application was successful and the label had been obtained, the project quickly reverted to showing its true colors. Along these lines, Pitte writes in the preface to Chevrier's book:

The main thing is the satisfaction displayed by the government, local representatives and elected officials, and professionals in the agri-food sector, in the restaurant business, in tourism, all the organizations that promote our food culture, and finally all the anonymous French people who see in this a happy recognition of this cherished part of their identity. (Pitte in Chevrier 2001: 7)

And Chevrier, evoking the "home for gastronomy":

A project like this could never be launched without a strong political will and leadership. The state, and also local and, especially, regional authorities need to feel invested in this showcase for French excellence. Of course, the food sector and industry are expected to support such an initiative, which is also designed to emphasize their vitality and to show off the quality of their technique and know-how to the world. (Chevrier 2001: 145)

Of course, once one has started down that shining path of "French excellence," it is only a question of which of the many wayside stands to stop at: The next one, according to the people I talked to, would be... wine. Or more precisely, because it is once again in the context of a new application for a UNESCO label: "grapes and wine." To be continued... 


\section{The French, Good Food and Heritage}

However, the inscription on the UNESCO list is not, or not only, incidental. We have to think of the GMF as recognition of French food culture: What began as an adjustment to fit the dictates of the UNESCO apparatus then became its own project. We can see that the remarks quoted above, like the book itself, have an internal function: They are intended to maintain the generated momentum. Similar to any other association of diverse parts, the one that propelled the French application to success depended on a delicate balance. This one relied on the French state and it still depends on its ability and resolve to fulfill the commitments implied in the application. Nevertheless, at the same time we should not overestimate the importance of the state's support, because we must recognize that the balance has now become less fragile if we look at the results of the inscription. After the montage that is the "gastronomic meal of the French" made the inscription, now it is the inscription that makes the montage. The story I have just told is the process of association on which the success of the application depended. The montage could still fall apart; it could still be denounced; but it is stronger now than it was, if only because the "gastronomic meal of the French" has become an entity in itself, distinctive and singular. It has its own website; 280 it is also, now, a brand - "gastronomic meal of the French: heritage of humanity" - which can be bestowed on any given project or initiative. ${ }^{281}$ This is, all in all, a very logical setup, and one which is very well accounted for by "translation vocabulary" (Callon 1986). The project's sponsors were able to "interest" the state in the project; the state saw "its" interest in it through a President interested in securing the support of farmers and in asserting the image of a "protector state" guarding against the negative effects of globalization; this interest, in turn, came at the price of a transformation in the targeted entity; it was then on behalf of that entity that people mobilized, and the resulting entity was the gastronomic meal of the French. We should not be surprised, therefore, to see that the author of the site - the MFPCA, as it happens plays along with the rules of the UNESCO inscription perfectly, in carefully laying out not only what the GMF is, but also what the application for the GMF was not. 282

\footnotetext{
280 According to the site's home page, it was created in 2011, a year after the UNESCO label was awarded; see Le repas gastronomique des Français 2011.

281 The brand can be bestowed on "initiatives - exhibits, conferences, educational programs, fairs, festivals, meetings, shows, and so on - that enhance the value of the 'gastronomic meal of the French' and increase the likelihood of it being carried on in future generations." A commission made up of representatives of the state and of the MFPCA (which reviews the application portfolios) decides which groups will be licensed to use the name; see Mission Française du Patrimoine et des Cultures Alimentaires (n.d.).

282 Namely, a recognition of recipes, of "product-specific signs of quality," "the attribution of a label with commercial value," "the celebration of an elitist practice of haute cuisine," "an award for the entirety of French food culture," or "a desire to appear at the top of the list of the best cuisines."
} 
In thinking about the effects of the inscription of the GMF on the UNESCO list, we should also consider the interests of some of the other parties involved, especially those of the clubs and associations in every corner of the country which celebrate various aspects of gastronomic culture. A significant number of these groups are represented in the "proofs of the community's free, prior and informed consent to the application." So here we have "the French" (at least 95\% of them) by way of their (self-)established agents. Let us suspend, at least for the moment, the social and feminist critique that would see the GMF as an expression of "a 'middle-class' or even squarely bourgeois version of French nationalism" (Hertz 2011: 229). We can say, then, that it is a safe bet that the vast majority of "the French" see themselves reflected in the prestigious distinction bestowed by this inscription: The GMF is something in which people recognize themselves; something they are part of; at the worst, maybe, they smile at this "cherished facet of our identity." What does this gastronomic meal of the French do to or for the French? A bit of collective recognition on the international stage cannot hurt. Indeed, there is a twofold benefit. France is the home of good food, joyful feasts with family and friends, and hospitality. We are experts at this. Our food is our heritage. However, in identifying this particular heritage as belonging to France's national community, does not the UNESCO inscription make France into a homeland of heritage itself? Because who, indeed, besides France and the French, could build heritage into a transcendent way of life?

\section{$7 \quad$ References}

Bellavance, Guy, Micheline Boivin, and Lise Santerre, eds. (2000): Démocratisation de la culture ou démocratie culturelle? Deux logiques d'action publique. Éditions de l'IQRC, Québec: Presses de l'Université Laval.

Bessy, Christian, and Francis Chateauraynaud (1995): Experts et faussaires. Pour une sociologie de la perception. Paris: Métailié.

Bortolotto, Chiara, ed. (2008): Il patrimonio immateriale secondo l'UNESCO: analisi e prospettive. Rome: Istituto poligrafico e Zecca dello Stato.

Callon, Michel (1986): Éléments pour une sociologie de la traduction: la domestication des coquilles Saint-Jacques et des marins-pêcheurs dans la baie de Saint-Brieuc. L'Année sociologique 36: 169-208.

Chevrier, Francis (2011): Notre gastronomie est une culture. Paris: François Bourin.

CREDOC (2009): Baromètre de la perception de l'alimentation. Baromètre 4. Étude réalisée pour le Ministère de l'Agriculture et de la Pêche. http://alimentation.gouv.fr/IMG/pdf/baromalim09pres-2_cle0d3a61.pdf $<$ accessed May 23, 2012>

Csergo, Julia, ed. (2001): Casse-croûte. Paris: Autrement. 
- ed. (2004): Histoire de l'alimentation. Quels enjeux pour la formation? Dijon:

Educagri.

- (2008): Patrimoine et pot-au-feu. Libération, October 10, 2008.

http://www.liberation.fr/vous/0101123337-patrimoine-et-pot-au-feu <accessed July 12, 2012>

- (2011): Le 'repas gastronomique des français' à l'Unesco: éléments d'une inscription au patrimoine culturel immatériel de l'humanité.

http://www.lemangeur-ocha.com/wp-content/uploads/2012/04/CSERGO-

repas-gastronomique-francais-patrimoine-unesco2.pdf

$<$ accessed July 12, 2012>

Deleuze, Gilles (1990): Post-scriptum sur les sociétés de contrôle. In Pourparlers 1972-1990. Gilles Deleuze, ed. Pp. 240-247. Paris: Éditions de Minuit.

Deleuze, Gilles, and Félix Guattari (1980): Mille plateaux. Capitalisme et schizophrénie, 2. Paris: Éditions de Minuit.

Fabre, Daniel (1997): Le patrimoine, l'ethnologie. In Science et conscience du patrimoine: actes des Entretiens du Patrimoine. Pierre Nora, ed. Pp. 59-72. Paris: Fayard - Éditions du Patrimoine.

Hafstein, Valdimar T. (2007): Sauvegarde du patrimoine immatériel et gouvernance communautaire. In 60 ans d'histoire de l'Unesco, Actes du colloque international, Paris, 16-18 novembre 2005. Jens Boel, ed. Pp. 337-348. Paris: Maison de l'Unesco.

- (2008): Inviting a Noisy Dance-Band into a Hospital: Listing the Intangible. In Il patrimonio immateriale secondo l'UNESCO: analisi e prospettive. Chiara Bortolotto, ed. Pp. 95-113. Rome: Istituto poligrafico e Zecca dello Stato.

- (2011): Célébrer les différences, renforcer la conformité. In Le patrimoine culturel immatériel. Enjeu d'une nouvelle catégorie. Chiara Bortolotto, ed. Pp. 75-97. Paris: MSH.

Hertz, Ellen (2011): On ne nait pas 'femme cuisinière', on le devient. Genre et transmission culturelle à l'Unesco. In Transmettre, quels(s) patrimoine(s). Autour du patrimoine culturel immatériel. Nicholas Adell and Yves Pourcher, eds. Pp. 223-238. Paris: Michel Houdiard Éditeur.

Hottin, Christian (2009): Compte-rendu des journées de Vitré sur les pratiques alimentaires. 3 avril 2009.

http://www.iiac.cnrs.fr/lahic/ateliers-et-ressources/atelier-patrimoineculturel/article/pci-chronique-scientifique-et. < accessed May 23, 2012>

IEHCA (n.d.): IEHCA - an introduction.

http://www.iehca.eu/IEHCA_v4/pdf/IEHCA_introduction.pdf < accessed May 29, 2012>

Institut du Gout (2005): Bienvenue.

http:/ /www.institutdugout.fr/index.htm < accessed May 29, 2012>.

Joutard, Phillip (2000[1993]): Une passion française: l'histoire. In Histoire de la

France. Choix culturels et mémoire. André Burguière, ed. Pp. 301-394. Paris:

Éditions du Seuil. 
Kalinowski, Isabelle (2005): Leçon wébériennes sur la science et la propagande. Precedes La science, profession et vocation. Max Weber. Marseille: Agone. MFPCA (2011): Mission Française du Patrimoine \& des Cultures Alimentaires. http://www.repasgastronomiquedesfrancais.org/mission-francaise-dupatrimoine-des-cultures-alimentaires / < accessed July 12, 2012>.

Mission Française du Patrimoine et des Cultures Alimentaires (n.d.): Conditions d'attribution et d'utilisation de l'emblème "repas gastronomique des Français Patrimoine de l'humanité".

http://www.repasgastronomiquedesfrancais.org/pdf/conditionsdatribution.pd $\mathrm{f}<$ accessed April 19, 2012>

Pitte, Jean-Robert (1991): Gastronomie française. Histoire et géographie d'une passion. Paris: Fayard.

Rautenberg, Michel (2003): L'intervention ethnologique. Témoignage et éléments de réflexion sur les relations entre recherche et action culturelle dans une direction régionale des affaires culturelles. In Pour une histoire des politiques du patrimoine. Philippe Poirrier and Loïc Vadelorge, eds. Pp. 469-489. Paris: Comité d'histoire du ministère de la culture, Fondation maison des sciences de l'homme.

Le repas gastronomique des Français (2011): Edito. http://www.repasgastronomiquedesfrancais.org/ < accessed April 19, 2012>

Ribaut, Jean-Claude (2010): La bonne chère, un art reconnu et désormais protégé. Le Monde, November 17, 2010.

Saillant, Francine, Mondher Kilani, and Florence Graezer Bideau, eds. (2011):

Manifeste de Lausanne. Pour une anthropologie non hégémonique. Montréal: Liber.

Sarkozy, Nicolas (2008): Inauguration du 45ème Salon de l'Agriculture.

http://www.elysee.fr/president/root/plugins/player/VideoPlayer.swf?config =http://www.elysee.fr/president $/$ root $/$ items $/ \mathrm{xml} /$ player.69.xml\&itemid=142 34\&menuOnOutside $=$ false $<$ accessed May 31, 2012>

Thiesse, Anne-Marie (1999): La création des identités nationale. Europe 18e-20e siècle. Paris: Éditions du Seuil.

Tornatore, Jean-Louis (2004): La difficile politisation du patrimoine ethnologique. Terrain 42: 149-160.

- (2011): Du patrimoine ethnologique au patrimoine culturel immatériel: suivre la voie politique de l'immatérialité culturelle. In Le patrimoine culturel immatériel. Enjeu d'une nouvelle catégorie. Chiara Bortolotto, ed. Pp. 213232. Paris: MSH.

UNESCO (2010): Gastronomic meal of the French.

http://www.unesco.org/culture/ich/index.php?RL=00437 < accessed May 31, 2012> 

Closing Commentaries 



\title{
Sand, Stability and Stakeholders
}

\author{
Donald L. Brenneis
}

Two images remain vividly in my mind when I think about the June 2011 conference that has led to this volume. Both figured in Ullrich Kockel's presentation of the dual Lithuanian-Russian administration of the Curonian Spit, a 98-kilometerlong sand spit, shaped in a large part by human interventions over the decades, separating a very large lagoon from the Baltic Sea. The first image can be seen here in his article: A chart of "stakeholders" - governmental, environmental, private, commercial - with interests in policy and practice on and around the spit. Schematic, formal, economically laid out, yet clearly reflecting a dauntingly intertwined set of not always compatible interests and values, it gives a strong sense of a complex system caught in time. The other image, one not appearing in this book, was a photograph of a portion of the beach; one in which the constantly shifting sands subject to wind, water and human activity - and the ongoing sand fences and other attempts to stabilize a constantly shifting landscape were dramatically evident. These images suggest two somewhat polar visions of the contemporary heritage scene. There are, on the one hand, the formal, somewhat static, institutional arrangements intended to capture and preserve the characteristics of many of the regimes considered here. On the other, the valued places, practices and products towards whose protection they are directed; elements that are always subject to transformation, innovation and re-evaluation. I was struck by the analogy between the papers here and that latter image, that is, a complex system of attempted control, definition and stability facing - and trying to preserve - a landscape always, except when fictionalized as static, in motion. 
The editors have invited me to highlight some of the recurrent themes directly addressed or indexed in these papers. This is not a formal commentary but, rather, a quite impressionistic rendering of some of the issues the authors bring to the table with élan, acuity and a strong sense of ethnographic texture. Each of these articles charts the complex intersections of the remarkable and the mundane, that is, of places, activities and types of knowledge that draw their value from their exemplary and singular qualities, and of the bureaucratic practices and institutions that frame, denominate and attempt to preserve them. Weber identified the routinization of charisma as a key issue for social analysis. These remarkable reports speak to a particular version of this question; heritage designation and preservation consistently bring the charismatic and the quotidian together. Each author provides a vivid and necessarily multisited ethnographic account of these intersections, and they do not tell a single or homogeneous story. Instead, we get a strong sense not only of themes and variations across cases, but also of the, at times, surprising transformations of the routine when trying to manage the remarkable.

I want to highlight five general themes that emerge from these essays. The first has to do with the crucial ways in which time, place, and time as somehow embodied in place figure in many of the cases. As one example, many of the sites that figure here lie on the margins. In some cases, again as with the Curonian spit, they lie literally at an ecotone, that is, a location where two ecological zones come together. Sometimes such ecotones are characterized by mixed assemblages - a bit of this, a bit of that - but they are also known among academic ecologists as zones in which more than the usual number of ideal types emerge; difference is most clearly marked not in the center but along the edges. Other ecotones are perhaps more analogical. The thought-provoking cluster of arguments Tornatore makes here about relationships between deterritorialization and the rise of ICH provide one instance. Similarly, Tauschek's essay charts the contact zones between different administrative circles, ones that rely on distinctive institutional logics, the intersection of which lead to, at times, unexpected outcomes. There is a longstanding argument in US history that the federal government was in many ways made on the western frontier. The edge required ordering in ways that the accustomed did not; it also afforded the possibility.

Time also figures centrally: Cyclical time (calendrical and otherwise), linear, irreversible and pivotal, that is, those moments in which things change irreversibly. Here, Leblon's paper is exemplary. The "cultural space of the yaaral and the degal" is defined by particular conjunctions of place and cyclical time, in this instance, linked to the transhumant movements of Fulbe pastoralists in Mali. These annual moments in situ are marked by a range of celebratory and competitive activities (to which the Fulbe people and UNESCO experts bring quite different perspectives). What is key here, however, is that these events provide something along the lines of repeatable chronotopes of a non-narrative sort, particularly resonant moments in particular places. Fournier's paper similarly highlights the seasonality of big head and dragon processions, even as the designated events themselves have shifted 
from local tradition to the larger audiences for tourist entertainment. Pichler's essay highlights time in another way, not in relation to annual cycles but in the attempt to restore "Havana vieja" in ways that bring some aspects of a complex past into an equally complex present. Finally, to turn to a place decidedly on the edge, NicCraith's exploration of Skellig Michael raises questions of telescoped time. The erasure of decades of lighthouse keepers in the interests of the older narrative of monastic life speaks effectively about where a tourist - as opposed to local - audience's sense of value lies.

A second recurrent theme is, to use Leblon's term, the "arena." Her study focuses both on the arenas provided by the two calendrical gatherings and the arenas that figure centrally in the heritagization process itself. For Fulbe participants, the yaaral and degal have long provided opportunities for intense sociality, esthetic competition and the focused and often highly performative negotiation of crucial political and ecological relationships. Similarly, both here and in many of the other cases considered here, the UNESCO processes depend on various arenas: for consultation, expert research, negotiation, and arbitration (to use Kuutma's term). As in the Fulbe gatherings, the outcomes of activities in these bureaucratic arenas are not guaranteed. The interaction is often rather tentative and subject to ongoing reworking. Kuutma provides a convincing general account of the structures and contradictions of institutional actors. Bureaucracies may be mundane, but they are often far from internally homogeneous and are working both with and against rival institutions. Swiss federalism provides a particularly rich context in which to think about such complex terrain, and Graezer Bideau's essay is an incisive account of the national nomination and designation process. She tracks potential nominees through different sites, with multiple audiences, and through a range of communicative processes, both face-to-face and highly mediated. This rich account raises broader questions of voice (who are the stakeholders, who has standing, what parties are in a position to make expert claims?) and of audience (who are the imagined targets of particular claims, who can make decisions and who will benefit from the designations?).

There is a parallel between the notion of arena here and the linguistic anthropological idea of the communicative event. These bureaucratic events, or, more properly, sequences of often quite distinct events over time, provide multiple arenas for consultation, contestation and, occasionally, agreement. One key point is that, as with the different kinds of political events on which anthropologists have focused, such heritage arenas are, at times, consequential for their outcomes; they move to particular kinds of closure as to policy and practice. Nevertheless, meetings of whatever sort are not always about decision-making, and their work often lies in the kinds of mutual engagement they make possible, even without clear-cut outcomes. New kinds of social relations and new institutional interactions emerge over the course of even ostensibly failed processes - and are often more consequential than a decision itself might be. Finally, the notion of arena points to the intense sociality of such events. An arena can provide opportunities for the emer- 
gence of differentiation, co-identification, alliance-building, and multiple other political outcomes. This is particularly striking in three essays. Graezer Bideau's article points to the "re-enactment" of federalism in the current Swiss consideration. Almost independent of outcomes, the process itself models participation in a quite particular polity. Cardeira da Silva's characterization of the "cosmopolitanism" emerging in the context of collaborative efforts to pursue status for Portuguese forts in Africa points to new alliances still in process and, again, not necessarily dependent on a final determination for their value. The networks of giglibuilding communities documented by Ballachino provide a similar example of emergent social linkages.

Closely linked to such arenas are the forms and technologies - oral, documentary, software-based, legal, regulatory - that figure centrally, if at times almost invisibly, in research, recognition and representation. In some ways the whole process is one of qualifying for inscription. Along the way, however, questions of translation (both across languages and between registers), classification, and the affordances and constraints, at times unrecognized, attendant on different forms and processes make a major difference. Given the emphasis on the singularity of the phenomena to be inscribed and protected, their exceptional qualities, the question of how institutions develop frameworks for comparison and commensuration is particularly salient: How does one fit the unique into such a framework?

Many of these essays address these formal dimensions. Bodolec's examination of the key role of translation - and of the transformations, in part linguistic, in part political, central to the heritage process in China - is especially rich. Particularly striking in the Chinese case is the de novo introduction of "excellence" as a criterion, moving a previously unarticulated variable into the center of the national evaluative process. France provides a further case, where the delicate balance of intracultural universalism and the kinds of special character required for designation is a major theme in the papers of Fournier and Bortolotto. The translation of potential eligibility across the national and transnational contexts poses real challenges. Tornatore's account of the designation process for the "French gastronomic meal" provides a particularly incisive and elegantly documented case, highlighting both the key role of ethnological data and the widespread, far from specified nature of the "meal" itself in making the designation possible. A final formal aspect of the inscription process has to do with the question of proxies. Given the complexity of cultural phenomena, what is taken - at various levels and by various actors - as standing for, or standing in for, culture? Proxies are a kind of synechdoche, that is, a part of a much more complex entity standing for the whole. Here again, Leblon's essay provides a thought-provoking example with what she terms "spectacular nomadism" and those events in which it is particularly evident and framed by elaborate performances being taken as a synechdoche for Fulbe nomadic life as a whole. This process effaces other aspects of Fulbe society and survival, for example, climate change and the restriction of herding range, that are more salient for the Fulbe themselves. As many of these essays demonstrate, the kinds of transla- 
tion central to the nomination and inscription process are almost unavoidably reductive: The practice, knowledge, landscape, building, or other phenomena under investigation can rarely speak adequately of and for the broader contextual complexities within which they figure.

A further theme infused throughout these essays is knowledge: The kinds of assumedly traditional knowledge central to intangible cultural heritage, the specialized knowledge of those disciplines involved in the discovery, research and inscription process, and the bureaucratic and political savvy of those who mediate the local, the scholarly and the regulatory. Key terms here are "expert" and "expertise." The papers point to multiple bodies of knowledge at play in the various arenas they depict, and it is clear that the recruitment, socialization and social capital of different kinds of expert play out quite differently. It is clear, however, that, in comparison to otherwise comparable regimes, there is less of an a priori assumption of the value of one kind of knowledge (usually transnational and universalizing) over another (usually the local knowledge that is crucial for "heritage" itself); knowledge itself is often up for negotiation. This suggests some interesting comparisons with other emergent transnational regimes; those institutions and practices linked to universal human rights, for example, afford less room for maneuver. Here again, questions of heritage bring the universal and the particular into complex and often unpredictable conversation. As a scholar based in the United States, I was also struck by the omnipresence of experts, of all sorts, in these accounts. "Expert" is clearly a category that works differently in EU and UN discourse than in the US, where "Experts" constitute a less immediately recognized category of actors, and where they are regarded, perhaps, with greater suspicion.

Finally, all these essays illuminate the centrality of value in the heritage process. Value is quite differently construed across the cases, and across different participants in each case: Is it financial (and linked to broader market contexts), a reflex of broader human rights, a source of identification and shared engagement, or affective, a source of pleasurable or otherwise intense experience? Scher's account of Barbados provides a particularly striking case, one in which the value of historical recognition is at most ambivalent, and often negative. Sanchez-Carretero's discussion of the Camino del Santiago lays out a complex array of motives and values at play. Clearly, however, the local view is decidedly of tourists as a "monocrop," whatever complicated aspirations might bring the tourists themselves to the Camino. The UNESCO-supported initiative for Uzbek textiles documented by Mentges also reveals a complex intersection of money, elite consolidation, nationbuilding, and the celebration of local knowledge.

In closing, I want to return to the two images in Kockel's presentation. One striking theme evident in all these essays is that it is not only "tradition" or "heritage" that is shifting and difficult to capture in a fixed moment. The multiple agencies involved in the inscription process are themselves in motion. For a range of reasons - among them the plethora of stakeholders, the range of knowledge and experts at play, and the ongoing tension between universalist values that sustain 
such programs and the extraordinary, singular, and particular practices and places that define their goals - these bureaucracies are shaped by contingency and consultation in ways that many institutions are not. Thinking with and through these essays illuminates not only the complex terrain of culture, tradition and their modern making, but also the ways in which institutional regimes are themselves under ongoing negotiation. We are all in many ways out on the shifting sands. This volume is invaluable in helping us to better know the territory and its continuing transformations. 


\title{
Managing Cultural Heritage as Neoliberal Governmentality
}

\author{
Rosemary J. Coombe
}

Critical cultural heritage scholarship is thriving, as the papers in this section of the volume clearly illustrate. They ethnographically explore the impact of fundamental changes in the understanding and management of "cultural heritage" as a category of legal, political and governmental significance. Areas of consensus and new forms of contestation are emerging in both the scholarship and practice of cultural heritage resource management, as new norms of heritage management and forms of valuation are interpreted and applied. The authors highlight the socially generative nature of the changing practices of heritage protection and the new objectifications, subjectivities, technologies, expertise, struggles, and vitalities that these new configurations of power and knowledge have energized and put into play.

In critical scholarship and practice, as well as within the institution of UNESCO itself, we have witnessed a rejection of the hegemony of "monumental heritage," a term that Laurajane Smith uses to describe the 19th-century European discourse of heritage that privileged the pastoral care of material artifacts as witnesses to history and works of art that reflected universal aesthetic values (Smith 2004, 2006). This dominant understanding of heritage was closely tied to a preoccupation with material forms of national patrimony as the privileged expression of the modern nation-state. Over two and half decades, governments in the global south, heritage scholars and practitioners, and ultimately international policy makers have undermined this dominant vision, emphasizing instead that the very concept of heritage demands greater attention to a wider range of manifestations of human life that more fully reflect the multiple forms in which communities vest significance. Although the World Heritage Convention stressed the concept of "the shared heritage" of humanity through its central focus on the concept of the 
"universal value" of heritage, it was routinely criticized for legitimizing a particular Western - if not Western European - perception of heritage both in policy and in practice. It was seen as Eurocentric both in its vision and its composition and unappreciative of the different manifestations and practices of heritage in Asian, African, South American and indigenous societies. From a greater understanding of the cultural values embedded in landscapes to a finer appreciation of intangible goods, such as ritual, ceremony, poetry, proverbs, foodways, dance, and song, cultural heritage is increasingly addressed not simply as static forms in need of preservation, but as dynamic resources that are both constitutive of identity and the basis for sustainable development projected into distinctive futures (Loulanski 2006). Nonetheless, ascertaining the best means for governing cultural heritage under this new set of premises has posed considerable challenges.

One significant set of challenges pertains to heightened controversies over the appropriate custodians of cultural heritage under international regimes in which states continue to be the dominant agents tasked with responsibilities, but human rights-inflected policies increasingly demand greater participation by minorities and indigenous peoples. States are required to maintain inventories of sites suitable for inclusion in a Tentative List of possible nominations for UNESCO status under the various Conventions, and for many years, have been encouraged to prepare these lists with the participation of a wide variety of stakeholders, including site managers, local and regional governments, local communities, nongovernmental organizations (NGOs), and other interested parties and partners. Simultaneously, states are subject to neoliberal pressures to decentralize control over cultural institutions and build new partnerships with private sector actors. The political shifts this is likely to auger may well set in force new challenges to national histories and new disputes about the proper holders of cultural distinctions, as well as tense negotiations over the reifications and objectifications, constructions and artifacts that best exemplify significance for non-national human collectivities (Breglia 2006). The international movement to recognize and valorize "the intangible cultural heritage" $(\mathrm{ICH})$ intensifies these processes by further localizing them and demanding "community" participation in activities that both underline the need for its international protection while "safeguarding" the specific values that such heritage has for communities that may be more fully constituted in the process.

If, as a matter of international law, states still have the primary obligations, the Convention for the Protection of the Intangible Cultural Heritage is structured so as to encourage state safeguarding activities primarily by raising awareness of $\mathrm{ICH}$ in communities and to actively encourage community involvement in implementation. Recognizing that global economic and cultural forces may be one of the threats to distinctive ICH held at the local level, communities and groups are ideally to be empowered and capacitated to maintain ICH as the source of their own identities (Blake 2009: 47). 
Nonetheless, there is plenty of evidence that the nature of community participation was a matter of great controversy during the Convention's negotiation by the Intergovernmental Committee. Certainly both experts and state parties were divided between those giving practitioner communities responsibilities and rights, while enabling them to exercise these, and those prioritizing state control and favoring only weak exhortations to encourage states to engage communities. Although the ultimate priority given to the involvement of communities and civil society is evident, the appropriate mechanisms to achieve this without state initiative are unclear. Indeed, the principle of community participation was difficult to implement even in negotiations. In more than ten governmental and non-governmental meetings, only two appear to have benefited from anything that might remotely be called the "active participation" of "representatives of communities and practitioners" (Coombe and Turcotte 2012: 293).

According to UNESCO insiders, the addition of the category of cultural landscape to the World Heritage List in 1992 was crucial for legitimating the heritage of local communities and indigenous peoples (Rossler 2006) that later became formalized in the ICH Convention and that has arguably spread as a norm of customary international law into international heritage protection policy more generally. Cultural landscapes, whether designed and created intentionally by humans, organically evolved as the result of human imperatives, or by recognizing the cultural values that natural areas hold as "associative cultural values" embedded in a people's spirituality, traditions and practices, this new category of inscription on the World Heritage List provided new opportunities for what became known under Article 8 (j) of the Convention on Biological Diversity as "traditional communities embodying traditional lifestyles relevant to the preservation of biological diversity." Indigenous peoples protected sacred sites and sacred groves long before nature reserves and protected conservation areas were established, and their practices were recognized as significant in protecting biological diversity following the Rio Earth Summit.

Such values travel between United Nations' institutions which are encouraged to find synergies. In 1998 UNESCO's Operational Guidelines were changed to allow for the inclusion of a "traditionally" managed natural site - East Rennell (Solomon Islands) - to be inscribed on the World Heritage List. Due to trends in international environmental policy and an increased global emphasis on indigenous rights, the involvement of local or 'traditional' communities in nomination processes was considered ever more desirable. In 2005, the Operational Guidelines for World Heritage sites formally encouraged community involvement. New governance structures combining community resource management systems and traditional national park management were envisioned involving multiple stakeholders 
while supporting community employment through national institutional support.

Using cultural heritage management to engineer social change from below not surprisingly entails the use of more abstract normative criteria and more "objective" evaluation practices, including new measures for ascertaining "impact" and doing "cost-benefit" analyses, all of which have effects on local social and political relations as peoples subject themselves to new forms of governance and embrace new forms of reflexivity with respect to their activities. Certainly many of these new accountings are quite alien to the kinds of practices that may be "safeguarded" under such programs, which are those that anthropologists conventionally studied in situ. This, as Laurent Fournier suggested at our original conference, pushes anthropologists studying these processes into research terrains that seem more akin to those of administrative sociology or institutional economics, where many of us are less than fully comfortable. As anthropologists, however, we have many skills at the ready to analyze these processes if we are prepared to explore heritage regimes as new regimes of power based on socially generative forms of neoliberal governmentality. Let us take each of these concepts - neoliberalism and governmentality - in turn.

Heritage regimes are increasingly neoliberal in obvious and not so obvious ways. Certainly we are witnessing a new dominance of market ideologies in heritage management and in its means of "valuation" with an increasing emphasis on investment in cultural resources and human capital so as to yield economic returns, adding value to them so as to encourage tourism, foster foreign direct investment, encourage product differentiation, and promote new commodifications of "cultural resources" (Yudice 2003), often through new uses of intellectual property vehicles (Coombe et al. 2007, Coombe and Aylwin 2011). Such discourses and practices of valuation are linked in important ways, not to a "withdrawal of the state" as neoliberalism is often popularly understood, but to a new decentralization and distribution of governmental powers. Instead of any simple abandonment of heritage management to "local authorities", we witness a devolution of authority to new agencies and coalitions of agencies, joint partnerships, public-private alliances, global-local or multi-scalar assemblages of NGOs, international authorities, and transnational agencies, as Keiko Miura (2011) so well illustrates with respect to the protection and safeguarding of the Angkor World Heritage site in Cambodia. Closer to home, Fournier (this volume) indicates some of the ironic consequences of French governmental decentralization for the project of recognizing ICH in a context in which the universalist values of the monumentalist heritage discourse still dominate amongst national policy experts, but the field of relevant interlocutors has expanded to include anthropologists, NGOs and those who occupy the newly minted subject position of "local practitioner."

This transformation and proliferation of relevant fields of influence and decision-making in heritage policy work make simple state-society dichotomies difficult to maintain, as Dong Wang in her presentation at our 2011 conference suggested (see also Wang 2010). Examining heritage governance of the Buddhist 
Longmen Grottoes in Luoyang, a World Heritage Site in Henan Province, Wang showed us how government in the locality was constituted synergistically through international policy, national legislation, local rules, and market needs in which no particular source of power appeared to be privileged. UNESCO requirements subject both public and private entities alike in distinct ways while legitimating a larger scope of autonomy for the municipality than would otherwise be permitted in the authoritarian state. Nonetheless, she suggested, local civil society appreciation for this heritage is often expressed as a matter of national prestige and pride. Indeed, the interpenetration of civil society, state and market forces she showed us exemplified in China may increasingly be more the norm in this field than anthropologists have thus far acknowledged. Maria Cardeira Da Silva (this volume) appropriately advises us to be aware of the horizontal and transversal relations between states and other organizations in this field of transnational governance, where state agency itself may often reflect various forms of cosmopolitan energies and ideologies. Ullrich Kockel (this volume) goes further still, asserting that the political category of "the state" can refer to any one of a number of levels of governance or a combination thereof represented by the coordinated activity of stakeholders from different sectors assisted by various so-called NGOs.

We need to understand neoliberal governmental intervention as assemblages, anthropologist Tania Li (2007a, 2007b) suggests -- a concept which helps to break down the image of government as the preserve of a monolithic state operating as a singular source of power and enables us to recognize the range of parties involved in attempts to regulate "the conditions under which lives are lived" (2007a: 25). Indeed, the concept of assemblages, abstractable, mobile and dynamic forms that move across and reconstitute society, culture and economy, has become crucial to the ways in which anthropologists have ethnographically studied globalization (Ong and Collier 2005) as a process under construction (Perry and Maurer 2003). While neoliberalism has spread across the globe, it has done so unevenly and inconsistently (Kingfisher and Maskovsky 2008). If neoliberal governmentality has fundamentally shaped "cultural realms in the production and affirmation of diversity through the commodification of difference" (Perreault and Martin 2005: 193), its mandates are interpreted and reworked by the subjects it enables, who may subvert the opportunities it affords for new purposes (Bondi and Laurie 2005). It has been suggested that neoliberalism as an analytic category is best approached as an assemblage of technologies, techniques and practices that are selectively appropriated, come into uncomfortable encounters with "local" politics and cultural understandings, and are mobile and connective rather than global in any universalizing fashion (Clarke 2008). As I have suggested elsewhere, they frequently come up against rights-based struggles (Coombe 2007, 2011a, 2011b).

As Adelheid Pichler (this volume) shows in her study of the reconstruction of Havana, we are witnessing the emergence of newly globalized local policy assemblages or governance structures which are subject to different forms of accountability than those expected of state governments. We need to consider these assem- 
blages as particular conjunctures - as so many of the papers in this volume do the intersection of multiple legal, economic, political, and policy forces and interests on many scales. The social benefits now deemed to accrue from cultural resource management in Havana, Pichler illustrates, serve to attract international cofinancing and NGO participation, as well as the energies of local officials and elites, while the expectation of profit attracts new venture capital. Significantly, she shows how the opportunity structures and even the predictable means by which cultural distinction is made legible and publicly "staged" for calculable forms of consumption may be appropriated by actors with alternative agendas. UNESCO interest in ICH clearly influenced the Cuban government to permit long suppressed Afro-Cuban religious groups to assume visibility in the public sphere as an instance of cultural diversity that served the needs of heritage tourism. By adopting the distinctive white dress of initiates into Afro-Cuban religions, female relatives and supporters of jailed dissidents use the markers of formerly oppressed religious groups to mark the continuing heritage of oppressing political dissent and denying freedom of expression. Thus they put these new governance strategies to work as human rights resources.

Heritage resource management, like other forms of neoliberal governmentality, legitimizes new relations of power and knowledge as it creates new subject positions for individuals and social groups, while fostering the articulation of collective subjectivities holding possessive relationships to culture. As many of the papers in this volume illustrate, the process involves practices of interpellation and pedagogy. Christina Sanchez-Carretero (this volume) shows how inclusion of the Camino de Santiago as a World Heritage Site "cultural itinerary" and the nomination process by which the Caminos del Norte are now applying for inclusion has shaped official Galician understandings of appropriate forms of community identity. The sites appear to have the necessary cultural significance to the Christian pilgrims and others who historically traversed these routes in religiously meaningful itineraries and to their descendants. In other words, although no particular significance to local communities needed to be demonstrated for the sites' inclusion as an example of world heritage, desires for local identification with the site are nonetheless fostered.

It appears that the increasing emphasis by UNESCO on community heritage values has influenced authorities in the area to adopt the localized politics of identity that constitutes an emergent norm in global heritage work. According to local officials, residents of Olveiroa must be made to participate in the construction and maintenance of "their heritage" and society must be activated as an integral part of the territory. People, in other words, need to be remade or revitalized so as to feel attached to the site as a recuperation of their heritage. How, exactly, this interpellation of Olveiroans as proud possessors of their heritage is to be accomplished is not made clear, but the official desire for them to constitute their identity with relationship to the site is clearly expressed (as it is in Havana). Although the process of seeking and extending these heritage designations was initiated by regional 
and state governments primarily for economic purposes without any grassroots participation, it has certainly met grassroots opposition. Local activists who seek to have the designation changed to World Heritage in Danger thereby indicate and condemn the failure of authorities to take the necessary care not only to protect the route from harmful forms of development, but also the failure to protect prospects for sustainable livelihoods in the area. These actors have found within UNESCO's structures, categories and practices effective public means to shame state authorities for their failures to protect the subject matter of UNESCO valuation and their failure to respect the evaluations of those subject to the negative effects of its governance as heritage.

In global heritage politics, we see an intensification of practices that exemplify what James Scott (1998) called "seeing like a state" by which I mean enhanced priorities given to practices of mapping territories and inventorying their cultural properties, qualities and attributes of significance while making these legible through new forms of documentation, archiving (Reddy 2006, Pigliasco 2009) and publication. Multilateral institutions, such as UNESCO increasingly construct cultural diversity and its manifestations in tangible and intangible heritage resources as a form of currency subject to international surveillance and scientific control. States and communities are encouraged to treat these as forms of capital to be developed and marketed, and to seek international partnerships with holders of necessary expertise to effectively accomplish this. Neoliberal governmentality largely depends on autonomous expert communities that translate governmental priorities into a wide variety of locales and provide new forms of legitimacy (Rose 1999) that promise technical expertise without political entanglements, but provide only fragile forms of authority open to multiple challenges (Tamm Hallstrom 2004).

Heritage resource management also mobilizes and constitutes new fields of expertise in its practices of subject formation. Its agents are encouraged to approach heritage goods both instrumentally and contractually and new technologies and practices of auditing, standardization, certification, and accreditation enable these perspectives. In the process, states are legitimized as key actors, but other agencies, particularly international NGOs and associated epistemic communities of scientists and other professionals are facilitated and empowered due to their authority to assimilate and develop rationalized and universalized knowledge as expertise (Mattli and Buthe 2003). The listing of the isolated monastic site of Skellig Michael as an organically evolved cultural landscape, Máiréad Nic Craith (this volume) illustrates, put into play a process in which boatmen to an uninhabited island were culturally nominated as "spiritual guardians," restoration activities were subjected to global archaeological scrutiny, the accredited specialized practices of international experts, and environmental directives while the entire management process brought under evidentiary regimes of documentation and publication subject to wider professional scrutiny ensuring the application of global best practices. Nonetheless, as Nic Craith reminds us, such attempts to wholly represent and 
capture heritage values are always necessarily incomplete; new understandings of cultural significance and value are always emerging. ICH never has singular values, but multiple and contested histories of significance that tend to be ignored or obscured in official accounts but are never fully contained.

Florence Graezer Bideau (this volume) illuminates the ways in which national inventories function as technologies of power, illustrating how the Swiss social imaginary and its ideologies and hierarchies were protected, performed and reproduced not only in the contents that were chosen as ICH in the implementation of the 2003 UNESCO Convention, but in the very processes of decision-making that the government put into place after it was ratified in 2008. Indeed, she astutely notes that the process worked to publicly inscribe what appeared to be a "popular" performance of the Swiss federal system itself, despite the rather dominant role assumed by holders of expert knowledge in representing, reorganizing and repackaging (as well as augmenting) the results of this self-consciously "participative" exercise in order, it appears, to best ensure that the end product was appropriately "Swiss" in stereotypical and exclusionary ways. The claim that Switzerland nonetheless lacks institutionalized cultural expertise seems to reflect an anxiety of French influence, and betrays the residual power of the monumental and aesthetic models of heritage that the 2003 Convention was expressly designed to undermine.

This is further illustrated in Laurent Fourier's essay (this volume), in which UNESCO's most recent universalist pretensions and particularistic preferences come up against those peculiar to the French nation state. Although French hegemony in UNESCO is much remarked upon, it has certainly been in decline, as a monumental view of heritage has given way to greater appreciation for "cultural diversity," intangible cultural heritage, traditional cultural expressions, and minority or community-based distinctions. These shifts in UNESCO's normative evaluations at millennium's end were motivated largely, it seems, by Asian countries who felt disadvantaged by modern Western processes of national cultural competition that focused on built environments and monumental edifices, but they were also, significantly, supported by anthropologists, many of them clearly influenced by indigenous rights movements and a more practice-based understanding of culture as lived heritage (Coombe and Turcotte 2012). Fournier quite rightly notes that "communities" have no legally recognized existence in France, but the same could be said about most state constitutions in industrialized societies. Nonetheless, "the concept of governmentality demands that we go beyond asking whether neoliberal rationality adequately represents society, to consider how it operates as a politics of truth that produces new forms of knowledge and expertise that govern new domains of regulation and intervention" (Coombe 2007: 286). For anthropologists, the field of cultural heritage management provides a unique opportunity to study processes of ethnogenesis and an exciting arena to deploy the insights of legal anthropology so as to explore constitutions of collective subjectivity and political economies of community construction (Coombe 2011a, b). 
The cultural heritage of the Curonian Spit, for example, has historically contributed to the making of German, Soviet and Lithuanian identities (Peleikis 2006) and now appears to be poised to assume a new profile as exemplifying a distinctive and shared European culture, which Ullrich Kockel (this volume) suggests, is likely to be a fraught process. Given that the local community is largely made up of relatively recent settlers for whom the heritage promoted is largely foreign, and that other groups returning to the area have different memories from different eras of state governance, it provides an excellent example of the contingency of the modern conjunction of the nation-state and its possessive relation to any singular culture whether defined anthropologically or aesthetically.

Ironically, the entrenchment of two distinctive understandings of culture in France (the ethnological and the monumental aesthetic) and a bureaucracy divided along these lines (Fournier, this volume), suggests that UNESCO's new norms and directions may face the most obstinate of obstacles in the country of the organization's headquarters. To the extent that France distinguishes itself as a nation by its principled commitment to universalism, formalist concepts of equality and an assimilationist model of nation-building exemplified by a globally admired high Culture of monuments and fine arts that represents universal values, its capacities to serve as a model in the field of cultural heritage now face considerable challenge. Nonetheless, this hegemonic template, in which a unified and singular state is socially married to a singular nation which is expressed by a distinctive culture continues to have profound weight, not only in France, I would suggest, but globally, despite the best efforts of UNESCO and human rights bodies to undermine and disassemble it.

Coming from a country (Canada) that maintains an ideology of two founding nations and must confront the postcolonial struggles of multiple First Nations peoples, I confess to finding this template for cultural valuation particularly oppressive and so, it would appear, do many others. As Philip Scher (this volume) so aptly explores in the Caribbean, international demands that states identify and invest in a distinctive national culture (often premised on interpretations of multilateral institutions and their legal instruments) may well be understood and experienced in people's everyday lives as a form of state discipline. The capacities to represent culture "possessively" are not held equally by states, even if the technologies for so doing appear to be accessible to all. In other words, not all countries are equally situated in terms of access to those "resources" deemed suitable for "nationbranding" as the Barbados example nicely illustrates.

Still, one wonders if this involves some failure of state imagination - it is not at all clear why a country's diaspora is not a part of its heritage (to shake up the territorial and temporal logic somewhat). Rihanna's birthplace, for example, might well attract tourists with Barbadian backgrounds and others wanting an intimate brush with home-grown celebrity. Brazil, for example, has attempted to claim caipoera as national cultural heritage, not by sequestering its practice, but by vesting mestres (expert practitioners) in its global diaspora with the status as ambassadors for a 
Brazilian culture understood to be a transnational force (Robitaille 2011, 2014). Moreover, countries in South America have recognized that indigenous cultural heritage spans national borders which have Spanish colonial origins and have collectively nominated transnational indigenous worldviews and cosmologies for UNESCO listing, investment and support. These examples suggest that the emphasis upon community in the management of ICH may spur more creative social articulations than those of nation branding.

In contrast to the anxiety about national cultural distinction that Scher's fieldwork suggests and the state discipline and surveillance it seems to foster, Gabriele Mentges (this volume) shows us that a possessive relationship to a distinctive culture was directly fostered in Uzbekistan through international tutelage. The state appears to have first acquired the need to produce and express its nationhood under Soviet governance in a process in which UNESCO appears to have been an effective facilitator. This work is now augmented by WIPO's agenda for "protecting" traditional knowledge and traditional cultural expressions by the development of new markets for handicrafts. The nation that is culturally expressed here appears to have a stronger relationship with international organizations than with the state, which seems to take many of its cues from them. This suggests that we consider the "performativity" of statehood in international arenas (Weber 1998) rather than simply naturalize the category and its constituents. Just as gender may be the performance of sex rather than its expression (Butler 1997, 1990), so, too, governments may need to act as if they are nations to be recognized as states. In a fascinating presentation at the 2011 conference, Sven Missling suggested that UNESCO provided some unique opportunities for nations to be "seen like a state" - a process which requires international recognition. Specifically, he discussed the Palestinian National Authority (PNA) initiative to nominate the birthplace of Jesus Christ in Bethlehem as a World Heritage Site, an act that was not wholly unreasonable given UNESCO support for the creation of inventories of Palestinian cultural heritage, its demand for accounts of protection measures and its recognition of Palestinian institutions as in need of capacity-building. Given that the PNA is neither a state nor a member of UNESCO, this nomination must be understood performatively as a national expression of state behavior and aspiration. As I wrote this commentary, the nomination was approved and this site inscribed on the international list on behalf of "Palestine." Such aspirations and other challenges to the modern dyadic bond of the nation-state would seem to be inevitable, if not necessarily anticipated, by the twin emphases of cultural diversity and community participatory empowerment that UNESCO has rolled out in the past decade. By acting like a state and demonstrating possession of those demarcated cultural attributes that allegedly define a nation, movements towards sovereignty may be assisted.

Aspirations for new forms of sovereignty, however, come from many quarters. Although none of the papers addressed indigenous communities or indigenist political movements, Anais Leblon's paper touched upon the still unexplored pos- 
sibility that the focus of attention, energy and investment that UNESCO processes bring to the "cultural" practices of those with land-based livelihoods might still be diverted to support local movements for rights to territory, resources and new forms of self-determination. Despite the predictable standardizations of the forms of cultural heritage the Malian state seemed prepared to encompass as falling within the UNESCO mandate - most of which had little to do with the increasingly threatened practices of raising and herding livestock and served largely to ratify the expertise of already privileged elites - Fulbe pastoralists look to the candidacy of the yaaral and degal as well as new UNESCO emphases on community participation as potential opportunities to address issues of social marginalization, land tenure, food security, and health. The structures and practices of heritage governmentality appear to constrain more than they enable local practitioners in this instance, but this appears to have more to do with the ideological legacies of prior heritage regimes than restrictions inherent in the new one.

Clearly it is rather too early to ascertain to what extent and how effectively these new and ambiguous international tools for cultural valorization and local development can be put to new ends, but it is not too soon to begin to critically consider the conditions that will thwart or advance struggles for social justice. The field of cultural heritage management is increasingly characterized by unique forms of legal pluralism that should attract the interest of legal anthropologists. We might anticipate also that new issues of anthropological ethics will emerge as field-based anthropologists, particularly students, are called upon to assist in nominations and inventorying processes or to intervene in their modification to better serve local interests. Anthropologists may also need to consider the impacts of their academic publications on local cultural understandings and agency in these new regimes. The relationship between applied and academic anthropologists in this field warrants attention. At the very least, anthropologists need to move beyond an emphasis upon the reifying and objectifying nature of preserving cultural heritage to consider the ways in which the new international emphasis on safeguarding living traditions and ensuring the participation of communities creates new opportunities for political aspiration, articulation and assemblage.

\section{References}

Blake, Janet E. (2009): UNESCO’s 2003 Convention on Intangible Cultural Heritage: The implications of community involvement in 'safeguarding'. In Intangible Cultural Heritage. Laurajane Smith and Natsuko Akagawa, eds. Pp. 46-57. London: Routledge.

Breglia, Lisa (2006): Monumental Ambivalence: The Politics of Heritage. Austin: University of Texas Press.

Butler, Judith (1990): Gender Trouble: Feminism and the Subversion of Identity. New York: Routledge. 
- (1997): Excitable Speech: A Politics of the Performative. New York: Routledge.

Clarke, John (2008): Living with/in and without neoliberalism. Focaal - European Journal of Anthropology 51: 135-47.

Collier, Stephen J., and Aiwa Ong (2005): Global Assemblages, Anthropological Problems. In Global Assemblages: Technology, Politics, and Ethics as

Anthropological Problems. Aihwa Ong and Stephen J. Collier, eds. Pp. 3-21.

Oxford, UK: Blackwell Publishing Ltd..

Coombe, Rosemary J. (2007): The Work of Rights in the Space of Neoliberal

Governmentality's Limits. A commentary on Li's "Governmentality."

Anthropologica 49(2): 284-289.

- (2011a): Possessing Culture: Political Economies of Community Subjects and their Properties. In Ownership and Appropriation. Mark Busse and Veronica Strang, eds. Pp. 105-127. London: Berg Publishers.

- (2011b): Cultural Agencies: 'Constructing' Community Subjects and their Rights. In Making and Unmaking Intellectual Property. Mario Biagioli, Peter Jaszi, and Martha Woodmansee, eds. Pp. 79-98. Chicago: University of Chicago Press.

Coombe, Rosemary J., and Nicole Aylwin (2011): Bordering Diversity and Desire:

Intellectual Property and Marking Place-based Products in Commerce.

Environment and Planning A: Society and Space New Borders of Consumption 43(9): 2027-2042.

Coombe, Rosemary J., and Joseph F. Turcotte. In press (2012): Indigenous

Cultural Heritage in Development and Trade: Perspectives from the Dynamics of Cultural Heritage Law and Policy. In International Trade in Indigenous Cultural Heritage. Christophe Graber, Karolina Kuprecht and Jessica Lai, eds. Pp. 272-305. Cheltenham: Edward Elgar.

Coombe, Rosemary J., Steven Schnoor, and Mohsen Ahmed (2007): Bearing

Cultural Distinction: Informational Capitalism and New Expectations for Intellectual Property. Intellectual Property and Social Justice. Symposium Issue. University of California-Davis Law Review 40(3): 891-917.

Kingfisher, Catherine, and Jeff Maskovsky (2008): Introduction: The Limits of

Neoliberalism. Critique of Anthropology 28(2): 115-126.

Laurie, Nina, and Liz Bondi (2005): Working the Spaces of Neoliberalism.

London: Blackwell.

Li, Tania M. (2007a): The Will to Improve: Governmentality, Development and the Practice of Politics. Durham: Duke University Press.

- (2007b): Governmentality. Anthropologica 49: 275-281.

Loulanski Tolina (2006): Revising the concept for cultural heritage: An argument for a functional approach. International Journal of Cultural Property 13: $207-$ 33.

Mattli, Walter, and Tim Buthe (2003): Setting International Standards: Technological Rationality or Primacy of Power? World Politics 56(Oct): 1-42. 
Miura, Keiko (2011): World Heritage Making in Angkor: Global, Regional, National and Local Actors, Interplays and Implications. In World Heritage Angkor and Beyond: Circumstances and Implications of UNESCO Listings in Cambodia. Brigitta Hauser-Schäublin, ed. Pp. 9-32. Göttingen: Universitätsverlag Göttingen.

Peleikis, Anja (2006): Tourism and the Making of Cultural Heritage: the case of Nida (Curonian spit), Lithuania. In Acta Historica Universitatis Klaipedensis Vol. XII, Studia Antropologica Vol. I, Pp. 101-114.

Perreault, Tom, and Patricia Martin (2005): Geographies of Neoliberalism in Latin America. Environment and Planning A 37: 191-201.

Perry, Richard W., and Bill Maurer, eds. (2003): Globalization Under Construction: Governmentality, Law, and Identity. Minneapolis: University of Minnesota Press.

Pigliasco, Guido C. (2009): Intangible Cultural Property: Tangible Databases, Visible Debates: The Sawau Project. International Journal of Cultural Property 16: $255-272$.

Reddy, Sita (2006): Making Heritage Legible: Who Owns Traditional Medical Knowledge? International Journal of Cultural Property 13: 161-188.

Robitaille, Laurence (2011): Brazilian Capoeira: From Localized Cultural Exchange to Transnational Vector of the 'Nation'. Paper presented at the Ninth Congress of the Cultural Studies Association, Colombia College, Chicago (IL), March 24-26.

- In press (2014): Promoting Capoeira, Branding Brazil: The Body as Marketing Device and Site of Cultural Transmission. Accepted for publication in special issue "The Culture Industries in the African Diaspora," X. O'Neal Livermon and J. Packman, eds. Black Music Research Journal.

Rose, Nicholas (1999): Powers of Freedom: Reframing Political Thought. New York: Cambridge University Press.

Rössler, Mechtild (2006): World Heritage Cultural Landscapes: A UNESCO Flagship Programme. Landscape Research 31(4): 333-53.

Scott, James C. (1998): Seeing Like a State: How Certain Schemes to Improve the Human Condition Have Failed. New Haven: Yale University Press.

Smith, Laurajane (2004): Archaeological Theory and the Politics of Cultural Heritage. London: Routledge.

- (2006): Uses of Heritage. London: Routledge.

Tamm Hallstrom, Kristina (2004): Organizing International Standardization: ISO and the IASC in Quest for Authority. Northampton, MA: Edward Elgar.

Wang, Dong (2010): Internationalizing Heritage: UNESCO and China's Longmen Grottoes. China Information 24(2): 123-147.

Weber, Cynthia (1998): Performative States. Millennium - Journal of International Studies 27: 77-95.

Yüdice, George (2003): The Expediency of Culture: Uses of Culture in the Global Era. Durham: Duke University Press. 



\section{Discussion}

\section{Laurajane Smith}

Four themes emerged as I listened to the papers on which this volume is based, which were presented at the Cultural Property DFG Research Group conference, Gottingen. These themes centered on the continued dominance of the Western Authorized Heritage Discourse (AHD), what might be called the colonial pathology of heritage collecting, the impact of tourism and the idea of heritage as a political resource. These are all issues that, to a lesser or greater extent, I have discussed or considered in previous work and publications (see, for instance, Smith 2006, 2011), however, I was struck anew by the degree to which the idea of the AHD, which I posited and critiqued back in 2006, is still so central within heritage practices.

The first theme is that of the continuing prevalence of the AHD and the consequences it has for community inclusion in heritage practices. A wide range of casestudies that came from several regions of the world were discussed at the conference. One common issue that was raised across most papers was a sense of frustration that centered on issues of community participation. Authors often expressed concern over the difficulty of incorporating community concerns into management issues, or it became apparent that communities and heritage professionals often appeared to misunderstand one another. Community or civic engagement, or what Greer (Greer; Harrison; McIntyre-Tamwoy 2002) refers to as "community-based" work, has been a dominant academic and policy issue in heritage studies and associated disciplines for over a decade (see Moser et al. 2002, Derry and Malloy 2003, Little and Shackel 2007, Smith and Waterton 2009, Waterton and Watson 2010, 
Robertson 2012, among others). However, much of this community work is frustrated or complicated by the frameworks within which heritage practices tend to be undertaken. International heritage policy and practice tends, as I have argued elsewhere, to be framed by the AHD. Such a framing often poses significant obstructions for the inclusion of community values or aspirations into management and conservation agendas (Smith 2006).

The AHD is a professional discourse that originated in 19th and 20th century European architectural and archaeological debates over the need to preserve what the discourse identified as the "fragile" and "non-renewable" past. This was to be preserved by experts for the benefit of "future generations," and advocates a conservation ethic that stresses the innate value or authenticity of original fabric. Age depth is valued, alongside monumentality, materiality and esthetic qualities. Experts are charged with a duty of care to look after the material remains inherited from the past, and to pass this on, unchanged, for the future (Smith 2006, Smith and Waterton 2012). It, therefore, privileges material heritage over the intangible, and expert knowledge and values over that of non-expert communities and other groups. Such a Eurocentric discourse has gained international authority as it has been mobilized by organizations such as UNESCO and ICOMOS (Smith 2006, Waterton 2010).

The AHD has little conceptual room for the meaningful inclusion of community concerns, as non-expert values simply make no sense or are marginalized within the discursive framework it offers. The papers in the volume reveal the degree of emphasis that is placed on expertise in the World Heritage listing and management processes. They also revealed the degree to which the World Heritage nomination process tends to render sub-state or sub-national communities invisible in this process. The AHD ensures this by either creating a situation whereby expert interests and values come into conflict with those of local communities, or by ensuring that experts and community groups will "talk past" one another and fail to understand each other's concerns or aspirations (see Smith and Waterton 2009, chapters in Gibson and Pendlebury 2009). While there is often a very strong commitment by heritage professionals and academics to be inclusive, this aim is often unconsciously thwarted by the conceptual and policy frameworks with which heritage work is undertaken, which are established and maintained by the AHD. Thus, the need to continue critically examining and reflecting on the nature of heritage discourses is a key issue that emerges from this volume. Moreover, it also points to the need to be aware and receptive to the possibility of the existence of conflicting or alternative heritage discourses. Such discourses can occur not only at community and other sub-national levels, but at national levels as well, particularly as nonWestern or non-European nations assert the legitimacy of their own particular understandings of heritage.

The second issue is associated with another consequence of the AHD and may be expressed through what Tindill (1999) identifies as the "pathology of collecting" 
associated with the acquisitiveness of Western cultures. The UNESCO World Heritage List and Convention have been extensively criticized for their Eurocentrism, to the extent that, as Meskell (2002: 569) notes, "world heritage is underpinned by the globalising of Western values." Indeed, Lowenthal (1998) argues that propagating the assumed universal significance of European history and culture is an active project of the World Heritage List (for a fuller critique, see Byrne 1991, Cleere 2001, Labadi 2007, Arantes 2008, Labadi and Long 2010, Daly and Winter 2012). Tied up in this exercise is the colonial pathology of collecting, whereby the collected become transformed and defined by the cultural perceptions of the collectors. The World Heritage List, currently framed by the AHD, works to define human history and culture within the Western, and more particularly European, assumptions and values that are embedded in it. It is important to note at this point that the World Heritage List itself is an act of heritage making which constructs a particular understanding of the nature and legitimacy of global human experiences and cultural expression.

Harvey (2001) notes that heritage is a verb not a noun or, as (Dicks 2000) suggests, a communicative act. I have argued that it is a performance in which historical and cultural meaning and social values are continually created and recreated (Smith 2006). Heritage is not a thing, and the division between intangible cultural heritage, material heritage and natural heritage is nonsensical. All heritage is intangible, in so far as heritage is a process of remembering and forgetting. Indeed, what we may call heritage places, sites, artifacts or even world heritage lists, are part of the range of cultural tools that are used to negotiate the meaning of the past for the present. This negotiation is inevitably done in the context of the cultural and political needs of the present. Thus, a further question that arose for me in considering the case-studies offered here is: If we accept that UNESCO is engaged in "heritage making" as I have defined it here, what and whose heritage is it making? The national and universalizing process of nomination and listing reflects the extent to which their remains, despite decades of critique and UNESCO's attempts to address this criticism through the recent conventions addressing intangible heritage and diversity, are subject to a continuing project of colonization that places European values as central to human history.

The third theme revolves around the issues of tourism and the economic value of heritage. Through the AHD, heritage is sold as something inherently "good," offering educational opportunities to "the public," and as a force that will contribute to social well-being. As Waterton (2010) has demonstrated in terms of the English AHD, heritage is discursively constructed as something possessing its own agency - it has the power to not only solve poverty, recession and unemployment but will also, somehow, provide cultural cohesion. In this context, heritage takes on a peculiar contradictory relationship with tourism. On the one hand, tourism is facilitated and encouraged by the listing of heritage items on state and international lists. Heritage as something inherently "good," educational and culturally fulfilling is a 
legitimate visitor destination, and the oft-asserted educational value of heritage must mean that visitors to sites are actively attracted by heritage agencies and professionals. Sites on the World Heritage List become "honey-pot" tourist destinations. However, on the other hand, and in apparently contradictory moves, heritage agencies working within the confines of the AHD, UNESCO included, tend to denigrate tourism as highly suspect and problematic. Ashworth (2009) identifies the degree of suspicion often leveled at tourists and tourism by heritage organizations and professionals, which is often tied to the so-called "vulgarity" of the fact that travel is now not only reserved for the social and cultural elites - it has become "mass." The apparent contradictions offered by an uneasy relationship of heritage with tourism is one that is worth exploration, particularly the idea that tourism is often only considered as a management issue, rather than a specific heritage value, needs questioning and rethinking.

Certainly, as Watson et al. (2012) argue, the time has arrived for a sustained and critical debate between tourism and heritage studies. In developing the debate on tourism, however, it may also be useful to consider what the contradictory discourse that UNESCO and many national heritage agencies propagate does and achieves. It may also be useful to consider what heritage is being made and remade by the interrelations of tourists-visitors and host communities. In considering this, it becomes useful to explore tourism, as much as heritage, as not simply an economic phenomenon, but as a process that also produces cultural products which do not always necessarily result in commodification or Disneyfication. Thus, it may be useful to ask what are the cultural or heritage moments that are generated by this interaction, and how are these moments initiated and framed by the World Heritage listing process and are, indeed, new forms of heritage,

The final theme to be explored here is the idea of heritage as a political global resource. Heritage is a vital resource in the politics of difference and recognition. Although this is sometimes dismissed as "identity politics," heritage nonetheless can play an important role in legitimizing or bolstering claims to social justice, which are often based on appeals to a particular cultural or historical status, or the experiences of disenfranchised groups. This does not mean to say that all such claims are legitimate and not open to examination, rather to simply note that heritage sites, places and intangible events are intimately linked to struggles over the equitable distribution of resources of power and privilege (Smith and Waterton 2009: 78-81).

Heritage as a resource in national and sub-national political conflicts has now been widely explored in the heritage literature (see, for instance, Silverman and Ruggles 2007, Langfield et al. 2010). However, what is often neglected is the degree to which the negotiations over the distribution of power are played out in the bureaucratic processes of listing, which occur not only at local and national levels, but also globally. Expertise and expert knowledge are continually mobilized as "technologies of government" to regulate or arbitrate over not only sub-state or 
sub-national interests, but also to regulate states themselves. As a technology of government, expert knowledge becomes mobilized by policy-makers to help them make sense of the social and cultural problems that confront them, making problems "tamable" and "thinkable" within bureaucratic frameworks (Rose and Miller 1992: 175). Heritage expertise is often mobilized to render social problems based on certain claims to heritage as apolitical managerial problems. Conflicts become reduced to disputes over the management of heritage sites and artifacts, conflicts that are, in turn, framed and resolved by heritage legislation and policy (see Smith 2004). This creates not only national, but also international mentalities of rule and governance which facilitate the defusing of conflicts over the interpretation of the past and certain contemporary expressions of culture. This ties back, of course, to the AHD, which both facilitates and is continually recreated and authorized in this process. Sometimes this governance can have highly positive outcomes for the interests involved, and sometimes it may not. However, the issue here is not so much the outcomes for specific cases or instances of conflict, but rather the fact that bodies of expert knowledge are used at all in these conflicts. The use of expertise, whether for radical or conservative political outcomes, may work to deny or marginalize the legitimacy of communities or other interests to have their own say and be listened to by public policy-makers. The issue that arises from these observations is the need to establish a framework for assessing the political and cultural consequences of UNESCO, state and individual expert action.

All four themes are interrelated and revolve around the unconscious cultural and political work that the AHD does in legitimizing expertise and marginalizing other interests (community, tourist, etc.) when it frames the policies and practices of heritage agencies. This is not to say that a position whereby expertise is vilified needs to be adopted, rather to argue that a deeper critical engagement that examines the wider political, economic and social consequences of heritage conservation and listing practices is needed. Heritage matters, but it matters not necessarily because it is nice, pretty or an expression of so-called "universal" values, it matters because how it is used has consequences for the individual, community, national, and global understanding of self and "other."

\section{References}

Arantes, Antonio A. (2008): Diversity, heritage and cultural politics. Theory, Culture and Society 47(7-8): 290-296.

Ashworth, Gregory J. (2009): Do tourists destroy the heritage they have come to experience? Tourism Recreation Research 34(1): 79-83.

Byrne, Denis (1991): Western hegemony in archaeological heritage management. History and Anthropology 5: 269-276. 
Cleere, Henry (2001): The uneasy bedfellows: Universality and cultural heritage. In Destruction and conservation of cultural property. Robert Layton, Peter G.

Stone and Julian Thomas, eds. Pp. 22-29. London: Routledge.

Daly, Patrick, and Tim Winter, eds. (2012): Routledge Handbook of Heritage in Asia. London: Routledge.

Derry, Linda, and Maureen Malloy, eds. (2003): Archaeologists and Local Communities: Partners in Exploring the Past. Washington, DC: Society for American Archaeology.

Dicks, Bella (2000): Heritage, Place and Community. Cardiff: University of Wales Press.

Gibson, Lisanne, and John R. Pendlebury, eds. (2009): Valuing Historic Environments. Farnham: Ashgate.

Greer, Shelley, Rodney Harrison, and Susan McIntyre-Tamwoy (2002): Community-based archaeology in Australia. World Archaeology 34(2): 265287.

Harvey, David C. (2001): Heritage pasts and heritage presents: Temporality, meaning and the scope of heritage studies. International Journal of Heritage Studies, 7(4): 319-338.

Labadi, Sophia (2007): Representations of the nation and cultural diversity in discourses on world heritage. Journal of Social Archaeology 7: 147-170.

Labadi, Sophia, and Colin Long, eds. (2010): Heritage and Globalization. London: Routledge.

Langfield, Michele, William Longan, and Máiréad Nic Craith, eds. (2010): Cultural Diversity, Heritage and Human Rights: Intersections in Theory and Practice. London: Routledge.

Little, Barbara J., and Paul A. Shackel, eds. (2007): Archaeology as a Tool of Civic Engagement. Lanham MD: AltaMira Press.

Lowenthal, David (1998): The heritage crusade and the spoils of history. Cambridge: Cambridge University Press.

Meskell, Lynn (2002): The intersections of identity and politics in archaeology. Annual Review of Anthropology 31: 279-301.

Moser, Stephanie, et al. (2002): Transforming archaeology through practice: Strategies for collaborative archaeology and the Community Archaeology Project at Quseir, Egypt. World Archaeology 34(2): 220-248.

Robertson, Iain J. M., ed. (2012): Heritage from Below. Farnham: Ashgate. Rose, Nikolas, and Peter Miller (1992): Political Power beyond the State:

Problematics of Government. British Journal of Sociology 43(2): 173-205.

Silverman, Helaine, and D. Fairchild Ruggles, eds. (2007): Cultural Heritage and Human Rights. New York: Springer.

Smith, Laurajane (2004): Archaeological Theory and the Politics of Cultural Heritage. London: Routledge.

- (2006): Uses of Heritage. London: Routledge. 
- (2011): El 'espejo patrimonial'. ¿ilusión narcisista o reflexiones múltiples? Antipoda 12: 39-63.

Smith, Laurajane, and Emma Waterton (2009): Heritage, Communities and Archaeology. London: Duckworth.

- (2012): Constrained by common sense: the Authorised Heritage Discourse in contemporary debates. In The Oxford Handbook of Public Archaeology. John Carman, Robin Skeates, and Carol McDavid, eds. Pp. 153-171. Oxford: Oxford University Press.

Tindill, Jackie (1999): When what's mine cannot be yours: Scientific constructions of heritage and the repatriation of human remains. Paper presented at the Fifth Annual Meeting of the European Association of Archaeologists. University of Bournemouth, UK, September, 14-19.

Waterton, Emma (2010): Politics, Policy and the Discourses of Heritage. Hampshire: Palgrave Macmillan.

Waterton, Emma, and Steve Watson, eds. (2010): Heritage and community engagement: collaboration or contestation? Special issue. International Journal of Heritage Studies 16(1-2).

Watson, Steve, Emma Waterton, and Laurajane Smith (2012): Moments, instances and experiences. In The Cultural Moment in Tourism. Laurajane Smith, Emma Waterton and Steve Watson, eds. Pp. 1-16. London: Routledge. 

A comparative assessment 



\title{
Thinking Through Heritage Regimes
}

\author{
Chiara De Cesari
}

\section{Introduction}

In Palestine's West Bank, the context that I know best and have studied for several years, there are many local civil society organizations dedicated to heritage preservation that essentially take care of a lot of the country's heritage. They have an ambiguous and rather conflicted relationship with the local UNESCO office, which they see as allied to the Palestinian Authority (PA), the quasi-state that runs the administration of the (still occupied) Palestinian territories. These nongovernmental organizations (NGOs) use a kinship metaphor to describe the alliance between UNESCO and the PA. At a conference on heritage conservation in Palestine, which was attended by many of the key players in the field, including representatives from the local Department of Antiquities, UNESCO, major donors, and various heritage NGOs, this alliance was repeatedly derided as a "marriage" that, tellingly, had received few blessings from civil society organizations. The latter, after all, were largely excluded from this union, or else subjected to stricter regulations as an indirect consequence thereof. UNESCO's response to such chiding tended to repeat itself. As one official put it, "[our] hands are tied [...] UNESCO is an intergovernmental organization. I cannot marry you [civil society heritage organizations], even though I would prefer to marry you rather than the 
Department of Antiquities." ${ }^{283}$ In other words, UNESCO is mandated to work with state institutions, and this mandate, though beneficial at the national level in terms of institution-building, is often an obstacle to community participation another purported principle of UNESCO's heritage programs. It is my argument, substantiated by many of the essays collected in this volume, that this marriage metaphor, far from being an expression of the exceptional Palestinian situation, applies in fact to several other contexts where UNESCO is active and UNESCOization is at work. I will argue below that UNESCO paradoxically empowers the state; however, it is important to specify that the opposite is also true, to a certain extent, especially given the supervisory function this international agency often carries out vis-à-vis the state.

\section{Heritage as Regime?}

It is good to think of heritage in terms of regime or regimes because this makes us focus on two aspects that I believe are crucial to understand how heritage works today. The first aspect concerns the relationship of heritage with government and the ways in which heritage conservation intersects with government, broadly conceived, in multiple ways. This development has to do, first and foremost, with the remarkable expansion of heritage conservation in terms of both the forms of culture and the practices it encompasses (heritage was essentially only about historic monuments and archaeology until twenty years ago) and the scope of its now global reach. A dimension of the fin-de-siècle memory boom, such expansion is deeply entangled with the growing role of culture as an economic factor (see Yudice 2003), and with the discovery of culture and particularly cultural heritage as a motor of socio-economic development. The end effect is that what we call heritage or heritagization has come to shape people's lives more and more - particularly by intervening in ways that make social regulation much more difficult to detect, because the latter looks, at least at first, very benign if not beneficial. Heritage defines a relatively recent way of talking about and organizing the relationship between people and significant aspects of their culture, and between people and their environments. As a transnational discourse with its own set of attached practices, heritage is developed, supported and promoted by a network of powerful institutions, among which UNESCO is at present most influential. As a body of ideas and practices, one of heritage's peculiar features is that, while deeply transnational, this discourse is intertwined with the history and logics of the nation-state. Thinking of heritage in terms of regime makes this tension immediately palpable and visible.

The politics of heritage tend to be understood as the misuse (often by undemocratic actors and authoritarian regimes) of something - the past - that should

283 My notes from the third day of the Conference on Cultural Heritage in Palestine, Jericho, February 22, 2006. 
instead be kept neutral and under the strict purview of technocratic expertise. Saddam Hussein's use of Babylonian heritage to bolster his legitimacy is a perfect example of this notion. However, the new politics of heritage that this volume tackles concerns the subtle politics of the everyday. Heritage politics for most contributors to this volume can no longer be seen as a despicable exception opposed to a technocratic norm, because heritage makes politics precisely through expertise. From this perspective, heritage intersects with "government" in the broader sense of Foucauldian governmentality (Foucault 1991; see also Rose; O’Malley; Valverde 2006). For Michael Foucault, governmentality defines the "conduct of conduct" of populations - often not immediately circumscribed as "government" per se achieved through the deployment of particular forms of knowledge by a multiplicity of different actors. Governmentality is to be located well beyond the traditional domains of political institutions (several allegedly non-political actors and bodies do indeed participate in this form of government), and encompasses many possible ways of shaping people's behavior by applying specialized bodies of knowledge. The contributions to this volume show that "heritage" constitutes one such unusual field of government.

The second meaning of "regime" as international regime points to one if not the key location of heritage politics today, namely, UNESCO, the United Nations agency responsible, among others, for cultural matters, and especially its heritage programs dealing with world (tangible) heritage and intangible heritage. Several essays in this volume investigate the work of this international agency and its growing role in shaping what it means to carry out heritage conservation all over the world. "Regime," in its international political meaning, refers to a set of "Implicit or explicit principles, norms, rules, and decision-making procedures" that regulate areas of international relations (such as International Conventions). It also refers to the international regulatory agencies entitled to manage these international domains - agencies which typically lie outside the control of national governments and constrain them. ${ }^{284}$ Instead, in the case of UNESCO, while frictions do indeed occur, what several essays of this volume delineate is a strong de facto alliance between national and international actors, similar to the situation captured by my initial vignette.

Clearly, UNESCO's action often ends up reinforcing the power and reach of the nation-state and its bureaucracy, and its ability to shape people's lives through heritage, for example, by empowering and expanding the state heritage infrastructure or reproducing national stereotypes (Askew 2010, De Cesari 2010b). This happens in spite of a strong participatory rhetoric emphasizing the necessity to involve local communities and a poorly defined "grassroots" in heritage decisionmaking - a principle which is the cornerstone of recent UNESCO policies, and particularly of the 2003 Intangible Heritage Convention. In a previous essay, I have emphasized how, contrary to UNESCO's universalizing aim of establishing a

${ }^{284}$ See http://en.wikipedia.org/wiki/Regime<accessed August 9, 2012>. 
common heritage for humanity, the World Heritage system not only draws upon the tradition of national heritages, but actually reproduces and amplifies this tradition's logic and its infrastructure (De Cesari 2010b). This, in turn, gives rise to numerous tensions in the universalist practices of the organization. I have also shown how the structural relation between World Heritage and the nation state as inscribed in UNESCO's constitution as an intergovernmental agency and in its mandate - can hinder wider participation and local involvement in the heritage process. ${ }^{285}$ Thus, despite the rhetoric of democratic participation, it is nation-states (and experts, see Smith 2006) that play the main part on the World Heritage stage and that are authorized as proper actors through the World Heritage process. Several essays in this volume detail these paradoxical dynamics.

Undeniably, UNESCO's action is characterized by a number of tensions or apparently contradictory features. UNESCO's rhetoric celebrates cultural diversity as its key value, and to be sure, this organization's interventions produce a rush for diversification since local and national actors tend to emphasize the specificity and exceptionality of their cultural practices in order to meet UNESCO's criteria. However, UNESCO is itself a powerful agent of homogenization of heritage practices all over the world, for it promotes a standardization of principles and procedures of conservation, as Chiara Bortolotto in this volume explains. This "UNESCOization" (Berliner 2012) could easily be seen as a form of cultural globalization.

A further tension is the one between centralization and decentralization of heritage management. This tension can be detected very clearly in the case of the Intangible Heritage Convention because the latter, when deployed in local contexts, both authorizes grassroots groups as legitimate stakeholders in heritage conservation and simultaneously produces an expansion of the cultural domains under the management of the state. ${ }^{286} \mathrm{I}$ will discuss the issue of centralization in more depth below; UNESCO itself is a good example to illustrate the opposing tendency towards decentralization (and transnationalization). Indeed, nowadays, we assist the growing outsourcing of some of the state's historical functions, including heritage management, to "non-governmental" sub-, supra- and especially trans-national entities, such as UNESCO, together with all kinds of mushrooming civil society associations and private groups devoted to heritage all over the world (De Cesari 2010a, 2011b).

Critical heritage scholars have tended to see only the first trends, particularly towards homogenization or cultural imperialism (e.g. Byrne 1991, Smith 2006). Several contributions to this volume show, however, that things are not so straightforward. We still do not know enough about the local impact of UNESCO's interventions and about what happens with the growing heritagization

\footnotetext{
${ }^{285}$ For example, only officially recognized States Parties to the 1972 Convention can nominate sites to be inscribed on the World Heritage List.

286 This tension also relates to how UNESCO promotes what Timothy Mitchell (2002) has called the "rule of experts" (for heritage, see Smith 2006) by making experts into the subjects of heritage while simultaneously empowering "local communities" to take part in conservation.
} 
of places, traditions and cultures worldwide. By calling attention to the ways in which the translation of UNESCO's policies into local contexts produces rather different effects, this volume demonstrates that this is a very important avenue for future research.

Given such shifting politics, it is legitimate to ask whether we should indeed talk about heritage regimes in the plural or not. Should we talk about one heritage regime as a rather Eurocentric discourse - one that is promoted by powerful institutions and increasingly appropriated by grassroots actors to advance their claims but that can ultimately be only detrimental to them, like a double-edged sword? Or should we rather, as anthropologists tend to do, think in terms of multiple overlapping and intersecting heritage regimes, related to the different scales and the actors that nurture and champion them?

\section{The Heritage Regime at Work}

Today, we observe a dramatic expansion of the heritage regime. Different actors, both national and grassroots, appropriate the language of heritage to advance their demands, as well as, increasingly, to gain access to funding and investments. In the context of the so-called creative economies, "culture" is being used today as a resource towards a variety of different ends, particularly to foster economic growth (Yudice 2003). Heritage as a peculiar kind of cultural practice is a very good example of this trend. Heritagization, especially for countries with scarce resources, is seen as a potential motor of socio-economic development and, as such, is promoted not only by UNESCO, but also by powerful development institutions, such as the World Bank (e.g. 2001), in the framework of tourism development schemes. Shared heritage is also understood as a means of reconciliation, particularly in postconflict contexts. This serves to complete an imagination of heritage that assigns it something close to a thaumaturgic capacity in what Wiktor Stoczkowski (2009: 8) has called a "secular soteriology." In other words, heritage is imagined as a therapy to cure all evils, from poverty to ethnic conflict. While governments increasingly use heritage to attract international investments or obtain development aid, grassroots, minority or indigenous actors champion it in the name of the politics of recognition (e.g. Lowenthal 1996, Weiss 2007).

In this context, UNESCO is increasingly present throughout the world, especially in the global south, shaping heritage practices along similar lines. Heritage can be promoted as a tool to strengthen not only people's identities, but also democracy, participation and sustainable development: This is the mantra recited by UNESCO experts, in a way that Maria Cardeira da Silva compares to the repetitive call to prayer of the Muslim almuezin. Yet, does heritage truly foster democracy and local development? What is interesting is that UNESCO's intervention affects in particular the traditional areas of anthropological expertise. Gabriele Mentges recounts how while UNESCO initiatives were not the focus of her research in Uz- 
bekistan, at least originally, she was forced to engage with it because she encountered "traces of UNESCO in all of the places I[she] visited." Thus, UNESCO's cultural work is something anthropologists can no longer ignore, even if heritage is far away from their concerns.

What is the meaning of this growing presence? How can we gauge its impact not only on national heritage infrastructures, but most importantly on people's lives, and crucially: What does it mean to rethink culture in terms of heritage? What happens when not only people's culture, but also their very lives (see Adell) are made into "heritage" and regimented by both national and transnational regimes? This is a matter of governmentality through culture and cultural heritage. These are the set of questions this volume begins to ask.

A related, interesting issue concerns the meaning of such developments for anthropology as a discipline and form of knowledge production. The proliferation of heritage undeniably coincides with the growing relevance of anthropology beyond its confines, and particularly of its understanding of culture as an everyday matter and a way of life. These developments, however, also imply a certain bureaucratization of anthropology, with its knowledge turned into itemized lists and standard formats (see Broccolini). For Jean-Louis Tornatore, the application of the Intangible Heritage Convention in Western countries constitutes a kind of "anthropological payback" forcing the objectification of the culture of those who used to objectify others in the past. At the same time, one could argue that the expansion of the heritage regime constitutes a kind of objectification of the discipline of anthropology itself. Following these introductory observations, I will now turn to the four main themes addressed by the contributions to this volume.

\section{Imperfect Translations}

Several contributors talk about the local deployments of the international heritage regime using a textual metaphor, that of translation. This use discloses the mainstay of several of the essays, which emphasize how the outcome of these processes of translation is neither homogeneous nor predetermined (see Bortolotto, da Silva, Tauschek). The etymological and semantic proximity in the original Latin roots between "translation" and "treason" (and, interestingly, "tradition" as well) points to an understanding of the local translation of the global language of heritage as a diverse and varied phenomenon that deserves careful inquiry. For Chiara Bortolotto, applied global policies are "domesticated" or "twisted" by local institutional structures and categories, resulting, in her view, in "different safeguarding approaches." Similarly, Markus Tauschek demonstrates that previous national and local institutions, as well as, in particular, older legislation, shape the implementation of new UNESCO policies in Belgium (see also Broccolini). For Tauschek, "national heritage policies can be seen as assemblages of different patrimonial paradigms, as creative contact zones between different heritage logics that compete 
against one another or that are combined in synergetic ways." Maria Cardeira da Silva calls attention to the "eloquent dialogues [between local, national and international heritage cultures] that are in danger of remaining concealed behind apparent conformity." The concrete implementation of UNESCO's policies, in other words, is far from true to the letter.

Frictions, misunderstandings and negotiations appear to be the hallmarks of this complex process of making the international heritage regime work in local contexts. Anna Tsing, in her wonderful 2005 book embarking upon an "ethnography of global connection," complicates and redefines the relationship of the local and the global, and uses the notion of friction to investigate cultural productivity in globalized times. According to Tsing (2005: 1-18), both the local and the global are produced within cultural dialogues, and universals, that is, "knowledge that moves - mobile and mobilizing - across localities and cultures" (7) are always already engaged in cross-cultural encounters dominated by "awkward, unequal, unstable, and creative" frictions (4). Among the cases discussed in this volume, frictions and misunderstandings between the different actors and scales involved characterize in particular the implementation of UNESCO's intangible heritage policies in China, France and Uzbekistan. As Tsing suggests, such misunderstandings are perhaps unexpectedly but undoubtedly productive in that they move things forward and allow for the flexible adaptation and ultimately the success (in the sense of a diffusion) of the heritage regime at the local level. In China, for example, a focus on the "elements of excellence of national Chinese culture" (Bodolec) distinguishes this country's intangible heritage policies, and this is in contradiction to the spirit of the 2003 Convention which promotes rather representativity and equal recognition for diverse cultural practices. In the case of France and its intangible heritage listings, the strongly universalist tenets of this centralist state seem to clash with the chief values of the 2003 Convention and its promotion of cultural diversity (see esp. Fournier). The case of Uzbekistan clearly shows how UNESCO's initiatives to promote transnational values and shared, non-national heritages, such as the Silk Road, can easily translate into blatantly nationalist policies and images. Another interesting case of friction between the scales is the situation described by Anais Leblon for Mali, where local stakeholders' expectations of obtaining development and food security are not met by programs of inventorying and cultural promotion.

Finally, as Marcus Tauschek rightly emphasizes - echoed also in Graezer Bideau - negotiations, compromises and a good degree of contingency decide the outcomes of nominations and the ultimate organization of management structures. An interesting example is the gastronomic meal of the French: In this case, not only the interests of the agri-food sector and restaurant businesses, but also former president Nicolas Sarkozy's advantage in appeasing his famers' constituency played a role in the nomination procedure. Undeniably, the local translations of the global heritage language depend on how the latter articulates with local cultural logics and political dynamics, and in fact it varies. As Alessandra Broccolini shows, heritage can clash but also articulate with other transnational languages, such as the animal 
rights discourse, in unexpected ways. For sure, a certain contingency and instability are hallmarks of this process of "vernacularization" (Merry 2006).

We tend to look at the workings of the international heritage regime from a top-down perspective, namely, by concentrating on what happens to the global heritage discourse once it is in action. It is crucial, however, to understand these processes from below as well, which means to understand the reasons why a group of people decides to appropriate the language of heritage to further their goals, and the kinds of imaginaries and expectations elicited by the heritage discourse. Heritagization for Mali villagers, for example, constitutes a potential means of achieving food security (cf. Leblon), while in other cases, it is used to negotiate "a place in the shadow of a would-be cosmopolitan modernity" (da Silva). The latter situation clearly applies in my own research on Palestinian heritage practices. Today, we are witness to a proliferation of heritage initiatives in the West Bank. They are carried out by a number of civil society organizations for whom "heritage" is a way to connect with transnational networks and culture flows. Speaking the global language of heritage bestows on practitioners a sense of being part of a broader transnational community with which they interact as equals, at least on the surface; it also bestows on practitioners a feeling of entitlement to a higher status in a cultural if not a quasi-moral sense.

I have used the term "appropriation" above to define the ways in which local stakeholders tactically approach the international heritage regime. This suggests that the heritage regime is something like a foreign language to most local stakeholders, ultimately impenetrable to impulses from below. In this regard, there is a rather hegemonic understanding in heritage studies. This, however, necessitates further scrutiny together with the vertical imaginary, so to speak, that grounds it that of a global discourse free-floating above local contexts and left untouched by its multiple territorializations. The view that the universalization of heritage - as pursued by UNESCO heritage policies - represents a case of Western hegemony, was firstly put forward by Denis Byrne in 1991 and later reiterated by, for example, Michael Herzfeld (2005) and Laurajane Smith (2006). While I fully share these scholars' concern for the central role of power and postcolonial politics in the making of the international heritage regime, my fieldwork in Palestine has made me question the notion of traveling heritage practices as always already oppressive. In part, these kinds of arguments reproduce the logic of accusations that perceive globalization as being fundamentally about cultural imperialism. But, as several anthropologists have noted (e.g. Inda and Rosaldo 2008), globalization is not a one-way movement, and global forms are always localized and appropriated in culturally specific ways. Scholars have given different names to this encounter between the local and the global in an effort to overcome simplistic dichotomies, so as to highlight complex processes of back-translation. Sally Engle Merry (2006), for example, coined the term "vernacularization," debating human rights and the way in which this universalist discourse percolates and comes to be reconstituted by the local. Tom Boellstorff (2003) thinks instead in terms of "dubbing," by com- 
paring the process of translation of globalizing cultures and subjectivities to the dubbing of movies. I believe with Anna Tsing (2005) that globally circulating discourses are produced within cross-cultural dialogues, and that even highly asymmetric ones change along with their movements. Thus, the investigation of the very making of a global language like heritage constitutes a promising avenue of future research. By inquiry into the making of the global heritage discourse, I mean looking at the myriad negotiations, compromises, unexpected events, and actors, and at the expectations and imaginations that go into the writing of, for example, an international convention; but I also mean investigating the ways in which local deployments change international policies.

\section{$5 \quad$ Heritage Effects}

What are the effects of the international heritage regime once it is deployed? What is its impact on people and institutions? The initial vignette taken from my own fieldwork signals a surprising development that is delineated in several contributions to this volume as well. Heritagization along the lines of UNESCO's directives and supervision produces more governmentality, that is, an expansion of the institutional dimension of the state apparatus and its potential to reach into previously unmapped cultural terrains.

First and foremost, UNESCOization triggers frictions and conflicts between the different scales and actors involved. This concerns diverse understandings of and stakes in heritage, and occurs between international and local experts and (what I call for the sake of clarity and brevity) the "grassroots," and also between the state and the grassroots (see Ballacchino, Broccolini, Graezer Bideau, Kockel, Leblon), between the different branches of the state (Broccolini, Tauschek) and between international experts and the state (see Nic Craith, also the cases of France as discussed by Fournier and Tornatore, and China as assessed by Bodolec).

Conflicts are known to be a regular occurrence in matters of heritage, as, for example, Tunbridge and Ashworth (1996) have elucidated with their notion of dissonance or dissonant heritage. What is peculiar about the international heritage regime, and especially the 2003 Convention, however, is a fundamental ambiguity concerning the very definition of one of its pillars, that is, the involvement of "local communities." It is this very ambiguity which is a major source of conflicts and misunderstandings. As several essays in this volume emphasize, "local community" is left undefined, and is, in fact, open to varied interpretations and to ideological manipulations (see also Smith and Waterton 2009). In my own fieldwork, for example, I have frequently noticed how the "local" is taken to refer, depending on the context, to both grassroots groups and professional heritage NGOs, who often have a stake themselves in this productive confusion. 
What is also peculiar about the international heritage regime in relation to its impact on "local communities" is a paradox, namely, that the former both empowers and disempowers the latter. The great paradox of the international heritage regime, in spite of its rhetoric emphasizing transnational, shared values as well as democratic participation, is that, in fact, it ends up dramatically empowering the nationstate. As most contributions show, the implementation of UNESCO's policies often means not only reinforcing traditional national heritages and close to stereotypical, hegemonic notions of national identity and national cultures -themselves frequently a product of colonial and postcolonial-nationalist authoritarian ideologies (as in the case of Uzbekistan described by Mentges; see also Bodolec, Graezer Bideau, Scher, Tornatore). UNESCO's intervention often leads to a reconfiguration and an expansion of the state infrastructure for heritage and cultural management, which also implies that domains of people's lives previously unregimented now pass under the state's purview. In cases of disputed or occupied territories, UNESCO's intervention also tacitly reconfirm a state's sovereignty over a disputed piece of territory, or else arouses expectations and tactics of self-determination depending on which actor, occupier or occupied it chooses to deal with (see da Silva; cf. De Cesari 2011a).

This seems like a curious twisting of UNESCO's stated aim of involving and empowering "local communities" (see Adell, Broccolini, Fournier, Mentges, Sánchez-Carretero). Marcus Tauschek rightly places a strong emphasis on the institutional productivity, so to speak, instigated by heritagization along UNESCO's lines, and he shows that the latter implies, first and foremost, an expansion of heritage legislation and a multiplication and restructuring of the governmental entities devoted to its enforcement. The case of China discussed by Bodolec also constitutes a very good case of the expansion and restructuring I have sketched above. In China, the ratification of the 2003 Convention provided an occasion for greater centralization because it triggered a reorganization and streamlining of the Chinese administrative structure for heritage management previously split between different local and national state departments. Anthropologist Jim Ferguson (1995) has convincingly argued that development projects most frequently fail to achieve their stated objectives; instead, more often than not, they contribute to expand the reach of the state into previously uncharted terrain. Championing what I call "heritageas-development," or the conversion of heritage into a form of socio-economic development, UNESCO often, if unintentionally, achieves similar results.

The majority of the contributions to this volume demonstrate that UNESCOization does not mean democratic involvement in heritage. Two essays, however, contend that in the cases of France and particularly Ireland (see Fournier and Nic Craith), UNESCO's and particularly ICOMOS's intervention has met its target of triggering more participation. What makes or could potentially make the difference? A possible answer is that the outcome of inscriptions and management plans depends ultimately on the experts who implement them and how knowledgeable they are of UNESCO's guidelines. It is true that, in spite of the participatory rheto- 
ric, it is experts who are eventually given the greater role in the framework of UNESCO's policies and, therefore, have a lot of power in their implementation. Yet, a note of caution is in order. The hands of experts are tied by a set of structural constraints as sketched above, inscribed as they are into UNESCO's constitution as an intergovernmental agency with a specific, state-supporting mandate. Playing the devil's advocate, one could ask whether heritagization itself can be an effective vehicle of democratization at all.

What is the real meaning of participation? Is it a "mechanism of empowerment or is it a tool for management," as Chiara Bortolotto asks? In other words, does it entail empowerment or governmentality? If, indeed, we take a Foucauldian approach - grounded in an active notion of power as something that controls precisely by empowering - the two must not exclude one another. Alessandra Broccolini and Markus Tauschek draw attention to the growth of bureaucracy tied to heritagization. Heritagization triggers extended surveys and inventories of cultural sites and practices, as well as new regulations as to what is "authentic" and worth preserving, how this is to be done, and who are the legitimate stakeholders and tradition bearers. Being observed, studied, regimented, and often put on display and pushed to perform previously habitual cultural practices, becoming heritage subjects entails being subjected to the gaze and purview of the state as well as of other transnational actors. Discussing intangible heritage in France, Adell has cogently argued that recent heritage policies concerning intangible heritage generate a kind of "re-subjectivation" since it is people and their very lives - rather than objects and sites - that are turned into heritage. This process entails a form of objectification as well by making visible and tangible through the heritage gaze what was previously intangible and taken for granted.

Heritagization can also change the agents of heritage, at least to a certain extent. I remember well the anger of one of my Palestinian informants and civil society activist who had been involved from early on in a conservation project in the old part of his village, and then felt undermined and disempowered when the intervention of other national and transnational heritage actors turned him "from [active] planner to [passive in his view] stakeholder." 287

In terms of tangible heritage, the "world-heritagization" of sites commonly acts as an obstacle to their use by local communities, who are subject to increased surveillance by state bureaucrats and experts. In fact it often leads to the outright suspension of everyday livelihood activities. This is exemplified by the situation in Salvador de Bahia (Collins 2008), where heritagization transformed once vibrant cultural spaces into what local inhabitants call tombados or "patrimonalized" but also "frozen" areas. When sites such as this fall under the strict control of experts and state bureaucracies, the result is not merely an extension of state power, but also the production and legitimation of expertise with its own domain of application, namely, fenced-off heritage sites.

${ }^{287}$ Interview with the author, Jerusalem, September 15, 2011. 
In some cases, and against the grain of UNESCO's stated objective of defending human rights, heritagization triggers the resurgence of traditional hierarchical and patriarchal structures, such as in Uzbekistan where such "retraditionalization" undeniably serves the state's authoritarian politics (see Mentges). In some other cases, patrimonialization produces, in the long-term, a form of dependency (De Cesari 2010c, Hodder 2012). The local communities affected might have been selfsufficient before UNESCOization, but tend to become reliant on development aid and tourist flows (cf. Leblon) in its aftermath.

Heritagization, by now a known phenomenon (e.g. Herzfeld 2010), often becomes associated with gentrification processes, especially in the case of large-scale projects of urban regeneration and requalification (see da Silva, Pichler). Turning Habana Vieja (Cuba) into a destination for cultural tourism resulted in a radical change of its social geography with the resettlement of $70 \%$ of the former inhabitants in the case of the old plaza studied by Pichler. In other cases (e.g. Meskell 2005, Herzfeld 2009), evictions rather than more consensual resettlements result from the intersection of heritage regulations with capital interests.

Undeniably, as already noted some time ago by Nezar Al-Sayyad (2001), we can observe an alliance between nationalist and capitalist interests and forces in promoting institutional heritages. These often convey power-laden, traditional ideas of national identity and culture which are easily deployed to attract tourists by evoking hegemonic transnational imaginaries. The stories told are veiled with colonial nostalgia, like Pichler suggests in the case of the renewal of Habana's Plaza Vieja (see also da Silva), or they represent the return of stratified, orientalist images: In Uzbekistan, for example, old orientalist stereotypes dating back from the time of 19th century colonialism are being recycled as symbols of a new national identity by an authoritarian regime, and this all with the blessing of UNESCO (see Mentges). Moreover, the relationship between nationalist and capitalist interests and forces goes two ways, because it is not simply a matter of nationalist images being used to promote investments and profit. Scher clearly delineates a phenomenon which intersects with heritage more and more, namely nation-branding. The latter defines the use of advertising techniques to promote nationalism; in this case, promoting the nation as a brand serves all kinds of interests, both political and economic, and is mobilized to attract investments and tourism, here in the case of Barbados, but evident also in the intersection of interests discussed by Tornatore for the French case.

Heritagization is increasingly being advocated as a tool of sustainable economic growth and socio-economic development, particularly in countries with scarce resources (many of us are familiar with narratives of heritage as "oil," especially valuable at times of otherwise greatly reduced economic growth). Yet, are such expectations of democratic development through heritage and UNESCOization corroborated by solid research? What happens under the cover of heritage-asdevelopment? More often than not, such expectations are left unattended if heritage projects do indeed get funding and manage to be completed - which is not at 
all always the case. Then, why do we insist on telling ourselves this tale of salvation through heritage? How can we come up with a more realistic story?

\section{Why We Need Ethnography}

To answer these questions - to gauge how heritage affects people's lives - we clearly need more ethnography. Several essays in this volume call for specificity and ethnographic detail and indeed we ought to continue along this path. In particular, we ought to unpack the rhetoric of democratic heritage and heritage-asdevelopment, and to trace the real meanings of "involvement," "local communities" and "development." We ought to see the real people and the true stories that hide behind such terms.

The problem that I see is that heritage scholars tend to be prisoners of the very language they should dissect and criticize. This is the abstract, technical language of heritage experts and practitioners - made up of buzzwords such as environmental assessment and management plan, but also best practices, sustainability, outstanding value, and stakeholder, to mention but a few. Annelise Riles $(2001,2004)$ has convincingly argued that anthropologists are often too familiar, too close to the technocratic language of development - itself a derivative of anthropological knowledge - to be able to "unwind" it: Yet, this is precisely the ethnographer's task. Something similar can be argued for heritage. Often too close to policymaking, we as critical scholars have difficulties probing heritage's very form of knowledge and its language. At the same time, there are great advantages in being close to policy-making because this makes our critical task more effective. Analyses and critiques of UNESCOization and heritage as regime are helpful precisely because we can put them to use by feeding the fruits of our necessarily critical work back into policy-making.

\section{$7 \quad$ References}

Al-Sayyad, Nezar (2001): Global Norms and Urban Forms in the Age of Tourism: Manufacturing Heritage, Consuming Tradition. In Consuming Tradition, Manufacturing Heritage: Global Norms and Urban Forms in the Age of Tourism. Nezar Al-Sayyad, ed. Pp. 1-33. New York: Routledge.

Askew, Marc (2010): The Magic List of Global Status: UNESCO, World Heritage and the Agenda of States. In Heritage and Globalisation. Sophia Labadi and Colin Long, eds. Pp. 19-44. New York: Routledge.

Berliner, David (2012): The Politics of Loss and Nostalgia in Luang Prabang (Lao PDR). In Routledge Handbook of Heritage in Asia. Patrick Daly and Tim Winter, eds. Pp. 234-246. New York: Routledge. 
Boellstorff, Tom (2003): Dubbing Culture: Indonesian Gay and Lesbi Subjectivities and Ethnography in an Already Globalized World. American Ethnologist 30(2): 225-242.

Byrne, Denis (1991): Western Hegemony in Archaeological Heritage Management. History and Anthropology 5: 269-276.

Collins, John (2008): "But What if I Should Need to Defecate in Your Neighborhood, Madame?" Empire, Redemption, and the "Tradition of the Oppressed" in a Brazilian World Heritage Site. Cultural Anthropology 23(2): 279-328.

De Cesari, Chiara (2010a): Creative Heritage: Palestinian Heritage NGOs and Defiant Arts of Government. American Anthropologist 112(4): 625-637.

- (2010b): World Heritage and Mosaic Universalism: A View from Palestine. Journal of Social Archaeology 10(3): 299-324.

- (2010c): Hebron, or Heritage as Technology of Life. Jerusalem Quarterly 41: 628.

- (2011a): World Heritage and National Sovereignty: On Palestine's UNESCO Bid. Leiden-Stanford Heritage Network, December 6, 2011.

http://www.networkedheritage.org/2011/12/06/world-heritage-and-

national-sovereignty-on-palestine $\% \mathrm{E} 2 \% 80 \% 99$ s-unesco-bid/ < accessed August $8,2012>$

- (2011b): Heritage by NGOs: Why Heritage Restoration Makes Sense under Occupation. Anthropology News, October 2011.

Ferguson, James (1990): The Anti-Politics Machine: “Development,” Depoliticization, and Bureaucratic Power in Lesotho. Cambridge: Cambridge University Press.

Foucault, Michel (1991): Governmentality. In The Foucault Effect: Studies in Governmentality. Graham Burchell, Colin Gordon, and Peter Miller, eds. Pp. 87-104. Chicago: University of Chicago Press.

Herzfeld, Michael (2005): Political Optics and the Occlusion of Intimate Knowledge. American Anthropologist 107(3): 369-376.

- (2009): Evicted from Eternity: The Restructuring of Modern Rome. Chicago: University of Chicago Press.

- (2010): Engagement, Gentrification, and the Neoliberal Hijacking of History. Current Anthropology 51(2): S259-S267.

Hodder, Ian (2012): Entangled: An Archaeology of the Relationships between Humans and Things. Oxford: John Wiley \& Sons.

Inda, Jonathan Xavier, and Renato Rosaldo (2008): Tracking Global Flows. In The Anthropology of Globalization: A Reader. Jonathan Xavier Inda and Renato Rosaldo, eds. Pp. 3-46. Oxford: Blackwell.

Lowenthal, David (1996): Possessed by the Past: The Heritage Crusade and the Spoils of History. New York: Free Press.

Merry, Sally Engle (2006): Transnational Human Rights and Local Activism: Mapping the Middle. American Anthropologist 108(1): 38-51. 
Meskell, Lynn (2005): Sites of Violence: Terrorism, Tourism, and Heritage in the Archaeological Present. In Embedding Ethics. Lynn Meskell and Peter Pels, eds. Pp. 123-146. Oxford: Berg.

Mitchell, Timothy (2002): Rule of Experts. Berkeley: University of California Press.

Riles, Annelise (2001): The Network Inside Out. Ann Arbor: University of Michigan Press.

- (2004): Real Time: Unwinding Technocratic and Anthropological Knowledge. American Ethnologist 31(3): 392-405.

Rose, Nikolas, Pat O’Malley, and Mariana Valverde (2006): Governmentality. Annual Review of Law and Social Sciences 2: 83-104.

Smith, Laurajane (2006): Uses of Heritage. London: Routledge.

Smith, Laurajane, and Emma Waterton (2009): Heritage, Communities and Archaeology. London: Duckworth.

Stoczkowski, Wiktor (2009): UNESCO's doctrine of human diversity: A secular soteriology? Anthropology Today 25(3): 7-11.

Tsing, Anna L. (2005): Friction: An Ethnography of Global Connection. Princeton: Princeton University Press.

Tunbridge, John E., and Gregory John Ashworth (1996): Dissonant Heritage: The Management of the Past as a Resource of Conflict. Chichester: John Wiley \& Sons.

Weiss, Lindsay (2007): Heritage-Making and Political Identity. Journal of Social Archaeology 7(3): 413-431.

World Bank (2001): Cultural Heritage and Development: A Framework for Action in the Middle East and North Africa. Washington D.C.: World Bank.

Yüdice, George (2003): The Expediency of Culture. Durham, NC: Duke University Press. 


\begin{abstract}
What happens when UNESCO heritage conventions are ratified by a state? How do UNESCO's global efforts interact with preexisting local, regional and state efforts to conserve or promote culture? What new institutions emerge to address the mandate? The contributors to this volume focus on the work of translation and interpretation that ensues once heritage conventions are ratified and implemented. With seventeen case studies from Europe, Africa, the Caribbean and China, the volume provides comparative evidence for the divergent heritage regimes generated in states that differ in history and political organization. The cases illustrate how UNESCO's aspiration to honor and celebrate cultural diversity diversifies itself. The very effort to adopt a global heritage regime forces myriad adaptations to particular state and interstate modalities of building and managing heritage.
\end{abstract}

